ORNL/TM-2012/303

\title{
Eastern Interconnection Demand Response Potential
}

\section{November 2012}

\author{
Prepared by \\ Youngsun Baek ${ }^{1}$ \\ Stanton W. Hadley ${ }^{1}$ \\ Rocío Uría-Martínez ${ }^{2}$ \\ Gbadebo Oladosu² \\ Alexander M. Smith ${ }^{1}$ \\ Fangxing $\mathrm{Li}^{1}$ \\ Paul N. Leiby ${ }^{2}$ \\ Russell Lee ${ }^{2}$
}

\footnotetext{
${ }^{1}$ Power and Energy Systems Group, Oak Ridge National Laboratory

${ }^{2}$ Energy Analysis Group, Oak Ridge National Laboratory
} 


\section{DOCUMENT AVAILABILITY}

Reports produced after January 1, 1996, are generally available free via the U.S. Department of Energy (DOE) Information Bridge.

Web site http://www.osti.gov/bridge

Reports produced before January 1, 1996, may be purchased by members of the public from the following source.

National Technical Information Service

5285 Port Royal Road

Springfield, VA 22161

Telephone 703-605-6000 (1-800-553-6847)

TDD 703-487-4639

Fax 703-605-6900

E-mail info@ntis.gov

Web site http://www.ntis.gov/support/ordernowabout.htm

Reports are available to DOE employees, DOE contractors, Energy Technology Data Exchange (ETDE) representatives, and International Nuclear Information System (INIS) representatives from the following source.

Office of Scientific and Technical Information

P.O. Box 62

Oak Ridge, TN 37831

Telephone 865-576-8401

Fax 865-576-5728

E-mail reports@osti.gov

Web site http://www.osti.gov/contact.html

This report was prepared as an account of work sponsored by an agency of the United States Government. Neither the United States Government nor any agency thereof, nor any of their employees, makes any warranty, express or implied, or assumes any legal liability or responsibility for the accuracy, completeness, or usefulness of any information, apparatus, product, or process disclosed, or represents that its use would not infringe privately owned rights. Reference herein to any specific commercial product, process, or service by trade name, trademark, manufacturer, or otherwise, does not necessarily constitute or imply its endorsement, recommendation, or favoring by the United States Government or any agency thereof. The views and opinions of authors expressed herein do not necessarily state or reflect those of the United States Government or any agency thereof. 
Power and Energy Systems Group

\title{
EASTERN INTERCONNECTION DEMAND RESPONSE POTENTIAL
}

\author{
Young Sun Baek \\ Stanton W. Hadley \\ Rocio Uria-Martinez \\ Gbadebo Oladosu \\ Alexander M. Smith \\ Fangxing Li \\ Paul N. Leiby \\ Russell Lee
}

Date Published: November 2012

Prepared by

OAK RIDGE NATIONAL LABORATORY

Oak Ridge, Tennessee 37831-6283

managed by

UT-BATTELLE, LLC

for the

U.S. DEPARTMENT OF ENERGY

under contract DE-AC05-00OR22725 



\section{CONTENTS}

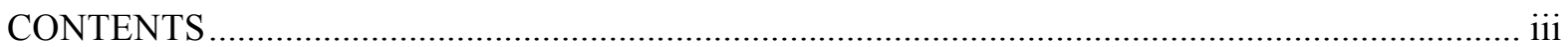

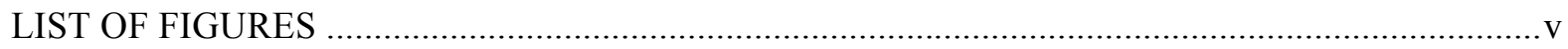

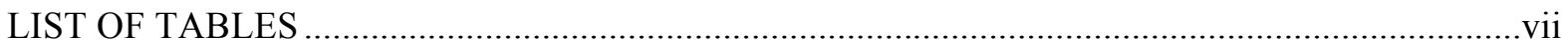

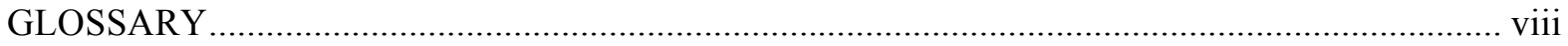

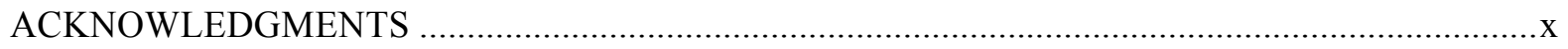

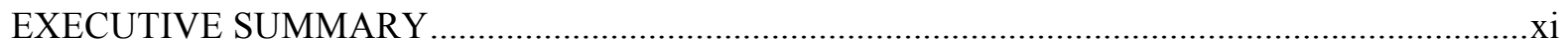

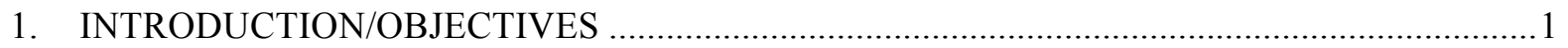

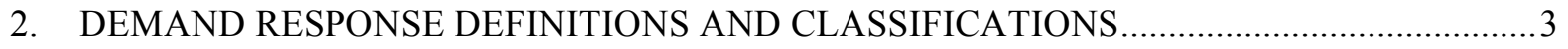

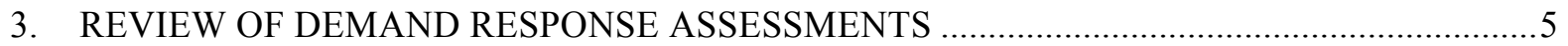

4. DEMAND RESPONSE ASSESSMENT UPDATES AND ORNL-NADR ANALYSIS ............14

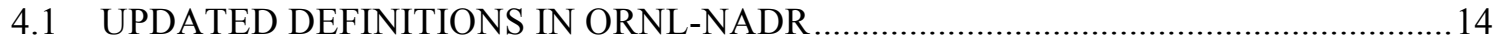

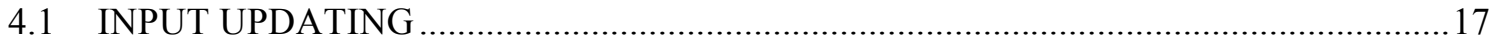

4.1.1 Baseline System Peak Load and Customer Population ........................................ 17

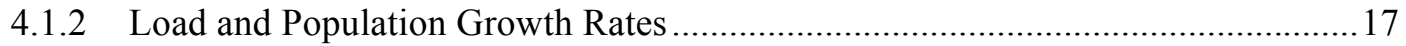

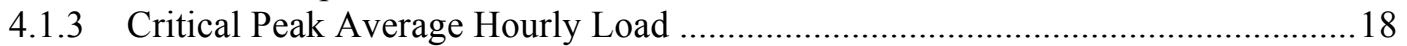

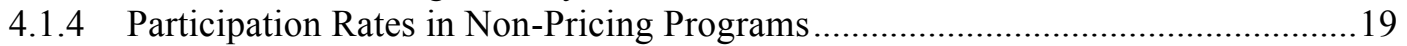

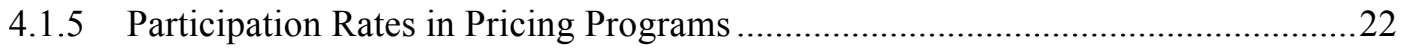

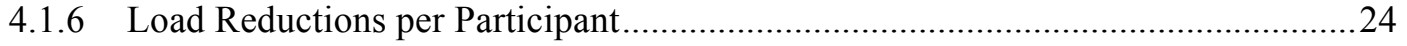

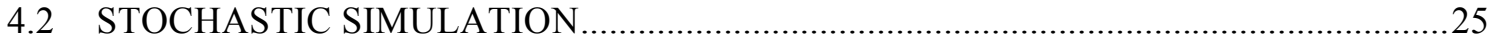

4.2.1 Initial Sensitivity Analysis with the Original NADR Model................................25

4.2.2 Dynamic Pricing Demand Response Specification in the Updated NADR Model 27

4.2.3 Monte Carlo Simulation of Demand Response under Dynamic Pricing ................28

5. EASTERN INTERCONNECTION DEMAND RESPONSE SCENARIO ANALYSIS RESULTS

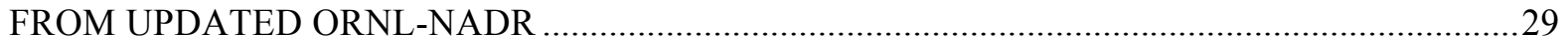

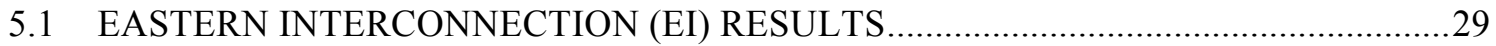

5.2 SUMMARY OF MONTE CARLO SIMULATION RESULTS AT EI LEVEL ................31

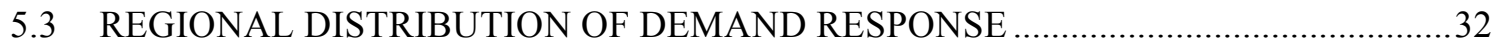

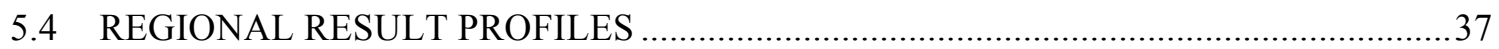

5.5 DEMAND RESPONSE SUPPLY CURVE FOR EIPC STUDY …...................................

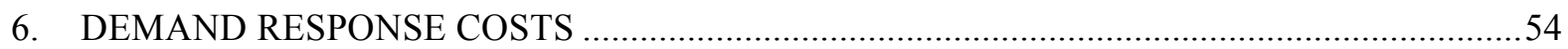

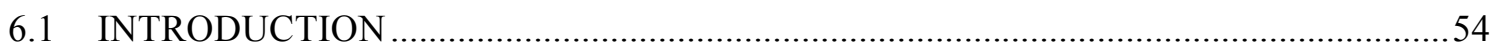

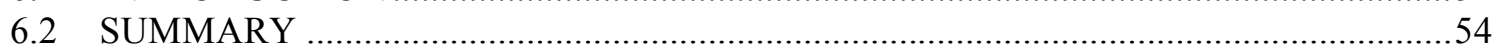

6.3 FINDINGS FROM PRIOR STUDIES OF DEMAND RESPONSE ….............................54

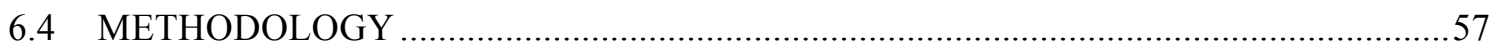

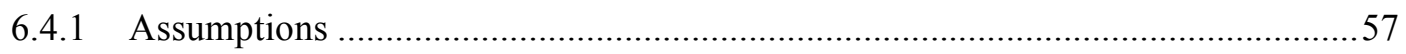

6.4.2 Analysis of AMI Business Cases in Societal Cost Test Framework .......................58

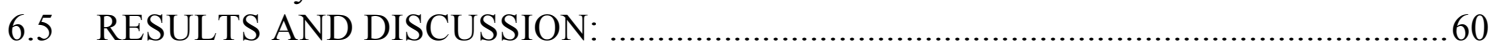

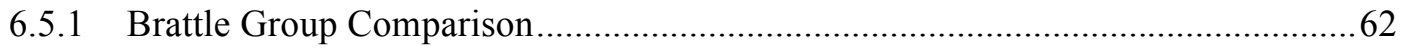

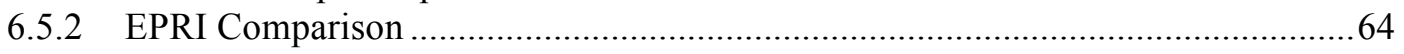

6.5.3 Discussion of Results according to Other Literature Findings ...............................65

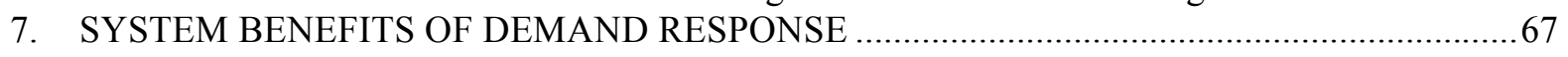

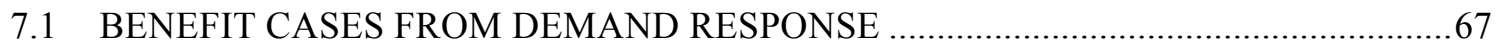

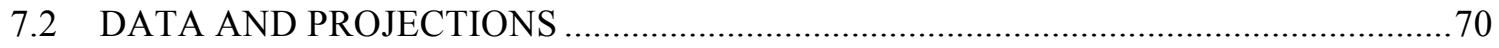

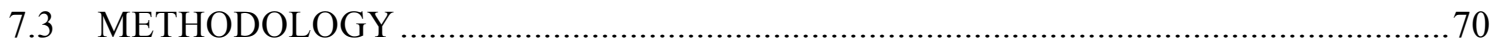

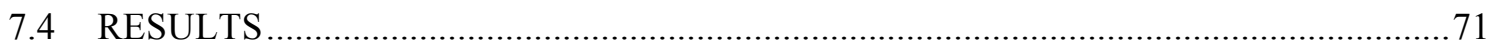

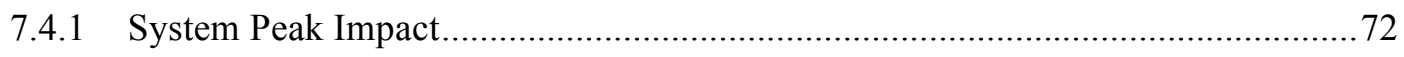




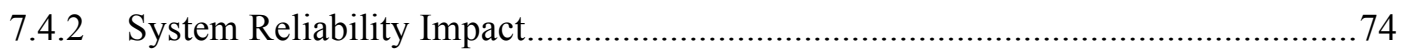

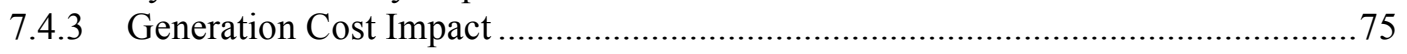

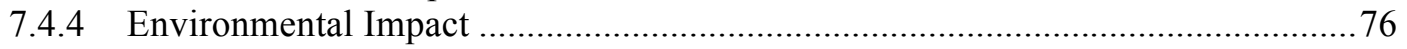

8. CHALLENGES TO DEMAND RESPONSE IMPLEMENTATION …................................... 79

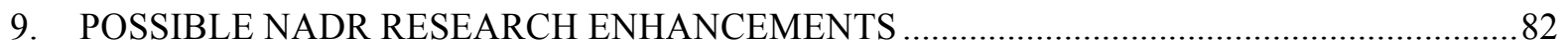

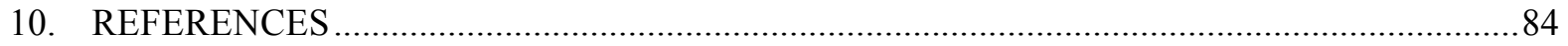

APPENDIX A. DEMAND RESPONSE LITERATURE REVIEW SUMMARIES ...................A-1 APPENDIX B. STATE-BY-STATE SCENARIO ANALYSIS RESULTS …............................ APPENDIX C. $\quad$ BENEFIT-COST TESTS TYPICALLY APPLIED TO DR PROGRAMS ........C-1 APPENDIX D. COST AND DEVICE DEPLOYMENT ESTIMATES FOR CENSUS DIVISIONS IN ORNL-NADR ..D-1 


\section{LIST OF FIGURES}

$\begin{array}{ll}\text { Figure } & \text { Page }\end{array}$

Figure 1: Potential Reduction in Summer Peak Demand from Demand Response Programs in Eastern

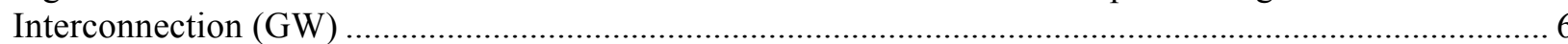
Figure 2: Dispatchable DR in Eastern Interconnection's Reliability Councils/NERC Regions (2009-2019)

Figure 3: Attainable Reductions in Summer Peak Demands by Region and Customer Type for Demand Response Programs (as of 2008) (FERC 2008) ................................................................................ 9 Figure 4: Maximum Aggregate Peak Demand Reductions Achieved Through Real-Time Pricing Programs for Eight Utility Companies Surveyed (Barbose, Goldman, and Neenan 2004) ...................... 11

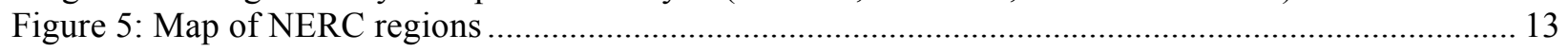

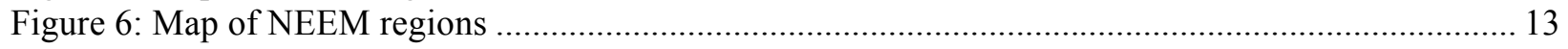

Figure 7: Key Building Blocks for Demand Response Impact Estimation in NADR (FERC 2009) ......... 14

Figure 8: U.S. summer electricity summer system peak load update ................................................... 17

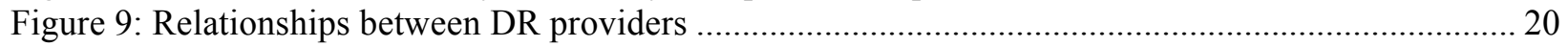

Figure 10: 2009 AMI Deployment Estimates for States in Eastern Interconnection............................... 23

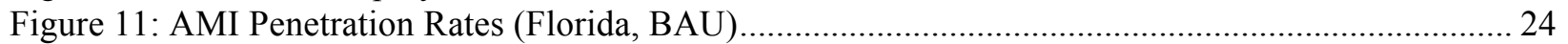

Figure 12: Percent Peak Load Reduction under Dynamic Pricing by Customer Type............................. 25

Figure 13: Sensitivity of Demand Response Potential to Selected Parameter Categories......................... 26

Figure 14: Elasticity of Demand Response Potential with respect to Selected Parameter Categories ....... 26

Figure 15: Relationship between Peak Load Reduction and Peak/Off-Peak Price Ratio (Maine, 2019) ... 27

Figure 16: EI Summer Peak Demand Forecast by Scenario ................................................................ 30

Figure 17: Potential Peak Reduction from Demand Response in EI, 2030 ........................................... 31

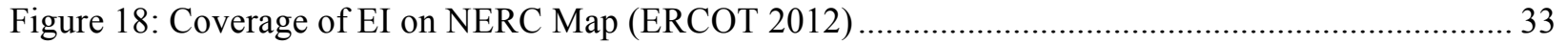

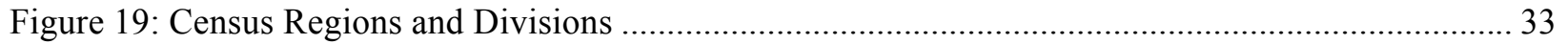

Figure 20: Demand Response Potential by Census Division and Scenario, 2030 …............................ 34

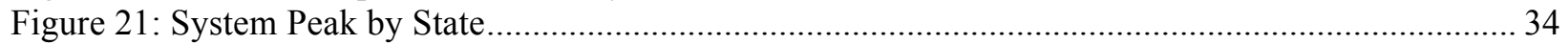

Figure 22: Top 10 States in System Peak (Y-axis: \% Peak Load Reduction) .......................................... 35

Figure 23: Top 10 States in Demand Response Potential under BAU (Y-axis: \% Peak Load Reduction) 36

Figure 24: Top 10 States in DR Potential under Full Deployment (Y-axis: Peak Load Reduction) .......... 36

Figure 25: New England Division System Peak Demand Forecasts by Scenario .................................... 37

Figure 26: New England Division DR Potential in 2030, by Scenario .................................................. 38

Figure 27: Middle Atlantic Division System Peak Demand Forecasts by Scenario ................................. 39

Figure 28: Middle Atlantic Division DR Potential in 2030, by Scenario ............................................... 40

Figure 29: East North Central Division System Peak Demand Forecasts by Scenario ............................ 41

Figure 30: East North Central Division DR Potential in 2030, by Scenario ......................................... 42

Figure 31: West North Central Division System Peak Demand Forecasts by Scenario ........................... 43

Figure 32: West North Central Division DR Potential in 2030, by Scenario ........................................ 44

Figure 33: South Atlantic Division System Peak Demand Forecasts by Scenario ................................... 45

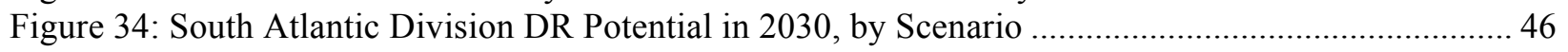

Figure 35: East South Central Division System Peak Demand Forecasts by Scenario ............................ 47

Figure 36: East South Central Division DR Potential in 2030, by Scenario ......................................... 48

Figure 37: West South Central Division System Peak Demand Forecasts by Scenario ............................ 49

Figure 38: West South Central Division DR Potential in 2030, by Scenario ....................................... 50

Figure 39: ORNL-NADR Runs with Variation in Critical Peak Price ................................................ 51

Figure 40: 5-Block Supply Curve Only with Pricing Programs in 2030 ............................................. 52

Figure 41: 6-Block Supply Curve and Model Curve with Allocated Non-Price DR in 2030 .................. 53

Figure 42: Total Costs of Demand Response for 2010-2030 in Eastern Interconnection (NPV, Millions) 61 
Figure 43: Total AMI Meters and Devices Deployed for 2010-2030 in Eastern Interconnection (Thousands). 61

Figure 44: Total Costs of AMI Deployment in 2010-2030 for the Eastern Interconnection (NPV, Millions)

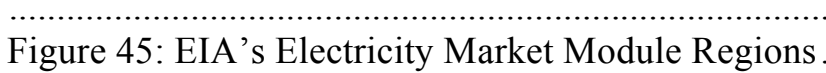
63

Figure 46: Energy Load Shape under No DR Case (NEWE region, August1-August6) .......................... 68

Figure 47: Energy Load Shape under DR-Notch Case (NEWE region, August1 - August6) ................... 69

Figure 48: Energy Load Shape under DR-Smart Case (NEWE region, August 1 - August 6)................. 69

Figure 49: Load Duration Curves and Power Plant Type Dispatch Order ............................................. 71

Figure 50: Annual Load Duration Curves under different scenarios (SRGW) ...................................... 72

Figure 51: Peak Portion of Load Duration Curve of SRGW ............................................................. 73 


\section{LIST OF TABLES}

Table

Page

Table 1: Key Differences in FERC's Assessment Scenario Assumptions 5

Table 2: Potential Peak Reduction from Utility-Administered Load Management Programs vs Reliability

Council Assessments (GW) . 9

Table 3: Proxy variables for Disaggregation of NERC region data into state-level data ......................... 12

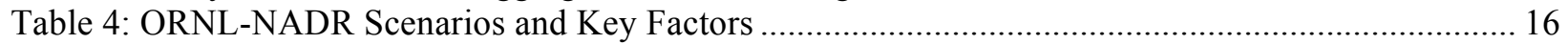

Table 5: Daily and Substitution Elasticities for Simulating Dynamic Pricing Demand Response............. 28

Table 6: Summary of Monte Carlo Simulation of Potential Peak Load Reduction from Demand Response in EI by Scenario, Pricing Program and Price, and Price Ratio $(\mathrm{GW})$................................................ 32

Table 7: Summary of Monte Carlo Simulation of Potential Peak Load Reduction from Demand Response in New England by Scenario, Pricing Program, and Price Ratio (MW) ............................................... 38

Table 8: Summary of Monte Carlo Simulation of Potential Peak Load Reduction from Demand Response in Middle Atlantic by Scenario, Pricing, and Price Ratio (MW) ............................................................ 40

Table 9: Summary of Monte Carlo Simulation of Potential Peak Load Reduction from Demand Response in East North Central by Scenario, Pricing Program, and Price Ratio (MW)......................................... 42

Table 10: Summary of Monte Carlo Simulation of Potential Peak Load Reduction from Demand Response in West North Central by Scenario, Pricing Program, and Price Ratio (MW) ......................... 44

Table 11: Summary of Monte Carlo Simulation of Potential Peak Load Reduction from Demand Response in South Atlantic by Scenario, Pricing Program, and Price Ratio (MW) ................................ 46

Table 12: Summary of Monte Carlo Simulation of Potential Peak Load Reduction from Demand Response in East South Central by Scenario, Pricing Program, and Price Ratio (MW) ......................... 48

Table 13: Summary of Monte Carlo Simulation of Potential Peak Load Reduction from Demand Response in West South Central by Scenario, Pricing Program, and Price Ratio (MW) ........................ 50

Table 14. DR Supply Curve as Proportion of Total DR Available in Region for EIPC Study ................. 52

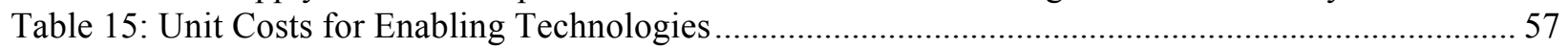

Table 16: Estimated Cost-per-Meter of Various AMI System Component............................................ 60

Table 17: Percent Differences between Brattle Group Estimates and ORNL-NADR analysis estimates using Brattle Group Deployment Assumptions ....

Table 18: Percent Differences between Brattle Group Estimates and ORNL-NADR analysis estimates

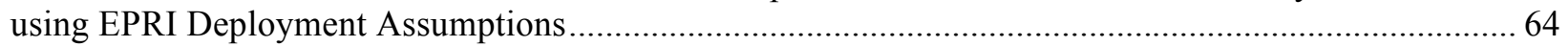

Table 19. Regional DR as Percentage of Peak Demand in 2030 under various scenarios ........................ 68

Table 20: Demand Response Scenarios used for Benefit Analysis ........................................................ 72

Table 21. System Peak Reductions with Increasing DR Penetration .................................................. 74

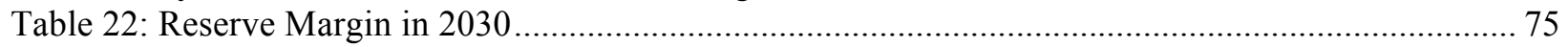

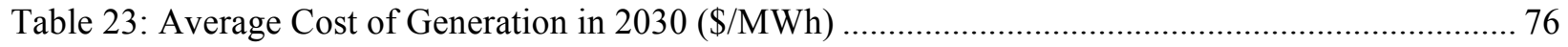

Table 24: Avoided Cost of Electricity Generation during the Peak Hours in 2030 (\$/MWh) .................. 76

Table 25: Change in Generation Volumes in 2030 due to DR program deployment (TWh) .................... 77

Table 26: Change in CO2 emissions in 2030 due to DR program deployment ........................................ 77 


\section{GLOSSARY}

\begin{tabular}{|c|c|}
\hline AEO & Annual Energy Outlook \\
\hline AGC & Automatic Generation Control \\
\hline AMI & Advance Meter Infrastructure \\
\hline AMR & Automated Meter Reading \\
\hline $\mathrm{AD}$ & Aggressive Deployment (ORNL-NADR Scenario) \\
\hline AP & Achievable Participation (Original NADR Scenario) \\
\hline BAU & Business As Usual \\
\hline C\&I & Commercial and Industrial \\
\hline CAC & Central Air-Conditioning \\
\hline CES & Constant Elasticity of Substitution \\
\hline CIS & Customer Information System \\
\hline CPP & Critical Peak Price \\
\hline $\mathrm{CT}$ & Combustion Turbine \\
\hline CPUC & California Public Utilities Commission \\
\hline DADS & Demand Response Availability Data System \\
\hline DLC & Direct Load Control \\
\hline DOE & Department of Energy \\
\hline DR & Demand Response \\
\hline EBAU & Expanded Business As Usual (Original NADR Scenario) \\
\hline OBAU & Optimistic Business As Usual (ORNL-NADR Scenario) \\
\hline $\mathrm{EE}$ & Energy Efficiency \\
\hline EI & Eastern Interconnection \\
\hline EIPC & Eastern Interconnection Planning Collaborative \\
\hline EISA & Energy Independence and Security Act \\
\hline EISPC & Eastern Interconnection State Planning Council \\
\hline ELCON & Electricity Consumer Resource Council \\
\hline EMM & Electricity Market Module \\
\hline EPRG & Electric Policy Research Group \\
\hline EPRI & Electric Power Research Institute \\
\hline ERCOT & Electric Reliability Council of Texas \\
\hline FERC & Federal Energy Regulatory Commission \\
\hline FD & Full Deployment (ORNL-NADR Scenario) \\
\hline FP & Full Participation (Original NADR Scenario) \\
\hline GIS & Geographic Information System \\
\hline GW & Giga-Watt \\
\hline ISO & Independent System Operator \\
\hline IOU & Investor-Owned Utility \\
\hline LDC & Load Duration Curve \\
\hline LMP & Locational Marginal Price \\
\hline LOLP & Loss of Load Probability \\
\hline LSE & Load-Serving Entity \\
\hline LTRA & Long Term Reliability Assessment \\
\hline MDMS & Meter Data Management Systems \\
\hline MISO & Midwest Independent System Operator \\
\hline
\end{tabular}




$\begin{array}{ll}\text { MW } & \text { Mega-Watt } \\ \text { MWG } & \text { Modeling Working Group } \\ \text { NADR } & \text { National Assessment of Demand Response (model) } \\ \text { NEEM } & \text { North American Electricity and Environment Model } \\ \text { NEMS } & \text { National Energy Modeling System } \\ \text { NERC } & \text { North American Electric Reliability Corporation } \\ \text { NPV } & \text { Net Present Value } \\ \text { NPVRR } & \text { Net Present Value revenue Requirements } \\ \text { ORCED } & \text { Oak Ridge Competitive Electricity Dispatch (model) } \\ \text { ORNL } & \text { Oak Ridge National Laboratory } \\ \text { PCT } & \text { Programmable Communicating Thermostat } \\ \text { PG\&E } & \text { Pacific Gas \& Electric } \\ \text { PLC } & \text { Power Line Carrier } \\ \text { PLMA } & \text { Peak Load Management Alliance } \\ \text { PLR } & \text { Peak Load Reductions } \\ \text { PMO } & \text { Program Management Office } \\ \text { PRISM } & \text { Pricing Impact Simulation Model } \\ \text { REC } & \text { Rural Electric Cooperative } \\ \text { RF } & \text { Radio Frequency } \\ \text { RTO } & \text { Regional Transmission Operator } \\ \text { RTP } & \text { Real Time Pricing } \\ \text { SGIC } & \text { Smart Grid Information Clearinghouse } \\ \text { SGIG } & \text { Smart Grid Investment Grant } \\ \text { SSC } & \text { Stakeholder Steering Committee } \\ \text { TOU } & \text { Time of Use } \\ \text { TRC } & \text { Total Resource Cost } \\ \text { TWh } & \text { Tera-Watt Hours }\end{array}$




\section{ACKNOWLEDGMENTS}

Funding for this research was provided by the Department of Energy (DOE) under the direction of David Meyer. The sponsorship is greatly appreciated.

Bob Pauley of Eastern Interconnection States Planning Council (EISPC) contributed meaningfully to the communications with EISPC and Navigant and the completion of this report.

Valuable comments on earlier drafts of this report were received from Greg Wikler (EnerNOC), Andy Satchwell (Lawrence Berkeley National Laboratory) and Nasr Alkadi (ORNL).

The authors are grateful for the willingness of these individuals to engage in a dialogue about the potential to expand demand-response resources in the Eastern Interconnection Area. Any errors that survived this review process are strictly the responsibility of the authors. 


\section{EXECUTIVE SUMMARY}

Demand response (DR), one of the key components in the Smart Grid initiative, has received increasing interest in recent years among power utilities, independent system operators, and policy makers. With this surge of interest in DR, in April 2010 the Department of Energy (DOE) issued a research call to provide technical support to the interconnection-level electric infrastructure planning projects they had issued earlier in the year. In Area of Interest 2, they identified a need/purpose: "The Eastern Interconnection States' Planning Council (EISPC) seeks to significantly improve the knowledge base and modeling capabilities of demand-side resources for purposes of transmission planning." In response to the research call, Oak Ridge National Laboratory (ORNL) conducted a research project to estimate the DR potential peak load reductions in the Eastern Interconnection area over the next two decades until 2030, as well as analyzed costs and benefits occurring out of the DR resources. This final report is the outcome of the study by a team of ORNL researchers with diverse backgrounds in engineering, economics, and public policy.

Ahead of quantitative analyses, an extensive review of existing DR assessments and projections from various sources was conducted. Then, four different DR deployment scenarios were developed: 1) Business-As-Usual (BAU), 2) Optimistic BAU, 3) Aggressive Deployment, and 4) Full Deployment. These scenarios varied in program participation rate, percentage of eligible customers, and scale of Advance Metering Infrastructure (AMI). The DR programs were classified into four different categories: pricing programs, direct load control (DLC), interruptible tariffs, and other DR programs. Based on the National Assessment of Demand Response (NADR) model developed by Federal Energy Regulatory Commission (FERC), the system peak demand by state and census division was forecasted. Key inputs and assumptions were updated with the latest data collected by FERC, Brattle Group, Energy Information Administration (EIA), and North American Electric Reliability Corporation (NERC). In addition, new equations considering the stochastic characteristic of the demand response programs were developed as an extension of the NADR model and the updated model was named ORNL-NADR. The detailed ORNLNADR specifications and scenario definitions are presented in Chapter 4.1.

Regional and state-level results of demand response potentials within the EI system are presented and analyzed in this report. ${ }^{3}$ Further, this report presents the analyses and results of the costs and benefits associated with demand response programs. The Oak Ridge Competitive Economic Dispatch (ORCED) model was used for the benefit analysis.

The unique contributions of this report can be summarized as follows:

1. Latest data from DR program surveys are used for this study;

2. Regression analysis is employed to address the issues related to the non-responding utilities in FERC's DR-AMI survey;

3. Monte Carlo simulation is employed to analyze the stochastic nature of the dynamic pricing program in terms of consumers' responsiveness to changes in peak to off-peak price ratios; and

4. Full-scale analyses of DR costs and benefits are conducted in this study.

\footnotetext{
${ }^{3}$ For detailed information, regional analysis is presented in Chapter 5.4 (Regional Result Profiles) and State-by-state results are provided in Appendix B.
} 
The major findings for EI are:

- System peak demand of EI begins at $569 \mathrm{GW}$ in 2009 and grows at an average annual growth rate of $1.2 \%$, reaching $724 \mathrm{GW}$ by 2030 under no DR assumption. Peak demand under BAU grows at a very similar rate overall. The reduction in peak demand under BAU, relative to the No DR forecast is $41 \mathrm{GW}$ by 2030 representing a $6 \%$ of peak demand. The Optimistic BAU scenario results in a further reduction in peak demand of $114 \mathrm{GW}(16 \%)$. The Aggressive Deployment scenario produces reduces the peak demand in 2030 by $24 \%$ (171 GW). The Full Deployment scenario produces the largest reduction of $219 \mathrm{GW}(30 \%)$ in 2030.

- The DR reduction amounts are limited in the number of hours they are available over a year, according to FERC's NADR model. At higher DR penetration rates, the system peak load reduction will be smaller than the percentages shown because the DR resource will be spread over more hours rather than concentrated at pre-fixed peak hours.

- According to $2030 \mathrm{DR}$ potential analysis by scenario, program type, and end-use sector, under BAU and Optimistic BAU, the largest gains come through interruptible tariffs and other DR. A significant growth in pricing programs (with and without enabling technologies) is noticed under the Aggressive and Full Deployment scenarios. DLC has a significant impact in the residential and small commercial and industrial (C\&I) sectors. The majority of DR comes from large C\&I customers primarily through interruptible tariffs and capacity and load bidding. In the residential sector, most untapped potential for DR comes from the pricing programs.

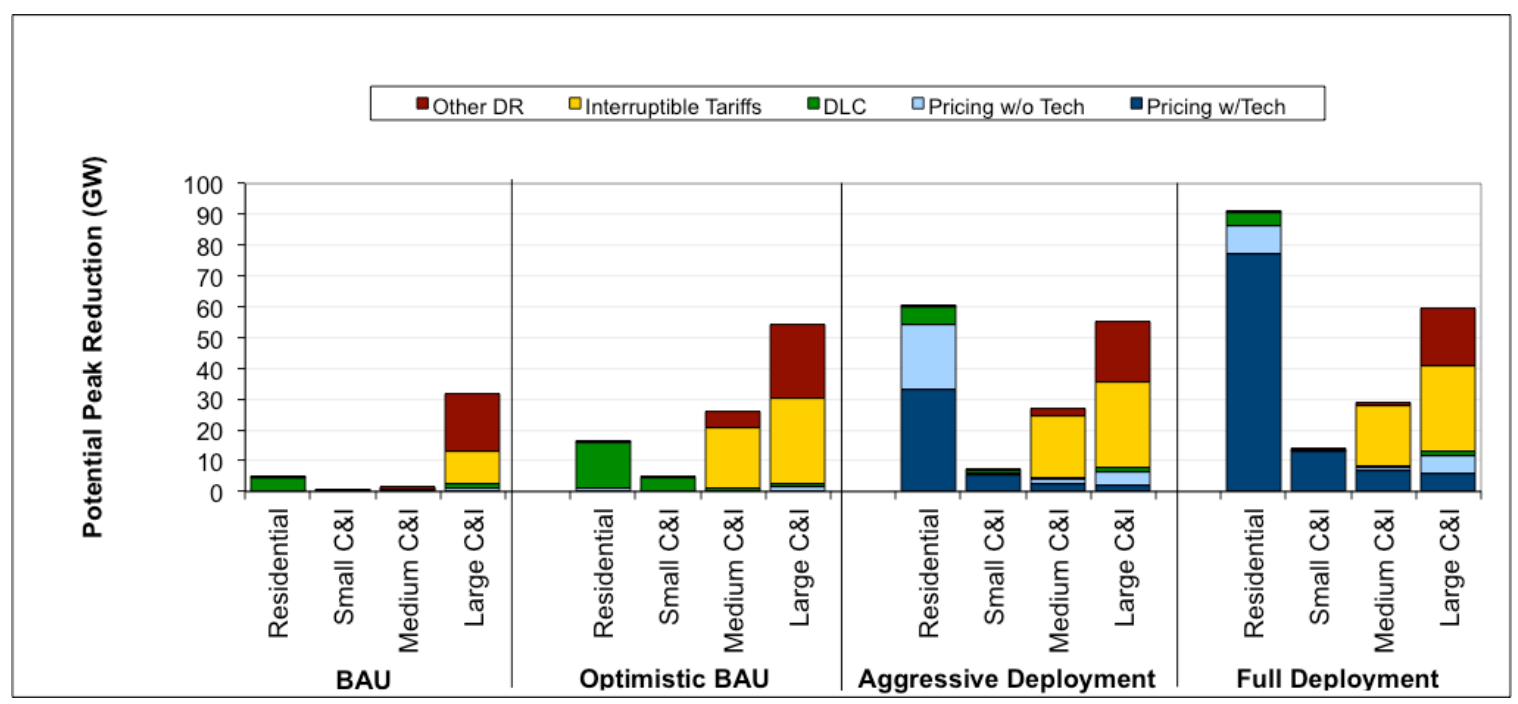

Potential Peak Reduction from Demand Response in EI, 2030

- Regionally, Middle Atlantic (9\%) and New England (7\%) have the highest estimates in terms of percentage peak load reduction under the BAU scenario in 2030. On the other hand, regions in the South such as East South Central (2\%) and West South Central (3\%) show relatively small existing programs possibly because they have historically had few DR programs.

- Central air conditioning saturation plays a key role in determining the magnitude of the Aggressive and Full Deployment demand response potentials. Regions that have hotter climate requiring high central air conditioning systems (such as the South Atlantic, East South Central, and West South Central Divisions) could achieve greater average-per-customer impacts from DLC and dynamic pricing programs. As a result, these regions tend to have larger overall 
potential under the Aggressive and Full Deployment scenarios where pricing programs play a more significant role than in the BAU and Optimistic BAU scenarios.

- Our Monte Carlo simulation varied the peak to off-peak price ratios for dynamic pricing programs. Table 6 in Chapter 5.2 presents the summary statistics from these simulations for three price ratios $(5,10$ and 15). The contribution from dynamic pricing to the peak load reduction without enabling technology varies substantially in the range between 27 and $73 \mathrm{GW}$ in the Aggressive Deployment scenario. The contributions from dynamic pricing without technology in the Full Deployment scenario are about half those in the Aggressive Deployment scenario. The results for pricing with technology programs show that the demand response are similar to those from the case without technology program under the Aggressive Deployment scenario (41 GW to $118 \mathrm{GW}$ ), but much larger under the Full Deployment scenario (101 GW to $276 \mathrm{GW}$ ).

- Using total resource cost test framework, we estimated the net present value (NPV) of DR costs for 20 years $(2010-2030)$ at a 3 percent discount rate. DR costs are assumed to primarily consist of the costs of advanced metering infrastructure (AMI) systems and load-controlling technologies (enabling technologies) such as DLC devices and Programmable Communicating Thermostats. The NPV of total DR costs ranges between $\$ 13$ billion (Low, Optimistic BAU) and \$77 billion (High, Full Deployment).

- We classified the system benefits into four categories: of 1) system peak impact, 2) system reliability impact, 3) avoided generation cost, and 4) environmental impact. DR significantly contributes to increasing the system reliability. The regional reserve margin increases by 13 (BAU) - 28 (Full Deployment) percentage points in 2030. On the other hand, the impacts on reduction in average generation cost and total $\mathrm{CO}_{2}$ emissions are not noticeable. This is because DR addresses only the peak hours (60 hours on average), which last less that $1 \%$ of a year.

The results in this report may serve as a decision-support information source for Eastern Interconnection States Planning Council (EISPC) and individual state representatives for transmission expansion planning. 



\section{INTRODUCTION/OBJECTIVES}

Historically, long-term planning within the electric sector was most concerned with providing sufficient generation and transmission resources to meet expected customer demand. The demands on the system were considered fixed and outside of the control of utilities. Small amounts of capacity were available through demand side management but these were not widely considered during long-term transmission planning. With the advent of increased demand response (DR) resources being made available to utilities through "smart grid" initiatives, less costly DR supplies, and greater difficulty in adding supply-side capacity, it has become increasingly necessary for planning to take into account these resources.

The extent of demand response (DR) penetration over the next two decades is one of many aspects to consider in estimating long-term transmission requirements. How do different volumes and types of DR change the requirements for new generation and transmission? Does DR reduce total energy use and emissions and by how much? What is the most efficient mix of resources (generation, DR, energy efficiency, energy storage, smart grid, distributed generation) to accomplish the overarching goals of reliable, affordable and clean electricity?

In April 2010 the U.S. Department of Energy (DOE) issued a research call to provide technical support to the interconnection-level electric infrastructure planning projects they had issued earlier in the year. In Area of Interest 2 they identified a need/purpose: “The Eastern Interconnection States' Planning Council (EISPC) seeks to significantly improve the knowledge base and modeling capabilities of demand-side resources, among other things, for purposes of transmission planning. These improvements are critical to the credibility of transmission expansion study work and the value of such work in formulating state and provincial policies.” (DOE 2010)

The scope of the project is "to accurately estimate the demand-side resource technical and economic potential in the power system of the Eastern Interconnection." It lists a number of possible topics that may be studied, including estimating energy efficiency, demand response, and distributed generation potentials for use by the EISPC and Eastern Interconnection Planning Collaborative (EIPC) in their studies, potential impacts of energy efficiency programs and policies, and technical assistance to these groups regarding demand resources.

A number of these activities were completed through ORNL work with the EIPC Stakeholder Steering Committee (SSC). These included working with various sub-groups of the Modeling Working Group to develop estimates of existing and possible energy efficiency amounts, demand response capacities, and distributed generation growth from photovoltaic solar installation. These projections were used in Phase I and Phase II of the EIPC long-term transmission study.

Another facet of the project is an analysis of the potential for energy efficiency across the Eastern Interconnection. This is being conducted by Georgia Institute of Technology under sub-contract to ORNL. They are using the EIA National Energy Modeling System (NEMS) to estimate the impact of carrying out different energy efficiency policies in the industrial, commercial, and residential sectors.

The work summarized in this report is in response to the DOE-requested topic "Updating the Federal Energy Regulatory Commission (FERC)'s A National Assessment of Demand Response Potential for derivation of demand response resource potential in load forecasts 10-years and 20-years in the future." This report summarizes the work done by ORNL in assessing DR potential, costs and system impact for the Eastern Interconnection. The ORNL team has conducted the following tasks as part of this assessment: 
- Reviewing/contrasting existing assessments of DR potential in Eastern Interconnection region in terms of results and methodologies

- Updating values and refining methodology to construct estimates of DR potential and system benefits for Eastern Interconnection

- Estimating implementation costs for different types of DR programs

- Estimating system benefits of DR programs

Besides extending and enhancing the FERC model, the report includes a survey of existing smart grid and demand response programs and studies for the cost estimates for future DR programs. It also conducts a benefits study of different types and levels of DR with regard to electric system operations, costs, and emissions.

Chapter 2 defines and classifies the different types of DR. Chapter 3 reviews various assessments to date. Chapter 4 describes the modifications to the NADR model definitions, inputs, and stochastic simulation. Chapter 5 presents results for the Eastern Interconnection regions. Chapter 6 covers our analysis of DR costs. Chapter 7 covers our analysis of the system benefits from DR using the ORCED model. Chapters 8 , 9, and 10 cover challenges to DR implementation, future possible R\&D, and references.

We hope that this report and associated model development will provide a valuable resource to states, planners, and other stakeholders in the electricity system. 


\section{DEMAND RESPONSE DEFINITIONS AND CLASSIFICATIONS}

FERC defines demand response as "the changes in electric usage by demand-side resources from their normal consumption patterns in response to changes in the price of electricity over time, or to incentive payments designed to induce lower electricity use at times of high wholesale market prices or when system reliability is jeopardized (FERC, 2009)." DR tariffs and incentive programs are offered by utility companies, system operators, utility companies, electricity cooperatives, municipal power agencies, and other load-serving entities, and they incentivize consumers to reduce their electricity consumption over a specific period of time (Isser 2009, FERC 2009, PLMA 2002). DR programs are quite diverse in the means through which they offer energy-consumption-reduction incentives.

Typical classifications of demand response programs include:

\section{- Administered by utilities (retail) vs. administered by ISOs/RTOs (wholesale)}

In competitive wholesale markets, there are two layers in DR provision. The system operator is required to match load and generation on a continuous basis but cannot provide balancing services directly. Instead, ISOs/RTOs design DR programs at the wholesale level. Demand response providers or curtailment service providers may function as intermediaries between the ISO and the end-use customers in the implementation of these programs. Demand response providers aggregate from multiple end customers the minimum load (e.g., $100 \mathrm{~kW}$ in CAISO) required to participate in the wholesale market from multiple end-use customers. Demand response providers and curtailment service providers can be utilities or other entities.

\section{- Emergency vs. economic programs}

Emergency Programs - These programs are only engaged during conditions that threaten grid stability. Customers who reduce loads are offered compensation based on a high minimum price (e.g. \$500/MWh) and an added rate that varies with the Locational Marginal Price (LMP) of their electricity (PLMA 2002).

Economic Programs - These programs involve day-ahead markets, in which electricity is purchased at least one day before it is consumed. Suppliers may offer hourly rates for electricity consumption in the future, and customers voluntarily reduce their electricity consumption based upon these future rates. Alternatively, customers may "bid" future electricity consumption volume reductions in return for customer-specified compensation levels; suppliers may then choose to purchase the optimal electricity consumption reductions from among customer offers. These programs require interval metering (PLMA 2002, FERC 2009).

\section{- Dispatchable vs. non-dispatchable}

Dispatchable programs allow the system operators to call upon DR resources to modify demand based on the status of the system. Non-dispatchable systems have pre-set signals on demand modification and so are under less control by operators.

Curtailable Load Programs - Large commercial and industrial customers (e.g. factories, retail stores) enter into contracts with their electricity suppliers to reduce their load on command from the supplier. Suppliers (e.g. a utility company) notify the customer between 30 minutes to one hour in advance of a requested load reduction. The customer is free to decide how to reduce its own load, and is compensated by the supplier at an agreed-upon rate (usually in the form of rebates to the customer's electricity bill). The customer and electricity supplier agree to perform these reductions a certain number of times per year 
(or per season) and with a certain frequency (e.g. 5 reductions, once every two months). Customer's reductions are measured with respect to a "baseline consumption level," i.e. the consumption that would normally occur without the customer's reduction efforts. This level is developed through energy modeling of the customer's consumption and is part of the contract established between the customer and the supplier. Interval Meters are used to monitor the customer's electricity consumption during the requested load reduction (PLMA 2002, FERC 2009).

Interruptible Load Programs - These programs are similar to Curtailable Load Programs, except that customers must be able to reduce most or all their load. Customers must be able to reduce a minimum (e.g. $1000 \mathrm{kWh}$ ) to qualify for these programs, which usually offer larger compensations than curtailable load programs (PLMA 2002).

Direct Load Control - These programs target residential and small industrial customers. The agreements made between customers and suppliers of electricity are similar to those found in Curtailable Load Programs; instead of the customer being free to choose how to reduce his or her load, however, the supplier directly controls the deactivation of specific appliances (e.g. cycling the air conditioning on and off). Special infrastructure is required for this, which may include additional lines for telecommunication being connected to the customer's location or special voltage-signaling devices being installed at the supplier's location (PLMA 2002).

Pricing Programs - These programs require advanced metering technologies to communicate real-time changes (hourly or more frequently) to customers. RTP categorizes further into three major sub-classes:

- "Real Time Pricing:" The supplier and the participating customer develop the customer's baseline electricity consumption profile through energy modeling. If the customer consumes more than the baseline during a particular hour of the year, it pays a tariff to the supplier for that hour; if the customer consumes less than the baseline for a particular hour during the year, it receives a premium payment from the supplier for that hour.

- "One-Part Tariffs:" Spot prices for retail electricity are provided on the hour (or more frequently) to the customer. The customer then voluntarily reduces electricity consumption to save money. These retail spot prices reflect aggregate supply and demand conditions in the wholesale market. One-Part Tariffs do not require baseline consumption estimates.

- "Super-Peak", "Critical Peak" or "Coincident Peak" Pricing: The customer simply agrees to be charged a higher price for certain hours of the year and to receive a discount on all other hours. Suppliers notify customers a day in advance of what the high-price hours will be, so that the customer can decide how best to manage its power demand (PLMA 2002, FERC 2009).

- Peak Time Rebate programs: Customers get a rebate for consuming less than its predetermined baseline usage during planned or emergency events for which they receive notification.

- Time-of-Use Rates (TOU) - These programs target all customers. Like RTP programs, TOU programs offer hourly rates to customers that induce voluntary electricity consumption reductions by the customers; unlike RTP programs, however, TOU hourly rates are fixed throughout the year so customers know well in advance what they will pay for electricity. (PLMA 2002, FERC 2009)

Pricing programs typically result in non-dispatchable DR resources since decisions on when and how much to modify the consumption profile relative to the baseline are made by the customer. Critical peak pricing with controlling technology is an exception. On the other hand, curtailable loads, interruptible loads and appliances with direct load control are DR resources whose dispatch is, to some degree, controlled by the system operator. 


\section{REVIEW OF DEMAND RESPONSE ASSESSMENTS}

The ORNL team conducted extensive review of existing assessments and projections as a first step in assessing electricity demand response potential to support EIPC's planning efforts for transmission grid expansion in the Eastern Interconnection. The studies and assessments that were reviewed are:

a) National level DR assessments conducted by FERC and EPRI (see Appendix A for a summary)

b) DR projections by ISOs/RTOs

c) DR projections by NERC and regional reliability councils

d) Utility-administered DR programs as reported in EIA Form 861

e) Other literature sources

Among these sources, some assess DR potential (source a), some project DR levels (sources b and c) and others calculate existing levels (source d).

\section{Review of national level assessments}

In Section 529 of the Energy Independence and Security Act (EISA), Congress mandated FERC to develop a process that would direct the nation towards achievement of its demand response potential. In particular, EISA required FERC to prepare a National Assessment of Demand Response Potential and a National Action Plan. The former, submitted to Congress in June 2009, evaluated state-level DR potential in 5 and 10 year horizons and identified barriers to implementation and policies that could bring down those barriers. Meanwhile, the Action Plan identifies tools to communicate with States, utilities and customers and to assist them in implementing demand response programs. The FERC assessment presents results for 4 scenarios: business as usual (BAU), expanded business as usual (EBAU), achievable participation $(A P)$ and full participation (FP). Table 1 shows the main attributes of those 4 scenarios. Four customer groups (residential, small C\&I, medium C\&I and large C\&I) and five program types (direct load control, interruptible demand, dynamic pricing with enabling technology, dynamic pricing without enabling technology, other) are considered. ${ }^{4}$

Table 1: Key Differences in FERC's Assessment Scenario Assumptions

\begin{tabular}{|l|c|c|c|c|}
\hline & Business-as- usual & $\begin{array}{c}\text { Expanded } \\
\text { business-as-usual }\end{array}$ & $\begin{array}{c}\text { Achievable } \\
\text { participation }\end{array}$ & Full participation \\
\hline AMI deployment & Partial deployment & Partial deployment & Full deployment & Full deployment \\
\hline $\begin{array}{l}\text { Dynamic pricing } \\
\text { participation (of eligible) }\end{array}$ & Today's level & $\begin{array}{c}\text { Voluntary (opt-in): } \\
5 \%\end{array}$ & $\begin{array}{c}\text { Default (opt-out): } \\
60-75 \%\end{array}$ & $\begin{array}{c}\text { Universal } \\
\text { (mandatory): } 100 \%\end{array}$ \\
\hline $\begin{array}{l}\text { Eligible customers offered } \\
\text { enabling tech }\end{array}$ & None & None & $95 \%$ & $100 \%$ \\
\hline $\begin{array}{l}\text { Eligible customers } \\
\text { accepting enabling tech }\end{array}$ & None & None & $60 \%$ & $100 \%$ \\
\hline $\begin{array}{l}\text { Basis for non-pricing } \\
\text { participation rate }\end{array}$ & Today's level & $\begin{array}{c}\text { "Best practices" } \\
\text { estimate }\end{array}$ & $\begin{array}{c}\text { "Best practices" } \\
\text { estimate }\end{array}$ & $\begin{array}{c}\text { "Best practices" } \\
\text { estimate }\end{array}$ \\
\hline
\end{tabular}

\footnotetext{
${ }^{4}$ Enabling technology refers to devices that automatically reduce consumption during high-priced hours. In the case of residential and small C\&I customers, it would typically be a programmable communicating thermostat. For large C\&I customers, it refers to automated demand response systems. The "Other DR Programs" category includes programs primarily available to medium and large C\&I customers such as capacity bidding and demand bidding. Residential direct load control refers exclusively to air conditioning appliances due to state-level saturation data for other candidate appliances (e.g., water heaters, pool pumps). Timeof-use rates are not included in the portfolio of DR programs captured in this assessment.
} 
The EPRI study evaluates both energy efficiency and demand response potentials. It considers a 20-year time horizon (2010-2030) and presents results at the Census Region level. Based on the concepts of technical potential and economic potential, this study provides results for two scenarios: maximum achievable potential (economic potential * market acceptance rate) and realistic achievable potential (maximum achievable potential * program implementation factor that reflects utility budget constraints and regulatory or political barriers/incentives in different regions). DR programs considered in this analysis include direct load control (for all sectors), dynamic pricing programs (for all sectors) and interruptible demand (for commercial and industrial sectors). No distinction is made between dynamic pricing with/without enabling technology. Moreover, commercial and industrial customers are considered as different groups with no distinction made by their size.

Figure 1 compares potential summer peak demand reductions for the years and scenarios highlighted in the FERC and EPRI studies. Results from the two studies are not directly comparable because of different programs, customer classifications, modeling horizon and other assumptions but it is still informative in that it reveals a much more optimistic assessment from the FERC study. Since the two studies use different summer peak demand baselines, the potential reductions shown in Figure 1 are expressed in absolute terms rather than as a percentage reduction relative to the baseline without DR. The FERC study uses as baseline the summer peak demand forecast from the NERC 2008 Long Term Reliability Assessment, which excludes the effects of demand response but includes the effect of energy efficiency and implies an average annual growth rate of $1.7 \%$. The EPRI study constructs its baseline starting from the AEO2008 Reference Case and assuming an average annual growth rate of $1.5 \%$.

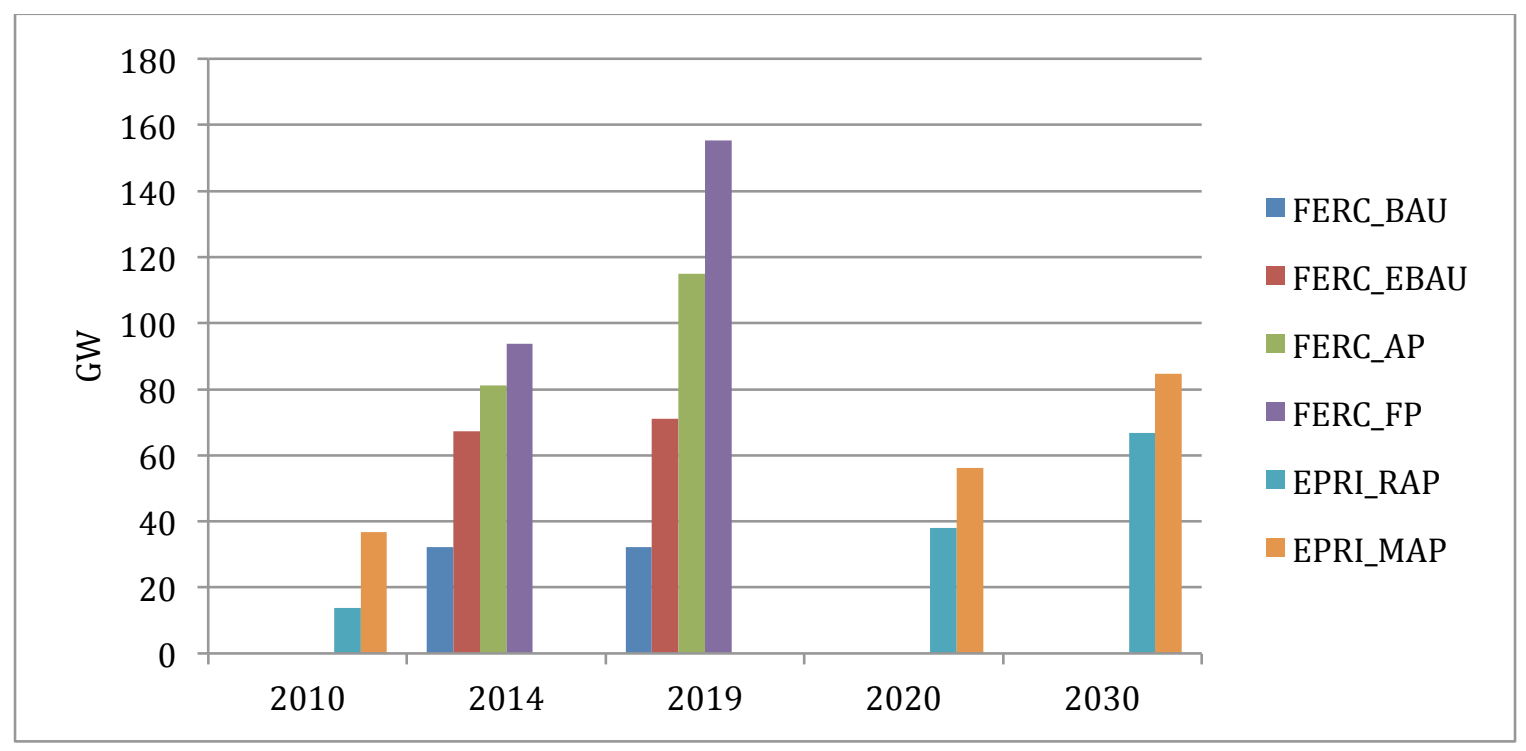

Figure 1: Potential Reduction in Summer Peak Demand from Demand Response Programs in Eastern Interconnection $(\mathbf{G W})^{5}$

The estimates from these two assessments differ significantly in potential summer peak demand reductions obtained from DR. However, both agree in that DR potential in the Eastern Interconnection represents between $80 \%$ and $90 \%$ of the U.S. total. In the FERC study the DR potential exceeded $100 \mathrm{GW}$ barrier by 2019 in the achievable participation and full participation scenarios, but not in any of the

\footnotetext{
${ }^{5}$ The figures in this graph correspond to a proxy of the Eastern Interconnection area defined as the Lower 48 minus Census Divisions 8 and 9.

FERC_BAU (FERC's Business-As-Usual Scenario); FERC_EBAU (FERC's Expanded BAU Scenario); FERC_AP (FERC's Achievable Participation Scenario); FERC_FP (FERC's Full Participation Scenario); E
} 
scenarios presented in the EPRI assessment. Achieving a $60 \mathrm{GW}$ reduction in the Eastern Interconnection's peak demand by 2014 would only require small modifications to current program offerings (i.e., transitioning to the expanded business-as-usual scenario) in the FERC analysis while it is not within the boundaries of realistic potential by 2020 under EPRI's assumptions.

\section{Combining projection data to produce aggregate, useful estimates}

A complete DR projection that would be useful to EIPC transmission planning efforts should distinguish between dispatchable and non-dispatchable resources. ${ }^{6}$ It should include ISO and utility-administered programs. It should cover the entire Eastern Interconnection territory and be disaggregated into the same spatial units as the electric system model in which demand response projections are going to be used. Sources b) through e) provide projections, but not in a form that could be directly used to estimate DR potential:

- Source b) does not account for utility-administered programs and a portion of the Eastern Interconnection is not within any ISO or RTO service territory

- Source c) covers the entire Eastern Interconnection territory but does not account for nondispatchable DR resources

- Source d) only provides an aggregate potential peak demand reduction for each utility with no clear way to disentangle dispatchable and non-dispatchable DR from that aggregate number

- Source d) only provides historical data

- Sources b), c) and d) are all updated on an annual basis

Figure 2 summarizes dispatchable DR as compiled from electric reliability council websites in the Eastern Interconnection for the 2010-2019 period (source $b$ in the list presented at the beginning of this chapter). Reliability councils must report to NERC every year on peak demand forecasts for the next ten years. Reliability councils collect data from utilities and/or ISOs in their respective service territories. Reliability council reports to NERC contain total versus net internal demand projections. The difference between those two magnitudes is demand response. However, NERC's purview is electric reliability so that only DR that could be directed by the system operator or balancing authority in case of emergency is considered in these reports. This estimate would be comparable to the dispatchable portion of the business as usual scenario in FERC's DR assessment.

\footnotetext{
${ }^{6}$ Dispatchability is a necessary attribute for DR to count as a resource in meeting reliability standards.
} 


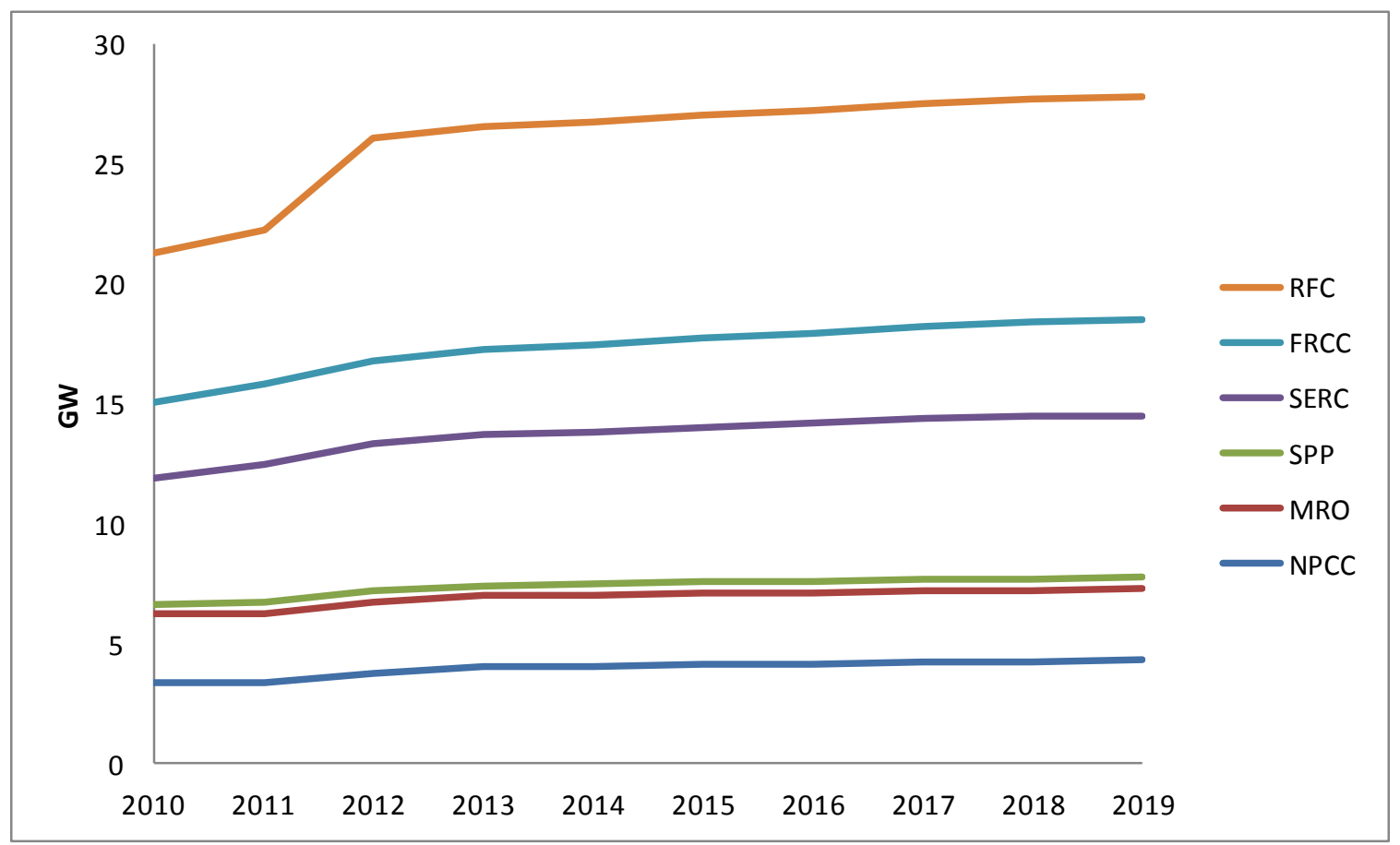

Figure 2: Dispatchable DR in Eastern Interconnection's Reliability Councils/NERC Regions (2009-2019)

Since there are no organized wholesale markets in their territories, FRCC, SERC and SPP numbers correspond exclusively to utility-administered programs. MRO numbers combine both utility administered and ISO-administered programs. RFC and NPCC numbers coincide with those reported by their corresponding ISOs.

According to these projections, the $30 \%$ increase in dispatchable DR (curtailable load + interruptible load + direct control load) projected from 2010 to 2019 would happen mostly in the first two years and mostly in the RFC region. NERC (2010) cautions that, in most cases, actual forecasting of DR is not done and projected numbers are based on the amount of capacity contracted in the current commitment period (generally 1 to 3 years forward). Such behavior is consistent with the very flat curves displayed in Figure 2 .

Previous studies have estimated potential peak demand reductions from DR at the NERC region level. One example is Cappers, Goldman, and Kathan (2009). Results from that study, summarized in Figure 3, differ significantly from the ones discussed above because they include dispatchable and non-dispatchable DR resources. Figure 3 reveals that existing demand response programs can reduce between 3\% and 9\% of peak summer electricity demands for most RTO and ISO regions, with the exception of the Midwest Reliability Region where demand response programs can reduce up to $20 \%$ of peak electricity demand. Some of the factors that help explaining regional differences in DR potential are central air conditioning penetration rates, customer type mix and cost effectiveness of enabling technology. 


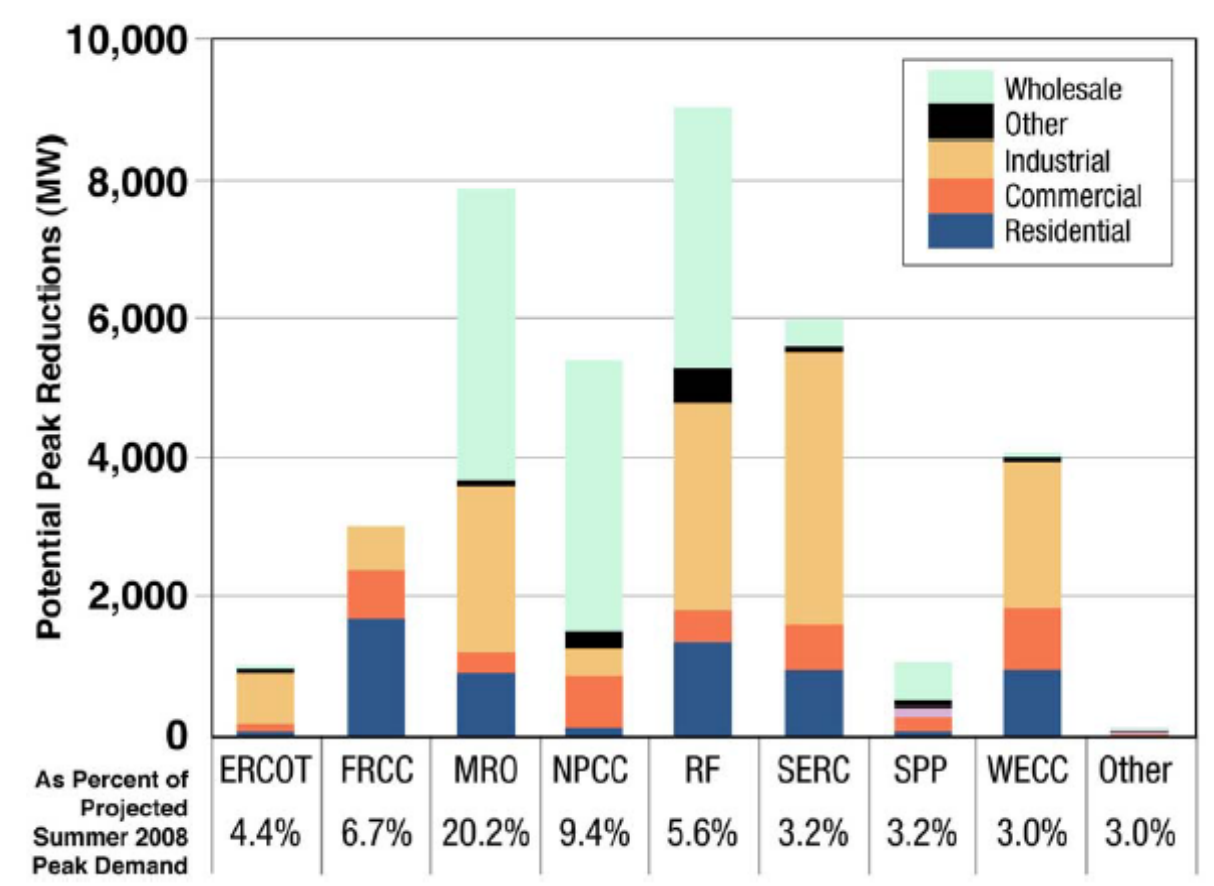

Figure 3: Attainable Reductions in Summer Peak Demands by Region and Customer Type for Demand Response Programs (as of 2008) (FERC 2008)

Table 2 combines information from reliability councils and EIA Form 861 (utility-administered DR programs) to estimate dispatchable and non-dispatchable DR portions at the NERC region level.

Table 2: Potential Peak Reduction from Utility-Administered Load Management Programs vs Reliability Council Assessments $(\mathrm{GW})^{7}$

\begin{tabular}{|l|c|c|c|c|}
\hline & $\begin{array}{c}\text { EIA Form } \\
\text { 861_Total } \\
\mathbf{( 2 0 0 9 )}\end{array}$ & $\begin{array}{c}\text { EIA Form 861_utilities } \\
\text { with no incentive } \\
\text { payments (2009) }\end{array}$ & $\begin{array}{c}\text { Reliability council } \\
\text { assessments (2010) }\end{array}$ & $\begin{array}{c}\text { Estimated total } \\
\text { dispatchable } \\
\mathbf{( 2 0 1 0 )}\end{array}$ \\
\hline NPCC & 0.43 & 0.07 & 3.32 & 3.68 \\
\hline RFC & 5.11 & 2.30 & 6.20 & 9.01 \\
\hline MRO & 4.58 & 2.46 & 2.90 & 5.02 \\
\hline SPP & 1.17 & 0.83 & 0.42 & 0.76 \\
\hline SERC & 5.15 & 2.54 & 5.26 & 5.26 \\
\hline FRCC & 3.04 & 0.25 & 3.19 & 3.19 \\
\hline Total & 19.48 & 8.45 & 21.29 & 26.92 \\
\hline
\end{tabular}

Sources: EIA Form 861 (2009), Reliability Council Regions LTRAs (2010)

For FRCC and SERC, the reliability council numbers are very close to those in EIA's Form 861 (the difference could be entirely due to the different years of reporting from both sources). This is consistent with the fact that in those two regions, DR is done entirely at the utility level because there are no ISOs/RTOs.

For SPP, the difference between the two numbers can be attributed to utility level programs not accounted by the reliability council.

\footnotetext{
${ }^{7}$ This is the potential given the existing number of customers, AMI devices and so forth.
} 
For MRO, the difference should be mostly explained by non-dispatchable programs provided by utilities in that area. Bharvirkar et al. (2008) studied the DR resources available within the Midwest Independent System Operator (MISO) service territory, finding a total of 4,727 MW of demand response resources available of which $90 \%$ were administered by utility companies.

For NPCC and RFC, the reliability council assessment accounts for the wholesale component of DR while the EIA Form accounts for the utility component.

The missing piece in estimating a total peak demand reduction number for the Eastern Interconnection from combining the information sources described at the beginning of this chapter would be to figure out what fraction of the utility-level programs reported in EIA Form 861 are non-dispatchable resources. There is no direct, accurate way of finding out that fraction with only the Form 861 information. However, an upper bound can be computed using information about whether a utility reports or not incentive payments since those normally correspond to dispatchable programs. The "estimated total dispatchable DR" for 2010 in Table 2 was computed as the sum of the reliability council assessment and EIA Form 861 net of the proxy for non-dispatchable resources. For SERC and FRCC, however, the reliability council assessment number is taken directly as the total dispatchable.

An upper bound to estimated total DR availability in the Eastern Interconnection in 2010 is approximately 35GW (see Table 2). How does this compare to the levels attributed by FERC and EPRI to Eastern Interconnection regions? It is close to the maximum achievable potential identified in the EPRI report for 2010. Dispatchable DR reported by reliability regions $(21.29 \mathrm{GW})$, far outstrips EPRI's realistic achievable potential (13.84 GW). On the other hand, it is higher than FERC's business as usual estimate for $2010(30.8 \mathrm{GW})$.

Need to refine assessment of peak demand reductions from non-dispatchable, price-based $D R$ programs

Demand reduction potential from dynamic pricing programs is more difficult to estimate than that from dispatchable DR programs. The largest divergence between estimates from FERC's achievable participation scenario in 2019 and estimates from EPRI's realistic achievable potential scenario in 2020 comes from estimated potential reductions attributed to dynamic pricing programs in both studies. Peak demand reductions from dynamic pricing depend largely on modeling assumptions about key parameters such as customer price elasticity and customer participation rates.

One of the first estimates of customer price elasticity in the context of a critical peak pricing program was developed by Charles River Associates with data from the California Statewide Pricing Pilot from 2500 residential and commercial customers distributed throughout the state participated in this pricing pilot study in 2003 and 2004. For residential customers, the critical peak price reduced demand on critical peak days by more than $14 \%$. Demand reductions were lower for small commercial (between $6 \%$ and $9 \%$ ) and medium commercial (between $8 \%$ and $10 \%$ ) customers. The daily price elasticity estimated for the residential sector was -0.041 while the elasticity of substitution was -0.086 (Charles Rivers Associates, 2005).

In a survey of utility companies providing real-time pricing programs, Barbose et al. (2004) found that such demand response programs effectively reduce $12 \%-33 \%$ of participating customers' peak demand in aggregate. Threshold prices at which customers in these programs start to reduce peak loads ranged from $\$ 0.12 / \mathrm{kWh}$ to $\$ 6.50 / \mathrm{kWh}$, although the high end of that range is shown to be an outlier in Figure 4. Most reductions came in the range of $10 \%-25 \%$ of aggregate peak demand and less than $\$ 1.75$ per $\mathrm{kWh}$. The relationship between maximum load reduction and price of electricity appears to be inverse, but this is likely due to system-specific phenomena affecting the customers of the utility companies that were surveyed (Barbose et al. 2004). 


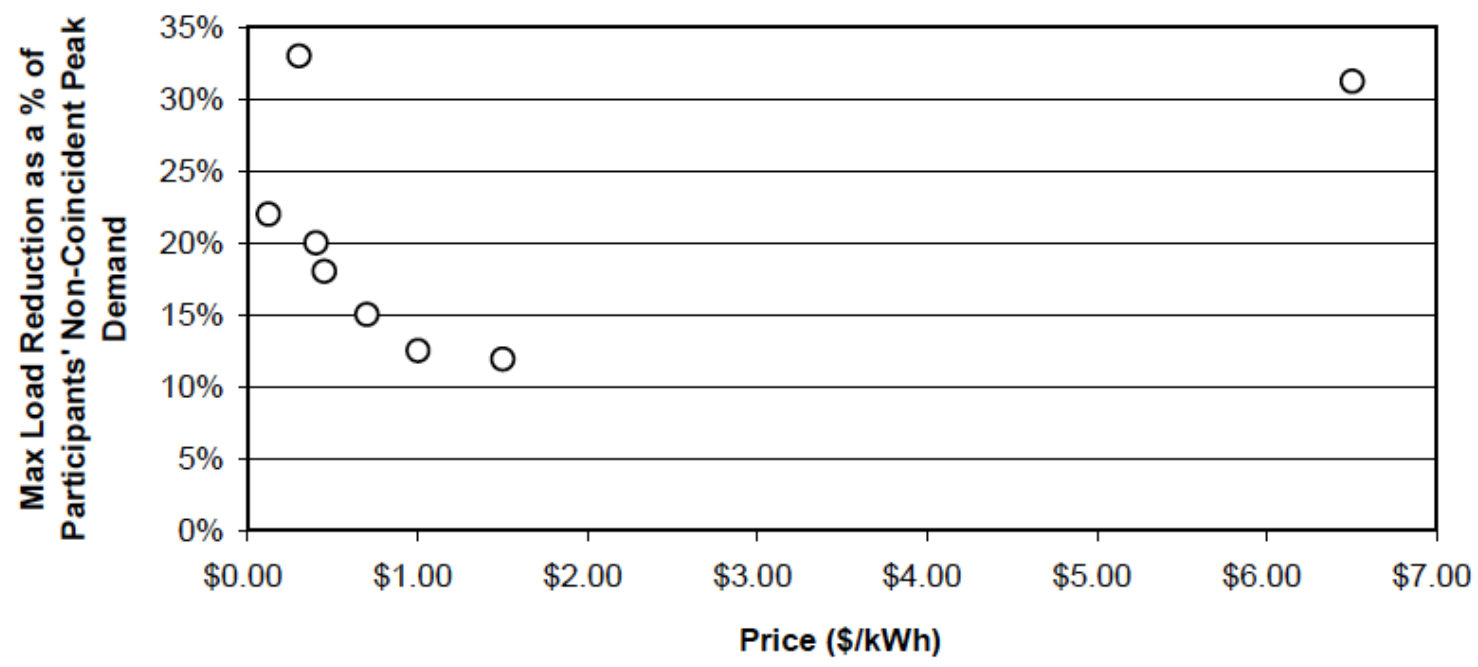

Figure 4: Maximum Aggregate Peak Demand Reductions Achieved Through Real-Time Pricing Programs for Eight Utility Companies Surveyed (Barbose, Goldman, and Neenan 2004)

Further data on dynamic pricing program performance will be key in sharpening the understanding of customer behavior under that type of DR programs. Two initiatives to gather this kind of data are currently in place: Smart Grid Investment Grant (SGIG) Consumer Behavior Studies and NERC's Demand Response Availability Data System (DADS). In this report, the uncertainty in peak load reduction from dynamic pricing programs is acknowledged by offering a range of results based on Monte Carlo simulations.

\section{Dealing with discrepancy in spatial units for assessment and system impact analyses}

FERC's assessment produced state-level data. NERC and ISO projections refer to their respective service territories. On the other hand, EIPC production cost and transmission planning analysis is performed using the North American Electricity and Environment Model (NEEM), which has a different regional disaggregation. Finally, for policy coordination among state representatives at EISPC, it is desirable to talk about DR potentials and system impacts at the state level.

These different regional classification requirements reveal the need to have a flexible way to move across different spatial aggregation levels. To achieve such flexibility, the ORNL team constructed proportioning matrices that allow transitioning between the various spatial units.

As discussed earlier, model used for FERC's National Assessment of Demand Response (NADR) has the capability to analyze state-by-state DR potential. The raw data of some inputs to NADR, however, are arranged by NERC region. Thus, a NERC-to-state proportioning method is required to break down NERC-level data into state. NERC region boundaries are not same as state boundaries, whereas census regions are collections of states. To address this issue, proportioning matrices are developed. They treat all these different spatial units as sets of counties and calculate weights based on county level variables such as population, number of households, or value of shipments.

The mapping methodology used here involves four steps:

- Using Geographic Information System (GIS), approximate NERC regional boundaries are depicted with county boundaries.

- Identify each county as one of eight NERC regions. 
- Using county FIPS codes as identifiers, combine geographic location with county-level socioeconomic and energy information.

- The set of attribute information are used to disaggregate NERC-level data into state. The candidate proxy variables to implement this disaggregation are displayed in Table 3.

Table 3: Proxy variables for Disaggregation of NERC region data into state-level data

\begin{tabular}{|l|l|l|}
\hline \multicolumn{1}{|c|}{ Data } & \multicolumn{1}{|c|}{ Attributes } & \multicolumn{1}{c|}{ Source } \\
\hline $\begin{array}{l}\text { NERC } \\
\text { Identification }\end{array}$ & $\begin{array}{l}\text { NERC region, FIPS code, County name, } \\
\text { State name }\end{array}$ & The Energy-Water Connection \\
Enecioeconomic/ & $\begin{array}{l}\text { Pop1990, Pop2000, Pop1990 per square } \\
\text { mile, Households, Female, Male, Race, } \\
\text { Population by Age, Marriage Status etc. }\end{array}$ & GIS-based data \\
\cline { 2 - 3 } & Population estimate 2009 & $\begin{array}{l}\text { U.S. Census Bureau, } \\
\text { Population Estimates data, } \\
\text { 2000-2009 }\end{array}$ \\
\cline { 2 - 4 } & $\begin{array}{l}\text { Residential population 2010, Housing units } \\
\text { 2010, Households 2005-2009, Per capita } \\
\text { income 2010, Median household income } \\
\text { 2010, Personal income 2010, Employment } \\
\text { in all industries 2010, Number of firms } \\
\text { 2010, Total value of manufacturing } \\
\text { shipments }\end{array}$ & $\begin{array}{l}\text { U.S. Census Bureau, } \\
\text { State \& County QuickFacts }\end{array}$ \\
\cline { 2 - 3 } & $\begin{array}{l}\text { Sum of plant nameplate capacity (MW) by } \\
\text { county }\end{array}$ & $\begin{array}{l}\text { eGRID Plant, Boiler, and } \\
\text { Generator Data, 2007 }\end{array}$ \\
\hline
\end{tabular}

The amount of peak load reduction by state is calculated using the fraction of each NERC region to the state. A matrix is developed to contain the conversion factors between NERC and state. Similar steps are conducted to translate results between state or NERC and NEEM regions. Figure 5 and Figure 6 show the geographic borders of the two regional definitions. 


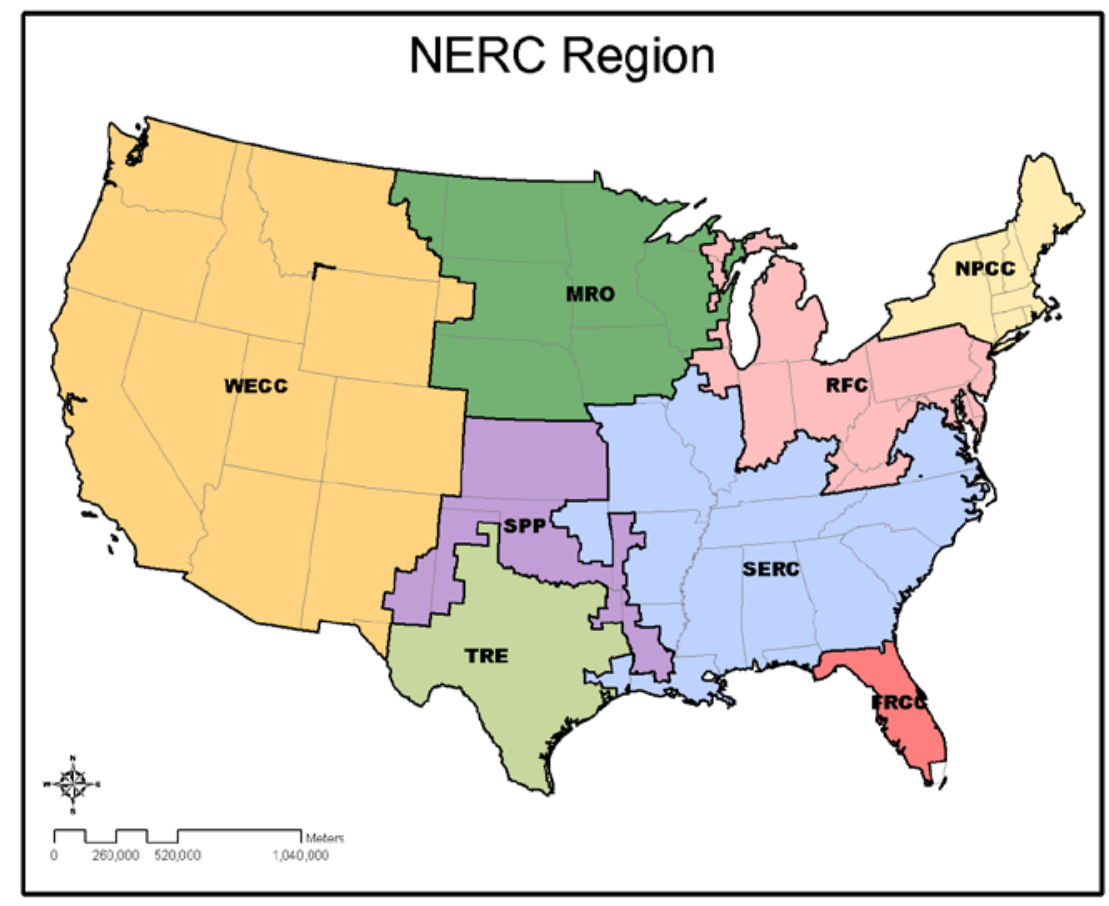

Figure 5: Map of NERC regions

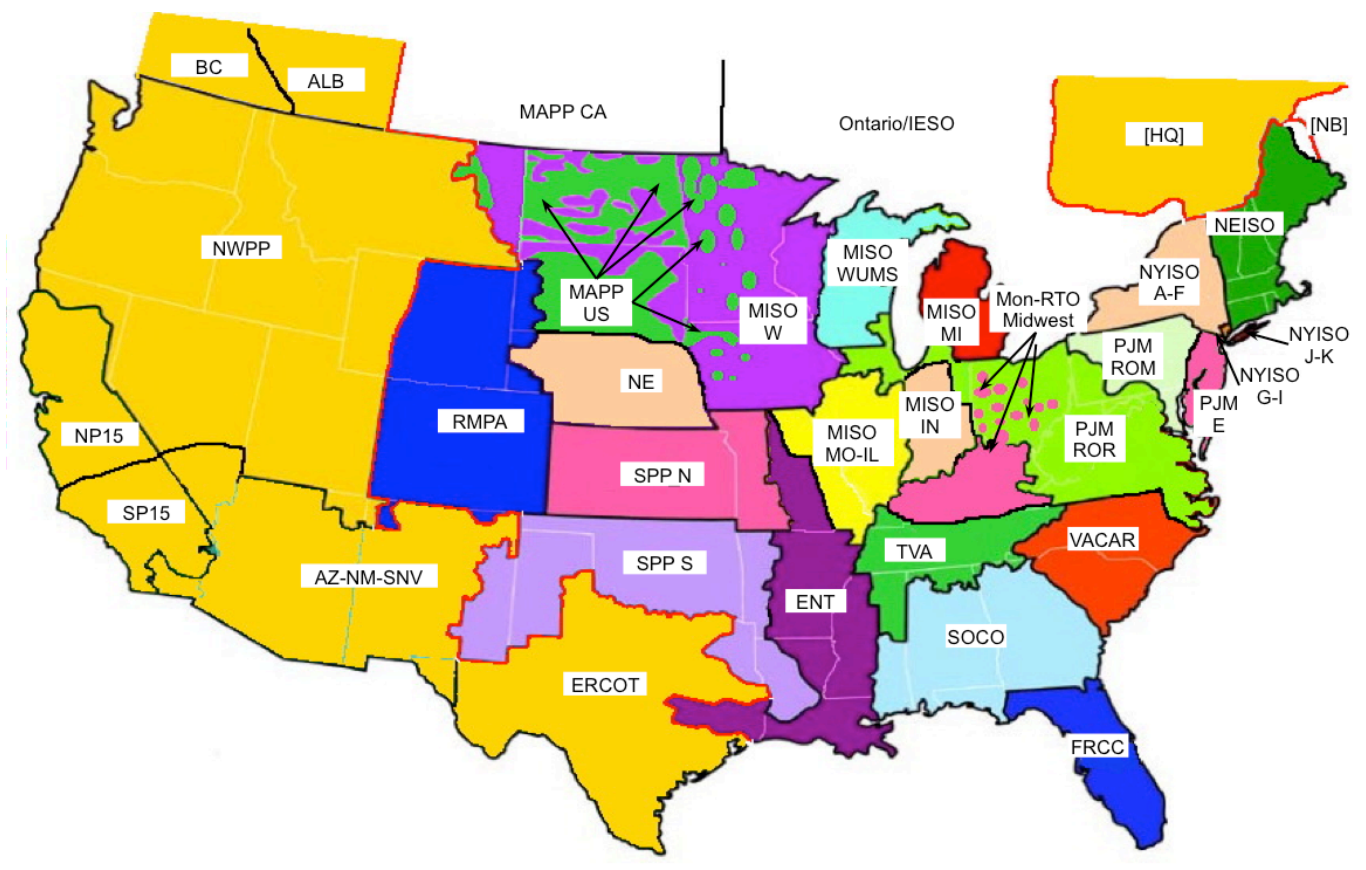

Figure 6: Map of NEEM regions 


\section{DEMAND RESPONSE ASSESSMENT UPDATES AND ORNL-NADR ANALYSIS}

FERC's assessment of DR potential is supported by two modeling tools. First, the NADR model uses information to determine DR potential by state and customer type. Second, the DRIVE model looks at system impacts that different DR mixes and total volumes would have on load profiles, plant utilization profiles, marginal prices, capacity additions, $\mathrm{CO} 2$ emissions and total system costs.

The current round of EISPC scenario analysis has used DR resource estimates from the original NADR model version. Taking advantage of its open spreadsheet nature, the ORNL team has modified NADR in order to derive updated, refined DR resource potential estimates for the Eastern Interconnection from 2009 to 2030. Those updated estimates were subsequently used as inputs to Oak Ridge Competitive Electricity Dispatch (ORCED) in order to assess DR system impacts.

\section{Proposed steps for updating/refining NADR}

Figure 7 summarizes the three key components for DR impact estimation in NADR. First, baseline loads must be defined that will convey, for each customer type and region, peak demand in absence of demand response. Second, the percentage reduction enabled by each type of program (by customer type and region) is estimated. Third, in order to translate average reductions per customer into system aggregate amounts, participation rates for each program and customer type are required. In order to distinguish the updated NADR from the original NADR model, we named the newly updated model ORNL-NADR.

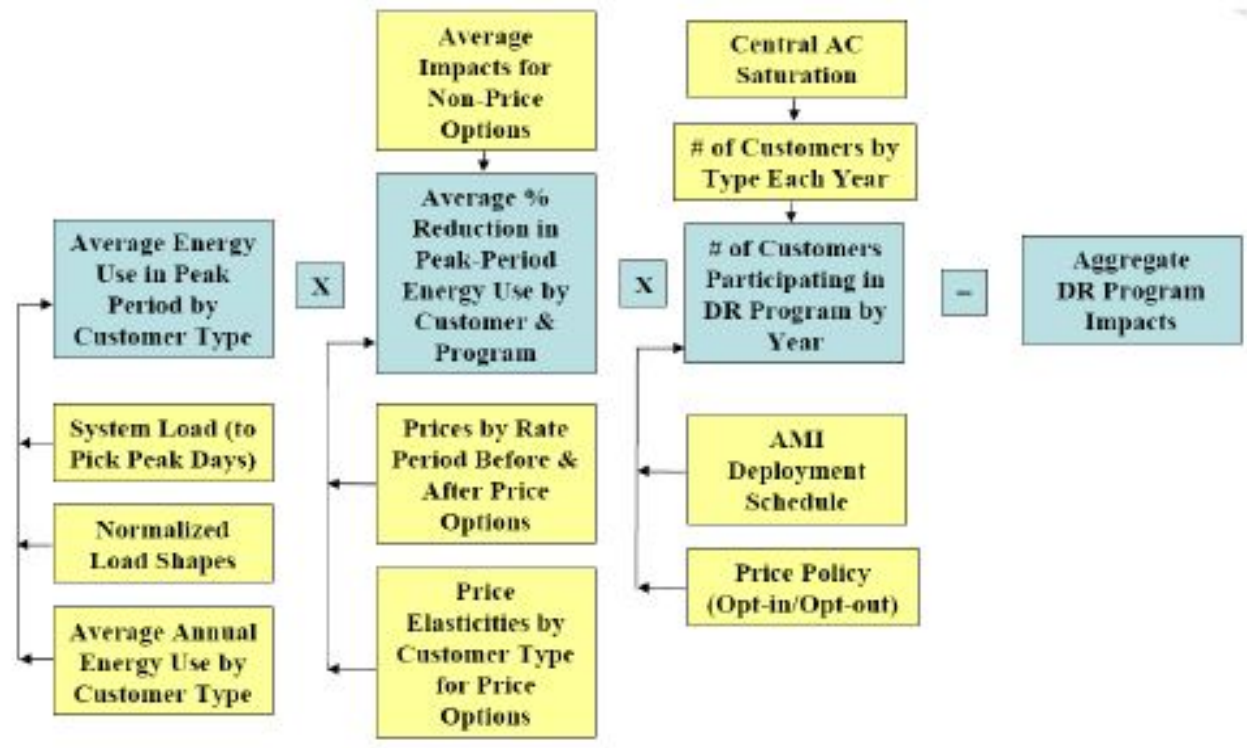

Figure 7: Key Building Blocks for Demand Response Impact Estimation in NADR (FERC 2009)

\subsection{UPDATED DEFINITIONS IN ORNL-NADR}

\section{Planning horizon}

The updated ORNL-NADR has an expanded planning horizon (2009-2030) relative to the original NADR (2009-2019). This adjustment has been made to suit the needs of EISPC whose transmission planning analysis is conducted with a 20 -year horizon. 


\section{Included Demand Response Programs}

The following programs, whose names correspond to those in the 2010 FERC Assessment on Demand Response and Advanced Metering, have been included in the ORNL-NADR version. ${ }^{8}$

- Direct load control

- Interruptible tariffs

- Pricing programs

- critical peak pricing

- critical peak pricing with load control

- time-of-use

- peak time rebate

- real time pricing

- Other DR programs

- demand bidding and buyback

- emergency demand response

- load as capacity resource

- $\quad$ system peak transmission tariff

- other

The main difference relative to the original NADR version is the inclusion of time-of-use rates within the pricing programs category.

\section{ORNL-NADR Scenario definitions}

The ORNL team developed four scenarios to assess the potential DR impact on system peak load reduction in the Eastern Interconnection area. The four ORNL-NADR scenarios are defined as follows:

Business-as-Usual (BAU) Scenario considers the amount of demand response that would take place if existing and currently planned demand response programs continued unchanged over until 2030.

Optimistic BAU Scenario is the BAU scenario with the inclusion of statistically imputed participation rates for non-reporting utilities. It assumes that non-reporting utilities to FERC 731 survey have the same level of enrolled customers as the reporting entities in the same level of revenue, summer peak, sector, and region.

Aggressive Deployment Scenario is an estimate of how much demand response would take place if 1) advanced metering infrastructure were universally deployed; 2) a dynamic pricing tariff were the default; and 3) other demand response programs, such as direct load control, were available to those who decide to opt out of dynamic pricing. It also assumes that 60 to 70 percent of eligible customers stay on dynamic pricing rates. In addition, 57 percent of the eligible customers use enabling technologies in states where programmable communicating thermostats are cost-effective.

Full Deployment Scenario is an estimate of how much cost-effective demand response would take place if 1) advanced metering infrastructure were universally deployed, 2) dynamic pricing were made the default tariff and offered with proven enabling technologies, and 3) all utilities were mandated to report their customers' DR participation rates to FERC. It assumes that all customers remain on the dynamic

\footnotetext{
${ }^{8}$ It should be noted that NADR focuses on estimating DR potential as a percentage of summer peak demand. DR resources that were reported in the FERC survey as dedicated to the provision of ancillary services were not included in our assessment.
} 
pricing tariff and use enabling technology where it is cost-effective.

Table 4 lists key factors that differentiate the scenarios.

Table 4: ORNL-NADR Scenarios and Key Factors

\begin{tabular}{|l|l|l|l|l|}
\hline & \multicolumn{1}{|c|}{ BAU } & \multicolumn{1}{|c|}{ Optimistic BAU } & \multicolumn{1}{|c|}{$\begin{array}{c}\text { Aggressive } \\
\text { Deployment }\end{array}$} & Full Deployment \\
\hline AMI deployment & Partial deployment & Partial deployment & Full deployment & Full deployment \\
\hline $\begin{array}{l}\text { Dynamic pricing } \\
\text { participation (of eligible) }\end{array}$ & Today's level & $\begin{array}{l}\text { Voluntary (opt-in); } \\
5 \%\end{array}$ & $\begin{array}{l}\text { Default (opt-out): } \\
60 \text { to } 70 \%\end{array}$ & $\begin{array}{l}\text { Universal } \\
\text { (mandatory) } 100 \%\end{array}$ \\
\hline $\begin{array}{l}\text { Eligible customers using } \\
\text { enabling technology }\end{array}$ & None & None & $57 \%$ & $100 \%$ \\
\hline $\begin{array}{l}\text { Basis for non-pricing } \\
\text { participation rate }\end{array}$ & Baseline level & $\begin{array}{l}\text { Best practices } \\
\text { estimate }\end{array}$ & $\begin{array}{l}\text { Best practices } \\
\text { estimate }\end{array}$ & $\begin{array}{l}\text { Best practices } \\
\text { estimate }\end{array}$ \\
\hline
\end{tabular}

As in the original NADR, these four scenarios have been designed such that the expected load reduction potential is smallest in the BAU case and largest in the rightmost column case. The BAU case is very conservative in that it does not expect any additional load reductions from DR programs beyond the ones already available in the baseline year. The Optimistic BAU case attains higher load reduction potential from non-pricing programs by adopting an upper bound on the participation rates in this kind of programs (entities that did not respond to the FERC survey are assumed to have the same penetration rates as the reporting entities with the same level of revenue, summer peak, sector and region rather than zero penetration) yet it still has barely no participation in dynamic pricing programs. The aggressive and Full Deployment scenarios assume, on top of the load reduction potential in the Optimistic BAU case, that advanced metering infrastructure is deployed for every customer in the country. The difference between them is that the Aggressive Deployment scenario models dynamic pricing programs as opt-out programs while in the Full Deployment scenario they become mandatory. Moreover, in the Full Deployment scenario, the $100 \%$ deployment figure refers not only to advanced metering infrastructure but also to enabling technology.

\section{Imputation method for baseline participation rates in non-pricing programs}

Data from EIA 861(2008) survey were merged with data from FERC Form 731 (2010) to estimate the DR enrollment status assuming that non-reported entities have the same level of participation as those entities who responded to the FERC survey (FERC 731 reports the results from that survey) if they were the same type of entity, collected similar amount of revenue, were located in the same state and had the same summer peak load. ${ }^{9}$ The econometric estimation of the participation rates assumed a logistic functional form.

The penetration rates resulting from this econometric estimation are used as inputs in the baseline year (2009) of the ORNL-NADR model. Penetration rates based on expert opinion as published in Faruqui and Mitarotonda (2009) are assumed for year 2020 except when the baseline percentage is higher or when the combination of DR program and customer type is not considered in the Faruqui and Mitarotonda report. In the former case, the baseline percentage is assumed to stay constant. In the latter case, the higher of the estimated baseline percentage or the maximum penetration rate in the original NADR is used.

\footnotetext{
${ }^{9}$ The entity types are classified into cooperatively-owned utility, curtailment service provider, Federal utility, investor-owned utility, municipal power agency, municipally-owned utility, political subdivision, retail power marketer and state utility.
} 


\subsection{INPUT UPDATING}

The NADR model was first released in 2009. It was conceived as a flexible tool in which inputs could be updated as better/most recent information became available. This section details all updates to the NADR input database conducted by the ORNL team.

\subsubsection{Baseline System Peak Load and Customer Population}

Baseline system peak load forecast: Figure 8 contrasts NADR's baseline system peak load, obtained from NERC's 2008 Long Term Reliability Assessment (LTRA), with subsequent versions of that same assessment. NERC revised its system peak load forecast downward in its 2009 and 2010 editions. The average annual growth rate went from $1.7 \%$ in the 2008 forecast to a $1.4 \%$ in the 2010 and 2011 versions. The system peak load in the updated ORNL-NADR version is based on the LTRA 2010 forecast. The method used to allocate the U.S. total system peak across states was the same as in the original NADR (i.e., it is based on the percentage of total electric sales for each state, except for Alaska, Hawaii and New York). ${ }^{10}$

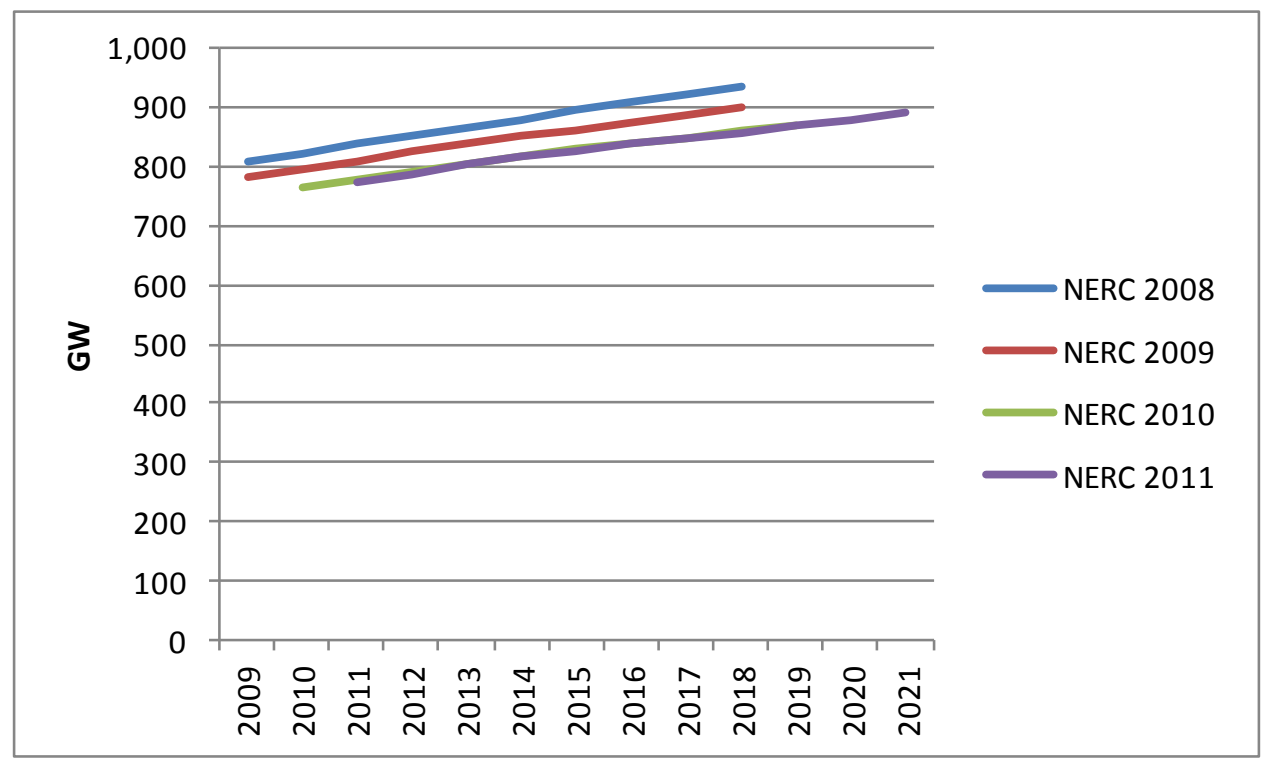

Figure 8: U.S. summer electricity summer system peak load update

Starting customer population: Updated values were obtained from http://www.eia.gov/electricity/data/state/ (number of retail customers by state by sector, based on information from EIA-Form 861, 2009)

\subsubsection{Load and Population Growth Rates}

Population growth rate: For residential customers, the source of the updated values is the U.S. Census Bureau (http://www.census.gov/population/www/projections/stproj.html). The latest state projections by age and sex were based on Census 2000 and released in 2005. Thus, there has been no update to the numbers used in the original NADR. For C\&I customers, the source are Supplemental Tables to

\footnotetext{
${ }^{10}$ NERC system peak load does not include Alaska and Hawaii so the estimates for these two states were based on EIA-Form 861 reported utility peak values for those two states. Also, since NERC reports a system peak load value for New York, that value was taken instead of relying on the allocation process for that state.
} 
AEO2012 (projections on commercial square feet by Census Division). [These tables were obtained via an email request to EIA].

Annual consumption growth rate: These rates were updated using the supplementary tables for AEO2010. These tables provide values for residential, commercial and industrial sectors. Commercial and industrial consumption projections were added up into a C\&I category whose growth rates are applied to the small, medium and large C\&I customer types in NADR.

Annual critical peak load growth: The updated rate was estimated using the following relationship

Peak load by rate class $=$ critical peak load per account $*$ number of accounts

Assuming peak load by rate class grows at the same rate as the NERC system peak, which is important to maintain consistency between the top down and bottom up growth rates used in the model:

1. Growth in number of accounts: Table D-1 from FERC (2009) is used in the original NADR to allocate total C\&I accounts among the small, medium and large categories. Those weights are applied to more updated information on number of accounts, taken from EIA Form 861 (2009).

2. Annual values for peak load by rate class are calculated by applying the system peak load growth rate to the baseline rate class peak load.

3. Annual values for number of accounts are obtained applying the \% growth rate in customer population to the baseline number of accounts computed in (1)

4. Annual critical peak load per customer is solved for by combining (2) \& (3).

5. Growth rate in annual critical peak load per customer is calculated.

\subsubsection{Critical Peak Average Hourly Load}

Load profile data by customer type is the starting point to calculate the average energy use in peak period by customer type (baseline, without demand response). However, utilities do not publish this kind of data. Thus, the original NADR version estimates baseline loads with an econometric model estimated using the limited available sample. The explanatory variables are dummy variables indicative of month of the year, day of the week and hour of the day, temperature and central air conditioning saturation.

The estimated model equation is as follows:

$$
\begin{aligned}
& \text { normalizedk } W_{x, t} \\
& =a_{x}+{ }_{i=5}^{9} b_{i} * \text { Month }_{i}+\underset{k=1}{\stackrel{7}{=}} c_{k} * \text { Dayof }_{\text {wee }}+ \\
& +{ }_{j=1}^{24} d_{j} * \text { Hour }_{J}+{ }_{j=1}^{24} e_{j} * \text { Hour }_{j} * \text { Whndholiday }+\underset{j \equiv 1}{24} f_{j} * \text { Hour }_{j} * \text { MondayFriday } \\
& ++\underset{j=1}{24} g_{j} * \text { Hour }_{j} * \text { CoolingDegreeHours } * \text { CACpenetration }+U_{x t}
\end{aligned}
$$

where:

normalizedkW is the normalized hourly load for state $x$ in period $t$

$x=$ state or utility

$t=$ period (hour)

$i=$ month of the year

$j=$ hour of the day

CoolingDegreeHours is the difference between observed temperature and 65 degrees Fahrenheit if observed temperature is above 65 ; otherwise, it takes a zero value.

CACpenetration refers to the percentage of residential customers with central air conditioning in state $\mathrm{x}$ 
MondayFriday takes the value 1 on Mondays and Fridays and zero otherwise

Wkndholiday takes the value 1 on weekends or holidays and zero otherwise

System load information is used to identify the 15 days with the largest peak loads. Then, the equation is used to estimate load for the 2 to $6 \mathrm{pm}$ timeframe on those 15 days. The average of the resulting 60 point estimates is the desired input variable (average energy use in peak period per customer type).

No new data were available to update the estimation of the load profiles for each state and customer type so that the estimated values from the original NADR were used. Baseline load profiles are an important ingredient in any DR analysis so further research in this area would be valuable. To ensure consistency between the system peak load based on NERC data and the critical peak average hourly load (calculated from the bottom up as number of participants * load per participant) were adjusted by the same percentage difference between the original and updated system peak load. For instance, since the updated system peak load in Alabama in 2009 was 2.7\% lower than in the original NADR, the critical peak load for all customer types in Alabama was also adjusted by that same percentage.

\subsubsection{Participation Rates in Non-Pricing Programs}

To update baseline year participation rates, the responses from the FERC Survey on Demand Response and Advanced Metering conducted in 2010 (FERC 2011b) were a key source. Specifically, responses from the following two survey questions were used.

Question 8: "Provide the following information (program type, number of customers, maximum demand of customers, potential peak reduction...) for each DR program and time-based rate/tariff your entity offered directly to retail customers during calendar year 2009, by customer, sector and state."

Question 9: "Provide the following information (program type, potential peak reduction, minimum reduction required for participation) for each DR program your entity offered to wholesale customers and curtailment service providers during calendar year 2009, by state.

Adjustments were necessary to avoid double counting retail and wholesale potential peak load reductions from DR programs using information from the FERC 2010 DR and AMI survey. The basis for adjusting for double counting is shown in Figure 9. Utilities offer retail programs to their customers. Part of the peak load reduction that results from these utility programs is enrolled into ISO/RTO wholesale programs. These amounts are reported in the survey and were therefore subtracted from the total peak load reduction potential reported by utilities and RTO/ISO combined. For the entire U.S., this amounted to $4.6 \mathrm{GW}$ out of the total $28 \mathrm{GW}$ of peak reduction potential coming from retail programs. 


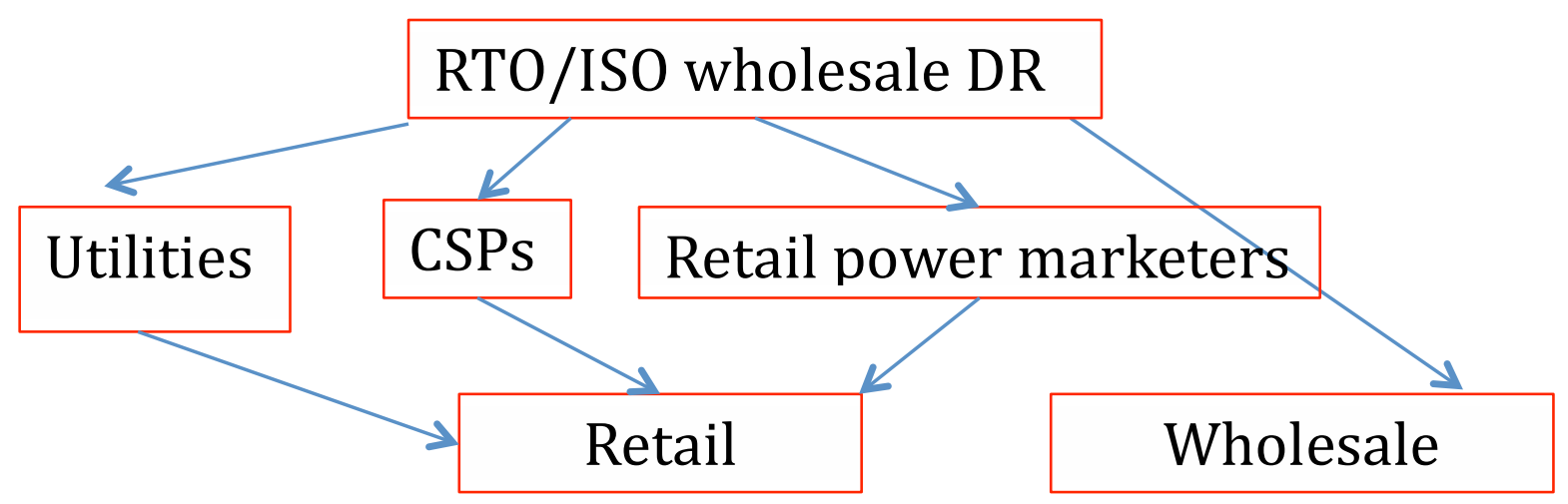

Figure 9: Relationships between DR providers ${ }^{11}$

As for the curtailment service providers and retail power marketers, these entities can offer DR programs to either retail or wholesale customers but, in any case, we assumed that they enroll $100 \%$ of the associated MW of potential peak load reduction into ISO/RTO programs. Thus, potential load reductions from these two types of entities were assumed to be entirely included within the potential peak load reductions reported by ISO/RTOs. An additional issue is that potential load reductions (in MWs) from a given utility program may be enrolled into an ISO/RTO program that falls under a different category. When that was the case, the adjustment was made to the "Other DR" category in the wholesale programs, since that is where the majority of DR activity by ISO/RTOs takes place.

Thus, the procedure used to avoid double counting of retail and wholesale DR programs is as follows. We have information on:

1. DR programs offered by utilities to retail customers

a. Amount of potential peak load reduction from these programs that is enrolled into RTOs/ISOs

2. DR programs offered by retail power marketers and curtailment service providers to retail customers

3. DR programs offered by retail power marketers and curtailment service providers to wholesale customers

4. DR resources enrolled in RTOs/ISOs (participants can include utilities, retail power marketers, curtailment service providers and wholesale customers (large C\&I))

Total amount of DR brought into ORNL-NADR $=1+4-1 \mathrm{a}$

The evolution of participation rates is mainly governed by two parameters: maximum percentage enrolled or notified in each DR type and years required to reach the maximum penetration. ${ }^{12}$ For non-pricing programs, the gap between current and maximum penetration is allocated over the allowed deployment

\footnotetext{
${ }^{11}$ The relationship between DR providers varies from market to market. For example, for NYISO: "The NYISO has four Demand Response programs: the Emergency Demand Response Program (EDRP), the ICAP Special Case Resources (SCR) program, the Day Ahead Demand Response Program (DADRP) and the Demand Side Ancillary Services Program (DSASP)" (http://www.nyiso.com/public/markets_operations/market data/demand response/index.jsp). However, for California, "Currently, demand response programs are administered by California's three regulated investor-owned utilities: PG\&E, SCE, and SDG\&E. Most of the utility demand response programs target large commercial and industrial customers that are equipped with meters that are capable of measuring and reporting energy usage in one hour intervals or less" (http://www.cpuc.ca.gov/PUC/energy/wholesale/01a cawholesale/MRTU/06 demandresponse.htm).

${ }^{12}$ It must be noted that neither direct load control for large C\&I customers nor interruptible contracts for residential or small C\&I customers are considered. As in the original NADR, the baseline penetration rates for those combinations of program and customer type are assumed to be $0 \%$.
} 
period (5-10 years) using an inverse normal distribution. Next, a list of all the variables regarding participation rates in non-pricing programs and if/how they were updated is presented:

\section{Direct load control market penetration in baseline year (\% of customers)}

For business as usual scenario, market penetration is based on number of customers enrolled (from the 2010 FERC survey on Demand Response and Advanced Metering, (FERC 2011)) and total number of customers for each state and type from EIA Form 861.

Problem: not all utilities report the number of customers enrolled in a given program and there are no data on number of customers enrolled in wholesale program so this will likely be an underestimation. For the rest of scenarios, imputation of participation rates to non-responding utilities to the FERC survey. The imputation is based on a regression, as described at the beginning of chapter 4 .

Direct load control maximum penetration of program (\% of customers): Based on high-case numbers from Faruqui and Mitarotonda (2011).

Years required to achieve maximum penetration in direct load control programs: 10 because the numbers in Faruqui and Mitarotonda represent projections for 2020.

Interruptible tariffs market penetration in baseline year (\% of customers): For business as usual scenario, market penetration is based on number of customers enrolled (from the 2010 FERC survey on Demand Response and Advanced Metering, FERC(2011)) and total number of customers for each state and type from EIA Form 861.

Interruptible tariffs market penetration in baseline year (\% of $M W)$ : NADR only allows medium and large C\&I customers to participate in interruptible tariffs. The assumption that the largest customers within these customer categories would be enrolled first leads to small percentages of participation accounting for higher percentages of load. The following assumptions were made:

- if penetration rate as percentage of customers is less than $10 \%$, the penetration rates as percentage of load is $2 *$ percentage of customers enrolled

- if penetration rate as percentage of customers is between $10 \%$ and $20 \%$, the penetration rates as percentage of load is $1.5^{*}$ percentage of customers enrolled

- if penetration rate as percentage of customers is between $20 \%$ and $30 \%$, the penetration rates as percentage of load is $1.2 *$ percentage of customers enrolled

- if penetration rate as percentage of customers is larger than $10 \%$, the penetration rates as percentage of load is equal to the percentage of customers enrolled

These assumptions are not backed for empirical data. Utility data on the size distribution of their customers would help refine this relationship but is not publicly available.

Interruptible tariffs maximum penetration (\% of customers in segment): Based on figures from Faruqui and Mitarotonda (2011) for C\&I customers. For residential customers, they do not consider this program type and, therefore, the numbers from the original NADR were used instead.

Interruptible tariffs maximum penetration (\% of $M W)$ : Same method and comments as for interruptible tariffs market penetration in baseline year (\% of MW)

Years required to achieve maximum penetration in interruptible tariffs: 5 for residential (because that is the number in the original NADR), 10 for C\&I customers (because projections in Faruqui and Mitarotonda are for 2020) 
Other DR programs penetration in baseline year (\% of customers): For business as usual scenario, market penetration is based on number of customers enrolled (from the 2010 FERC survey on Demand Response and Advanced Metering, FERC(2011)) and total number of customers for each state and type from EIA Form 861.

Problem: no data on number of customers enrolled in wholesale program so this will likely be an underestimation (particularly important for this program category because most of these programs are wholesale). For the rest of scenarios, imputation of participation rates to non-responding utilities to the FERC survey. The imputation is based on a regression.

Other DR programs penetration in baseline year (\% of $M W)$ : Same method and comments as for interruptible tariffs market penetration in baseline year (\% of MW)

Other DR programs maximum penetration (\% of customers in segment): Based on values for Faruqui and Mitarotonda (2011) for C\&I customers. Their expert survey did not consider the Other DR program category for residential customers so the original numbers for NADR were kept there.

Other DR programs maximum penetration (\% of $M W)$ : Same method and comments as for interruptible tariffs market penetration in baseline year (\% of MW)

Years required to achieve maximum penetration in other DR programs: 5 years for residential customers (since that is the number in the original NADR) and 10 years for C\&I customers (since projections in Faruqui and Mitarotonda are for 2020).

\subsubsection{Participation Rates in Pricing Programs}

Participation in dynamic pricing programs is largely driven by the pace of AMI deployment. Advanced metering is a necessary infrastructure component for supporting mass-market pricing programs. However, as will be further explained in chapter 6 , it is not a sufficient condition for implementing price-responsive DR. A utility also needs a meter data management system and billing system that will support priceresponsive DR options (FERC,2009). AMI penetration rates in the NADR model combined information from multiple sources up to 2008. Updated estimates have become available since then which can be used to revise the baseline (year 2009) penetration rates and the subsequent deployment schedule. The ORNL team pulled information from the following sources:

- FERC 2010 Assessment of Demand Response and Advanced Metering. This survey was sent to all utilities in the country and elicited a response rate of $52.1 \%$.

- EIA Form 861 (file 8), which contains information on the numbers of automatic meter reading (AMR) and AMI devices for all utilities.

- EIA Form 826 "Monthly Electric Utility Sales/Revenue Data", which started reporting AMI information in year 2011 for a sample of utilities.

- Smart Grid Information Clearinghouse (SGIC) (http://www.sgiclearinghouse.org/)

- Recovery Act Smart Grid Programs (http://www.smartgrid.gov/)

Figure 10 compares NADR 2009 AMI deployment rates with those estimated in the most recent FERC AMI survey. 


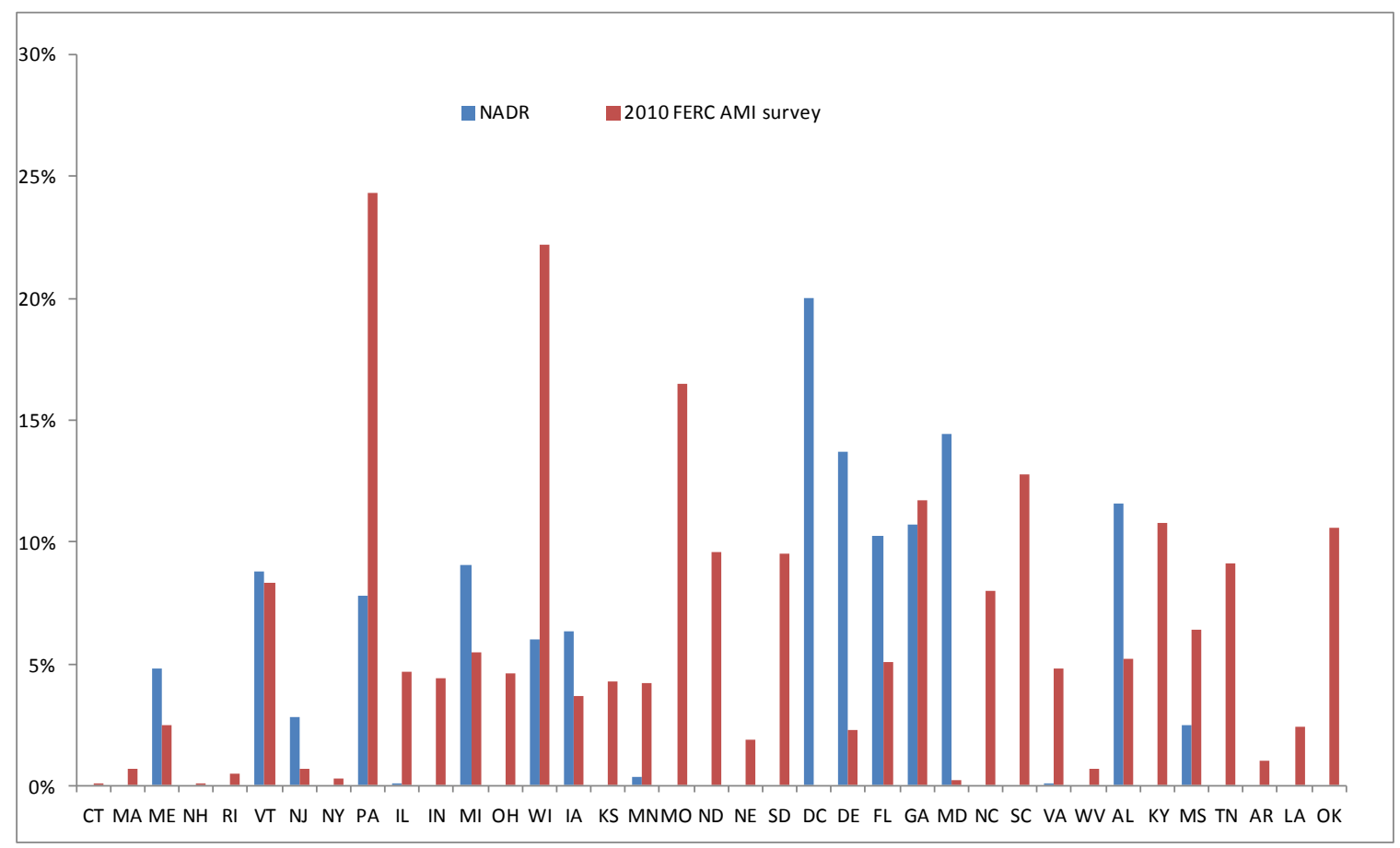

Figure 10: 2009 AMI Deployment Estimates for States in Eastern Interconnection

For those states in which the 2010 FERC AMI Survey estimate is larger than the NADR estimate (CT, NH, RI, NY, PA, IL, IN, WI, KS, MN, MO, ND, NE, SD, GA,NC, SC,VA, WV, KY, MS, TN, AR, LA, $\mathrm{OK})$, the difference reflects more recent installation numbers. For the rest, the smaller number of meters in the more recent survey reflects the more restrictive definition of AMI that has emerged in the last few years. According to the 2010 FERC AMI Survey, advanced meters are those that "measure and record usage data at hourly intervals or more frequently and provide usage data to both consumers and energy companies at least once daily".

NADR assumes a piecewise linear AMI deployment path which varies by state and scenario but not across customer types. That assumption was maintained in the updated ORNL-NADR runs. ${ }^{13}$ The information from SGIG projects provides a good window into expected deployments in the next few years. Penetration rates for 2014 can be derived from those data. As for the target penetration rates by the end of its planning period (2019), same as in NADR are used with 100\% AMI deployment achieved in every state in the Aggressive Deployment and Full Deployment scenarios. For the rest of scenarios, the penetration rate assigned to each utility is based on its size, on whether it already had AMR infrastructure and on whether it has committed to AMI deployment (BAU and expanded BAU scenarios). Thus, resulting penetration rates in each state depend on the composition of utilities in each of them.

Figure 11 shows an example of the revised deployment paths, based on updated 2009 and 2014 estimates.

\footnotetext{
13 Amongst the utilities that reported having installed any AMI devices in the FERC 2010 AMI Survey, the average penetration rate was $64 \%$ for residential customers and $44 \%$ for C\&I customers
} 


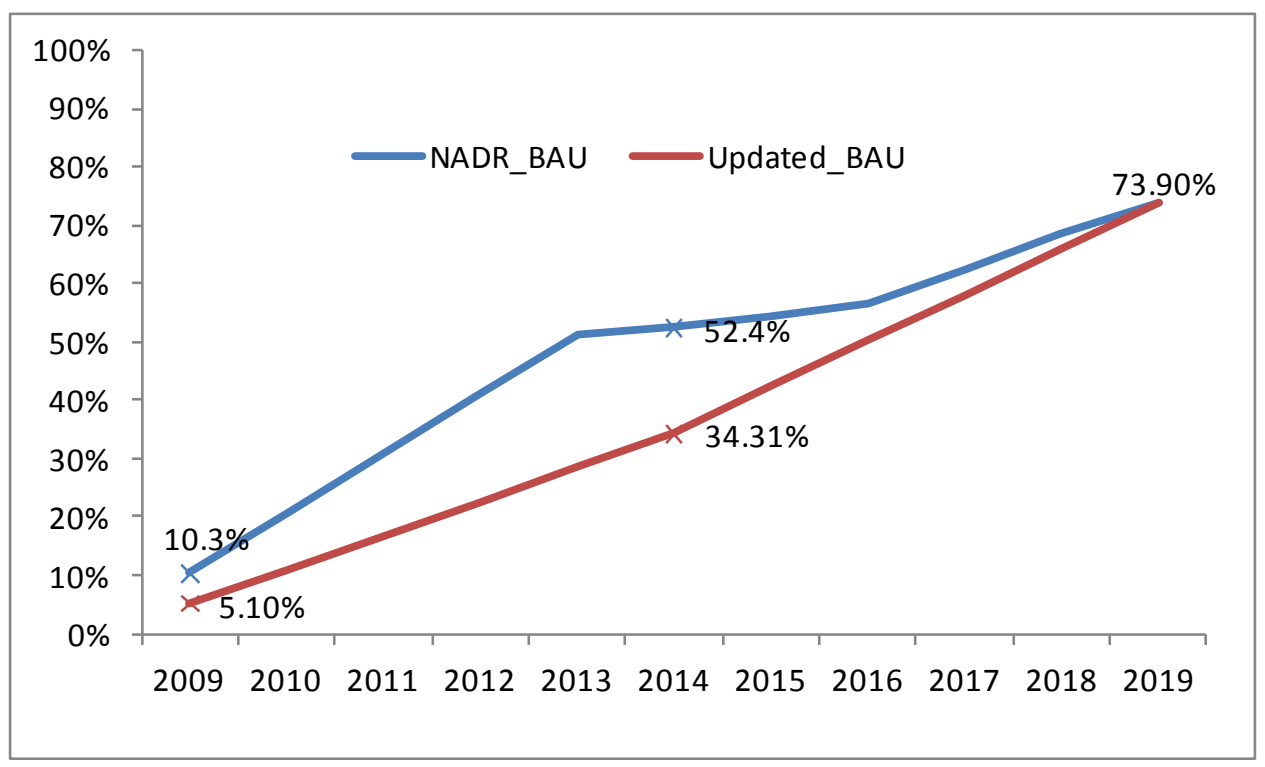

Figure 11: AMI Penetration Rates (Florida, BAU)

The Aggressive Deployment and Full Deployment scenarios assume a 100\% participation rate by 2020 for pricing programs. It supposes that all utilities will have AMI meters in place for all customers, along with the MDMS and billing systems required to support price-based DR, by 2020. The BAU and Optimistic $B A U$ scenarios assume partial deployment by 2020 that would stay constant out to 2030. It supposes that AMI deployment plans for each state would be based largely on a continuation of current trends. It assumes participation increases from utilities that already have or are currently deploying AMI systems and other utilities that, based on a variety of data sources, have expressed interest in or believed to have a higher probability of installing these systems.

These two alternative scenarios should not be interpreted as forecasts of actual AMI meter and system deployment. The Full Deployment scenario is based on the assumption that all customers will have smart meters and that enrolling in dynamic pricing programs will be mandatory by 2020 . This assumption is combined with a variety of information and assumptions that drive the likely sequence of installation across utilities in a state and across states. The partial deployment scenario is probably closer to what might actually occur, but it is not a true forecast either, since a true forecast would require conducting business cases for each load serving entity and an assessment of the likely barriers to deployment in each state. Such work was beyond the scope of this analysis.

\subsubsection{Load Reductions per Participant}

For non-pricing DR programs, the percentage load reduction must be based on understanding the particular devices that the system operator can curtail and which fraction of each customer's load these represent or on the contractually set demand reductions. Currently, NADR focuses on direct load control devices for air conditioning appliances. Since no new data were available, the updated ORNL-NADR maintains the same estimates of load reduction per participant in direct load control, interruptible tariffs and other DR programs.

For dynamic pricing programs, assessing load reductions requires estimates of elasticities and peak to offpeak price spreads, and other consumer characteristics. The original NADR model uses impact multipliers that reflect the enhanced response by customers with enabling technology and the impact of humidity to 
fine tune baseline percentage reduction estimates. ${ }^{14}$ These multipliers are given as percentage load reductions for each new-to-old price ratio (where "old" refers to a flat price) from 1 to 8 in increments of 0.1 as shown in Figure 12. also shows that the relationship between the percentage load reductions and price ratios can be approximated with a log-linear function.

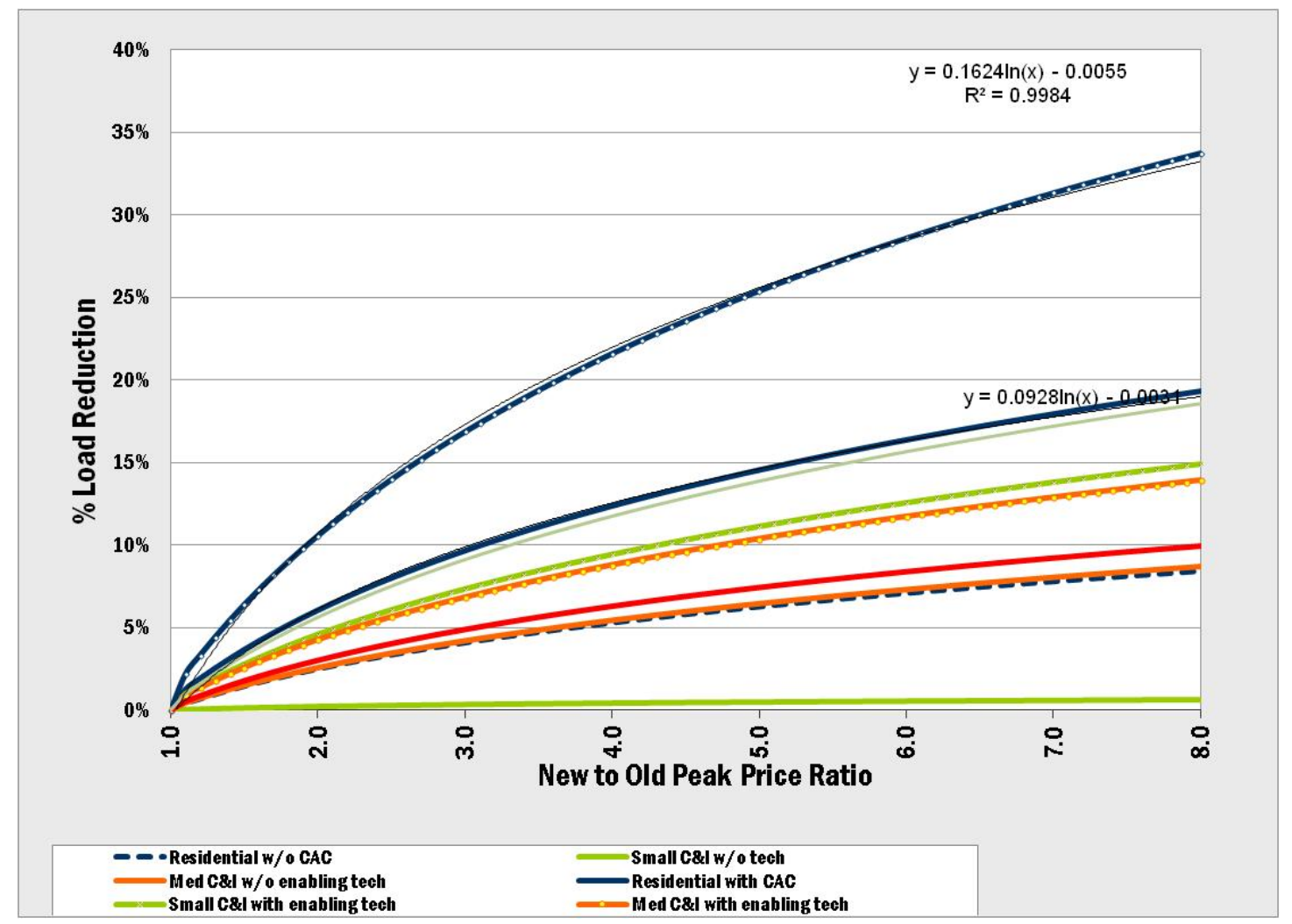

Figure 12: Percent Peak Load Reduction under Dynamic Pricing by Customer Type

Recognizing that load reduction percentages from dynamic pricing are key and depend on highly uncertain parameters led the ORNL team to select them as target for stochastic simulations. This involved substantial modifications to modeling of load reduction from dynamic pricing in the NADR model. That effort will be described in the next subsection.

\subsection{STOCHASTIC SIMULATION}

\subsubsection{Initial Sensitivity Analysis with the Original NADR Model}

Initial "uncertainty" analysis was conducted based on the results of FERC's achievable participation scenario to identify those parameter categories that are key drivers of DR potential. Refinement of those crucial parameters should subsequently receive the most time and effort. The selected variables for which the sensitivity analysis was conducted and the range of impacts are shown in Figure 13.

\footnotetext{
${ }^{14}$ NADR currently assumes that $40 \%$ of the large C\&I customers and at least $70 \%$ of the small and medium C\&I customers are eligible for enabling technology. There is wide variation in these percentages for the residential sector ranging from $2.5 \%$ in Alaska to $87.5 \%$ in Georgia.
} 


\section{Sensitivity Effect by Category (GW)}

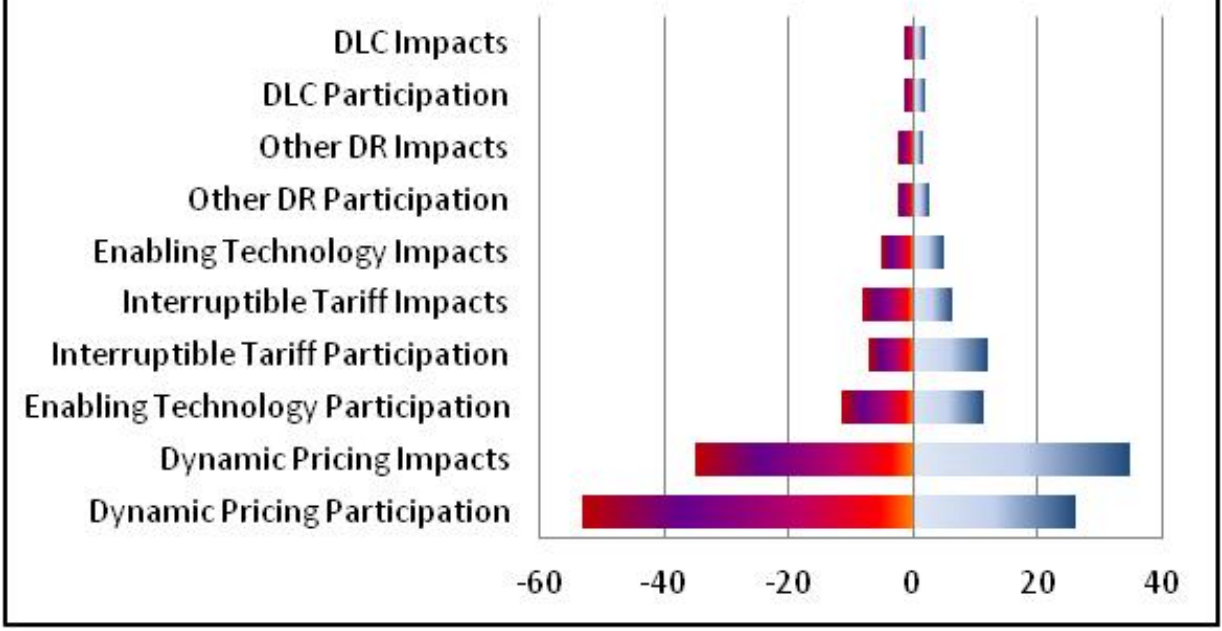

Figure 13: Sensitivity of Demand Response Potential to Selected Parameter Categories

The nominal impacts displayed in Figure 13 are transformed into elasticities in Figure 14 after identifying the range of values considered for each variable and the base DR potential under the achievable participation scenario.

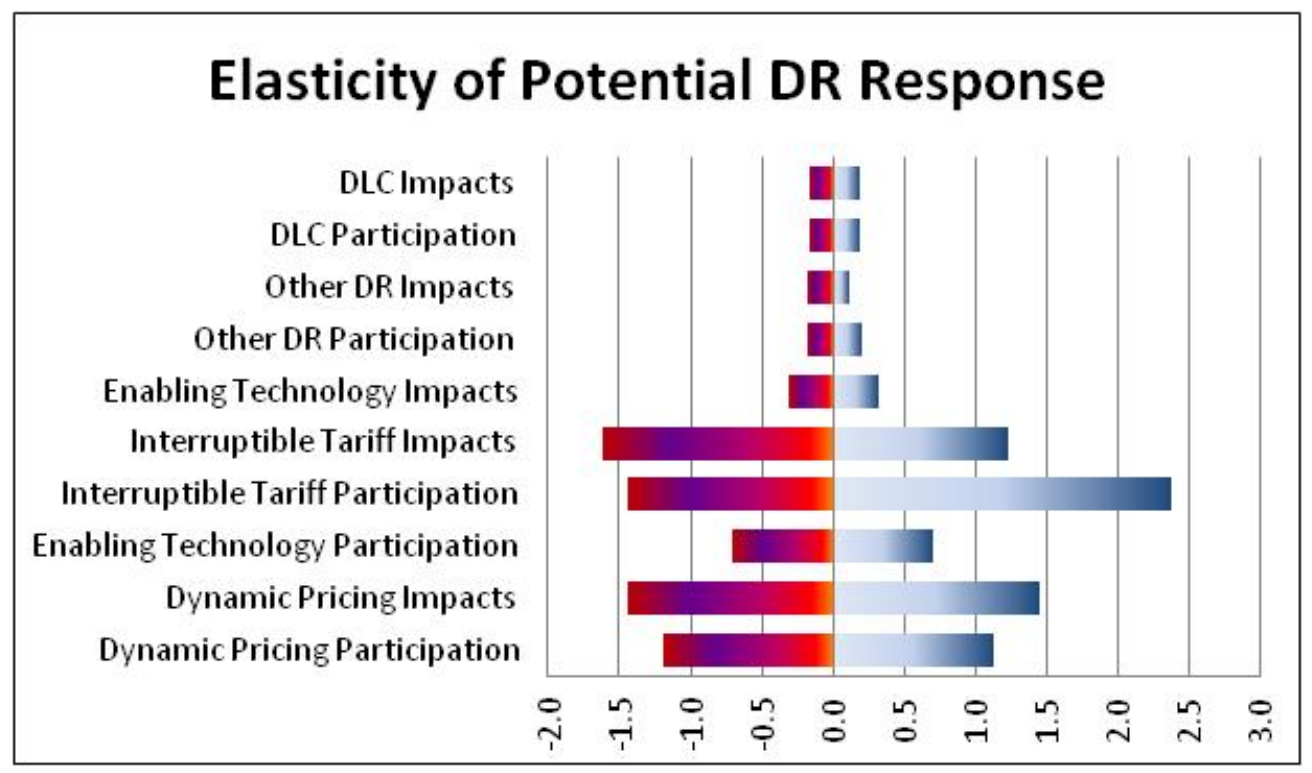

Figure 14: Elasticity of Demand Response Potential with respect to Selected Parameter Categories

Participation rates and impacts due to dynamic pricing and interruptible tariff programs are, by far, the main drivers of the DR potential that could be attained under the achievable participation scenario. Dynamic pricing impact was selected for further investigation using Monte Carlo simulation. Simulations were performed to demonstrate the effect of parameter changes on the distribution of demand response under dynamic pricing. This was done by in the original NADR model by replacing the price impact table with the functions fitted to this data as shown in Figure 12. Coefficients were specified as triangular distributions with lower and upper bounds assumed to be $70 \%$ and $130 \%$ of the estimated coefficients in 
Figure 12. Figure 15 displays the resulting distribution of demand response and shows that the variation under dynamic pricing can be substantial.

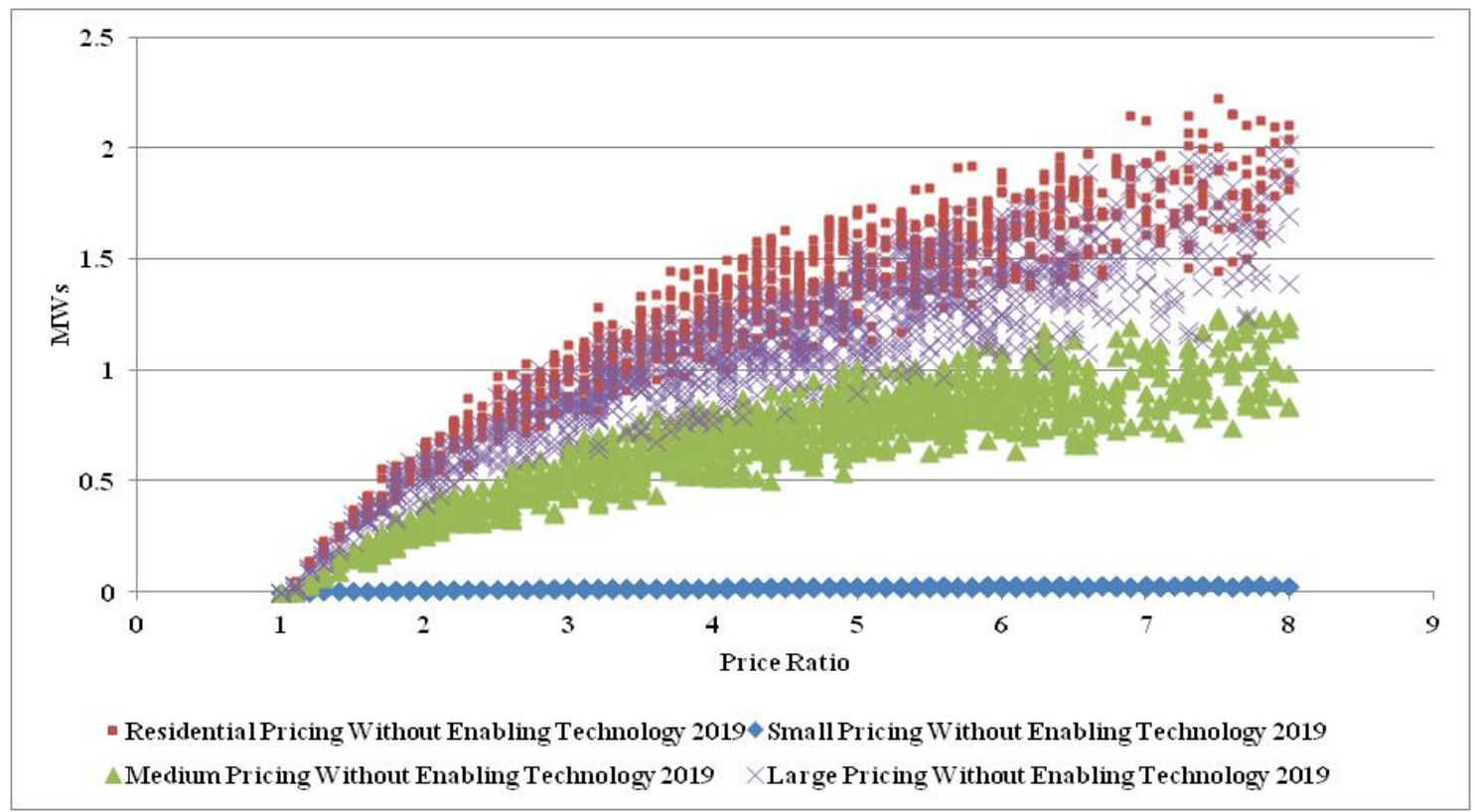

Figure 15: Relationship between Peak Load Reduction and Peak/Off-Peak Price Ratio (Maine, 2019)

\subsubsection{Dynamic Pricing Demand Response Specification in the Updated NADR Model}

The peak load reduction multipliers in the original NADR model were generated from results of simulations with PRISM (Pricing Impact Simulation Model). Percentage load reductions in PRISM are calculated using Constant Elasticity of Substitution (CES) functions. The CES function is given by Faruqui and Sergici (2010):

$\ln \left(\frac{Q_{p}}{Q_{o p}}\right)=\alpha+\sum_{i=1}^{n} \theta_{i} * D_{i}+\sigma * \ln \left(\frac{P_{p}}{P_{o p}}\right)+\delta *\left(C D H_{p}-C D H_{o p}\right)+\gamma *\left(C D H_{p}-C D H_{o p}\right) *$ $\ln \left(\frac{P_{p}}{P_{o p}}\right)+\rho * C A C_{i} * \ln \left(\frac{P_{p}}{P_{o p}}\right)$

and implies an elasticity of substitution given as:

$E S=\sigma+\gamma *\left(C D H_{p}-C D H_{o p}\right)+\rho *(C A C)$

where

$Q_{p}, Q_{o p}=$ Peak and Off-peak period average energy use per hour;

$P_{p}, P_{o p}=$ Peak and Off-peak period average energy use per hour

$E S=$ Elasticity of substitution between peak and off-peak periods

$D_{i}$ is a fixed effects variable that takes the value 1 for customer $i$ and zero otherwise $\mathrm{CDH}_{p}, \mathrm{CDH}_{o p}$ are cooling degree hours on peak and off-peak days

$C A C_{i}$ is a dummy variable that takes the value 1 when a customer has central air conditioning

The ORNL team implemented the PRISM CES function directly in NADR to calculate peak load reductions on critical peak days. This enables more flexibility in investigating the determinants of 
customer demand response to price changes such as different elasticities, and accounts for changes in total domestic (or off-peak) customer load.

The elasticities used in the PRISM simulations to generate the impact multipliers in the original NADR model are shown in Table 5, and were also used for the CES function in this study. These parameters are based heavily on data collected from the California Pilot Survey on critical peak pricing and might not be an accurate representation of customer behavior in the Eastern Interconnection. Thus, further research that explores regional differences on the behavior of customers participating in dynamic pricing programs is needed.

Table 5: Daily and Substitution Elasticities for Simulating Dynamic Pricing Demand Response

\begin{tabular}{|l|c|c|c|c|c|c|c|c|}
\hline & \multicolumn{3}{|c|}{ Residential } & \multicolumn{2}{c|}{$\begin{array}{c}\text { Small } \\
\text { C\&I }\end{array}$} & \multicolumn{2}{c|}{$\begin{array}{c}\text { Medium } \\
\text { C\&I }\end{array}$} & $\begin{array}{c}\text { Large } \\
\text { C\&I }\end{array}$ \\
\hline & $\begin{array}{c}\text { w/o } \\
\text { CAC }\end{array}$ & $\begin{array}{c}\text { with } \\
\text { CAC }\end{array}$ & $\begin{array}{c}\text { with } \\
\text { tech. }\end{array}$ & $\begin{array}{c}\text { w/o } \\
\text { tech. }\end{array}$ & $\begin{array}{c}\text { with } \\
\text { tech. }\end{array}$ & $\begin{array}{c}\text { w/o } \\
\text { techn. }\end{array}$ & $\begin{array}{c}\text { with } \\
\text { tech. }\end{array}$ & $\begin{array}{c}\text { w/o } \\
\text { tech. }\end{array}$ \\
\hline $\begin{array}{l}\text { Critical Day Substitution } \\
\text { Elasticity }\end{array}$ & -0.0472 & -0.1383 & -0.3523 & -0.0010 & -0.0892 & -0.0412 & -0.0815 & -0.0500 \\
\hline Critical Day Daily Elasticity & -0.0330 & -0.0487 & -0.0677 & -0.0010 & -0.0250 & -0.0250 & -0.0250 & -0.0200 \\
\hline
\end{tabular}

In addition, state level average electricity price for 2011 were estimated for residential and C\&I customers from EIA data (derived from Form EIA-826). This provides the data for the off-peak, and initial peak prices used in estimating demand response from dynamic pricing.

\subsubsection{Monte Carlo Simulation of Demand Response under Dynamic Pricing}

In addition to implementing the CES function, the ORNL team made additional changes to the NADR model to enable a Monte Carlo simulation of dynamic pricing programs. The main steps of the Monte Carlo analysis are:

1. Triangular distributions were attached to critical day substitution and daily elasticity parameters with the mean values set as in Table 5. Upper and lower bounds were specified as $30 \%$ and $200 \%$ of the mean levels, respectively. In the absence of information on the empirical distribution of each of these parameters or their correlation across customer categories all the parameters were driven by a single random variable in the Monte Carlo simulation. Thus, the distribution of these parameters are assumed to be perfectly correlated, so that they change in the same direction and by the same percentage on each draw. Variations in the critical price or critical price to off-peak price ratio were also specified as triangular distributions. A separate option was also implemented to simulate a fixed sequence of prices or price ratios. The simulations in this report are based on the latter option.

2. A Monte Carlo simulation consisting of 1000 simulations for each combination of state and scenario was performed. This consisted of five critical to off-peak price ratios $(2,5,10,15$ and 20) and 200 draws of the elasticity parameters. There were a total of 148,000 replications for the 37 states of the Eastern Interconnection.

Summary statistics of the Monte Carlo simulation results at the national and regional levels are presented in the next sections. A table of summary statistics is also included in each state's profile in Appendix B. 


\section{EASTERN INTERCONNECTION DEMAND RESPONSE SCENARIO ANALYSIS RESULTS FROM UPDATED ORNL-NADR}

This chapter summarizes the key findings and results from the ORNL-NADR assessment for the eastern interconnection. The demand response potentials are presented across scenarios, program types, customer classes, and regions and states. The state-by-state result summaries are in Appendix B.

\subsection{EASTERN INTERCONNECTION (EI) RESULTS}

Figure 16 illustrates the potential impact of demand response on peak demand over the analysis horizon. ${ }^{15}$ The black dashed line represents an EI peak demand forecast that does not include any demand response, as provided by the North American Electric Reliability Corporation (NERC). ${ }^{16}$ System peak demand begins at $569 \mathrm{GW}$ in 2009 and grows at an average annual growth rate of $1.2 \%$, reaching $724 \mathrm{GW}$ by 2030. Peak demand under BAU grows at a very similar rate overall. The reduction in peak demand under BAU, relative to the No DR forecast is $41 \mathrm{GW}$ by 2030 representing a $6 \%$ reduction in peak demand. ${ }^{17}$ The Optimistic BAU scenario results in a further reduction in peak demand of $114 \mathrm{GW}(16 \%)$. The Aggressive Deployment scenario produces even larger reduction in peak demand and reduces the peak demand in 2030 by 24\% (171 GW). The Full Deployment scenario produces the largest reduction of 219 GW (30\%) in 2030. The peak demand estimates under the Aggressive Deployment and Full Deployment scenarios show a dip between 2019 and 2020, after the reductions increase at constant rates. The pattern is a result of assumed market penetration schedule of new demand response programs and an Aggressive Deployment of AMI provided by the SGIG. The aggressive AMI deployment directly affects the growth of dynamic pricing programs over time. At higher DR penetration rates, the actual system peak will not be reduced by the full DR amount because the resource will be spread over more hours rather than concentrated at the system peak. Detailed discussions about the relationship between percentage peak load reduction and DR-effective hours are presented in Chapter 7.4.

\footnotetext{
${ }^{15} 2009$ is considered to be the base year because the majority of input data were collected and updated from the year. 2030 is the end year of the analysis horizon.

${ }^{16}$ The No DR baseline is derived from 2010 NERC data for total summer demand, which excludes the effects of demand response but includes the effects of energy efficiency. The results from 2010 Long Term Reliability Assessment were inputted for updating system peak levels (Source: http://www.nerc.com/files/2010\%20LTRA.pdf).

${ }^{17}$ The DR potential estimate under the ORNL's BAU scenario was comparable to the result of the assessment of demand response and energy efficiency potential released by Global Energy Partners in 2010 (Global Energy Partners 2010).
} 


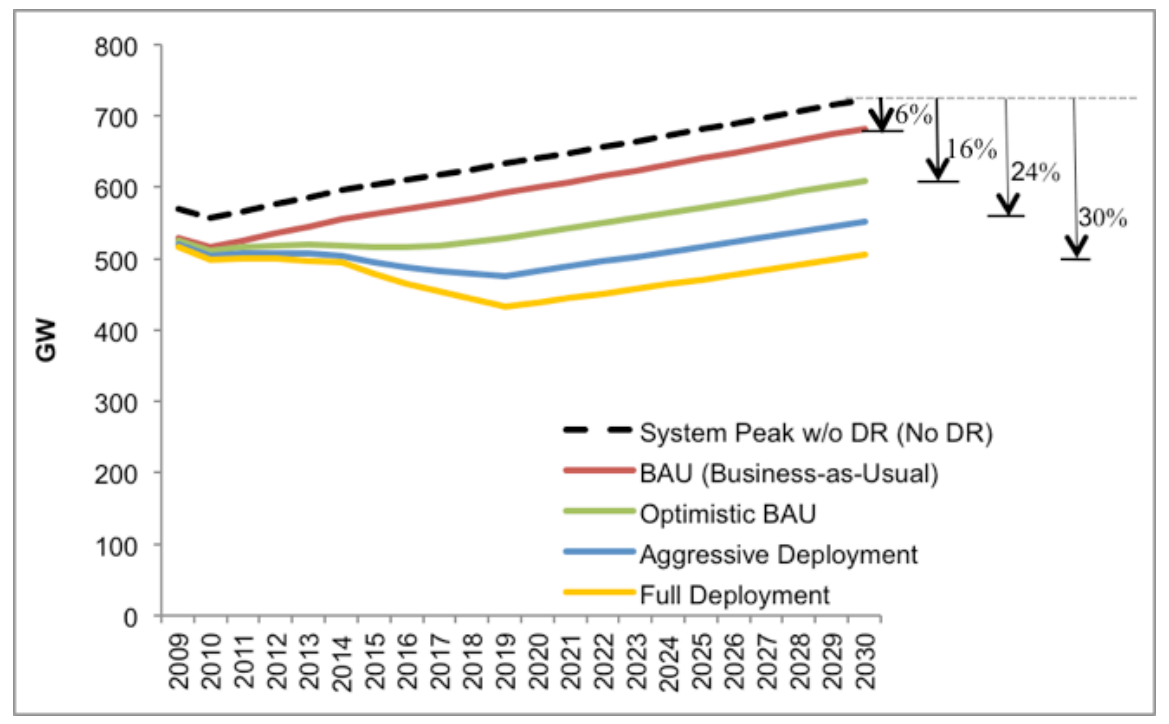

Figure 16: EI Summer Peak Demand Forecast by Scenario

The results of the four scenarios in ORNL-NADR are in fact estimates of potential, rather than projections of what is likely to occur. The numbers reported in this study should be interpreted as the amount of demand response that could potentially be achieved under a variety of assumptions about the types of programs pursued and the overall cost-effectiveness and penetration of the programs (FERC, 2009). By quantifying potential opportunities that exist in each state and region, these estimates can serve as a reference for understanding the various pathways for pursuing increased levels of demand response. As with any model-based analysis in economics, the estimates in this assessment are subject to a number of contingencies, most of them arising from limitations in the data that are used to estimate the model parameters (FERC, 2009).

Further, we must point out that the peak reductions due to DR in Figure 16 are based on the total amount of DR available. Most DR resources are only available for a limited number of hours over the year. As a consequence, not all DR will be called upon at the same time, especially if the DR represents a large fraction of demand. The full system peak may only fall by one half to two thirds of the DR depending on the load shape for the region and the time available for individual DR resources. This is described in more detail in Chapter 7.

The difference in peak load reduction between BAU and Optimistic BAU is 10 percent points in 2030. As explained earlier in chapter 4, the main difference in assumption is that how the FERC 731 survey represents the actual participation in demand response programs. The difference is how the potential for aggressively pursuing non-pricing programs is treated for the utilities that did not reported any existing participation to FERC. The Optimist BAU, Aggressive and Full Deployment scenarios use the imputed participation rates for non-reported utilities to FERC 731 survey. An econometric analysis was conducted for estimating the participation rate for non-reported utilities with the variables of summer peak, revenue, region, and program type. Under BAU and Optimistic BAU, the largest gains in demand response impacts can be made through interruptible tariffs and other demand response programs (Figure 17). On the other hand, a significant growth in pricing programs (with and without enabling technologies) is noticed under the Aggressive and Full Deployment scenarios. As different scenarios show their potentials in various degrees, so do the customer segments. DLC is the option that has a significant impact on the residential and small C\&I sectors. The majority of demand response comes from large commercial and industrial customers primarily through interruptible tariffs and capacity and load bidding programs. However, in the residential sector, most untapped potential for demand response comes from the pricing 
programs. As seen below, the impacts from the residential class drives the major differences across the demand response potential scenarios.

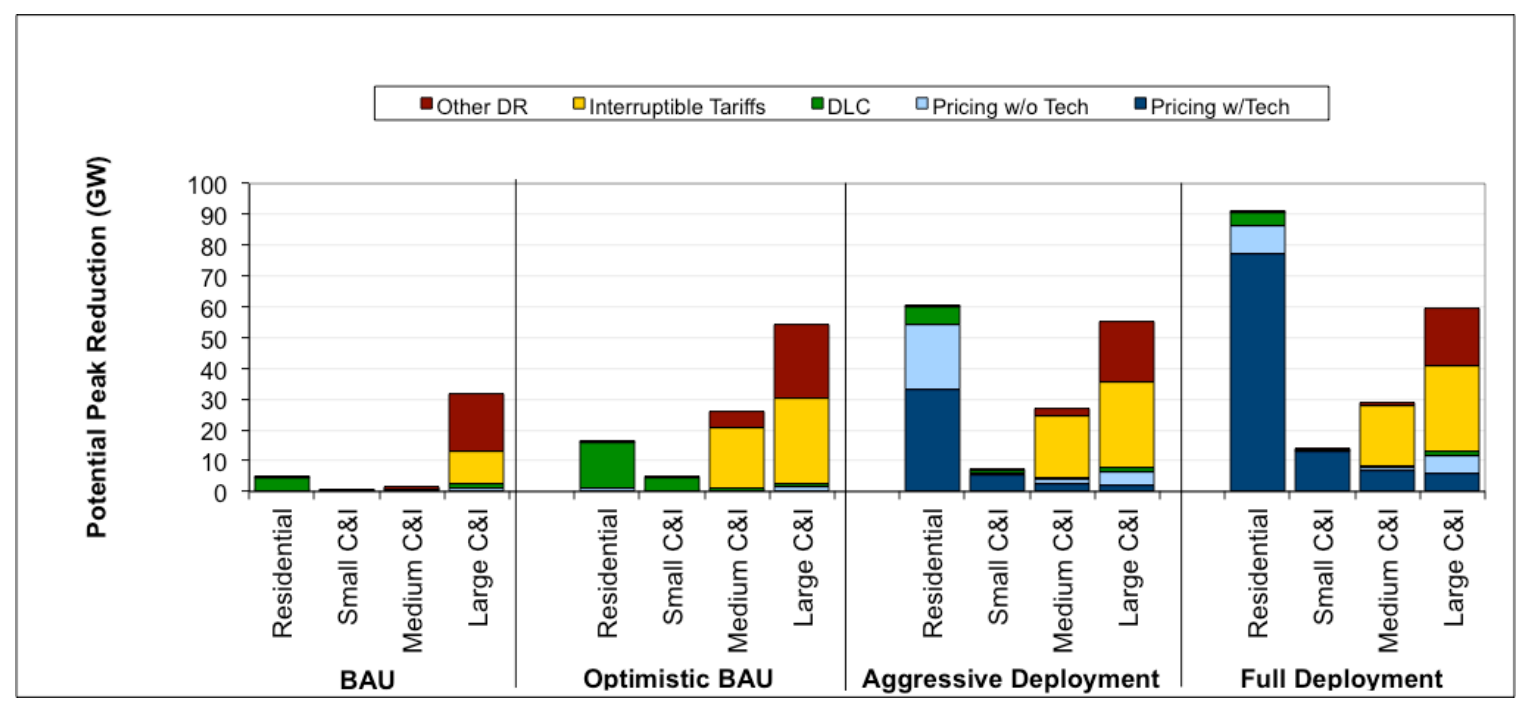

Figure 17: Potential Peak Reduction from Demand Response in EI, 2030

\subsection{SUMMARY OF MONTE CARLO SIMULATION RESULTS AT EI LEVEL}

The uncertainty in the estimates of demand response from pricing programs is investigated with a Monte Carlo simulation varying the critical-peak to off-peak price ratios, and the price response parameters in the CES function used to model dynamic pricing programs in the ORNL-NADR model. Table 6 presents the summary statistics from these simulations for the entire Eastern Interconnection for three price ratios $(5,10$ and 15$)$. It shows that under the BAU scenario pricing programs contribute only $3 \mathrm{GW}$ to the total estimated DR in 2030 (41 GW), and all of these were from dynamic pricing without enabling technology. Under the Optimistic BAU scenario, the contribution from dynamic pricing slightly increased from 5 to 8 GW in 2030. The contribution of dynamic pricing without enabling technology increased substantially from 27 to $73 \mathrm{GW}$ in the Aggressive Deployment scenario. Table 6 shows that contributions of dynamic pricing without technology in the Full Deployment scenario are about half of those in the Aggressive Deployment scenario. The results for pricing with technology programs show that the demand response are similar to those from the without technology program under the Aggressive Deployment scenario (41 $\mathrm{GW}$ to $118 \mathrm{GW})$, but much larger under the Full Deployment scenario (101 GW to $276 \mathrm{GW})$. 
Table 6: Summary of Monte Carlo Simulation of Potential Peak Load Reduction from Demand Response in EI by Scenario, Pricing Program and Price, and Price Ratio (GW)

\begin{tabular}{|c|c|c|c|c|c|c|c|c|c|c|c|c|}
\hline \multirow[b]{3}{*}{ BAU } & \multicolumn{3}{|c|}{2015} & \multicolumn{3}{|c|}{2020} & \multicolumn{3}{|c|}{2025} & \multicolumn{3}{|c|}{2030} \\
\hline & Mean & Lower & Upper & Mean & Lower & Upper I & Mean & Lower & Upper I & Mean 1 & Lower & Upper \\
\hline & & & & & & & & & & & & \\
\hline \multicolumn{13}{|l|}{ Pricing with Technology } \\
\hline 5 & 0 & 0 & 0 & 0 & 0 & 0 & 0 & 0 & 0 & 0 & 0 & 0 \\
\hline 10 & 0 & 0 & 0 & 0 & 0 & 0 & 0 & 0 & 0 & 0 & 0 & 0 \\
\hline 15 & 0 & 0 & 0 & 0 & 0 & 0 & 0 & 0 & 0 & 0 & 0 & 0 \\
\hline \multicolumn{13}{|l|}{ Pricing without Technology } \\
\hline 5 & 3 & 3 & 3 & 3 & 3 & 3 & 3 & 3 & 3 & 3 & 3 & 3 \\
\hline 10 & 3 & 3 & 3 & 3 & 3 & 3 & 3 & 3 & 3 & 3 & 3 & 3 \\
\hline 15 & 3 & 3 & 3 & 3 & 3 & 3 & 3 & 3 & 3 & 3 & 3 & 3 \\
\hline \multicolumn{13}{|l|}{ Optimistic BAU } \\
\hline \multicolumn{13}{|l|}{ Pricing with Technology } \\
\hline $\begin{array}{r}5 \\
10\end{array}$ & $\begin{array}{l}0 \\
0\end{array}$ & 0 & 0 & $\begin{array}{l}0 \\
0\end{array}$ & 0 & $\begin{array}{l}0 \\
0\end{array}$ & $\begin{array}{l}0 \\
0\end{array}$ & $\begin{array}{l}0 \\
0\end{array}$ & $\begin{array}{l}0 \\
0\end{array}$ & $\begin{array}{l}0 \\
0\end{array}$ & $\begin{array}{l}0 \\
0\end{array}$ & 0 \\
\hline $\begin{array}{l}10 \\
15\end{array}$ & $\begin{array}{l}0 \\
0\end{array}$ & 0 & 0 & 0 & 0 & 0 & 0 & 0 & 0 & 0 & 0 & 0 \\
\hline \multicolumn{13}{|l|}{ Pricing without Technology } \\
\hline 5 & 4 & 4 & 4 & 5 & 4 & 5 & 5 & 4 & 5 & 5 & 4 & 5 \\
\hline 10 & 5 & 4 & 5 & 6 & 5 & 6 & 6 & 5 & 7 & 6 & 5 & 7 \\
\hline 15 & 5 & 4 & 6 & 6 & 5 & 7 & 7 & 6 & 8 & 7 & 6 & 8 \\
\hline \multicolumn{13}{|l|}{$\begin{array}{l}\text { Aggressive Deployment } \\
\text { Pricing with Technology }\end{array}$} \\
\hline 5 & 20 & 15 & 26 & 47 & 37 & 57 & 50 & 39 & 60 & 52 & 41 & 64 \\
\hline 10 & 30 & 22 & 37 & 70 & 54 & 83 & 74 & 57 & 88 & 78 & 60 & 93 \\
\hline 15 & 36 & 27 & 46 & 84 & 67 & 105 & 89 & 70 & 111 & 94 & 74 & 118 \\
\hline \multicolumn{13}{|l|}{ Pricing without Technology } \\
\hline 5 & 15 & 12 & 18 & 31 & 25 & 36 & 32 & 26 & 38 & 33 & 27 & 40 \\
\hline 8 & 21 & 17 & 25 & 45 & 36 & 52 & 47 & 38 & 54 & 49 & 40 & 57 \\
\hline 15 & 25 & 19 & 31 & 53 & 43 & 66 & 56 & 45 & 69 & 59 & 47 & 73 \\
\hline \multicolumn{13}{|l|}{$\begin{array}{l}\text { Full Deployment } \\
\text { Pricing with Technology }\end{array}$} \\
\hline J & 49 & 39 & 61 & 114 & 91 & 137 & 120 & 96 & 145 & 127 & 101 & 154 \\
\hline 10 & 73 & 53 & 90 & 169 & 129 & 201 & 178 & 135 & 212 & 188 & 141 & 223 \\
\hline 15 & 87 & 66 & 109 & 202 & 163 & 247 & 212 & 171 & 261 & 224 & 179 & 276 \\
\hline \multicolumn{13}{|l|}{ Pricing without Technology } \\
\hline 5 & 9 & 7 & 11 & 17 & 14 & 20 & 17 & 14 & 21 & 18 & 15 & 22 \\
\hline 10 & 12 & 10 & 15 & 24 & 20 & 29 & 25 & 21 & 30 & 26 & 22 & 31 \\
\hline 15 & 14 & 11 & 17 & 29 & 23 & 34 & 30 & 24 & 35 & 31 & 25 & 36 \\
\hline
\end{tabular}

\subsection{REGIONAL DISTRIBUTION OF DEMAND RESPONSE}

Figure 18 shows the coverage of the Eastern Interconnection on the NERC map. In this study, the results were broken down at the level of census divisions to identify regional differences in demand response potential. Out of nine census divisions in the US, seven divisions such as the New England, Middle Atlantic, East North Central, West North Central, South Atlantic, East South Central, and West South Central census divisions are defined as the Eastern Interconnection area (Figure 19). Regional differences in demand response potential are driven by many factors including customer mix, market penetration of central air conditioning equipment, cost-effectiveness of new demand response programs, per-customer impacts from existing programs, participation in existing programs, and AMI deployment plans (FERC, 2009). 


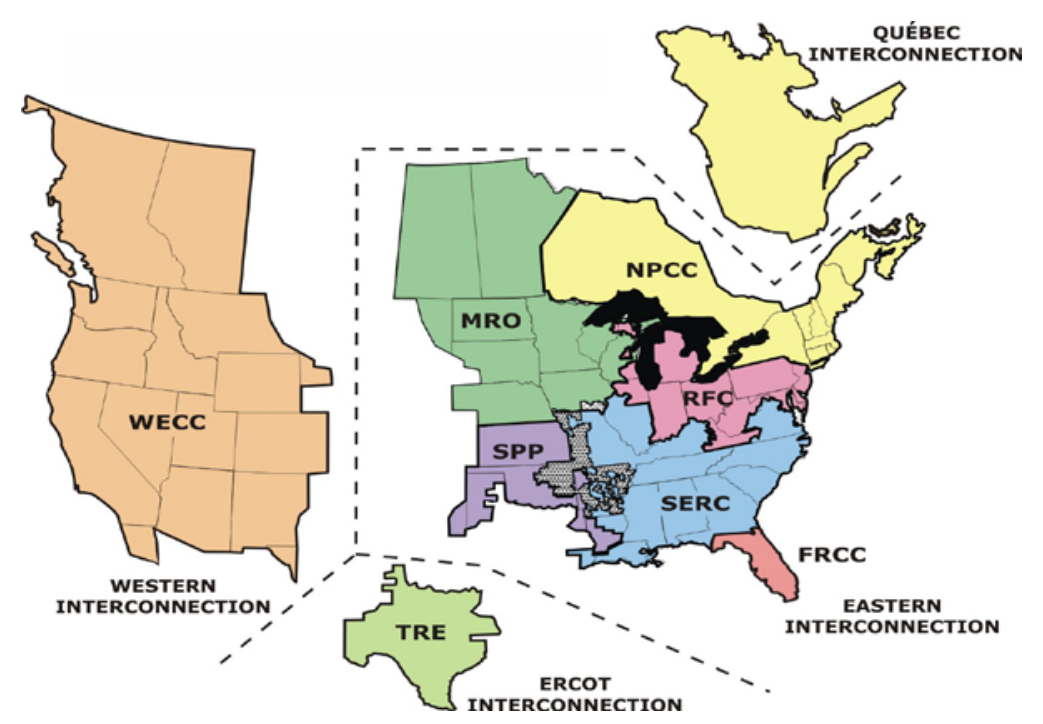

Figure 18: Coverage of EI on NERC Map (ERCOT 2012)

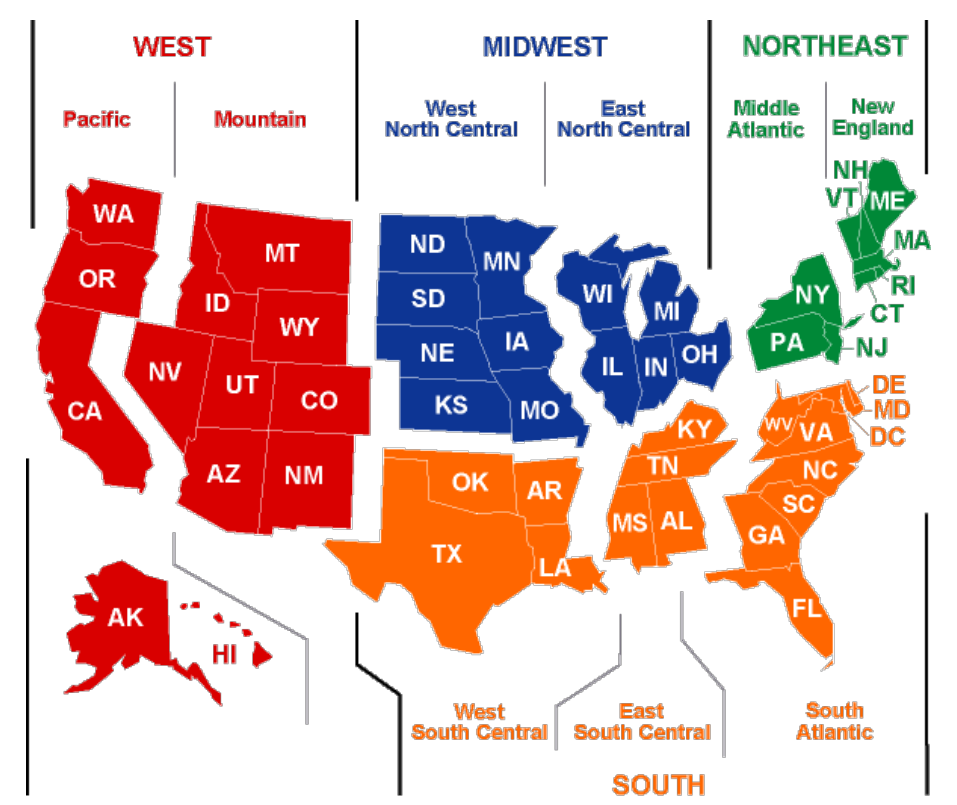

Figure 19: Census Regions and Divisions

A summary of the regional demand response potential estimates by scenario is provided in Figure 20 . The regions show the largest existing (BAU) impacts have both wholesale demand response programs and utility/load serving entity programs. Thus, Middle Atlantic (9\%) and New England (7\%) have the highest estimates for the BAU scenario. On the other hand, regions in the South such as East South Central (2\%) and West South Central (3\%) show relatively small existing programs due to the deficiency of wholesaleorganized markets. Central air conditioning saturation plays a key role in determining the magnitude of the Aggressive and Full Deployment demand response potentials. Regions have hotter climate that requires high central air conditioning systems such as the South Atlantic, East South Central, and West South Central Divisions could achieve greater average-per-customer impacts from DLC and dynamic pricing programs (FERC, 2009). As a result, these regions in the South tend to have larger overall potential under the Aggressive and Full Deployment scenarios where dynamic pricing plays a more significant role than in the BAU and Optimistic BAU scenarios. 


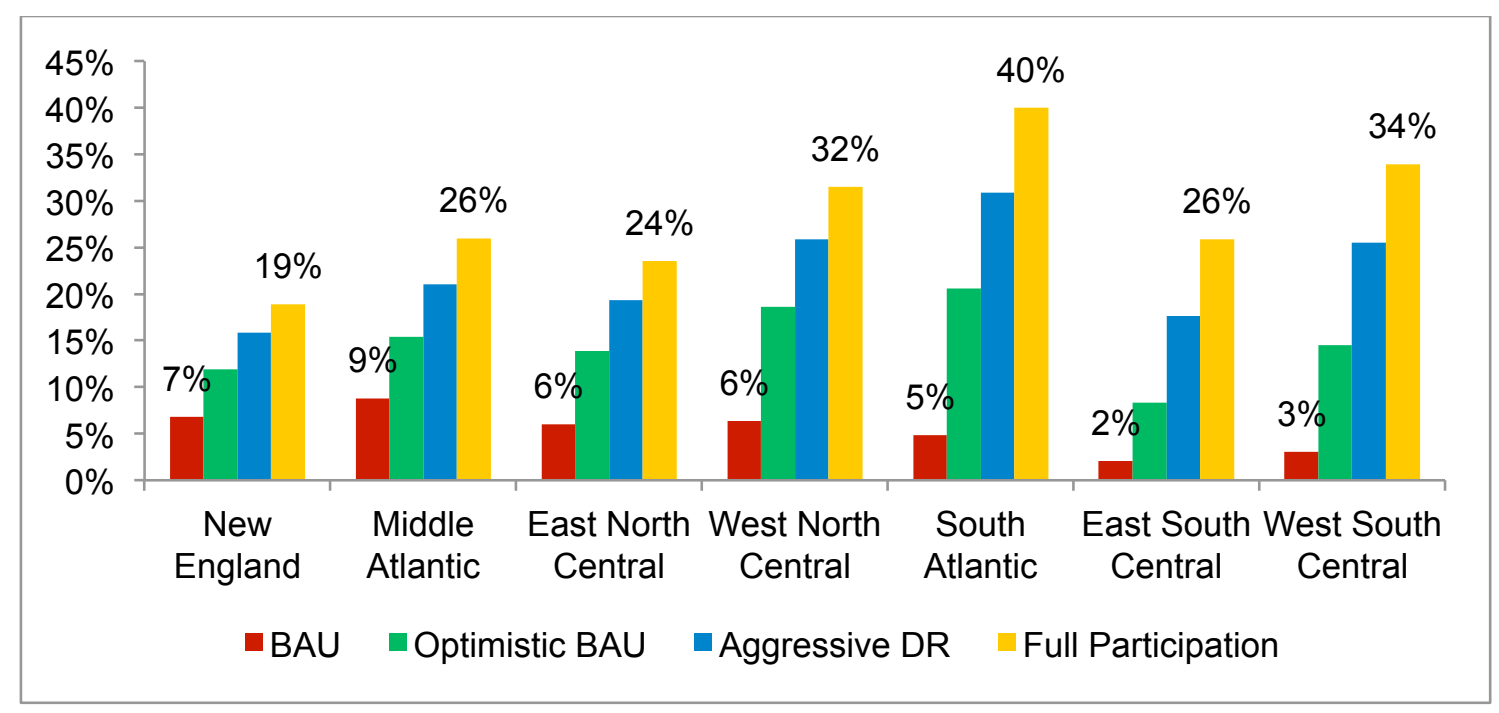

Figure 20: Demand Response Potential by Census Division and Scenario, 2030

At the most granular level, demand response potential was estimated for each 37 states $^{18}$ in the Eastern Interconnection Area. Florida does not have the highest penetration of demand response, though they are the number-one state in system peak (Figure 21 and Figure 22). However, Pennsylvania and New York have actively deployed high levels of demand response to cope with their high system peak demand.

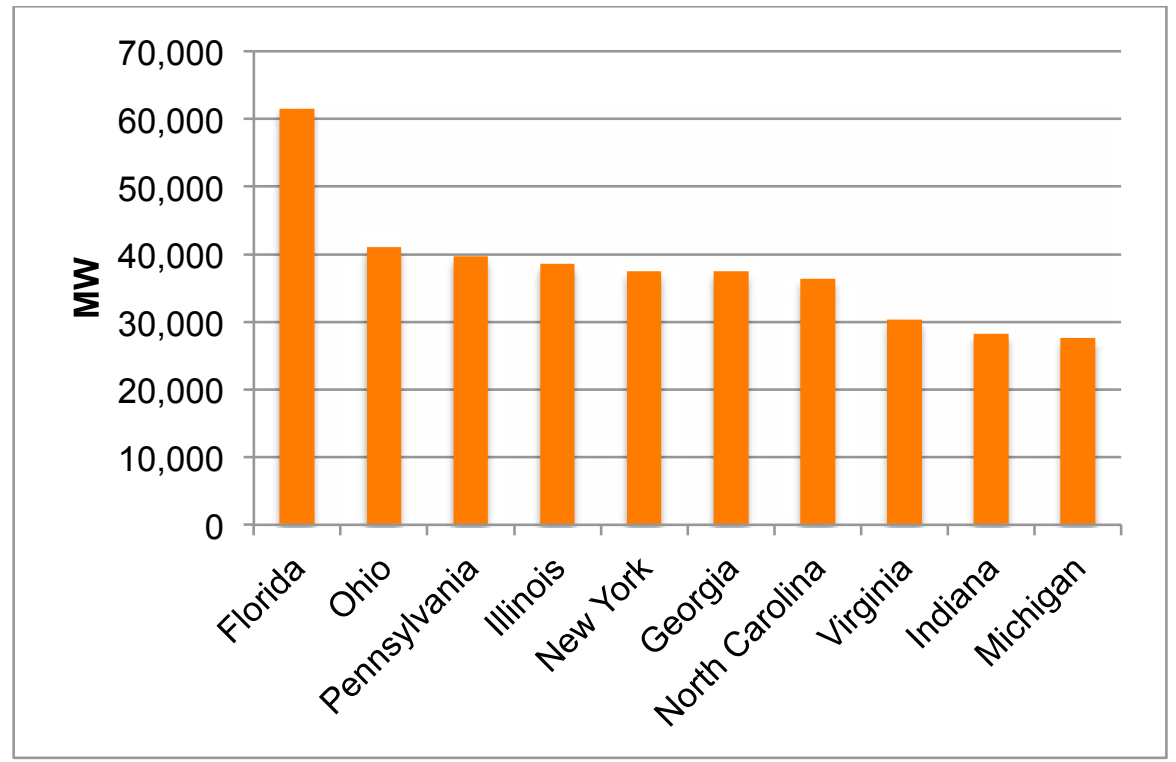

Figure 21: System Peak by State

\footnotetext{
${ }^{18}$ This study includes 37 states in the Eastern Interconnection: Alabama, Arkansas, Connecticut, DC, Delaware, Florida, Georgia, Illinois, Indiana, Iowa, Kansas, Kentucky, Louisiana, Maine, Maryland, Massachusetts, Michigan, Minnesota, Mississippi, Missouri, Nebraska, New Hampshire, New Jersey, New York, North Carolina, North Dakota, Ohio, Oklahoma, Pennsylvania, Rhode Island, South Carolina, South Dakota, Tennessee, Vermont, West Virginia, and Wisconsin.
} 


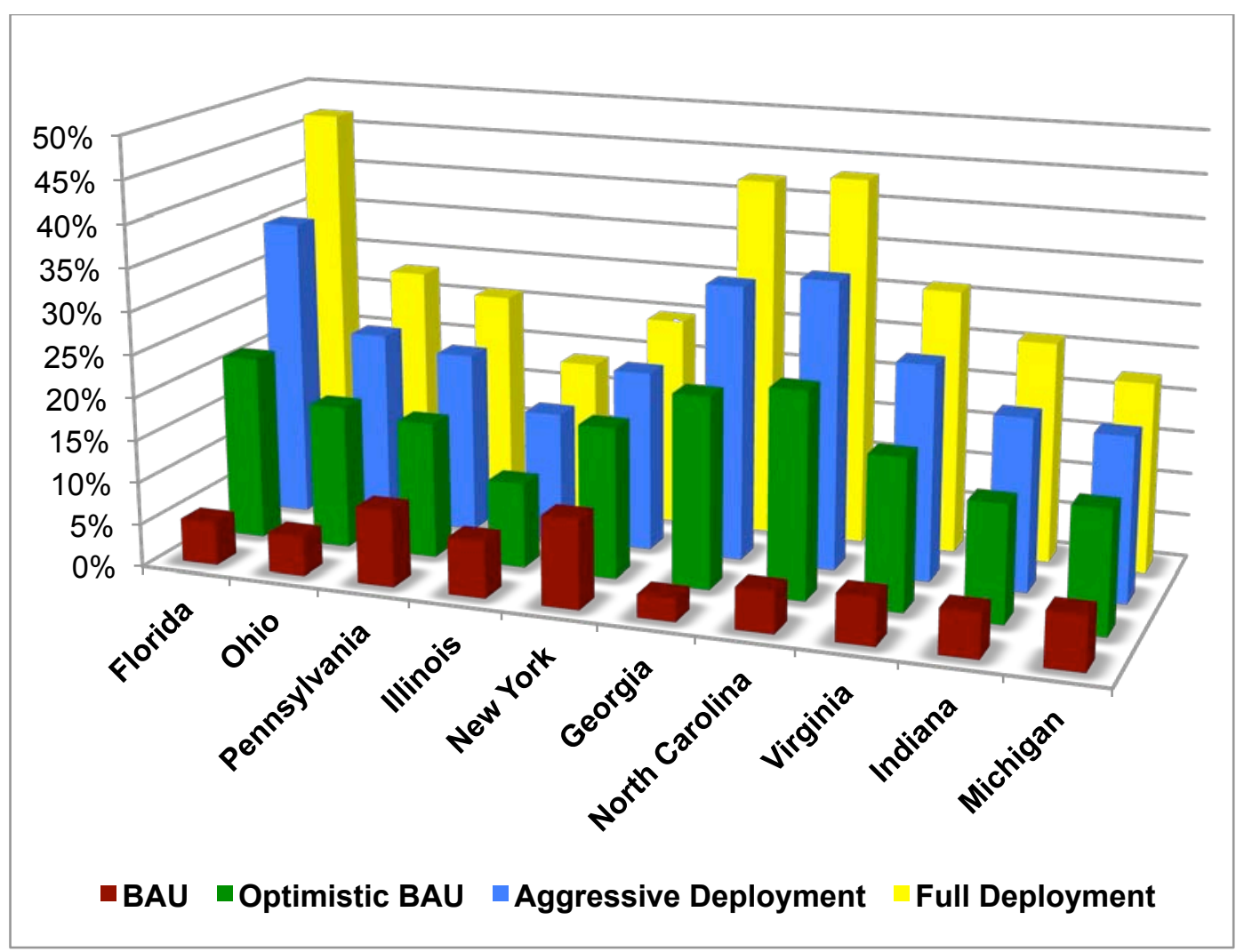

Figure 22: Top 10 States in System Peak (Y-axis: \% Peak Load Reduction)

Figure 23 shows top 10 states in the demand response potential under BAU. Maine shows a $15 \%$ peak load reduction already under BAU. Because the already untapped amount of demand response is large under BAU, its growth of demand response is relatively small in the Full Deployment scenario.

Oklahoma, Iowa, and Arkansas have a high level of demand response under BAU and have a great potential to grow as well thanks to the high CAC saturation rate and interruptible load resources. 


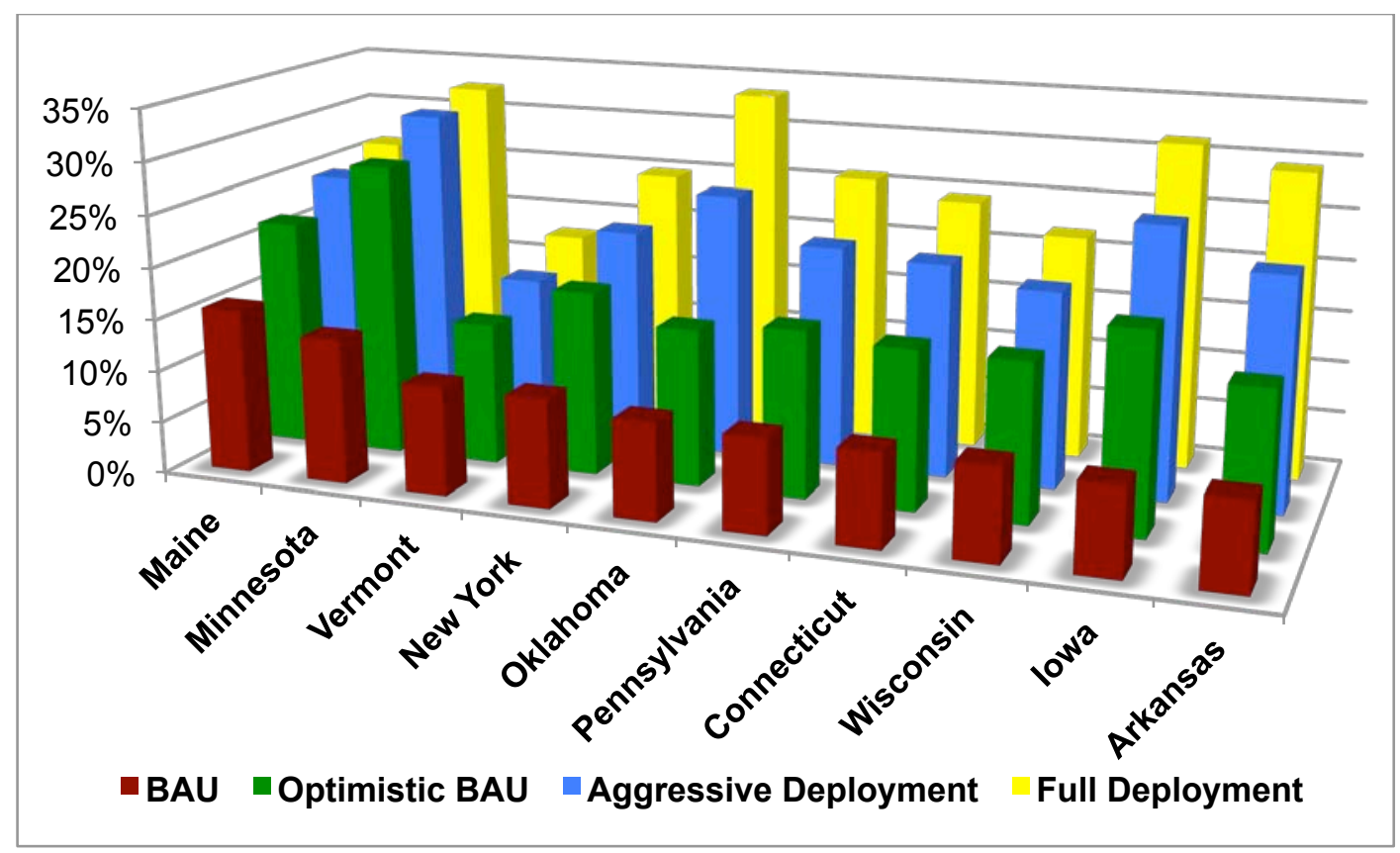

Figure 23: Top 10 States in Demand Response Potential under BAU (Y-axis: \% Peak Load Reduction)

Under the Full deployment scenario, a significant growth in \% peak load reduction is anticipated in the southern states, because of the high level of CAC saturation and relatively large untapped demand response potentials today (Figure 24).

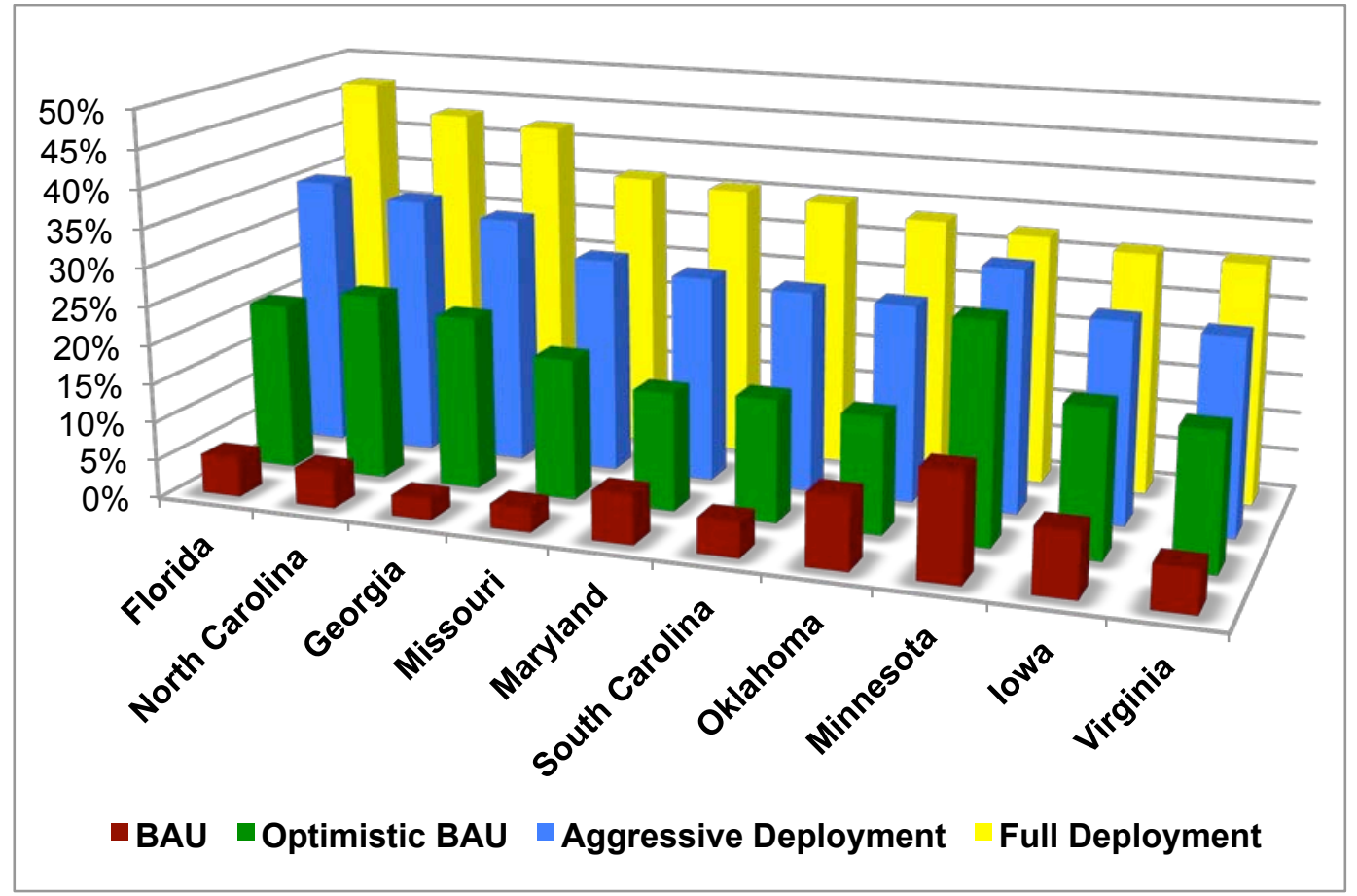

Figure 24: Top 10 States in DR Potential under Full Deployment (Y-axis: Peak Load Reduction) 


\subsection{REGIONAL RESULT PROFILES}

\section{New England Census Division Profile}

The New England census division is comprised of Maine, New Hampshire, Vermont, Massachusetts, Connecticut, and Rhode Island. The summer peak of the division is $24 \mathrm{GW}$ and the winter peak is 19 $\mathrm{GW}$. The division has a 1\% AMI penetration rate and a 17\% CAC penetration rate.

In the year 2030, the system peak without DR would be $33 \mathrm{GW}$, the DR potential peak load reduction will be $2 \mathrm{GW}(7 \%)$ under BAU, $4 \mathrm{GW}(12 \%)$ under Optimistic BAU, $5 \mathrm{GW}(16 \%)$ under Aggressive Deployment, and 6 GW (19\%) under Full Deployment (Figure 25).

Key drivers of New England's demand response potential include Other DR such as capacity bidding and interruptible tariffs. The potential from pricing programs grows under Aggressive Deployment and Full Deployment scenarios. Many large C\&I customers participate in New England RTO's Forward Capacity Market, a market for bidding demand reductions. This participation is captured in the Other DR program category, which is the primary source of the strong peak load reductions under the BAU and all other scenarios. Low CAC saturation in this division restricts residential participation (Figure 26).

Table 7 provides summary statistics of the Monte Carlo simulation for dynamic pricing programs in the New England census division. Demand response from the pricing without technology program was about $91 \mathrm{MW}$ under the BAU scenario, and increased slightly under the Optimistic BAU scenario to a range of 109 to $177 \mathrm{MW}$ in 2030. In the Aggressive and Full Deployment scenarios the range of demand response is 352 to $2044 \mathrm{MW}$ in 2030. Demand response from the pricing with technology program are zero in the first two scenarios, but are 197 to $1494 \mathrm{MW}$ and 536 to $3581 \mathrm{MW}$ under the Aggressive and Full Deployment scenarios, respectively.

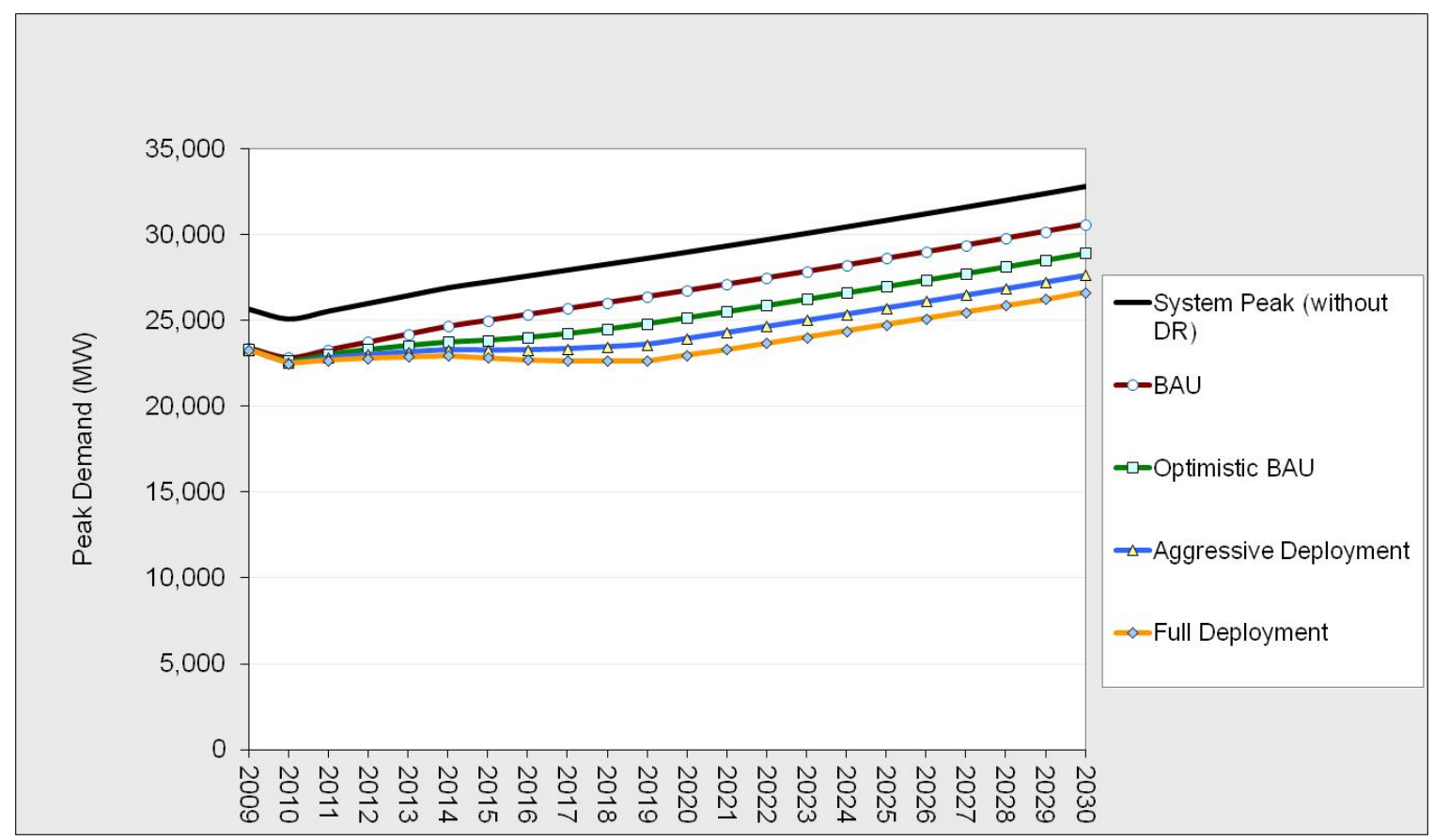

Figure 25: New England Division System Peak Demand Forecasts by Scenario 


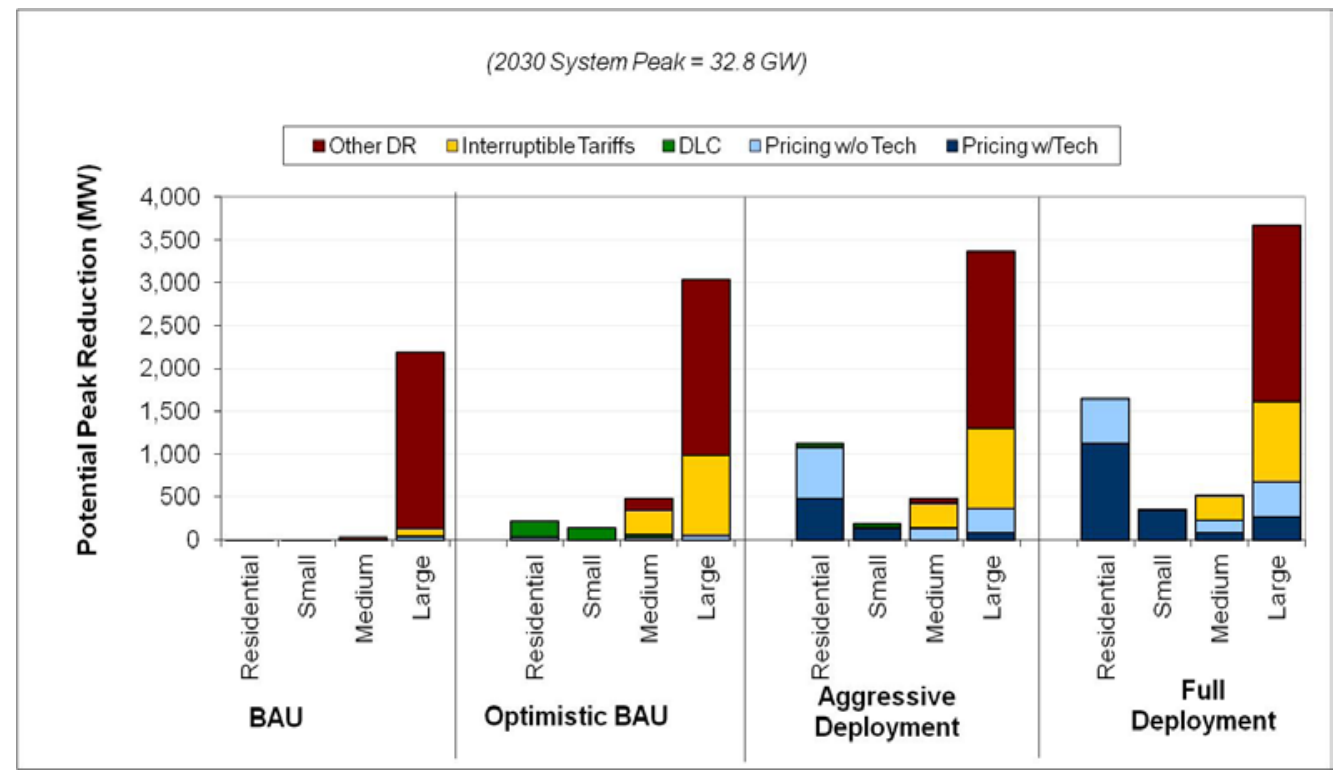

Figure 26: New England Division DR Potential in 2030, by Scenario

Table 7: Summary of Monte Carlo Simulation of Potential Peak Load Reduction from Demand Response in New England by Scenario, Pricing Program, and Price Ratio (MW)

\begin{tabular}{|c|c|c|c|c|c|c|c|c|c|c|c|c|}
\hline & \multicolumn{3}{|c|}{2015} & \multicolumn{3}{|c|}{2020} & \multicolumn{3}{|c|}{2025} & \multicolumn{3}{|c|}{2030} \\
\hline & Mean & Lower & Upper & Mean & Lower & Upper & Mean & Lower & Upper & Mean & Lower & Upper \\
\hline \multicolumn{13}{|l|}{ BAU } \\
\hline \multicolumn{13}{|l|}{ Pricing with Technology } \\
\hline 5 & 0 & 0 & 0 & 0 & 0 & 0 & 0 & 0 & 0 & 0 & 0 & 0 \\
\hline 10 & 0 & 0 & 0 & 0 & 0 & 0 & 0 & 0 & 0 & 0 & 0 & 0 \\
\hline 15 & 0 & 0 & 0 & 0 & 0 & 0 & 0 & 0 & 0 & 0 & 0 & 0 \\
\hline \multicolumn{13}{|l|}{ Pricing without Technology } \\
\hline 5 & 91 & 91 & 91 & 91 & 91 & 91 & 91 & 91 & 91 & 91 & 91 & 91 \\
\hline 10 & 91 & 91 & 91 & 91 & 91 & 91 & 91 & 91 & 91 & 91 & 91 & 91 \\
\hline 15 & 91 & 91 & 91 & 91 & 91 & 91 & 91 & 91 & 91 & 91 & 91 & 91 \\
\hline \multicolumn{13}{|l|}{$\begin{array}{l}\text { Optimistic BAU } \\
\text { Pricing with Technology }\end{array}$} \\
\hline ricing viti rectimoiogy & 0 & 0 & 0 & 0 & 0 & 0 & 0 & 0 & 0 & 0 & 0 & 0 \\
\hline 10 & 0 & 0 & 0 & 0 & 0 & 0 & 0 & 0 & 0 & 0 & 0 & 0 \\
\hline 15 & 0 & 0 & 0 & 0 & 0 & 0 & 0 & 0 & 0 & 0 & 0 & 0 \\
\hline \multicolumn{13}{|l|}{ Pricing without Technology } \\
\hline 5 & 118 & 102 & 130 & 123 & 108 & 137 & 124 & 109 & 138 & 125 & 109 & 139 \\
\hline 10 & 130 & 109 & 146 & 138 & 115 & 157 & 139 & 116 & 158 & 140 & 116 & 160 \\
\hline 15 & 136 & 107 & 159 & 147 & 113 & 173 & 148 & 114 & 175 & 149 & 114 & 177 \\
\hline \multicolumn{13}{|l|}{$\begin{array}{l}\text { Aggressive Deployment } \\
\text { Pricing with Technology }\end{array}$} \\
\hline ricing witn lecniology & 248 & 83 & 366 & 553 & 187 & 824 & 566 & 192 & 842 & 579 & 197 & 861 \\
\hline 10 & 365 & 152 & 555 & 813 & 360 & 1253 & 831 & 370 & 1281 & 851 & 380 & 1311 \\
\hline 15 & 443 & 180 & 653 & 985 & 402 & 1429 & 1007 & 412 & 1461 & 1031 & 423 & 1494 \\
\hline \multicolumn{13}{|l|}{ Pricing without Technology } \\
\hline 5 & 400 & 234 & 528 & 733 & 340 & 1021 & 750 & 346 & 1044 & 766 & 352 & 1068 \\
\hline 8 & 560 & 331 & 753 & 1067 & 605 & 1529 & 1092 & 621 & 1565 & 1118 & 637 & 1601 \\
\hline 15 & 668 & 345 & 955 & 1294 & 711 & 1798 & 1324 & 729 & 1840 & 1355 & 748 & 1884 \\
\hline \multicolumn{13}{|l|}{\begin{tabular}{|l|} 
Full Deployment \\
Pricing with Technology
\end{tabular}} \\
\hline 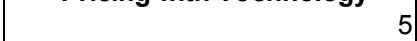 & 591 & 220 & 896 & 1337 & 509 & 1994 & 1369 & 522 & 2039 & 1401 & 536 & 2084 \\
\hline 10 & 896 & 370 & 1345 & 2002 & 847 & 3021 & 2048 & 871 & 3090 & 2096 & 895 & 3161 \\
\hline 15 & 1013 & 381 & 1593 & 2290 & 886 & 3425 & 2343 & 907 & 3502 & 2398 & 928 & 3581 \\
\hline \multicolumn{13}{|l|}{ Pricing without Technology } \\
\hline 5 & 415 & 228 & 552 & 782 & 374 & 1085 & 801 & 383 & 1112 & 820 & 393 & 1139 \\
\hline 10 & 593 & 321 & 833 & 1155 & 653 & 1611 & 1183 & 669 & 1651 & 1213 & 685 & 1691 \\
\hline 15 & 679 & 370 & 964 & 1338 & 693 & 1947 & 1371 & 710 & 1995 & 1405 & 728 & 2044 \\
\hline
\end{tabular}




\section{Middle Atlantic Census Division Profile}

The Middle Atlantic census division is comprised of New Jersey, New York, and Pennsylvania. The summer peak of the division is $85 \mathrm{GW}$ and the winter peak is $66 \mathrm{GW}$. The division has a $9 \% \mathrm{AMI}$ penetration rate and a $41 \% \mathrm{CAC}$ penetration rate.

In the year 2030, the system peak without DR would be $98 \mathrm{GW}$, the DR potential peak load reduction will be 9 GW (9\%) under BAU, 15 GW (15\%) under Optimistic BAU, 21 GW (21\%) under Aggressive Deployment, and 26 GW (26\%) under Full Deployment (Figure 27).

Similar to New England states, the Middle Atlantic states experience high levels of participation in DR programs offered through organized markets. New Jersey, New York, and Pennsylvania currently have high levels of Large C\&I participation in PJM and NYISO capacity market DR programs, and these levels remain high throughout all four scenarios. New Jersey and Pennsylvania experience high levels of growth in pricing programs with enabling technologies under the Aggressive Deployment and Full Deployment scenarios, thanks to the moderate $(\sim 50 \%)$ rates of CAC saturation in each state. Significant AMI deployment is projected in the next few years through SGIG (Smart Grid Investment Grant)-funded projects under American Recovery and Reinvestment Act of 2009 (Figure 28).

Table 8 provides summary statistics of the Monte Carlo simulation for dynamic pricing programs in the Middle Atlantic census division. Demand response from the pricing without technology program was about $68 \mathrm{MW}$ under the BAU scenario, and increased slightly under the Optimistic BAU scenario to a range of 120 to $439 \mathrm{MW}$ in 2030. In the Aggressive and Full Deployment scenarios the range of demand response is 642 to $5930 \mathrm{MW}$ in 2030. Demand response from the pricing with technology program are zero in the first two scenarios, but are 1582 to $9552 \mathrm{MW}$ and 3831 to $21177 \mathrm{MW}$ under the Aggressive and Full Deployment scenarios, respectively.

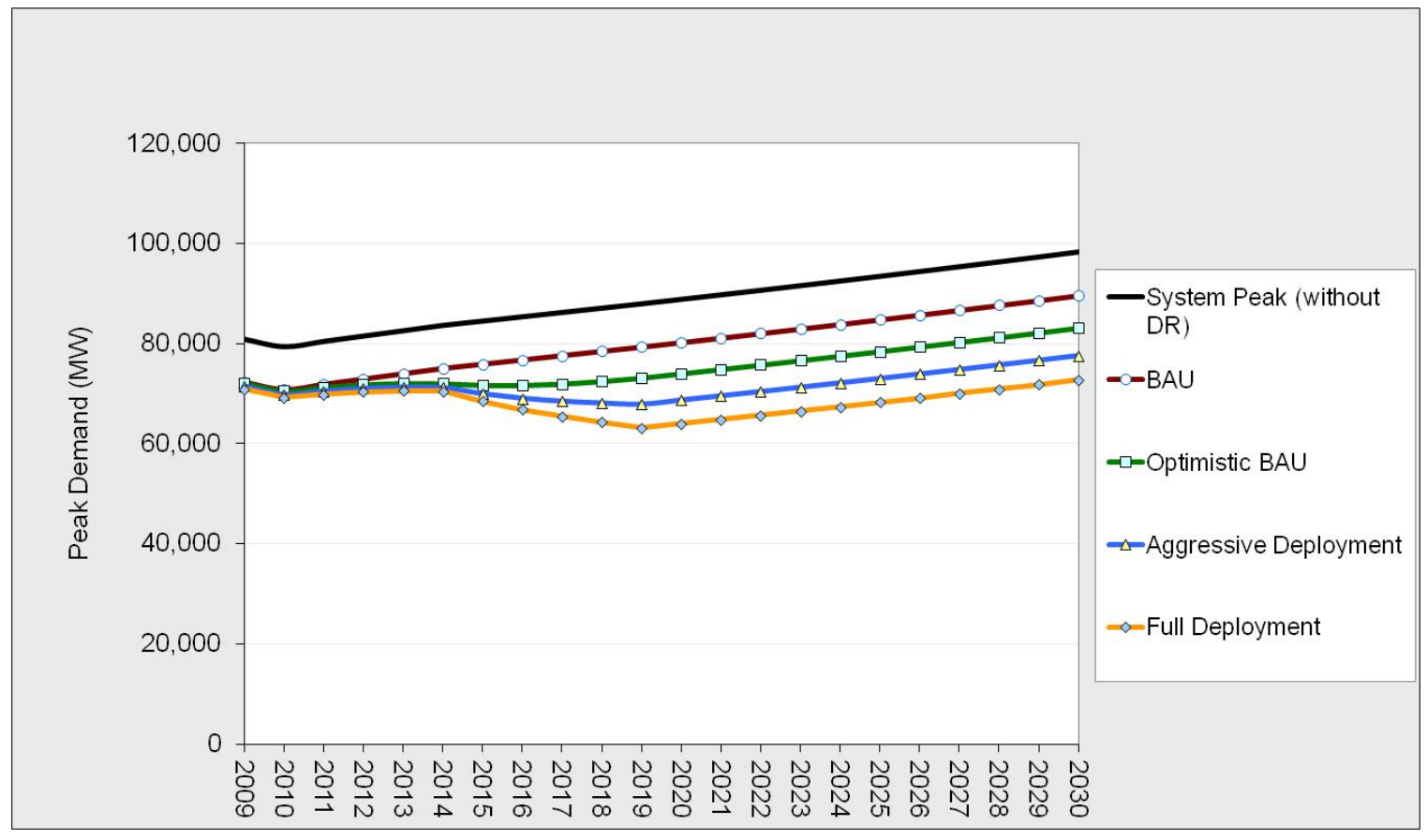

Figure 27: Middle Atlantic Division System Peak Demand Forecasts by Scenario 


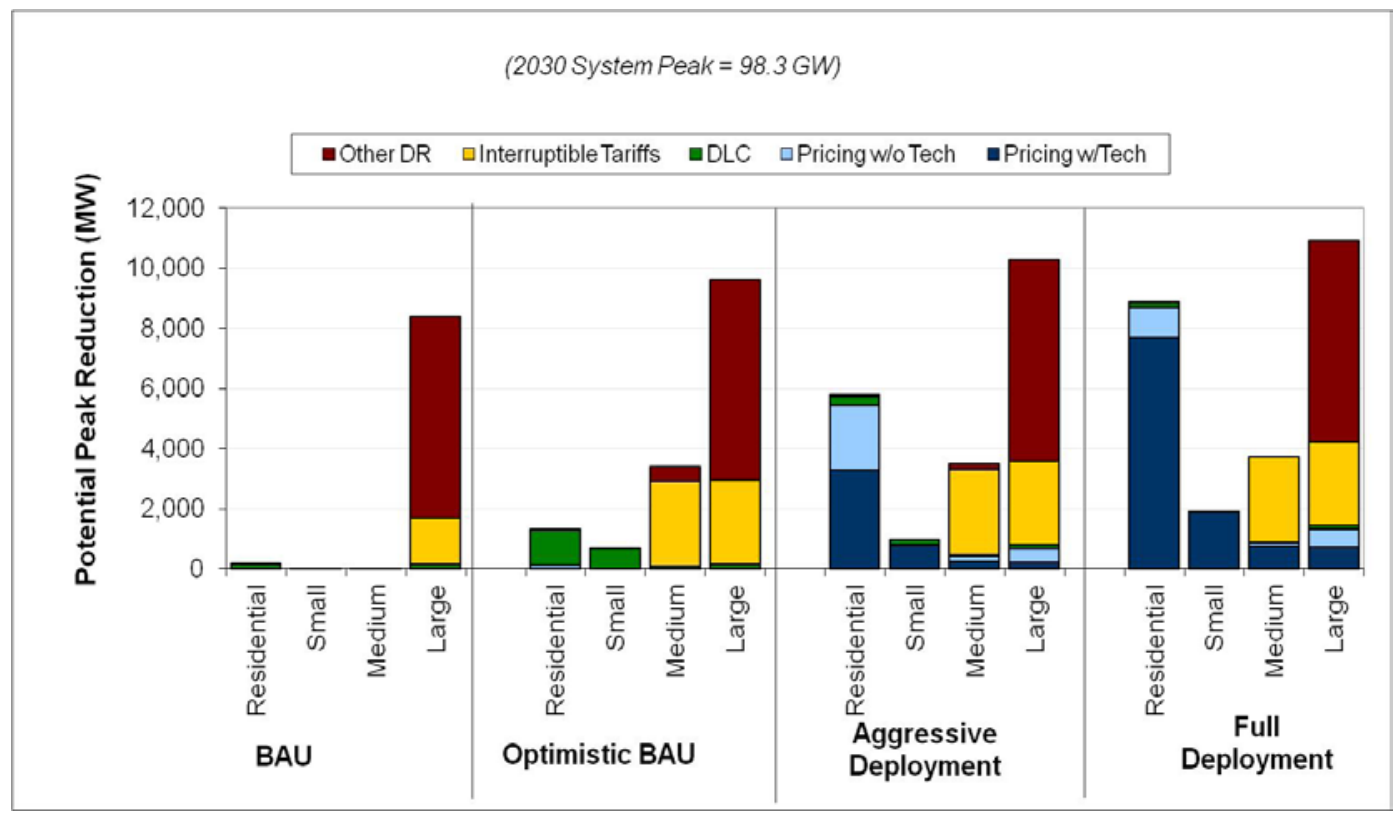

Figure 28: Middle Atlantic Division DR Potential in 2030, by Scenario

Table 8: Summary of Monte Carlo Simulation of Potential Peak Load Reduction from Demand Response in Middle Atlantic by Scenario, Pricing, and Price Ratio (MW)

\begin{tabular}{|c|c|c|c|c|c|c|c|c|c|c|c|c|}
\hline & \multicolumn{3}{|c|}{2015} & \multicolumn{3}{|c|}{2020} & \multicolumn{3}{|c|}{2025} & \multicolumn{3}{|c|}{2030} \\
\hline & Mean & Lower & Upper & Mean & Lower & Upper & Mean & Lower & Upper & Mean & Lower & Upper \\
\hline \multicolumn{13}{|l|}{ BAU } \\
\hline \multicolumn{13}{|l|}{ Pricing with Technology } \\
\hline 5 & 0 & 0 & 0 & 0 & 0 & 0 & 0 & 0 & 0 & 0 & 0 & 0 \\
\hline 10 & 0 & 0 & 0 & 0 & 0 & 0 & 0 & 0 & 0 & 0 & 0 & 0 \\
\hline 15 & 0 & 0 & 0 & 0 & 0 & 0 & 0 & 0 & 0 & 0 & 0 & 0 \\
\hline \multicolumn{13}{|l|}{ Pricing without Technology } \\
\hline & 68 & 68 & 68 & 68 & 68 & 68 & 68 & 68 & 68 & 68 & 68 & 68 \\
\hline 10 & 68 & 68 & 68 & 68 & 68 & 68 & 68 & 68 & 68 & 68 & 68 & 68 \\
\hline 15 & 68 & 68 & 68 & 68 & 68 & 68 & 68 & 68 & 68 & 68 & 68 & 68 \\
\hline \multicolumn{13}{|l|}{$\begin{array}{l}\text { Optimistic BAU } \\
\text { Pricing with Technology }\end{array}$} \\
\hline 5 & 0 & 0 & 0 & 0 & 0 & 0 & 0 & 0 & 0 & 0 & 0 & 0 \\
\hline 10 & 0 & 0 & 0 & 0 & 0 & 0 & 0 & 0 & 0 & 0 & 0 & 0 \\
\hline 15 & 0 & 0 & 0 & 0 & 0 & 0 & 0 & 0 & 0 & 0 & 0 & 0 \\
\hline \multicolumn{13}{|l|}{ Pricing without Technology } \\
\hline 5 & 120 & 86 & 142 & 198 & 118 & 254 & 200 & 119 & 257 & 203 & 120 & 261 \\
\hline 10 & 142 & 97 & 185 & 258 & 160 & 364 & 261 & 162 & 369 & 264 & 163 & 374 \\
\hline 15 & 159 & 99 & 212 & 303 & 157 & 427 & 307 & 159 & 433 & 311 & 160 & 439 \\
\hline \multicolumn{13}{|l|}{\begin{tabular}{|l|} 
Aggressive Deployment \\
Pricing with Technology
\end{tabular}} \\
\hline 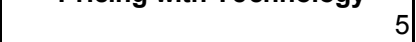 & 1076 & 423 & 1654 & 3436 & 1533 & 5244 & 3495 & 1558 & 5335 & 3556 & 1582 & 5428 \\
\hline 10 & 1625 & 555 & 2391 & 5190 & 1930 & 7662 & 5279 & 1962 & 7795 & 5370 & 1994 & 7932 \\
\hline 15 & 1908 & 664 & 2926 & 6091 & 2310 & 9236 & 6197 & 2347 & 9393 & 6304 & 2386 & 9552 \\
\hline \multicolumn{13}{|l|}{ Pricing without Technology } \\
\hline 5 & 698 & 311 & 1042 & 2106 & 1015 & 3200 & 2138 & 1028 & 3248 & 2172 & 1042 & 3298 \\
\hline 8 & 1035 & 393 & 1503 & 3211 & 1260 & 4729 & 3260 & 1278 & 4803 & 3311 & 1296 & 4878 \\
\hline 15 & 1210 & 463 & 1836 & 3771 & 1516 & 5755 & 3829 & 1537 & 5841 & 3888 & 1558 & 5930 \\
\hline \multicolumn{13}{|l|}{$\begin{array}{l}\text { Full Deployment } \\
\text { Pricing with Technology }\end{array}$} \\
\hline 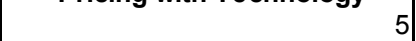 & 2588 & 1026 & 3970 & 8235 & 3711 & 12495 & 8377 & 3770 & 12708 & 8522 & 3831 & 12926 \\
\hline 10 & 3764 & 1440 & 5679 & 12021 & 5123 & 17501 & 12230 & 5206 & 17791 & 12444 & 5290 & 18087 \\
\hline 15 & 4652 & 2030 & 6713 & 14758 & 7003 & 20500 & 15013 & 7113 & 20835 & 15273 & 7225 & 21177 \\
\hline \multicolumn{13}{|l|}{ Pricing without Technology } \\
\hline 5 & 438 & 218 & 644 & 1301 & 625 & 1974 & 1320 & 633 & 2003 & 1340 & 642 & 2033 \\
\hline 10 & 618 & 286 & 932 & 1889 & 926 & 2874 & 1918 & 943 & 2916 & 1947 & 960 & 2959 \\
\hline 15 & 763 & 323 & 1116 & 2353 & 986 & 3429 & 2389 & 1004 & 3479 & 2424 & 1022 & 3529 \\
\hline
\end{tabular}




\section{East North Central Census Division Profile}

The East North Central census division is comprised of Michigan, Wisconsin, Ohio, Indiana, and Illinois. The summer peak of the division is $200 \mathrm{GW}$ and the winter peak is $161 \mathrm{GW}$. The division has a $6 \% \mathrm{AMI}$ penetration rate and a $61 \% \mathrm{CAC}$ penetration rate.

In the year of 2030, the system peak without DR would be $154 \mathrm{GW}$, the DR potential peak load reduction will be 9 GW (6\%) under BAU, 21 GW (14\%) under Optimistic BAU, 30 GW (19\%) under Aggressive Deployment, and 36 GW (24\%) under Full Deployment (Figure 29).

Heavy and energy-intensive industries are prevalent in this division. Michigan's interruptible tariff program is one of the largest in the country in terms of MW reduction. At the same time, this division exhibits a great potential for DR, particularly in pricing programs due to the above-average CAC saturations in three of its largest states (Wisconsin, Ohio, and Indiana). Throughout all four scenarios, Illinois and Michigan maintain high levels of C\&I participation in Other DR and Interruptible Tariffs. The East North Central census division shows a very similar participation pattern to the Eastern Interconnection overall (Figure 30).

Table 9 provides summary statistics of the Monte Carlo simulation for dynamic pricing programs in the East North Central census division. Demand response from the pricing without technology program was about $176 \mathrm{MW}$ under the BAU scenario, and increased to a range of 302 to $704 \mathrm{MW}$ in 2030 under the Optimistic BAU scenario. In the Aggressive and Full Deployment scenarios the range of demand response is 2424 to $12370 \mathrm{MW}$ in 2030. Demand response from the pricing with technology program are zero in the first two scenarios, but are 1447 to $9342 \mathrm{MW}$ and 3517 to $22350 \mathrm{MW}$ under the Aggressive and Full Deployment scenarios, respectively.

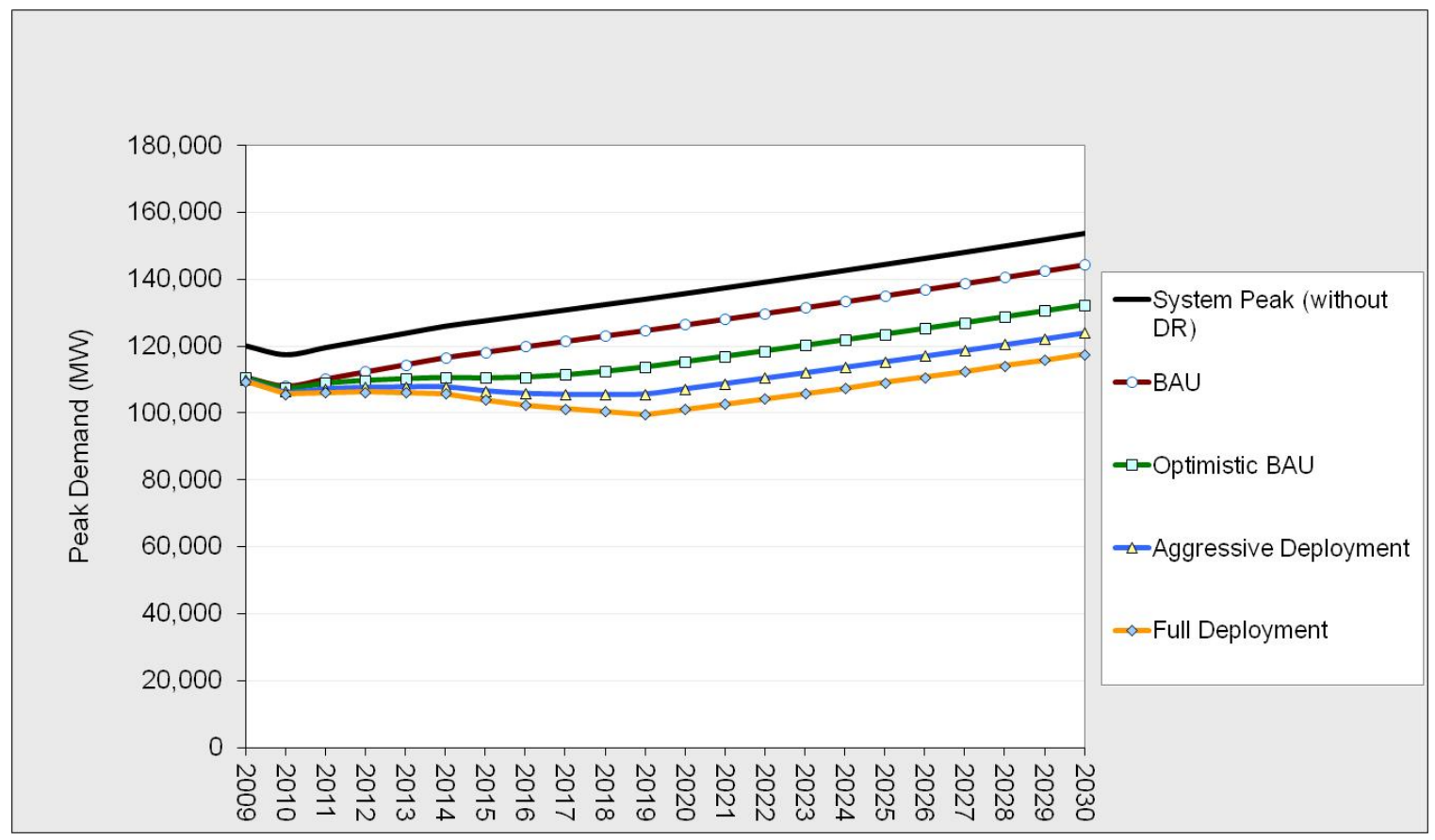

Figure 29: East North Central Division System Peak Demand Forecasts by Scenario 


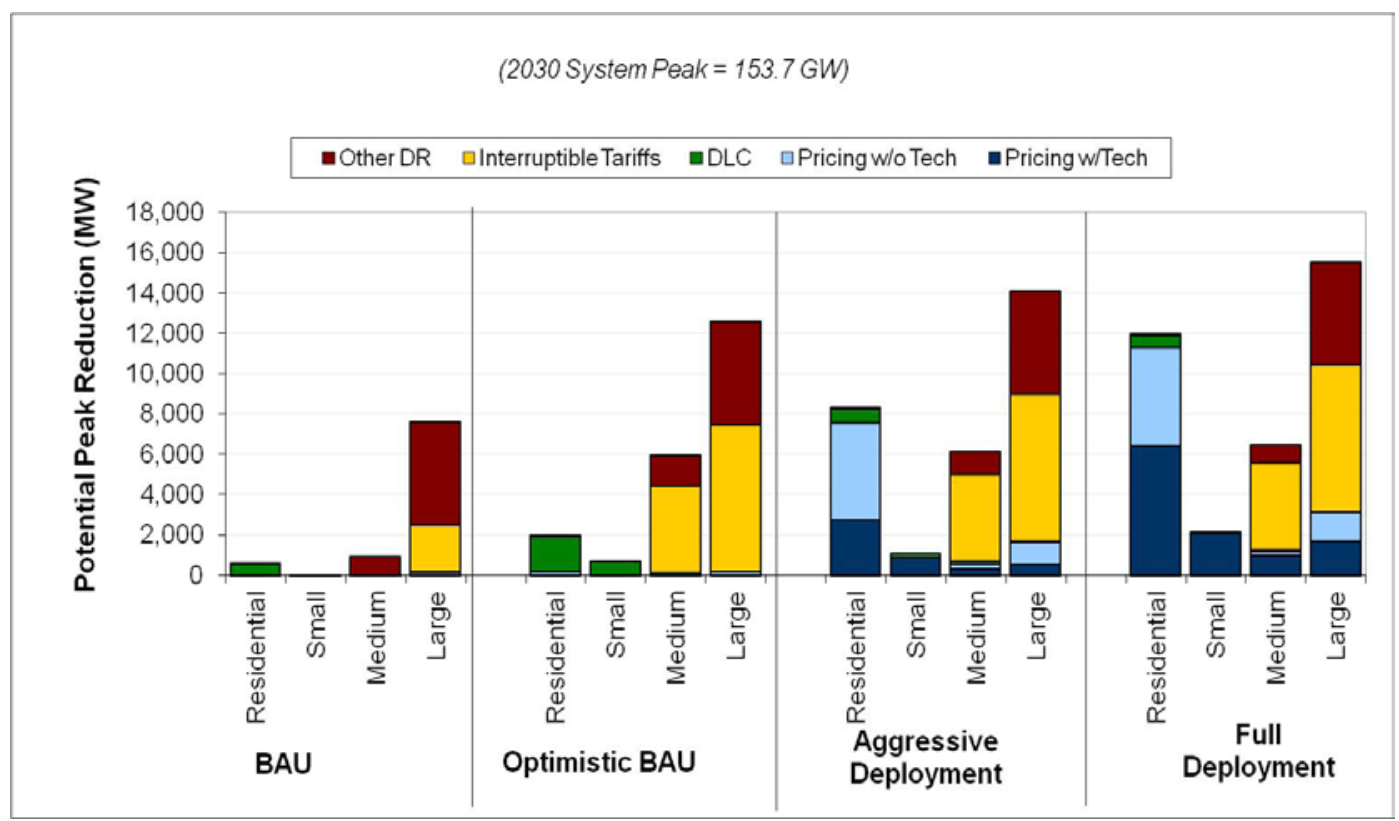

Figure 30: East North Central Division DR Potential in 2030, by Scenario

Table 9: Summary of Monte Carlo Simulation of Potential Peak Load Reduction from Demand Response in East North Central by Scenario, Pricing Program, and Price Ratio (MW)

\begin{tabular}{|c|c|c|c|c|c|c|c|c|c|c|c|c|}
\hline & \multicolumn{3}{|c|}{2015} & \multicolumn{3}{|c|}{2020} & \multicolumn{3}{|c|}{2025} & \multicolumn{3}{|c|}{2030} \\
\hline & Mean & Lower & Upper & Mean & Lower & Upper & Mean & Lower & Upper & Mean & Lower & Upper \\
\hline & \multicolumn{12}{|c|}{ BAU } \\
\hline \multicolumn{13}{|l|}{ Pricing with Technology } \\
\hline 5 & 0 & 0 & 0 & 0 & 0 & 0 & 0 & 0 & 0 & 0 & 0 & 0 \\
\hline 10 & 0 & 0 & 0 & 0 & 0 & 0 & 0 & 0 & 0 & 0 & 0 & 0 \\
\hline 15 & 0 & 0 & 0 & 0 & 0 & 0 & 0 & 0 & 0 & 0 & 0 & 0 \\
\hline \multicolumn{13}{|l|}{ Pricing without Technology } \\
\hline 5 & 176 & 176 & 176 & 176 & 176 & 176 & 176 & 176 & 176 & 176 & 176 & 176 \\
\hline 10 & 176 & 176 & 176 & 176 & 176 & 176 & 176 & 176 & 176 & 176 & 176 & 176 \\
\hline 15 & 176 & 176 & 176 & 176 & 176 & 176 & 176 & 176 & 176 & 176 & 176 & 176 \\
\hline \multicolumn{13}{|l|}{$\begin{array}{l}\text { Optimistic BAU } \\
\quad \text { Pricing with Technology }\end{array}$} \\
\hline 5 & 0 & 0 & 0 & 0 & 0 & 0 & 0 & 0 & 0 & 0 & 0 & 0 \\
\hline 10 & 0 & 0 & 0 & 0 & 0 & 0 & 0 & 0 & 0 & 0 & 0 & 0 \\
\hline 15 & 0 & 0 & 0 & 0 & 0 & 0 & 0 & 0 & 0 & 0 & 0 & 0 \\
\hline \multicolumn{13}{|l|}{ Pricing without Technology } \\
\hline 5 & 321 & 250 & 388 & 375 & 297 & 464 & 380 & 300 & 470 & 384 & 302 & 476 \\
\hline 10 & 392 & 255 & 507 & 473 & 297 & 618 & 479 & 300 & 627 & 486 & 302 & 636 \\
\hline 15 & 438 & 290 & 555 & 538 & 343 & 682 & 546 & 346 & 693 & 553 & 350 & 704 \\
\hline \multicolumn{13}{|l|}{$\begin{array}{l}\text { Aggressive Deployment } \\
\text { Pricing with Technology }\end{array}$} \\
\hline 5 & 1450 & 651 & 1988 & 3436 & 1372 & 4788 & 3512 & 1409 & 4887 & 3590 & 1447 & 4989 \\
\hline 10 & 2096 & 926 & 2967 & 4960 & 2036 & 7115 & 5070 & 2091 & 7262 & 5183 & 2148 & 7415 \\
\hline 15 & 2590 & 1126 & 3655 & 6133 & 2401 & 8961 & 6268 & 2465 & 9148 & 6407 & 2531 & 9342 \\
\hline \multicolumn{13}{|l|}{ Pricing without Technology } \\
\hline 5 & 2317 & 1279 & 3209 & 4651 & 2546 & 6344 & 4741 & 2586 & 6471 & 4833 & 2628 & 6602 \\
\hline 8 & 3367 & 1569 & 4890 & 6838 & 3426 & 9801 & 6973 & 3492 & 9995 & 7111 & 3559 & 10193 \\
\hline 15 & 4061 & 2272 & 5753 & 8314 & 4953 & 11494 & 8479 & 5050 & 11725 & 8648 & 5148 & 11962 \\
\hline \multicolumn{13}{|l|}{$\begin{array}{l}\text { Full Deployment } \\
\text { Pricing with Technology }\end{array}$} \\
\hline 5 & 3568 & 1662 & 5353 & 8313 & 3332 & 12632 & 8503 & 3423 & 12913 & 8699 & 3517 & 13203 \\
\hline 10 & 5306 & 2637 & 7546 & 12388 & 5684 & 18006 & 12670 & 5848 & 18394 & 12962 & 6019 & 18794 \\
\hline 15 & 6316 & 3345 & 9077 & 14824 & 7237 & 21420 & 15162 & 7451 & 21878 & 15512 & 7672 & 22350 \\
\hline \multicolumn{13}{|l|}{ Pricing without Technology } \\
\hline 5 & 2521 & 1215 & 3532 & 4807 & 2321 & 6738 & 4909 & 2372 & 6881 & 5013 & 2424 & 7028 \\
\hline 10 & 3700 & 1749 & 5319 & 7209 & 3555 & 10543 & 7363 & 3641 & 10770 & 7523 & 3730 & 11003 \\
\hline 15 & 4361 & 2414 & 6189 & 8502 & 4482 & 11868 & 8686 & 4582 & 12116 & 8875 & 4684 & 12370 \\
\hline
\end{tabular}




\section{West North Central Census Division Profile}

The West North Central census division is comprised of North Dakota, Minnesota, South Dakota, Iowa, Nebraska, Kansas, and Missouri. The summer peak of the division is $92 \mathrm{GW}$ and the winter peak is 79 GW. The division has a $9 \%$ AMI penetration rate and a $71 \%$ CAC penetration rate.

In the year of 2030, the system peak without DR would be $78 \mathrm{GW}$, the DR potential peak load reduction will be $5 \mathrm{GW}$ (6\%) under BAU, $15 \mathrm{GW}$ (19\%) under Optimistic BAU, $20 \mathrm{GW}$ (26\%) under Aggressive Deployment, and 25 GW (32\%) under Full Deployment (Figure 31).

Due to high levels of CAC saturation in its western-most states and large Interruptible Tariff programs in Iowa, Nebraska, and Minnesota, the West North Central census division develops a very well-rounded DR program portfolio under scenarios of higher participation; Interruptible Tariff programs for large C\&I customers maintain high levels of participation, and pricing programs grow tremendously under Aggressive and Full Deployment scenarios. Enabling technologies are not cost-effective for many customers in this division (e.g., Minnesota), however, resulting in higher-than-usual levels of DLC and Pricing without Tech program participation. This division shows a good combination of multiple programs (Figure 32).

Table 10 provides summary statistics of the Monte Carlo simulation for dynamic pricing programs in the West North Central census division. Demand response from the pricing without technology program was about $631 \mathrm{MW}$ under the BAU scenario, and increased to a range of 675 to $900 \mathrm{MW}$ in 2030 under the Optimistic BAU scenario. In the Aggressive and Full Deployment scenarios the range of demand response is 1227 to $6655 \mathrm{MW}$ in 2030. Demand response from the pricing with technology program are zero in the first two scenarios, but are 1616 to $8834 \mathrm{MW}$ and 4336 to $21778 \mathrm{MW}$ under the Aggressive and Full Deployment scenarios, respectively.

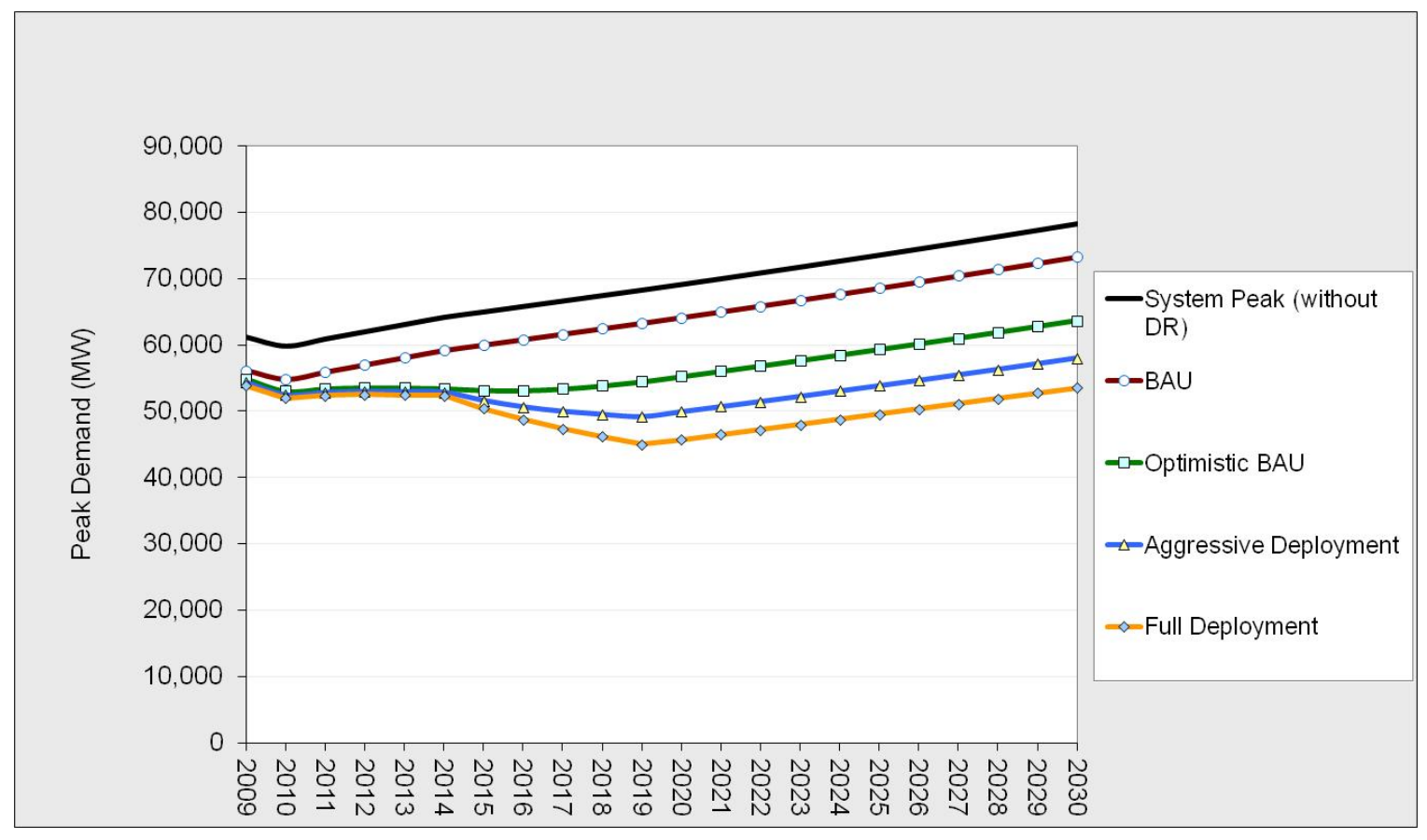

Figure 31: West North Central Division System Peak Demand Forecasts by Scenario 


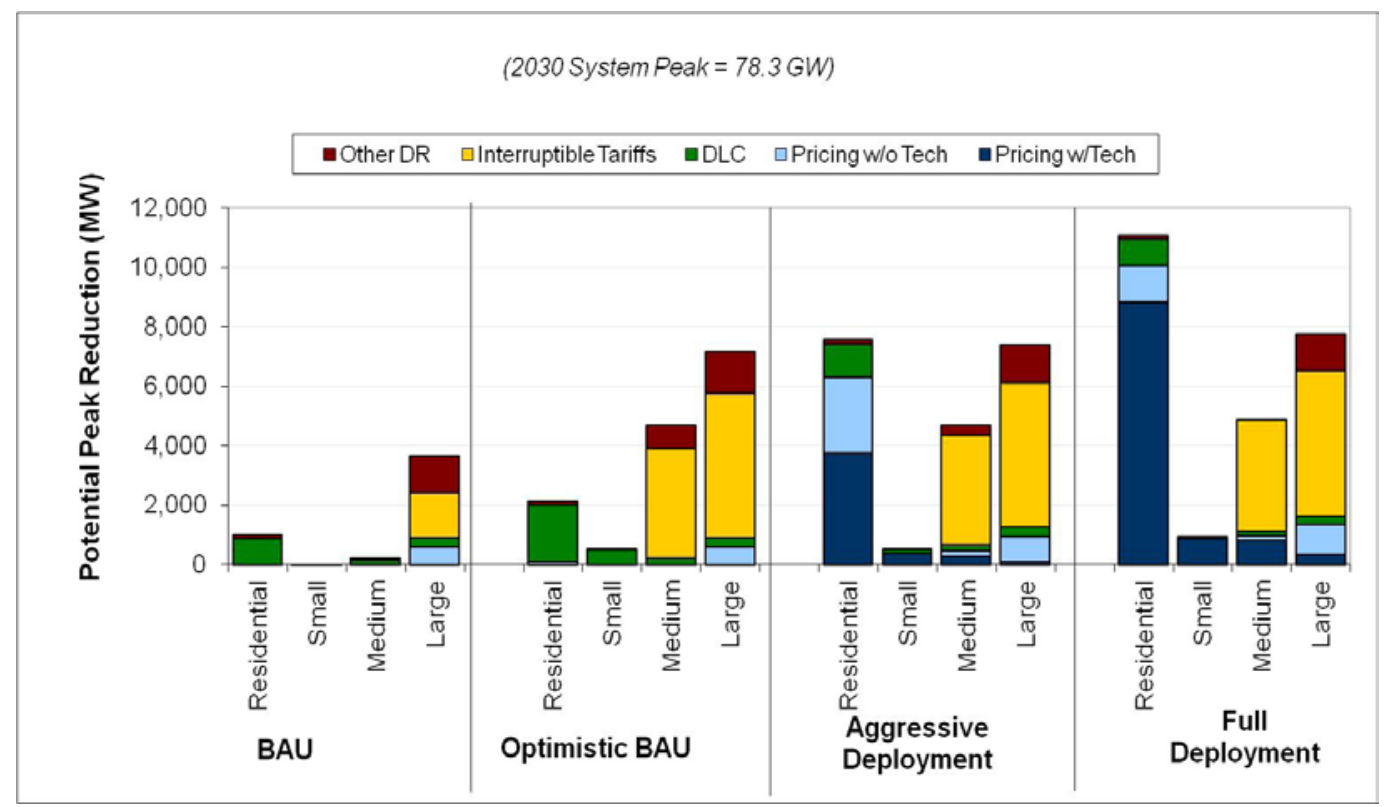

Figure 32: West North Central Division DR Potential in 2030, by Scenario

Table 10: Summary of Monte Carlo Simulation of Potential Peak Load Reduction from Demand Response in West North Central by Scenario, Pricing Program, and Price Ratio (MW)

\begin{tabular}{|c|c|c|c|c|c|c|c|c|c|c|c|c|}
\hline & \multicolumn{3}{|c|}{2015} & \multicolumn{3}{|c|}{2020} & \multicolumn{3}{|c|}{2025} & \multicolumn{3}{|c|}{2030} \\
\hline & Mean & Lower & Upper & Mean & Lower & Upper & Mean & Lower & Upper & Mean & Lower & Upper \\
\hline \multicolumn{13}{|l|}{ BAU } \\
\hline \multicolumn{13}{|l|}{ Pricing with Technology } \\
\hline 5 & 0 & 0 & 0 & 0 & 0 & 0 & 0 & 0 & 0 & 0 & 0 & 4 \\
\hline 10 & 0 & 0 & 0 & 0 & 0 & 0 & 0 & 0 & 0 & 0 & 0 & 0 \\
\hline 15 & 0 & 0 & 0 & 0 & 0 & 0 & 0 & 0 & 0 & 0 & 0 & 0 \\
\hline \multicolumn{13}{|l|}{ Pricing without Technology } \\
\hline 5 & 631 & 631 & 631 & 631 & 631 & 631 & 631 & 631 & 631 & 631 & 631 & 631 \\
\hline 10 & 631 & 631 & 631 & 631 & 631 & 631 & 631 & 631 & 631 & 631 & 631 & 631 \\
\hline 15 & 631 & 631 & 631 & 631 & 631 & 631 & 631 & 631 & 631 & 631 & 631 & 631 \\
\hline \multirow{2}{*}{\multicolumn{13}{|c|}{\begin{tabular}{|l|} 
Optimistic BAU \\
$\quad$ Pricing with Technology
\end{tabular}}} \\
\hline & & & & & & & & & & & & \\
\hline 5 & 0 & 0 & 0 & 0 & 0 & 0 & 0 & 0 & 0 & 0 & 0 & 0 \\
\hline 10 & 0 & 0 & 0 & 0 & 0 & 0 & 0 & 0 & 0 & 0 & 0 & 0 \\
\hline & 0 & 0 & 0 & 0 & 0 & 0 & 0 & 0 & 0 & 0 & 0 & 0 \\
\hline \multicolumn{13}{|l|}{ Pricing without Technology } \\
\hline 5 & 674 & 651 & 689 & 733 & 673 & 769 & 736 & 674 & 773 & 739 & 675 & 777 \\
\hline 10 & 694 & 659 & 720 & 783 & 697 & 848 & 787 & 699 & 855 & 792 & 701 & 862 \\
\hline 15 & 706 & 674 & 733 & 814 & 735 & 884 & 819 & 738 & 892 & 825 & 741 & 900 \\
\hline \multicolumn{13}{|l|}{$\begin{array}{l}\text { Aggressive Deployment } \\
\text { Pricing with Technology }\end{array}$} \\
\hline 5 & 967 & 440 & 1363 & 3334 & 1527 & 4641 & 3423 & 1571 & 4764 & 3515 & 1616 & 4891 \\
\hline 10 & 1456 & 673 & 2026 & 5021 & 2464 & 7005 & 5156 & 2536 & 7191 & 5295 & 2609 & 7382 \\
\hline & 1674 & 782 & 2440 & 5788 & 2700 & 8386 & 5944 & 2777 & 8607 & 6104 & 2857 & 8834 \\
\hline \multicolumn{13}{|l|}{ Pricing without Technology } \\
\hline 5 & 1201 & 901 & 1436 & 2756 & 1674 & 3654 & 2824 & 1706 & 3753 & 2895 & 1739 & 3858 \\
\hline 8 & 1496 & 1091 & 1845 & 3860 & 2411 & 5207 & 3966 & 2465 & 5361 & 4075 & 2520 & 5520 \\
\hline 15 & 1642 & 1158 & 2128 & 4426 & 2507 & 6280 & 4550 & 2563 & 6464 & 4679 & 2621 & 6655 \\
\hline \multicolumn{13}{|l|}{$\begin{array}{l}\text { Full Deployment } \\
\text { Pricing with Technology }\end{array}$} \\
\hline 5 & 2310 & 1155 & 3256 & 7951 & 4105 & 11228 & 8167 & 4219 & 11526 & 8389 & 4336 & 11833 \\
\hline 10 & 3454 & 1525 & 5082 & 11907 & 5479 & 17307 & 12229 & 5630 & 17769 & 12559 & 5787 & 18244 \\
\hline 15 & 4049 & 2128 & 6078 & 13929 & 7410 & 20662 & 14307 & 7612 & 21212 & 14696 & 7820 & 21778 \\
\hline \multicolumn{13}{|l|}{ Pricing without Technology } \\
\hline 5 & 914 & 769 & 1057 & 1814 & 1178 & 2438 & 1864 & 1200 & 2516 & 1916 & 1227 & 2597 \\
\hline 10 & 1050 & 815 & 1246 & 2409 & 1396 & 3263 & 2484 & 1431 & 3373 & 2563 & 1467 & 3488 \\
\hline 15 & 1141 & 830 & 1393 & 2807 & 1528 & 3888 & 2900 & 1568 & 4042 & 2997 & 1609 & 4202 \\
\hline
\end{tabular}




\section{South Atlantic Census Division Profile}

The South Atlantic census division is comprised of Delaware, Maryland, DC, West Virginia, Virginia, North Carolina, South Carolina, Georgia, Florida. The summer peak of the division is $210 \mathrm{GW}$ and the winter peak is $211 \mathrm{GW}$. The division has a $6 \%$ AMI penetration rate and $78 \%$ CAC penetration rate.

In the year of 2030, the system peak without DR would be $220 \mathrm{GW}$, the DR potential peak load reduction will be $11 \mathrm{GW}(5 \%)$ under BAU, $45 \mathrm{GW}$ (21\%) under Optimistic BAU, $68 \mathrm{GW}(31 \%)$ under Aggressive Deployment, and 88 GW (40\%) under Full Deployment (Figure 33).

Under the Aggressive Deployment and Full Deployment scenarios, all states in the South Atlantic division experience large growth in residential pricing programs (except for Washington, DC, for which enabling technologies are not cost-effective) due to the medium-to-high-levels of CAC saturation in the division. Certain states, such as Maryland and West Virginia, also maintain high participation from Large C\&I customers in Other DR and Interruptible Tariffs. Most states in the South Atlantic currently exhibit small DR activities (as reflected in the BAU), making the South Atlantic a high potential division for DR (Figure 34).

Table 11 provides summary statistics of the Monte Carlo simulation for dynamic pricing programs in the South Atlantic census division. Demand response from the pricing without technology program was about $190 \mathrm{MW}$ under the BAU scenario, and increased to a range of 561 to $2026 \mathrm{MW}$ in 2030 under the Optimistic BAU scenario. In the Aggressive and Full Deployment scenarios the range of demand response is 1231 to $21713 \mathrm{MW}$ in 2030. Demand response from the pricing with technology program are zero in the first two scenarios, but are 9567 to $43761 \mathrm{MW}$ and 17331 to $104944 \mathrm{MW}$ under the Aggressive and Full Deployment scenarios, respectively.

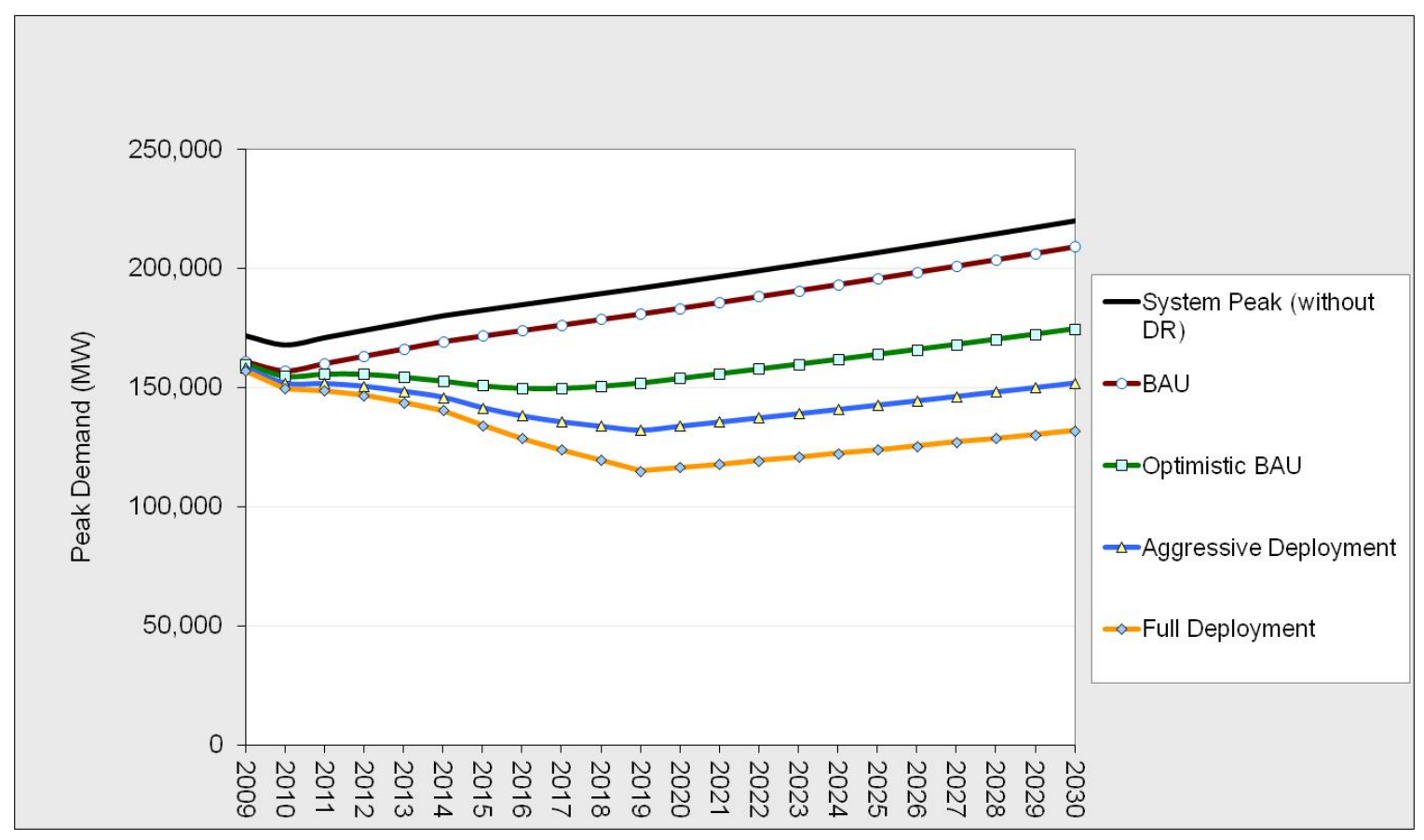

Figure 33: South Atlantic Division System Peak Demand Forecasts by Scenario 


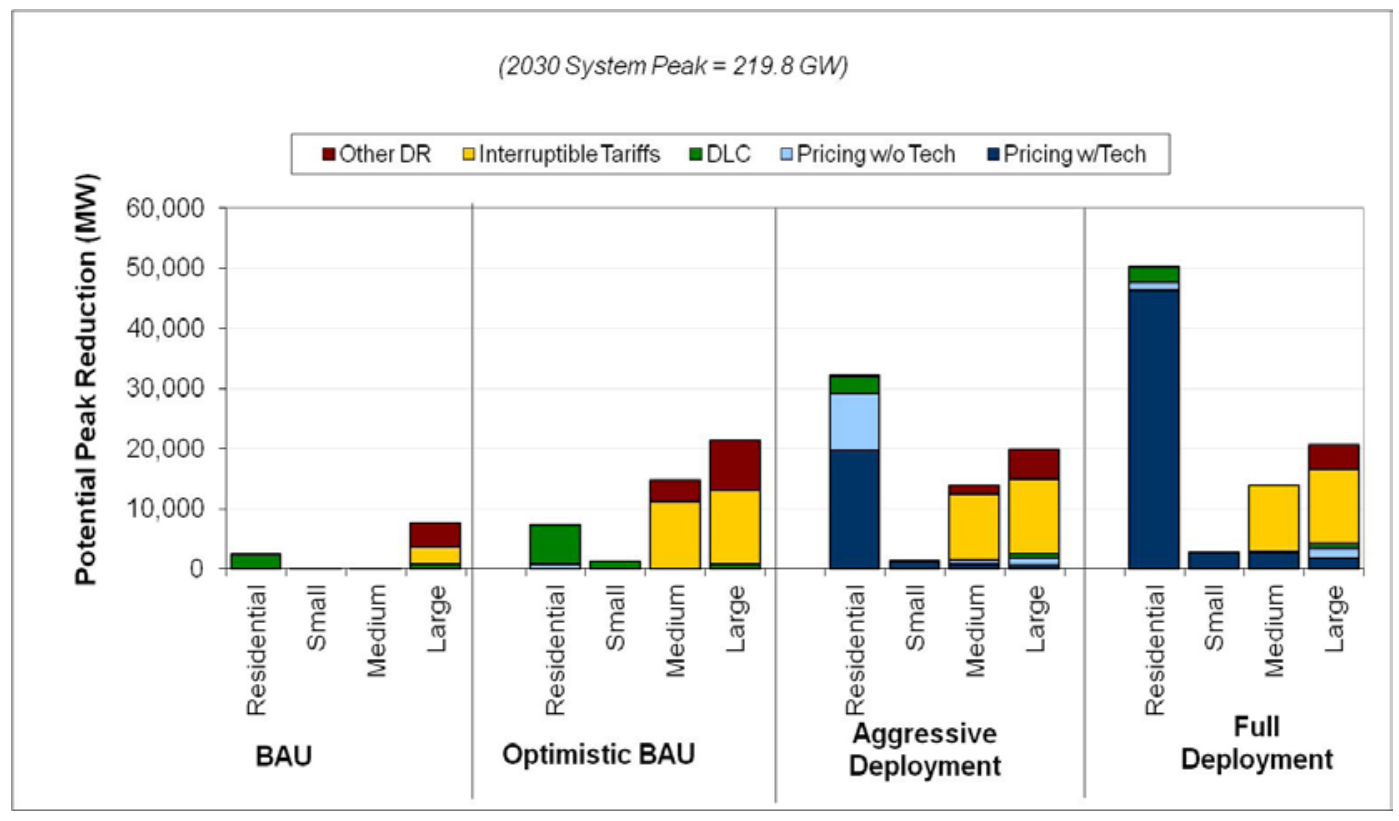

Figure 34: South Atlantic Division DR Potential in 2030, by Scenario

Table 11: Summary of Monte Carlo Simulation of Potential Peak Load Reduction from Demand Response in South Atlantic by Scenario, Pricing Program, and Price Ratio (MW)

\begin{tabular}{|c|c|c|c|c|c|c|c|c|c|c|c|c|}
\hline & \multicolumn{3}{|c|}{2015} & \multicolumn{3}{|c|}{2020} & \multicolumn{3}{|c|}{2025} & \multicolumn{3}{|c|}{2030} \\
\hline & Mean & Lower & Upper & Mean & Lower & Upper & Mean & Lower & Upper & Mean & Lower & Upper \\
\hline \multicolumn{13}{|l|}{ BAU } \\
\hline \multicolumn{13}{|l|}{ Pricing with Technology } \\
\hline 5 & 0 & 0 & 0 & 0 & 0 & 0 & 0 & 0 & 0 & 0 & 0 & \\
\hline 10 & 0 & 0 & 0 & 0 & 0 & 0 & 0 & 0 & 0 & 0 & 0 & 0 \\
\hline 15 & 0 & 0 & 0 & 0 & 0 & 0 & 0 & 0 & 0 & 0 & 0 & 0 \\
\hline \multicolumn{13}{|l|}{ Pricing without Technology } \\
\hline & 190 & 190 & 190 & 190 & 190 & 190 & 190 & 190 & 190 & 190 & 190 & 190 \\
\hline 10 & 190 & 190 & 190 & 190 & 190 & 190 & 190 & 190 & 190 & 190 & 190 & 190 \\
\hline 15 & 190 & 190 & 190 & 190 & 190 & 190 & 190 & 190 & 190 & 190 & 190 & 190 \\
\hline \multirow{2}{*}{\multicolumn{13}{|c|}{$\begin{array}{l}\text { Optimistic BAU } \\
\quad \text { Pricing with Technology }\end{array}$}} \\
\hline & & & & & & & & & & & & \\
\hline 10 & 0 & 0 & 0 & 0 & 0 & $\begin{array}{l}0 \\
0\end{array}$ & 0 & 0 & $\begin{array}{l}0 \\
0\end{array}$ & 0 & 0 & 0 \\
\hline 15 & 0 & 0 & 0 & 0 & 0 & 0 & 0 & 0 & 0 & 0 & 0 & 0 \\
\hline \multicolumn{13}{|l|}{ Pricing without Technology } \\
\hline 5 & 547 & 381 & 718 & 805 & 514 & 1075 & 854 & 537 & 1147 & 908 & 561 & 1225 \\
\hline 10 & 728 & 454 & 972 & 1099 & 654 & 1501 & 1170 & 687 & 1606 & 1247 & 722 & 1719 \\
\hline 15 & 852 & 553 & 1093 & 1315 & 796 & 1763 & 1403 & 839 & 1890 & 1499 & 886 & 2026 \\
\hline \multicolumn{13}{|l|}{$\begin{array}{l}\text { Aggressive Deployment } \\
\text { Pricing with Technology }\end{array}$} \\
\hline 5 & 6544 & 3407 & 8884 & 14781 & 8422 & 20288 & 15868 & 8974 & 21835 & 17043 & 9567 & 23510 \\
\hline 10 & 9736 & 5775 & 13486 & 21946 & 11860 & 29839 & 23559 & 12649 & 32128 & 25301 & 13495 & 34606 \\
\hline 15 & 11844 & 7196 & 16728 & 26657 & 16394 & 37802 & 28622 & 17493 & 40664 & 30744 & 18671 & 43761 \\
\hline \multicolumn{13}{|c|}{ Pricing without Technology } \\
\hline 5 & 3388 & 1899 & 4507 & 7423 & 4424 & 10095 & 7951 & 4697 & 10844 & 8522 & 4990 & 11654 \\
\hline 8 & 4993 & 3076 & 6787 & 11032 & 6303 & 15001 & 11821 & 6704 & 16118 & 12671 & 7133 & 17326 \\
\hline 15 & 6059 & 3834 & 8427 & 13419 & 8262 & 18820 & 14380 & 8801 & 20210 & 15418 & 9378 & 21713 \\
\hline \multicolumn{13}{|l|}{$\begin{array}{l}\text { Full Deployment } \\
\text { Pricing with Technology }\end{array}$} \\
\hline 5 & 15808 & 6442 & 22627 & 35687 & 15297 & 50760 & 38312 & 16278 & 54539 & 41148 & 17331 & 58626 \\
\hline 10 & 23254 & 13068 & 31966 & 52618 & 30130 & 72770 & 56502 & 32139 & 78250 & 60700 & 34294 & 84181 \\
\hline 15 & 28036 & 16627 & 40482 & 63218 & 35619 & 90903 & 67869 & 37969 & 97508 & 72893 & 40490 & 104944 \\
\hline \multicolumn{13}{|c|}{ Pricing without Technology } \\
\hline 5 & 1081 & 614 & 1436 & 2147 & 1119 & 2983 & 2278 & 1173 & 3170 & 2418 & 1231 & 3370 \\
\hline 10 & 1551 & 984 & 2006 & 3164 & 2068 & 4178 & 3358 & 2187 & 4442 & 3566 & 2314 & 4724 \\
\hline 15 & 1873 & 1211 & 2690 & 3842 & 2389 & 5581 & 4078 & 2521 & 5926 & 4330 & 2663 & 6295 \\
\hline
\end{tabular}




\section{East South Central Census Division Profile}

The East South Central census division is comprised of Kentucky, Tennessee, Mississippi, and Alabama. The summer peak of the division is $104 \mathrm{GW}$ and the winter peak is $102 \mathrm{GW}$. The division has a $8 \%$ AMI penetration rate and a $81 \%$ CAC penetration rate.

In the year of 2030, the system peak without DR would be $90 \mathrm{GW}$, the DR potential peak load reduction will be $2 \mathrm{GW}(2 \%)$ under BAU, $7 \mathrm{GW}$ (8\%) under Optimistic BAU, $16 \mathrm{GW}$ (18\%) under Aggressive Deployment, and 23 GW (26\%) under Full Deployment (Figure 35).

The Growth in DR peak load reduction is largely driven by the Residential pricing programs. The high levels of CAC saturation in this division drive this growth in DR activity. Also, most states in the East South Central division do not currently maintain high levels of DR participation. Alabama, which maintains high participation by Large C\&I in Interruptible Tariffs programs, is a notable exception (Figure 36).

Table 12 provides summary statistics of the Monte Carlo simulation for dynamic pricing programs in the East South Central census division. Demand response from the pricing without technology program was about $140 \mathrm{MW}$ under the BAU scenario, and increased to a range of 193 to $512 \mathrm{MW}$ in 2030 under the Optimistic BAU scenario. In the Aggressive and Full Deployment scenarios the range of demand response is 501 to $7311 \mathrm{MW}$ in 2030. Demand response from the pricing with technology program are zero in the first two scenarios, but are 3322 to $15003 \mathrm{MW}$ and 7228 to $35326 \mathrm{MW}$ under the Aggressive and Full Deployment scenarios, respectively.

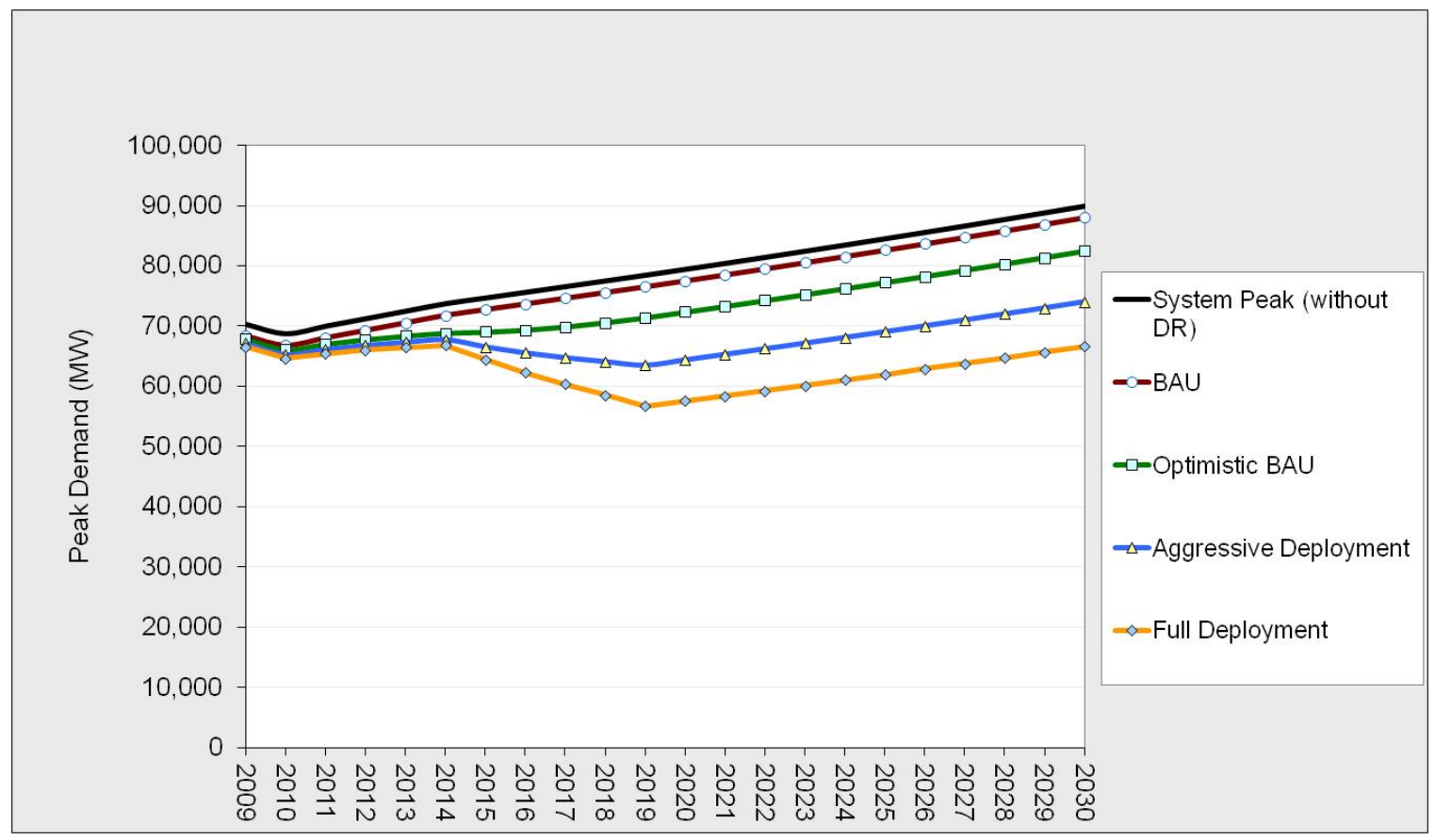

Figure 35: East South Central Division System Peak Demand Forecasts by Scenario 


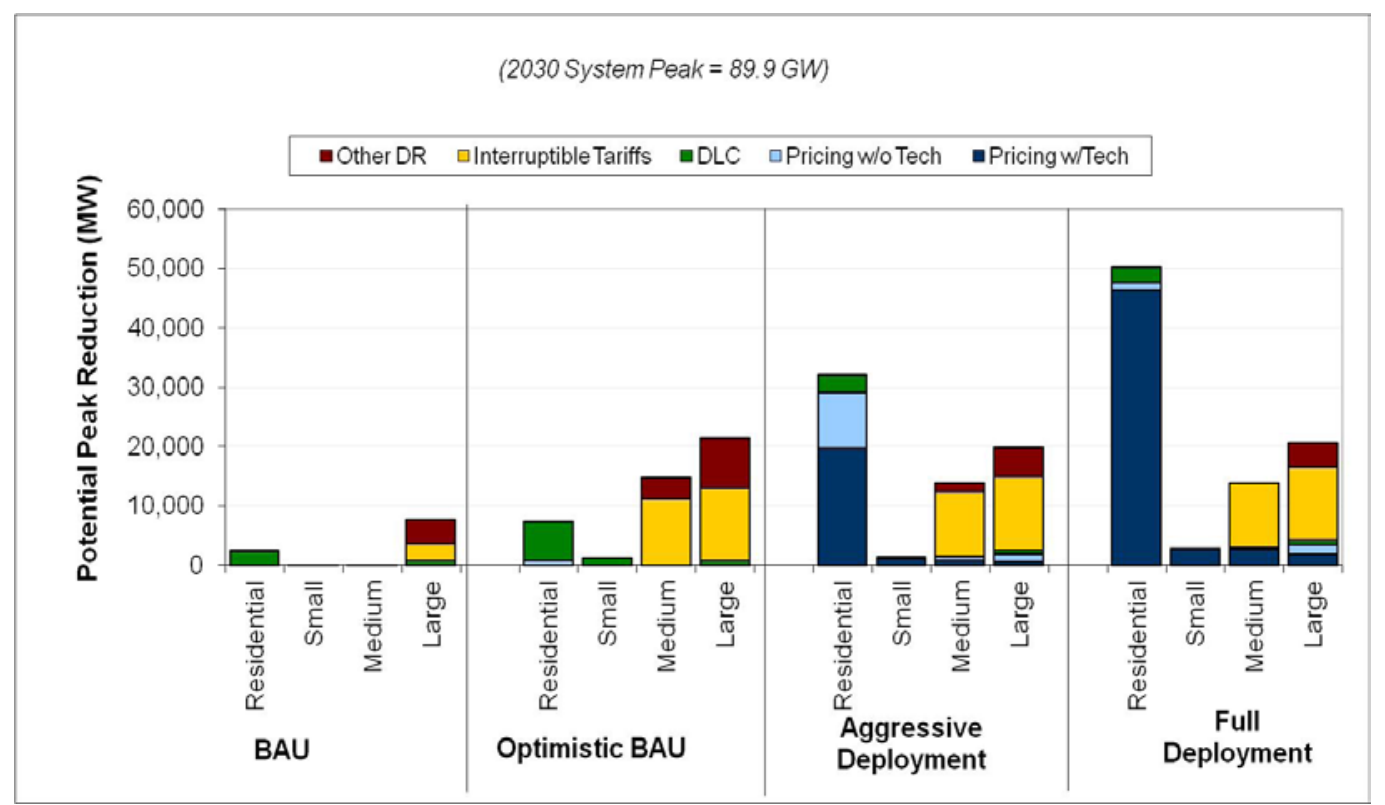

Figure 36: East South Central Division DR Potential in 2030, by Scenario

Table 12: Summary of Monte Carlo Simulation of Potential Peak Load Reduction from Demand Response in East South Central by Scenario, Pricing Program, and Price Ratio (MW)

\begin{tabular}{|c|c|c|c|c|c|c|c|c|c|c|c|c|}
\hline & \multicolumn{3}{|c|}{2015} & \multicolumn{3}{|c|}{2020} & \multicolumn{3}{|c|}{2025} & \multicolumn{3}{|c|}{2030} \\
\hline & Mean & Lower & Upper & Mean & Lower & Upper & Mean & Lower & Upper & Mean & Lower & Upper \\
\hline & \multicolumn{12}{|c|}{ BAU } \\
\hline \multicolumn{13}{|l|}{ Pricing with Technology } \\
\hline 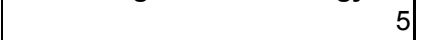 & 0 & 0 & 0 & 0 & 0 & 0 & 0 & 0 & 0 & 0 & 0 & 0 \\
\hline 10 & 0 & 0 & 0 & 0 & 0 & 0 & 0 & 0 & 0 & 0 & 0 & 0 \\
\hline 15 & 0 & 0 & 0 & 0 & 0 & 0 & 0 & 0 & 0 & 0 & 0 & 0 \\
\hline \multicolumn{13}{|l|}{ Pricing without Technology } \\
\hline & 140 & 140 & 140 & 140 & 140 & 140 & 140 & 140 & 140 & 140 & 140 & 140 \\
\hline 10 & 140 & 140 & 140 & 140 & 140 & 140 & 140 & 140 & 140 & 140 & 140 & 140 \\
\hline 15 & 140 & 140 & 140 & 140 & 140 & 140 & 140 & 140 & 140 & 140 & 140 & 140 \\
\hline \multicolumn{13}{|l|}{\begin{tabular}{|l|} 
Optimistic BAU \\
Pricing with Technology
\end{tabular}} \\
\hline 5 & 0 & 0 & 0 & 0 & 0 & 0 & 0 & 0 & 0 & 0 & 0 & \\
\hline 10 & 0 & 0 & 0 & 0 & 0 & 0 & 0 & 0 & 0 & 0 & 0 & 0 \\
\hline 15 & 0 & 0 & 0 & 0 & 0 & 0 & 0 & 0 & 0 & 0 & 0 & 0 \\
\hline \multicolumn{13}{|l|}{ Pricing without Technology } \\
\hline 5 & 189 & 164 & 210 & 260 & 190 & 317 & 264 & 192 & 322 & 268 & 193 & 328 \\
\hline 10 & 215 & 171 & 251 & 329 & 219 & 428 & 334 & 222 & 437 & 341 & 225 & 446 \\
\hline 15 & 233 & 174 & 277 & 372 & 233 & 490 & 379 & 235 & 501 & 386 & 238 & 512 \\
\hline \multicolumn{13}{|l|}{$\begin{array}{l}\text { Aggressive Deployment } \\
\text { Pricing with Technology }\end{array}$} \\
\hline 5 & 1668 & 960 & 2348 & 5606 & 3137 & 7866 & 5790 & 3228 & 8130 & 5980 & 3322 & 8403 \\
\hline 10 & 2473 & 1073 & 3524 & 8262 & 3607 & 11991 & 8532 & 3712 & 12384 & 8812 & 3821 & 12792 \\
\hline 15 & 2848 & 1578 & 4175 & 9574 & 5330 & 14071 & 9884 & 5480 & 14528 & 10206 & 5635 & 15003 \\
\hline \multicolumn{13}{|l|}{ Pricing without Technology } \\
\hline 5 & 848 & 533 & 1162 & 2718 & 1562 & 3796 & 2805 & 1607 & 3921 & 2896 & 1654 & 4050 \\
\hline 8 & 1228 & 583 & 1722 & 4024 & 1786 & 5811 & 4153 & 1838 & 5998 & 4287 & 1891 & 6193 \\
\hline 15 & 1415 & 817 & 2051 & 4679 & 2658 & 6864 & 4827 & 2731 & 7084 & 4981 & 2807 & 7311 \\
\hline \multicolumn{13}{|l|}{$\begin{array}{l}\text { Full Deployment } \\
\text { Pricing with Technology }\end{array}$} \\
\hline - & 3882 & 2190 & 5621 & 13035 & 6821 & 19196 & 13464 & 7021 & 19848 & 13910 & 7228 & 20527 \\
\hline 10 & 5929 & 3183 & 8236 & 19914 & 9758 & 28184 & 20575 & 10046 & 29132 & 21263 & 10345 & 30119 \\
\hline 15 & 6809 & 2843 & 9773 & 22813 & 9442 & 33119 & 23561 & 9745 & 34201 & 24339 & 10060 & 35326 \\
\hline \multicolumn{13}{|l|}{ Pricing without Technology } \\
\hline 5 & 307 & 204 & 419 & 937 & 465 & 1329 & 973 & 482 & 1381 & 1011 & 501 & 1435 \\
\hline 10 & 443 & 262 & 592 & 1427 & 760 & 1974 & 1483 & 791 & 2051 & 1542 & 823 & 2133 \\
\hline 15 & 511 & 250 & 719 & 1663 & 622 & 2404 & 1729 & 648 & 2498 & 1797 & 674 & 2597 \\
\hline
\end{tabular}




\section{West South Central Census Division Profile}

The West South Central census division is comprised of Oklahoma, Arkansas, Louisiana, and Texas. The summer peak of the division is $47 \mathrm{GW}$ and the winter peak is $41 \mathrm{GW}$. The division has a $5 \% \mathrm{AMI}$ penetration rate and a $76 \% \mathrm{CAC}$ penetration rate.

In the year of 2030, the system peak without DR would be -- GW, the DR potential peak load reduction will be $4 \mathrm{GW}(3 \%)$ under BAU, $21 \mathrm{GW}(15 \%)$ under Optimistic BAU, $37 \mathrm{GW}(26 \%)$ under Aggressive Deployment, and 50 GW (34\%) under Full Deployment (Figure 37).

In a manner similar to that of the East South Central division, the West South Central division experiences its largest growth in Residential pricing programs thanks to high CAC saturation rates in its states (Figure 38). Arkansas is noteworthy for also experiencing high growth in participation from Large C\&I customers in Other DR and Interruptible Tariff programs. Arkansas also maintains significant amounts of DLC throughout all four scenarios for its Residential and Small C\&I customers.

Table 13 provides summary statistics of the Monte Carlo simulation for dynamic pricing programs in the West South Central census division. Demand response from the pricing without technology program was about $930 \mathrm{MW}$ under the BAU scenario, and increased to a range of 1076 to $2184 \mathrm{MW}$ in 2030 under the Optimistic BAU scenario. In the Aggressive and Full Deployment scenarios the range of demand response is 1482 to $15414 \mathrm{MW}$ in 2030 . Demand response from the pricing with technology program are zero in the first two scenarios, but are 4216 to $28014 \mathrm{MW}$ and 9872 to $70162 \mathrm{MW}$ under the Aggressive and Full Deployment scenarios, respectively.

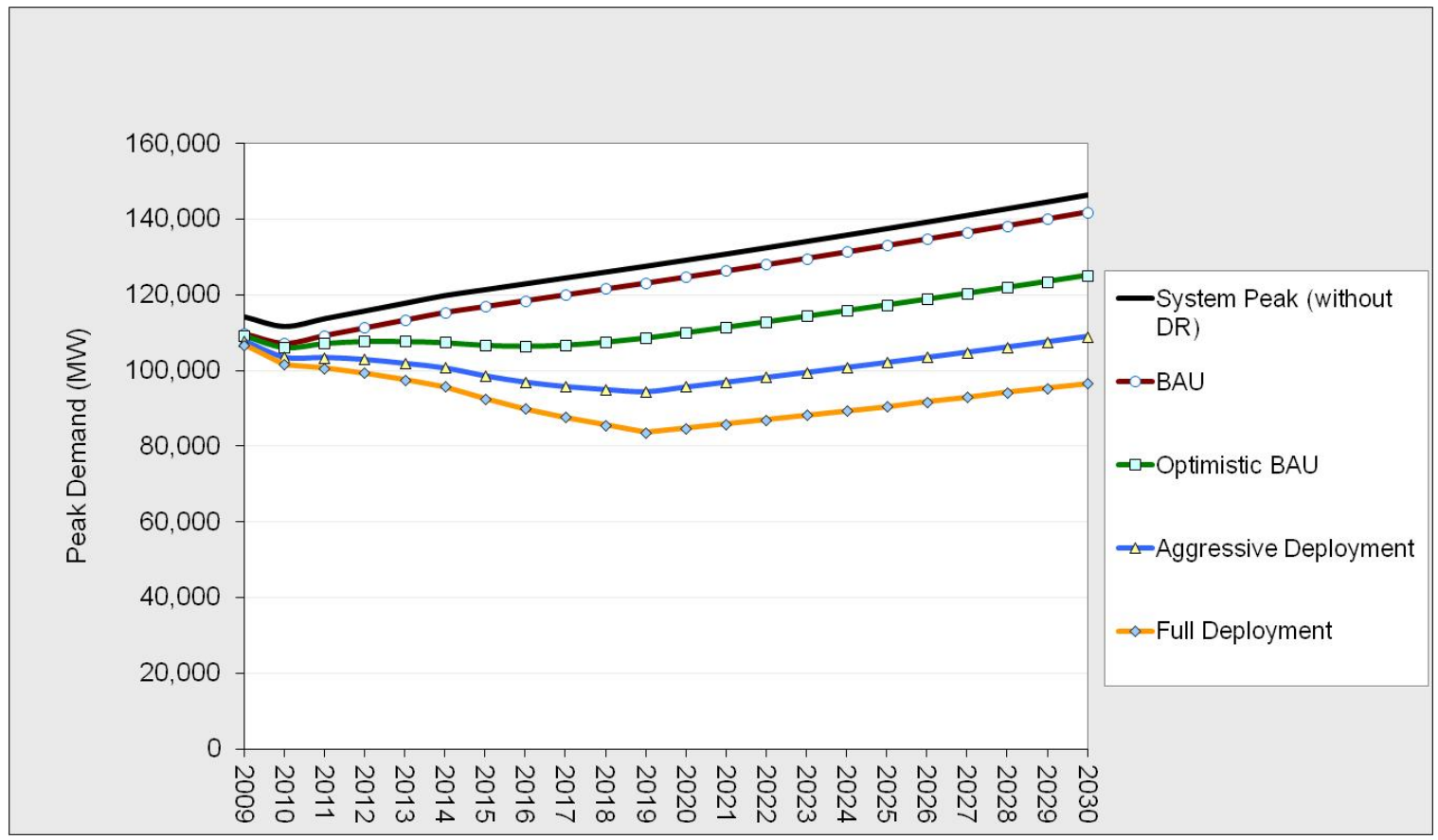

Figure 37: West South Central Division System Peak Demand Forecasts by Scenario 


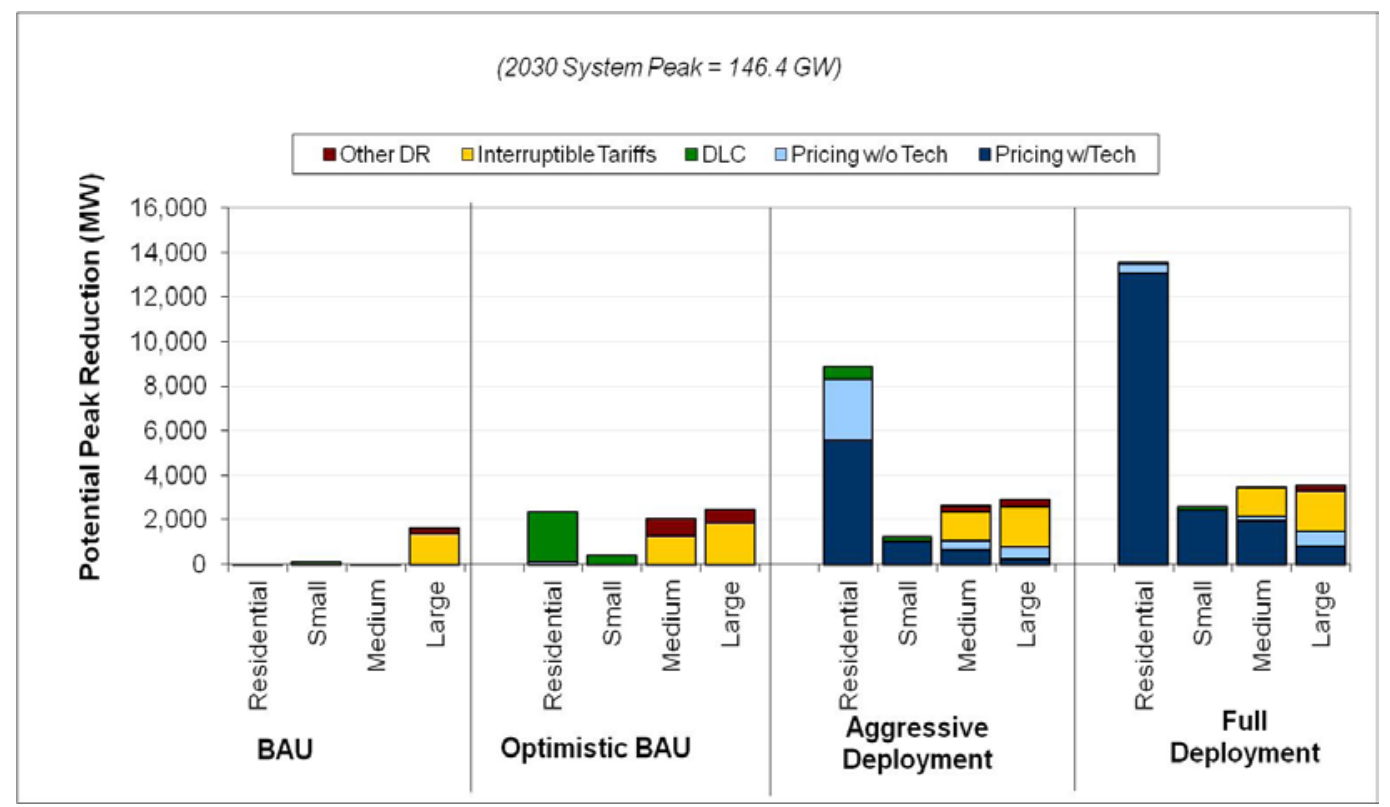

Figure 38: West South Central Division DR Potential in 2030, by Scenario

Table 13: Summary of Monte Carlo Simulation of Potential Peak Load Reduction from Demand Response in West South Central by Scenario, Pricing Program, and Price Ratio (MW)

\begin{tabular}{|c|c|c|c|c|c|c|c|c|c|c|c|c|}
\hline & \multicolumn{3}{|c|}{2015} & \multicolumn{3}{|c|}{2020} & \multicolumn{3}{|c|}{2025} & \multicolumn{3}{|c|}{2030} \\
\hline & Mean & Lower & Upper & Mean & Lower & Upper & Mean & Lower & Upper & Mean & Lower & Upper \\
\hline & \multicolumn{12}{|c|}{ BAU } \\
\hline \multicolumn{13}{|l|}{ Pricing with Technology } \\
\hline 5 & 0 & 0 & 0 & 0 & 0 & 0 & 0 & 0 & 0 & 0 & 0 & \\
\hline 10 & 0 & 0 & 0 & 0 & 0 & 0 & 0 & 0 & 0 & 0 & 0 & 0 \\
\hline & 0 & 0 & 0 & 0 & 0 & 0 & 0 & 0 & 0 & 0 & 0 & 0 \\
\hline \multicolumn{13}{|l|}{ Pricing without Technology } \\
\hline & 930 & 930 & 930 & 930 & 930 & 930 & 930 & 930 & 930 & 930 & 930 & 930 \\
\hline 10 & 930 & 930 & 930 & 930 & 930 & 930 & 930 & 930 & 930 & 930 & 930 & 930 \\
\hline 15 & 930 & 930 & 930 & 930 & 930 & 930 & 930 & 930 & 930 & 930 & 930 & 930 \\
\hline \multirow{2}{*}{\multicolumn{13}{|c|}{\begin{tabular}{|l|} 
Optimistic BAU \\
$\quad$ Pricing with Technology
\end{tabular}}} \\
\hline & & & & & & & & & & & & \\
\hline 5 & 0 & 0 & 0 & 0 & 0 & 0 & 0 & 0 & 0 & 0 & 0 & 0 \\
\hline 10 & 0 & 0 & 0 & 0 & 0 & 0 & 0 & 0 & 0 & 0 & 0 & \\
\hline & 0 & 0 & 0 & 0 & 0 & 0 & 0 & 0 & 0 & 0 & 0 & 0 \\
\hline \multicolumn{13}{|l|}{ Pricing without Technology } \\
\hline 5 & 1229 & 1027 & 1397 & 1323 & 1059 & 1540 & 1351 & 1067 & 1582 & 1380 & 1076 & 1628 \\
\hline 10 & 1391 & 1086 & 1647 & 1533 & 1142 & 1866 & 1574 & 1154 & 1930 & 1619 & 1167 & 1998 \\
\hline 15 & 1494 & 1109 & 1773 & 1667 & 1167 & 2027 & 1717 & 1182 & 2102 & 1771 & 1199 & 2184 \\
\hline \multicolumn{13}{|l|}{$\begin{array}{l}\text { Aggressive Deployment } \\
\text { Pricing with Technology }\end{array}$} \\
\hline 5 & 4956 & 1878 & 7662 & 9152 & 3804 & 13965 & 9708 & 4003 & 14833 & 10304 & 4216 & 15762 \\
\hline 10 & 7177 & 2734 & 11227 & 13328 & 5616 & 20398 & 14130 & 5905 & 21668 & 14989 & 6213 & 23029 \\
\hline & 9174 & 3232 & 13562 & 16827 & 6584 & 24825 & 17864 & 6928 & 26364 & 18975 & 7295 & 28014 \\
\hline \multicolumn{13}{|l|}{ Pricing without Technology } \\
\hline 5 & 3461 & 1857 & 4867 & 5562 & 2758 & 8038 & 5846 & 2855 & 8487 & 6151 & 2959 & 8967 \\
\hline 8 & 4620 & 2300 & 6754 & 7736 & 3715 & 11393 & 8151 & 3859 & 12044 & 8596 & 4012 & 12741 \\
\hline 15 & 5683 & 2556 & 7986 & 9595 & 4226 & 13756 & 10134 & 4407 & 14557 & 10711 & 4600 & 15414 \\
\hline \multicolumn{13}{|l|}{$\begin{array}{l}\text { Full Deployment } \\
\text { Pricing with Technology }\end{array}$} \\
\hline the & 12023 & 4455 & 18262 & 22180 & 8912 & 33337 & 23529 & 9377 & 35418 & 24973 & 9872 & 37649 \\
\hline 10 & 18085 & 7330 & 27181 & 33221 & 15021 & 49497 & 35252 & 15754 & 52566 & 37428 & 16536 & 55856 \\
\hline 15 & 21565 & 8407 & 33809 & 39591 & 17558 & 62312 & 42014 & 18441 & 66102 & 44610 & 19383 & 70162 \\
\hline \multicolumn{13}{|l|}{ Pricing without Technology } \\
\hline 5 & 1667 & 1174 & 2084 & 2271 & 1424 & 3025 & 2356 & 1452 & 3159 & 2447 & 1482 & 3302 \\
\hline 10 & 2060 & 1321 & 2646 & 3009 & 1736 & 3986 & 3140 & 1782 & 4180 & 3280 & 1831 & 4386 \\
\hline 15 & 2290 & 1390 & 3075 & 3452 & 1927 & 4970 & 3611 & 1991 & 5220 & 3780 & 2058 & 5485 \\
\hline
\end{tabular}




\subsection{DEMAND RESPONSE SUPPLY CURVE FOR EIPC STUDY}

EIPC's modeling working group (MWG) has modeled demand response as Pseudo generators in the NEEM model. The model does not limit DR to maximum length of run or total amount of operation over year and uses price as a lever so that DR is dispatched semi-realistically. In Phase I of the modeling, the amount of DR was calculated based on NADR's default ratio of critical peak price (CPP) to old price (average price) of 8 . With the default ratio of CPP to average price and a rough estimate of average retail electricity price, the average price of DR was set at $\$ 750 / \mathrm{MWh}$. The estimated DR price was applied to the dispatch process in NEEM. However, because it applied a single price to the entire DR available and the average DR price of $\$ 750 / \mathrm{MWh}$ was too high to be called on, a more realistic DR supply curve was needed. Therefore, the MWG decided to use a tiered pricing arrangement for DR in the second phase of the study with GE MAPS model, which has 6 different DR price blocks and still keeps the average price of DR at $\$ 750 / \mathrm{MWh}$.

In response to the MWG's request, we created a national stepwise DR supply curve in 2030 based on ORNL-NADR. Under the Full Deployment scenario of ORNL-NADR, we ran multiple cases to see how system peak load would respond to changes in CPP. We ran 30 different cases with a variation of CPP ranging from $\$ 50$ to $\$ 1,500 / \mathrm{MWh}$ (Figure 39).

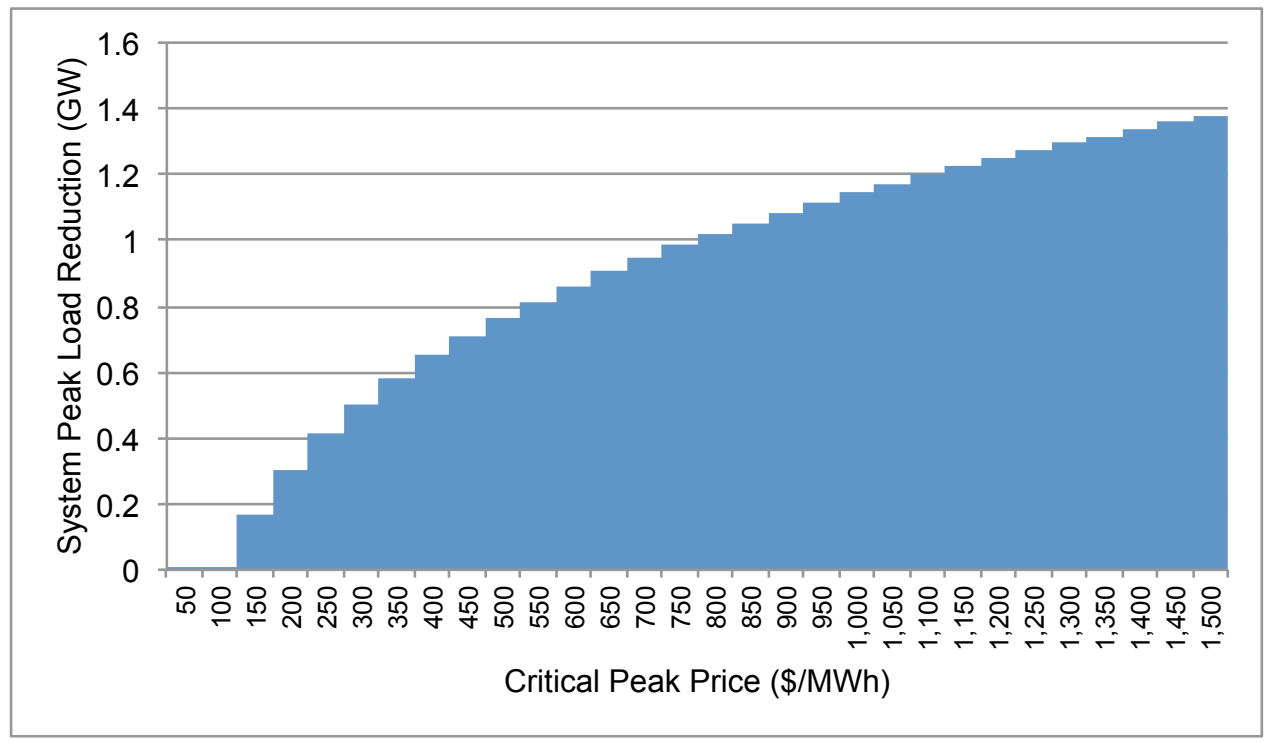

Figure 39: ORNL-NADR Runs with Variation in Critical Peak Price

Figure 40 illustrates a supply curve for pricing-related full DR deployment and its 5-block supply curve in comparison with the supply curve used in the NEEM for phase I (red line). The red line was driven based on the FERC's 2009 NADR results and shows the maximum DR available in 2030 is 209 GW. 


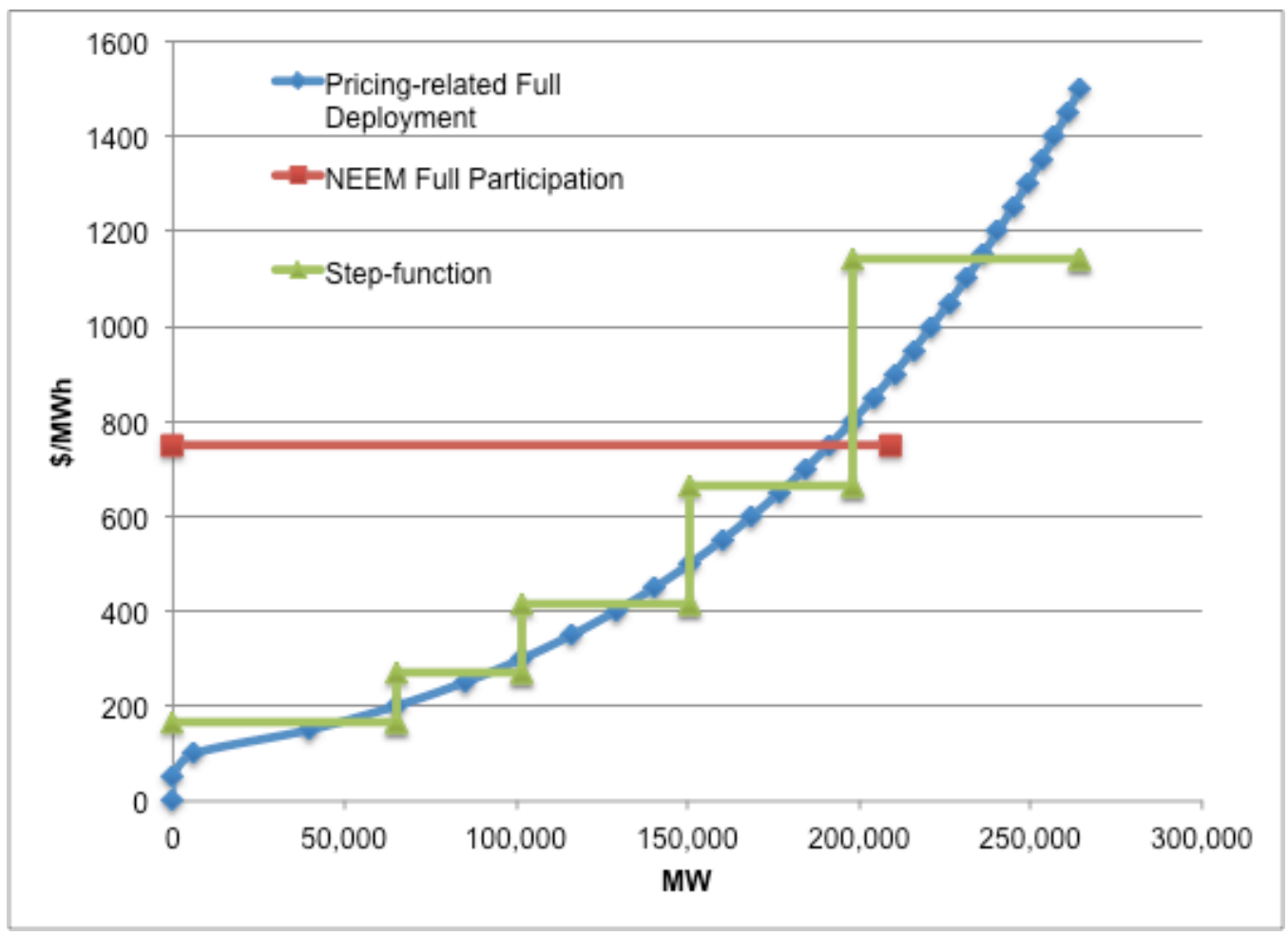

Figure 40: 5-Block Supply Curve Only with Pricing Programs in 2030

Actual DR would have a mixture of programs that dispatchers call upon. Some programs have no specific price but have time or frequency limits. Some allow customers to vary their response at different price points. In addition, the variation in CPP addresses only the impact from pricing programs (Figure 39 and Figure 40). To reflect such DR supply from non-pricing programs, we chose to allocate non-pricing DR amount into each block proportionally (Figure 41). A 70\% of peak load reductions (PLR) came from nonpricing DR was distributed into the first five price blocks, and the rest $30 \%$ of PLR was allocated to a new 6th price block. The price for this last block was set so that the weighted average of DR price stayed at $\$ 750 / \mathrm{MWh}$. A $22 \%$ of maximum DR available could be supplied at the first price block of $\$ 165 / \mathrm{MWh}$ and possibly replace advanced-combustion turbine (CT) options as pseudo-generators in the dispatch process. The last price block represents exceptionally expensive DR options such as rotational blackout that involve high societal costs but are not included in the typical DR program categories.

The resulting six blocks with both their price and the fraction of total DR, as used in the EIPC Phase 2 study, are shown in Table 14. Each region's total DR potential for the scenario in question was multiplied by the fractions from the table and priced at the amount shown. This simplified the supply curve for modeling each region's DR amounts for the purpose of the analysis. The results can be seen in the final report from the EIPC when it is published.

Table 14. DR Supply Curve as Proportion of Total DR Available in Region for EIPC Study

\begin{tabular}{|c|c|c|c|}
\hline \multirow[t]{2}{*}{ Block } & \multirow{2}{*}{$\begin{array}{c}\text { Price } \\
\$ / M W h\end{array}$} & \multicolumn{2}{|c|}{ \% of Total Capacity } \\
\hline & & Incremental & Cumulative \\
\hline 1 & 165 & $22 \%$ & $22 \%$ \\
\hline 2 & 273 & $12 \%$ & $34 \%$ \\
\hline 3 & 418 & $16 \%$ & $50 \%$ \\
\hline 4 & 665 & $16 \%$ & $66 \%$ \\
\hline 5 & 1,142 & $22 \%$ & $88 \%$ \\
\hline 6 & 2,100 & $12 \%$ & $100 \%$ \\
\hline
\end{tabular}




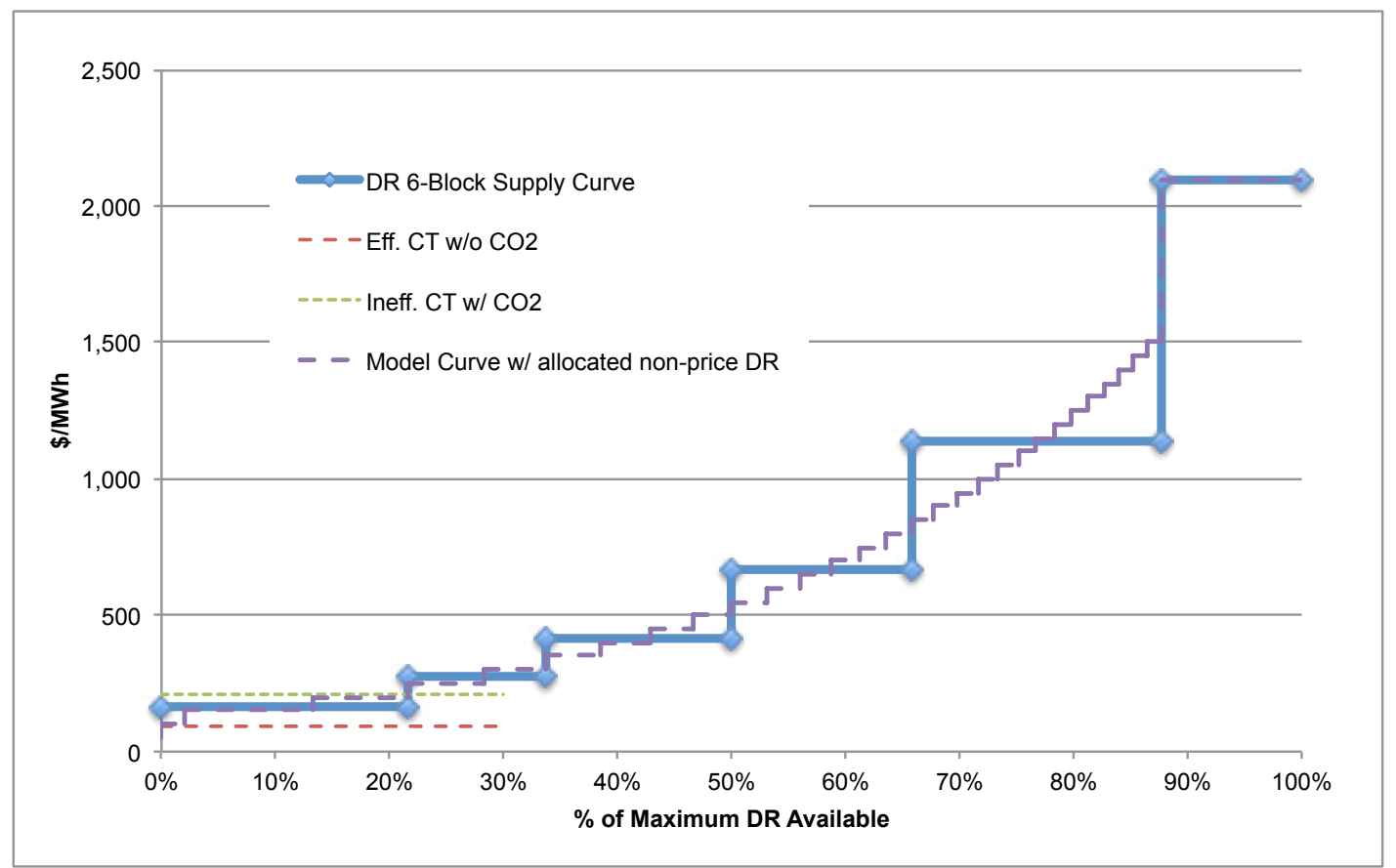

Figure 41: 6-Block Supply Curve and Model Curve with Allocated Non-Price DR in 2030 


\section{DEMAND RESPONSE COSTS}

\subsection{INTRODUCTION}

Although Demand Response (DR) has many applications in electricity markets, other alternatives exist for any given application. While DR can reduce reserve requirements, enable greater participation in capacity bidding programs, provide grid relief during emergency conditions, and reduce the overall capital and operating costs of electric power systems, other alternatives exist to serve these applications. ${ }^{19}$

Because many technological alternatives exist for a given electricity market application, cost estimates become valuable tools for comparing across alternatives. This chapter provides cost estimates for the DR deployed in the Eastern Interconnection forecast in this report. The scope of the chapter is limited to the costs of DR, and costs of alternative technologies will not be described. Readers should carefully note the framework and assumptions used in this analysis, especially when using this analysis to compare DR to alternatives.

\subsection{SUMMARY}

This chapter presents estimates of DR program costs under the Total Resource Cost Test (TRC) framework of benefit-cost analysis. DR costs are assumed to primarily consist of the costs of advanced metering infrastructure (AMI) systems and load-controlling technologies ("Enabling Technologies"), an assumption well-supported by DR literature. Costs-per-unit of AMI and Enabling Technology are estimated from a review of literature and public utility regulatory commission dockets containing AMI business cases filed by electric utility companies. These costs-per-unit are applied to AMI and Enabling Technology deployment data from the ORNL-NADR, using further assumptions about AMI and ET deployment practices garnered from the reviewed AMI business cases. The resulting costs are forecast for each state, sector, and year of the ORNL-NADR model. Costs are aggregated into census regions and provided for the EI. These results are compared to other studies of AMI costs and discussed with respect to the literature reviewed.

\subsection{FINDINGS FROM PRIOR STUDIES OF DEMAND RESPONSE}

\section{Demand Response Cost Drivers}

The primary costs associated with DR programs are the costs of deploying AMI and Enabling Technologies (Gellings et al. 2011, Chupka et al. 2008). AMI is necessary to enable many DR programs that require interval metering to measure peak load reduction and/or communication of price signals. AMI is also useful for load profiling, which helps define parameters of customer-utility DR contracts. Supporting the interconnectedness of AMI and DR, utility companies applying to deploy AMI have portrayed DR benefits as attributable to AMI investments (Heffner 2010). Utility companies such as Pacific Gas and Electric and Centerpoint Energy Houston Electric have used benefits from forecasted DR load reductions to cost-justify AMI investments (Agerter and Ouborg 2005, Standish 2008).

While AMI investments can yield great energy savings benefits from DR programs, DR is not necessarily the strongest driver behind AMI investment. Utility companies can achieve significant net benefits

\footnotetext{
${ }^{19}$ Energy efficiency can reduce reserve requirements, distributed generation can enable greater capacity bidding, improved sensor systems can help avert emergency conditions altogether, and improved generation technologies can reduce capital and operating costs, to name a small subset of technologies capable of performing DR functions.
} 
through deploying AMI because AMI reduces the operating costs of utility metering systems. For many utilities, it is less expensive to deploy and operate AMI systems than to employ a metering-reading labor force, even if that labor force uses Automated Meter Reading (AMR) technologies. AMI can also reduce revenue losses by improving estimation and validation processes, and AMI can help utilities prevent electricity theft via improved tampering protection and remote disconnection features (Maters, et al. 2010; McIndoo 2008; Haney, Jamasb, and Pollitt 2009).

Conversely, some DR programs do not require AMI to achieve significant energy reductions. Programs that involve utility control of customer devices or that require large C\&I customers to reduce load in a manner of their choosing in response to utility phone calls have existed in previous decades and do not require AMI. While AMI can help enhance the load impacts of these programs by improving the accuracy of customer load reduction measurement and verification, certain DR programs are perfectly functional without AMI investment (Federal Energy Regulatory Commission 2009).

While some DR programs function without AMI investment, such programs may require investment in Enabling Technologies. Enabling Technologies are necessary for specific DR programs that provide a reduced rate or monthly bill rebate to customers in exchange for utility control of customer loads. Enabling Technologies are devices that enable a utility to unilaterally limit customer loads. Among residential customers, for example, utilities may control the loads from central air conditioning (CAC) and water heating through Enabling Technologies (Federal Energy Regulatory Commission 2008, 2009).

Other monetized costs to utilities and customers arise from DR programs. The cost to utilities of compensating customers for participating in DR programs is one example of a monetized cost of DR. This monetized cost to the utility is a direct, monetized benefit to the customers participating in the DR program (Heffner 2010).

Non-monetized costs also arise from DR programs and can be even more significant than monetized costs in shaping DR program deployment. One example of non-monetized DR costs is cost to consumers of behavioral changes, such as the inconvenience to residential customers of shifting laundry activities from on-peak periods to off-peak periods. The impacts of such non-monetized costs can be observed in features of DR contracts such as duration and frequency limits on DR events and overall participation in DR programs.

\section{Costs of Advanced Metering Infrastructure and Enabling Technologies}

"Estimating the Costs and Benefits of the Smart Grid," a report published in 2011 by the Electric Power Research Institute (EPRI), provides estimates of per-unit costs of AMI and its technological subcomponents as well as forecasts of AMI costs from 2010 to 2030 for the entire United States. Assuming an $83 \%$ average market saturation of smart meters across all customer types and all states in the US, EPRI concluded that AMI investment between 2010 and 2030 would range from $\$ 15$ to $\$ 42$ billion. By contrast, EPRI estimated that between $\$ 338$ and $\$ 476$ billion of investment would be necessary to thoroughly modernize the entire U.S. electricity grid by 2030 (Gellings et al. 2011).

To form its unit cost estimates, EPRI gathered information from electric utility companies that were deploying the first wave of Smart Grid Infrastructure Grant (SGIG)-funded AMI projects. These utilities included FirstEnergy, Dayton Power and Light, Idaho Power Company, Southern California Edison, and San Diego Gas \& Electric. The unit cost estimates formed from this information represent an estimate of actual costs to be incurred by utilities deploying AMI From this analysis, EPRI assumed four separate per-unit costs for AMI deployment: lower-bound estimates of $\$ 77$ per unit for residential customers and $\$ 140$ per unit for commercial and industrial (C\&I) customers, and upper-bound estimates of $\$ 165$ per unit for residential customers and $\$ 565$ per unit for C\&I customers (Gellings et al. 2011, pp. 6-13 to 6-14). 
The Brattle Group's "Transforming America's Power Industry: The Investment Challenge 2010-2030" provides a cursory estimate of AMI costs for the 2010 to 2030 period. Assuming AMI saturation rates of $30 \%$ among residential customers and 50\% among commercial and industrial (C\&I) customers reached by 2030, the Brattle Group calculated a total cost of $\$ 27$ billion for AMI system deployments from 2010 to 2030. Assuming 12\% residential, 20\% C\&I AMI saturation rates reached by 2030, the Brattle Group calculated a total cost of $\$ 19$ billion for AMI system deployments from 2010 to 2030. Through review of California shareholder filings for AMI budget approval, the Brattle Group estimated the cost of an AMI system per residential customer to be $\$ 300$ and per C\&I customer to be $\$ 1,500$. The Brattle Group estimated that approximately $\$ 880$ billion of investment would be necessary for modernizing the U.S. electricity grid by 2030 (Chupka et al. 2008).

A 2009 publication from Cambridge University's Electricity Policy Research Group (EPRG) titled "Smart Metering and Electricity Demand: Technology, Economics, and International Experience" provides a review of international experience with AMI deployment. The EPRG finds that advanced meters frequently have useful lives of 15 years, in contrast to the 20 -year useful lives held by traditional electromechanical meters. The EPRG also finds that large-scale, centrally-managed deployments of AMI may have greater potential to reduce the costs-per-advanced meter of the deployment than small-scale, de-centralized deployments due to economies of scale. Economies of scale can also lower marginal costs if AMI deployments are accelerated rather than phased-in. The EPRG finds that radio-frequency (RF) communications technologies are more cost-effective for sending signals to advanced meters located in more densely-populated areas than are power-line-carrier (PLC) communications technologies (Haney, Jamasb, and Pollitt 2009).

AMI deployments have been observed to be subject to industrial learning effects, which is to say that the marginal cost of a product decreases as cumulative production increases. Navigant Energy Consulting studied many cases of AMI deployments funded by the Department of Energy's Smart Grid Investment Grants, finding that the costs per AMI meter deployed declined as utility companies deployed a greater cumulative number of advanced meters (Chan et al 2011).

The Federal Energy Regulatory Commission (FERC)'s 2009 National Assessment of Demand Response provides estimates of unit costs for Enabling Technologies. The FERC assesses two particular kinds of Enabling Technologies - Direct Load Control (DLC) switches and Programmable Communicating Thermostats (PCTs). DLC switches are used by utility companies administering DLC programs to remotely control a customer's load devices, while PCTs are used to control CAC units via price signals from a utility. Table 15 below provides the unit costs of DLC devices and PCTs estimated by FERC (these unit costs were used in the original NADR and thus the customers sectors match those in the ORNL-NADR) (Federal Energy Regulatory Commission 2009). An earlier study of Enabling Technology costs by the California Energy Commission's Public Interest Energy Research supports the costs estimated by FERC (Nancy, Haiad, et al. 2005). 
Table 15: Unit Costs for Enabling Technologies

\begin{tabular}{c|c|c} 
& Programmable Communicating Thermostat & Direct Load Control Switch \\
\hline Residential & $\$ 200.00$ & $\$ 200.00$ \\
\hline Small C\&I & $\$ 350.00$ & $\$ 350.00$ \\
\hline Med. C\&I & $\$ 1,050$ & $\$ 1,050$ \\
\hline Large C\&I & $\$ 13,500$ & $\$ 1,050^{20}$
\end{tabular}

\section{Insights into the Next Wave of Advanced Metering Infrastructure Deployment}

Recent insights into the AMI market show that rural electric cooperatives (RECs) and municipally-owned electricity systems ("Munis") are likely to be the next major deployers of AMI systems. GreenTech Media's Zach Pollock states that most U.S. investor-owned utilities (IOUs) have already deployed AMI or are in the process of deploying AMI systems (Pollock and Clavenna 2012). RECs led the U.S. in AMI deployments in 2010; according to a FERC study published in 2011, 25\% of REC meters were advanced while only approximately $8 \%$ of meters nationwide were advanced (Federal Energy Regulatory Commission 2011). RECs have particularly strong incentives to deploy AMI due to the large metering costs intrinsic to rural areas (Roche 2011).

\section{Review of AMI Business Cases}

For detailed data on AMI deployment costs, twenty separate AMI business cases were reviewed and analyzed. These business cases were filed by utility companies in support of applications to public utility regulatory commissions for approval of AMI deployment. Each business case describes the costs of the AMI system that the utility company expects to incur and for which the utility company requests revenue recovery. As such, these expected costs of AMI deployment are passed on to ratepayers instead of the actual costs incurred by the utility from the AMI deployment.

The AMI business cases provide examples of the scale (i.e. number of meters) of AMI deployments, the timing of AMI deployments, various technological features of AMI deployments, and the costs of AMI deployments. While estimating exact costs for future AMI system deployments over a twenty-year period is impossible, these examples of AMI system cost forecasts provide sufficient information for estimating a reasonable range of AMI deployment costs for a twenty-year future.

\subsection{METHODOLOGY}

\subsubsection{Assumptions}

\section{Total Resource Cost Test Framework}

This analysis presents the costs of DR under the TRC framework, which is intended to evaluate a utility's investment decisions from the perspective of all society (including the utility and its customers). The TRC framework considers three categories of cost for an energy program: Installation Costs, Overhead Costs, and Incremental Costs (Environmental Protection Agency 2008). These categories may be respectively described as:

\footnotetext{
${ }^{20}$ The FERC did not estimate unit costs for Large C\&I DLC switches because no Large C\&I participating in DLC programs were forecast in their 2009 analysis. The ORNL-NADR forecasts a small number of Large C\&I participants in DLC programs, however, so the unit costs for Medium C\&I DLC switches has been assumed for Large C\&I DLC switches.
} 
Installation costs - the costs necessary to acquire equipment, install equipment at customer sites, acquire and setup infrastructure to support program, acquire and setup/integrate necessary utility systems to manage program, and the management/labor costs of these acquisitions, installations, and setups.

Overhead costs - the costs of operating the program, such as maintaining the equipment and infrastructure, fees associated with software or service licensing/contracts, and payments to personnel for operating and administering program.

Incremental costs - these are installation costs that occur in the operation phase of the program, i.e. after deployment and the associated installation costs have already taken place. These can include equipment replacement (in the case of failure or end-of-life), equipment upgrades, and incremental expansion of the program due to new enrollees.

Alternative benefit-cost frameworks and the variables they consider are presented in Appendix C.

Monetized costs of DR programs that are incurred as costs by one party in a DR program but incurred as monetized benefits by another party in a DR program are ignored by the TRC. A utility's cost of compensating customers participating DR is a direct benefit to the customers being compensated, for example, and this cost is therefore ignored by the TRC. The Program Administrator Cost Test, Ratepayer Impact Measure, and Participant Cost Tests account for monetized costs ignored by the TRC (see Appendix C for more detail).

Non-monetized costs are considered by the TRC framework, but are not captured by this analysis. The non-monetized welfare impacts of DR can vary widely due to the variety of programs through which DR can be implemented; the valuation made by utility firms upon peak load relief, lost sales, and load loss; and the distribution of valuations of electricity consumption by different customer sectors and within each customer sector. A separate study would be appropriate in scale and scope for characterizing the nonmonetized welfare impacts of $\mathrm{DR}^{21}$.

\subsubsection{Analysis of AMI Business Cases in Societal Cost Test Framework}

The costs presented in the AMI business cases were analyzed within the framework of the TRC. The AMI systems reviewed had four key categories of Installation Costs:

- Meters - the costs incurred through procurement of advanced meter hardware, such as advanced meters and communication modules, and installation of advanced meter hardware at customer sites.

- Information Technology Systems - costs incurred through the procurement of hardware and software necessary to receive and manage data from the installed advanced meters. Such systems frequently involve Meter Data Management Systems (MDMS), customer information systems (CIS), and billing systems that are capable of handling interval data (i.e. consumption data collected on the hour or more frequently).

\footnotetext{
${ }^{21}$ A calculation of consumer welfare change resulting from the DR programs modeled in this study was prepared but ultimately discarded due to lack of data for a complimentary calculation of producer welfare changes. Readers interested in the consumer welfare calculation are encouraged to contact the authors for more information.
} 
- Communications Networks - costs incurred through procurement of telecommunications technologies necessary for carrying data between utilities' Information Technology Systems and advanced meters. Technologies frequently used to form Communications Networks include:

- Power-line carrier (PLC) networks - these networks convey voltage-based signals between utilities and advanced meters through existing power distribution lines. PLC networks are reported to be the most cost-effective option for rural areas (Greer, Bates, et al. 2008).

- Wi-Max networks - these networks use extant wireless radio frequency telecommunications towers to gather data from nearby advanced meters via wireless signaling. This type of network is also referred to as "point-multipoint" and "RadioFrequency-star."

- Radio-frequency (RF) Mesh - these networks use each advanced meter as a communications relay to send data from the advanced meter to the utility through wireless signaling. RF Mesh networks are reported to be the most cost-effective option for urban areas (PECO Energy Company 2009).

- Deployment Management - costs incurred through the additional human resources necessary to deploy the AMI system. These costs include the installation and programming costs for Information Technology Systems and Communications Networks and costs attributable to Project Management Offices (PMOs).

AMI systems also incur Overhead Costs through the human resources used to manage the Information Technology Systems and Communications Networks; human resources used to maintain the advanced meters, Information Technology Systems, and Communications Networks; and any on-going software, hardware, or frequency spectrum licenses that the utility may need to pay on a recurring basis. The DLC and PCT devices used to enable DLC DR programs and enhance dynamic pricing DR programs also contribute to the Installation Costs of DR programs, though not to the costs of AMI. While some utilities have deployed DLC devices and PCTs in conjunction with AMI systems, DLC devices and PCTs were not found to be essential components of AMI systems in the review of AMI business cases. As such, these devices are treated separately from AMI systems in the cost analysis.

To develop a range of estimates for the costs of AMI systems, the Deployment Costs and Operating Costs per advanced meter deployed were calculated along each cost category for each AMI business case reviewed. This necessitated converting all values reported in the AMI business cases into nominal values. Though most AMI business cases reported costs in this manner, two cases reported Net Present Value (NPV) costs and another reported Net Present Value Revenue Requirements (NPVRR). Annuity calculations using discount and tax rates provided in the AMI business cases under the assumption that the AMI systems would be deployed over a five year period were made to convert the NPVs and NPVRRs into NFVs. The assumption that the AMI deployments would be achieved within five years is supported by an average five-year deployment period among the AMI plans reviewed. Additionally, certain utility firms didn't disaggregate their reported costs sufficiently to fit into the cost categories used in this study. To facilitate calculation of a cost-per-unit for all cost categories, 11 out of the 100 values used were fixed as the average of all utilities who had reported disaggregated costs suitable for categorization. The category most sensitive to this approximation was Deployment Management, for which 6 of the 20 values were fixed as the mean of utilities who had reported Deployment Management costs. 
These cost-per-meter estimates were broken into quartiles to form a high cost estimate, a medium cost estimate, and a low cost estimate for each cost category. From these estimates, three different cost scenarios were calculated - one in which the high cost estimate was used for all categories ("High cost scenario"), one in which the medium cost estimate was used for all categories ("Medium cost scenario"), and one in which the low cost estimate was used for all categories ("Low cost scenario"). Table 16 below provides the cost per advanced meter deployed for each cost scenario and each cost category.

Table 16: Estimated Cost-per-Meter of Various AMI System Component

\begin{tabular}{l|c|c|c|c|c}
\hline Scenario & Meters & $\begin{array}{c}\text { IT } \\
\text { Systems }\end{array}$ & $\begin{array}{c}\text { Communications } \\
\text { Network }\end{array}$ & $\begin{array}{c}\text { Deployment } \\
\text { Management }\end{array}$ & $\begin{array}{c}\text { Annualized } \\
\text { AMI O\&M }\end{array}$ \\
\hline High & $\$ 243.43$ & $\$ 64.58$ & $\$ 66.33$ & $\$ 81.19$ & $\$ 22.74$ \\
\hline Medium & $\$ 189.98$ & $\$ 27.07$ & $\$ 42.76$ & $\$ 63.00$ & $\$ 7.32$ \\
\hline Low & $\$ 128.61$ & $\$ 10.73$ & $\$ 11.47$ & $\$ 27.67$ & $\$ 4.74$
\end{tabular}

These cost-per-meter estimates were applied to the AMI deployment forecasts of the ORNL-NADR model to calculate high, medium, and low total AMI cost estimates.

The ORNL-NADR forecasts system ramp-up deployment periods to 2020. Growth in AMI after 2020 represents the addition of customers who are new to the utility altogether, referred to as "meter growth." Meter growth consists of new customers having new meters installed at their point of consumption, such as newly-constructed homes or business facilities. The new meters are supported by Information Technology Systems and Communications Networks deployed in 2010-2020. In other words, no new Information Technology Systems and Communications Networks are deployed in 2020-2030.

Cost-per-meter estimates for Information Technology Systems, Communications Networks, and Labor and Management were not applied after 2020 due to the assumption that Information Technology Systems and Communications Networks would be deployed only during deployment ramp-up periods. As such, the Deployment Management costs associated with these activities are also applied only during the 2010-2020 deployment ramp-up period.

Unit costs of DLC devices and PCTs were applied to the ORNL-NADR's forecasts of the number of customers using DLC devices and PCTs to produce total costs of DLC devices and PCTs for the EI to 2030 .

Net present values were calculated using a 3\% discount rate from the costs calculated for each cost component and year in the 2010-2030 analysis period. The discount rate was chosen on the basis of guidance from The Office of Management and Budget's Circular A-4, which prescribes a discount rate of $3 \%$ for projects of significant relevance to societal welfare (Office of Management and Budget 2003)..

\subsection{RESULTS AND DISCUSSION ${ }^{22}$ :}

The total costs of DR for the EI for each deployment scenario and cost scenario are displayed in Figure 42. Figure 43 displays the number of AMI meters deployed in each deployment scenario. Appendix D contains estimates for all census regions.

\footnotetext{
${ }^{22}$ Further results and calculations are available upon request to the authors
} 


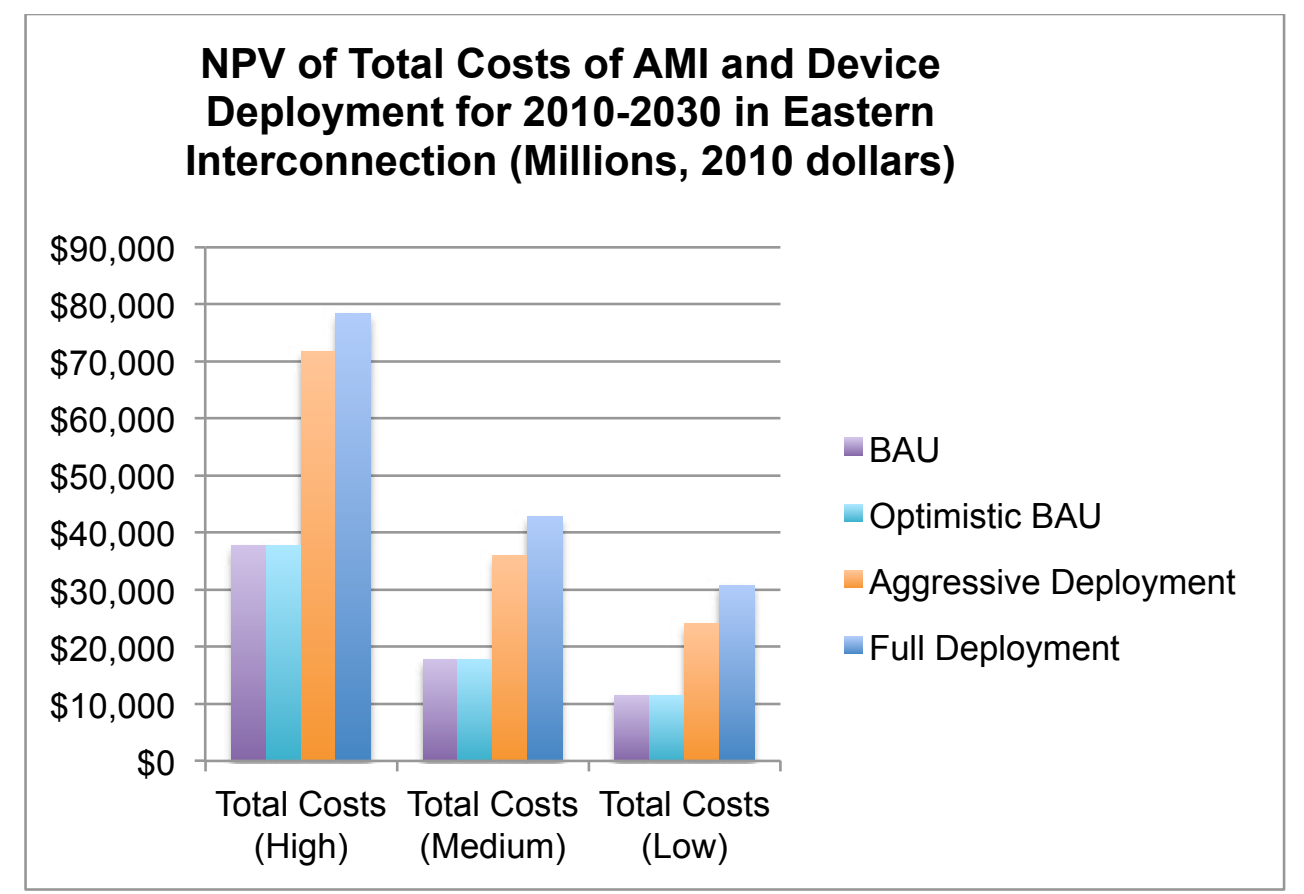

Figure 42: Total Costs of Demand Response for 2010-2030 in Eastern Interconnection (NPV, Millions)

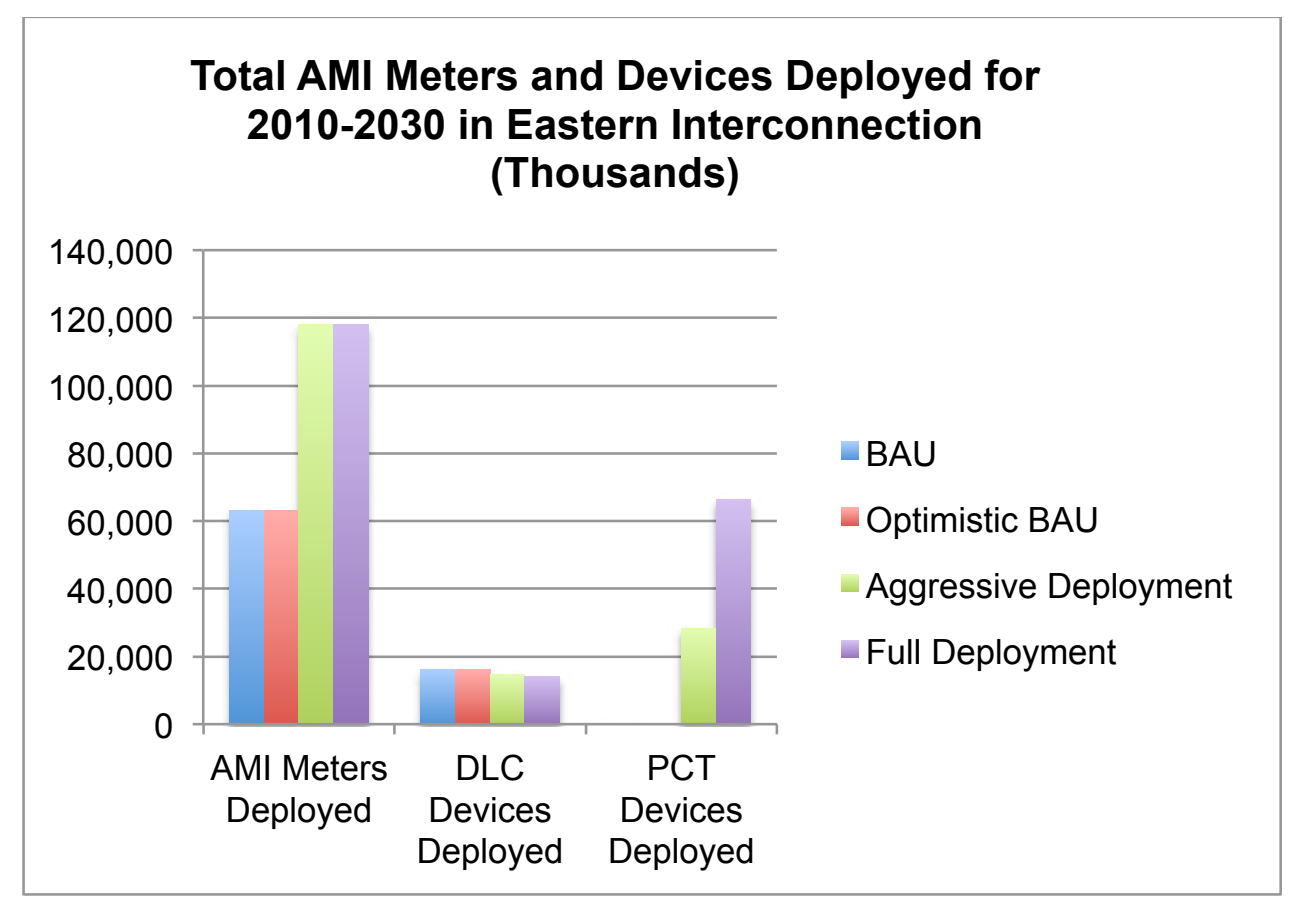

Figure 43: Total AMI Meters and Devices Deployed for 2010-2030 in Eastern Interconnection (Thousands)

Analysis of the total cost results shows strong sensitivity of the overall results toward the unit cost for the Meters and Annual O\&M categories, as well as the timing with which advanced meters are deployed throughout the EI. The total costs of Meters and Annual O\&M through 2030 together compose over 70\% of the costs of AMI systems for most states, and AMI systems are greater than $90 \%$ of the costs of DR for most states. 
The general dominance of the Annual O\&M cost category is due to the fact that Annual O\&M costs grow with the cumulative number of meters deployed. Even if no new advanced meters are deployed, the existing advanced meter stocks still incurs Annual O\&M expenses as part of the TRC test's "Overhead Cost" category. Meters, Information Technology Systems, Communications Networks, and Deployment Management costs all grow with the annual incremental number of meters deployed, i.e. new meter deployments in each year. If no new meters are deployed, no costs within these categories are incurred and the relative portion of total cost contributed by these categories diminishes.

Given the dependence of Annual O\&M costs on cumulative advanced meter deployment, earlier deployment schedules lead to greater total costs over a fixed period than do later deployment schedules. Because the ORNL-NADR assumes that the AMI penetration rate for each state reaches its 2030 level in 2020, greater costs are incurred than would be if deployments were linear through 2030 or delayed to a later period. This is an artifice of the ORNL-NADR's deployment period being fixed, however, as Annual O\&M costs would be incurred for the lifetime of all AMI. Postponing deployments of cost-effective AMI systems would have no benefit to society.

The cost-dominance of Meters is primarily due to the large unit costs of advanced meters assumed in this study. As demonstrated in Table X4, unit costs assumed for Information Technology Systems, Communications Networks, and Deployment Management are an order of magnitude less than the unit costs of advance meters assumed in this study.

DLC switches and PCT costs are the least contributive to overall DR costs. These devices can function independently of the AMI system, and therefore only contribute the unit costs of deploying the devices themselves. This amounts to less than $10 \%$ of DR costs for most states.

\subsubsection{Brattle Group Comparison}

For comparison to prior studies by the Brattle Group and EPRI, which each analyze the costs of only AMI, the costs of AMI produced by the ORNL analysis are displayed in Figure 44 below. 


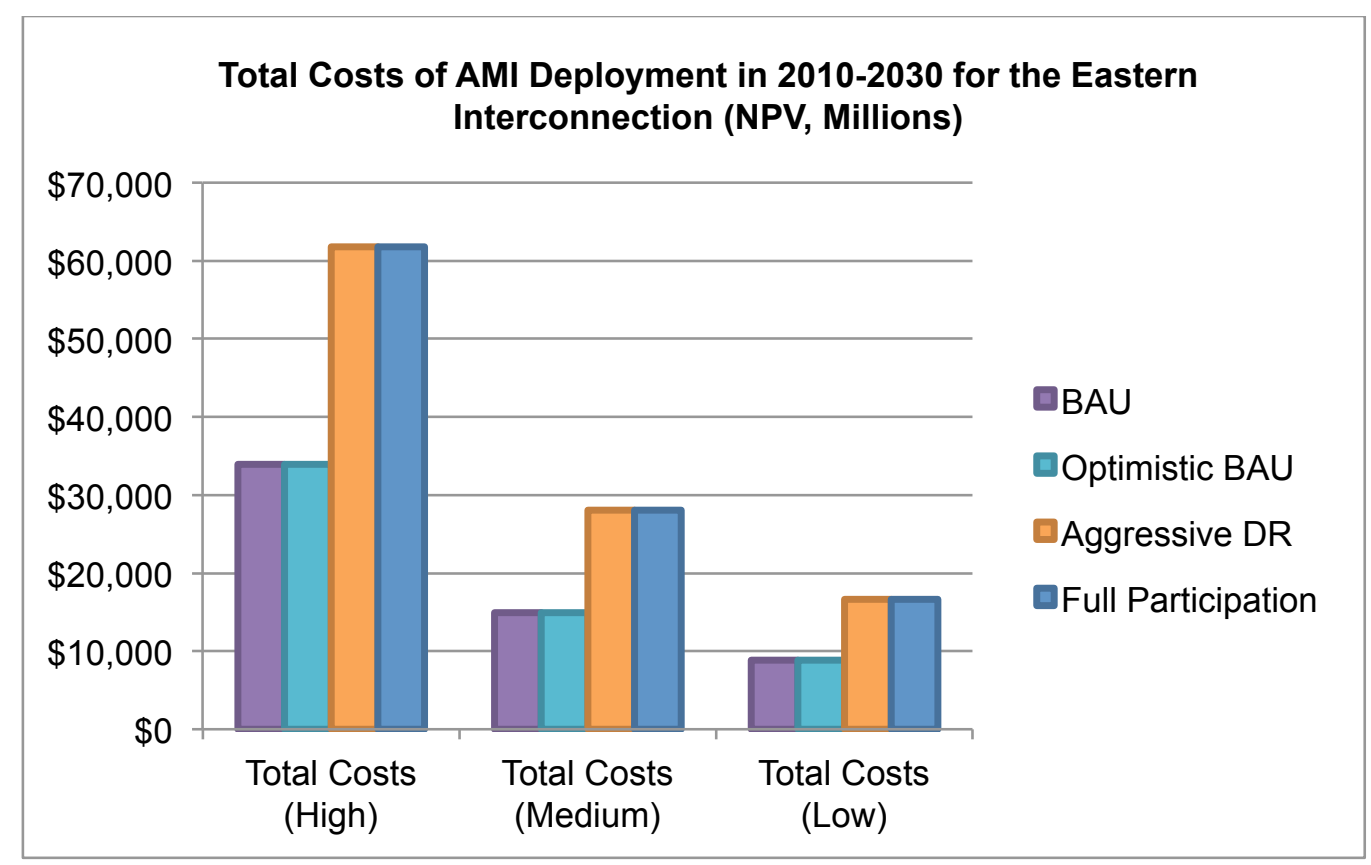

Figure 44: Total Costs of AMI Deployment in 2010-2030 for the Eastern Interconnection (NPV, Millions)

Comparison of the ORNL results with Brattle and EPRI results also necessitates applying the deployment assumptions used in each study. The effects of deployment assumptions upon total costs of AMI systems are highly significant, as it is reasonable to assume that larger assumed deployments will lead to larger total cost. As the deployment assumptions vary between the ORNL-NADR study, EPRI's study, and the Brattle Group's study, the deployment assumptions used in the EPRI study and in the Brattle Group study were applied to the ORNL-NADR analysis to produce more comparable results.

Table 17 displays the percent differences from the High and Low estimates by the Brattle Group produced by the ORNL-NADR analysis when Brattle Group deployment assumptions are applied. In Table 17, positive values represent the percent by which the Brattle Group's results exceeded the results of the ORNL-NADR analysis under the Brattle Group's deployment assumptions.

Since all values in Table 17 are positive and greater than $20 \%$, the comparison reveals the strong influence of the Brattle Group's assumed costs-per-unit of AMI deployment. While the Brattle Group assumed per-unit costs of AMI systems for residential customers that differed little from the assumed perunit costs of the ORNL-NADR study, the Brattle Group assumed per-unit costs of AMI systems for commercial and industrial customers that are an order of magnitude above those assumed in the ORNLNADR study. This leads the Brattle Group analysis to forecast total AMI costs well in excess of the ORNL-NADR analysis, even when deployment assumptions from the Brattle Group analysis are applied to both.

Table 17: Percent Differences between Brattle Group Estimates and ORNL-NADR analysis estimates using Brattle Group Deployment Assumptions

\begin{tabular}{|l|c|c|c|c|c|c|}
\hline Assumptions & \multicolumn{3}{|c|}{$\$ 27$ billion } & \multicolumn{3}{c|}{$\$ 19$ billion } \\
\hline & $\begin{array}{c}\text { Total Costs } \\
\text { (High) }\end{array}$ & $\begin{array}{c}\text { Total Costs } \\
\text { (Medium) }\end{array}$ & $\begin{array}{c}\text { Total Costs } \\
\text { (Low) }\end{array}$ & $\begin{array}{c}\text { Total Costs } \\
\text { (High) }\end{array}$ & $\begin{array}{c}\text { Total Costs } \\
\text { (Medium) }\end{array}$ & $\begin{array}{c}\text { Total Costs } \\
\text { (Low) }\end{array}$ \\
\hline BAU & $73 \%$ & $85 \%$ & $91 \%$ & $61 \%$ & $79 \%$ & $87 \%$ \\
\hline Optimistic BAU & $73 \%$ & $85 \%$ & $91 \%$ & $61 \%$ & $79 \%$ & $87 \%$ \\
\hline Aggressive DR & $53 \%$ & $75 \%$ & $84 \%$ & $33 \%$ & $64 \%$ & $77 \%$ \\
\hline Full Participation & $53 \%$ & $75 \%$ & $84 \%$ & $33 \%$ & $64 \%$ & $77 \%$ \\
\hline
\end{tabular}


The Brattle Group's assumption of $\$ 1500$ per unit of AMI deployed to C\&I customers may be unrepresentative of the costs of AMI due to the source of the estimate, namely California utility shareholder filings in support of AMI deployments. California utilities were first-movers in large-scale AMI deployment, being the first utilities in the nation to deploy AMI to the entirety of their respective customer bases. This first-mover status may have led the utilities to over-estimate their costs due to uncertainty and lack of industry experience with AMI technology at such large scales. California utilities are also some of the largest in the U.S. and serve some of the highest-income ratepayers in the U.S., which allows them to bear investment costs that most other utilities could not afford. The tendency toward aggressive, innovative business strategies among California utilities may have led to AMI deployment costs that were inflated beyond what a small, conservative utility company would have borne. Overall, it is difficult to argue that California utility companies and their AMI deployment characteristics are representative of utility companies around the nation, which is one reason that the ORNL-NADR cost analysis examined AMI business cases beyond (but including) those of California utilities. Given that the Brattle Group's study of AMI costs was made in 2008, however, it is unlikely that alternative sources of information were available when the Brattle Group formed its estimates of per-unit AMI costs.

\subsubsection{EPRI Comparison}

To facilitate comparison to the EPRI study, the deployment assumptions made by EPRI were applied to the ORNL-NADR analysis. Application of EPRI deployment assumptions reveals that the differences between the results of the EPRI analysis and the ORNL-NADR analysis are driven by factors other than the costs-per-unit assumptions in each. Table 18 displays the percent differences between the EPRI High and Low estimates and the results of the ORNL-NADR analysis using EPRI deployment assumptions. Under these assumptions, the High cost scenario produces results that are approximately equal to those of the EPRI High estimate; the Medium cost scenario produces results that are approximately equal to the EPRI Low estimate.

Table 18: Percent Differences between Brattle Group Estimates and ORNL-NADR analysis estimates using EPRI Deployment Assumptions

\begin{tabular}{|l|c|c|c|c|c|c|}
\hline & \multicolumn{3}{|c|}{$\$ 42$ billion } & \multicolumn{3}{c|}{$\$ 19$ billion } \\
\hline & $\begin{array}{c}\text { Total Costs } \\
\text { (High) }\end{array}$ & $\begin{array}{c}\text { Total Costs } \\
\text { (Medium) }\end{array}$ & $\begin{array}{c}\text { Total Costs } \\
(\text { Low) }\end{array}$ & $\begin{array}{c}\text { Total Costs } \\
\text { (High) }\end{array}$ & $\begin{array}{c}\text { Total Costs } \\
\text { (Medium) }\end{array}$ & $\begin{array}{c}\text { Total Costs } \\
\text { (Low) }\end{array}$ \\
\hline BAU & $15 \%$ & $57 \%$ & $73 \%$ & $-138 \%$ & $-20 \%$ & $25 \%$ \\
\hline Optimistic BAU & $15 \%$ & $57 \%$ & $73 \%$ & $-138 \%$ & $-20 \%$ & $25 \%$ \\
\hline Aggressive DR & $15 \%$ & $57 \%$ & $73 \%$ & $-138 \%$ & $-20 \%$ & $25 \%$ \\
\hline Full Participation & $15 \%$ & $57 \%$ & $73 \%$ & $-138 \%$ & $-20 \%$ & $25 \%$ \\
\hline
\end{tabular}

Two factors largely explain the differences between the EPRI results and the ORNL-NADR results: the $20 \%$ difference in maximum residential AMI penetration rates, and the assumed timing of AMI deployments. The 100\% residential AMI deployment rate assumed in the ORNL-NADR's Aggressive DR and Full Participation deployment scenarios yields total cost estimates in the High cost scenario that are almost twice the EPRI High estimate - $\$ 62$ billion. As mentioned in the review of studies, however, EPRI uses lower costs-per-unit for residential AMI deployment than does ORNL-NADR. When the maximum residential AMI deployment in ORNL-NADR is brought from $100 \%$ down to the $80 \%$ assumed by EPRI, the EPRI results exceed the ORNL-NADR results. Therefore the deployment to the remaining $20 \%$ of customers not captured by the EPRI deployment assumptions significantly increases the total costs of AMI deployment, a conclusion supported by the dominant proportion of electric power customers that fall into the residential classification. 
The timing of AMI deployment influences the total cost of AMI through discounting factors and Annualized O\&M costs. The EPRI analysis assumes a linear deployment schedule, such that $1 / 20^{\text {th }}$ of AMI deployments achieved in 2030 are deployed in each year between 2010 and 2030. Conversely, the ORNL-NADR analysis assumes a ramp-up period during which AMI deployment rates increase drastically between 2010 and 2020 and after which AMI deployment rates remain constant. This leads to AMI deployments occurring later in the EPRI analysis and earlier in the ORNL-NADR analysis. Net present value analysis leads costs incurred earlier to be greater than costs incurred later, thus increasing the costs of the ORNL-NADR AMI deployments beyond the costs of the EPRI AMI deployments ceteris paribus.

The Annualized O\&M costs applied to AMI systems also bring greater costs to earlier schedules of AMI deployment. Because Annualized O\&M costs are applied every year to cumulative AMI deployment, greater total O\&M costs will be brought upon AMI systems that deploy earlier in a modeled timeframe. This is an artifice of the respective modeling frameworks used in the EPRI study and the ORNL-NADR study, as AMI systems deployed at different schedules would incur similar lifetime costs. The costs of the AMI system deployed later simply lag the costs of the AMI system deployed earlier. Because the ORNLNADR analysis and the EPRI analysis both the same fixed time period, however, the earlier schedule of AMI deployment in the EPRI analysis significantly reduces the estimated costs of AMI relative to the ORNL-NADR estimated costs of AMI.

\subsubsection{Discussion of Results according to Other Literature Findings}

The literature findings discussed above provide multiple reasons to expect the results of this analysis to overestimate the future TRC-test costs of DR in the EI. The cost-reducing learning effects of cumulative deployment found by Navigant are not captured in this study, and large deployments of AMI in the EI are likely to yield such unit cost reductions through learning (Navigant 2011). A coordinated AMI deployment across multiple utilities could reduce costs relative to the costs of independent AMI deployments, such as those from which the cost assumptions for the ORNL-NADR analysis were drawn (Haney et al. 2009). RECs and Muni's may be the next major market for AMI deployments, in which case the cost forecasts would likely be lower and more accurate than those forecast by IOUs according to Roger Levy. Finally, utilities deploying AMI may capitalize on existing AMR meter hardware and communications infrastructure to reduce costs in ways not observed during the review of AMI business cases in the ORNL-NADR analysis. These unaccounted-for effects could reduce the costs of DR encountered by utilities, and could lead to rate reductions for customers that would decrease the costs of DR under the TRC framework.

The literature findings discussed above also provide multiple reasons to expect the results of this analysis to underestimate the future TRC-test costs of DR in the EI. Certain monetized costs of DR programs that are not related to AMI, PCTs, or DLC switches, such as costs of consumer education and costs of submitting rate cases to utility regulators, are not captured in this analysis. The non-monetized welfare losses that will certainly affect the extent to which DR is deployed are also not captured by this analysis. If retail customers become less price-elastic toward bulk electric power, as will likely be the case during further transition in the United States toward a digital economy, the costs of DR in terms of welfare lost through consumer behavioral change may contribute significantly to DR costs. More research in this area is desirable.

Given the extent of empirical review used in forming the cost assumptions for this analysis, however, the estimates produced remain reasonable. The DR cost drivers described above should be considered by electric utility companies and electric utility regulators as opportunities for mitigating DR costs. Regulators seeking greater DR in their territories should examine how to improve the influence of the cost-reducing factors and mitigate the influence of the cost-increasing factors mentioned above; for 
example, a regulator might organize a coordinated AMI deployment in her territory or encourage distributed generation in his territory to increase bulk power price elasticity among retail customers. This analysis upholds the finding of the FERC that regulators have great influence over both the deployment of DR and its costs (FERC 2009). 


\section{SYSTEM BENEFITS OF DEMAND RESPONSE}

Changes in demand caused by demand response programs would affect not only the dispatch of existing plants but also the additions of advanced generation technologies, the retirements of old coal-firing plants, and the finances of the market. We analyzed the impact of the demand response programs on the grid in 2030 and the consequent level of benefits in terms of reduction in electricity price and green house gas $\left(\mathrm{CO}_{2}\right)$ emissions, reserve margin, loss of load probability (LOLP), avoided electricity generation, and consequently avoided cost. To find the new market equilibrium after the deployment of demand response programs, we used the Oak Ridge Competitive Electricity Dispatch Model (ORCED) developed to simulate the operations and costs of regional power markets depending on various factors including fuel prices, initial mix of generation capacity, and customer response to electricity prices (Hadley 2008; Hadley 1998; Hirst and Hadley 1999). In ORCED, over 19,000 plant units in the nation are aggregated into up to 200 plant groups per region. Then, ORCED dispatches the power plant groups in each region to meet the electricity demands for a given year. In our analysis, we show various demand, supply, and dispatch patterns affected by demand response across the Eastern Interconnection area classified by EIA's Electricity Market Module (EMM) regions (see Figure 45). Out of 22 EMM regions, 17 regions are assumed as the Eastern Interconnection area. ${ }^{23}$

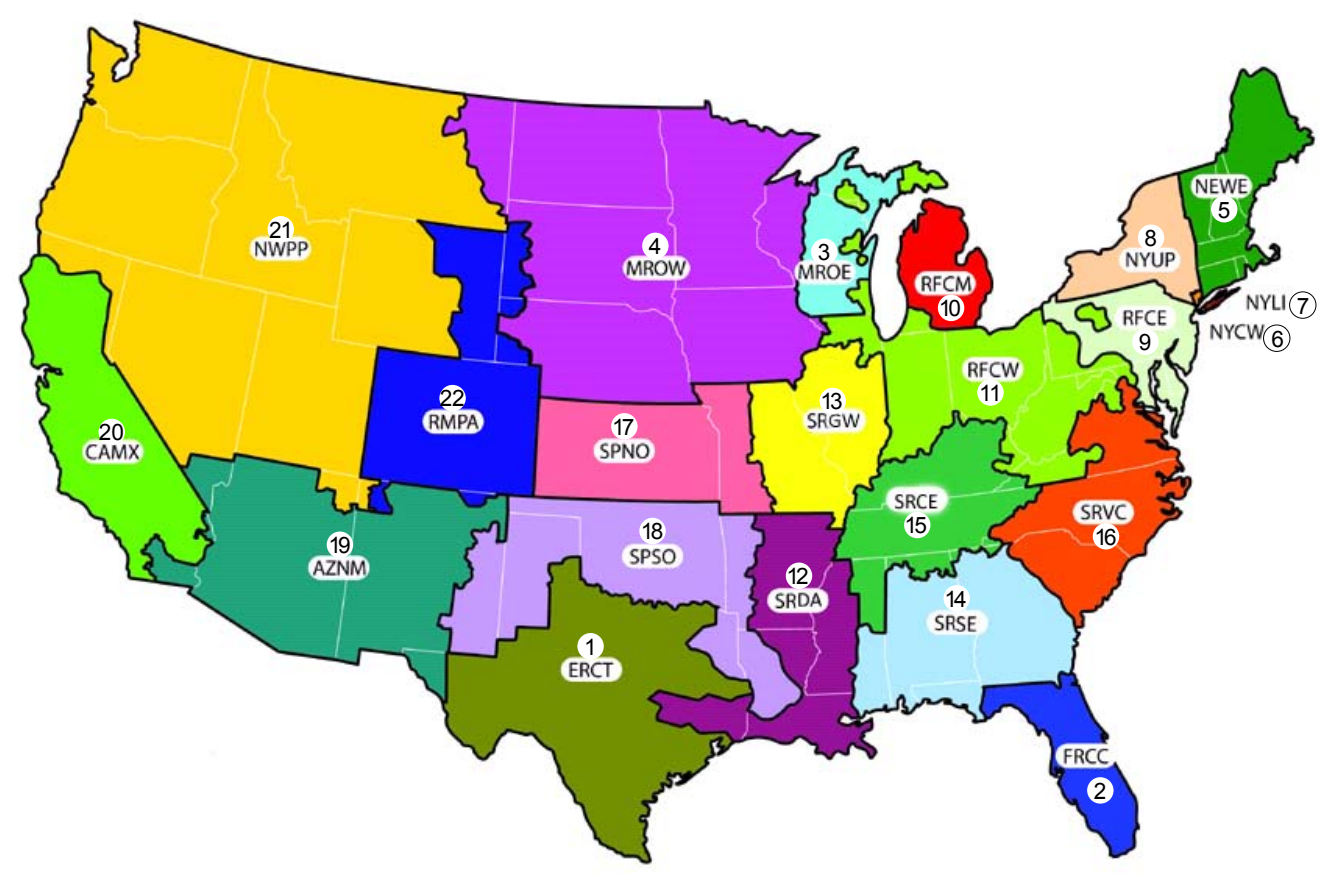

Source: Annual

Energy Outlook 2011, EIA

Figure 45: EIA's Electricity Market Module Regions

\subsection{BENEFIT CASES FROM DEMAND RESPONSE}

To see how demand response influences the electricity grid in 2030, we developed seven different cases depending on \% peak load reduction (\%PLR) and time period when the savings happen. The range of \%

\footnotetext{
${ }^{23}$ Regions from 2 to 18 are defined as the Eastern Interconnection area in this analysis. 2 FRCC (FRCC All); 3 MORE (MRO East), 4 MROW (MRO West); 5 NEWE (NPCC New England); 6 NYCW (NPCC NYC/Westchester); 7 NYLI (NPCC Long Island); 8 NYUP (NPCC Upstate NY); 9 RFCE (RFC East); 10 RFCM (RFC Michigan); 11 RFCW (RFC West); 12 SRDA (SERC Delta); 13 SRGW (SERC Gateway); 14 SRSE (SERC Southeastern); 15 SRCE (SERC Central); 16 SRVC (SERC VACAR); 17 SPNO (SPP North); 18 SPSO (SPP South).
} 
PLR for each scenario was set according to the ORNL-NADR results discussed in Chapter 5. Table 19 shows the regional amount of capacity savings as a percentage of peak demand. The four levels of DR represent the BAU scenario, the Optimistic BAU scenario, the Aggressive Deployment of DR, and Full Deployment in DR programs.

Table 19. Regional DR as Percentage of Peak Demand in 2030 under various scenarios

\begin{tabular}{ccccc}
\hline & BAU & $\begin{array}{c}\text { Optimistic } \\
\text { BAU }\end{array}$ & $\begin{array}{c}\text { Aggressive } \\
\text { Deployment }\end{array}$ & $\begin{array}{c}\text { Full } \\
\text { Deployment }\end{array}$ \\
\hline FRCC & $5 \%$ & $22 \%$ & $35 \%$ & $47 \%$ \\
MROE & $9 \%$ & $15 \%$ & $19 \%$ & $22 \%$ \\
MROW & $9 \%$ & $20 \%$ & $26 \%$ & $29 \%$ \\
NEWE & $7 \%$ & $12 \%$ & $16 \%$ & $19 \%$ \\
NYCW & $10 \%$ & $18 \%$ & $21 \%$ & $25 \%$ \\
NYLI & $10 \%$ & $18 \%$ & $21 \%$ & $25 \%$ \\
NYUP & $10 \%$ & $18 \%$ & $21 \%$ & $25 \%$ \\
RFCE & $7 \%$ & $15 \%$ & $22 \%$ & $29 \%$ \\
RFCM & $6 \%$ & $14 \%$ & $19 \%$ & $22 \%$ \\
RFCW & $6 \%$ & $15 \%$ & $21 \%$ & $26 \%$ \\
SRDA & $4 \%$ & $12 \%$ & $21 \%$ & $29 \%$ \\
SRGW & $4 \%$ & $15 \%$ & $23 \%$ & $29 \%$ \\
SRSE & $3 \%$ & $18 \%$ & $27 \%$ & $36 \%$ \\
SRCE & $1 \%$ & $8 \%$ & $18 \%$ & $27 \%$ \\
SRVC & $5 \%$ & $20 \%$ & $30 \%$ & $38 \%$ \\
SPNO & $2 \%$ & $12 \%$ & $21 \%$ & $29 \%$ \\
SPSO & $6 \%$ & $13 \%$ & $23 \%$ & $31 \%$ \\
\hline
\end{tabular}

Three demand response cases were developed to analyze various demand response benefit cases.

No DR case: This case considers a situation before demand response programs are deployed. It is used as a reference case. Figure 46 shows the hourly load curve for one week out of the representative year studied for New England, one of the regions.

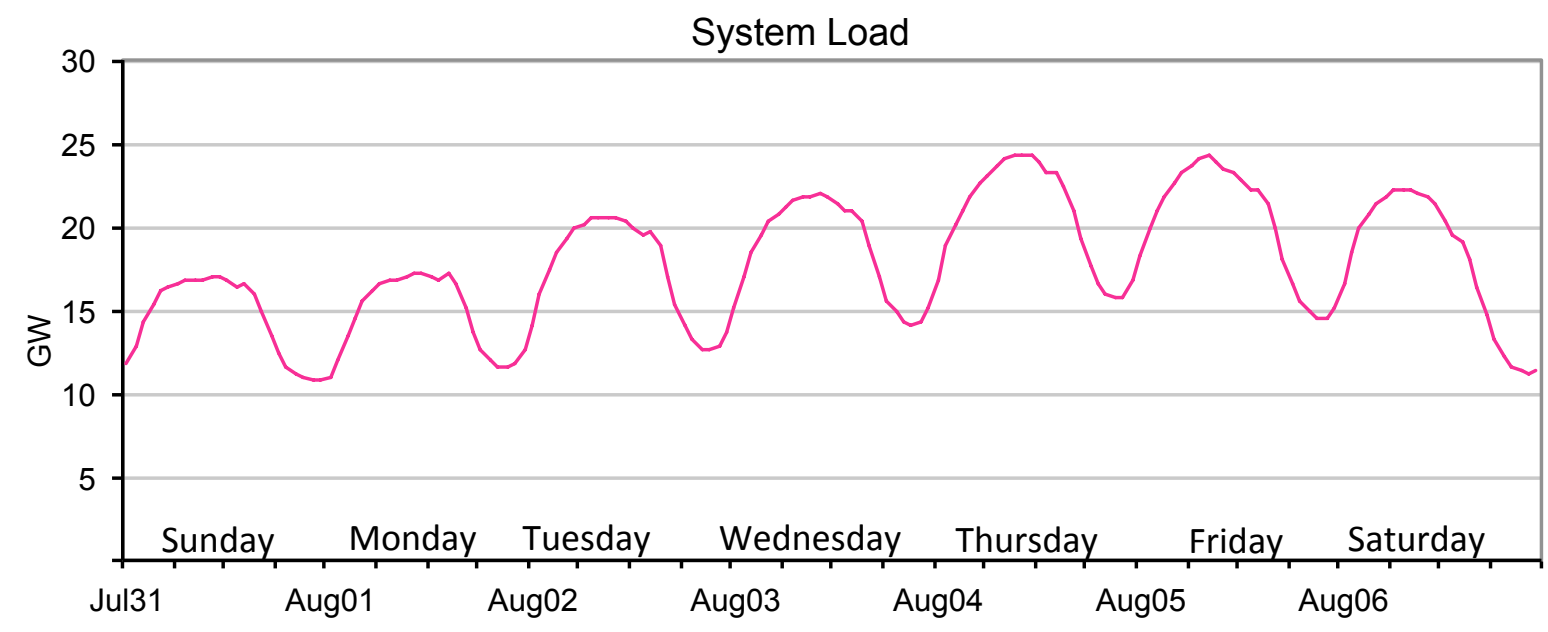

Figure 46: Energy Load Shape under No DR Case (NEWE region, August1-August6)

DR-Notch case: This case assumes that the peak demand declines consistently by a certain percentage only during the pre-specified peak hours. This case refers to specific time periods representing when DR 
has a high probability of being used. The "peak hours" on a "typical event day" is defined as hours between 2 and $6 \mathrm{pm}$ on the top 15 system load days (60 hours a year) (FERC 2009). This definition from FERC is simplified from the variety of programs currently existing. Regional \% PLR is applied to define the scale of DR impact in each region. This scenario does not consider load shifting between peak and off-peak hours. This "Notch" was on only applied to the BAU scenario because under a high DR penetration it was unrealistic that all DR would be used only during the specific four hours on the fifteen highest summer days. Figure 47 shows the same week as above but with the DR applied in the two highest days since those two days are among the 15 days with highest demands.

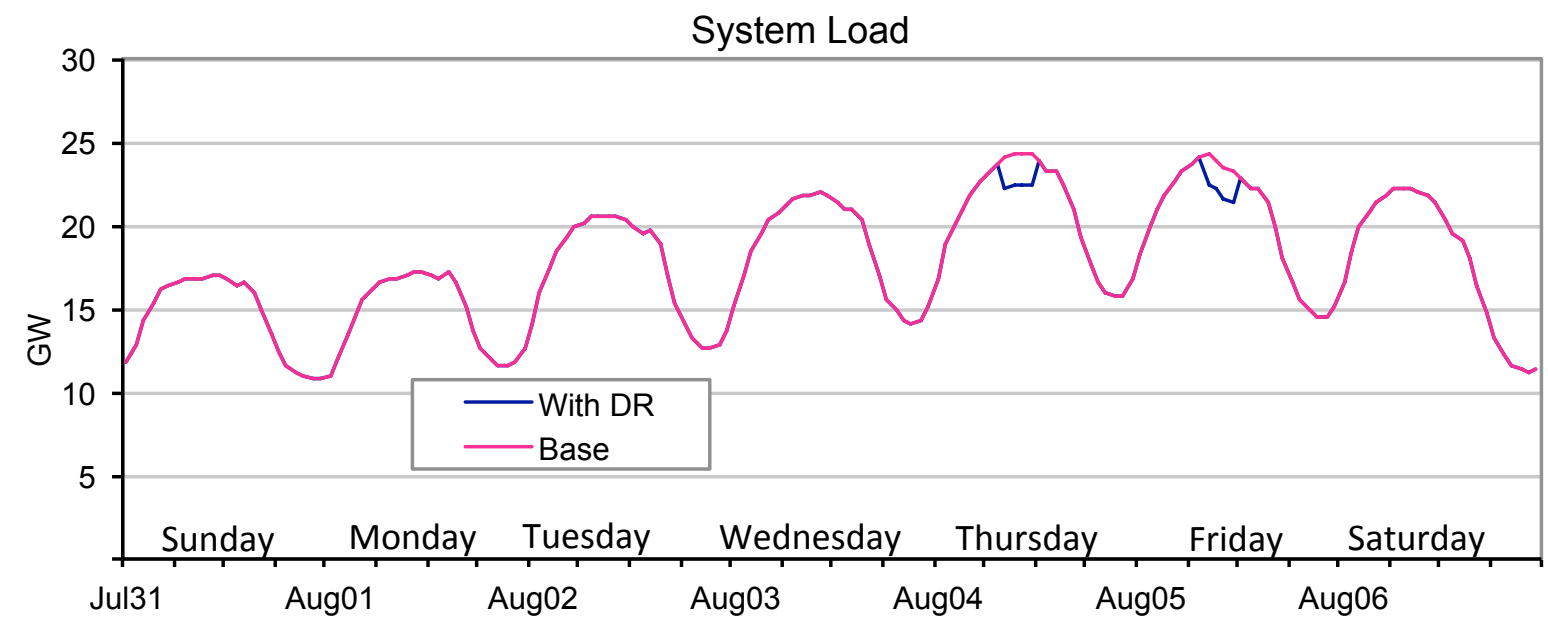

Figure 47: Energy Load Shape under DR-Notch Case (NEWE region, August1 - August6)

DR-Smart case: This case assumes that DR is designed and implemented to meet a certain target-power level (P) over a year. First, we estimated the energy-avoided by the forecasted ORNL-NADR peak load impacts by assuming it to be equivalent to that in the DR-Notch case. We calculated a peak demand level (P) that makes the amount of avoided energy from the Smart case the same as that from the Notch case. In other words, the peak demands above $\mathrm{P}$ are clipped throughout the year while the total energy saved is the same as in the notch definition. DR may be applied more times than the notch's fifteen days and in more hours than just $2 \mathrm{pm}$ to $6 \mathrm{pm}$, but the total energy over the year is equal. Figure 48 shows the impact on the same week as the other two graphs above. Less DR is used on these days, but the DR is applied to other days such that total demand is never above the new peak amount, in this case $23.5 \mathrm{GW}$.

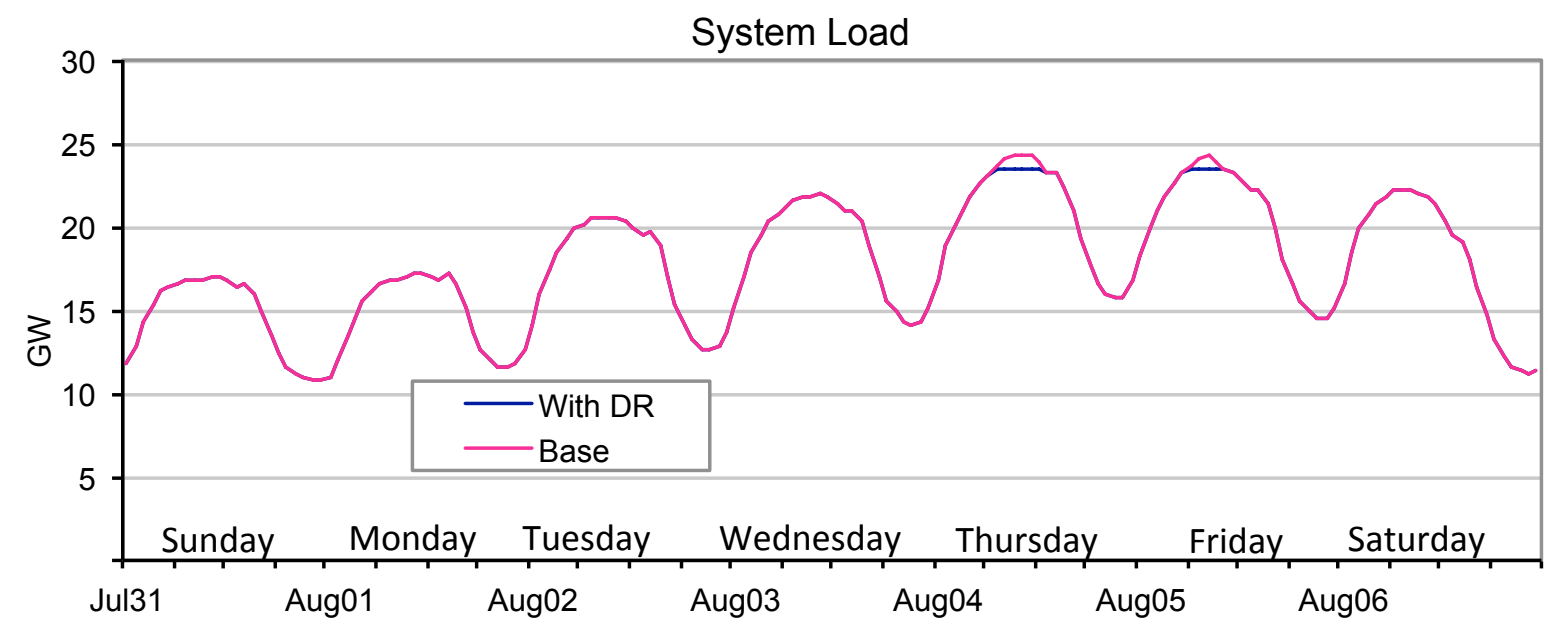

Figure 48: Energy Load Shape under DR-Smart Case (NEWE region, August 1 - August 6) 
In practical terms, the actual response of DR will be more complex than either of these methods. The notch method does not capture peaks outside of its summertime block, such as winter mornings or high demands after $6 \mathrm{pm}$. The smart DR assumes that DR resources are flexible enough to precisely shave the peak demands, and in some hours calls on more capacity reductions than are available. (To examine this, we added a "constrained" BAU scenario where the DR in any hour cannot exceed the NADR-calculated amount, even if it is only called upon for a few hours. The other DR scenarios are not affected by this problem.) In none of the cases are the DR resources adjusted based on supply changes such as outages from power plants.

\subsection{DATA AND PROJECTIONS}

This benefit analysis uses two publicly available data sources to set the supply and demand levels. The Annual Electric Balancing Authority Area and Planning Area Report of the Federal Energy Regulatory Commission (FERC Form 714) was used to update Load Duration Curves (LDCs) of the demand module. FERC Form 714 contains hourly load by utilities or their regional system operators. Data was also retrieved from regional transmission operators where available. Daylight saving time by utilities was adjusted to have a consistent time format across regions. Hourly load graphs for several days before and after the spring and fall shift were compared to ensure consistency. Because the data on the hourly imports and exports are not available in FERC Form 714, the total net energy load as compared to the net generation for a region in AEO 2011 was used to adjust the load reflecting imports and exports of electricity of the region.

The input data for the supply module is updated by 2011 input data for the Electricity Market Module (EMM) of EIA's National Energy Modeling System (NEMS). AEO 2011 re-classifies the old 13 EMM regions into 22 subregions. Input file Pltf860.txt in NEMS provided information of summer/ winter capacity, heat rate, emission rates of $\mathrm{NO}_{\mathrm{X}}$ and $\mathrm{SO}_{\mathrm{X}}$ of 18,570 existing and planned plants. This study also used the cumulative unplanned additions forecast of AEO2011 to consider not only the existing and planned plants but also 525 unplanned (but expected) plant additions by 2030 .

\subsection{METHODOLOGY}

This study used the ORCED model to simulate the operations and costs of regional power markets depending on various factors including fuel prices, initial mix of generation capacity, and customer response to electricity prices. ORCED consists of three modules of supply, demand, and dispatch.

Demand Module: The year 2030 hourly loads were retrieved from all utilities that submitted data to the FERC Form 714 database, as well from regional transmission organizations. These were converted to Load Duration Curves, rearranging the demands from highest to lowest. The typical shape of LDC is the navy-color curve in Figure 49. These were consolidated into the 22 EMM regions and escalated to match the 2030 demands based on the AEO2011 reference case. The demand module then consolidated the 8,760 hours of demands into three LDCs, one each for summer, winter, and off-peak seasons. 


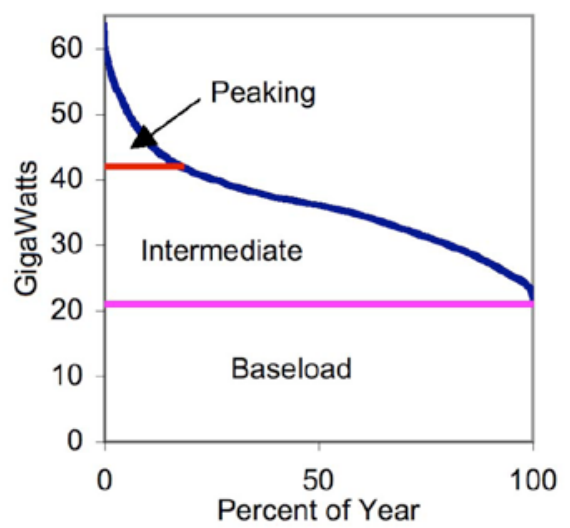

Figure 49: Load Duration Curves and Power Plant Type Dispatch Order

Supply Module: The list of units for each region that are operating in 2030 were consolidated into up to 200 power plant groups based on their technology, fuel type, and operating cost. For each season, the 200 plants from the supply module were sorted in order of increasing variable costs. The order may be different in each season because some costs (e.g., $\mathrm{NO}_{\mathrm{X}}$ emission credits) might only be added to the summer season, depending on the scenario. The power capacities are adjusted by season for planned and forced outages.

Dispatch Module: This module dispatched the 200 plant groups created in the supply module to meet the demand. The steps began with altering the LDCs for hydro and pumped storage production. It then proceeded to dispatch the plants for each season using a modified Balleriaux-Booth procedure for unserved energy calculations (Vardi and Avi-Ithak 1981). Figure 49 shows an example of the LDC for a region along with the types of pants that are used to fulfill those demands. Some plants are most effective at providing power essentially all the time, or "baseload" power. They typically have low variable costs but may have high fixed costs. Intermediate or "load-following" plants are called on to meet the demand of a significant fraction of the year, but still cycle on and off. Peaking plants are called on least frequently, during high demand times only to meet capacity emergencies. They have the highest marginal costs but typically have low fixed costs either because of their low-cost technology or because they are old, fully depreciated plants. The amount of generation by each plant was then calculated. Lastly, time-dependent prices and costs were calculated. ORCED has the capability for a plant to use a price other than its variable cost for its bid price into the market. By default, ORCED sets the price of "must-run" and intermittent plants to zero so that they are always called upon; intermittent plants have high outage rates to simulate their variable output. The seasonal results are then combined for a yearly result. Emissions and other financial parameters are last to be calculated. Since demand fluctuates over the year, some plants are called on more often than others in the electricity supply portfolio.

\subsection{RESULTS}

We ran 7 benefit cases for 17 EMM regions separately with ORCED, as listed in Table 20. A comprehensive benefit analysis for the Eastern Interconnection is presented in this section. Four different types of benefits were examined: 1) system peak reduction, 2) system reliability improvement, 3) cost reduction, and 4) emissions reduction. 
Table 20: Demand Response Scenarios used for Benefit Analysis

\begin{tabular}{lc}
\hline \multicolumn{1}{c}{ DR Benefit Case } & Regional \% Peak Load Reduction \\
\hline No DR (Reference Case) & $0 \%$ \\
DR-Notch-BAU & $1-10 \%$ (Ave. 5\%) \\
DR-Smart-BAU & $1-10 \%($ Ave. $5 \%)$ \\
DR-Smart-Optimistic BAU & $8-22 \%($ Ave. $15 \%)$ \\
DR-Smart-Aggressive Deployment & $16-35 \%$ Ave. $23 \%)$ \\
DR-Smart-Full Deployment & $19-47 \%$ Ave. 30\%) \\
Energy Efficiency ${ }^{24}$ & A 5\%-point decrease across both peak and \\
& off-peak hours \\
\hline
\end{tabular}

\subsubsection{System Peak Impact}

The most direct impact of DR was the reduction in system peak demand. Earlier chapters describe how the NADR model calculated the amount of DR potentially available in MW as compared to the peak demand in the region, as listed in Table 19. In ORCED, this DR was made available as a resource either during the "notch" hours or as a peak clipping mechanism, but with the limit of 60 hours total per DR resource. Each region was modeled; Figure 50 shows the resulting annual LDCs for each of the scenarios for the region SRGW (SERC Gateway, including eastern Missouri and southern Illinois). This region was selected for graphing since its percentage reductions from DR are close to the average for all regions and all of its demand reductions are in the summer season.

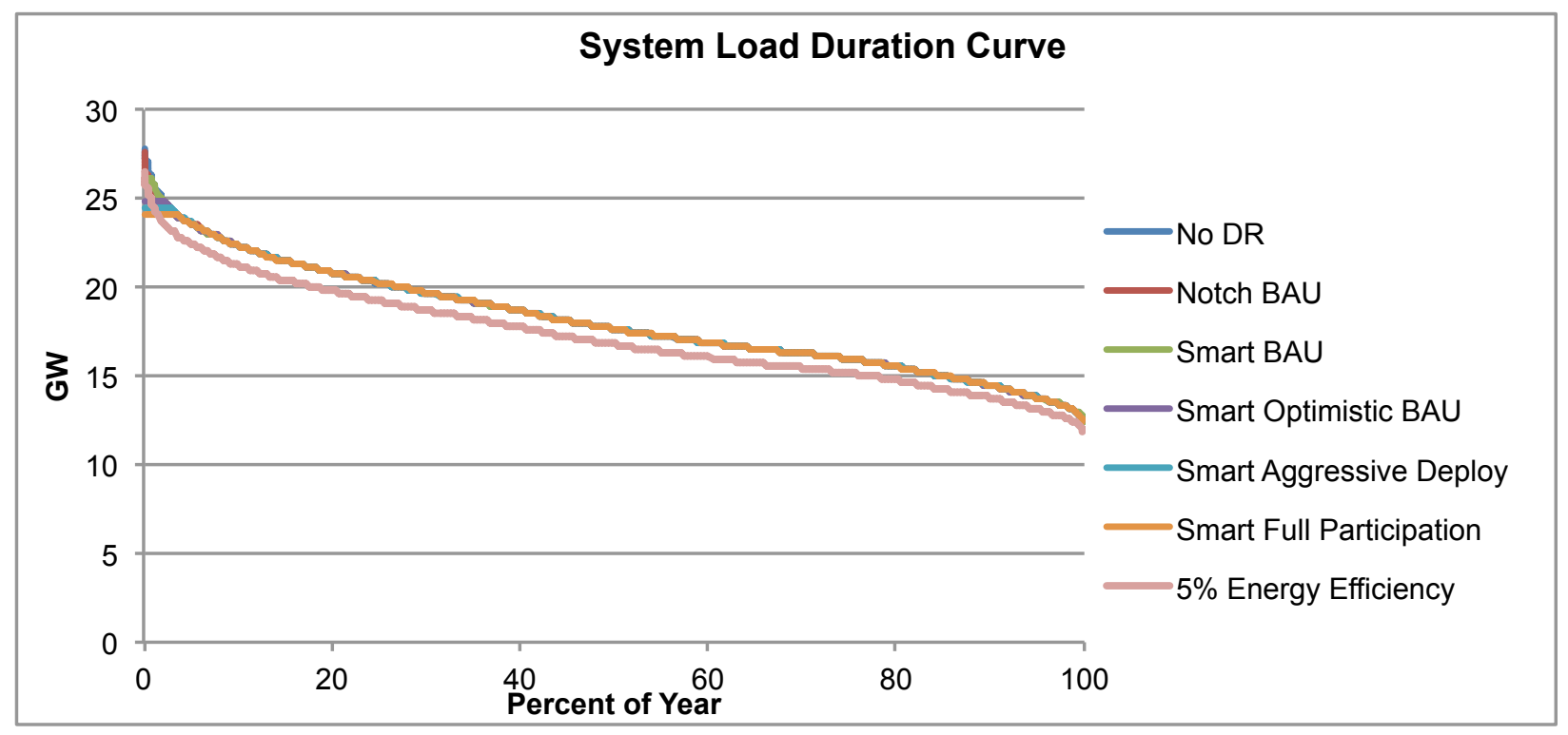

Figure 50: Annual Load Duration Curves under different scenarios (SRGW)

Figure 51 is a magnification of Load Duration Curve (LDC) showing the top $4 \%$ of the year. The Notch scenario reduced demand by roughly $950 \mathrm{MW}$ for 60 hours, but these were not necessarily during the peak hours, so there were some discontinuities where peak hours had no reduction. An additional curve has been added labeled Constrained BAU that is the Smart-BAU with the DR amount constrained so that the amount dispatched was never more than the $950 \mathrm{MW}$ calculated by NADR. The peak was reduced by $950 \mathrm{MW}$ in the peak hours and then declined so that the peak flattened at $25.9 \mathrm{GW}$. The three Smart

\footnotetext{
${ }^{24}$ We developed Energy Efficiency case for a comparison purpose.
} 
scenarios have clipped peaks at 26.1 GW (BAU), 24.9 GW (Optimistic BAU), 24.4 GW (Aggressive Deploy) and 24.1 GW (Full Participation).

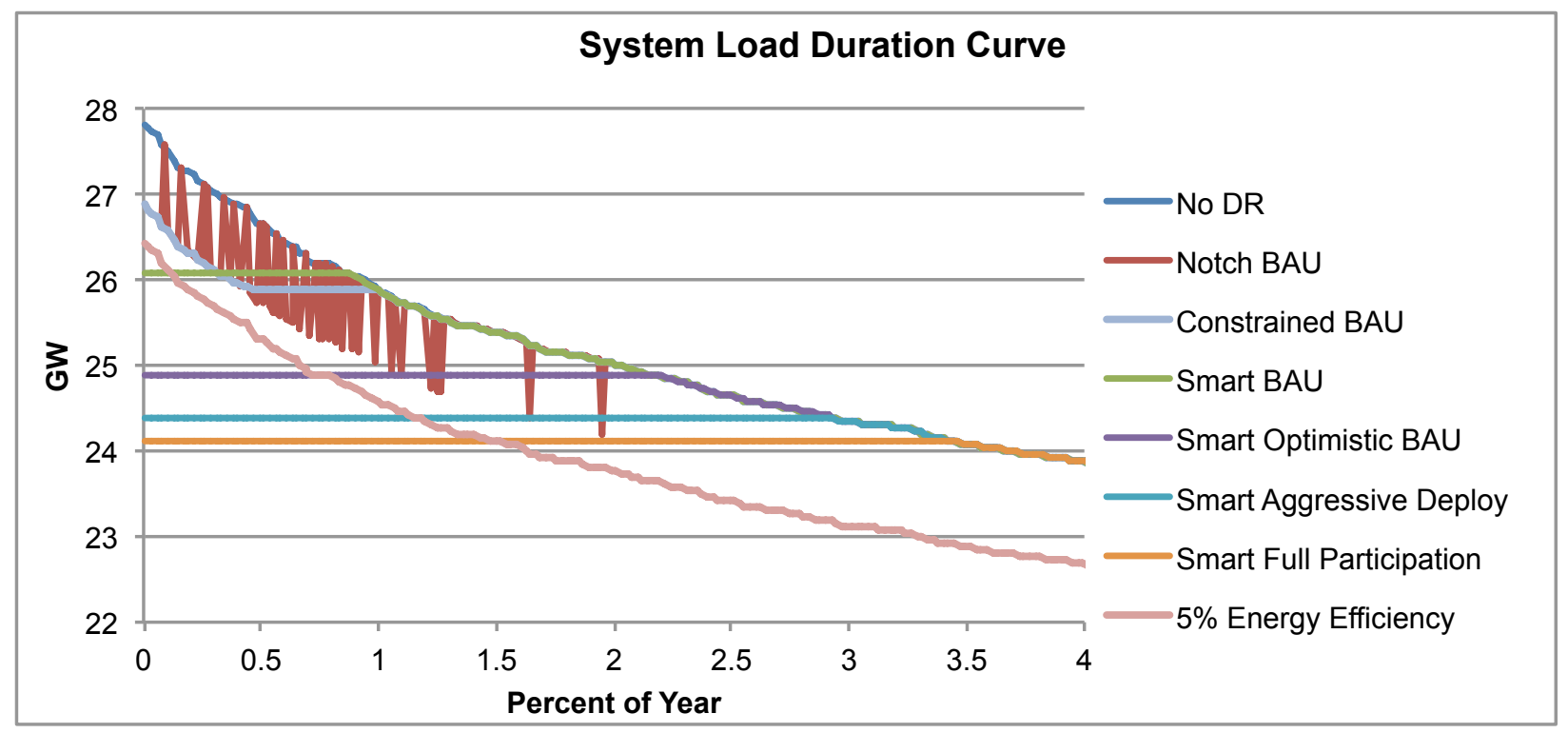

Figure 51: Peak Portion of Load Duration Curve of SRGW

A number of insights can be derived from these figures. First, the three BAU cases (Notch, Smart, and Constrained) all had the same amount of energy reduction but had very different impacts on the LDC. The Notch was applied to a four-hour block on the fifteen highest days, but that block may not result in a true flattening of the peak. As a consequence, DR was applied in some lower demand hours, which were further to the right on the LDC and so dissipated the impact of DR. The peak demand in the Notch case was 27.6 GW, a decrease of only $260 \mathrm{MW}$. Contrarily, the Smart BAU flattened the peak at $26.1 \mathrm{GW}$ and reduced demand during all of the 76 highest hours. Some hours had more DR called upon (up to 1,700 MW) while others less, but the total energy reduction was the same as in the Notch scenario. The third BAU scenario shown, Constrained, still limited the DR impact to only $950 \mathrm{MW}$ but applied these to the highest demands so the system peak dropped the full $950 \mathrm{MW}$ to $26.9 \mathrm{GW}$.

Another key insight was that in high penetration scenarios the final peak system load was reduced by much less than the DR percentage. For example, in the FP scenario the DR amounted to $29 \%$ of peak demand (Table 19), but reduced the peak by just $16 \%$ or $3.7 \mathrm{GW}$.

Theoretically, all of the DR could be called upon during the top 60 hours, but then they would drop demand $29 \%$ for only those hours but have no impact on hours 61 and beyond. Instead, it is "smarter" to spread the DR around; this ends up with it being used in 303 hours (3.5\% of the year) in the FP scenario. Only some participants were called upon during each occasion so that their annual participation was still only 60 hours or less. Table 21 shows the DR available as a percentage of peak demand (from Table 19) along with the actual system peak reduction as DR is spread to flatten the peaks (in the Smart scenarios) or misses some peaks out of the 2-6pm target in the Notch scenario.

Note how even with large increases in DR percentage from the Optimistic BAU to Full Participation, the actual system peak was not heavily impacted in most regions. In SRGW for example, the DR \% rose from $15 \%$ to $29 \%$ between these two scenarios, but the system peak reduction only changed from $12 \%$ to $16 \%$. The DR became energy-limited rather than capacity-limited. Much of any additional DR had to be spread over more hours so had less effect on the system peak. 
Table 21. System Peak Reductions with Increasing DR Penetration

\begin{tabular}{|c|c|c|c|c|c|c|c|c|c|c|}
\hline & \multicolumn{4}{|c|}{ DR-BAU } & \multicolumn{2}{|c|}{$\begin{array}{c}\text { DR-Optimistic } \\
\text { BAU }\end{array}$} & \multicolumn{2}{|c|}{$\begin{array}{c}\text { DR-Aggressive } \\
\text { Deployment }\end{array}$} & \multicolumn{2}{|c|}{$\begin{array}{c}\text { DR-Full } \\
\text { Deployment }\end{array}$} \\
\hline & \multirow[b]{2}{*}{ DR } & \multicolumn{3}{|c|}{ System Peak Reduced } & \multirow[b]{2}{*}{ DR } & \multirow{2}{*}{$\begin{array}{c}\text { System } \\
\text { Peak } \\
\text { Reduced }\end{array}$} & \multirow[b]{2}{*}{ DR } & \multirow{2}{*}{$\begin{array}{c}\text { System } \\
\text { Peak } \\
\text { Reduced }\end{array}$} & \multirow[b]{2}{*}{ DR } & \multirow{2}{*}{$\begin{array}{c}\text { System } \\
\text { Peak } \\
\text { Reduced }\end{array}$} \\
\hline & & Notch & Constrained & Smart & & & & & & \\
\hline FRCC & $5 \%$ & $0 \%$ & $5 \%$ & $15 \%$ & $22 \%$ & $19 \%$ & $35 \%$ & $21 \%$ & $47 \%$ & $22 \%$ \\
\hline MROE & $9 \%$ & $2 \%$ & $9 \%$ & $10 \%$ & $15 \%$ & $12 \%$ & $19 \%$ & $13 \%$ & $22 \%$ & $13 \%$ \\
\hline MROW & $9 \%$ & $0 \%$ & $9 \%$ & $11 \%$ & $20 \%$ & $14 \%$ & $26 \%$ & $16 \%$ & $29 \%$ & $16 \%$ \\
\hline NEWE & $7 \%$ & $0 \%$ & $7 \%$ & $10 \%$ & $12 \%$ & $12 \%$ & $16 \%$ & $13 \%$ & $19 \%$ & $14 \%$ \\
\hline NYCW & $10 \%$ & $1 \%$ & $10 \%$ & $10 \%$ & $18 \%$ & $12 \%$ & $21 \%$ & $13 \%$ & $25 \%$ & $13 \%$ \\
\hline NYLI & $10 \%$ & $3 \%$ & $10 \%$ & $14 \%$ & $18 \%$ & $17 \%$ & $21 \%$ & $17 \%$ & $25 \%$ & $18 \%$ \\
\hline NYUP & $10 \%$ & $1 \%$ & $10 \%$ & $13 \%$ & $18 \%$ & $16 \%$ & $21 \%$ & $17 \%$ & $25 \%$ & $18 \%$ \\
\hline RFCE & $7 \%$ & $2 \%$ & $7 \%$ & $11 \%$ & $15 \%$ & $14 \%$ & $22 \%$ & $16 \%$ & $29 \%$ & $18 \%$ \\
\hline RFCM & $6 \%$ & $2 \%$ & $6 \%$ & $8 \%$ & $14 \%$ & $11 \%$ & $19 \%$ & $13 \%$ & $22 \%$ & $14 \%$ \\
\hline RFCW & $6 \%$ & $2 \%$ & $6 \%$ & $8 \%$ & $15 \%$ & $12 \%$ & $21 \%$ & $13 \%$ & $26 \%$ & $14 \%$ \\
\hline SRDA & $4 \%$ & $2 \%$ & $4 \%$ & $8 \%$ & $12 \%$ & $11 \%$ & $21 \%$ & $13 \%$ & $29 \%$ & $14 \%$ \\
\hline SRGW & $4 \%$ & $1 \%$ & $4 \%$ & $7 \%$ & $15 \%$ & $12 \%$ & $23 \%$ & $14 \%$ & $29 \%$ & $16 \%$ \\
\hline SRSE & $3 \%$ & $1 \%$ & $3 \%$ & $5 \%$ & $18 \%$ & $10 \%$ & $27 \%$ & $11 \%$ & $36 \%$ & $13 \%$ \\
\hline SRCE & $1 \%$ & $1 \%$ & $1 \%$ & $6 \%$ & $8 \%$ & $11 \%$ & $18 \%$ & $13 \%$ & $27 \%$ & $15 \%$ \\
\hline SRVC & $5 \%$ & $0 \%$ & $5 \%$ & $6 \%$ & $20 \%$ & $10 \%$ & $30 \%$ & $12 \%$ & $38 \%$ & $13 \%$ \\
\hline SPNO & $2 \%$ & $2 \%$ & $2 \%$ & $5 \%$ & $12 \%$ & $12 \%$ & $21 \%$ & $15 \%$ & $29 \%$ & $16 \%$ \\
\hline SPSO & $6 \%$ & $4 \%$ & $6 \%$ & $9 \%$ & $13 \%$ & $11 \%$ & $23 \%$ & $14 \%$ & $31 \%$ & $15 \%$ \\
\hline
\end{tabular}

Lastly, Figure 50 shows how small an impact DR had on the total energy demand. It had an effect on less than $4 \%$ of the year's demand, while energy efficiency can have a much more extensive effect. The area between the base and other curves represent the amount of energy saved. The LDC with a 5\% reduction over all hours has much more total space between the two curves than any of the DR scenarios. This is quantified later in this report. Energy efficiency programs are discussed in more detail in the companion study From Georgia Institute of Technology Estimating the Energy-Efficiency Potential in the Eastern Interconnection (Brown, et al, 2012). This "smart" use of DR resources clips the peak at 24,100 MW.

\subsubsection{System Reliability Impact}

Related to the reduction in peak demand is the second type of benefit, improved system reliability. Our modeling did not include reducing the amount of generating capacity, which means that the reserve margin would increase as system peaks declined. We found that the DR programs significantly contribute to increasing the reserve margin in each region (see Table 22). The reserve margin in this analysis is defined as follows:

$$
\text { Regional Reserve Margin }=\frac{(\text { Total Generation Capacity }-85 \% \text { of Wind Capacity })}{(\text { Regional Demand }- \text { DR Load Impact })}
$$

This equation reduces regional capacity by $85 \%$ of the wind capacity in the region to represent the variable nature of wind. This value is roughly in alignment with what is used in various reliability regions. Secondly, this equation does not incorporate the impact of exports or imports into a region. Those regions planning on exports will have a higher reserve margin in this table, while those that heavily utilize imports will have a low or negative reserve margin.

For example, both NYCW and NYLI show negative values of reserve margin. This result can be explained by the fact that NYCW and NYLI highly depend on electricity from upstate New York or 
RFCE region to meet their regional demand. MROE and NEWE show positive but relatively low levels in reserve margin. MROE imports electricity from the neighboring MROW, and NEWE internationally imports electricity from Canada. ${ }^{25}$ In addition to reserve margin, we checked changes in LOLP to validate the changes in system reliability under different scenarios. The LOLP decreases below 1 day per 10 year in most of the regions with the addition of DR. NYCW region showed one of the highest impacts on LOLP and its LOLP dropped from 6.8 (under BAU) to 0.4 (under Full Deployment-Smart).

Table 22: Reserve Margin in $\mathbf{2 0 3 0}^{26}$

\begin{tabular}{|c|c|c|c|c|c|c|}
\hline & BAU-Notch & BAU-Smart & $\begin{array}{c}\text { Optimist } \\
\text { BAU-Smart }\end{array}$ & $\begin{array}{c}\text { Aggressive } \\
\text { Deployment } \\
\text {-Smart }\end{array}$ & $\begin{array}{c}\text { Full } \\
\text { Deployment } \\
\text {-Smart }\end{array}$ & \\
\hline FRCC & $23 \%$ & $27 \%$ & $29 \%$ & $36 \%$ & $39 \%$ & $41 \%$ \\
\hline MROE & $2 \%$ & $4 \%$ & $13 \%$ & $15 \%$ & $17 \%$ & $18 \%$ \\
\hline MROW & $19 \%$ & $20 \%$ & $34 \%$ & $39 \%$ & $41 \%$ & $42 \%$ \\
\hline NEWE & $0 \%$ & $1 \%$ & $12 \%$ & 14 & $16 \%$ & $17 \%$ \\
\hline NYCW & $-16 \%$ & $-15 \%$ & $-7 \%$ & $-5 \%$ & $-4 \%$ & $-3 \%$ \\
\hline NYLI & $-13 \%$ & $-10 \%$ & $1 \%$ & $4 \%$ & $5 \%$ & $6 \%$ \\
\hline NYUP & $32 \%$ & $33 \%$ & $52 \%$ & $57 \%$ & $58 \%$ & $60 \%$ \\
\hline RFCE & $12 \%$ & $14 \%$ & $26 \%$ & $31 \%$ & $33 \%$ & $36 \%$ \\
\hline RFCM & $15 \%$ & $17 \%$ & $25 \%$ & $29 \%$ & $32 \%$ & $33 \%$ \\
\hline RFCW & $19 \%$ & $22 \%$ & $30 \%$ & $35 \%$ & $38 \%$ & $39 \%$ \\
\hline SRDA & $34 \%$ & $36 \%$ & $46 \%$ & $51 \%$ & $54 \%$ & $56 \%$ \\
\hline SRGW & $26 \%$ & $27 \%$ & $36 \%$ & $43 \%$ & $47 \%$ & $49 \%$ \\
\hline SRSE & $31 \%$ & $32 \%$ & $38 \%$ & $46 \%$ & $48 \%$ & $50 \%$ \\
\hline SRCE & $15 \%$ & $17 \%$ & $23 \%$ & $29 \%$ & $33 \%$ & $35 \%$ \\
\hline SRVC & $19 \%$ & $22 \%$ & $26 \%$ & $33 \%$ & $35 \%$ & $37 \%$ \\
\hline SPNO & $18 \%$ & $21 \%$ & $25 \%$ & $34 \%$ & $38 \%$ & $41 \%$ \\
\hline SPSO & $13 \%$ & $17 \%$ & $24 \%$ & $27 \%$ & $31 \%$ & $33 \%$ \\
\hline
\end{tabular}

Of course, any region may choose to retire, deactivate, or mothball old capacity, or not build new capacity if they use the DR resources available in their region. However, attempting to determine how many and which plants to deactivate was beyond the scope of this study.

\subsubsection{Generation Cost Impact}

The third type of benefit from the demand response programs is reduction in production cost. Table 23 shows the reduction in average cost per MWh under different scenarios. It indicates that the average costs are not significantly affected by the penetration of demand response programs even under the Full deployment scenario. Regionally, NYLI and NEWE regions in Full Deployment-Smart scenario show the highest impact of $2 \%$ reduction in average cost.

Whereas the impact on the average production cost is small, the demand response programs significantly contribute to subduing the cost during the peak hours. Table 24 shows the cost of avoided electricity by DR during the peak hours. In general, the per-MWh avoided cost under the BAU-Smart scenario is the greatest during peak hours. It is because the scenario addresses the actual peak hours rather than the prespecified time slots and targets the tiptop of the peak loads. Since relatively expensive generation options

${ }^{25}$ The international import is not captured by NEMS supply data that we used for setting the supply module of ORCED.

${ }^{26}$ The input dataset for the supply module in ORCED was updated by NEMS for AEO 2011 and LDCs in the demand module were generated based on FERC's 714 data. The difference in data source might cause an inaccurate estimate of LOLP and reserve margin that are calculated in the dispatch module where the supply and the demand meet. Furthermore, the model used calculates a relative LOLP that only treats a fraction of the plants as stochastic. 
are involved to meet peak demand in general, demand response programs are able subdue the increase in price by shaving off the peak loads.

Table 23: Average Cost of Generation in $2030(\$ / M W h)$

\begin{tabular}{lccrrrr}
\hline (\$/MWh) & No DR & $\begin{array}{c}\text { BAU- } \\
\text { Notch }\end{array}$ & $\begin{array}{c}\text { BAU- } \\
\text { Smart }\end{array}$ & $\begin{array}{c}\text { Optimist } \\
\text { BAU-Smart }\end{array}$ & $\begin{array}{c}\text { Aggressive } \\
\text { Deployment- } \\
\text { Smart }\end{array}$ & $\begin{array}{c}\text { Full } \\
\text { Deployment- } \\
\text { Smart }\end{array}$ \\
\hline FRCC & 54.9 & 54.9 & 54.9 & 54.8 & 54.7 & 54.7 \\
MROE & 49.2 & 49.1 & 49.1 & 49.0 & 49.0 & 49.0 \\
MROW & 43.1 & 43.0 & 43.0 & 43.0 & 43.0 & 43.0 \\
NEWE & 52.7 & 52.6 & 52.6 & 52.6 & 52.5 & 52.5 \\
NYCW & 70.2 & 70.0 & 70.0 & 69.9 & 69.9 & 69.8 \\
NYLI & 84.5 & 83.8 & 83.7 & 83.2 & 83.0 & 82.8 \\
NYUP & 37.5 & 37.5 & 37.5 & 37.5 & 37.5 & 37.4 \\
RFCE & 46.1 & 46.0 & 45.9 & 45.8 & 45.8 & 45.8 \\
RFCM & 43.6 & 43.5 & 43.5 & 43.5 & 43.4 & 43.4 \\
RFCW & 40.8 & 40.7 & 40.7 & 40.7 & 40.7 & 40.7 \\
SRDA & 45.6 & 45.6 & 45.6 & 45.6 & 45.6 & 45.6 \\
SRGW & 40.7 & 40.6 & 40.6 & 40.6 & 40.6 & 40.5 \\
SRSE & 48.0 & 48.0 & 48.0 & 48.0 & 48.0 & 47.9 \\
SRCE & 36.9 & 36.9 & 36.9 & 36.8 & 36.8 & 36.8 \\
SRVC & 47.2 & 47.2 & 47.2 & 47.2 & 47.1 & 47.1 \\
SPNO & 66.9 & 66.9 & 66.9 & 66.9 & 66.8 & 66.9 \\
SPSO & 47.2 & 47.1 & 47.1 & 47.1 & 47.0 & 47.0 \\
\hline
\end{tabular}

Table 24: Avoided Cost of Electricity Generation during the Peak Hours in 2030 ( $\$ / M W h)$

\begin{tabular}{lrrrrr}
\hline BAU-Notch & BAU-Smart & $\begin{array}{c}\text { Optimist } \\
\text { BAU-Smart }\end{array}$ & $\begin{array}{c}\text { Aggressive } \\
\text { Deployment- } \\
\text { Smart }\end{array}$ & $\begin{array}{c}\text { Full } \\
\text { Deployment- } \\
\text { Smart }\end{array}$ \\
\hline FRCC & & & 96 & 90 \\
MROE & 87 & 134 & 98 & 109 & 108 \\
MROW & 114 & 117 & 111 & 82 & 80 \\
NEWE & 83 & 101 & 86 & 128 & 123 \\
NYCW & 140 & 184 & 141 & 127 & 120 \\
NYLI & 126 & 155 & 131 & 356 & 348 \\
NYUP & 345 & 387 & 368 & 45 & 59 \\
RFCE & 48 & 16 & 31 & 179 & 155 \\
RFCM & 224 & 297 & 216 & 105 & 101 \\
RFCW & 107 & 117 & 107 & 86 & 83 \\
SRDA & 99 & 112 & 97 & 60 & 58 \\
SRGW & 62 & 74 & 62 & 92 & 91 \\
SRSE & 84 & 106 & 98 & 61 & 61 \\
SRCE & 57 & 62 & 62 & 73 & 70 \\
SRVC & 72 & 73 & 84 & 79 & 78 \\
SPNO & 83 & 105 & 84 & 98 & 88 \\
SPSO & 90 & 117 & 107 & 93 & 93 \\
\hline
\end{tabular}

\subsubsection{Environmental Impact}

In addition to the cost reduction and the improved system reliability, DR also results in environmental benefits. In general, the amount of green house gas emissions is proportional to the electricity generation. The total amount of reduction in electricity generation by DR in the Eastern Interconnection is $2 \sim 11 \mathrm{TWh}$ 
by scenario in 2030 . Table 25 shows that, compared to the energy efficiency, the impact of DR on reduction in total electricity generation is small. It is because energy efficiency shifts down the absolute levels of electricity demand across the entire year, DR addresses only the peak hours that occupy less than $1 \%$ of a year. Decreases in $\mathrm{CO}_{2}$ emissions by scenario and region are shown in Table 26. In the Eastern Interconnection area, 5 25 million tons of $\mathrm{CO}_{2}$ could be avoided by DR in 2030. Some regions where the peak demand is served by a variety of other generation options that are cleaner than fossil fuels might not be able to expect a significant reduction in GHG emission from DR.

Table 25: Change in Generation Volumes in 2030 due to DR program deployment (TWh)

\begin{tabular}{|c|c|c|c|c|c|c|}
\hline (TWh) & $\begin{array}{l}\text { BAU- } \\
\text { Notch }\end{array}$ & BAU-Smart & $\begin{array}{r}\text { Optimist } \\
\text { BAU-Smart }\end{array}$ & $\begin{array}{r}\text { Aggressive } \\
\text { Deployment- } \\
\text { Smart }\end{array}$ & $\begin{array}{r}\text { Full } \\
\text { Deploymen } \\
\text { t-Smart }\end{array}$ & $\begin{array}{l}\text { 5\% Energy } \\
\text { Efficiency }\end{array}$ \\
\hline FRCC & -0.15 & -0.15 & -0.67 & -1.06 & -1.43 & -11.97 \\
\hline MROE & -0.04 & -0.04 & -0.06 & -0.08 & -0.09 & -1.69 \\
\hline MROW & -0.21 & -0.21 & -0.48 & -0.62 & -0.69 & -11.86 \\
\hline NEWE & -0.08 & -0.06 & -0.13 & -0.20 & -0.25 & -6.78 \\
\hline NYCW & -0.07 & -0.06 & -0.12 & -0.14 & -0.16 & -1.21 \\
\hline NYLI & -0.03 & -0.03 & -0.06 & -0.07 & -0.08 & -0.62 \\
\hline NYUP & -0.10 & -0.10 & -0.18 & -0.21 & -0.25 & -5.11 \\
\hline RFCE & -0.25 & -0.24 & -0.54 & -0.79 & -1.05 & -16.07 \\
\hline RFCM & -0.08 & -0.08 & -0.18 & -0.25 & -0.29 & -5.73 \\
\hline RFCW & -0.39 & -0.39 & -0.98 & -1.38 & -1.70 & -33.64 \\
\hline SRDA & -0.07 & -0.07 & -0.20 & -0.34 & -0.47 & -7.11 \\
\hline SRGW & -0.05 & -0.05 & -0.20 & -0.31 & -0.39 & -7.95 \\
\hline SRSE & -0.09 & -0.09 & -0.56 & -0.83 & -1.11 & -14.38 \\
\hline SRCE & -0.03 & -0.03 & -0.22 & -0.49 & -0.74 & -12.24 \\
\hline SRVC & -0.20 & -0.20 & -0.80 & -1.21 & -1.53 & -16.12 \\
\hline SPNO & -0.02 & -0.02 & -0.11 & -0.20 & -0.27 & -3.73 \\
\hline SPSO & -0.09 & -0.09 & -0.22 & -0.40 & -0.54 & -7.41 \\
\hline EI Total & -1.95 & -1.92 & -5.71 & -8.57 & -11.05 & -163.62 \\
\hline
\end{tabular}

Table 26: Change in $\mathrm{CO} 2$ emissions in 2030 due to DR program deployment

\begin{tabular}{|c|c|c|c|c|c|}
\hline (Million tons) & BAU-Notch & BAU-Smart & $\begin{array}{c}\text { Optimist } \\
\text { BAU-Smart }\end{array}$ & $\begin{array}{c}\text { Aggressive } \\
\text { Deployment- } \\
\text { Smart }\end{array}$ & $\begin{array}{c}\text { Full } \\
\text { Deployment- } \\
\text { Smart }\end{array}$ \\
\hline MROE & -0.10 & -0.10 & -0.17 & -0.21 & -0.25 \\
\hline FRCC & -0.35 & -0.44 & -1.65 & -2.45 & -3.18 \\
\hline MROW & -0.63 & -0.53 & -1.24 & -1.60 & -1.80 \\
\hline NEWE & -0.23 & -0.28 & -0.52 & -0.66 & -0.75 \\
\hline NYCW & -0.18 & -0.20 & -0.34 & -0.39 & -0.45 \\
\hline NYLI & -0.13 & -0.13 & -0.24 & -0.27 & -0.32 \\
\hline NYUP & -0.17 & -0.18 & -0.31 & -0.35 & -0.42 \\
\hline RFCE & -0.87 & -0.93 & -1.79 & -2.38 & -2.80 \\
\hline RFCM & -0.22 & -0.23 & -0.47 & -0.59 & -0.71 \\
\hline RFCW & -0.93 & -0.98 & -2.28 & -3.17 & -3.77 \\
\hline SRDA & -0.12 & -0.13 & -0.33 & -0.59 & -0.81 \\
\hline SRGW & -0.14 & -0.14 & -0.50 & -0.75 & -1.01 \\
\hline SRSE & -0.25 & -0.14 & -1.03 & -1.45 & -1.90 \\
\hline SRCE & -0.13 & -0.08 & -0.44 & -1.02 & -1.36 \\
\hline SRVC & -0.25 & -0.48 & -1.54 & -2.21 & -2.58 \\
\hline SPNO & -0.06 & -0.07 & -0.31 & -0.52 & -0.67 \\
\hline SPSO & -0.20 & -0.24 & -0.55 & -0.95 & -1.28 \\
\hline EI Total & -4.96 & -5.28 & -13.72 & -19.58 & -24.04 \\
\hline
\end{tabular}


On balance, the results from the ORCED benefits analysis show that DR programs are able to significantly increase the system reliability in the Eastern Interconnection area by increasing the reserve margin and reducing LOLP days. By avoiding the peak period, customers will benefit from the subdued electricity prices. While both energy efficiency and demand response are expected to influence the electricity market in general and contribute to curtailing the fossil fuel consumption for electricity generation, the time periods when the savings happen and the magnitude of the impacts vary tremendously. The impact of EE was distributed across the entire year, whereas that of DR was focused on the peak periods. As a consequence, DR is beneficial to emergency controls and grid reliability and is anticipated to contribute to controlling the supplies and prices during the peak hours. This result is explained by the fact that DR is originally designed to cope with supply-deficiency situations during the peak hours. 


\section{CHALLENGES TO DEMAND RESPONSE IMPLEMENTATION}

\section{Assessing Costs and Benefits of Demand Response}

Difficulty in assessing some of the costs and benefits of DR programs obstructs wider program implementation. In declaring cost-effectiveness estimation protocols for DR programs administered by utility companies in California, for example, the California Public Utilities Commission (CPUC) explicitly stated that certain costs and benefits are "difficult, if not impossible, to calculate" (CPUC 2010). The CPUC's protocols require utilities to provide estimates of these uncertain costs and benefits using either "a reasonable and transparent method" or a qualitative discussion of the likelihood and extent of [such costs and benefits]" (CPUC 2010). The CPUC (2010) lists the following benefits and costs of DR programs as particularly challenging to assess:

Environmental Benefits - Through inducing reductions in electricity consumption, DR programs simultaneously reduce the emissions associated with electricity generation. As with all pollution reductions, the benefits are difficult to assess because they are spread over such a large population and monetary values have not yet been well-mapped to particular pollutants. A more-certain benefit that DR programs provide is avoiding the additional costs of meeting environmental regulations during construction of new power plants; these costs are already accounted for in the avoided generation benefits of demand response, however (CPUC 2008).

Market Benefits - Mitigating electricity price volatility is a chief benefit of DR programs; other similar benefits include increasing the reliability of the electricity grid and increasing market efficiency. Although the ultimate form of these benefits is both quantifiable and monetary (e.g. consumers and producers should have more wealth in a more efficient market), mapping these benefits to DR programs is difficult because of the nature of electricity price volatility, market efficiency, and grid reliability as dependent upon aggregate supply and aggregate demand. It is always challenging to assign particular features of the aggregate market to specific individual actors, such as attributing a certain percent reduction in electricity price volatility to a specific DR program (CPUC 2008).

Transaction Costs and Value of Service Lost - These costs are highly dependent upon the customer's own preferences and valuations. The transaction costs may include time spent learning about available DR programs, time spent completing an application for a DR program, and time spent performing energy audits. To know these costs, the customer's valuation of each of these quantities of time is necessary. Value of Service Lost refers to the gains from electricity use that would have been realized had the customer not reduced electricity use at all. These frequently include productivity values (e.g. the output produced with a given amount of electricity) and comfort values (e.g. the greater amount of satisfaction one feels from a hot shower instead of a warm shower). Both of these costs would require customers to self-identify (in honesty) what these amounts of comfort, productivity, or time are worth in monetary terms (CPUC 2008).

The CPUC protocols released in 2010 are the culmination of several preliminary studies, stakeholder feedback sessions, and utility surveys that began with the reporting of internal cost-effectiveness protocols by three large California utilities: Pacific Gas \& Electric, San Diego Gas \& Electric, and Consolidated Edison (CPUC 2005a; CPUC 2005b; CPUC 2005c; Barkovich, Ellis, Jordan, et al. 2007; CPUC 2008; CPUC 2010). The Total Resource Cost (TRC) test calculates costs and benefits for society, understood as the LSE and its customers and it is the most commonly applied test by utilities trying to justify their DR programs in front of their public utility commissions.

Another helpful methodological guide is the one published by EPRI in 2010 regarding the approach to quantify benefits and costs of smart grid demonstration projects. Like in the case of DR programs, smart 
grid programs generate benefits and costs to participant customers, non-participant customers, utilities and society as a whole. Benefits in this handbook are classified in 4 main categories: economic, reliability and power quality, environmental and security and safety.

\section{Regulatory issues}

Discriminatory treatment to non-generation resources: Since the approval of FERC Order 890 in 2007, RTOs and ISOs are required to evaluate non-generation resources, such as DR and storage, on a comparable basis to services provided by generation resources in meeting mandatory reliability standards, providing ancillary services and planning expansion of the transmission grid. Before this ruling, much of the potential value of DR resources was not being realized as, in many cases, DR was not allowed to provide ancillary services and could not be counted as capacity for reliability planning purposes.

Discriminatory treatment to fast-response resources: FERC Order 755, published in November 2011, will matter for DR resources providing frequency regulation service in organized wholesale electric markets. It establishes that resources participating in regulation markets should receive compensation with two elements: a capacity element that includes the opportunity cost of the marginal unit providing the service during each hour and a payment for performance. This second payment is a dollar amount per MW up or down of regulation service provided such that those resources that can respond very fast and accurately to the automatic generation control (AGC) signal (e.g., flywheels, batteries, fast hydro and DR) get paid more than slower units.

Compensation: Another challenging issue for implementation of DR programs is determining fair compensation to program participants. As described above, programs such as Curtailing Load and Interruptible Load involve paying participating customers to compensate them for the value of electricity service they lose when making their demand reductions. This issue was the subject of debate after FERC distributed a Notice of Proposed Rulemaking (NOPR RM10-17) stating that it would soon set a standard compensation rate to be paid by all electricity suppliers to customers participating in DR programs (Boshar 2010). Certain members of FERC as well as consumer advocates argued in favor of paying DR participants the Locational Marginal Price (LMP) in return for their demand reductions, while electricity supplier advocates argued for payments below the LMP.

The argument in favor of the LMP centered on treating DR resources as avoided capacity expansions. Since the LMP is used to cover the costs of capacity expansions (including additional transmission infrastructure and distribution costs), it seems reasonable to pay DR participants the LMP for helping suppliers to avoid the costs that suppliers would need to recover through the LMP (Boshar 2010, FERC 2011). Additionally, consumer advocacy group Electricity Consumer Resource Council (ELCON) argued that the LMP would help compensate DR participants for the shared benefits their demand reductions created, such as increased grid stability and market efficiency (Boshar 2010).

The counterargument offered by the Electricity Power Supply Association and other supply-side advocates stated that paying the LMP to DR participants would exacerbate the economic inefficiencies of the electricity market. Supply advocates, with the support of economist William Hogan from Harvard's Kennedy School of Government, argued that only a select few DR customers needed to be compensated at all for their reductions and that no compensation should be equal to or greater than the LMP (FERC 2011, Boshar 2010). Hogan's work on this issue concludes that only customers who do not pay the LMP for their electricity should be compensated for their demand reductions. Hogan and fellow critics argued that the LMP would be an overcompensating amount to pay to DR participants (Boshar 2010).

On March 24, 2011, The FERC issued its final rule on DR compensation. The FERC ultimately chose to make payment of the LMP the policy to which all DR program providers (i.e. electricity suppliers) must subscribe: 
"...We find, based on the record here that, when a demand response resource has the capability to balance supply and demand as an alternative to a generation resource, and when dispatching and paying LMP to that demand response resource is shown to be costeffective as determined by the net benefits test described herein, payment by an RTO or ISO of compensation other than the LMP is unjust and unreasonable. When these conditions are met, we find that payment of LMP to these resources will result in just and reasonable rates for ratepayers. As stated in the NOPR, we believe paying demand response resources the LMP will compensate those resources in a manner that reflects the marginal value of the resource to each RTO and ISO." (FERC 2011, paragraph 47)

While FERC's decision may have temporarily abated the DR program compensation debate, many of the challenges to DR implementation remain unanswered. Further research is necessary to establish the costs of DR programs and their consumption-curtailing effectiveness. 


\section{POSSIBLE NADR RESEARCH ENHANCEMENTS}

\section{A) Revising participation hierarchy}

Modeling tools designed to assess demand response potential in a given region typically assume no overlaps in demand response participation (i.e.,if a customer enrolls in a particular kind of program is automatically taken out of the pool of available customers for the rest of program). Therefore, the order in which customers are selected is important.

Since no additional information regarding this aspect of DR program design is available, the ORNL team has maintained the participation hierarchy from the original NADR. First, interruptible tariffs customers are chosen. Second the remaining customers are used as the available pool for applying participation rates related to dynamic pricing programs. Third, dynamic pricing non-participants with central AC are the pool eligible for direct load control programs. Lastly, remaining non-participants in any of the above programs are the eligible population for enrolling in Other DR programs.

The chosen participation hierarchy used explains some apparently odd results in the scenario analysis. For instance, for D.C., the load reduction potential under the "Optimistic BAU" scenario is higher than in the "Full Deployment" scenario, which given the additive nature of these scenarios, should not be the case. The explanation is that the increase in load reduction associated with universal participation in dynamic pricing is more than offset by reductions in load reduction from C\&I customers that were enrolled in different programs in other scenarios.

\section{B) Representation of DR program penetration rates}

Currently, NADR takes a simple, linear interpolation approach to represent the transition from current market penetration to maximum market penetration in a pre-specified number of years, where those 3 parameters are program specific.

Alternative, more sophisticated approaches to estimate rates of adoption and attrition have been used in particular case studies. For instance, Brattle Group has forecasted enrollment on non-residential DR programs by one particular utility (PG\&E) from 2011 to 2021 (see Wharton and Palmer, 2011). In this analysis, probabilities of enrolment in mutually exclusive programs are obtained using a multilogit choice model (and portfolio analysis to account for instances of dual enrollment). Then, the evolution of enrolment rates over time is characterized using a Markov chain.

\section{C) Investigating demand reduction potential at the appliance level}

NADR provides aggregate percentage load reduction from each program type rather than considering separately the reduction potential from specific types of appliances. Starke et al.(2011) discuss differences in the DR value of different residential sector appliances. Some of the key attributes to consider are whether a load can be ramped to different consumption levels, has thermal storage capabilities or would need supplementary add-on devices or retrofitting is crucial in capturing a load's DR value. Water heaters, refrigerators and HVAC units have the potential to provide the most demand reduction. Another reason why having appliance-level data is important is to model rebound effects associated with DR dispatch. Black et al. (2008) highlight the importance of distinguishing between instantaneous loads like lighting which, if dispatched as DR, would not have an associated rebound effect and deferrable or thermal demand which would shift to later hours. The current version of NADR does not account at all for possible rebound effects. 


\section{D) Update econometric estimation of load profile curves for each state and customer type}

Several issues are worth noting regarding the current set of econometric estimates for load profile curves.

- The equation estimation is based on data from 2008 or earlier. As indicated in Figure 8 for the NERC system peak load, electricity consumption fell significantly due to the recession that, officially, started in December 2007. For the analysis summarized in this report, an adjustment factor was applied to the critical peak load for each state. However, it does not distinguish across customer types despite it being likely that the impact of the weakened macroeconomic conditions was different for a large industrial customer than for a residential customer. To capture those changes, a re-estimation of the load profile curves with more recent data would be advisable.

- The equation estimation is based on a data panel with significant geographical gaps. No data are available for many states in the Eastern Interconnection (Wisconsin, North Dakota, South Dakota, Minnesota, Iowa, Nebraska, Kansas, West Virginia, Virginia, Florida, Georgia, Kentucky, Tennessee, Alabama, Mississippi, Arkansas, Louisiana, Oklahoma). Were there any idiosyncrasies in load profiles in Census Divisions 4 or 6, they would not be captured by the above equation. The ORNL team is looking for ways to refine estimation of baseline peak loads.

- This approach assumes that only the summer peaks are important for demand response. The equation only looks at load profile during months 5 through 9 (i.e., May through September) and focuses on the interaction between temperatures and central air conditioning.

- This approach is geared towards examining the impacts of one particular dynamic pricing program: critical peak pricing.

\section{E) Investigate duration and timing of DR programs}

While the amount of potential DR can be calculated to be a rather large percentage of the peak demand, the limited hours that it is available will reduce the overall impact on peaks, as shown in Chapter 7. Our assumption, consistent with the FERC NADR study, was that an individual DR resource could be called upon a maximum of 60 hours over a year. Actual DR programs may have more or fewer hours of availability, depending on the type and end-user preferences. With increasing DR penetration, this could have a large impact on the ultimate change in peak demand. While some work has been done in this area through FERC's DRIVE (Demand Response Impact and Value Estimation) model, further research is needed to find the range of availabilities of different DR programs and their impact on overall peak levels over the year. 


\section{REFERENCES}

Agerter, L. L., \& Ouborg, P. (2005). Preliminary AMI Business Case Analysis of Pacific Gas and Electric Company (U 39-E). Analysis. San Francisco, California. Retrieved from http://sites.energetics.com/MADRI/toolbox/pdfs/business cases/pge businesscase.pdf

Barbose, G.; Goldman, C.; and Neenan, B. (2004) A survey of utility experience with real time pricing. Retrieved June 13, 2011 from http://eetd.lbl.gov/ea/EMS/EMS_pubs.html

Barkovich, B.; Ellis, J.; Jordan, L.H.; et al. (2007) Joint coments of California Large Energy Consumers Association, Comverge, Inc., Division of Ratepayer Advocates, Energyconnect, Inc., Enernoc, Inc., Ice Energy, Inc., Pacific Gas and Electric Company (U 39-M), San Diego Gas \& Electric company (U 902-E), Southern California Edison Company (U 338-E) and the Utility Reform Network recommending a demand response cost effectiveness evaluation framework: R.07-01-041 Retrieved June 11, 2011 from http://www.nwcouncil.org/energy/dr/meetings/2008_01/ConsensusCADRCEEvaluationFramework11 1907.pdf

Bharvirkar, R.; Goldman, C.; Heffner, G.; and Sedano, R. (2008) Coordination of retail demand response with Midwest ISO wholesale markets. Retrieved June 13, 2011 from http://eetd.lbl.gov/ea/EMS/EMS pubs.html

Boshar, G. (2010) ELCON, EPSA, and Harvard's Hogan face off over demand response compensation rules. SNL Energy Power Daily. May 17, 2010. Retrieved June 5, 2011 from http://proquest.umi.com/pqdweb?did=2353266341\&Fmt=3\&clientld=30287\&RQT =309\&VName $=\mathrm{P}$ DQ

Brown, Marilyn and Yu Wang (2012) Estimating the Energy-Efficiency Potential in the Eastern Interconnection, ORNL/TM-2012/568, prepared by Georgia Institute of Technology for Oak Ridge National Laboratory, November.

Buckner, David E. (2009) Direct Testimony of David E. Buckner on behalf of Mississippi Power Company before the Mississippi Public Service Commission. Mississippi Public Service Commission Docket No. '09-UA-398

Cappers, P.; Goldman, C.; and Kathan, D. (2009) Demand response in U.S. electricity markets: Empirical evidence. Retrieved June 13, 2011 from http://eetd.lbl.gov/ea/EMS/EMS pubs.html

Casady, S. (2008). September 2008 AMI Plan Biannual Report, Decsion No. 68112, Docket No. E01345A-03-0775 and E-01345A-04-0657. Paragraph. Phoenix, Arizona. Retrieved from http://images.edocket.azcc.gov/docketpdf/0000088550.pdf

Cawley, J. H., Christy, T. J., Pizzingrilli, K., Gardner, W. E., \& Powelson, R. F. (2009). Smart Meter Procurement and Installation: Implementation Order. Harrisburg, Pennsylvania. Retrieved from www.puc.state.pa.us/electric/Act129/Smart_Meter_Technology.aspx

Chan, M., et al. (2011) Preliminary US DOE Smart Grid Investment Grant Program Advanced Metering Infrastructure Asset Costs: A comparison to costs published by the EPRI and the Brattle Group. Navigant Energy Consulting for the US Association of Energy Economics, October 8-11, 2011.

Charles Rivers Associates (2005). Impact Evaluation of the California Statewide Pricing Pilot, Marc 16. 
Downloadable from http://www.calmac.org/publications/2005-03-24_SPP FINAL REP.pdf

Chupka, M. W., Earle, R., Fox-penner, P., \& Hledik, R. (2008). Transforming America's Power Industry: The Investment Challenge 2010-2030. Prism. Retrieved from http://www.eei.org/ourissues/finance/Documents/Transforming Americas Power Industry.pdf

Clavenna, Scott; Pollock, Zach. (2012) Can the smart meter and AMI market continue its meteoric growth? (Audiorecording/Interview/Podcast). Available at http://www.greentechmedia.com/articles/read/podcast-the-smart-grid-ami-market-q1-20121/

Connecticut Light and Power Company (2010) Plan-it-Wise Recommendations. Connecticut Department of Public Utility Control Docket No. 05-10-03RE01.

CPUC (2005a) Audit report: Pacific Gas \& Electric Company interruptible load management program for years 2001, 2002, and 2003. Retrieved June 7, 2011 from http://docs.cpuc.ca.gov/published/Report/46797.PDF

CPUC (2005b) Audit report: San Diego Gas \& Electric interruptible load management program for years 2001, 2002, and 2003. Retrieved June 7, 2011 from http://docs.cpuc.ca.gov/published/Report/46796.PDF

CPUC (2005c) Audit report: Southern California Edison Company interruptible load management program for years 2001, 2002, and 2003. Retrieved June 7, 2011 from http://docs.cpuc.ca.gov/published/Report/46798.PDF

CPUC (2008) Attachment A: Draft demand response cost effectiveness protocols: R.07-01-041. Retrieved June 11, 2011 from http://docs.cpuc.ca.gov/efile/RULINGS/80858.pdf

CPUC (2010) Attachment 1: 2010 demand response cost effectiveness protocols. Retrieved June 11, 2011 from http://docs.cpuc.ca.gov/WORD_PDF/AGENDA_DECISION/128212.pdf

Curry, Kimberly A., et al. (2009) Application of Baltimore Gas and Electric Company for Authorization to Deploy a Smart Grid Initiative and to Establish a Surcharge Mechanism for the Recovery of Costs. Public Service Commission of Maryland Md. E-6: Rider 30, Md. G-9: Rider 13. Baltimore, Maryland.

Dayton Power and Light Company (2007) AMI Costs \& Benefits: Public Utilities Commission of Ohio AMI Workshop \#5. Public Utility Commission of Ohio Case No. 07-646-EL-UNC.

Energy Information Administration. (2011). Form 861 Data: 2010. Retrieved from http://205.254.135.24/cneaf/electricity/page/eia861.html

Environmental Protection Agency (2008) Understanding Cost-effectiveness of Energy Efficiency Programs: Best Practices, Technical Methods, and Emerging Issues for Policy-Makers. Available at www.epa.gov/eeactionplan

EPRI (2010). Methodological approach for estimating the benefits and costs of smart grid demonstration projects. Report number 1020342.

EPRI (2009). Assessment of Achievable Potential from Energy Efficiency and Demand Response Programs in the U.S. Report number 1016987. 
EPRI (2009). Assessment of Achievable Potential from Energy Efficiency and Demand Response Programs in the U.S. Report number 1016987.

EPRI (2009). Assessment of Achievable Potential from Energy Efficiency and Demand Response Programs in the U.S. Report number 1016987.

ERCOT Image Source: http://www.ercot.com/content/news/mediakit/maps/NERC_Interconnections_color.jpg

Farmer, L., Hatch-Miller, J., Mundell, W. A., Spitzer, M., Gleason, M., \& Mayes, K. K. (2005). In the Matter of the Application of Arizona Public Service Company for a Declaratory Order Regarding Bill Estimation Procedures. Direct. Phoenix, Arizona. Retrieved from http://images.edocket.azcc.gov/docketpdf/0000028339.pdf

Faruqui, A. and D. Mitarotonda (2011). "Energy efficiency and demand response in 2020- a survey of expert opinion". Available at http://www.brattle.com/ documents/UploadLibrary/Upload990.pdf

Faruqui,A. and S. Sergici (2010). "Household response to dynamic pricing of electricity: a survey of 15 experiments". Journal of Regulatory Economics 38: 193-225.

Federal Energy Regulatory Commission (FERC) (2008). Assessment of demand response and advanced metering, staff report. Retrieved May 20, 2011 from http://www.ferc.gov/legal/staff-reports/12-08demand-response.pdf

FERC (2009) A National Assessment of Demand Response Potential NADR prepared by the Brattle Group, Freeman, Sullivan \& Co, Global Energy Partners, LLC.. Retrieved May 20, 2011 from http://www.ferc.goc/legal/staff-reports/06-09-demand-response.pdf

FERC (2010). National Action Plan on Demand Response. Available at http://www.ferc.gov/legal/staffreports/06-17-10-demand-response.pdf

FERC (2011) Demand response compensation in organized wholesale electricity markets: Final rule. Federal Register, 76(57), 16658-16682

FERC(2011b). Assessment of Demand Response and Advanced Metering. Staff Report. Available at http://www.ferc.gov/legal/staff-reports/2010-dr-report.pdf

FirstEnergy (2007) Public Utilities Commission of Ohio Smart Metering Workshop: Ohio Edison Company, The Cleveland Electric Illuminating Company, And The Toledo Edison Company. Public Utilities Commission of Ohio Case No. 07-646-EL-COI.

Gellings, C. (2011). Estimating the Costs and Benefits of the Smart Grid. Power. Palo Alto, California. Retrieved from http://www.rmi.org/Content/Files/EstimatingCostsSmartGRid.pdf

Goldman, C.; Hopper, N.; Bharvirkar, R.; Neenan, B.; and Cappers, P. (2007) Estimating demand response market potential among large commercial and industrial customers: A scoping study. Retrieved June 13, 2011 from http://eetd.lbl.gov/ea/EMS/EMS pubs.html

Global Energy Partners (2010). Assessment of Demand Response and Energy Efficiency Potential, Volume 2 Eastern Interconnection Analysis. Report \#1314 prepared for Midwest ISO. November 2010 . 
Greer, J. A., Bates, T. L., Murphy, M. C., Pruett, K. R., Puckett, J. R., \& Sherburne, J. M. (2008). Oncor Electric Delivery Company LLC's Request for Approval of AMS Deployment Plan and Request for AMS Surcharge. Austin, Texas. Retrieved from http://interchange.puc.state.tx.us/WebApp/Interchange/application/dbapps/filings/pgControl.asp?TXT CNTRL NO $=35718 \&$ TXT UTILITY TYPE $=$ A\&TXT CNTRL NO=\&TXT ITEM MATCH $=1 \&$ TXT ITEM NO=\&TXT N UTILITY $=\& T X T \_N \_F I L E ~ P A R T Y=\& T X T \_D O C ~ T Y P E=A L L \& T X T$ D FROM $=05 \% 2 \mathrm{~F} 28 \% 2 \mathrm{~F} 2008 \& \mathrm{TXT} \mathrm{D}$ TO $=05 \% 2 \mathrm{~F} 28 \% 2 \mathrm{~F} 2008 \& \mathrm{TXT}$ NEW $=$ true

Hadley, Stan, and Eric Hirst, Possible Effects of Competition on Electricity Consumers in the Pacific Northwest, ORNL/CON-455, Oak Ridge National Laboratory, January 1998. http://www.osti.gov/bridge/servlets/purl/573097-f30IwT/webviewable/

Hadley, Stanton W., The Oak Ridge Competitive Electricity Dispatch (ORCED) Model, ORNL/TM2007/230, Oak Ridge National Laboratory, June 2008. http://apps.ornl.gov/ pts/prod/pubs/ldoc9472_orced_modelfinal.pdf

Hadsell, L.; Marthe, A.; and Shawky, H.A. (2004) Estimating the volatility of wholesale electricity spot prices in the US. The Energy Journal, 25(4), 23-40

Haney, A. B., Jamasb, T., \& Pollitt, M. G. (2009). Smart Metering and Electricity Demand: Technology, Economics, and International Experience. Cambridge, United Kingdom.

Heffner, G. (2010) Demand Response Valuation Frameworks Paper. Lawrence Berkeley National Laboratory. LBNL-2489E. Available at http://escholarship.org/uc/item/401781d4

Hirst, Eric and Stan Hadley, Maintaining Generation Adequacy in a Restructuring U.S. Electricity Industry, ORNL/CON-472, Oak Ridge National Laboratory, October 1999. http://www.osti.gov/bridge/servlets/purl/15044-quHiN1/webviewable/

Isser, S. (2009) What is demand response. Electric Light \& Power. Retrieved May 31, 2011 from (homepage) www.elp.com

Jenkins, Nancy; Haiad, Carlos; Price, Snuller; Horii, Brian; Mahone, Douglas; McHugh, Jon; Tyler, Matt; Saxena, Mudit; Reiss, Rachael. (2005) Case Update: Programmable Communicating Thermostats PIER Buildings Program, SCE Codes \& Standards Program, CEC Title 24 Workshop. Public Interest Energy Research (PIER).

Kiergan, Christopher D.; Freeman, Kent K. (2009) Verified Petition of Duke Energy Indiana, Inc. Requesting the Indiana Utility Regulatory Commision to Approve an Alternative Regulatory Plan Pursuant to IND. Code sub-section 8-1-2.5-1, ET SEQ., for the Implementation of an Electric Distribution System "SmartGrid" and Advanced Metering Infrastructure... Indiana Utility Regulatory Commission Cause No. 43501.

Lafferty, R.; Hunger, D.; Ballard, J.; Mahrenholz, G.; Mead, D.; Bandera, D. (2001) Demand Responsiveness in Electricity Markets. Federal Energy Regulatory Commission. Available online at: http://www.naseo.org/committees/energyproduction/documents/demand responsiveness in electricit y markets.pdf

LBNL (2007b) Deemed savings estimates for Legacy Air Conditioning and Water Heating direct load control programs in PJM region. Retrieved June 13, 2011 from 
http://eetd.lbl.gov/ea/EMS/EMS pubs.html

Li, F., Hadley, S., Leiby, P., Oladosu, G., Lee, R., Uria-Martinez, R., Baek, Y. S., et al. (2012). Interim Project Report: Eastern Interconnection Demand Response.

Maters, Bruce R., et al. (2010) In the matter of the application of the Detroit Edison Company for authority to increase its rates, amend its rate schedules and rules governing the distribution and supply of electric energy, and for miscellaneous accounting authority. Michigan Public Service Commission Case No. U-16472 (Paperless e-file).

McIndoo, W. (2008). In the Matter of Idaho Power Company's Application to Accelerate Depreciation of Existing Metering Equipment to be Replaced by Advanced Metering Infrastructure ("AMI") Installation; and to Implement Revised Depreciation Rates for the Company's Electric Pl. Salem, Oregon. Retrieved from http://edocs.puc.state.or.us/efdocs/UAA/ue202uaa11834.pdf

Office of Management and Budget (2003) Circular A-4. Available online at: http://www.whitehouse.gov/omb/circulars_a004_a-4

PBS (2011) Public vs. private power: From FDR to today. Retrieved June 17, 2011 from http://www.pbs.org/wgbh/pages/frontline/shows/blackout/regulation/timeline.html

PECO Energy Company. (2009). Petition of PECO Energy Company for Approval of its Smart Meter Technology and Installation Plan. Harrisburg, Pennsylvania. Retrieved from www.puc.state.pa.us/electric/Act129/Smart_Meter_Technology.aspx

PLMA (2002) Demand response: Design principles for creating customer and market value. Retrieved June 02, 2011 from http://www.peaklma.com/publications.aspx

PLMA (2004) Final results of the EEI/PLMA 2003 demand response benchmarking survey. Retrieved June 02, 2011 from http://www.peaklma.com/publications.aspx

Pollock, Z; Clavenna, S. (2012) Can the Smart Meter and AMI Market Continue its Meteoric Growth?. Podcast: The Smart Grid AMI Market, Q1 2012. Accessed July 2, 2012. Available online at http://www.greentechmedia.com/articles/read/podcast-the-smart-grid-ami-market-q1-20121/

Potts, George W. (2009) Potomac Electric Power Company, Delmarva Power \& Light Company, before the Public Service Commission of Maryland, Direct Testimony of George W. Potts. Public Service Commission of Maryland Case No. 9207.

Roche, Jim (2011) Advanced Metering Infrastructure: The Rural Co-op Perspective. In Electricity Light and Power magazine. Available at http://www.elp.com/elp/en-us/index/display/elp-article-tooltemplate.articles.utility-automation- engineering-td.volume-13.issue-7.features.advanced-meteringinfrastructure-the-rural-co-op- perspective.html

Rumolo, D. J. (2006). Compliance Filings as Required by Decision No. 68112, Docket No's. E-01345A03-0775 and E-01345A-04-0657. Reading. Phoenix, Arizona. Retrieved from http://images.edocket.azcc.gov/docketpdf/0000046608.pdf

Shigekawa, J. T., Reed, B. A., \& Combs, J. S. (2007). Southern California Edison Company's (U 338-E) Application for Approval of Advanced Metering Infrastructure Deployment Activities and Cost Recovery Mechanism. San Francisco, California. Retrieved from 
http://asset.sce.com/microsite/Documents/ESC/A0707XXXSCEAMIPhaseIIIApplication.pdf

Sloneker, K. L. (2008). Direct Testimony of Karen L. Sloneker on Behalf of Columbus Southern Power Company and Ohio Power Company. Columbus, Ohio. Retrieved from https://aepohio.com/global/utilities/lib/docs/info/news/rates/OH/Sloneker testimony 1232011 Final. $\mathrm{pdf}$

Smith, A. M., Hadley, S. W., \& Brown, M. A. (2011). A Model for Estimating Costs of Demand Response Programs: Providing Supplementary Analysis to the Eastern Interconnection Planning Collaborative. Atlanta, Georgia.

Snook, L. R. (2009). March 2009 AMI Plan Biannual ACC Report, Decision No. 68112, Docket No. E01345A-03-0775 and E-01345A-04-0657. Regulation. Phoenix, Arizona. Retrieved from http://images.edocket.azcc.gov/docketpdf/0000094364.pdf

Standish, T.R., et al. (2008). Application of CenterPoint Energy Houston Electric, LLC, for Approval of Deployment Plan and Request for Surcharge for an Advanced Metering System. Public Utility Commission of Texas Docket No. 35639.

Starke, M.: Onar, O.; Devault, B. (2011). Key Residential Building Equipment Technologies for Control and Grid Support-PART I (Residential). ORNL/TM-2011/143.

Thompson, V. L., \& Morton, K. M. (2005). Application of San Diego Gas \& Electric Company (U-902E) for Adoption of an Advanced Metering Infrastructure Deployment Scenario and Associated Cost Recovery and Rate Design. San Francisco, California: California Public Utilities Commission. Retrieved from http://www.smartgridinformation.info/pdf/2092 doc 1.pdf

US Department of Energy. (2006). Benefits of Demand Response in Electricity Markets and Recommendations for Achieving Them. Retrieved from www.smartgrid.gov

U.S. Department of Energy, \& Office of Electricity Delivery and Energy Reliability. (2010). Smart Future Greater Philadelphia. Retrieved April 16, 2012, from www.smartgrid.gov/project/peco smart future greater philadelphia

Vardi, J. and B. Avi-Ithak. 1981. Electric Energy Generation Economics, Reliability, and Rates. MIT Press, Cambridge, MA.

West Penn Power Company. (2009). Pennsylvania Act 129: Smart Meter Technology Procurement and Installation Plan. System. Harrisburg, Pennsylvania. Retrieved from http://www.puc.state.pa.us/pcdocs/1051015.pdf

Wharton, J.B.; Palmer, J. (2011). “PG\&E'S No-Residential Enrollment Forecast”. Retrieved November 1, 2011 from http://www.brattle.com/Publications/ReportsPresentations.asp?PublicationID=1313

Whitehurst, Stacy, et al. (2010) Texas-New Mexico Power Company's Request for Approval of an Advance Metering System (AMS) Deployment and AMS Surcharge. Public Utility Commission of Texas Control Number 38306.

Wisconsin Power and Light Company. (2007). Application of Wisconsin Power and Light Company for a Certificate of Authority to Purchase, Install and Place into Operation an Advanced Metering Infrastructure System in the Entire WPL Natural Gas Service Territory. Madison, Wisconsin. 
Retrieved from http://psc.wi.gov/apps35/ERF_view/viewdoc.aspx?docid=83859 


\section{APPENDIX A. DEMAND RESPONSE LITERATURE REVIEW SUMMARIES}

Report name: Assessment of Achievable Potential form Energy Efficiency and Demand Response Programs in the U.S. (2010-2030)

Institution: EPRI (with collaboration of Global Energy Partners and The Brattle Group)

Date of release: January 2009

\section{Key definitions}

\section{Baseline demand}

AEO 2008 Reference Case forecast for total electricity consumption (adding back the effect of accountedfor energy efficiency programs)

NERC 2007 Peak Demand and Energy Projection Bandwidths extrapolated to 2030

\section{Included DR programs}

Residential sector: direct load control for air conditioning, direct load control for water heating and dynamic pricing programs including time-of-use (TOU), critical-peak pricing (CPP), real-time pricing (RTP) and peak time rebates)

Commercial sector: direct load control management for cooling, lighting and other uses, interruptible demand (e.g., interruptible, demand bidding, emergency, ancillary services) and dynamic pricing programs (TOU, CPP, RTP).

Industrial sector: direct control load management for process, interruptible demand (e.g., interruptible, demand bidding, emergency, ancillary services) and dynamic pricing programs (TOU, CPP, RTP).

Excluded DR programs

Spatial scope

United States

Spatial disaggregation

Census Division

Temporal disaggregation

Annual

Temporal scope

2010-2030

\section{Technological detail}

For the residential and commercial sectors, the study implemented a bottom-up approach for determining electric energy efficiency savings potential

For the industrial sector, the study applied a top-down approach in which the sector forecast is allocated to end uses and regions. The study used a modeling tool (LoadMAPTM, created by Global Energy

Partners) for forecasting energy use, peak demand and energy efficiency and demand response savings, which incorporates a comprehensive technology database that includes the latest findings from EPRI energy efficiency research.

\section{Dynamic pricing representation}

\section{Load curves}

\section{Elasticities}

\section{Main result}

Achievable potential savings by 2030 is $7 \%$ to $9 \%$ of peak demand. The expected savings from DR measures are roughly equal across the three sectors. Direct load control, dynamic pricing and interruptible demand deliver similar levels of savings.

Report name: Demand Response Impact and Value Estimation Model

Institution: Brattle Group

Date of release: 


\section{Key definitions}

\section{Baseline demand}

AEO Annual peak demand forecast without new DR (Note: AEO uses NERC's forecast as its default peak demand forecast)

\section{Included DR programs}

Dynamic pricing without enabling technology

Dynamic pricing with enabling technology

Direct load control

Interruptible tariffs

Capacity bidding, demand bidding and other aggregator offerings to medium and large commercial and industrial customers

\section{Excluded DR programs}

Time of use rates (although there is a table that can be used to implement a TOU rate where the peak period is defined as the five hours preceding the hour of the system peak on all weekdays), back-up generation, permanent load shifting and plug-in hybrid vehicles

\section{Spatial scope}

National

\section{Spatial disaggregation}

State-by-state or 13 NERC subregions

Temporal disaggregation

Annual

Temporal scope

2009-2019

\section{Technological detail}

Bottom-up approach.

It takes into consideration the characteristics of specific regional, state or utility power system (e.g., the existing supply mix, projections of fuel prices, the cost of new capacity, planned capacity additions by technology type)

It incorporates detailed information on current DR program enrollment by customer class (residential, small commercial and industrial (C\&I), medium C\&I and large C\&I and the resulting peak load reductions.

\section{Dynamic pricing representation}

Load curves- Hourly load shapes are constructed aggregating those in 2005's FERC Form 714 database. This information is used to establish the relative shape of hourly loads. The absolute magnitude of these estimates does not matter as they are scaled to the peak and energy demand forecasts.

\section{Main result}

Elasticities- Taken from FERC's National Assessment of Demand Response study

It calculates total potential peak reduction by state under each different program considered and under four different scenarios which reflect different levels of AMI deployment, enabling technology eligibility, dynamic pricing participation rates and non-pricing participation rates.

Report name: Electricity Market Module of the National Energy Modeling System (NEMS), Model Documentation Report

Institution: EIA

Date of release: May 2010

\section{Key definitions}

Smart grid technologies include a wide array of measurement, communications and control equipment 
employed throughout the transmission and distribution system that will enable real-time monitoring of the production, flow and use of power from generator to consumer.

Baseline demand

AEO total electricity consumption by Census division and end use

Included DR programs

It models smart grid to the extent that it was initiated by ARRA

Excluded DR programs

AEO always seeks to represent existing policies but not potential new ones

Spatial scope

United States

Spatial disaggregation

13 NERC and sub-NERC regions

Temporal disaggregation

Annual results although some variables are constructed with finer granularity (e.g., hourly loads)

Temporal scope

2010-2035

Technological detail

Bottom-up estimates of hourly load curves based on individual end uses and user classes, such as is done for some utilities, was viewed as not-yet workable at the national level. "At present, the end-use load shape data readily available for this effort are not of sufficient quality to allow the construction of system load shapes from the ground up"

Dynamic pricing representation

Load curves- the Electricity Load and Demand submodule develops load shape information for individual end-uses (e.g., heating, lighting, AC). There are also system load shapes that vary by region, season and time of day.

Elasticities-

\section{Main result}

Smart grid initiatives included in AEO2010 have three effects: line loss reductions (from $6.9 \%$ in 2008 to $5.3 \%$ in 2025), peak demand reduction (3\% of what would otherwise be in 2035), enhanced price responsiveness (no information on how this effect is implemented/assessed)

Report name: National Assessment of Demand Response

Institution: FERC (with The Brattle Group, Freeman, Sullivan \& Co. and Global Energy Partners)

Date of release: June 2009

Source link: http://www.ferc.gov/industries/electric/indus-act/demand-response/dr-potential/ assessment.asp (accessed on February 9, 2011)

http://www.eei.org/ourissues/electricitydistribution/Documents/appendixH final.pdf (appendix on estimation of price impacts using PRISM model, accessed on February 9, 2011)

\section{Key definitions}

Demand response- Changes in electric usage by end-use customers from their normal consumption patterns in response to changes in the price of electricity over time, or to incentive payments design to induce lower electricity use at times of high wholesale market prices or when system reliability is jeopardized.

Smart grid-Broad concept that includes advanced, grid-friendly appliances that communicate with each other and whose operation can be managed remotely or locally on households through a digital home energy management system.

\section{Baseline demand}


NERC's summer peak demand forecast (version that includes energy efficiency and excludes DR)

\section{Included DR programs}

\Dynamic pricing (two types of dynamic pricing are included: with/without enabling technologies. The enabling technology for residential and small and medium commercial and industrial customers is a programmable communicating thermostat and, for large commercial and industrial customers, is an automated response system)

\section{$\square$ Time of use rates \\ $\square$ Critical peak pricing $\square$ Real-time pricing \\ 冈Direct load control \\ 冈Interruptible tariffs \\ \Capacity bidding, demand bidding and other aggregator offerings \\ Smart grid}

Other excluded programs: back-up generation, permanent load shifting, plug-in hybrid vehicles, distributed energy resources, targeted energy efficiency programs and technology-enabled DR programs with the capability of providing ancillary services in wholesale market.

\section{Technological detail}

Bottom up. It constructs load curves starting from a cross-section of available utility-level data. It uses all available data on participation rates by type of program and type of customer (residential, small commercial and industrial (C\&I), medium C\&I and large C\&I).

\section{DR treatment}

There are three fundamental building blocks for estimating DR potential:

1. An estimate of average energy use during peak periods when DR programs are likely to be used (between 2 and $6 \mathrm{pm}$ on the top 15 system load days in each state) but before demand response impacts take effect

Lack of data on energy use during peak periods is a big challenge. Most utilities might have aggregate hourly load data but not for a representative sample of customers. One of the important contributions of this report is that FERC/Brattle Group/Global Energy Partners used cross section of available hourly load data (from utilities in 21 states) and regression analysis to develop normalized load shapes for five customer segments: residential customers with and without central air conditioning, small non-residential customers (less than $20 \mathrm{~kW})$, medium non-residential customers (20-200 kW) and large non-residential customers (peak demand exceeding $200 \mathrm{~kW}$ ). The explanatory variables used for the regression analysis were (weather, central AC saturation and seasonal, monthly, day-of-week and hourly usage patterns).

2. An estimate of the change in energy use during peak periods resulting from customer participation in DR programs and response to DR price signals and incentives

DR potential for non-price based DR options is based on average values determined through analysis of data from existing programs

DR potential for price-based DR options was determined using the normalized load shapes and estimates of price elasticities (see table D-13 of Appendix D of the report). Peak period prices during high demand days are assumed to be 8 times higher than those in a static rate (5-to-1 for large C\&I customers since most are already under TOU rates). This price ratio is intended to depict the ratio between an average price and a dynamic price that reflects a large portion of the avoided cost of capacity being incorporated into the small number of hours in which peak-period dynamic price signals are into effect. A twoequation CES demand system is used to estimate how electricity demand would change in response to time-varying prices. One equation determines the rate at which consumers substitute off-peak energy use for peak-period energy use and the second equation estimates the overall demand for energy. Price elasticities and impacts estimates from 15 dynamic pricing pilots were synthesized to produce impact estimates for each state using the Pricing Impact Simulation Model (PRISM), originally created by 
Charles River Associates for the California Statewide Pricing Pilot study. One important feature of PRISM is its capability to model nonlinearities in the estimation of usage impacts when price changes extend from minimal to maximal. Differences in impacts across states are driven by differences in central AC saturation rates, climate and the effect of enabling technology.

3. An estimate of the number of customers that participate in DR programs (eligible customers*participation rate)

\section{Spatial scope \\ United States}

7. Spatial disaggregation

State

8. Temporal scope

2010-2019

9. Temporal detail

Annual (but load curves are estimated hourly and the impact of dynamic pricing on peak demand focuses on the period from 2:00 pm to 6:00 pm during the top 15 system load days)

\section{Main results}

The range of total potential reductions in peak demand by 2019 relative to the baseline described above goes from $4 \%$ in the business as usual scenario to $20 \%$ in the full participation scenario (universally deployed AMI, dynamic pricing as default and other programs available to those opting out of dynamic pricing with full participation in all programs where and when it is cost effective to do so).

Largest untapped DR potential by sector is in residential sector.

Largest untapped DR potential by program is in dynamic pricing programs

There are multiple barriers to realizing full DR potential:

Regulatory (general): retail-wholesale disconnect, perception of gaming, lack of real-time info sharing (ISOs and utilities), lack of reliability/predictability in DR (relative to supply-side resources), policy restrictions on demand response, ineffective program design, financial disincentives for utilities (DR programs will reduce their revenues), disagreement on cost-effectiveness analysis, lack of retail competition, market structures oriented toward accommodating supply-side resources.

Economic: inaccurate price signals, lack of sufficient financial incentives to induce participation (it is argued that one way to improve incentives would be for utilities to take out from rates the implied hedging cost they now charge for dealing with price volatility in the context of flat retail rates) Technological: lack of advanced metering infrastructure (only one US utility, PPL, has in place all the infrastructure needed to put all of its customers on default dynamic pricing), lack of cost-effective enabling technologies, concerns about technological obsolescence and cost recovery, lack of interoperability and open standards

Other: lack of customer awareness and education, risk aversion, fear of customer backlash, perceived lack of ability to respond, perceived temporary nature of DR impacts, concern over environmental impacts (if a DR program shifts load from peak to off-peak hours in which coal plants are on the margin, it could result in an increase in emissions).

\section{Links to other studies}

Baseline demand is an input from NERC

Peak demand reduction results for the different scenarios are an input from Brattle's DRIVE model Peak demand reduction in response to dynamic pricing is an input from PRISM model

Report name: 2010 Long-Term Reliability Assessment

Institution: NERC (based on data and information submitted by each of the 8 Regional Entities in May 
$2010^{27}$ )

Date of release: October 2010

Source link: http://www.nerc.com/files/2010_LTRA_v2-.pdf

\section{Key definitions}

Demand response- Changes in electric use by demand-side resources from their normal consumption patterns in response to changes in the price of electricity or to incentive payments designed to induce lower electricity use at times of high wholesale market prices or when system reliability is jeopardized. Response fatigue- A characteristic of demand resources who enroll on a DR program because of the financial incentives. Once the electric supply to their equipment has actually been interrupted a number of times, the inconvenience outweighs the cost savings and they may potentially withdraw from the program.

Demand Response Availability Data System (DADS)- NERC initiative for developing data collection requirements regarding DR and a uniform system to measure delivered DR and to specify statistics that quantify DR performance. DADS Phase I started in 2010 and collects historical DR performance data on a voluntary basis. Phase II will impose mandatory submittal.

\section{Baseline demand}

NERC's peak summer demand forecast (without energy efficiency and without demand response). Supply and demand projections are based on industry forecasts submitted in May 2010. NERC validates them to ensure correctness and consistency.

\section{Included DR programs}

$\triangle$ Dynamic pricing

冈Time of use rates

\Critical peak pricing

冈Real-time pricing

冈irect load control

\Interruptible tariffs

$\square$ Capacity bidding, demand bidding and other aggregator offerings

$\square$ Smart grid

Other included programs: load as capacity resource, ancillary DR which provides spinning and nonspinning reserves as well as regulation, emergency-voluntary DR and system peak response transmission tariff.

Note: NERC includes only existing and planned DR programs in its peak demand forecasts.

\section{Technological detail}

No technological detail is provided here. NERC validates and aggregates DR projections from each of the regional entities.

\section{DR treatment}

Each Regional Entity must discuss in its self-assessment how they represent DR and what are the planning approaches currently used to ensure DR resources perform as expected. Those details are not included in this report.

6. Spatial scope

United States

7. Spatial disaggregation

NERC regions

8. Temporal scope

Annual

Corporation, Southwest Power Pool (SPP), Texas Reliability Entity (TRE), Western Electricity Coordinating Council (WECC). 


\section{Temporal detail}

2009-2019

10. Main results

Expected contributions from DR are 30,000MW in 2010 and 40,000MW in 2030. Most of the increase takes place during the first three years. The plateau effect from 2014 to 2019 represents uncertainty in committing DR beyond what is currently planned and contracted. Not only DR deployment is uncertain but also its long-term responsibility (concept of response fatigue).

Among the benefits of DR is its ability to provide ancillary services and to help integrating renewables. 11. Links to other studies

NERC's peak demand forecast is a reference/baseline for AEO, FERC's DR assessment and EPRI's DR assessment. 



\section{APPENDIX B. STATE-BY-STATE SCENARIO ANALYSIS RESULTS}

Below are results for each of the states in the Eastern Interconnection, similar to the analysis in Chapter 5. The first graph shows the amount of DR potential in MW for each of the four scenarios by type and customer class. The table following provides the values of the bars in the graph. The next graph shows the potential peak demand growth if the full DR potential is available for peak reduction. (Note that in Chapter 7 we show that if DR is limited in the number of hours that it is available, the impact on peak demand is greatly lessened under high DR penetration amounts.)

The last table in each section shows the results of the Monte Carlo simulations and the effect of increasing peak prices on those DR categories that are price-responsive. As the peak prices rise to $5 \mathrm{X}, 10 \mathrm{X}$, and $15 \mathrm{X}$ the average price, the amount of DR available increases. 


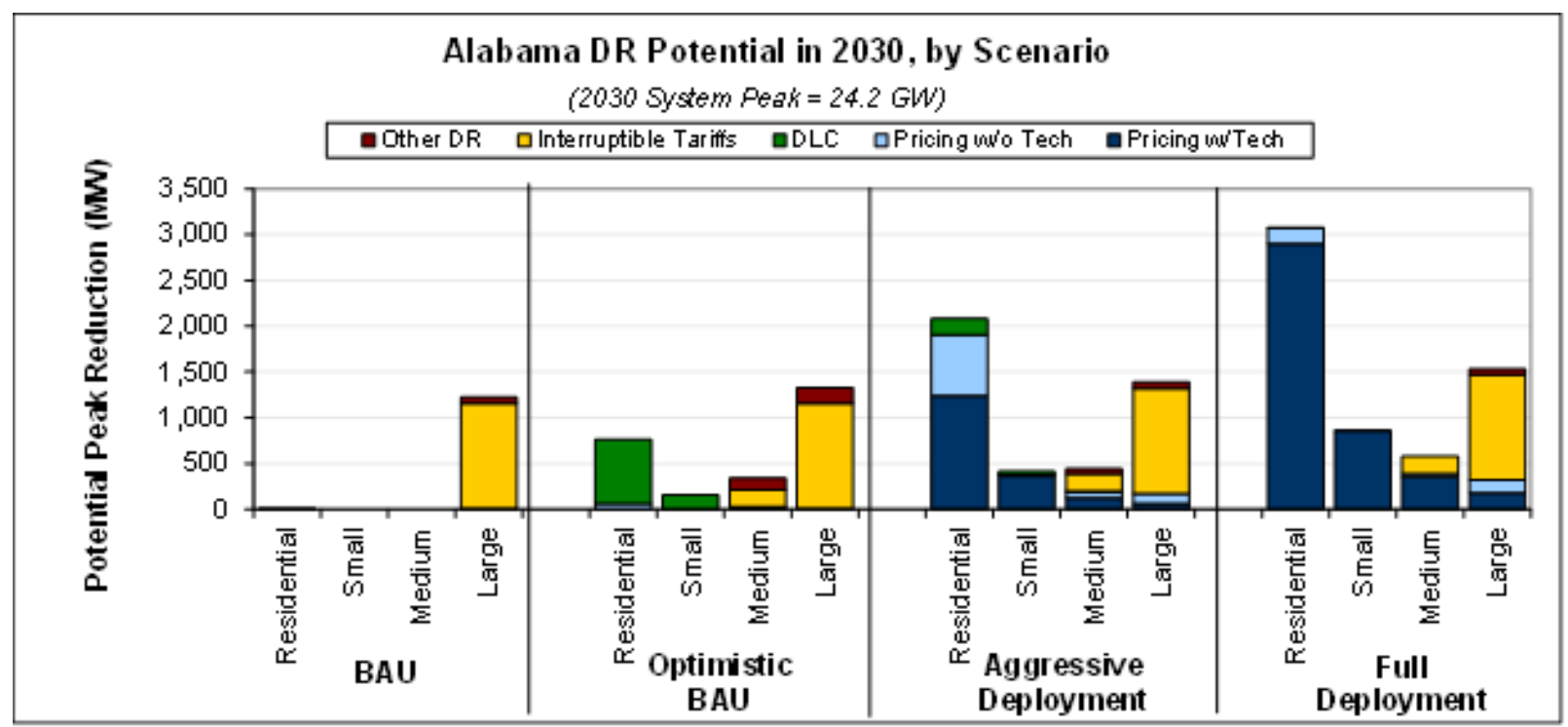

Total Potential Peak Reduction from Demand Response in Alabama, 2030

\begin{tabular}{|c|c|c|c|c|c|c|c|c|c|c|}
\hline & $\begin{array}{l}\text { Residential } \\
\text { (MW) }\end{array}$ & $\begin{array}{l}\text { Residential } \\
\text { ( } \% \text { of } \\
\text { svstem) }\end{array}$ & $\begin{array}{l}\text { Small C\&I } \\
(\mathrm{MW})\end{array}$ & $\begin{array}{l}\text { Small C\&I } \\
\text { (\% of } \\
\text { svstem) }\end{array}$ & $\begin{array}{l}\text { Med. C\&I } \\
(\mathrm{MW})\end{array}$ & $\begin{array}{l}\text { Med C\&I } \\
\text { ( } \% \text { of } \\
\text { svstem) }\end{array}$ & $\begin{array}{l}\text { Large C\&I } \\
(\mathrm{MW})\end{array}$ & $\begin{array}{l}\text { Large C\&I } \\
\text { ( } \% \text { of } \\
\text { svstem) }\end{array}$ & $\begin{array}{l}\text { Total } \\
(\mathrm{MW})\end{array}$ & $\begin{array}{l}\text { Total } \\
\text { ( } \% \text { of } \\
\text { svstem) }\end{array}$ \\
\hline \multicolumn{11}{|l|}{ BAU } \\
\hline Pricing with Technology & 0 & $0.0 \%$ & 0 & $0.0 \%$ & 0 & $0.0 \%$ & 0 & $0.0 \%$ & 0 & $0.0 \%$ \\
\hline Pricing without Technology & 1 & $0.0 \%$ & 0 & $0.0 \%$ & 0 & $0.0 \%$ & 10 & $0.0 \%$ & 11 & $0.1 \%$ \\
\hline Automated/Direct Load Control & 7 & $0.0 \%$ & 0 & $0.0 \%$ & 0 & $0.0 \%$ & 0 & $0.0 \%$ & 7 & $0.0 \%$ \\
\hline Interruptible/Curtailable Tariffs & 0 & $0.0 \%$ & 0 & $0.0 \%$ & 0 & $0.0 \%$ & 1,148 & $5.4 \%$ & 1,148 & $5.4 \%$ \\
\hline Other DR Programs & 0 & $0.0 \%$ & 0 & $0.0 \%$ & 0 & $0.0 \%$ & 62 & $0.3 \%$ & 62 & $0.3 \%$ \\
\hline Total & $\overline{88}$ & $0.0 \%$ & 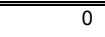 & $0.0 \%$ & 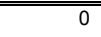 & $0.0 \%$ & $\overline{~ 1,220}$ & $5.8 \%$ & $\begin{array}{l}1,228 \\
\end{array}$ & $\overline{5.8 \%}$ \\
\hline \multicolumn{11}{|l|}{ Optimistic BAU } \\
\hline Pricing with Technology & 0 & $0.0 \%$ & 0 & $0.0 \%$ & 0 & $0.0 \%$ & 0 & $0.0 \%$ & 0 & $0.0 \%$ \\
\hline Pricing without Technology & 62 & $0.3 \%$ & 1 & $0.0 \%$ & 8 & $0.0 \%$ & 10 & $0.0 \%$ & 80 & $0.4 \%$ \\
\hline Automated/Direct Load Control & 700 & $3.3 \%$ & 154 & $0.7 \%$ & 16 & $0.1 \%$ & 0 & $0.0 \%$ & 870 & $4.1 \%$ \\
\hline Interruptible/Curtailable Tariffs & 0 & $0.0 \%$ & 0 & $0.0 \%$ & 187 & $0.9 \%$ & 1,148 & $5.4 \%$ & 1,335 & $6.3 \%$ \\
\hline Other DR Programs & 0 & $0.0 \%$ & 0 & $0.0 \%$ & 128 & $0.6 \%$ & 166 & $0.8 \%$ & 294 & $1.4 \%$ \\
\hline Total & 762 & $3.6 \%$ & 155 & $0.7 \%$ & 339 & $1.6 \%$ & $\overline{1,324}$ & $6.3 \%$ & 2,580 & $12.2 \%$ \\
\hline \multicolumn{11}{|l|}{ Aggressive Deployment } \\
\hline Pricing with Technology & 1,240 & $5.9 \%$ & 365 & $1.7 \%$ & 121 & $0.6 \%$ & 61 & $0.3 \%$ & 1,786 & $8.5 \%$ \\
\hline Pricing without Technology & 662 & $3.1 \%$ & 6 & $0.0 \%$ & 72 & $0.3 \%$ & 111 & $0.5 \%$ & 851 & $4.0 \%$ \\
\hline Automated/Direct Load Control & 181 & $0.9 \%$ & 40 & $0.2 \%$ & 7 & $0.0 \%$ & 0 & $0.0 \%$ & 228 & $1.1 \%$ \\
\hline Interruptible/Curtailable Tariffs & 0 & $0.0 \%$ & 0 & $0.0 \%$ & 187 & $0.9 \%$ & 1,148 & $5.4 \%$ & 1,335 & $6.3 \%$ \\
\hline Other DR Programs & 0 & $0.0 \%$ & 0 & $0.0 \%$ & 53 & $0.3 \%$ & 69 & $0.3 \%$ & 122 & $0.6 \%$ \\
\hline Total & 2,083 & $9.9 \%$ & 411 & $1.9 \%$ & 440 & $2.1 \%$ & 1,388 & $6.6 \%$ & 4,322 & $20.5 \%$ \\
\hline \multicolumn{11}{|l|}{ Full Deployment } \\
\hline Pricing with Technology & 2,900 & $13.7 \%$ & 854 & $4.0 \%$ & 354 & $1.7 \%$ & 178 & $0.8 \%$ & 4,285 & $20.3 \%$ \\
\hline Pricing without Technology & 170 & $0.8 \%$ & 3 & $0.0 \%$ & 35 & $0.2 \%$ & 143 & $0.7 \%$ & 352 & $1.7 \%$ \\
\hline Automated/Direct Load Control & 7 & $0.0 \%$ & 0 & $0.0 \%$ & 0 & $0.0 \%$ & 0 & $0.0 \%$ & 7 & $0.0 \%$ \\
\hline Interruptible/Curtailable Tariffs & 0 & $0.0 \%$ & 0 & $0.0 \%$ & 187 & $0.9 \%$ & 1,148 & $5.4 \%$ & 1,335 & $6.3 \%$ \\
\hline Other DR Programs & 0 & $0.0 \%$ & 0 & $0.0 \%$ & 0 & $0.0 \%$ & 62 & $0.3 \%$ & 62 & $0.3 \%$ \\
\hline 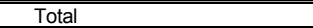 & 3,076 & $\overline{14.6 \%}$ & 857 & 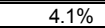 & 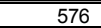 & $2.7 \%$ & $\overline{1,531}$ & $7.3 \%$ & 6,041 & $28.6 \%$ \\
\hline
\end{tabular}




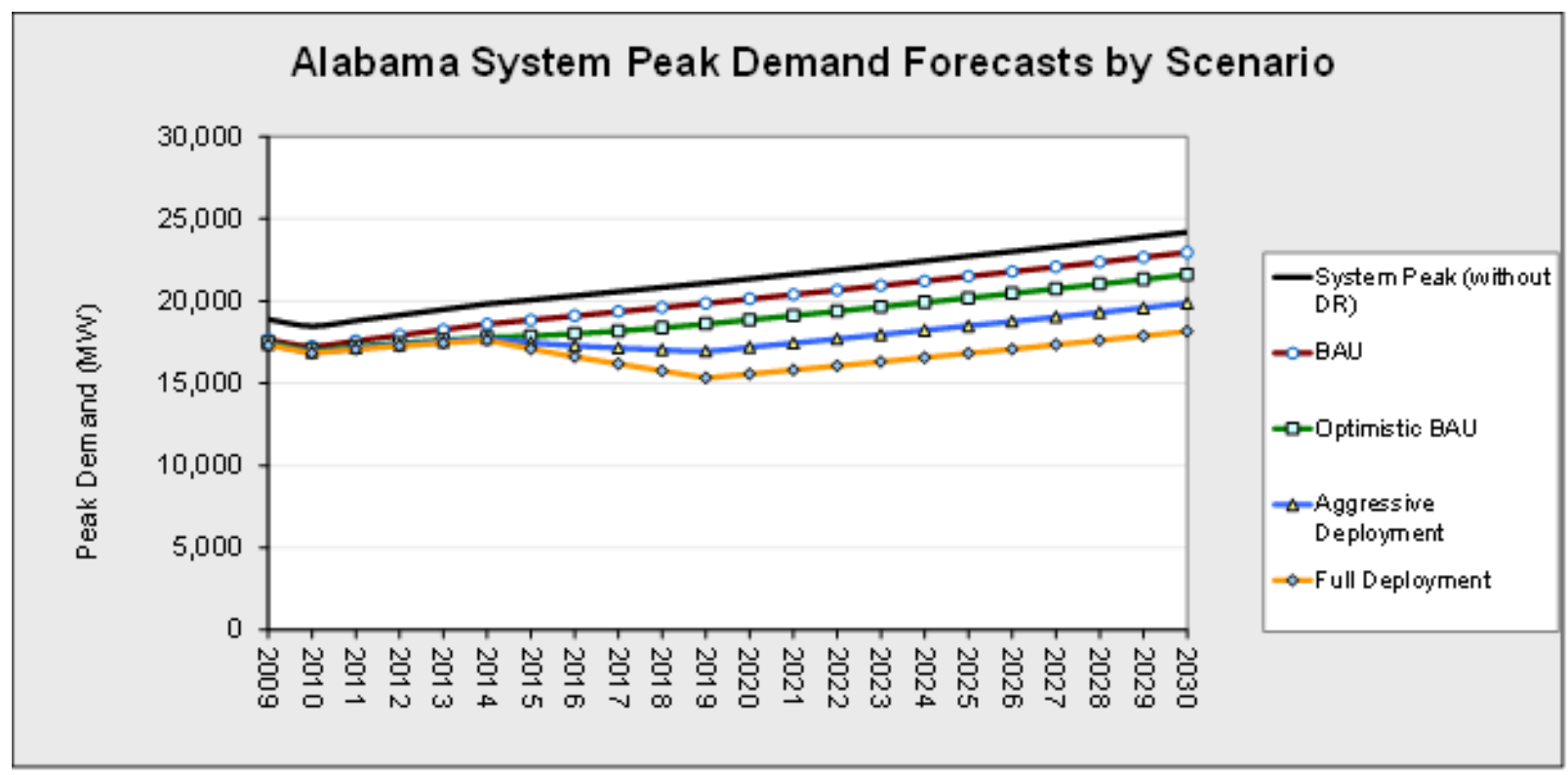

Summary of Monte Carlo Simulation of Potential Peak Load Reduction from Demand Response in Alabama by Scenario, Pricing Program and Price Ratio (MW)

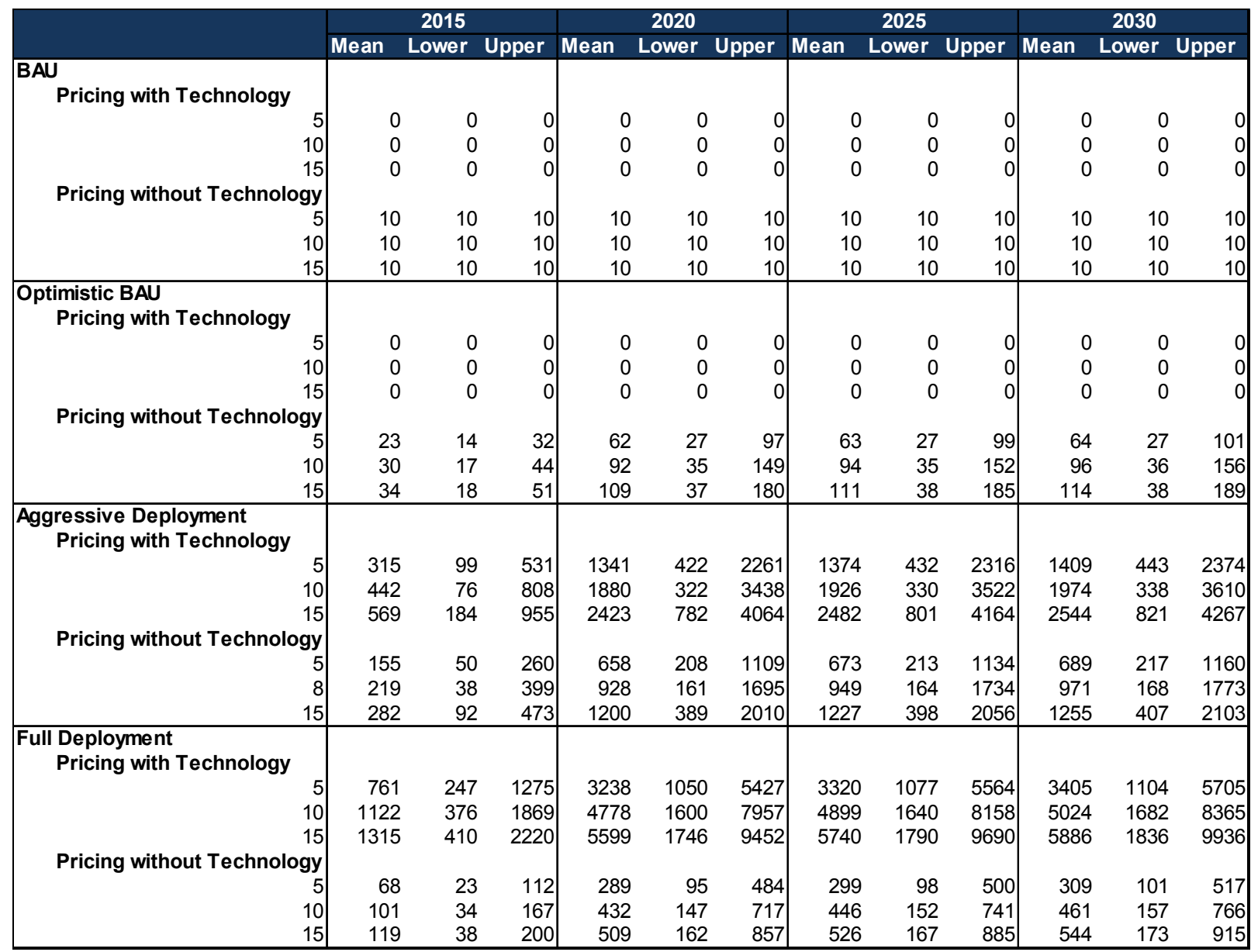




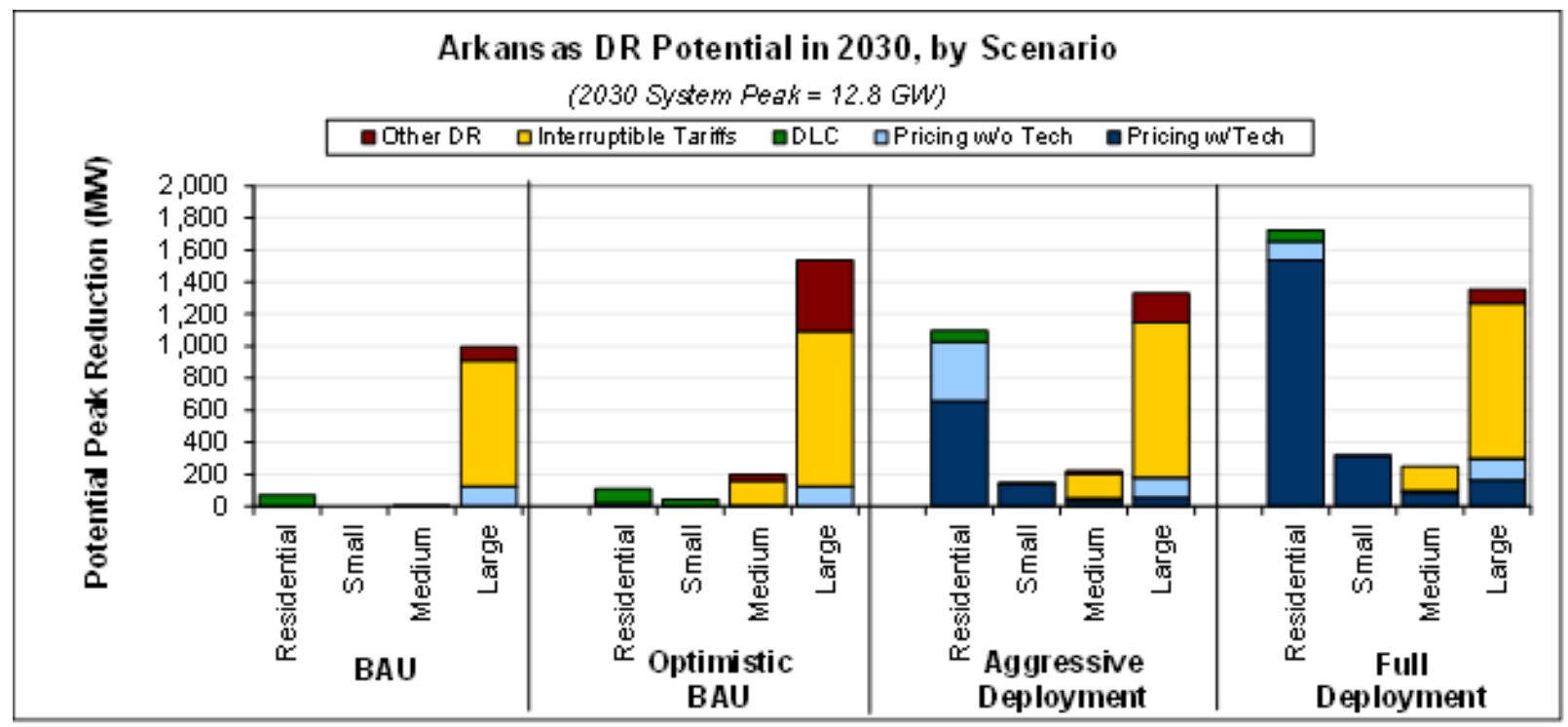

Total Potential Peak Reduction from Demand Response in Arkansas, 2030

\begin{tabular}{|c|c|c|c|c|c|c|c|c|c|c|}
\hline & $\begin{array}{l}\text { Residential } \\
\quad(\mathrm{MW})\end{array}$ & $\begin{array}{l}\text { Residential } \\
\text { ( } \% \text { of } \\
\text { svstem) }\end{array}$ & $\begin{array}{l}\text { Small C\&I } \\
(\mathrm{MW})\end{array}$ & $\begin{array}{c}\text { Small C\&I } \\
\text { (\% of } \\
\text { svstem) }\end{array}$ & $\begin{array}{l}\text { Med. C\&I } \\
(\mathrm{MW})\end{array}$ & $\begin{array}{l}\text { Med C\&I } \\
\text { ( } \% \text { of } \\
\text { svstem) }\end{array}$ & $\begin{array}{l}\text { Large C\&I } \\
\quad(\mathrm{MW})\end{array}$ & $\begin{array}{l}\text { Large C\&I } \\
\text { ( } \% \text { of } \\
\text { svstem) }\end{array}$ & $\begin{array}{l}\text { Total } \\
(\mathrm{MW})\end{array}$ & $\begin{array}{c}\text { Total } \\
\text { ( } \% \text { of } \\
\text { svstem) }\end{array}$ \\
\hline \multicolumn{11}{|l|}{ BAU } \\
\hline Pricing with Technology & 0 & $0.0 \%$ & 0 & $0.0 \%$ & 0 & $0.0 \%$ & 0 & $0.0 \%$ & 0 & $0.0 \%$ \\
\hline Pricing without Technology & 0 & $0.0 \%$ & 0 & $0.0 \%$ & 0 & $0.0 \%$ & 122 & $1.1 \%$ & 122 & $1.1 \%$ \\
\hline Automated/Direct Load Control & 70 & $0.6 \%$ & 0 & $0.0 \%$ & 1 & $0.0 \%$ & 1 & $0.0 \%$ & 73 & $0.6 \%$ \\
\hline Interruptible/Curtailable Tariffs & 0 & $0.0 \%$ & 0 & $0.0 \%$ & 2 & $0.0 \%$ & 786 & $7.0 \%$ & 788 & $7.0 \%$ \\
\hline Other DR Programs & 0 & $0.0 \%$ & 0 & $0.0 \%$ & 0 & $0.0 \%$ & 85 & $0.8 \%$ & 85 & $0.8 \%$ \\
\hline Total & 70 & $0.6 \%$ & 0 & $0.0 \%$ & 3 & $0.0 \%$ & 994 & $8.9 \%$ & $\begin{array}{l}1,067 \\
\end{array}$ & $9.5 \%$ \\
\hline \multicolumn{11}{|l|}{ Optimistic BAU } \\
\hline Pricing with Technology & 0 & $0.0 \%$ & 0 & $0.0 \%$ & 0 & $0.0 \%$ & 0 & $0.0 \%$ & 0 & $0.0 \%$ \\
\hline Pricing without Technology & 20 & $0.2 \%$ & 0 & $0.0 \%$ & 1 & $0.0 \%$ & 122 & $1.1 \%$ & 143 & $1.3 \%$ \\
\hline Automated/Direct Load Control & 86 & $0.8 \%$ & 42 & $0.4 \%$ & 4 & $0.0 \%$ & 1 & $0.0 \%$ & 133 & $1.2 \%$ \\
\hline Interruptible/Curtailable Tariffs & 0 & $0.0 \%$ & 0 & $0.0 \%$ & 154 & $1.4 \%$ & 970 & $8.7 \%$ & 1,123 & $10.0 \%$ \\
\hline Other DR Programs & 0 & $0.0 \%$ & 0 & $0.0 \%$ & 40 & $0.4 \%$ & 443 & $4.0 \%$ & 483 & $4.3 \%$ \\
\hline Total & 106 & $1.0 \%$ & 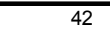 & $0.4 \%$ & 199 & $1.8 \%$ & $\begin{array}{l}1,535 \\
\end{array}$ & $\overline{13.7 \%}$ & $\begin{array}{l}1,882 \\
\end{array}$ & $16.8 \%$ \\
\hline \multicolumn{11}{|l|}{ Aggressive Deployment } \\
\hline Pricing with Technology & 656 & $5.9 \%$ & 135 & $1.2 \%$ & 30 & $0.3 \%$ & 56 & $0.5 \%$ & 877 & $7.8 \%$ \\
\hline Pricing without Technology & 372 & $3.3 \%$ & 2 & $0.0 \%$ & 18 & $0.2 \%$ & 122 & $1.1 \%$ & 514 & $4.6 \%$ \\
\hline Automated/Direct Load Control & 70 & $0.6 \%$ & 11 & $0.1 \%$ & 2 & $0.0 \%$ & 1 & $0.0 \%$ & 84 & $0.8 \%$ \\
\hline Interruptible/Curtailable Tariffs & 0 & $0.0 \%$ & 0 & $0.0 \%$ & 154 & $1.4 \%$ & 970 & $8.7 \%$ & 1,123 & $10.0 \%$ \\
\hline Other DR Programs & 0 & $0.0 \%$ & 0 & $0.0 \%$ & 16 & $0.1 \%$ & 181 & $1.6 \%$ & 197 & $1.8 \%$ \\
\hline Total & 1,098 & $9.8 \%$ & 148 & $1.3 \%$ & 220 & $2.0 \%$ & 1,329 & $11.9 \%$ & 2,795 & $25.0 \%$ \\
\hline \multicolumn{11}{|l|}{ Full Deployment } \\
\hline Pricing with Technology & 1,534 & $13.7 \%$ & 317 & $2.8 \%$ & 87 & $0.8 \%$ & 164 & $1.5 \%$ & 2,102 & $18.8 \%$ \\
\hline Pricing without Technology & 119 & $1.1 \%$ & 1 & $0.0 \%$ & 9 & $0.1 \%$ & 133 & $1.2 \%$ & 261 & $2.3 \%$ \\
\hline Automated/Direct Load Control & 70 & $0.6 \%$ & 0 & $0.0 \%$ & 1 & $0.0 \%$ & 1 & $0.0 \%$ & 73 & $0.6 \%$ \\
\hline Interruptible/Curtailable Tariffs & 0 & $0.0 \%$ & 0 & $0.0 \%$ & 154 & $1.4 \%$ & 970 & $8.7 \%$ & 1,123 & $10.0 \%$ \\
\hline Other DR Programs & 0 & $0.0 \%$ & 0 & $0.0 \%$ & 0 & $0.0 \%$ & 85 & $0.8 \%$ & 85 & $0.8 \%$ \\
\hline Total & 1,723 & $15.4 \%$ & 318 & $2.8 \%$ & 251 & $2.2 \%$ & 1,353 & $12.1 \%$ & 3,645 & $32.6 \%$ \\
\hline
\end{tabular}




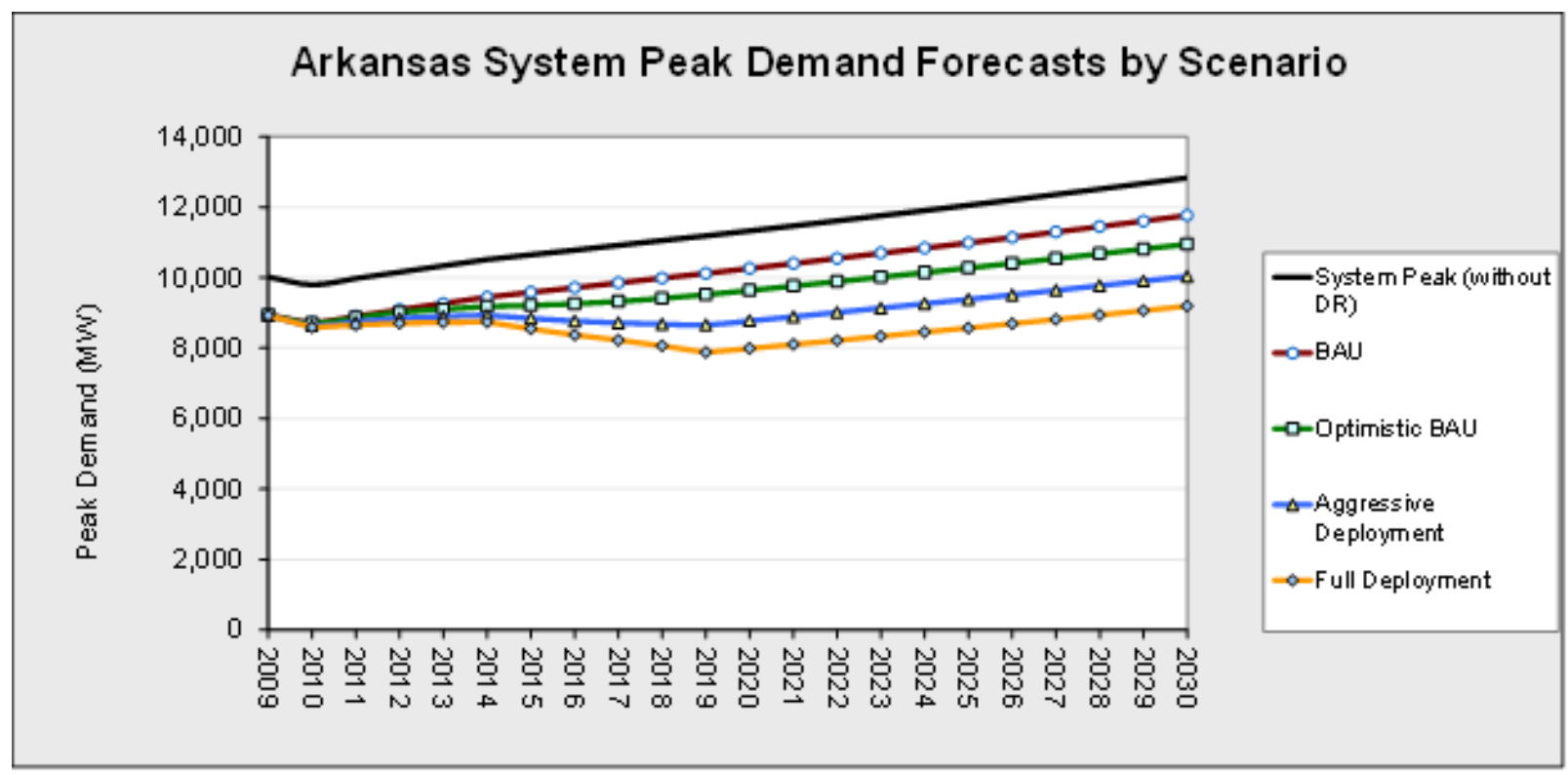

Summary of Monte Carlo Simulation of Potential Peak Load Reduction from Demand Response in Arkansas by Scenario, Pricing Program and Price Ratio (MW)

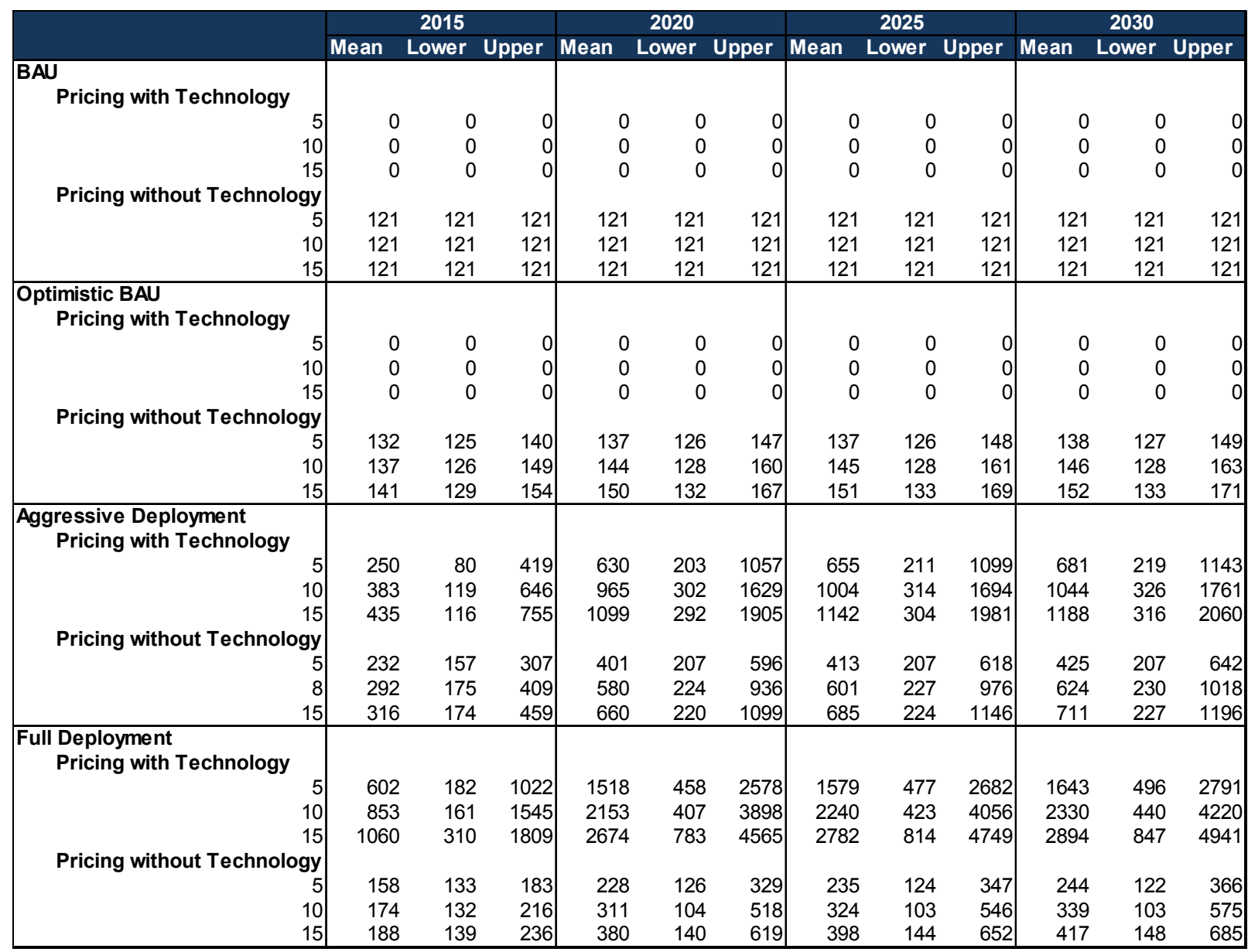




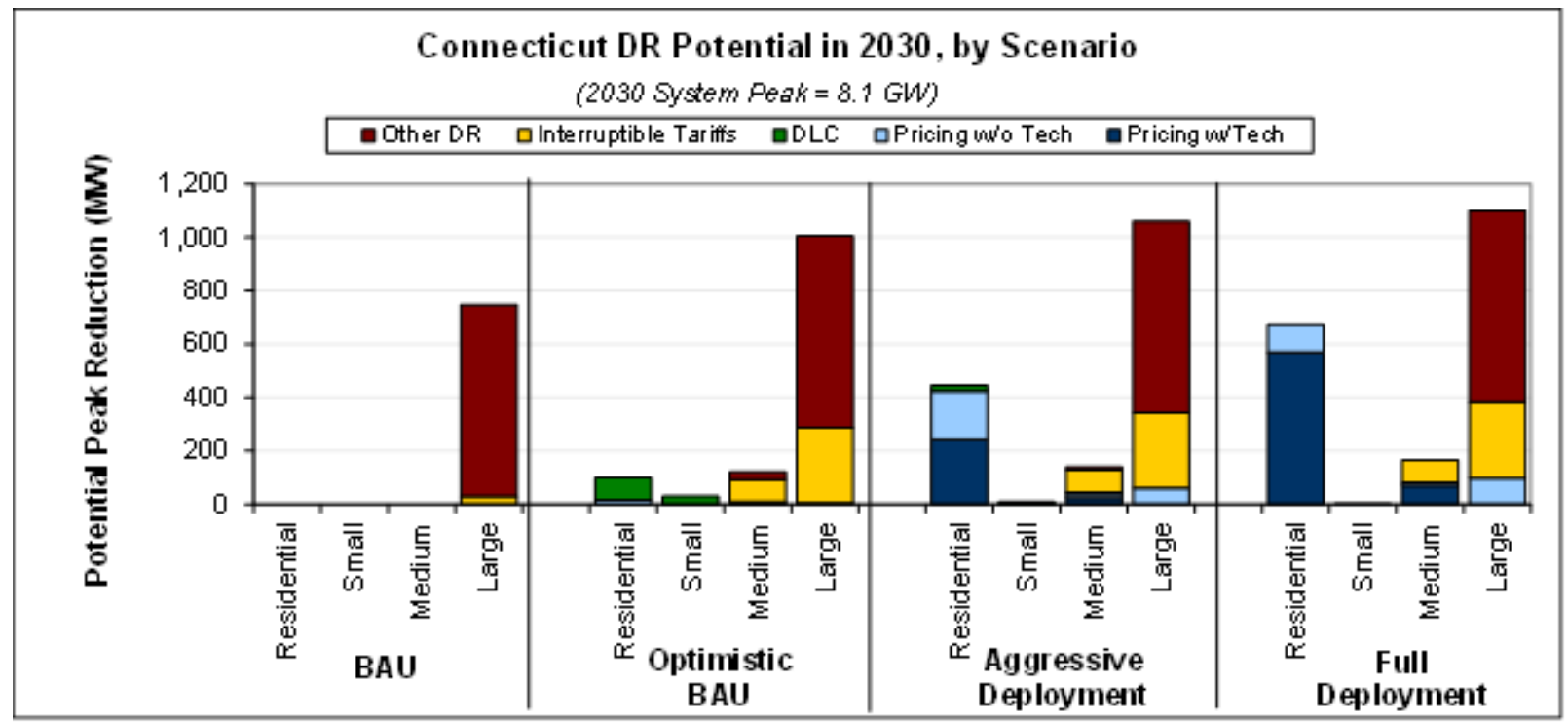

Total Potential Peak Reduction from Demand Response in Connecticut, 2030

\begin{tabular}{|c|c|c|c|c|c|c|c|c|c|c|}
\hline & $\begin{array}{l}\text { Residential } \\
\text { (MW) }\end{array}$ & $\begin{array}{l}\text { Residential } \\
\text { (\% of } \\
\text { svstem) }\end{array}$ & $\begin{array}{l}\text { Small C\&I } \\
(\mathrm{MW})\end{array}$ & $\begin{array}{c}\text { Small C\&I } \\
\text { (\% of } \\
\text { svstem) }\end{array}$ & $\begin{array}{l}\text { Med. C\&I } \\
(\mathrm{MW})\end{array}$ & $\begin{array}{c}\text { Med C\&I } \\
\text { ( } \% \text { of } \\
\text { svstem) }\end{array}$ & $\begin{array}{l}\text { Large C\&I } \\
\quad(\mathrm{MW})\end{array}$ & $\begin{array}{l}\text { Large C\&I } \\
\text { (\% of } \\
\text { svstem) }\end{array}$ & $\begin{array}{l}\text { Total } \\
\text { (MW) }\end{array}$ & $\begin{array}{c}\text { Total } \\
\text { (\% of } \\
\text { svstem) }\end{array}$ \\
\hline \multicolumn{11}{|l|}{ BAU } \\
\hline Pricing with Technology & 0 & $0.0 \%$ & 0 & $0.0 \%$ & 0 & $0.0 \%$ & 0 & $0.0 \%$ & 0 & $0.0 \%$ \\
\hline Pricing without Technology & 0 & $0.0 \%$ & 0 & $0.0 \%$ & 0 & $0.0 \%$ & 0 & $0.0 \%$ & 0 & $0.0 \%$ \\
\hline Automated/Direct Load Control & 0 & $0.0 \%$ & 0 & $0.0 \%$ & 0 & $0.0 \%$ & 0 & $0.0 \%$ & 0 & $0.0 \%$ \\
\hline Interruptible/Curtailable Tariffs & 0 & $0.0 \%$ & 0 & $0.0 \%$ & 0 & $0.0 \%$ & 29 & $0.4 \%$ & 29 & $0.4 \%$ \\
\hline Other DR Programs & 0 & $0.0 \%$ & 0 & $0.0 \%$ & 0 & $0.0 \%$ & 718 & $10.2 \%$ & 718 & $10.2 \%$ \\
\hline Total & 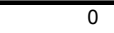 & $0.0 \%$ & 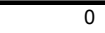 & $0.0 \%$ & 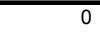 & $0.0 \%$ & 747 & $10.6 \%$ & 747 & $10.6 \%$ \\
\hline \multicolumn{11}{|l|}{ Optimistic BAU } \\
\hline Pricing with Technology & 0 & $0.0 \%$ & 0 & $0.0 \%$ & 0 & $0.0 \%$ & 0 & $0.0 \%$ & 0 & $0.0 \%$ \\
\hline Pricing without Technology & 16 & $0.2 \%$ & 0 & $0.0 \%$ & 2 & $0.0 \%$ & 4 & $0.1 \%$ & 22 & $0.3 \%$ \\
\hline Automated/Direct Load Control & 84 & $1.2 \%$ & 29 & $0.4 \%$ & 6 & $0.1 \%$ & 0 & $0.0 \%$ & 120 & $1.7 \%$ \\
\hline Interruptible/Curtailable Tariffs & 0 & $0.0 \%$ & 0 & $0.0 \%$ & 85 & $1.2 \%$ & 283 & $4.0 \%$ & 368 & $5.2 \%$ \\
\hline Other DR Programs & 0 & $0.0 \%$ & 0 & $0.0 \%$ & 28 & $0.4 \%$ & 718 & $10.2 \%$ & 745 & $10.6 \%$ \\
\hline Total & 100 & $1.4 \%$ & 29 & $0.4 \%$ & 122 & $1.7 \%$ & 1,004 & $\overline{14.2 \%}$ & 1 & $17.8 \%$ \\
\hline \multicolumn{11}{|l|}{ Aggressive Deployment } \\
\hline Pricing with Technology & 243 & $3.4 \%$ & 0 & $0.0 \%$ & 24 & $0.3 \%$ & 0 & $0.0 \%$ & 267 & $3.8 \%$ \\
\hline Pricing without Technology & 181 & $2.6 \%$ & 1 & $0.0 \%$ & 17 & $0.2 \%$ & 60 & $0.8 \%$ & 258 & $3.7 \%$ \\
\hline Automated/Direct Load Control & 22 & $0.3 \%$ & 8 & $0.1 \%$ & 3 & $0.0 \%$ & 0 & $0.0 \%$ & 32 & $0.5 \%$ \\
\hline Interruptible/Curtailable Tariffs & 0 & $0.0 \%$ & 0 & $0.0 \%$ & 85 & $1.2 \%$ & 283 & $4.0 \%$ & 368 & $5.2 \%$ \\
\hline Other DR Programs & 0 & $0.0 \%$ & 0 & $0.0 \%$ & 12 & $0.2 \%$ & 718 & $10.2 \%$ & 729 & $10.3 \%$ \\
\hline Total & 446 & $6.3 \%$ & 9 & $0.1 \%$ & 140 & $2.0 \%$ & 1,060 & $15.0 \%$ & 1,654 & $23.4 \%$ \\
\hline \multicolumn{11}{|l|}{ Full Deployment } \\
\hline Pricing with Technology & 569 & $8.1 \%$ & 0 & $0.0 \%$ & 70 & $1.0 \%$ & 0 & $0.0 \%$ & 639 & $9.1 \%$ \\
\hline Pricing without Technology & 101 & $1.4 \%$ & 1 & $0.0 \%$ & 11 & $0.2 \%$ & 99 & $1.4 \%$ & 213 & $3.0 \%$ \\
\hline Automated/Direct Load Control & 0 & $0.0 \%$ & 0 & $0.0 \%$ & 0 & $0.0 \%$ & 0 & $0.0 \%$ & 0 & $0.0 \%$ \\
\hline Interruptible/Curtailable Tariffs & 0 & $0.0 \%$ & 0 & $0.0 \%$ & 85 & $1.2 \%$ & 283 & $4.0 \%$ & 368 & $5.2 \%$ \\
\hline Other DR Programs & 0 & $0.0 \%$ & 0 & $0.0 \%$ & 0 & $0.0 \%$ & 718 & $10.2 \%$ & 718 & $10.2 \%$ \\
\hline Total & (670 & (9.5\% & 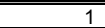 & $0.0 \%$ & 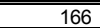 & $2.4 \%$ & 1,100 & $\begin{array}{l}15.6 \% \\
\end{array}$ & 1,937 & $27.5 \%$ \\
\hline
\end{tabular}




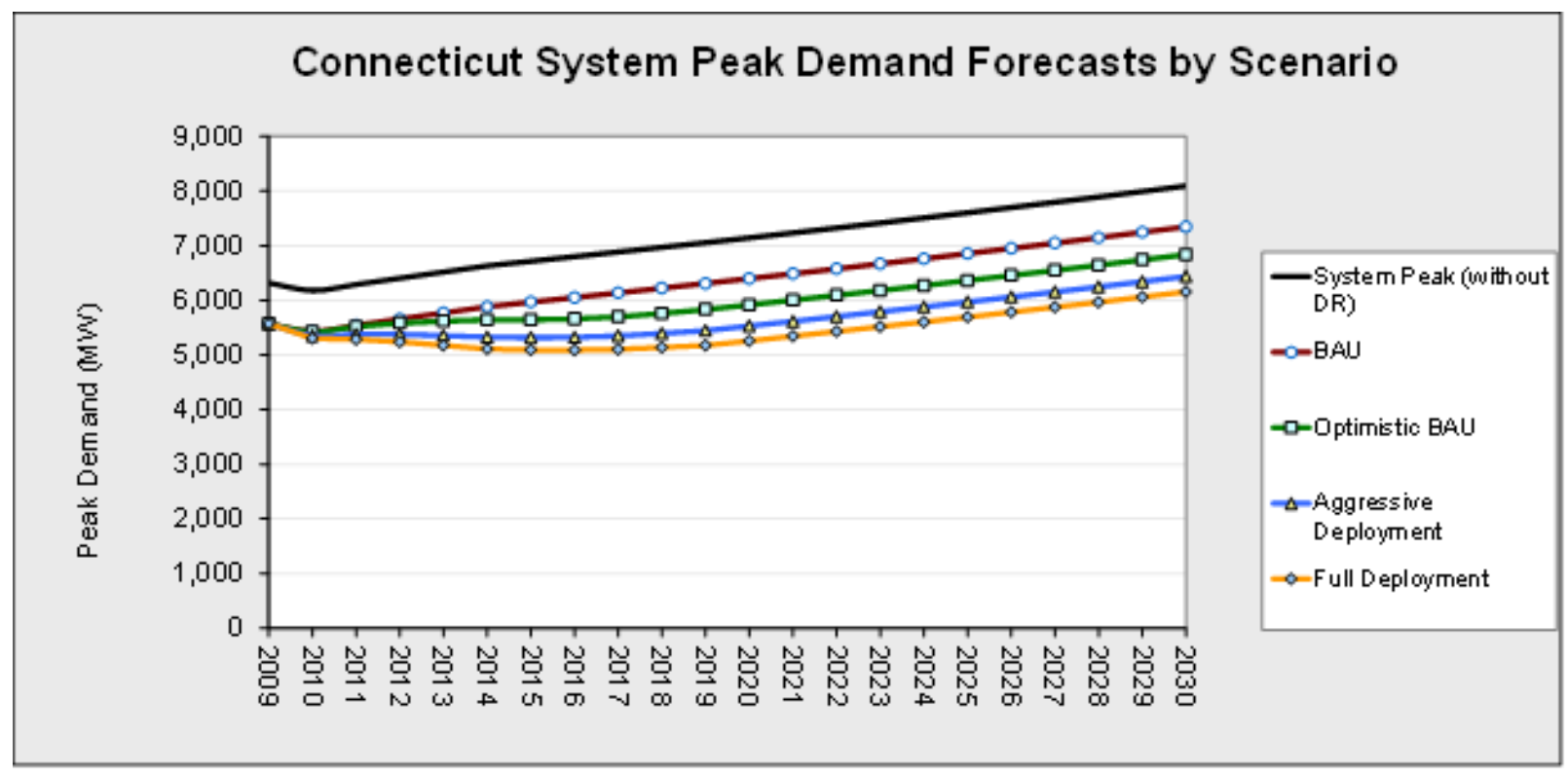

Summary of Monte Carlo Simulation of Potential Peak Load Reduction from Demand Response in Connecticut by Scenario, Pricing Program and Price Ratio (MW)

\begin{tabular}{|c|c|c|c|c|c|c|c|c|c|c|c|c|}
\hline & \multicolumn{3}{|c|}{2015} & \multicolumn{3}{|c|}{2020} & \multicolumn{3}{|c|}{2025} & \multicolumn{3}{|c|}{2030} \\
\hline & Mean & Lower & Upper & Mean & Lower & Upper & Mean & Lower & Upper & \multicolumn{3}{|c|}{ Mean Lower Upper } \\
\hline \multirow{2}{*}{\multicolumn{13}{|c|}{${ }_{\text {Prici }}^{\text {BAU }}$}} \\
\hline & & & & & & & & & & & & \\
\hline 5 & 0 & 0 & 0 & 0 & 0 & 0 & 0 & 0 & 0 & 0 & 0 & \\
\hline 10 & 0 & 0 & 0 & 0 & 0 & 0 & 0 & 0 & 0 & 0 & 0 & \\
\hline 15 & 0 & 0 & 0 & 0 & 0 & 0 & 0 & 0 & 0 & 0 & 0 & \\
\hline \multicolumn{13}{|l|}{ Pricing without Technology } \\
\hline 5 & 0 & 0 & 0 & 0 & 0 & 0 & 0 & 0 & 0 & 0 & 0 & \\
\hline 10 & 0 & 0 & 0 & 0 & 0 & 0 & 0 & 0 & 0 & 0 & 0 & \\
\hline 15 & 0 & 0 & 0 & 0 & 0 & 0 & 0 & 0 & 0 & 0 & 0 & \\
\hline \multicolumn{13}{|l|}{$\begin{array}{l}\text { Optimistic BAU } \\
\quad \text { Pricing with Technology }\end{array}$} \\
\hline Pricing with l ecnnology & 0 & 0 & 0 & 0 & 0 & 0 & 0 & 0 & 0 & 0 & 0 & \\
\hline 10 & 0 & 0 & 0 & 0 & 0 & 0 & 0 & 0 & 0 & 0 & 0 & \\
\hline 15 & 0 & 0 & 0 & 0 & 0 & 0 & 0 & 0 & 0 & 0 & 0 & \\
\hline \multicolumn{13}{|l|}{ Pricing without Technology } \\
\hline 5 & 17 & 5 & 29 & 17 & 5 & 29 & 17 & 6 & 29 & 18 & 6 & \\
\hline 10 & 26 & 10 & 42 & 26 & 10 & 43 & 27 & 10 & 43 & 27 & 10 & \\
\hline 15 & 30 & 9 & 51 & 30 & 9 & 51 & 31 & 10 & 52 & 31 & 10 & 5 \\
\hline \multicolumn{13}{|l|}{\begin{tabular}{|c|} 
Aggressive Deployment \\
Pricing with Technology
\end{tabular}} \\
\hline 5 & 158 & 49 & 268 & 201 & 62 & 340 & 204 & 63 & 346 & 208 & 64 & \\
\hline 10 & 233 & 89 & 377 & 296 & 113 & 479 & 301 & 115 & 487 & 306 & 117 & \\
\hline 15 & 283 & 86 & 480 & 359 & 110 & 609 & 365 & 111 & 619 & 372 & 113 & 63 \\
\hline \multicolumn{13}{|l|}{ Pricing without Technology } \\
\hline 5 & 163 & 51 & 276 & 206 & 64 & 348 & 210 & 65 & 355 & 215 & 67 & 36 \\
\hline 8 & 242 & 93 & 391 & 305 & 117 & 493 & 311 & 120 & 503 & 318 & 122 & 51 \\
\hline 15 & 295 & 91 & 499 & 372 & 115 & 629 & 380 & 117 & 642 & 387 & 120 & 65 \\
\hline \multicolumn{13}{|l|}{$\begin{array}{l}\text { Full Deployment } \\
\text { Pricing with Technology }\end{array}$} \\
\hline 5 & 362 & 99 & 624 & 459 & 126 & 792 & 467 & 128 & 806 & 475 & 130 & 819 \\
\hline 10 & 559 & 166 & 952 & 709 & 211 & 1208 & 721 & 214 & 1228 & 734 & 218 & 1249 \\
\hline & 618 & 129 & 1107 & 784 & 164 & 1404 & 797 & 166 & 1428 & 811 & 169 & 145 \\
\hline \multicolumn{13}{|l|}{ Pricing without Technology } \\
\hline 5 & 138 & 38 & 237 & 172 & 48 & 297 & 177 & 49 & 304 & 181 & 50 & 311 \\
\hline 10 & 214 & 65 & 364 & 269 & 81 & 456 & 275 & 83 & 467 & 282 & 85 & $47 \varepsilon$ \\
\hline 15 & 238 & 51 & 425 & 299 & 64 & 533 & 306 & 66 & 545 & 313 & 67 & 558 \\
\hline
\end{tabular}




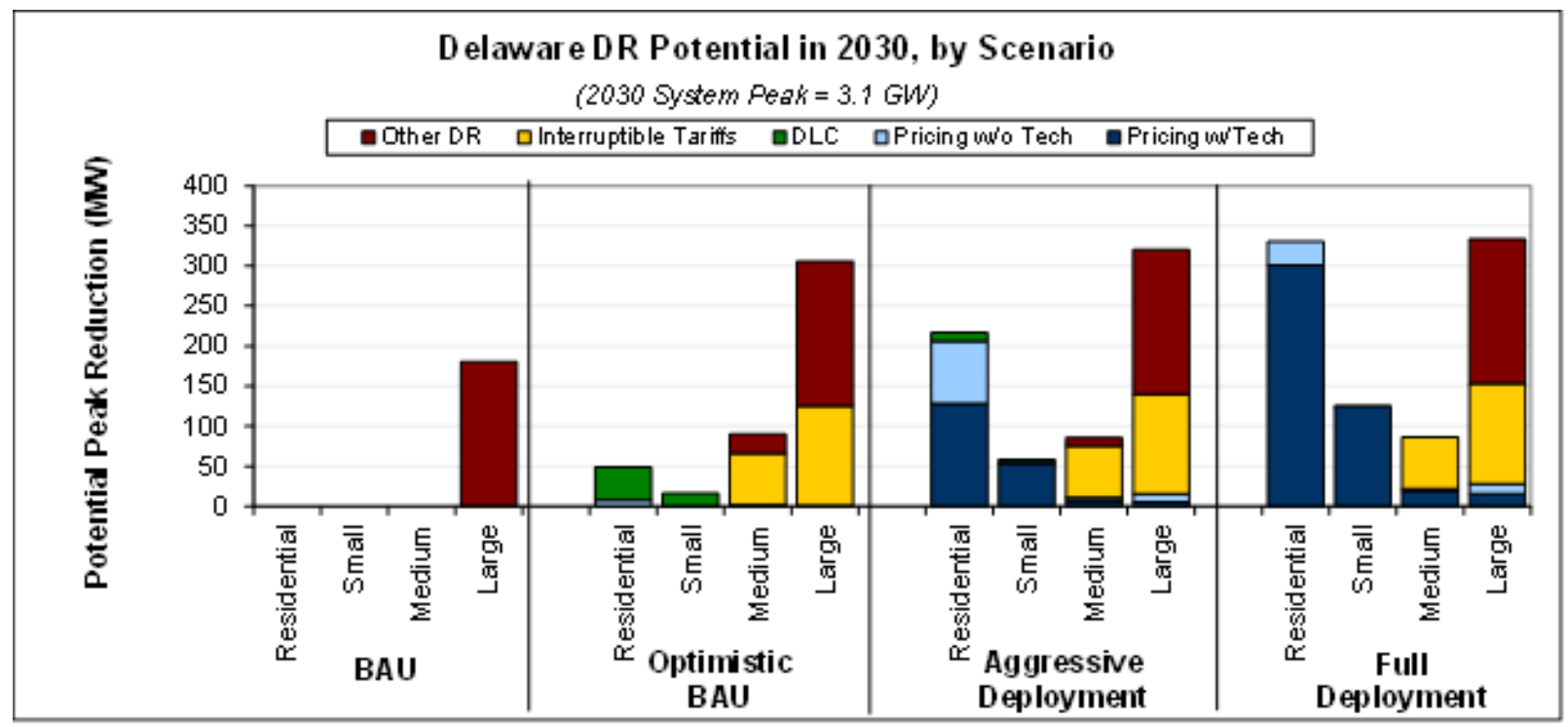

Total Potential Peak Reduction from Demand Response in Delaware, 2030

\begin{tabular}{|c|c|c|c|c|c|c|c|c|c|c|}
\hline & $\begin{array}{l}\text { Residential } \\
\text { (MW) }\end{array}$ & $\begin{array}{l}\text { Residential } \\
\text { ( } \% \text { of } \\
\text { svstem) }\end{array}$ & $\begin{array}{c}\text { Small C\&I } \\
(\mathrm{MW})\end{array}$ & $\begin{array}{l}\text { Small C\&I } \\
\text { (\% of } \\
\text { svstem) }\end{array}$ & $\begin{array}{l}\text { Med. C\&I } \\
(\mathrm{MW})\end{array}$ & $\begin{array}{l}\text { Med C\&I } \\
\text { ( } \% \text { of } \\
\text { svstem) }\end{array}$ & $\begin{array}{l}\text { Large C\&I } \\
(\mathrm{MW})\end{array}$ & $\begin{array}{l}\text { Large C\&I } \\
\text { (\% of } \\
\text { svstem) }\end{array}$ & $\begin{array}{l}\text { Total } \\
\text { (MW) }\end{array}$ & $\begin{array}{c}\text { Total } \\
\text { ( } \% \text { of } \\
\text { svstem) }\end{array}$ \\
\hline \multicolumn{11}{|l|}{ BAU } \\
\hline Pricing with Technology & 0 & $0.0 \%$ & 0 & $0.0 \%$ & 0 & $0.0 \%$ & 0 & $0.0 \%$ & 0 & $0.0 \%$ \\
\hline Pricing without Technology & 0 & $0.0 \%$ & 0 & $0.0 \%$ & 0 & $0.0 \%$ & 0 & $0.0 \%$ & 0 & $0.0 \%$ \\
\hline Automated/Direct Load Control & 0 & $0.0 \%$ & 0 & $0.0 \%$ & 0 & $0.0 \%$ & 0 & $0.0 \%$ & 0 & $0.0 \%$ \\
\hline Interruptible/Curtailable Tariffs & 0 & $0.0 \%$ & 0 & $0.0 \%$ & 0 & $0.0 \%$ & 0 & $0.0 \%$ & 0 & $0.0 \%$ \\
\hline Other DR Programs & 0 & $0.0 \%$ & 0 & $0.0 \%$ & 0 & $0.0 \%$ & 180 & $6.7 \%$ & 180 & $6.7 \%$ \\
\hline Total & 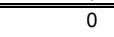 & $0.0 \%$ & 0 & $0.0 \%$ & 0 & $0.0 \%$ & 180 & $6.7 \%$ & 180 & $6.7 \%$ \\
\hline \multicolumn{11}{|l|}{ Optimistic BAU } \\
\hline Pricing with Technology & 0 & $0.0 \%$ & 0 & $0.0 \%$ & 0 & $0.0 \%$ & 0 & $0.0 \%$ & 0 & $0.0 \%$ \\
\hline Pricing without Technology & 8 & $0.3 \%$ & 0 & $0.0 \%$ & 1 & $0.0 \%$ & 1 & $0.0 \%$ & 9 & $0.3 \%$ \\
\hline Automated/Direct Load Control & 41 & $1.5 \%$ & 16 & $0.6 \%$ & 1 & $0.0 \%$ & 0 & $0.0 \%$ & 58 & $2.1 \%$ \\
\hline Interruptible/Curtailable Tariffs & 0 & $0.0 \%$ & 0 & $0.0 \%$ & 65 & $2.4 \%$ & 125 & $4.6 \%$ & 189 & $7.0 \%$ \\
\hline Other DR Programs & 0 & $0.0 \%$ & 0 & $0.0 \%$ & 24 & $0.9 \%$ & 180 & $6.7 \%$ & 204 & $7.6 \%$ \\
\hline Total & 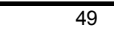 & $1.8 \%$ & 16 & $0.6 \%$ & $\overline{90}$ & $3.3 \%$ & 306 & $\overline{111.3 \%}$ & 460 & $17.1 \%$ \\
\hline \multicolumn{11}{|l|}{ Aggressive Deployment } \\
\hline Pricing with Technology & 129 & $4.8 \%$ & 53 & $2.0 \%$ & 7 & $0.2 \%$ & 5 & $0.2 \%$ & 194 & $7.2 \%$ \\
\hline Pricing without Technology & 77 & $2.9 \%$ & 1 & $0.0 \%$ & 4 & $0.1 \%$ & 10 & $0.4 \%$ & 92 & $3.4 \%$ \\
\hline Automated/Direct Load Control & 11 & $0.4 \%$ & 4 & $0.2 \%$ & 0 & $0.0 \%$ & 0 & $0.0 \%$ & 15 & $0.6 \%$ \\
\hline Interruptible/Curtailable Tariffs & 0 & $0.0 \%$ & 0 & $0.0 \%$ & 65 & $2.4 \%$ & 125 & $4.6 \%$ & 189 & $7.0 \%$ \\
\hline Other DR Programs & 0 & $0.0 \%$ & 0 & $0.0 \%$ & 10 & $0.4 \%$ & 180 & $6.7 \%$ & 190 & $7.1 \%$ \\
\hline Total & 217 & $8.0 \%$ & 58 & $2.2 \%$ & 86 & $3.2 \%$ & 320 & $11.9 \%$ & 681 & $25.3 \%$ \\
\hline \multicolumn{11}{|l|}{ Full Deployment } \\
\hline Pricing with Technology & 301 & $11.2 \%$ & 125 & $4.6 \%$ & 19 & $0.7 \%$ & 16 & $0.6 \%$ & 461 & $17.1 \%$ \\
\hline Pricing without Technology & 29 & $1.1 \%$ & 1 & $0.0 \%$ & 2 & $0.1 \%$ & 13 & $0.5 \%$ & 44 & $1.6 \%$ \\
\hline Automated/Direct Load Control & 0 & $0.0 \%$ & 0 & $0.0 \%$ & 0 & $0.0 \%$ & 0 & $0.0 \%$ & 0 & $0.0 \%$ \\
\hline Interruptible/Curtailable Tariffs & 0 & $0.0 \%$ & 0 & $0.0 \%$ & 65 & $2.4 \%$ & 125 & $4.6 \%$ & 189 & $7.0 \%$ \\
\hline Other DR Programs & 0 & $0.0 \%$ & 0 & $0.0 \%$ & 0 & $0.0 \%$ & 180 & $6.7 \%$ & 180 & $6.7 \%$ \\
\hline $\begin{array}{l}\text { Total } \\
\end{array}$ & 330 & $12.2 \%$ & 125 & $4.6 \%$ & 86 & $3.2 \%$ & 333 & $12.4 \%$ & 875 & $32.5 \%$ \\
\hline
\end{tabular}




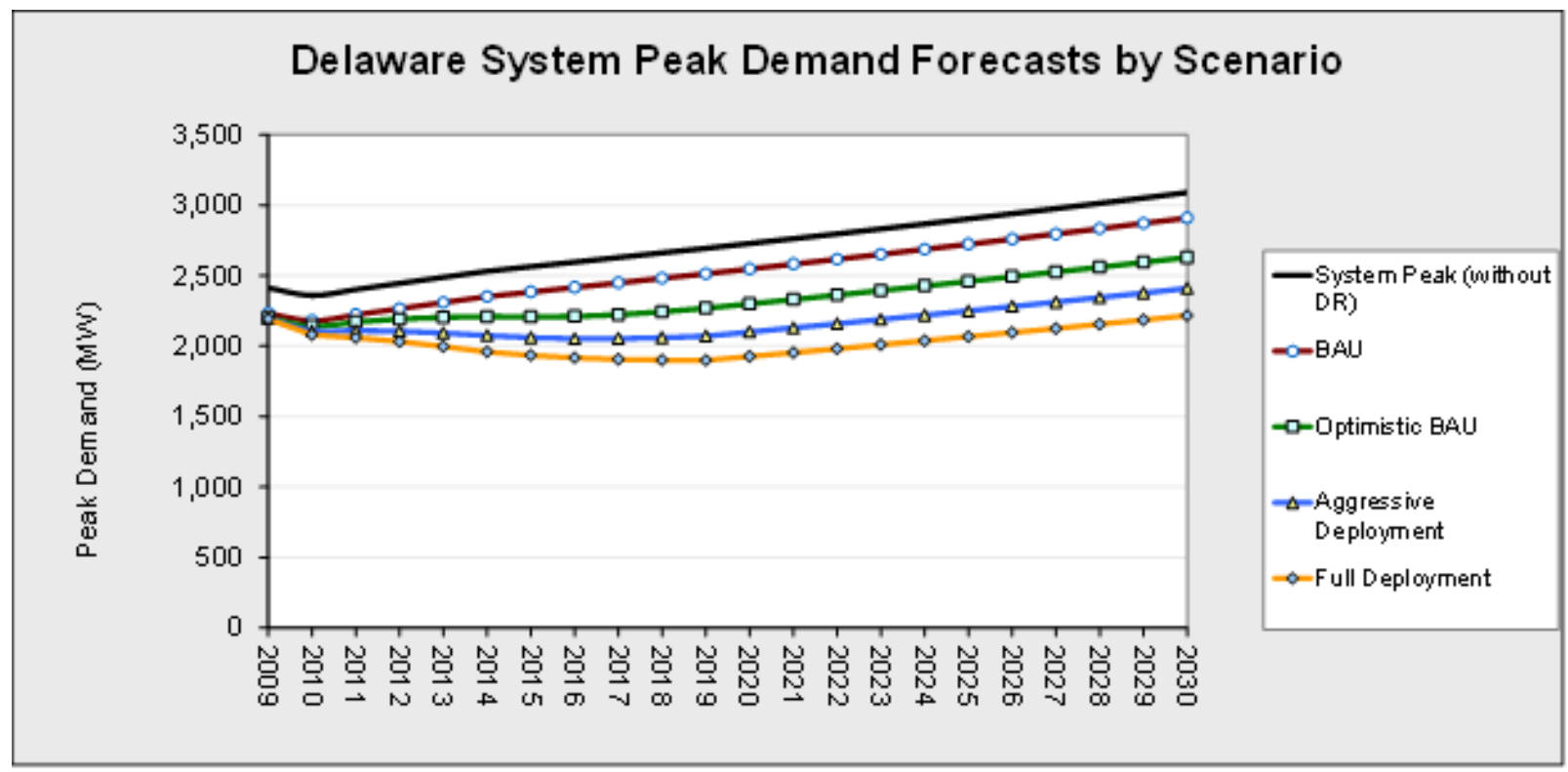

Summary of Monte Carlo Simulation of Potential Peak Load Reduction from Demand Response in Delaware by Scenario, Pricing Program and Price Ratio (MW)

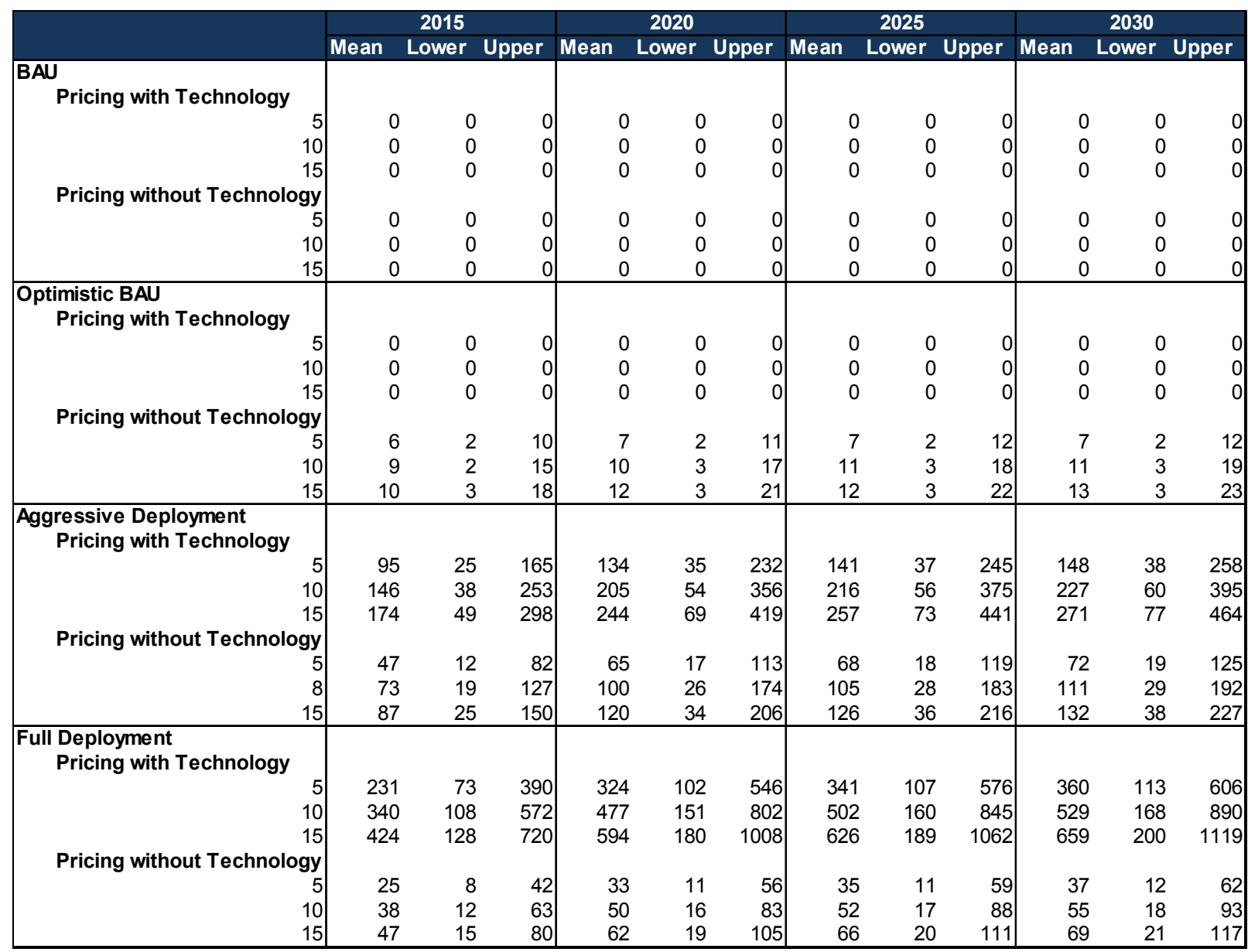




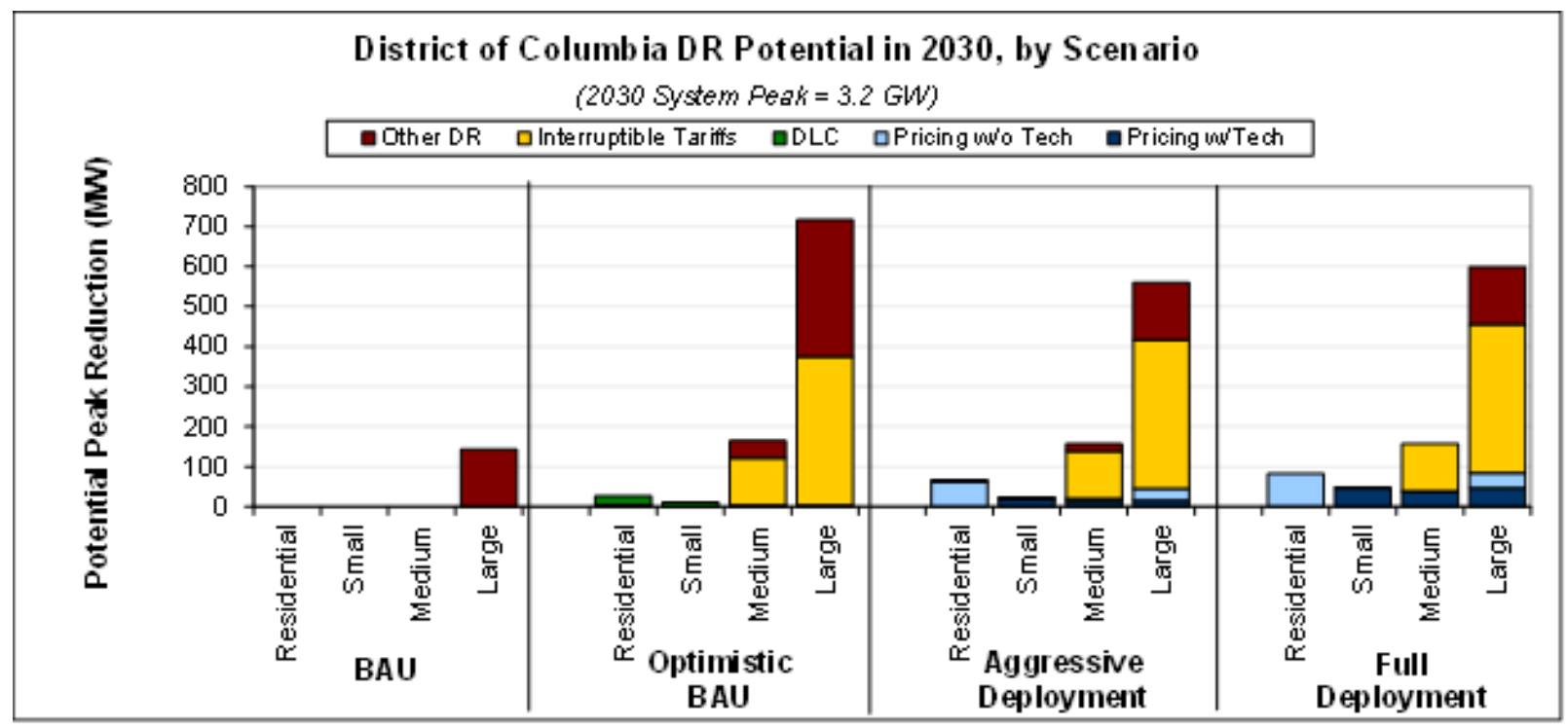

Total Potential Peak Reduction from Demand Response in District of Columbia, 2030

\begin{tabular}{|c|c|c|c|c|c|c|c|c|c|c|}
\hline & $\begin{array}{l}\text { Residential } \\
\text { (MW) }\end{array}$ & $\begin{array}{l}\text { Residential } \\
\text { ( } \% \text { of } \\
\text { svstem) }\end{array}$ & $\begin{array}{c}\text { Small C\&I } \\
(\mathrm{MW})\end{array}$ & $\begin{array}{l}\text { Small C\&I } \\
\text { (\% of } \\
\text { svstem) }\end{array}$ & $\begin{array}{l}\text { Med. C\&I } \\
(\mathrm{MW})\end{array}$ & $\begin{array}{l}\text { Med C\&I } \\
\text { ( } \% \text { of } \\
\text { svstem) }\end{array}$ & $\begin{array}{l}\text { Large C\&I } \\
(\mathrm{MW})\end{array}$ & $\begin{array}{l}\text { Large C\&I } \\
\text { (\% of } \\
\text { svstem) }\end{array}$ & $\begin{array}{l}\text { Total } \\
\text { (MW) }\end{array}$ & $\begin{array}{c}\text { Total } \\
\text { ( } \% \text { of } \\
\text { svstem) }\end{array}$ \\
\hline \multicolumn{11}{|l|}{ BAU } \\
\hline Pricing with Technology & 0 & $0.0 \%$ & 0 & $0.0 \%$ & 0 & $0.0 \%$ & 0 & $0.0 \%$ & 0 & $0.0 \%$ \\
\hline Pricing without Technology & 0 & $0.0 \%$ & 0 & $0.0 \%$ & 0 & $0.0 \%$ & 0 & $0.0 \%$ & 0 & $0.0 \%$ \\
\hline Automated/Direct Load Control & 0 & $0.0 \%$ & 0 & $0.0 \%$ & 0 & $0.0 \%$ & 0 & $0.0 \%$ & 0 & $0.0 \%$ \\
\hline Interruptible/Curtailable Tariffs & 0 & $0.0 \%$ & 0 & $0.0 \%$ & 0 & $0.0 \%$ & 0 & $0.0 \%$ & 0 & $0.0 \%$ \\
\hline Other DR Programs & 0 & $0.0 \%$ & 0 & $0.0 \%$ & 0 & $0.0 \%$ & 143 & $5.2 \%$ & 143 & $5.2 \%$ \\
\hline Total & 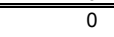 & $0.0 \%$ & 0 & $0.0 \%$ & 0 & $0.0 \%$ & 143 & $5.2 \%$ & 143 & $5.2 \%$ \\
\hline \multicolumn{11}{|l|}{ Optimistic BAU } \\
\hline Pricing with Technology & 0 & $0.0 \%$ & 0 & $0.0 \%$ & 0 & $0.0 \%$ & 0 & $0.0 \%$ & 0 & $0.0 \%$ \\
\hline Pricing without Technology & 4 & $0.1 \%$ & 0 & $0.0 \%$ & 1 & $0.0 \%$ & 3 & $0.1 \%$ & 8 & $0.3 \%$ \\
\hline Automated/Direct Load Control & 23 & $0.8 \%$ & 10 & $0.4 \%$ & 2 & $0.1 \%$ & 0 & $0.0 \%$ & 35 & $1.3 \%$ \\
\hline Interruptible/Curtailable Tariffs & 0 & $0.0 \%$ & 0 & $0.0 \%$ & 118 & $4.3 \%$ & 371 & $13.5 \%$ & 489 & $17.7 \%$ \\
\hline Other DR Programs & 0 & $0.0 \%$ & 0 & $0.0 \%$ & 43 & $1.6 \%$ & 343 & $12.4 \%$ & 386 & $14.0 \%$ \\
\hline Total & 27 & $1.0 \%$ & 11 & $0.4 \%$ & $\overline{164}$ & $6.0 \%$ & 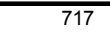 & $26.0 \%$ & 918 & $33.3 \%$ \\
\hline \multicolumn{11}{|l|}{ Aggressive Deployment } \\
\hline Pricing with Technology & 0 & $0.0 \%$ & 20 & $0.7 \%$ & 12 & $0.4 \%$ & 16 & $0.6 \%$ & 48 & $1.7 \%$ \\
\hline Pricing without Technology & 62 & $2.2 \%$ & 0 & $0.0 \%$ & 7 & $0.3 \%$ & 29 & $1.1 \%$ & 98 & $3.6 \%$ \\
\hline Automated/Direct Load Control & 6 & $0.2 \%$ & 3 & $0.1 \%$ & 1 & $0.0 \%$ & 0 & $0.0 \%$ & 9 & $0.3 \%$ \\
\hline Interruptible/Curtailable Tariffs & 0 & $0.0 \%$ & 0 & $0.0 \%$ & 118 & $4.3 \%$ & 371 & $13.5 \%$ & 489 & $17.7 \%$ \\
\hline Other DR Programs & 0 & $0.0 \%$ & 0 & $0.0 \%$ & 18 & $0.7 \%$ & 144 & $5.2 \%$ & 162 & $5.9 \%$ \\
\hline Total & 68 & $2.5 \%$ & 23 & $0.8 \%$ & 157 & $5.7 \%$ & 560 & $20.3 \%$ & 808 & $29.3 \%$ \\
\hline \multicolumn{11}{|l|}{ Full Deployment } \\
\hline Pricing with Technology & 0 & $0.0 \%$ & 47 & $1.7 \%$ & 36 & $1.3 \%$ & 47 & $1.7 \%$ & 129 & $4.7 \%$ \\
\hline Pricing without Technology & 82 & $3.0 \%$ & 0 & $0.0 \%$ & 4 & $0.1 \%$ & 38 & $1.4 \%$ & 124 & $4.5 \%$ \\
\hline Automated/Direct Load Control & 0 & $0.0 \%$ & 0 & $0.0 \%$ & 0 & $0.0 \%$ & 0 & $0.0 \%$ & 0 & $0.0 \%$ \\
\hline Interruptible/Curtailable Tariffs & 0 & $0.0 \%$ & 0 & $0.0 \%$ & 118 & $4.3 \%$ & 371 & $13.5 \%$ & 489 & $17.7 \%$ \\
\hline Other DR Programs & 0 & $0.0 \%$ & 0 & $0.0 \%$ & 0 & $0.0 \%$ & 143 & $5.2 \%$ & 143 & $5.2 \%$ \\
\hline Total & 82 & $3.0 \%$ & 47 & $1.7 \%$ & 157 & $5.7 \%$ & 599 & $21.7 \%$ & 886 & $32.1 \%$ \\
\hline
\end{tabular}




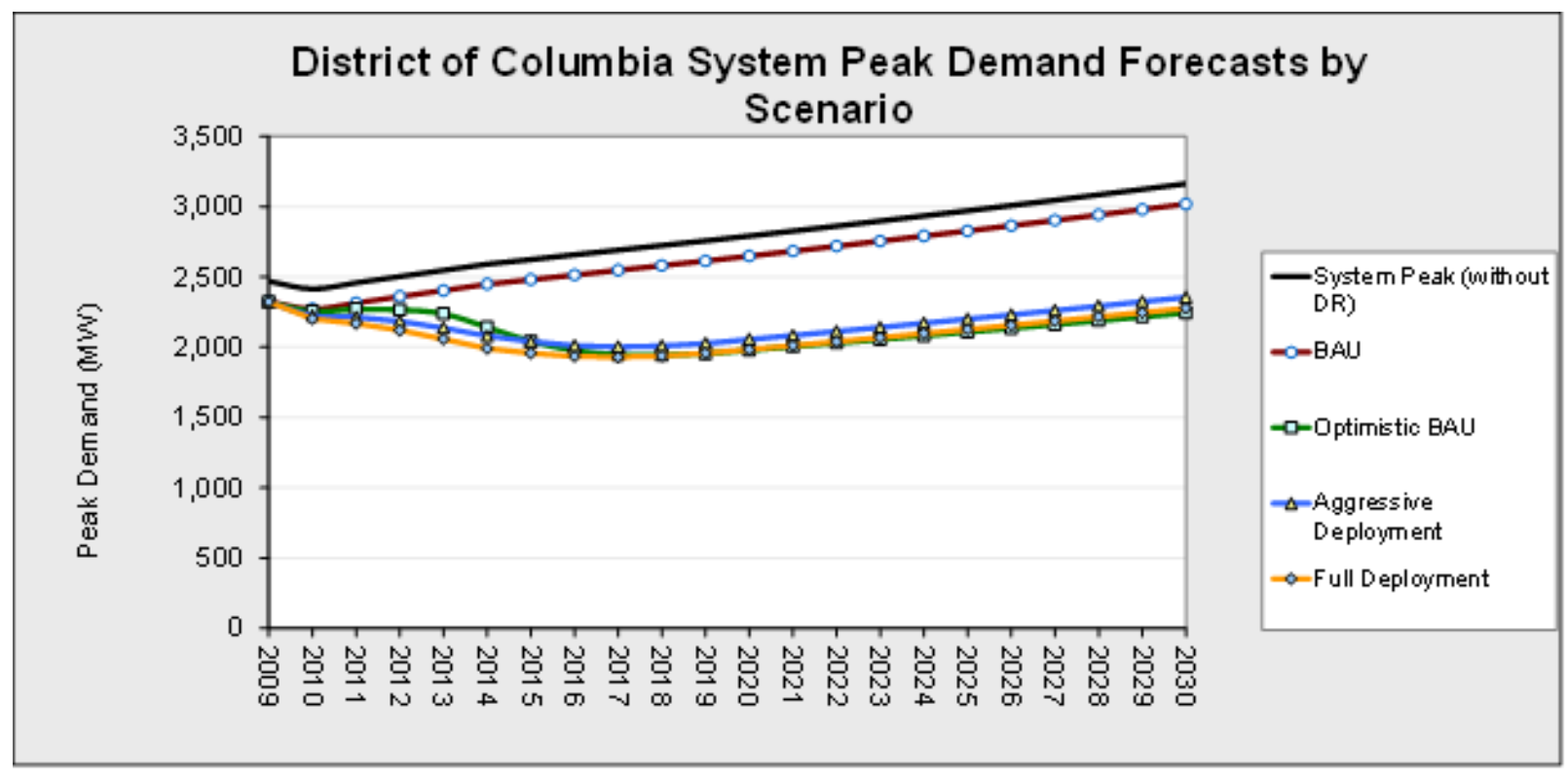

Summary of Monte Carlo Simulation of Potential Peak Load Reduction from Demand Response in District of Columbia by Scenario, Pricing Program and Price Ratio (MW)

\begin{tabular}{|c|c|c|c|c|c|c|c|c|c|c|c|c|}
\hline & \multicolumn{3}{|c|}{2015} & \multicolumn{3}{|c|}{2020} & \multicolumn{3}{|c|}{2025} & \multicolumn{3}{|c|}{2030} \\
\hline & Mean & Lower & Upper & Mean & Lower & Upper & Mean & Lower & Upper & Mean & Lower & Upper \\
\hline & \multicolumn{12}{|c|}{ BAU } \\
\hline \multicolumn{13}{|l|}{ Pricing with Technology } \\
\hline 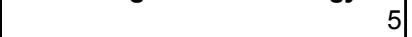 & 0 & 0 & 0 & 0 & 0 & 0 & 0 & 0 & 0 & 0 & 0 & 0 \\
\hline 10 & 0 & 0 & 0 & 0 & 0 & 0 & 0 & 0 & 0 & 0 & 0 & 0 \\
\hline 15 & 0 & 0 & 0 & 0 & 0 & 0 & 0 & 0 & 0 & 0 & 0 & 0 \\
\hline \multicolumn{13}{|l|}{ Pricing without Technology } \\
\hline 5 & 0 & 0 & 0 & 0 & 0 & 0 & 0 & 0 & 0 & 0 & 0 & 0 \\
\hline 10 & 0 & 0 & 0 & 0 & 0 & 0 & 0 & 0 & 0 & 0 & 0 & 0 \\
\hline 15 & 0 & 0 & 0 & 0 & 0 & 0 & 0 & 0 & 0 & 0 & 0 & 0 \\
\hline \multicolumn{13}{|l|}{$\begin{array}{l}\text { Optimistic BAU } \\
\text { Pricing with Technology }\end{array}$} \\
\hline 5 & 0 & 0 & 0 & 0 & 0 & 0 & 0 & 0 & 0 & 0 & 0 & 0 \\
\hline 10 & 0 & 0 & 0 & 0 & 0 & 0 & 0 & 0 & 0 & 0 & 0 & 0 \\
\hline 15 & 0 & 0 & 0 & 0 & 0 & 0 & 0 & 0 & 0 & 0 & 0 & 0 \\
\hline \multicolumn{13}{|l|}{ Pricing without Technology } \\
\hline 5 & 8 & 3 & 12 & 7 & 3 & 11 & 7 & 3 & 12 & 7 & 3 & 12 \\
\hline 10 & 11 & 4 & 19 & 11 & 3 & 18 & 11 & 4 & 18 & 11 & 4 & 19 \\
\hline 15 & 13 & 4 & 22 & 12 & 3 & 20 & 12 & 4 & 21 & 13 & 4 & 22 \\
\hline \multicolumn{13}{|l|}{$\begin{array}{l}\text { Aggressive Deployment } \\
\text { Pricing with Technology }\end{array}$} \\
\hline 5 & 39 & 11 & 67 & 37 & 10 & 63 & 39 & 11 & 67 & 42 & 12 & 72 \\
\hline 10 & 55 & 12 & 98 & 52 & 12 & 93 & 56 & 12 & 99 & 59 & 13 & 105 \\
\hline 15 & 68 & 20 & 117 & 64 & 19 & 110 & 69 & 20 & 117 & 73 & 21 & 125 \\
\hline \multicolumn{13}{|l|}{ Pricing without Technology } \\
\hline 5 & 84 & 23 & 146 & 80 & 22 & 138 & 82 & 23 & 141 & 84 & 23 & 145 \\
\hline 8 & 121 & 27 & 214 & 114 & 25 & 203 & 117 & 26 & 208 & 120 & 27 & 213 \\
\hline 15 & 149 & 43 & 256 & 142 & 41 & 242 & 145 & 42 & 248 & 148 & 43 & 254 \\
\hline \multicolumn{13}{|l|}{$\begin{array}{l}\text { Full Deployment } \\
\text { Pricing with Technology }\end{array}$} \\
\hline - & 99 & 21 & 176 & 92 & 19 & 165 & 98 & 21 & 176 & 105 & 22 & 187 \\
\hline 10 & 155 & 42 & 267 & 145 & 39 & 250 & 154 & 42 & 266 & 164 & 44 & 284 \\
\hline 15 & 188 & 59 & 317 & 176 & 55 & 297 & 187 & 59 & 316 & 200 & 62 & 337 \\
\hline \multicolumn{13}{|l|}{ Pricing without Technology } \\
\hline & 99 & 21 & 177 & 94 & 20 & 169 & 96 & 20 & 172 & 98 & 20 & 176 \\
\hline 10 & 156 & 42 & 270 & 148 & 40 & 257 & 151 & 41 & 262 & 155 & 41 & 268 \\
\hline 15 & 190 & 59 & 321 & 181 & 56 & 306 & 185 & 57 & 312 & 189 & 59 & 319 \\
\hline
\end{tabular}




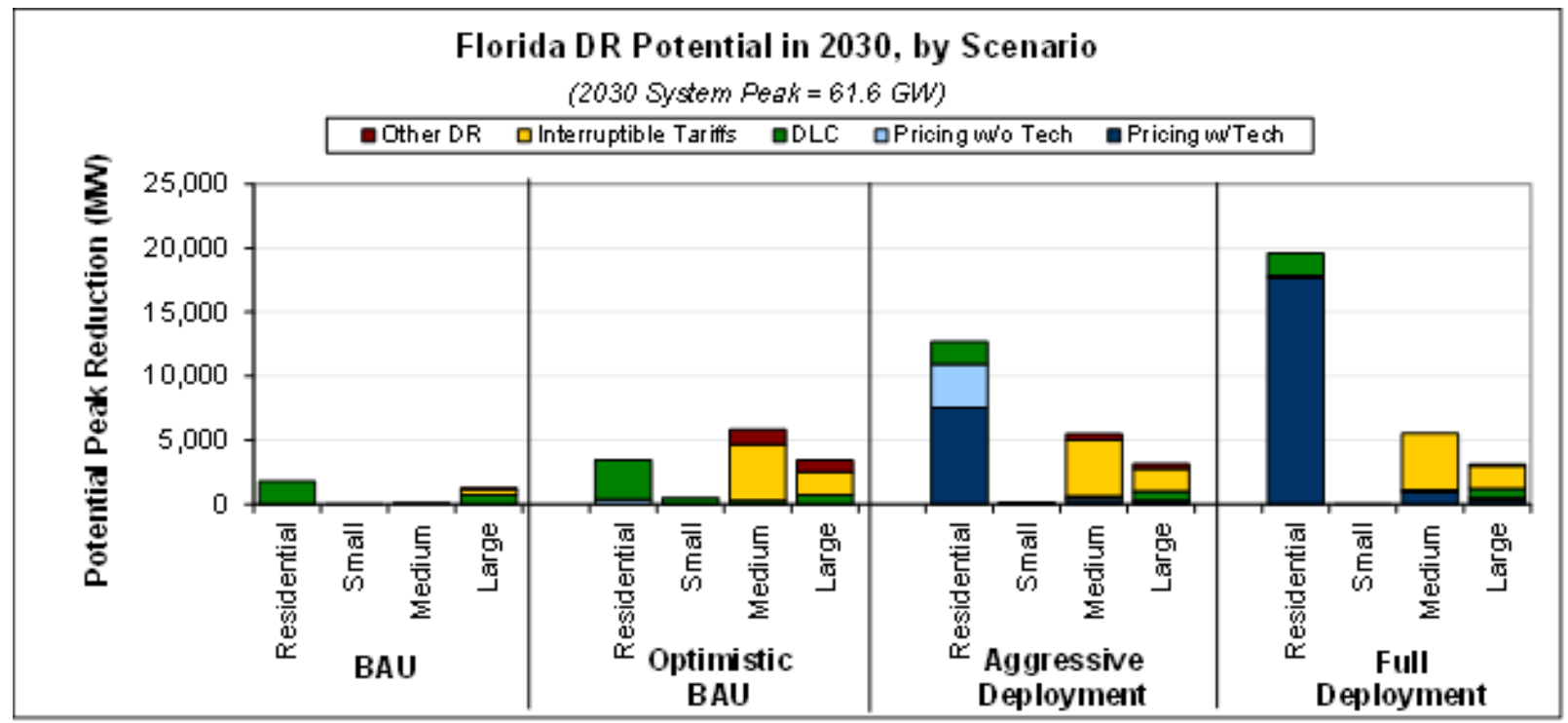

Total Potential Peak Reduction from Demand Response in Florida, 2030

\begin{tabular}{|c|c|c|c|c|c|c|c|c|c|c|}
\hline & $\begin{array}{l}\text { Residential } \\
\text { (MW) }\end{array}$ & $\begin{array}{l}\text { Residential } \\
\text { ( } \% \text { of } \\
\text { svstem) }\end{array}$ & $\begin{array}{l}\text { Small C\&I } \\
(\mathrm{MW})\end{array}$ & $\begin{array}{l}\text { Small C\&I } \\
\text { ( } \% \text { of } \\
\text { svstem) }\end{array}$ & $\begin{array}{l}\text { Med. C\&I } \\
(\mathrm{MW})\end{array}$ & $\begin{array}{l}\text { Med C\&I } \\
\text { ( } \% \text { of } \\
\text { svstem) }\end{array}$ & $\begin{array}{l}\text { Large C\&I } \\
(\mathrm{MW})\end{array}$ & $\begin{array}{l}\text { Large C\&I } \\
\text { ( } \% \text { of } \\
\text { svstem) }\end{array}$ & $\begin{array}{l}\text { Total } \\
\text { (MW) }\end{array}$ & $\begin{array}{l}\text { Total } \\
\text { ( } \% \text { of } \\
\text { svstem) }\end{array}$ \\
\hline \multicolumn{11}{|l|}{ BAU } \\
\hline Pricing with Technology & 0 & $0.0 \%$ & 0 & $0.0 \%$ & 0 & $0.0 \%$ & 0 & $0.0 \%$ & 0 & $0.0 \%$ \\
\hline Pricing without Technology & 17 & $0.0 \%$ & 0 & $0.0 \%$ & 0 & $0.0 \%$ & 11 & $0.0 \%$ & 28 & $0.1 \%$ \\
\hline Automated/Direct Load Control & 1,764 & $3.3 \%$ & 0 & $0.0 \%$ & 100 & $0.2 \%$ & 722 & $1.3 \%$ & 2,586 & $4.8 \%$ \\
\hline Interruptible/Curtailable Tariffs & 0 & $0.0 \%$ & 0 & $0.0 \%$ & 0 & $0.0 \%$ & 414 & $0.8 \%$ & 414 & $0.8 \%$ \\
\hline Other DR Programs & 0 & $0.0 \%$ & 0 & $0.0 \%$ & 0 & $0.0 \%$ & 113 & $0.2 \%$ & 113 & $0.2 \%$ \\
\hline Total & $\bar{~} 1,781$ & $3.3 \%$ & 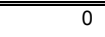 & $0.0 \%$ & $\overline{100}$ & $0.2 \%$ & $\overline{~ 1,260}$ & $2.3 \%$ & 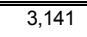 & $\overline{5.9 \%}$ \\
\hline \multicolumn{11}{|l|}{ Optimistic BAU } \\
\hline Pricing with Technology & 0 & $0.0 \%$ & 0 & $0.0 \%$ & 0 & $0.0 \%$ & 0 & $0.0 \%$ & 0 & $0.0 \%$ \\
\hline Pricing without Technology & 379 & $0.7 \%$ & 0 & $0.0 \%$ & 23 & $0.0 \%$ & 14 & $0.0 \%$ & 416 & $0.8 \%$ \\
\hline Automated/Direct Load Control & 3,077 & $5.7 \%$ & 492 & $0.9 \%$ & 237 & $0.4 \%$ & 722 & $1.3 \%$ & 4,528 & $8.4 \%$ \\
\hline Interruptible/Curtailable Tariffs & 0 & $0.0 \%$ & 0 & $0.0 \%$ & 4,400 & $8.2 \%$ & 1,785 & $3.3 \%$ & 6,185 & $11.5 \%$ \\
\hline Other DR Programs & 0 & $0.0 \%$ & 0 & $0.0 \%$ & 1,145 & $2.1 \%$ & 904 & $1.7 \%$ & 2,049 & $3.8 \%$ \\
\hline Total & 3,456 & $6.4 \%$ & 492 & $0.9 \%$ & $\overline{5,804}$ & $10.8 \%$ & 3,425 & $6.4 \%$ & 13,178 & $24.5 \%$ \\
\hline \multicolumn{11}{|l|}{ Aggressive Deployment } \\
\hline Pricing with Technology & 7,533 & $14.0 \%$ & 0 & $0.0 \%$ & 318 & $0.6 \%$ & 94 & $0.2 \%$ & 7,945 & $14.8 \%$ \\
\hline Pricing without Technology & 3,393 & $6.3 \%$ & 6 & $0.0 \%$ & 190 & $0.4 \%$ & 172 & $0.3 \%$ & 3,761 & $7.0 \%$ \\
\hline Automated/Direct Load Control & 1,764 & $3.3 \%$ & 128 & $0.2 \%$ & 100 & $0.2 \%$ & 722 & $1.3 \%$ & 2,714 & $5.1 \%$ \\
\hline Interruptible/Curtailable Tariffs & 0 & $0.0 \%$ & 0 & $0.0 \%$ & 4,400 & $8.2 \%$ & 1,785 & $3.3 \%$ & 6,185 & $11.5 \%$ \\
\hline Other DR Programs & 0 & $0.0 \%$ & 0 & $0.0 \%$ & 476 & $0.9 \%$ & 375 & $0.7 \%$ & 851 & $1.6 \%$ \\
\hline Total & 12,690 & $23.6 \%$ & 134 & $0.2 \%$ & 5,483 & $10.2 \%$ & 3,149 & $5.9 \%$ & 21,456 & $40.0 \%$ \\
\hline \multicolumn{11}{|l|}{ Full Deployment } \\
\hline Pricing with Technology & 17,620 & $32.8 \%$ & 0 & $0.0 \%$ & 930 & $1.7 \%$ & 276 & $0.5 \%$ & 18,826 & $35.1 \%$ \\
\hline Pricing without Technology & 195 & $0.4 \%$ & 8 & $0.0 \%$ & 92 & $0.2 \%$ & 223 & $0.4 \%$ & 517 & $1.0 \%$ \\
\hline Automated/Direct Load Control & 1,764 & $3.3 \%$ & 0 & $0.0 \%$ & 100 & $0.2 \%$ & 722 & $1.3 \%$ & 2,586 & $4.8 \%$ \\
\hline Interruptible/Curtailable Tariffs & 0 & $0.0 \%$ & 0 & $0.0 \%$ & 4,400 & $8.2 \%$ & 1,785 & $3.3 \%$ & 6,185 & $11.5 \%$ \\
\hline Other DR Programs & 0 & $0.0 \%$ & 0 & $0.0 \%$ & 0 & $0.0 \%$ & 113 & $0.2 \%$ & 113 & $0.2 \%$ \\
\hline 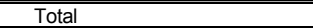 & $\overline{19,579}$ & $36.5 \%$ & 8 & $0.0 \%$ & $\overline{5,521}$ & $\overline{10.3 \%}$ & 3,119 & $5.8 \%$ & 28,227 & $\overline{52.6 \%}$ \\
\hline
\end{tabular}




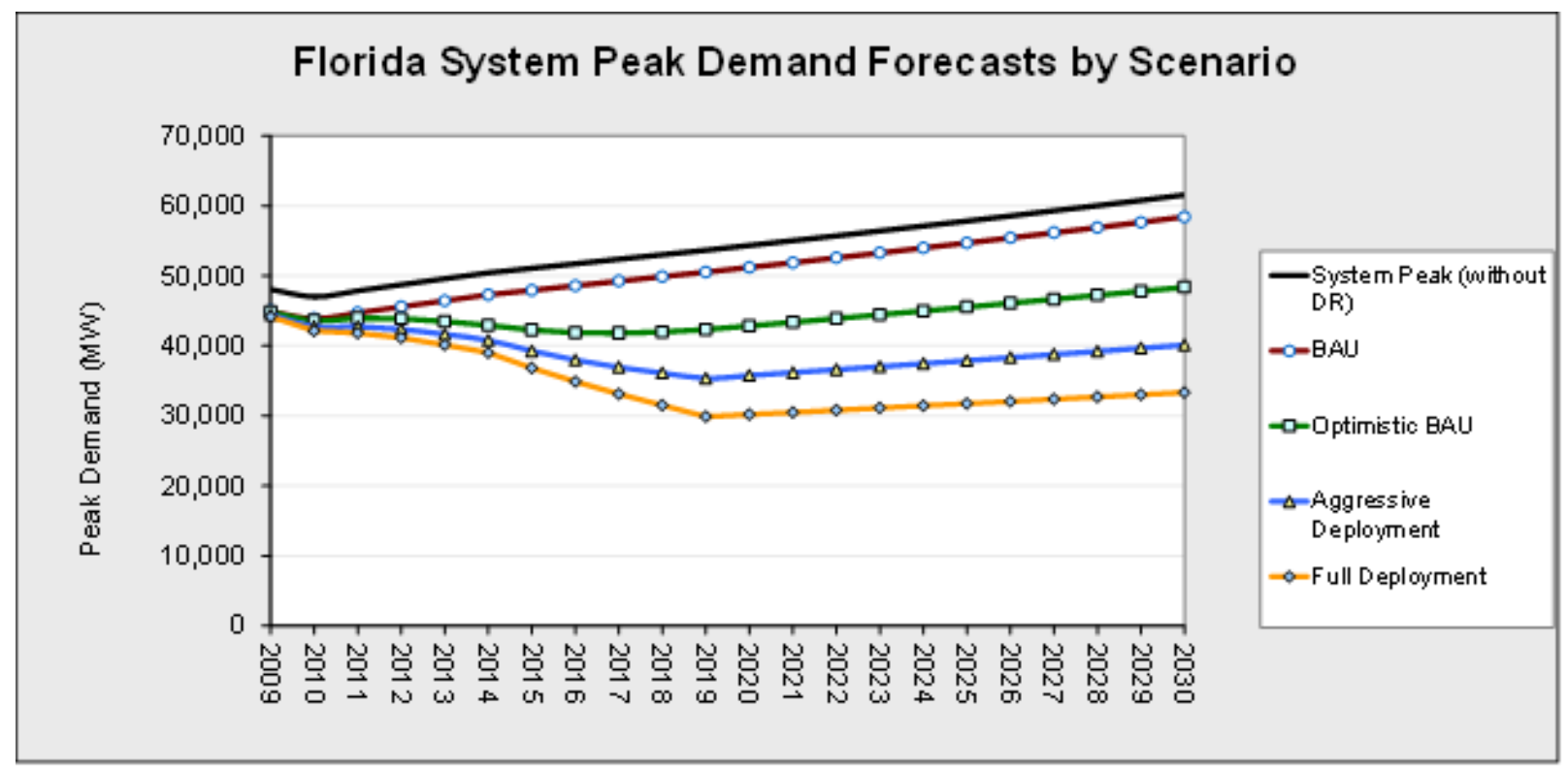

Summary of Monte Carlo Simulation of Potential Peak Load Reduction from Demand Response in Florida by Scenario, Pricing Program and Price Ratio (MW)

\begin{tabular}{|c|c|c|c|c|c|c|c|c|c|c|c|c|}
\hline & \multicolumn{3}{|c|}{2015} & \multicolumn{3}{|c|}{2020} & \multicolumn{3}{|c|}{2025} & \multicolumn{3}{|c|}{2030} \\
\hline & Mean & Lower & Upper & Mean & Lower & Upper & Mean & Lower & Upper & Mean & Lower & Upper \\
\hline \multicolumn{13}{|l|}{ BAU } \\
\hline 5 & 0 & 0 & 0 & 0 & 0 & 0 & 0 & 0 & 0 & 0 & 0 & \\
\hline 10 & 0 & 0 & 0 & 0 & 0 & 0 & 0 & 0 & 0 & 0 & 0 & \\
\hline 15 & 0 & 0 & 0 & 0 & 0 & 0 & 0 & 0 & 0 & 0 & 0 & \\
\hline \multicolumn{13}{|l|}{ Pricing without Technology } \\
\hline & 27 & 27 & 27 & 27 & 27 & 27 & 27 & 27 & 27 & 27 & 27 & \\
\hline 10 & 27 & 27 & 27 & 27 & 27 & 27 & 27 & 27 & 27 & 27 & 27 & 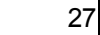 \\
\hline 15 & 27 & 27 & 27 & 27 & 27 & 27 & 27 & 27 & 27 & 27 & 27 & 27 \\
\hline \multirow{2}{*}{\multicolumn{13}{|c|}{$\begin{array}{l}\text { Optimistic BAU } \\
\quad \text { Pricing with Technology }\end{array}$}} \\
\hline & & & & & & & & & & & & \\
\hline 10 & 0 & 0 & 0 & 0 & 0 & 0 & 0 & 0 & 0 & 0 & 0 & \\
\hline 15 & 0 & 0 & 0 & 0 & 0 & 0 & 0 & 0 & 0 & 0 & 0 & \\
\hline \multicolumn{13}{|l|}{ Pricing without Technology } \\
\hline & 148 & 53 & 243 & 274 & 89 & 459 & 301 & 97 & 504 & 330 & 105 & 55 \\
\hline 10 & 198 & 39 & 357 & 370 & 64 & 677 & 406 & 69 & 743 & 446 & 75 & 81 \\
\hline 15 & 254 & 67 & 440 & 477 & 120 & 834 & 523 & 131 & 916 & 575 & 143 & 100 \\
\hline \multicolumn{13}{|l|}{\begin{tabular}{|l} 
Aggressive Deployment \\
Pricing with Technology
\end{tabular}} \\
\hline 5 & 2160 & 558 & 3762 & 4949 & 1278 & 8621 & 5443 & 1405 & 9480 & 5985 & 1545 & 1042 \\
\hline 10 & 3198 & 932 & 5464 & 7328 & 2135 & 12521 & 8059 & 2348 & 13769 & 8862 & 2582 & 1514 \\
\hline 15 & 3951 & 1164 & 6737 & 9053 & 2668 & 15438 & 9955 & 2933 & 16976 & 10947 & 3226 & 1866 \\
\hline \multicolumn{13}{|l|}{ Pricing without Technology } \\
\hline 5 & 1047 & 271 & 1823 & 2375 & 615 & 4135 & 2606 & 674 & 4538 & 2861 & 740 & 498 \\
\hline 8 & 1553 & 454 & 2652 & 3522 & 1029 & 6015 & 3865 & 1129 & 6601 & 4242 & 1239 & 724 \\
\hline 15 & 1920 & 568 & 3273 & 4354 & 1287 & 7422 & 4779 & 1412 & 8145 & 5245 & 1550 & 894 \\
\hline \multirow{2}{*}{\multicolumn{13}{|c|}{$\begin{array}{l}\text { Full Deployment } \\
\text { Pricing with Technology }\end{array}$}} \\
\hline & & & & & & & & & & & & \\
\hline 10 & 8002 & 2226 & 13778 & 18279 & 5084 & 31475 & 20092 & 5587 & 34596 & 22085 & 6142 & 3802 \\
\hline & 9404 & 2775 & 16033 & 21484 & 6339 & 36628 & 23614 & 6967 & 40260 & 25957 & 7659 & 4425 \\
\hline \multicolumn{13}{|l|}{ Pricing without Technology } \\
\hline 5 & 192 & 60 & 323 & 394 & 123 & 666 & 425 & 133 & 717 & 457 & 143 & 77 \\
\hline 10 & 289 & 82 & 495 & 594 & 169 & 1019 & 640 & 182 & 1097 & 689 & 196 & 118 \\
\hline 15 & 341 & 103 & 579 & 702 & 212 & 1192 & 756 & 228 & 1283 & 814 & 246 & 138 \\
\hline
\end{tabular}




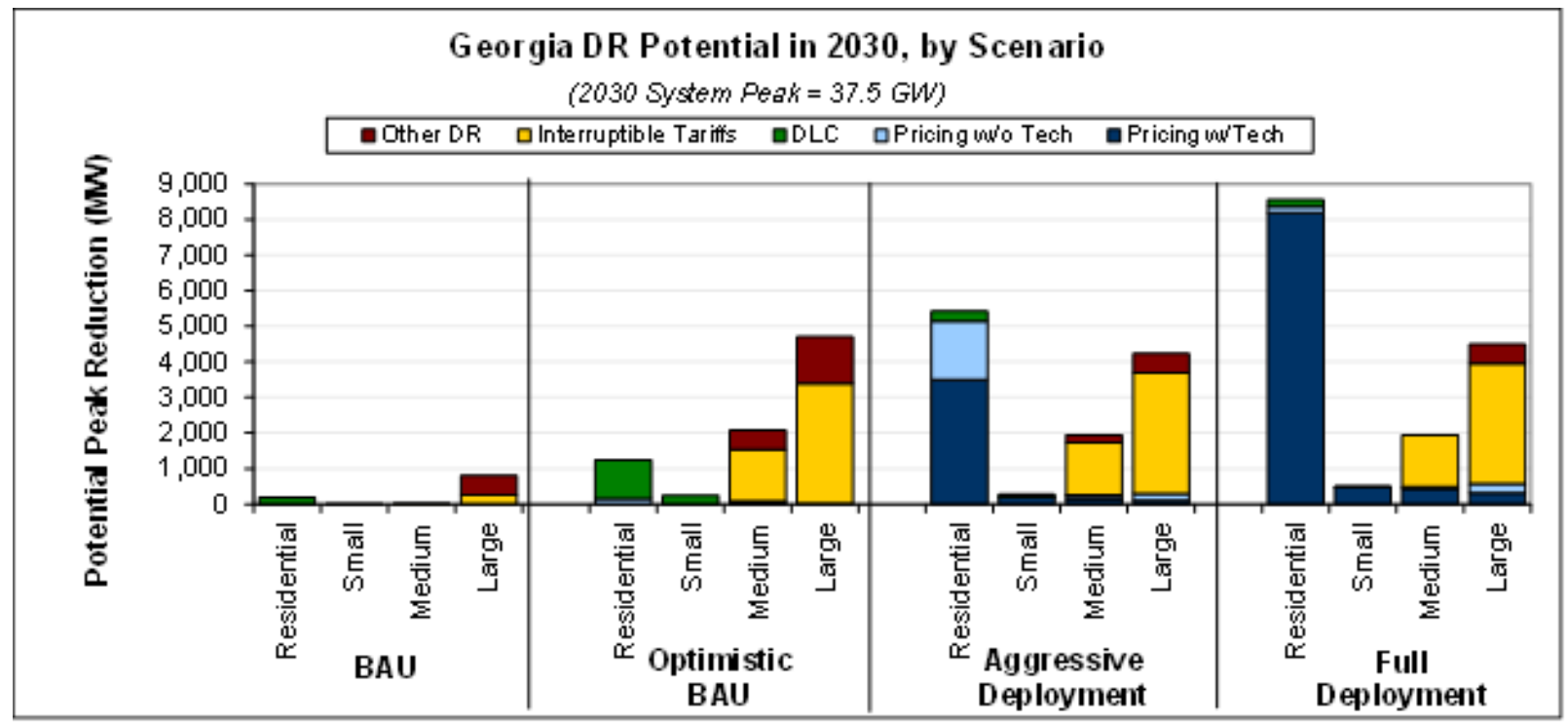

Total Potential Peak Reduction from Demand Response in Georgia, 2030

\begin{tabular}{|c|c|c|c|c|c|c|c|c|c|c|}
\hline & $\begin{array}{l}\text { Residential } \\
\quad(\mathrm{MW})\end{array}$ & $\begin{array}{l}\text { Residential } \\
\text { ( } \% \text { of } \\
\text { svstem) }\end{array}$ & $\begin{array}{l}\text { Small C\&I } \\
(\mathrm{MW})\end{array}$ & $\begin{array}{c}\text { Small C\&I } \\
\text { (\% of } \\
\text { svstem) }\end{array}$ & $\begin{array}{l}\text { Med. C\&I } \\
(\mathrm{MW})\end{array}$ & $\begin{array}{l}\text { Med C\&I } \\
\text { ( } \% \text { of } \\
\text { svstem) }\end{array}$ & $\begin{array}{l}\text { Large C\&I } \\
\quad(\mathrm{MW})\end{array}$ & $\begin{array}{l}\text { Large C\&I } \\
\text { ( } \% \text { of } \\
\text { svstem) }\end{array}$ & $\begin{array}{l}\text { Total } \\
(\mathrm{MW})\end{array}$ & $\begin{array}{c}\text { Total } \\
\text { ( } \% \text { of } \\
\text { svstem) }\end{array}$ \\
\hline \multicolumn{11}{|l|}{ BAU } \\
\hline Pricing with Technology & 0 & $0.0 \%$ & 0 & $0.0 \%$ & 0 & $0.0 \%$ & 0 & $0.0 \%$ & 0 & $0.0 \%$ \\
\hline Pricing without Technology & 1 & $0.0 \%$ & 0 & $0.0 \%$ & 7 & $0.0 \%$ & 4 & $0.0 \%$ & 12 & $0.0 \%$ \\
\hline Automated/Direct Load Control & 189 & $0.6 \%$ & 9 & $0.0 \%$ & 0 & $0.0 \%$ & 0 & $0.0 \%$ & 197 & $0.6 \%$ \\
\hline Interruptible/Curtailable Tariffs & 0 & $0.0 \%$ & 0 & $0.0 \%$ & 1 & $0.0 \%$ & 262 & $0.8 \%$ & 263 & $0.8 \%$ \\
\hline Other DR Programs & 0 & $0.0 \%$ & 0 & $0.0 \%$ & 0 & $0.0 \%$ & 538 & $1.6 \%$ & 538 & $1.6 \%$ \\
\hline Total & 190 & $0.6 \%$ & 9 & $0.0 \%$ & 7 & $0.0 \%$ & 804 & $2.5 \%$ & $\begin{array}{l}1,010 \\
\end{array}$ & $3.1 \%$ \\
\hline \multicolumn{11}{|l|}{ Optimistic BAU } \\
\hline Pricing with Technology & 0 & $0.0 \%$ & 0 & $0.0 \%$ & 0 & $0.0 \%$ & 0 & $0.0 \%$ & 0 & $0.0 \%$ \\
\hline Pricing without Technology & 161 & $0.5 \%$ & 0 & $0.0 \%$ & 10 & $0.0 \%$ & 19 & $0.1 \%$ & 190 & $0.6 \%$ \\
\hline Automated/Direct Load Control & 1,089 & $3.3 \%$ & 245 & $0.7 \%$ & 67 & $0.2 \%$ & 0 & $0.0 \%$ & 1,401 & $4.3 \%$ \\
\hline Interruptible/Curtailable Tariffs & 0 & $0.0 \%$ & 0 & $0.0 \%$ & 1,456 & $4.5 \%$ & 3,382 & $10.4 \%$ & 4,839 & $14.8 \%$ \\
\hline Other DR Programs & 0 & $0.0 \%$ & 0 & $0.0 \%$ & 542 & $1.7 \%$ & 1,301 & $4.0 \%$ & 1,843 & $5.6 \%$ \\
\hline Total & $\overline{~ 1,251}$ & $3.8 \%$ & 245 & $0.8 \%$ & 2,075 & $6.4 \%$ & 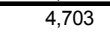 & $\overline{14.4 \%}$ & 8,273 & $25.3 \%$ \\
\hline \multicolumn{11}{|l|}{ Aggressive Deployment } \\
\hline Pricing with Technology & 3,504 & $10.7 \%$ & 204 & $0.6 \%$ & 150 & $0.5 \%$ & 108 & $0.3 \%$ & 3,966 & $12.1 \%$ \\
\hline Pricing without Technology & 1,637 & $5.0 \%$ & 4 & $0.0 \%$ & 90 & $0.3 \%$ & 197 & $0.6 \%$ & 1,927 & $5.9 \%$ \\
\hline Automated/Direct Load Control & 282 & $0.9 \%$ & 63 & $0.2 \%$ & 28 & $0.1 \%$ & 0 & $0.0 \%$ & 373 & $1.1 \%$ \\
\hline Interruptible/Curtailable Tariffs & 0 & $0.0 \%$ & 0 & $0.0 \%$ & 1,456 & $4.5 \%$ & 3,382 & $10.4 \%$ & 4,839 & $14.8 \%$ \\
\hline Other DR Programs & 0 & $0.0 \%$ & 0 & $0.0 \%$ & 224 & $0.7 \%$ & 545 & $1.7 \%$ & 769 & $2.4 \%$ \\
\hline Total & 5,422 & $16.6 \%$ & 271 & $0.8 \%$ & 1,948 & $6.0 \%$ & 4,232 & $13.0 \%$ & 11,874 & $36.4 \%$ \\
\hline \multicolumn{11}{|l|}{ Full Deployment } \\
\hline Pricing with Technology & 8,196 & $25.1 \%$ & 478 & $1.5 \%$ & 439 & $1.3 \%$ & 316 & $1.0 \%$ & 9,428 & $28.9 \%$ \\
\hline Pricing without Technology & 169 & $0.5 \%$ & 2 & $0.0 \%$ & 43 & $0.1 \%$ & 255 & $0.8 \%$ & 469 & $1.4 \%$ \\
\hline Automated/Direct Load Control & 189 & $0.6 \%$ & 9 & $0.0 \%$ & 0 & $0.0 \%$ & 0 & $0.0 \%$ & 197 & $0.6 \%$ \\
\hline Interruptible/Curtailable Tariffs & 0 & $0.0 \%$ & 0 & $0.0 \%$ & 1,456 & $4.5 \%$ & 3,382 & $10.4 \%$ & 4,839 & $14.8 \%$ \\
\hline Other DR Programs & 0 & $0.0 \%$ & 0 & $0.0 \%$ & 0 & $0.0 \%$ & 538 & $1.6 \%$ & 538 & $1.6 \%$ \\
\hline Total & 8,553 & $26.2 \%$ & 489 & $1.5 \%$ & 1,938 & $5.9 \%$ & 4,490 & $13.7 \%$ & 15,471 & $47.4 \%$ \\
\hline
\end{tabular}




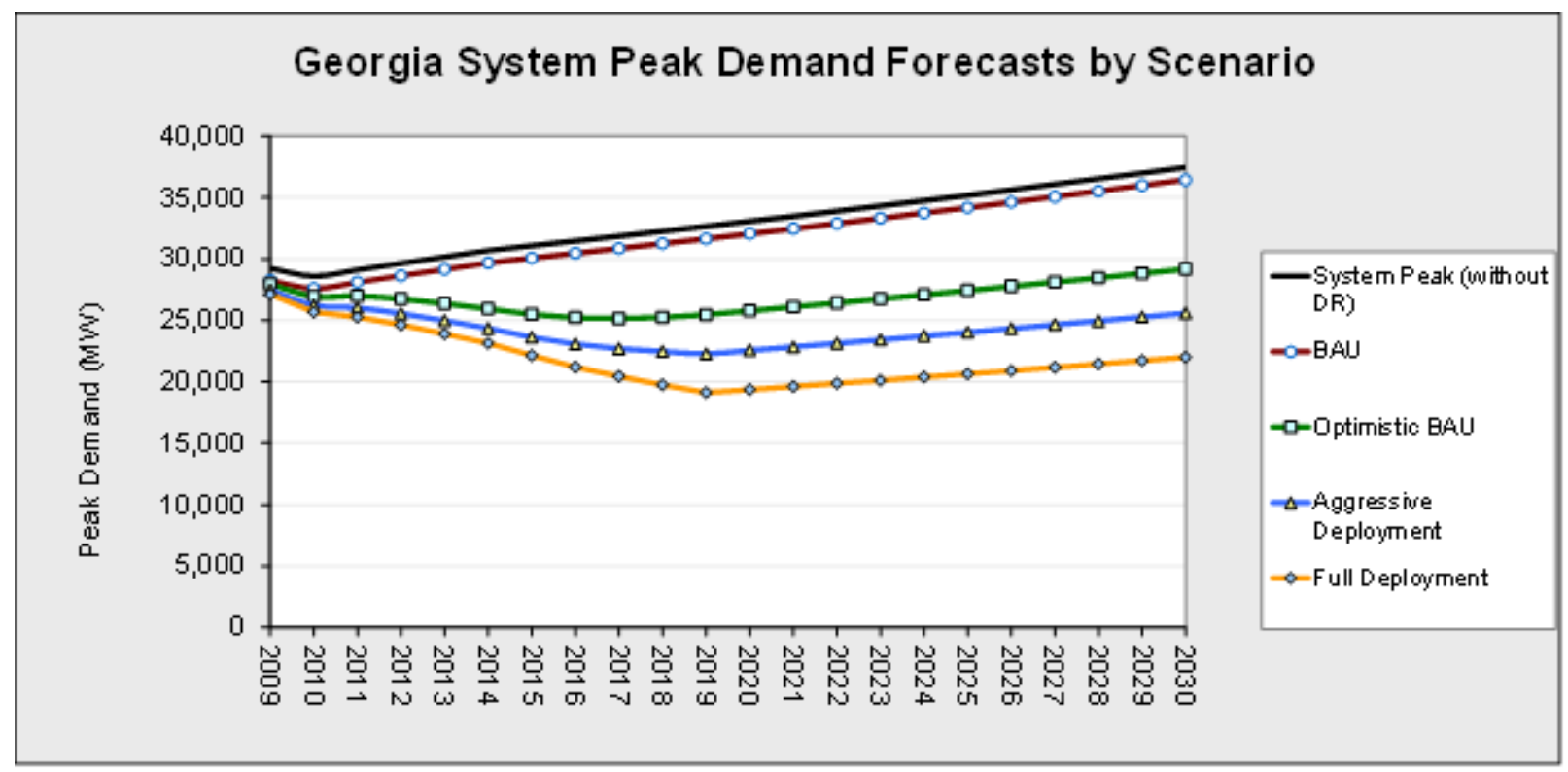

Summary of Monte Carlo Simulation of Potential Peak Load Reduction from Demand Response in Georgia by Scenario, Pricing Program and Price Ratio (MW)

\begin{tabular}{|c|c|c|c|c|c|c|c|c|c|c|c|c|}
\hline & \multicolumn{3}{|c|}{2015} & \multicolumn{3}{|c|}{2020} & \multicolumn{3}{|c|}{2025} & \multicolumn{3}{|c|}{2030} \\
\hline & Mean & Lower & Upper & Mean & Lower & Upper & Mean & Lower & Upper & \multicolumn{3}{|c|}{ Lower Upper } \\
\hline BAU & \multicolumn{12}{|c|}{ Pricing with Technology } \\
\hline 5 & 0 & 0 & 0 & 0 & 0 & 0 & 0 & 0 & 0 & 0 & 0 & \\
\hline 10 & 0 & 0 & 0 & 0 & 0 & 0 & 0 & 0 & 0 & 0 & 0 & \\
\hline 15 & 0 & 0 & 0 & 0 & 0 & 0 & 0 & 0 & 0 & 0 & 0 & \\
\hline \multicolumn{13}{|l|}{ Pricing without Technology } \\
\hline & 11 & 11 & 11 & 11 & 11 & 11 & 11 & 11 & 11 & 11 & 11 & \\
\hline 10 & 11 & 11 & 11 & 11 & 11 & 11 & 11 & 11 & 11 & 11 & 11 & 11 \\
\hline 15 & 11 & 11 & 11 & 11 & 11 & 11 & 11 & 11 & 11 & 11 & 11 & 111 \\
\hline \multirow{2}{*}{\multicolumn{13}{|c|}{$\begin{array}{l}\text { Optimistic BAU } \\
\text { Pricing with Technology }\end{array}$}} \\
\hline & & & & & & & & & & & & \\
\hline 10 & 0 & 0 & 0 & 0 & 0 & 0 & 0 & 0 & 0 & 0 & 0 & \\
\hline 15 & 0 & 0 & 0 & 0 & 0 & 0 & 0 & 0 & 0 & 0 & 0 & \\
\hline \multicolumn{13}{|l|}{ Pricing without Technology } \\
\hline & 102 & 30 & 173 & 131 & 37 & 226 & 140 & 39 & 241 & 149 & 41 & 257 \\
\hline 10 & 161 & 56 & 265 & 209 & 72 & 345 & 222 & 77 & 367 & 237 & 82 & 392 \\
\hline 15 & 179 & 54 & 304 & 232 & 70 & 395 & 248 & 74 & 421 & 264 & 79 & 44 \\
\hline \multicolumn{13}{|l|}{\begin{tabular}{|l|} 
Aggressive Deployment \\
Pricing with Technology
\end{tabular}} \\
\hline 5 & 1564 & 473 & 2656 & 2763 & 835 & 4690 & 2945 & 890 & 5000 & 3140 & 949 & 5330 \\
\hline 10 & 2346 & 732 & 3961 & 4144 & 1292 & 6996 & 4417 & 1377 & 7458 & 4709 & 1468 & 7950 \\
\hline 15 & 2770 & 788 & 4751 & 4891 & 1392 & 8391 & 5214 & 1484 & 8945 & 5559 & 1582 & 9535 \\
\hline \multicolumn{13}{|l|}{ Pricing without Technology } \\
\hline 5 & 791 & 240 & 1342 & 1372 & 416 & 2328 & 1462 & 443 & 2481 & 1559 & 472 & 264 \\
\hline 8 & 1189 & 372 & 2006 & 2062 & 645 & 3480 & 2198 & 688 & 3709 & 2343 & 733 & 395 \\
\hline 15 & 1405 & 402 & 2409 & 2438 & 697 & 4178 & 2598 & 743 & 4454 & 2770 & 792 & 474 \\
\hline \multicolumn{13}{|l|}{$\begin{array}{l}\text { Full Deployment } \\
\text { Pricing with Technology }\end{array}$} \\
\hline 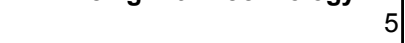 & 3636 & 1109 & 6163 & 6401 & 1952 & 10850 & 6823 & 2081 & 11566 & 7274 & 2218 & 12330 \\
\hline 10 & 5329 & 1355 & 9302 & 9380 & 2384 & 16376 & 10000 & 2542 & 17458 & 10660 & 2710 & 1861 \\
\hline & 6617 & 1777 & 11457 & 11648 & 3127 & 20170 & 12417 & 3334 & 21501 & 13237 & 3554 & 2292 \\
\hline \multicolumn{13}{|l|}{ Pricing without Technology } \\
\hline 5 & 231 & 72 & 391 & 368 & 114 & 622 & 392 & 121 & 663 & 418 & 129 & 707 \\
\hline 10 & 341 & 89 & 594 & 543 & 141 & 945 & 579 & 151 & 1007 & 617 & 161 & 1073 \\
\hline 15 & 425 & 117 & 734 & 677 & 186 & 1168 & 721 & 198 & 1245 & 769 & 211 & 132 \\
\hline
\end{tabular}




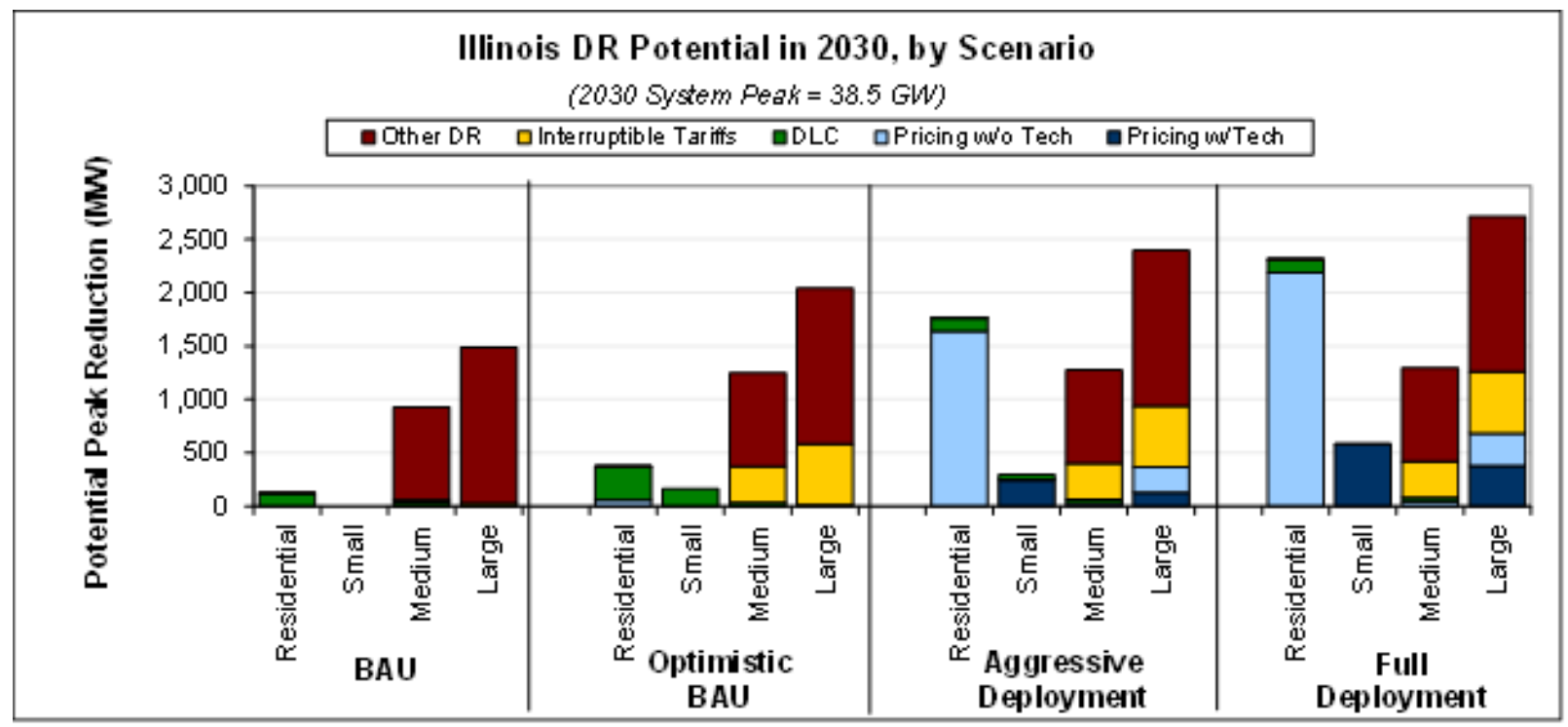

Total Potential Peak Reduction from Demand Response in Illinois, 2030

\begin{tabular}{|c|c|c|c|c|c|c|c|c|c|c|}
\hline & $\begin{array}{l}\text { Residential } \\
\quad(\mathrm{MW})\end{array}$ & $\begin{array}{l}\text { Residential } \\
\text { ( } \% \text { of } \\
\text { svstem) }\end{array}$ & $\begin{array}{l}\text { Small C\&I } \\
(\mathrm{MW})\end{array}$ & $\begin{array}{c}\text { Small C\&I } \\
\text { (\% of } \\
\text { svstem) }\end{array}$ & $\begin{array}{l}\text { Med. C\&I } \\
(\mathrm{MW})\end{array}$ & $\begin{array}{l}\text { Med C\&I } \\
\text { ( } \% \text { of } \\
\text { svstem) }\end{array}$ & $\begin{array}{l}\text { Large C\&I } \\
\quad(\mathrm{MW})\end{array}$ & $\begin{array}{l}\text { Large C\&I } \\
\text { ( } \% \text { of } \\
\text { svstem) }\end{array}$ & $\begin{array}{l}\text { Total } \\
(\mathrm{MW})\end{array}$ & $\begin{array}{c}\text { Total } \\
\text { ( } \% \text { of } \\
\text { svstem) }\end{array}$ \\
\hline \multicolumn{11}{|l|}{ BAU } \\
\hline Pricing with Technology & 0 & $0.0 \%$ & 0 & $0.0 \%$ & 0 & $0.0 \%$ & 0 & $0.0 \%$ & 0 & $0.0 \%$ \\
\hline Pricing without Technology & 0 & $0.0 \%$ & 0 & $0.0 \%$ & 1 & $0.0 \%$ & 2 & $0.0 \%$ & 3 & $0.0 \%$ \\
\hline Automated/Direct Load Control & 122 & $0.4 \%$ & 0 & $0.0 \%$ & 36 & $0.1 \%$ & 0 & $0.0 \%$ & 158 & $0.5 \%$ \\
\hline Interruptible/Curtailable Tariffs & 1 & $0.0 \%$ & 0 & $0.0 \%$ & 19 & $0.1 \%$ & 28 & $0.1 \%$ & 47 & $0.1 \%$ \\
\hline Other DR Programs & 4 & $0.0 \%$ & 0 & $0.0 \%$ & 874 & $2.6 \%$ & 1,457 & $4.3 \%$ & 2,335 & $6.9 \%$ \\
\hline Total & $\overline{127}$ & $0.4 \%$ & 0 & $0.0 \%$ & 929 & $2.8 \%$ & $1,1,486$ & $4.4 \%$ & 2,543 & $7.6 \%$ \\
\hline \multicolumn{11}{|l|}{ Optimistic BAU } \\
\hline Pricing with Technology & 0 & $0.0 \%$ & 0 & $0.0 \%$ & 0 & $0.0 \%$ & 0 & $0.0 \%$ & 0 & $0.0 \%$ \\
\hline Pricing without Technology & 56 & $0.2 \%$ & 0 & $0.0 \%$ & 1 & $0.0 \%$ & 13 & $0.0 \%$ & 71 & $0.2 \%$ \\
\hline Automated/Direct Load Control & 316 & $0.9 \%$ & 163 & $0.5 \%$ & 36 & $0.1 \%$ & 0 & $0.0 \%$ & 515 & $1.5 \%$ \\
\hline Interruptible/Curtailable Tariffs & 1 & $0.0 \%$ & 0 & $0.0 \%$ & 338 & $1.0 \%$ & 571 & $1.7 \%$ & 910 & $2.7 \%$ \\
\hline Other DR Programs & 4 & $0.0 \%$ & 0 & $0.0 \%$ & 874 & $2.6 \%$ & 1,457 & $4.3 \%$ & 2,335 & $6.9 \%$ \\
\hline Total & 377 & $1.1 \%$ & 164 & $0.5 \%$ & $\overline{1,249}$ & $3.7 \%$ & 2,041 & $\begin{array}{ll}6.1 \% \\
\end{array}$ & 3,831 & $11.4 \%$ \\
\hline \multicolumn{11}{|l|}{ Aggressive Deployment } \\
\hline Pricing with Technology & 0 & $0.0 \%$ & 248 & $0.7 \%$ & 0 & $0.0 \%$ & 130 & $0.4 \%$ & 378 & $1.1 \%$ \\
\hline Pricing without Technology & 1,642 & $4.9 \%$ & 5 & $0.0 \%$ & 28 & $0.1 \%$ & 236 & $0.7 \%$ & 1,911 & $5.7 \%$ \\
\hline Automated/Direct Load Control & 122 & $0.4 \%$ & 42 & $0.1 \%$ & 36 & $0.1 \%$ & 0 & $0.0 \%$ & 200 & $0.6 \%$ \\
\hline Interruptible/Curtailable Tariffs & 1 & $0.0 \%$ & 0 & $0.0 \%$ & 338 & $1.0 \%$ & 571 & $1.7 \%$ & 910 & $2.7 \%$ \\
\hline Other DR Programs & 4 & $0.0 \%$ & 0 & $0.0 \%$ & 874 & $2.6 \%$ & 1,457 & $4.3 \%$ & 2,335 & $6.9 \%$ \\
\hline Total & 1,769 & $5.3 \%$ & 295 & $0.9 \%$ & 1,276 & $3.8 \%$ & 2,394 & $7.1 \%$ & 5,734 & $17.1 \%$ \\
\hline \multicolumn{11}{|l|}{ Full Deployment } \\
\hline Pricing with Technology & 0 & $0.0 \%$ & 581 & $1.7 \%$ & 0 & $0.0 \%$ & 379 & $1.1 \%$ & 960 & $2.9 \%$ \\
\hline Pricing without Technology & 2,189 & $6.5 \%$ & 3 & $0.0 \%$ & 47 & $0.1 \%$ & 306 & $0.9 \%$ & 2,545 & $7.6 \%$ \\
\hline Automated/Direct Load Control & 122 & $0.4 \%$ & 0 & $0.0 \%$ & 36 & $0.1 \%$ & 0 & $0.0 \%$ & 158 & $0.5 \%$ \\
\hline Interruptible/Curtailable Tariffs & 1 & $0.0 \%$ & 0 & $0.0 \%$ & 338 & $1.0 \%$ & 571 & $1.7 \%$ & 910 & $2.7 \%$ \\
\hline Other DR Programs & 4 & $0.0 \%$ & 0 & $0.0 \%$ & 874 & $2.6 \%$ & 1,457 & $4.3 \%$ & 2,335 & $6.9 \%$ \\
\hline Total & 2,316 & $6.9 \%$ & 583 & $1.7 \%$ & 1,295 & $3.9 \%$ & 2,713 & $8.1 \%$ & 6,908 & $20.6 \%$ \\
\hline
\end{tabular}




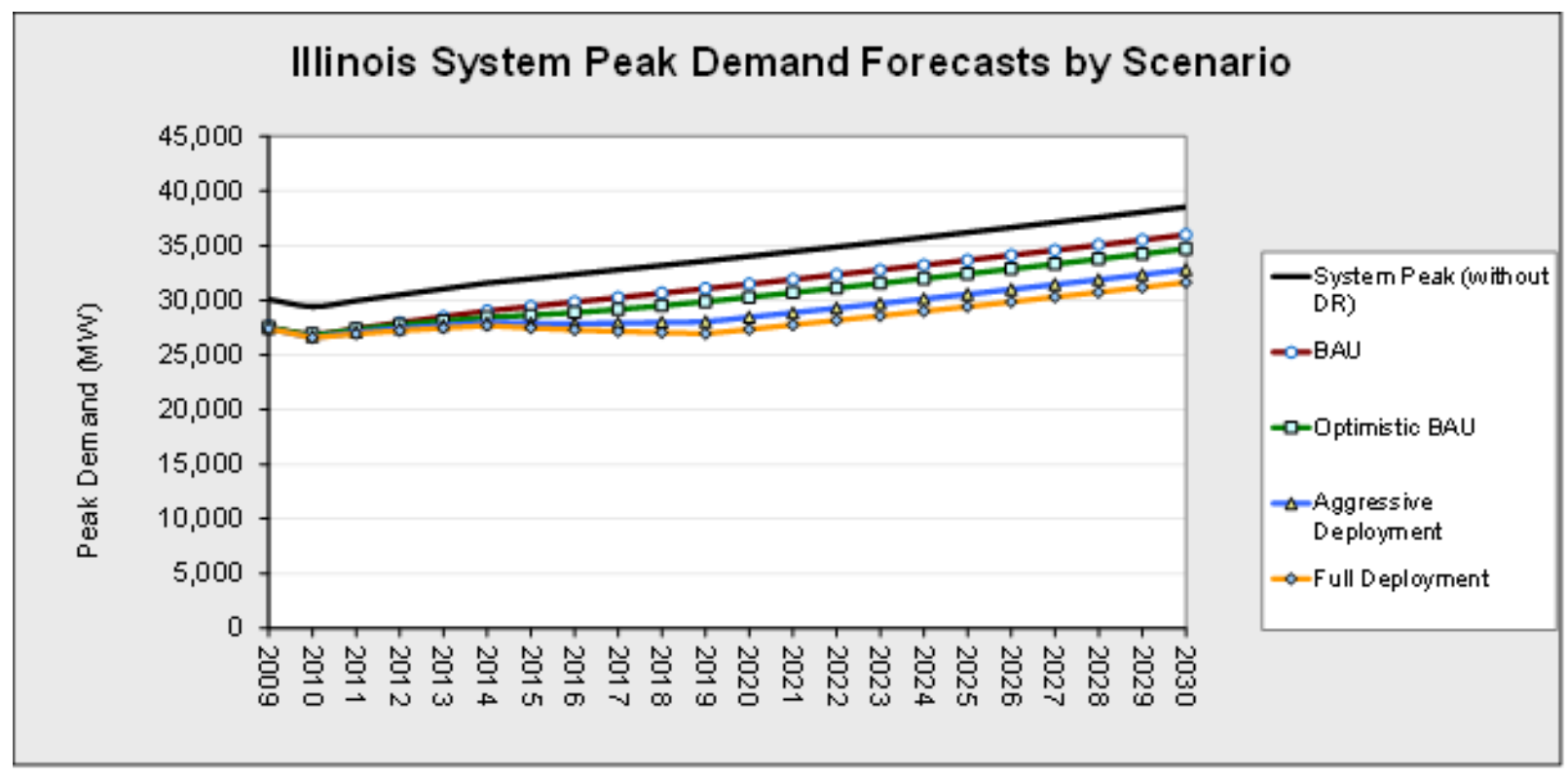

Summary of Monte Carlo Simulation of Potential Peak Load Reduction from Demand Response in Illinois by Scenario, Pricing Program and Price Ratio (MW)

\begin{tabular}{|c|c|c|c|c|c|c|c|c|c|c|c|c|}
\hline & \multicolumn{3}{|c|}{2015} & \multicolumn{3}{|c|}{2020} & \multicolumn{3}{|c|}{2025} & \multicolumn{3}{|c|}{2030} \\
\hline & Mean & Lower & Upper & \multirow[t]{2}{*}{ Mean } & Lower & Upper & \multirow[t]{2}{*}{ Mean } & \multicolumn{2}{|c|}{ Lower Upper } & \multirow[t]{2}{*}{ Mean } & Lower & Upper \\
\hline${ }_{\text {Pricing with Technology }}$ & \multicolumn{9}{|c|}{ Pricing with Technology } & & & \\
\hline 5 & 0 & 0 & 0 & 0 & 0 & 0 & 0 & 0 & 0 & 0 & 0 & 0 \\
\hline 10 & 0 & 0 & 0 & 0 & 0 & 0 & 0 & 0 & 0 & 0 & 0 & 0 \\
\hline 15 & 0 & 0 & 0 & 0 & 0 & 0 & 0 & 0 & 0 & 0 & 0 & 0 \\
\hline \multicolumn{13}{|l|}{ Pricing without Technology } \\
\hline & 2 & 2 & 2 & 2 & 2 & 2 & 2 & 2 & 2 & 2 & 2 & 2 \\
\hline 10 & 2 & 2 & 2 & 2 & 2 & 2 & 2 & 2 & 2 & 2 & 2 & 2 \\
\hline 15 & 2 & 2 & 2 & 2 & 2 & 2 & 2 & 2 & 2 & 2 & 2 & 2 \\
\hline \multicolumn{13}{|l|}{$\begin{array}{l}\text { Optimistic BAU } \\
\text { Pricing with Technology }\end{array}$} \\
\hline 5 & 0 & 0 & 0 & 0 & 0 & 0 & 0 & 0 & 0 & 0 & 0 & 0 \\
\hline 10 & 0 & 0 & 0 & 0 & 0 & 0 & 0 & 0 & 0 & 0 & 0 & 0 \\
\hline 15 & 0 & 0 & 0 & 0 & 0 & 0 & 0 & 0 & 0 & 0 & 0 & 0 \\
\hline \multicolumn{13}{|l|}{ Pricing without Technology } \\
\hline 5 & 33 & 9 & 57 & 54 & 14 & 93 & 55 & 14 & 95 & 56 & 15 & 97 \\
\hline 10 & 48 & 12 & 84 & 79 & 18 & 139 & 80 & 19 & 142 & 82 & 19 & 145 \\
\hline 15 & 60 & 16 & 103 & 98 & 26 & 170 & 100 & 27 & 173 & 102 & 27 & 176 \\
\hline \multicolumn{13}{|l|}{$\begin{array}{l}\text { Aggressive Deployment } \\
\text { Pricing with Technology }\end{array}$} \\
\hline (25) & 124 & 38 & 211 & 298 & 90 & 505 & 309 & 93 & 525 & 321 & 97 & 546 \\
\hline 10 & 190 & 56 & 325 & 455 & 133 & 777 & 473 & 138 & 807 & 491 & 144 & 839 \\
\hline 15 & 228 & 75 & 381 & 546 & 179 & 912 & 567 & 186 & 948 & 590 & 194 & 986 \\
\hline \multicolumn{13}{|l|}{ Pricing without Technology } \\
\hline 5 & 595 & 179 & 1012 & 1464 & 439 & 2489 & 1490 & 447 & 2533 & 1517 & 455 & 2579 \\
\hline 8 & 915 & 265 & 1565 & 2251 & 652 & 3849 & 2291 & 664 & 3918 & 2332 & 676 & 3988 \\
\hline 15 & 1101 & 359 & 1844 & 2708 & 881 & 4535 & 2757 & 897 & 4616 & 2806 & 913 & 4699 \\
\hline \multicolumn{13}{|l|}{\begin{tabular}{|l|} 
Full Deployment \\
Pricing with Technology
\end{tabular}} \\
\hline 5 & 322 & 107 & 537 & 763 & 254 & 1272 & 793 & 264 & 1322 & 824 & 275 & 1374 \\
\hline 10 & 495 & 157 & 833 & 1173 & 372 & 1974 & 1219 & 387 & 2051 & 1267 & 402 & 2132 \\
\hline 15 & 564 & 156 & 971 & 1335 & 369 & 2300 & 1387 & 384 & 2390 & 1442 & 399 & 2484 \\
\hline \multicolumn{13}{|l|}{ Pricing without Technology } \\
\hline 5 & 788 & 261 & 1314 & 1938 & 641 & 3234 & 1972 & 653 & 3291 & 2008 & 665 & 3350 \\
\hline 10 & 1217 & 383 & 2051 & 2994 & 941 & 5047 & 3047 & 958 & 5136 & 3102 & 975 & 5228 \\
\hline 15 & 1388 & 380 & 2397 & 3416 & 933 & 5898 & 3476 & 950 & 6003 & 3539 & 967 & 6110 \\
\hline
\end{tabular}




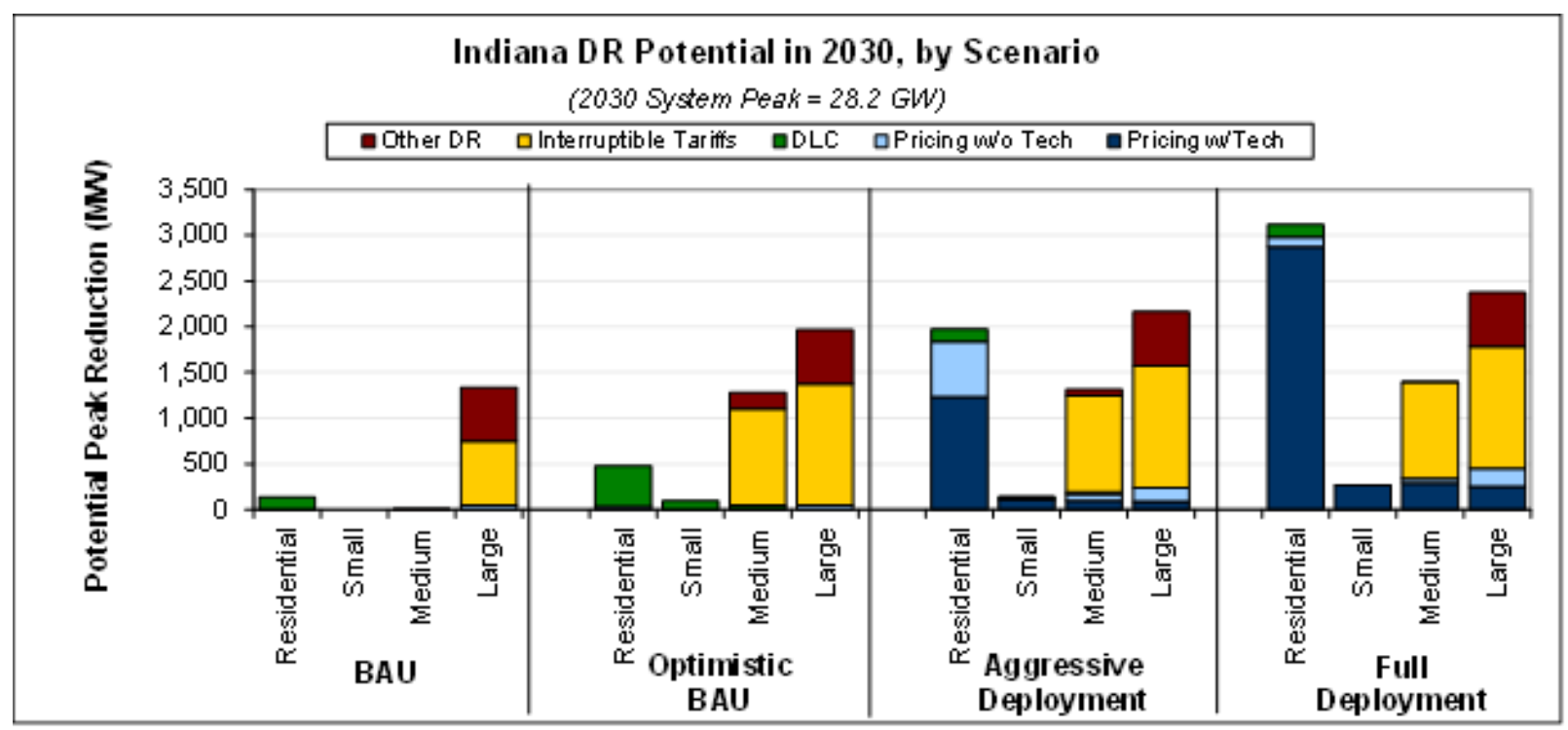

Total Potential Peak Reduction from Demand Response in Indiana, 2030

\begin{tabular}{|c|c|c|c|c|c|c|c|c|c|c|}
\hline & $\begin{array}{l}\text { Residential } \\
\quad(\mathrm{MW})\end{array}$ & $\begin{array}{l}\text { Residential } \\
\text { ( } \% \text { of } \\
\text { svstem) }\end{array}$ & $\begin{array}{l}\text { Small C\&l } \\
(\mathrm{MW})\end{array}$ & $\begin{array}{c}\text { Small C\&I } \\
\text { (\% of } \\
\text { svstem) }\end{array}$ & $\begin{array}{l}\text { Med. C\&I } \\
(\mathrm{MW})\end{array}$ & $\begin{array}{l}\text { Med C\&I } \\
\text { ( } \% \text { of } \\
\text { svstem) }\end{array}$ & $\begin{array}{l}\text { Large C\&I } \\
\quad(\mathrm{MW})\end{array}$ & $\begin{array}{c}\text { Large C\&I } \\
\text { ( } \% \text { of } \\
\text { svstem) }\end{array}$ & $\begin{array}{l}\text { Total } \\
\text { (MW) }\end{array}$ & $\begin{array}{c}\text { Total } \\
\text { ( } \% \text { of } \\
\text { svstem) }\end{array}$ \\
\hline \multicolumn{11}{|l|}{ BAU } \\
\hline Pricing with Technology & 0 & $0.0 \%$ & 0 & $0.0 \%$ & 0 & $0.0 \%$ & 0 & $0.0 \%$ & 0 & $0.0 \%$ \\
\hline Pricing without Technology & 0 & $0.0 \%$ & 0 & $0.0 \%$ & 0 & $0.0 \%$ & 45 & $0.2 \%$ & 46 & $0.2 \%$ \\
\hline Automated/Direct Load Control & 134 & $0.5 \%$ & 0 & $0.0 \%$ & 2 & $0.0 \%$ & 0 & $0.0 \%$ & 136 & $0.6 \%$ \\
\hline Interruptible/Curtailable Tariffs & 0 & $0.0 \%$ & 0 & $0.0 \%$ & 0 & $0.0 \%$ & 702 & $2.9 \%$ & 702 & $2.9 \%$ \\
\hline Other DR Programs & 0 & $0.0 \%$ & 0 & $0.0 \%$ & 1 & $0.0 \%$ & 589 & $2.4 \%$ & 590 & $2.4 \%$ \\
\hline Total & 134 & $0.5 \%$ & 0 & $0.0 \%$ & 3 & $0.0 \%$ & $1,1,336$ & $5.4 \%$ & $\begin{array}{l}1,474 \\
\end{array}$ & $6.0 \%$ \\
\hline \multicolumn{11}{|l|}{ Optimistic BAU } \\
\hline Pricing with Technology & 0 & $0.0 \%$ & 0 & $0.0 \%$ & 0 & $0.0 \%$ & 0 & $0.0 \%$ & 0 & $0.0 \%$ \\
\hline Pricing without Technology & 35 & $0.1 \%$ & 0 & $0.0 \%$ & 4 & $0.0 \%$ & 45 & $0.2 \%$ & 85 & $0.3 \%$ \\
\hline Automated/Direct Load Control & 442 & $1.8 \%$ & 95 & $0.4 \%$ & 41 & $0.2 \%$ & 0 & $0.0 \%$ & 578 & $2.4 \%$ \\
\hline Interruptible/Curtailable Tariffs & 0 & $0.0 \%$ & 0 & $0.0 \%$ & 1,056 & $4.3 \%$ & 1,332 & $5.4 \%$ & 2,388 & $9.7 \%$ \\
\hline Other DR Programs & 0 & $0.0 \%$ & 0 & $0.0 \%$ & 179 & $0.7 \%$ & 589 & $2.4 \%$ & 768 & $3.1 \%$ \\
\hline Total & 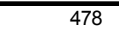 & $1.9 \%$ & 95 & $0.4 \%$ & $1,1,280$ & 5.2\% & $\begin{array}{l}1,967 \\
\end{array}$ & $8.0 \%$ & $3,3,820$ & $15.5 \%$ \\
\hline \multicolumn{11}{|l|}{ Aggressive Deployment } \\
\hline Pricing with Technology & 1,229 & $5.0 \%$ & 112 & $0.5 \%$ & 98 & $0.4 \%$ & 85 & $0.3 \%$ & 1,525 & $6.2 \%$ \\
\hline Pricing without Technology & 610 & $2.5 \%$ & 2 & $0.0 \%$ & 71 & $0.3 \%$ & 155 & $0.6 \%$ & 838 & $3.4 \%$ \\
\hline Automated/Direct Load Control & 134 & $0.5 \%$ & 24 & $0.1 \%$ & 17 & $0.1 \%$ & 0 & $0.0 \%$ & 175 & $0.7 \%$ \\
\hline Interruptible/Curtailable Tariffs & 0 & $0.0 \%$ & 0 & $0.0 \%$ & 1,056 & $4.3 \%$ & 1,332 & $5.4 \%$ & 2,388 & $9.7 \%$ \\
\hline Other DR Programs & 0 & $0.0 \%$ & 0 & $0.0 \%$ & 73 & $0.3 \%$ & 589 & $2.4 \%$ & 662 & $2.7 \%$ \\
\hline Total & 1,973 & $8.0 \%$ & 139 & $0.6 \%$ & 1,315 & $5.3 \%$ & 2,162 & $8.8 \%$ & 5,588 & $22.7 \%$ \\
\hline \multicolumn{11}{|l|}{ Full Deployment } \\
\hline Pricing with Technology & 2,874 & $11.7 \%$ & 263 & $1.1 \%$ & 288 & $1.2 \%$ & 249 & $1.0 \%$ & 3,674 & $14.9 \%$ \\
\hline Pricing without Technology & 107 & $0.4 \%$ & 1 & $0.0 \%$ & 48 & $0.2 \%$ & 201 & $0.8 \%$ & 357 & $1.5 \%$ \\
\hline Automated/Direct Load Control & 134 & $0.5 \%$ & 0 & $0.0 \%$ & 2 & $0.0 \%$ & 0 & $0.0 \%$ & 136 & $0.6 \%$ \\
\hline Interruptible/Curtailable Tariffs & 0 & $0.0 \%$ & 0 & $0.0 \%$ & 1,056 & $4.3 \%$ & 1,332 & $5.4 \%$ & 2,388 & $9.7 \%$ \\
\hline Other DR Programs & 0 & $0.0 \%$ & 0 & $0.0 \%$ & 1 & $0.0 \%$ & 589 & $2.4 \%$ & 590 & $2.4 \%$ \\
\hline Total & 3,115 & $12.7 \%$ & 264 & $1.1 \%$ & $1,1,395$ & $5.7 \%$ & 2,372 & $9.6 \%$ & 7,146 & $29.0 \%$ \\
\hline
\end{tabular}




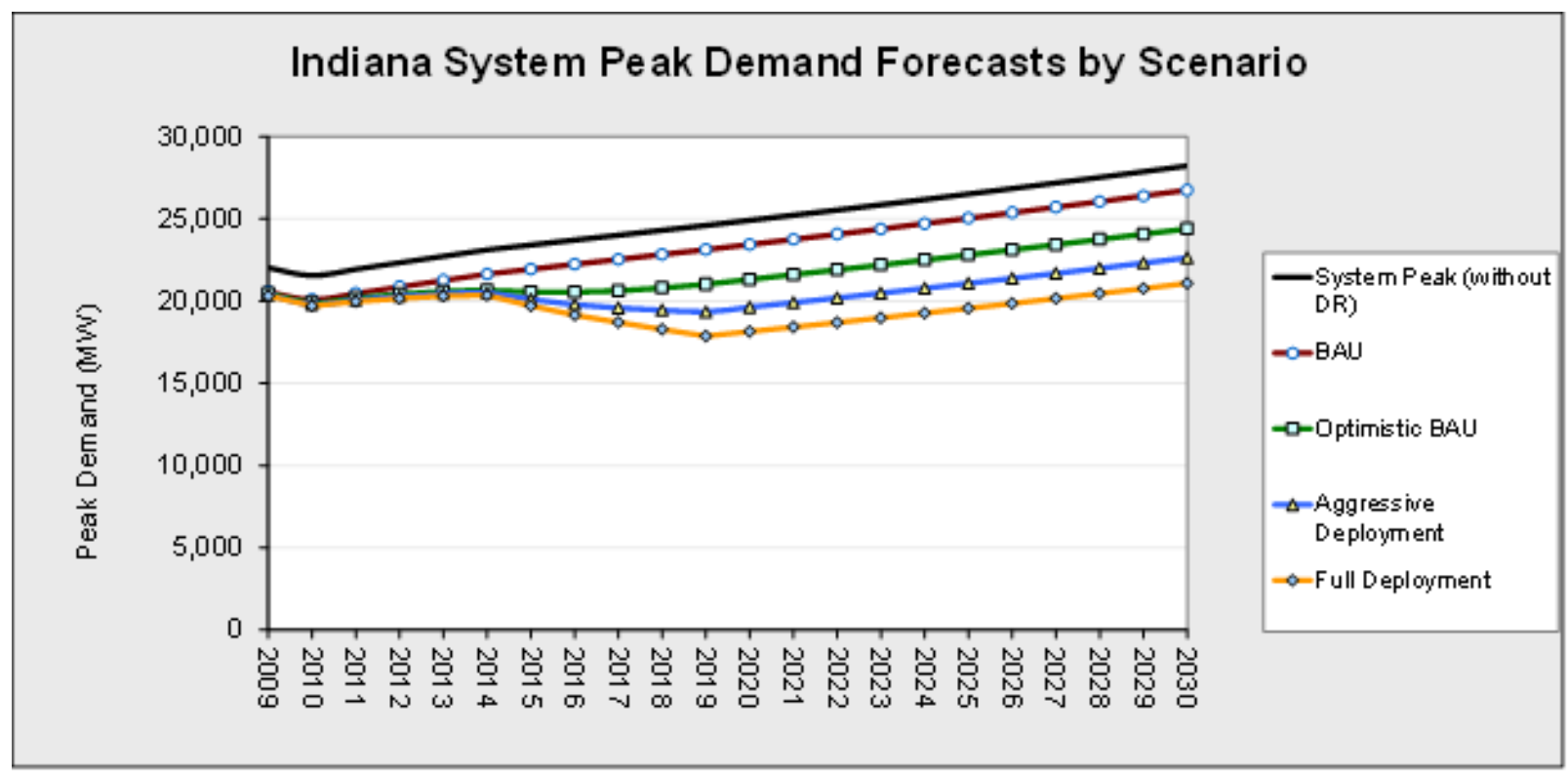

Summary of Monte Carlo Simulation of Potential Peak Load Reduction from Demand Response in Indiana by Scenario, Pricing Program and Price Ratio (MW)

\begin{tabular}{|c|c|c|c|c|c|c|c|c|c|c|c|c|}
\hline & \multicolumn{3}{|c|}{2015} & \multicolumn{3}{|c|}{2020} & \multicolumn{3}{|c|}{2025} & \multicolumn{3}{|c|}{2030} \\
\hline & Mean & Lower & Upper & Mean & Lower & Upper & Mean & Lower & Upper & Mean & Lower & Upper \\
\hline \multirow{2}{*}{\multicolumn{13}{|c|}{ BAU }} \\
\hline & & & & & & & & & & & & \\
\hline 5 & 0 & 0 & 0 & 0 & 0 & 0 & 0 & 0 & 0 & 0 & 0 & c \\
\hline 10 & 0 & 0 & 0 & 0 & 0 & 0 & 0 & 0 & 0 & 0 & 0 & \\
\hline 15 & 0 & 0 & 0 & 0 & 0 & 0 & 0 & 0 & 0 & 0 & 0 & \\
\hline \multicolumn{13}{|l|}{ Pricing without Technology } \\
\hline & 45 & 45 & 45 & 45 & 45 & 45 & 45 & 45 & 45 & 45 & 45 & 45 \\
\hline 10 & 45 & 45 & 45 & 45 & 45 & 45 & 45 & 45 & 45 & 45 & 45 & 45 \\
\hline 15 & 45 & 45 & 45 & 45 & 45 & 45 & 45 & 45 & 45 & 45 & 45 & 45 \\
\hline \multicolumn{13}{|l|}{\begin{tabular}{|l|} 
Optimistic BAU \\
Pricing with Technology
\end{tabular}} \\
\hline 5 & 0 & 0 & 0 & 0 & 0 & 0 & 0 & 0 & 0 & 0 & 0 & \\
\hline 10 & 0 & 0 & 0 & 0 & 0 & 0 & 0 & 0 & 0 & 0 & 0 & \\
\hline 15 & 0 & 0 & 0 & 0 & 0 & 0 & 0 & 0 & 0 & 0 & 0 & ( \\
\hline \multicolumn{13}{|l|}{ Pricing without Technology } \\
\hline 5 & 57 & 49 & 65 & 74 & 54 & 94 & 74 & 54 & 95 & 75 & 54 & 96 \\
\hline 10 & 63 & 51 & 74 & 89 & 60 & 118 & 90 & 60 & 120 & 91 & 61 & 121 \\
\hline 15 & 67 & 52 & 82 & 100 & 62 & 138 & 101 & 62 & 140 & 102 & 63 & 142 \\
\hline \multicolumn{13}{|l|}{\begin{tabular}{|l|} 
Aggressive Deployment \\
Pricing with Technology
\end{tabular}} \\
\hline 5 & 329 & 116 & 542 & 1175 & 414 & 1936 & 1203 & 424 & 1982 & 1231 & 434 & 2028 \\
\hline 10 & 473 & 139 & 807 & 1689 & 496 & 2882 & 1728 & 507 & 2949 & 1769 & 519 & 3019 \\
\hline & 580 & 225 & 935 & 2071 & 804 & 3338 & 2120 & 823 & 3416 & 2169 & 843 & 3496 \\
\hline \multicolumn{13}{|l|}{ Pricing without Technology } \\
\hline & 197 & 89 & 305 & 668 & 237 & 1099 & 685 & 243 & 1127 & 702 & 248 & 1156 \\
\hline 8 & 278 & 94 & 462 & 963 & 284 & 1641 & 987 & 292 & 1683 & 1013 & 299 & 1726 \\
\hline 15 & 339 & 137 & 542 & 1183 & 462 & 1905 & 1213 & 474 & 1953 & 1244 & 486 & 2003 \\
\hline \multicolumn{13}{|l|}{$\begin{array}{l}\text { Full Deployment } \\
\text { Pricing with Technology }\end{array}$} \\
\hline Pricing Witn lecnnology & 762 & 189 & 1334 & 2709 & 673 & 4745 & 2774 & 690 & 4858 & 2841 & 706 & 4975 \\
\hline 10 & 1130 & 321 & 1939 & 4019 & 1143 & 6896 & 4115 & 1170 & 7061 & 4214 & 1198 & 7230 \\
\hline 15 & 1412 & 452 & 2371 & 5021 & 1609 & 8432 & 5141 & 1647 & 8634 & 5264 & 1687 & 8841 \\
\hline \multicolumn{13}{|l|}{ Pricing without Technology } \\
\hline 5 & 94 & 41 & 147 & 297 & 75 & 519 & 307 & 78 & 537 & 318 & 80 & 555 \\
\hline 10 & 135 & 48 & 223 & 444 & 129 & 759 & 459 & 133 & 785 & 475 & 138 & 812 \\
\hline 15 & 168 & 61 & 276 & 556 & 182 & 931 & 575 & 188 & 963 & 595 & 194 & 996 \\
\hline
\end{tabular}




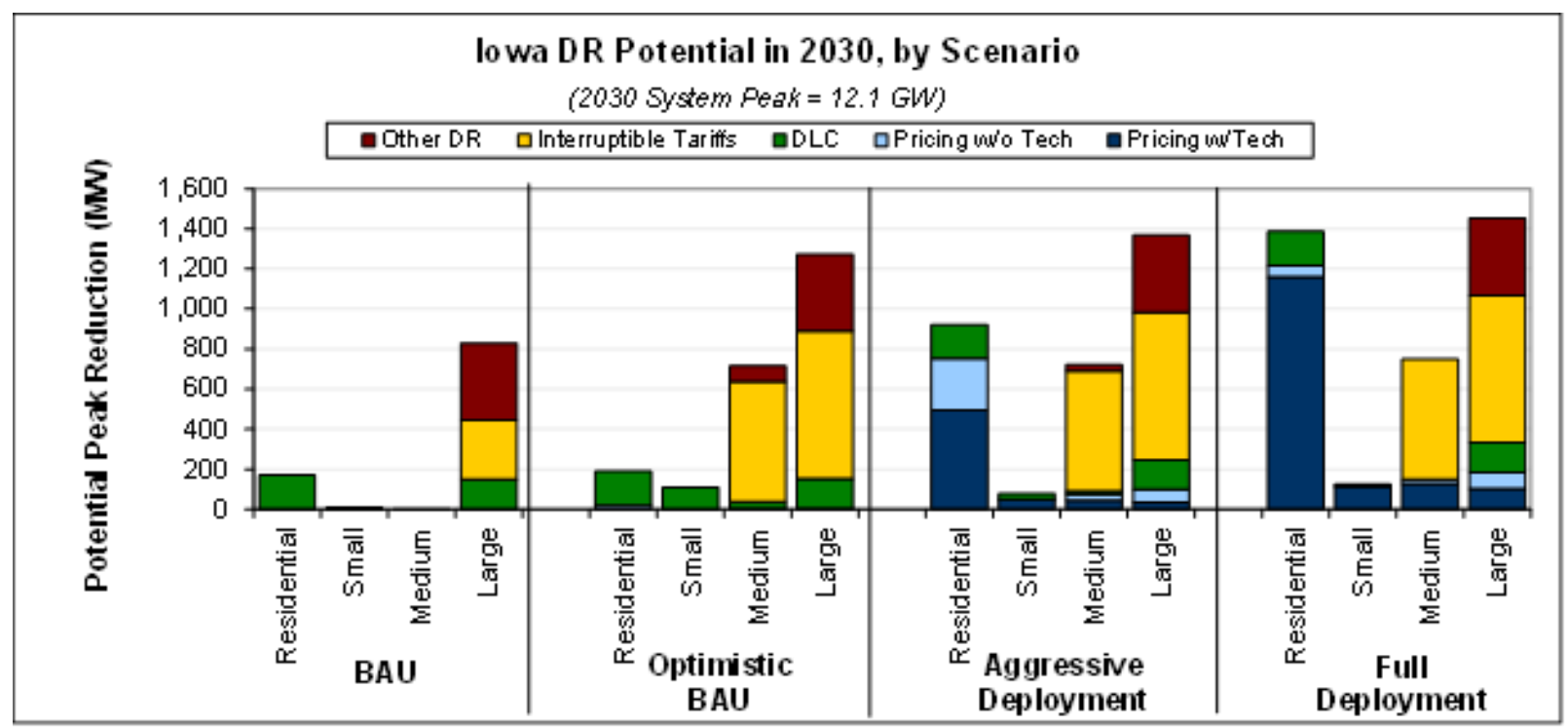

Total Potential Peak Reduction from Demand Response in Iowa, 2030

\begin{tabular}{|c|c|c|c|c|c|c|c|c|c|c|}
\hline & $\begin{array}{l}\text { Residential } \\
\quad(\mathrm{MW})\end{array}$ & $\begin{array}{l}\text { Residential } \\
\text { ( } \% \text { of } \\
\text { svstem) }\end{array}$ & $\begin{array}{l}\text { Small C\&I } \\
(\mathrm{MW})\end{array}$ & $\begin{array}{c}\text { Small C\&I } \\
\text { (\% of } \\
\text { svstem) }\end{array}$ & $\begin{array}{l}\text { Med. C\&I } \\
(\mathrm{MW})\end{array}$ & $\begin{array}{l}\text { Med C\&I } \\
\text { ( } \% \text { of } \\
\text { svstem) }\end{array}$ & $\begin{array}{l}\text { Large C\&I } \\
\quad(\mathrm{MW})\end{array}$ & $\begin{array}{l}\text { Large C\&I } \\
\text { ( } \% \text { of } \\
\text { svstem) }\end{array}$ & $\begin{array}{l}\text { Total } \\
(\mathrm{MW})\end{array}$ & $\begin{array}{c}\text { Total } \\
\text { ( } \% \text { of } \\
\text { svstem) }\end{array}$ \\
\hline \multicolumn{11}{|l|}{ BAU } \\
\hline Pricing with Technology & 0 & $0.0 \%$ & 0 & $0.0 \%$ & 0 & $0.0 \%$ & 0 & $0.0 \%$ & 0 & $0.0 \%$ \\
\hline Pricing without Technology & 0 & $0.0 \%$ & 1 & $0.0 \%$ & 1 & $0.0 \%$ & 2 & $0.0 \%$ & 4 & $0.0 \%$ \\
\hline Automated/Direct Load Control & 170 & $1.6 \%$ & 7 & $0.1 \%$ & 0 & $0.0 \%$ & 147 & $1.4 \%$ & 324 & $3.1 \%$ \\
\hline Interruptible/Curtailable Tariffs & 0 & $0.0 \%$ & 0 & $0.0 \%$ & 0 & $0.0 \%$ & 295 & $2.8 \%$ & 295 & $2.8 \%$ \\
\hline Other DR Programs & 0 & $0.0 \%$ & 0 & $0.0 \%$ & 0 & $0.0 \%$ & 385 & $3.7 \%$ & 385 & $3.7 \%$ \\
\hline Total & 170 & $1.6 \%$ & 8 & $0.1 \%$ & 1 & $0.0 \%$ & 829 & $7.9 \%$ & $\begin{array}{l}1,008 \\
\end{array}$ & $9.6 \%$ \\
\hline \multicolumn{11}{|l|}{ Optimistic BAU } \\
\hline Pricing with Technology & 0 & $0.0 \%$ & 0 & $0.0 \%$ & 0 & $0.0 \%$ & 0 & $0.0 \%$ & 0 & $0.0 \%$ \\
\hline Pricing without Technology & 20 & $0.2 \%$ & 1 & $0.0 \%$ & 3 & $0.0 \%$ & 4 & $0.0 \%$ & 28 & $0.3 \%$ \\
\hline Automated/Direct Load Control & 170 & $1.6 \%$ & 108 & $1.0 \%$ & 34 & $0.3 \%$ & 147 & $1.4 \%$ & 458 & $4.3 \%$ \\
\hline Interruptible/Curtailable Tariffs & 0 & $0.0 \%$ & 0 & $0.0 \%$ & 600 & $5.7 \%$ & 737 & $7.0 \%$ & 1,337 & $12.7 \%$ \\
\hline Other DR Programs & 0 & $0.0 \%$ & 0 & $0.0 \%$ & 79 & $0.7 \%$ & 385 & $3.7 \%$ & 464 & $4.4 \%$ \\
\hline Total & 190 & $1.8 \%$ & 109 & $1.0 \%$ & 715 & $6.8 \%$ & $\overline{1,273}$ & $\overline{12.1 \%}$ & 2,287 & $21.7 \%$ \\
\hline \multicolumn{11}{|l|}{ Aggressive Deployment } \\
\hline Pricing with Technology & 495 & $4.7 \%$ & 49 & $0.5 \%$ & 44 & $0.4 \%$ & 35 & $0.3 \%$ & 623 & $5.9 \%$ \\
\hline Pricing without Technology & 256 & $2.4 \%$ & 1 & $0.0 \%$ & 31 & $0.3 \%$ & 63 & $0.6 \%$ & 353 & $3.3 \%$ \\
\hline Automated/Direct Load Control & 170 & $1.6 \%$ & 28 & $0.3 \%$ & 14 & $0.1 \%$ & 147 & $1.4 \%$ & 359 & $3.4 \%$ \\
\hline Interruptible/Curtailable Tariffs & 0 & $0.0 \%$ & 0 & $0.0 \%$ & 600 & $5.7 \%$ & 737 & $7.0 \%$ & 1,337 & $12.7 \%$ \\
\hline Other DR Programs & 0 & $0.0 \%$ & 0 & $0.0 \%$ & 32 & $0.3 \%$ & 385 & $3.7 \%$ & 418 & $4.0 \%$ \\
\hline Total & 922 & $8.7 \%$ & 78 & $0.7 \%$ & 721 & $6.8 \%$ & 1,368 & $13.0 \%$ & 3,089 & $29.3 \%$ \\
\hline \multicolumn{11}{|l|}{ Full Deployment } \\
\hline Pricing with Technology & 1,159 & $11.0 \%$ & 115 & $1.1 \%$ & 128 & $1.2 \%$ & 102 & $1.0 \%$ & 1,504 & $14.3 \%$ \\
\hline Pricing without Technology & 57 & $0.5 \%$ & 1 & $0.0 \%$ & 21 & $0.2 \%$ & 82 & $0.8 \%$ & 162 & $1.5 \%$ \\
\hline Automated/Direct Load Control & 170 & $1.6 \%$ & 7 & $0.1 \%$ & 0 & $0.0 \%$ & 147 & $1.4 \%$ & 324 & $3.1 \%$ \\
\hline Interruptible/Curtailable Tariffs & 0 & $0.0 \%$ & 0 & $0.0 \%$ & 600 & $5.7 \%$ & 737 & $7.0 \%$ & 1,337 & $12.7 \%$ \\
\hline Other DR Programs & 0 & $0.0 \%$ & 0 & $0.0 \%$ & 0 & $0.0 \%$ & 385 & $3.7 \%$ & 385 & $3.7 \%$ \\
\hline $\begin{array}{l}\text { Total } \\
\end{array}$ & 1,386 & $13.1 \%$ & 124 & $1.2 \%$ & 749 & $7.1 \%$ & 1,453 & $13.8 \%$ & 3,712 & $35.2 \%$ \\
\hline
\end{tabular}




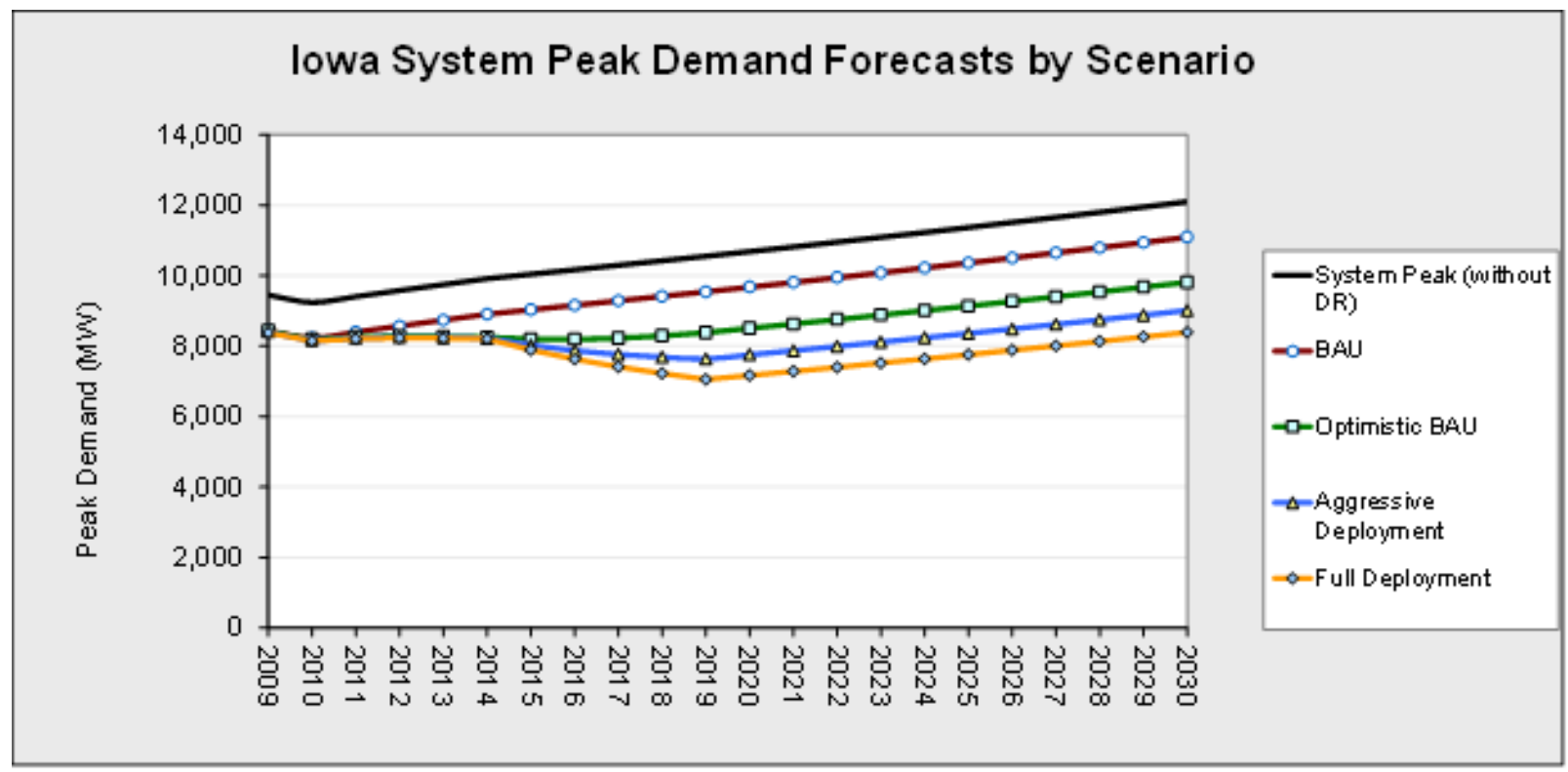

Summary of Monte Carlo Simulation of Potential Peak Load Reduction from Demand Response in Iowa by Scenario, Pricing Program and Price Ratio (MW)

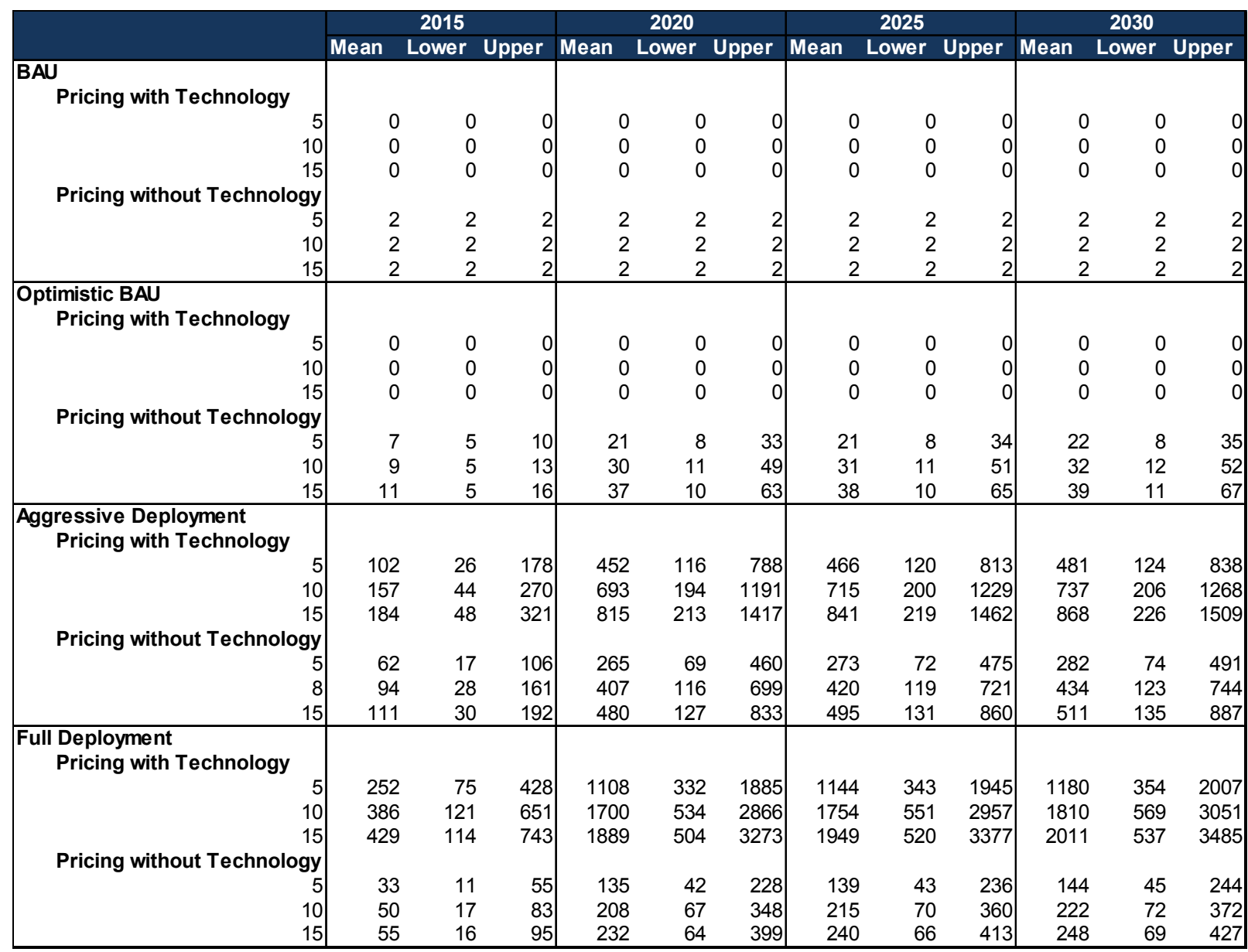




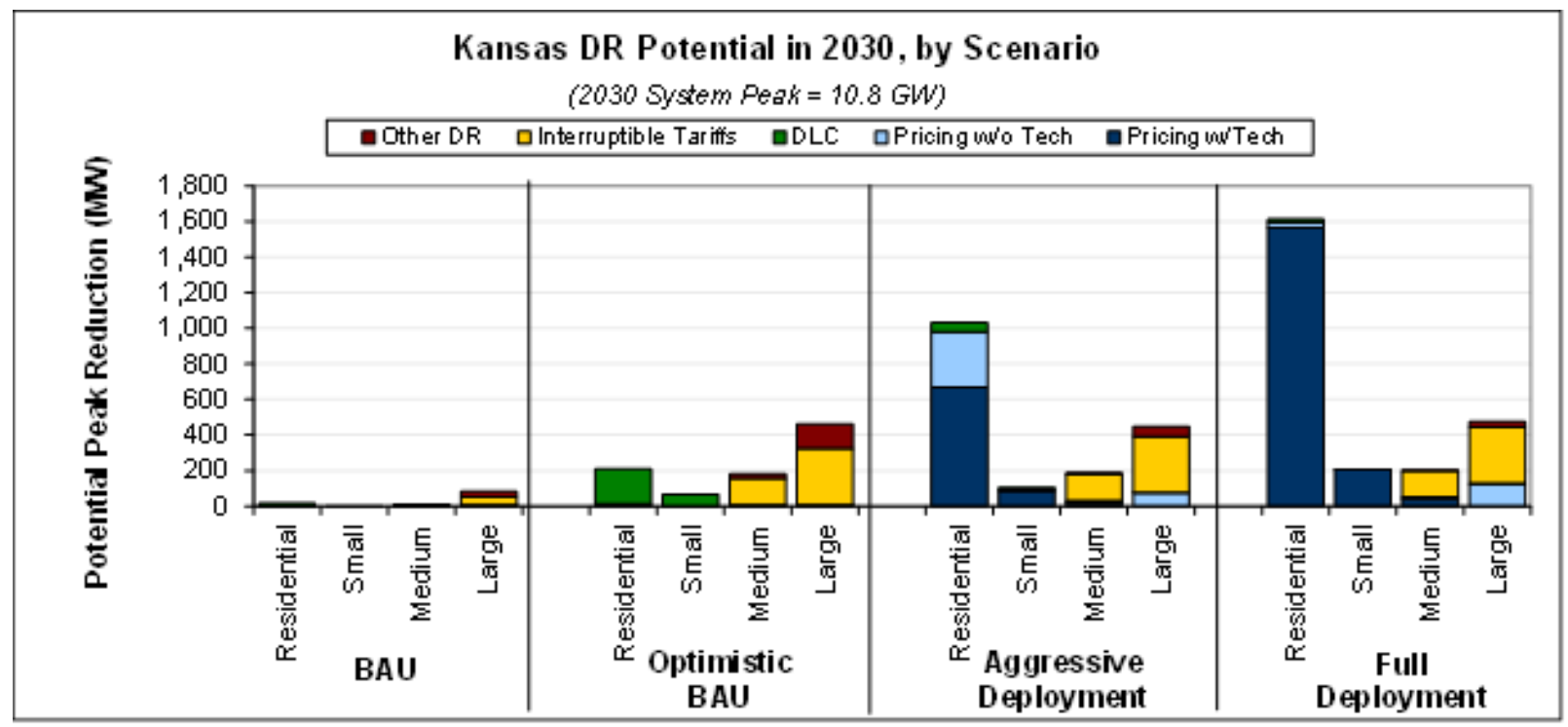

Total Potential Peak Reduction from Demand Response in Kansas, 2030

\begin{tabular}{|c|c|c|c|c|c|c|c|c|c|c|}
\hline & $\begin{array}{l}\text { Residential } \\
\text { (MW) }\end{array}$ & $\begin{array}{l}\text { Residential } \\
\text { ( } \% \text { of } \\
\text { svstem) }\end{array}$ & $\begin{array}{l}\text { Small C\&I } \\
\text { (MW) }\end{array}$ & $\begin{array}{l}\text { Small C\&I } \\
\text { (\% of } \\
\text { svstem) }\end{array}$ & $\begin{array}{l}\text { Med. C\&I } \\
(\mathrm{MW})\end{array}$ & $\begin{array}{l}\text { Med C\&I } \\
\text { ( } \% \text { of } \\
\text { svstem) }\end{array}$ & $\begin{array}{l}\text { Large C\&I } \\
(\mathrm{MW})\end{array}$ & $\begin{array}{l}\text { Large C\&I } \\
\text { ( } \% \text { of } \\
\text { svstem) }\end{array}$ & $\begin{array}{l}\text { Total } \\
\text { (MW) }\end{array}$ & $\begin{array}{c}\text { Total } \\
\text { ( } \% \text { of } \\
\text { svstem) }\end{array}$ \\
\hline \multicolumn{11}{|l|}{ BAU } \\
\hline Pricing with Technology & 0 & $0.0 \%$ & 0 & $0.0 \%$ & 0 & $0.0 \%$ & 0 & $0.0 \%$ & 0 & $0.0 \%$ \\
\hline Pricing without Technology & 1 & $0.0 \%$ & 0 & $0.0 \%$ & 2 & $0.0 \%$ & 6 & $0.1 \%$ & 9 & $0.1 \%$ \\
\hline Automated/Direct Load Control & 16 & $0.2 \%$ & 1 & $0.0 \%$ & 6 & $0.1 \%$ & 2 & $0.0 \%$ & 25 & $0.3 \%$ \\
\hline Interruptible/Curtailable Tariffs & 0 & $0.0 \%$ & 0 & $0.0 \%$ & 0 & $0.0 \%$ & 44 & $0.5 \%$ & 44 & $0.5 \%$ \\
\hline Other DR Programs & 0 & $0.0 \%$ & 0 & $0.0 \%$ & 0 & $0.0 \%$ & 30 & $0.3 \%$ & 30 & $0.3 \%$ \\
\hline Total & $\overline{177}$ & $0.2 \%$ & 1 & $0.0 \%$ & 8 & $0.1 \%$ & 83 & $0.9 \%$ & 109 & $1.2 \%$ \\
\hline \multicolumn{11}{|l|}{ Optimistic BAU } \\
\hline Pricing with Technology & 0 & $0.0 \%$ & 0 & $0.0 \%$ & 0 & $0.0 \%$ & 0 & $0.0 \%$ & 0 & $0.0 \%$ \\
\hline Pricing without Technology & 14 & $0.1 \%$ & 0 & $0.0 \%$ & 2 & $0.0 \%$ & 6 & $0.1 \%$ & 22 & $0.2 \%$ \\
\hline Automated/Direct Load Control & 196 & $2.1 \%$ & 65 & $0.7 \%$ & 6 & $0.1 \%$ & 2 & $0.0 \%$ & 269 & $2.9 \%$ \\
\hline Interruptible/Curtailable Tariffs & 0 & $0.0 \%$ & 0 & $0.0 \%$ & 148 & $1.6 \%$ & 315 & $3.4 \%$ & 463 & $4.9 \%$ \\
\hline Other DR Programs & 0 & $0.0 \%$ & 0 & $0.0 \%$ & 25 & $0.3 \%$ & 138 & $1.5 \%$ & 163 & $1.7 \%$ \\
\hline Total & 209 & $2.2 \%$ & 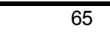 & $0.7 \%$ & 181 & $1.9 \%$ & 462 & $4.9 \%$ & 917 & $9.8 \%$ \\
\hline \multicolumn{11}{|l|}{ Aggressive Deployment } \\
\hline Pricing with Technology & 669 & $7.1 \%$ & 88 & $0.9 \%$ & 14 & $0.1 \%$ & 0 & $0.0 \%$ & 771 & $8.2 \%$ \\
\hline Pricing without Technology & 311 & $3.3 \%$ & 2 & $0.0 \%$ & 10 & $0.1 \%$ & 76 & $0.8 \%$ & 398 & $4.2 \%$ \\
\hline Automated/Direct Load Control & 50 & $0.5 \%$ & 17 & $0.2 \%$ & 6 & $0.1 \%$ & 2 & $0.0 \%$ & 74 & $0.8 \%$ \\
\hline Interruptible/Curtailable Tariffs & 0 & $0.0 \%$ & 0 & $0.0 \%$ & 148 & $1.6 \%$ & 315 & $3.4 \%$ & 463 & $4.9 \%$ \\
\hline Other DR Programs & 0 & $0.0 \%$ & 0 & $0.0 \%$ & 10 & $0.1 \%$ & 56 & $0.6 \%$ & 66 & $0.7 \%$ \\
\hline Total & 1,030 & $11.0 \%$ & 106 & $1.1 \%$ & 188 & $2.0 \%$ & 449 & $4.8 \%$ & 1,773 & $18.9 \%$ \\
\hline \multicolumn{11}{|l|}{ Full Deployment } \\
\hline Pricing with Technology & 1,566 & $16.7 \%$ & 206 & $2.2 \%$ & 40 & $0.4 \%$ & 0 & $0.0 \%$ & 1,812 & $19.3 \%$ \\
\hline Pricing without Technology & 30 & $0.3 \%$ & 1 & $0.0 \%$ & 7 & $0.1 \%$ & 126 & $1.3 \%$ & 164 & $1.7 \%$ \\
\hline Automated/Direct Load Control & 16 & $0.2 \%$ & 1 & $0.0 \%$ & 6 & $0.1 \%$ & 2 & $0.0 \%$ & 25 & $0.3 \%$ \\
\hline Interruptible/Curtailable Tariffs & 0 & $0.0 \%$ & 0 & $0.0 \%$ & 148 & $1.6 \%$ & 315 & $3.4 \%$ & 463 & $4.9 \%$ \\
\hline Other DR Programs & 0 & $0.0 \%$ & 0 & $0.0 \%$ & 0 & $0.0 \%$ & 30 & $0.3 \%$ & 30 & $0.3 \%$ \\
\hline $\begin{array}{l}\text { Total } \\
\end{array}$ & 1,612 & $17.2 \%$ & 207 & $2.2 \%$ & 201 & $2.1 \%$ & 4744 & $5.0 \%$ & 2,494 & $26.6 \%$ \\
\hline
\end{tabular}




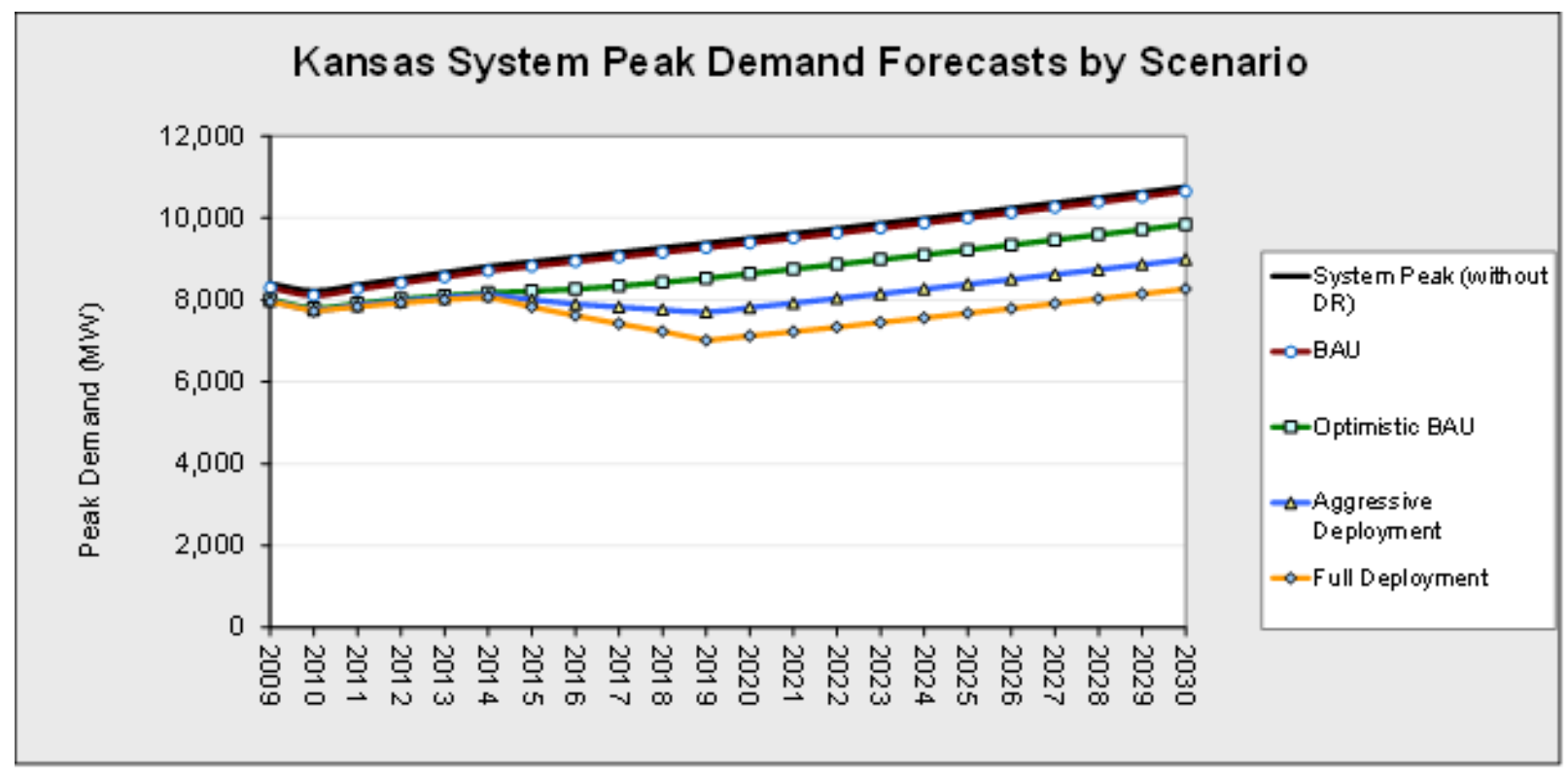

Summary of Monte Carlo Simulation of Potential Peak Load Reduction from Demand Response in Kansas by Scenario, Pricing Program and Price Ratio (MW)

\begin{tabular}{|c|c|c|c|c|c|c|c|c|c|c|c|c|}
\hline & \multicolumn{3}{|c|}{2015} & \multicolumn{3}{|c|}{2020} & \multicolumn{3}{|c|}{2025} & \multicolumn{3}{|c|}{2030} \\
\hline & Mean & Lower & Upper & Mean & Lower & Upper & Mean & Lower & Upper & Mean & Lower & Upper \\
\hline & \multicolumn{12}{|c|}{ BAU } \\
\hline \multicolumn{13}{|l|}{ Pricing with Technology } \\
\hline 5 & 0 & 0 & 0 & 0 & 0 & 0 & 0 & 0 & 0 & 0 & 0 & \\
\hline 10 & 0 & 0 & 0 & 0 & 0 & 0 & 0 & 0 & 0 & 0 & 0 & \\
\hline 15 & 0 & 0 & 0 & 0 & 0 & 0 & 0 & 0 & 0 & 0 & 0 & \\
\hline \multicolumn{13}{|l|}{ Pricing without Technology } \\
\hline 5 & 9 & 9 & 9 & 9 & 9 & 9 & 9 & 9 & 9 & 9 & 9 & \\
\hline 10 & 9 & 9 & 9 & 9 & 9 & 9 & 9 & 9 & 9 & 9 & 9 & \\
\hline 15 & 9 & 9 & 9 & 9 & 9 & 9 & 9 & 9 & 9 & 9 & 9 & \\
\hline \multirow{2}{*}{\multicolumn{13}{|c|}{\begin{tabular}{|l|} 
Optimistic BAU \\
$\quad$ Pricing with Technology
\end{tabular}}} \\
\hline & & & & & & & & & & & & \\
\hline $\begin{array}{r}5 \\
10\end{array}$ & 0 & 0 & 0 & 0 & 0 & 0 & 0 & 0 & 0 & 0 & 0 & \\
\hline 15 & 0 & 0 & 0 & 0 & 0 & 0 & 0 & 0 & 0 & 0 & 0 & \\
\hline \multicolumn{13}{|l|}{ Pricing without Technology } \\
\hline 5 & 12 & 10 & 15 & 19 & 12 & 25 & 19 & 12 & 26 & 19 & 12 & 2 \\
\hline 10 & 15 & 11 & 18 & 24 & 14 & 34 & 24 & 14 & 34 & 25 & 14 & \\
\hline 15 & 16 & 11 & 20 & 27 & 15 & 39 & 27 & 15 & 39 & 27 & 15 & \\
\hline \multicolumn{13}{|l|}{$\begin{array}{l}\text { Aggressive Deployment } \\
\text { Pricing with Technology }\end{array}$} \\
\hline 5 & 148 & 50 & 246 & 583 & 197 & 969 & 594 & 201 & 988 & 606 & 205 & 100 \\
\hline 10 & 219 & 73 & 366 & 863 & 286 & 1440 & 880 & 292 & 1467 & 896 & 297 & 149 \\
\hline 15 & 258 & 67 & 449 & 1015 & 263 & 1766 & 1034 & 268 & 1800 & 1053 & 273 & 183 \\
\hline \multicolumn{13}{|l|}{ Pricing without Technology } \\
\hline 5 & 82 & 29 & 134 & 318 & 108 & 527 & 324 & 110 & 539 & 331 & 112 & 55 \\
\hline 8 & 121 & 41 & 201 & 471 & 157 & 785 & 481 & 160 & 802 & 492 & 164 & 81 \\
\hline 15 & 142 & 37 & 247 & 554 & 145 & 964 & 566 & 148 & 985 & 578 & 151 & 1006 \\
\hline \multicolumn{13}{|l|}{$\begin{array}{l}\text { Full Deployment } \\
\text { Pricing with Technology }\end{array}$} \\
\hline 5 & 330 & 91 & 569 & 1298 & 360 & 2237 & 1323 & 366 & 2280 & 1348 & 373 & 232 \\
\hline 10 & 535 & 173 & 897 & 2104 & 682 & 3526 & 2144 & 694 & 3593 & 2184 & 708 & 366 \\
\hline 15 & 585 & 164 & 1007 & 2302 & 645 & 3959 & 2345 & 657 & 4034 & 2390 & 669 & 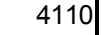 \\
\hline \multicolumn{13}{|l|}{ Pricing without Technology } \\
\hline 5 & 38 & 12 & 63 & 142 & 40 & 244 & 147 & 42 & 252 & 152 & 43 & 261 \\
\hline 10 & 60 & 21 & 100 & 231 & 76 & 386 & 239 & 79 & 399 & 247 & 81 & 412 \\
\hline 15 & 66 & 20 & 112 & 253 & 73 & 434 & 262 & 75 & 449 & 271 & 78 & 46 \\
\hline
\end{tabular}




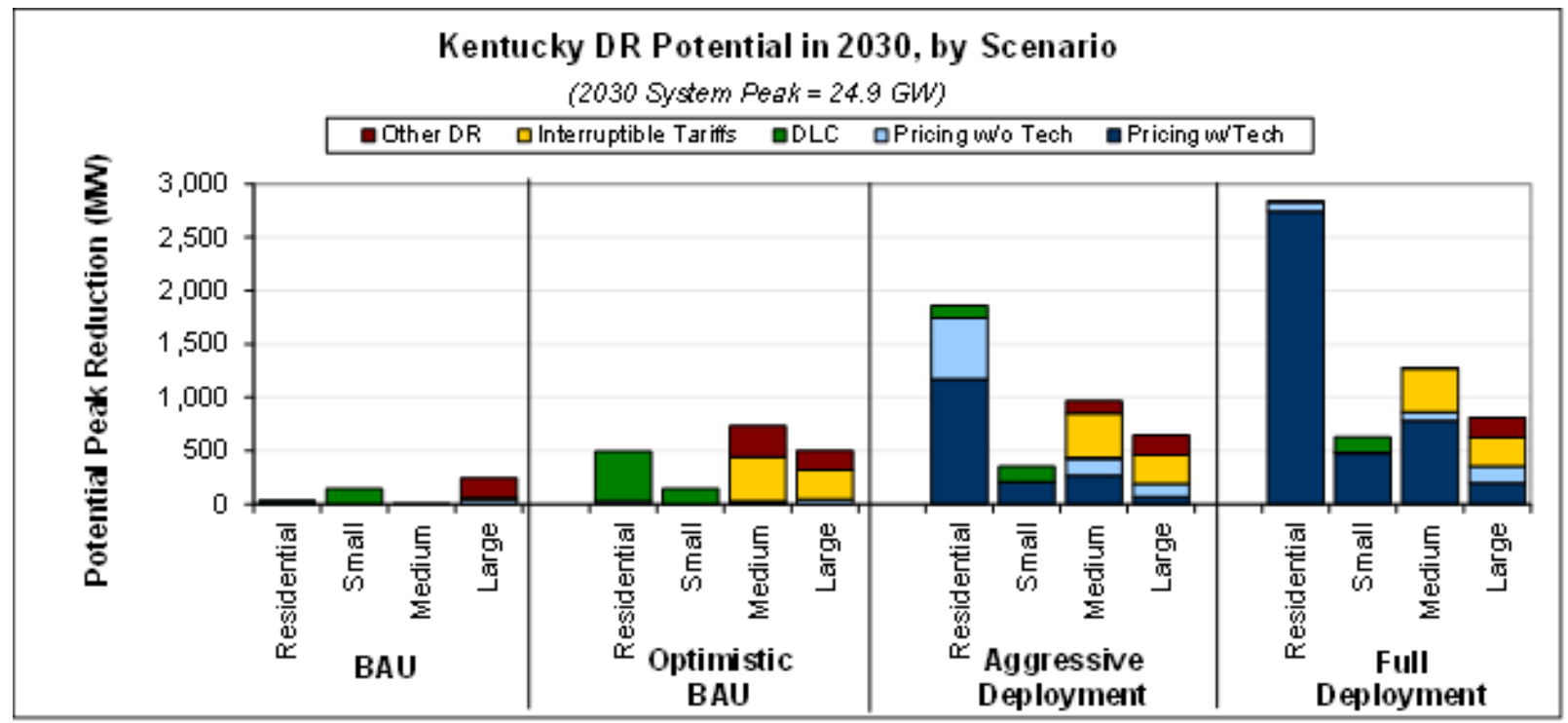

Total Potential Peak Reduction from Demand Response in Kentucky, 2030

\begin{tabular}{|c|c|c|c|c|c|c|c|c|c|c|}
\hline & $\begin{array}{l}\text { Residential } \\
\quad(\mathrm{MW})\end{array}$ & $\begin{array}{l}\text { Residential } \\
\text { ( } \% \text { of } \\
\text { svstem) }\end{array}$ & $\begin{array}{l}\text { Small C\&I } \\
(\mathrm{MW})\end{array}$ & $\begin{array}{c}\text { Small C\&I } \\
\text { (\% of } \\
\text { svstem) }\end{array}$ & $\begin{array}{l}\text { Med. C\&I } \\
(\mathrm{MW})\end{array}$ & $\begin{array}{l}\text { Med C\&I } \\
\text { ( } \% \text { of } \\
\text { svstem) }\end{array}$ & $\begin{array}{l}\text { Large C\&I } \\
\quad(\mathrm{MW})\end{array}$ & $\begin{array}{l}\text { Large C\&I } \\
\text { ( } \% \text { of } \\
\text { svstem) }\end{array}$ & $\begin{array}{l}\text { Total } \\
(\mathrm{MW})\end{array}$ & $\begin{array}{c}\text { Total } \\
\text { ( } \% \text { of } \\
\text { svstem) }\end{array}$ \\
\hline \multicolumn{11}{|l|}{ BAU } \\
\hline Pricing with Technology & 0 & $0.0 \%$ & 0 & $0.0 \%$ & 0 & $0.0 \%$ & 0 & $0.0 \%$ & 0 & $0.0 \%$ \\
\hline Pricing without Technology & 22 & $0.1 \%$ & 0 & $0.0 \%$ & 0 & $0.0 \%$ & 45 & $0.2 \%$ & 67 & $0.3 \%$ \\
\hline Automated/Direct Load Control & 11 & $0.1 \%$ & 145 & $0.7 \%$ & 0 & $0.0 \%$ & 0 & $0.0 \%$ & 156 & $0.7 \%$ \\
\hline Interruptible/Curtailable Tariffs & 0 & $0.0 \%$ & 0 & $0.0 \%$ & 0 & $0.0 \%$ & 15 & $0.1 \%$ & 15 & $0.1 \%$ \\
\hline Other DR Programs & 0 & $0.0 \%$ & 0 & $0.0 \%$ & 5 & $0.0 \%$ & 185 & $0.9 \%$ & 190 & $0.9 \%$ \\
\hline Total & 33 & $0.2 \%$ & 145 & $0.7 \%$ & 5 & $0.0 \%$ & 245 & $1.1 \%$ & 428 & $2.0 \%$ \\
\hline \multicolumn{11}{|l|}{ Optimistic BAU } \\
\hline Pricing with Technology & 0 & $0.0 \%$ & 0 & $0.0 \%$ & 0 & $0.0 \%$ & 0 & $0.0 \%$ & 0 & $0.0 \%$ \\
\hline Pricing without Technology & 27 & $0.1 \%$ & 0 & $0.0 \%$ & 9 & $0.0 \%$ & 45 & $0.2 \%$ & 81 & $0.4 \%$ \\
\hline Automated/Direct Load Control & 467 & $2.1 \%$ & 145 & $0.7 \%$ & 22 & $0.1 \%$ & 0 & $0.0 \%$ & 634 & $2.9 \%$ \\
\hline Interruptible/Curtailable Tariffs & 0 & $0.0 \%$ & 0 & $0.0 \%$ & 413 & $1.9 \%$ & 273 & $1.3 \%$ & 686 & $3.2 \%$ \\
\hline Other DR Programs & 0 & $0.0 \%$ & 0 & $0.0 \%$ & 288 & $1.3 \%$ & 185 & $0.9 \%$ & 473 & $2.2 \%$ \\
\hline Total & 494 & $2.3 \%$ & 145 & $0.7 \%$ & 732 & $3.4 \%$ & 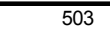 & $2.3 \%$ & $\begin{array}{l}1,874 \\
\end{array}$ & $8.6 \%$ \\
\hline \multicolumn{11}{|l|}{ Aggressive Deployment } \\
\hline Pricing with Technology & 1,171 & $5.4 \%$ & 205 & $0.9 \%$ & 268 & $1.2 \%$ & 67 & $0.3 \%$ & 1,712 & $7.9 \%$ \\
\hline Pricing without Technology & 572 & $2.6 \%$ & 4 & $0.0 \%$ & 160 & $0.7 \%$ & 122 & $0.6 \%$ & 858 & $3.9 \%$ \\
\hline Automated/Direct Load Control & 119 & $0.5 \%$ & 145 & $0.7 \%$ & 9 & $0.0 \%$ & 0 & $0.0 \%$ & 273 & $1.3 \%$ \\
\hline Interruptible/Curtailable Tariffs & 0 & $0.0 \%$ & 0 & $0.0 \%$ & 413 & $1.9 \%$ & 273 & $1.3 \%$ & 686 & $3.2 \%$ \\
\hline Other DR Programs & 0 & $0.0 \%$ & 0 & $0.0 \%$ & 117 & $0.5 \%$ & 185 & $0.9 \%$ & 302 & $1.4 \%$ \\
\hline Total & 1,862 & $8.6 \%$ & 354 & $1.6 \%$ & 967 & $4.5 \%$ & 647 & $3.0 \%$ & 3,830 & $17.6 \%$ \\
\hline \multicolumn{11}{|l|}{ Full Deployment } \\
\hline Pricing with Technology & 2,739 & $12.6 \%$ & 481 & $2.2 \%$ & 783 & $3.6 \%$ & 196 & $0.9 \%$ & 4,199 & $19.3 \%$ \\
\hline Pricing without Technology & 90 & $0.4 \%$ & 2 & $0.0 \%$ & 78 & $0.4 \%$ & 158 & $0.7 \%$ & 327 & $1.5 \%$ \\
\hline Automated/Direct Load Control & 11 & $0.1 \%$ & 145 & $0.7 \%$ & 0 & $0.0 \%$ & 0 & $0.0 \%$ & 156 & $0.7 \%$ \\
\hline Interruptible/Curtailable Tariffs & 0 & $0.0 \%$ & 0 & $0.0 \%$ & 413 & $1.9 \%$ & 273 & $1.3 \%$ & 686 & $3.2 \%$ \\
\hline Other DR Programs & 0 & $0.0 \%$ & 0 & $0.0 \%$ & 5 & $0.0 \%$ & 185 & $0.9 \%$ & 190 & $0.9 \%$ \\
\hline$\overline{\text { Total }}$ & 2,840 & $13.1 \%$ & 628 & $2.9 \%$ & 1,279 & $5.9 \%$ & 812 & $3.7 \%$ & 5,559 & $25.6 \%$ \\
\hline
\end{tabular}




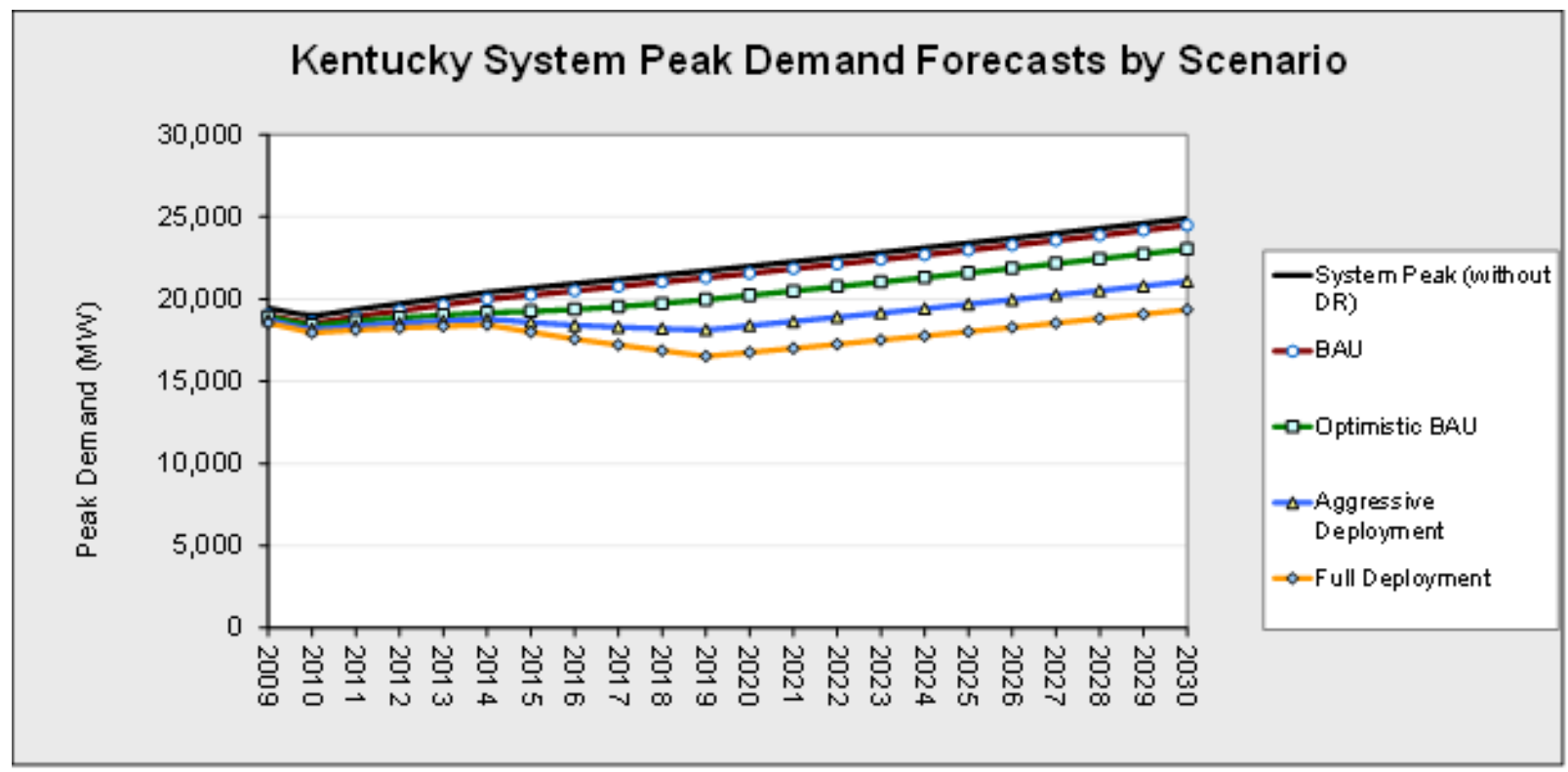

Summary of Monte Carlo Simulation of Potential Peak Load Reduction from Demand Response in Kentucky by Scenario, Pricing Program and Price Ratio (MW)

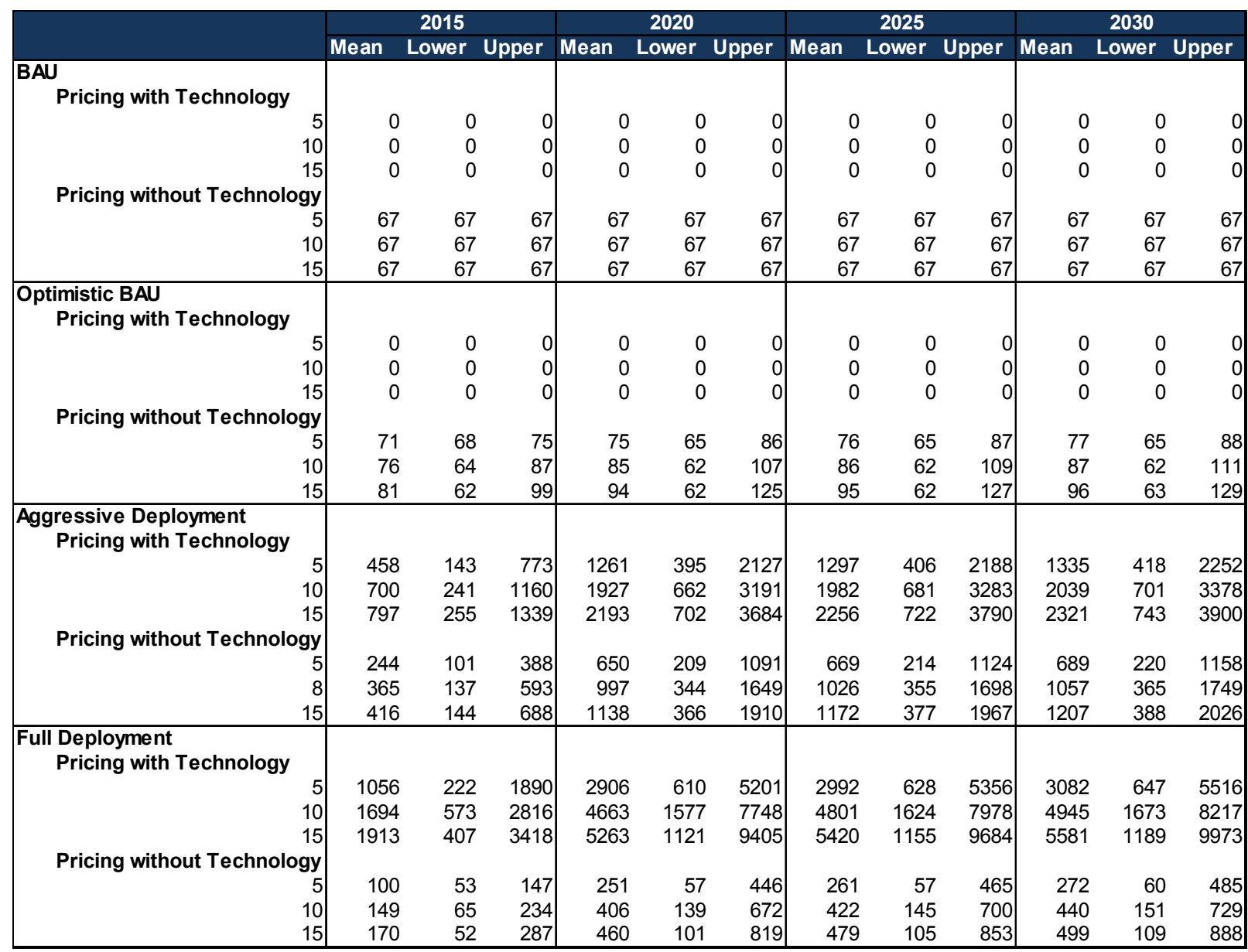




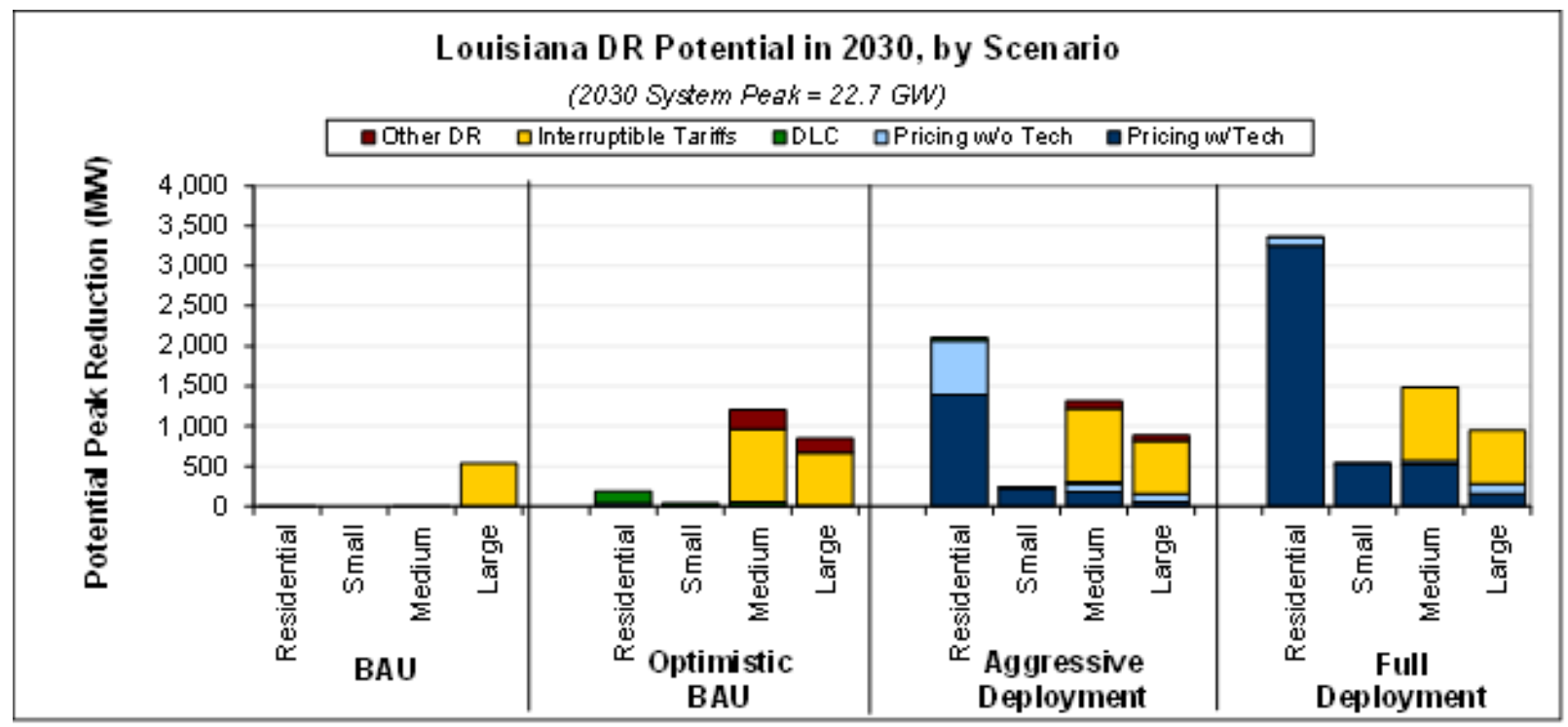

Total Potential Peak Reduction from Demand Response in Louisiana, 2030

\begin{tabular}{|c|c|c|c|c|c|c|c|c|c|c|}
\hline & $\begin{array}{l}\text { Residential } \\
\quad(\mathrm{MW})\end{array}$ & $\begin{array}{l}\text { Residential } \\
\text { ( } \% \text { of } \\
\text { svstem) }\end{array}$ & $\begin{array}{l}\text { Small C\&I } \\
(\mathrm{MW})\end{array}$ & $\begin{array}{c}\text { Small C\&I } \\
\text { (\% of } \\
\text { svstem) }\end{array}$ & $\begin{array}{l}\text { Med. C\&I } \\
(\mathrm{MW})\end{array}$ & $\begin{array}{l}\text { Med C\&I } \\
\text { ( } \% \text { of } \\
\text { svstem) }\end{array}$ & $\begin{array}{l}\text { Large C\&I } \\
\quad(\mathrm{MW})\end{array}$ & $\begin{array}{l}\text { Large C\&I } \\
\text { ( } \% \text { of } \\
\text { svstem) }\end{array}$ & $\begin{array}{l}\text { Total } \\
(\mathrm{MW})\end{array}$ & $\begin{array}{c}\text { Total } \\
\text { ( } \% \text { of } \\
\text { svstem) }\end{array}$ \\
\hline \multicolumn{11}{|l|}{ BAU } \\
\hline Pricing with Technology & 0 & $0.0 \%$ & 0 & $0.0 \%$ & 0 & $0.0 \%$ & 0 & $0.0 \%$ & 0 & $0.0 \%$ \\
\hline Pricing without Technology & 0 & $0.0 \%$ & 0 & $0.0 \%$ & 1 & $0.0 \%$ & 0 & $0.0 \%$ & 1 & $0.0 \%$ \\
\hline Automated/Direct Load Control & 0 & $0.0 \%$ & 0 & $0.0 \%$ & 0 & $0.0 \%$ & 0 & $0.0 \%$ & 0 & $0.0 \%$ \\
\hline Interruptible/Curtailable Tariffs & 0 & $0.0 \%$ & 0 & $0.0 \%$ & 0 & $0.0 \%$ & 535 & $2.7 \%$ & 535 & $2.7 \%$ \\
\hline Other DR Programs & 0 & $0.0 \%$ & 0 & $0.0 \%$ & 0 & $0.0 \%$ & 0 & $0.0 \%$ & 0 & $0.0 \%$ \\
\hline Total & 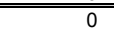 & $0.0 \%$ & 0 & $0.0 \%$ & 1 & $0.0 \%$ & 535 & $2.7 \%$ & 537 & $2.7 \%$ \\
\hline \multicolumn{11}{|l|}{ Optimistic BAU } \\
\hline Pricing with Technology & 0 & $0.0 \%$ & 0 & $0.0 \%$ & 0 & $0.0 \%$ & 0 & $0.0 \%$ & 0 & $0.0 \%$ \\
\hline Pricing without Technology & 39 & $0.2 \%$ & 0 & $0.0 \%$ & 7 & $0.0 \%$ & 4 & $0.0 \%$ & 51 & $0.3 \%$ \\
\hline Automated/Direct Load Control & 151 & $0.8 \%$ & 38 & $0.2 \%$ & 46 & $0.2 \%$ & 0 & $0.0 \%$ & 234 & $1.2 \%$ \\
\hline Interruptible/Curtailable Tariffs & 0 & $0.0 \%$ & 0 & $0.0 \%$ & 915 & $4.6 \%$ & 663 & $3.4 \%$ & 1,579 & $8.0 \%$ \\
\hline Other DR Programs & 0 & $0.0 \%$ & 0 & $0.0 \%$ & 237 & $1.2 \%$ & 178 & $0.9 \%$ & 415 & $2.1 \%$ \\
\hline Total & 190 & $1.0 \%$ & 38 & $0.2 \%$ & 1,205 & $6.1 \%$ & 846 & $4.3 \%$ & 2,279 & $11.5 \%$ \\
\hline \multicolumn{11}{|l|}{ Aggressive Deployment } \\
\hline Pricing with Technology & 1,389 & $7.0 \%$ & 229 & $1.2 \%$ & 178 & $0.9 \%$ & 53 & $0.3 \%$ & 1,849 & $9.4 \%$ \\
\hline Pricing without Technology & 679 & $3.4 \%$ & 4 & $0.0 \%$ & 106 & $0.5 \%$ & 97 & $0.5 \%$ & 887 & $4.5 \%$ \\
\hline Automated/Direct Load Control & 38 & $0.2 \%$ & 10 & $0.0 \%$ & 19 & $0.1 \%$ & 0 & $0.0 \%$ & 67 & $0.3 \%$ \\
\hline Interruptible/Curtailable Tariffs & 0 & $0.0 \%$ & 0 & $0.0 \%$ & 915 & $4.6 \%$ & 663 & $3.4 \%$ & 1,579 & $8.0 \%$ \\
\hline Other DR Programs & 0 & $0.0 \%$ & 0 & $0.0 \%$ & 97 & $0.5 \%$ & 73 & $0.4 \%$ & 170 & $0.9 \%$ \\
\hline Total & 2,107 & $10.7 \%$ & 242 & $1.2 \%$ & 1,315 & $6.7 \%$ & 886 & $4.5 \%$ & 4,551 & $23.0 \%$ \\
\hline \multicolumn{11}{|l|}{ Full Deployment } \\
\hline Pricing with Technology & 3,250 & $16.5 \%$ & 535 & $2.7 \%$ & 520 & $2.6 \%$ & 156 & $0.8 \%$ & 4,460 & $22.6 \%$ \\
\hline Pricing without Technology & 107 & $0.5 \%$ & 2 & $0.0 \%$ & 52 & $0.3 \%$ & 126 & $0.6 \%$ & 287 & $1.5 \%$ \\
\hline Automated/Direct Load Control & 0 & $0.0 \%$ & 0 & $0.0 \%$ & 0 & $0.0 \%$ & 0 & $0.0 \%$ & 0 & $0.0 \%$ \\
\hline Interruptible/Curtailable Tariffs & 0 & $0.0 \%$ & 0 & $0.0 \%$ & 915 & $4.6 \%$ & 663 & $3.4 \%$ & 1,579 & $8.0 \%$ \\
\hline Other DR Programs & 0 & $0.0 \%$ & 0 & $0.0 \%$ & 0 & $0.0 \%$ & 0 & $0.0 \%$ & 0 & $0.0 \%$ \\
\hline Total & 3,358 & $17.0 \%$ & 537 & $2.7 \%$ & 1,487 & $7.5 \%$ & 945 & $4.8 \%$ & 6,326 & $32.0 \%$ \\
\hline
\end{tabular}




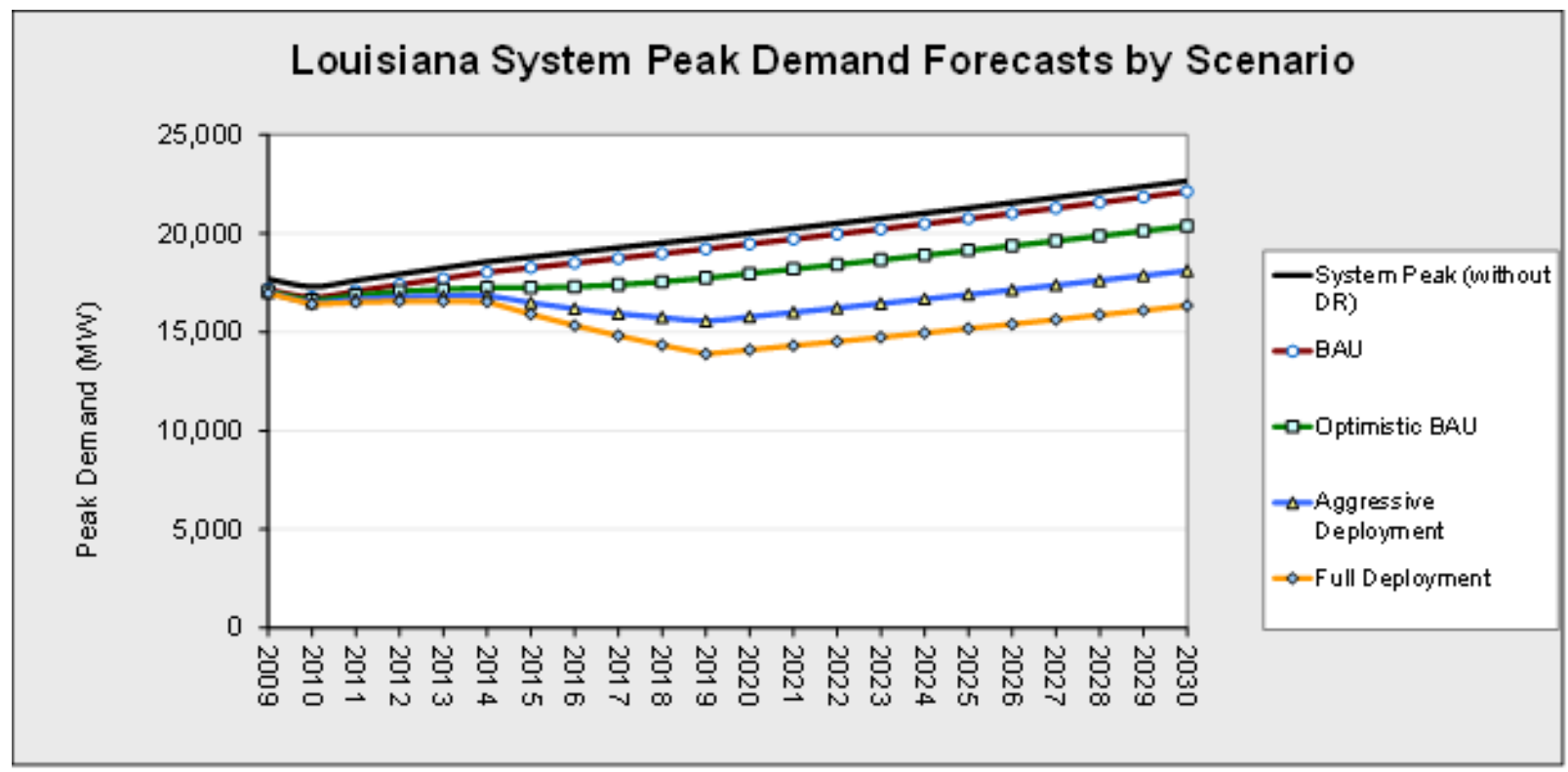

Summary of Monte Carlo Simulation of Potential Peak Load Reduction from Demand Response in Louisiana by Scenario, Pricing Program and Price Ratio (MW)

\begin{tabular}{|c|c|c|c|c|c|c|c|c|c|c|c|c|}
\hline & \multicolumn{3}{|c|}{2015} & \multicolumn{3}{|c|}{2020} & \multicolumn{3}{|c|}{2025} & \multicolumn{3}{|c|}{2030} \\
\hline & Mean & Lower & Upper & \multirow[t]{2}{*}{ Mean } & Lower & Upper & \multirow[t]{2}{*}{ Mean } & Lower & Upper & \multirow[t]{2}{*}{ Mean } & Lower & Upper \\
\hline BAU & & & & & & & & & & & & \\
\hline 5 & 0 & 0 & 0 & 0 & 0 & 0 & 0 & 0 & 0 & 0 & 0 & \\
\hline 10 & 0 & 0 & 0 & 0 & 0 & 0 & 0 & 0 & 0 & 0 & 0 & \\
\hline 15 & 0 & 0 & 0 & 0 & 0 & 0 & 0 & 0 & 0 & 0 & 0 & \\
\hline Pricing without Technology & & & & & & & & & & & & \\
\hline 5 & 1 & 1 & 1 & 1 & 1 & 1 & 1 & 1 & 1 & 1 & 1 & \\
\hline 10 & 1 & 1 & 1 & 1 & 1 & 1 & 1 & 1 & 1 & 1 & 1 & \\
\hline 15 & 1 & 1 & 1 & 1 & 1 & 1 & 1 & 1 & 1 & 1 & 1 & \\
\hline $\begin{array}{l}\text { Optimistic BAU } \\
\text { Pricing with Tech }\end{array}$ & & & & & & & & & & & & \\
\hline 5 & 0 & 0 & 0 & 0 & 0 & 0 & 0 & 0 & 0 & 0 & 0 & \\
\hline 10 & 0 & 0 & 0 & 0 & 0 & 0 & 0 & 0 & 0 & 0 & 0 & \\
\hline 15 & 0 & 0 & 0 & 0 & 0 & 0 & 0 & 0 & 0 & 0 & 0 & \\
\hline Pricing without Tec & & & & & & & & & & & & \\
\hline & 20 & 5 & 36 & 37 & 9 & 64 & 38 & 10 & 66 & 39 & 10 & \\
\hline 10 & 30 & 8 & 52 & 54 & 15 & 94 & 56 & 15 & 97 & 57 & 15 & \\
\hline 15 & 38 & 10 & 66 & 68 & 18 & 119 & 70 & 18 & 122 & 72 & 19 & 12 \\
\hline $\begin{array}{l}\text { Aggressive Deployment } \\
\text { Pricing with Technology }\end{array}$ & & & & & & & & & & & & \\
\hline 5 & 457 & 142 & 773 & 1350 & 418 & 2282 & 1383 & 429 & 2338 & 1417 & 439 & 2395 \\
\hline 10 & 692 & 185 & 1199 & 2041 & 545 & 3538 & 2091 & 558 & 3624 & 2143 & 572 & 371 \\
\hline 15 & 807 & 182 & 1431 & 2381 & 537 & 4225 & 2439 & 550 & 4328 & 2499 & 564 & 443 \\
\hline Pricir & & & & & & & & & & & & \\
\hline 5 & 224 & 70 & 379 & 662 & 206 & 1118 & 678 & 211 & 1145 & 695 & 216 & 117 \\
\hline 8 & 341 & 91 & 590 & 1005 & 270 & 1740 & 1030 & 276 & 1783 & 1055 & 283 & 182 \\
\hline 15 & 399 & 91 & 707 & 1175 & 267 & 2083 & 1204 & 274 & 2134 & 1234 & 281 & 218 \\
\hline $\begin{array}{l}\text { Full Deployment } \\
\text { Pricing with Technology }\end{array}$ & & & & & & & & & & & & \\
\hline 5 & 1146 & 387 & 1906 & 3382 & 1141 & 5624 & 3469 & 1170 & 5767 & 3558 & 1201 & 591 \\
\hline 10 & 1635 & 431 & 2838 & 4823 & 1272 & 8375 & 4946 & 1305 & 8587 & 5074 & 1339 & 880 \\
\hline 15 & 1902 & 479 & 3325 & 5613 & 1414 & 9813 & 5756 & 1450 & 10061 & 5904 & 1488 & 1032 \\
\hline Pricing without Technology & & & & & & & & & & & & \\
\hline 5 & 78 & 27 & 130 & 235 & 80 & 390 & 245 & 84 & 407 & 256 & 88 & 42 \\
\hline 10 & 113 & 30 & 196 & 338 & 91 & 585 & 353 & 95 & 611 & 369 & 99 & 63 \\
\hline 15 & 132 & 34 & 230 & 396 & 102 & 690 & 413 & 107 & 720 & 432 & 111 & 75 \\
\hline
\end{tabular}




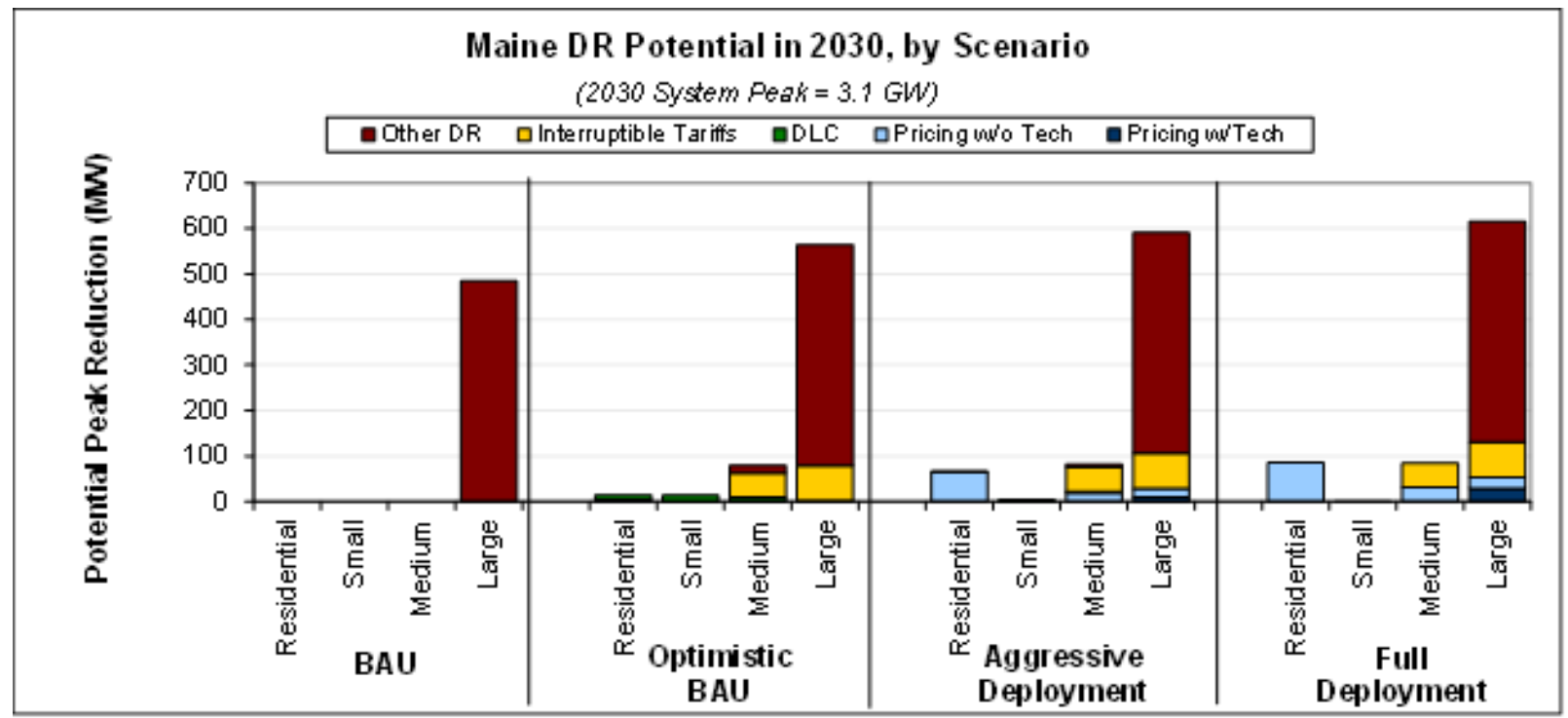

Total Potential Peak Reduction from Demand Response in Maine, 2030

\begin{tabular}{|c|c|c|c|c|c|c|c|c|c|c|}
\hline & $\begin{array}{l}\text { Residential } \\
\text { (MW) }\end{array}$ & $\begin{array}{l}\text { Residential } \\
\text { ( } \% \text { of } \\
\text { svstem) }\end{array}$ & $\begin{array}{c}\text { Small C\&I } \\
(\mathrm{MW})\end{array}$ & $\begin{array}{c}\text { Small C\&I } \\
\text { ( } \% \text { of } \\
\text { svstem) }\end{array}$ & $\begin{array}{l}\text { Med. C\&I } \\
(\mathrm{MW})\end{array}$ & $\begin{array}{l}\text { Med C\&I } \\
(\% \text { of } \\
\text { svstem) }\end{array}$ & $\begin{array}{l}\text { Large C\&I } \\
(\mathrm{MW})\end{array}$ & $\begin{array}{l}\text { Large C\&I } \\
\text { (\% of } \\
\text { svstem) }\end{array}$ & $\begin{array}{l}\text { Total } \\
\text { (MW) }\end{array}$ & $\begin{array}{c}\text { Total } \\
\text { ( } \% \text { of } \\
\text { svstem) }\end{array}$ \\
\hline \multicolumn{11}{|l|}{ BAU } \\
\hline Pricing with Technology & 0 & $0.0 \%$ & 0 & $0.0 \%$ & 0 & $0.0 \%$ & 0 & $0.0 \%$ & 0 & $0.0 \%$ \\
\hline Pricing without Technology & 0 & $0.0 \%$ & 0 & $0.0 \%$ & 0 & $0.0 \%$ & 0 & $0.0 \%$ & 0 & $0.0 \%$ \\
\hline Automated/Direct Load Control & 0 & $0.0 \%$ & 0 & $0.0 \%$ & 0 & $0.0 \%$ & 0 & $0.0 \%$ & 0 & $0.0 \%$ \\
\hline Interruptible/Curtailable Tariffs & 0 & $0.0 \%$ & 0 & $0.0 \%$ & 0 & $0.0 \%$ & 0 & $0.0 \%$ & 0 & $0.0 \%$ \\
\hline Other DR Programs & 0 & $0.0 \%$ & 0 & $0.0 \%$ & 0 & $0.0 \%$ & 484 & $18.1 \%$ & 484 & $18.1 \%$ \\
\hline Total & $\overline{0}$ & $0.0 \%$ & $\overline{0}$ & $0.0 \%$ & 0 & $0.0 \%$ & 484 & $18.1 \%$ & 484 & $18.1 \%$ \\
\hline \multicolumn{11}{|l|}{ Optimistic BAU } \\
\hline Pricing with Technology & 0 & $0.0 \%$ & 0 & $0.0 \%$ & 0 & $0.0 \%$ & 0 & $0.0 \%$ & 0 & $0.0 \%$ \\
\hline Pricing without Technology & 3 & $0.1 \%$ & 0 & $0.0 \%$ & 1 & $0.0 \%$ & 2 & $0.1 \%$ & 6 & $0.2 \%$ \\
\hline Automated/Direct Load Control & 10 & $0.4 \%$ & 13 & $0.5 \%$ & 8 & $0.3 \%$ & 0 & $0.0 \%$ & 31 & $1.2 \%$ \\
\hline Interruptible/Curtailable Tariffs & 0 & $0.0 \%$ & 0 & $0.0 \%$ & 53 & $2.0 \%$ & 78 & $2.9 \%$ & 131 & $4.9 \%$ \\
\hline Other DR Programs & 0 & $0.0 \%$ & 0 & $0.0 \%$ & 17 & $0.6 \%$ & 484 & $18.1 \%$ & 502 & $18.7 \%$ \\
\hline Total & 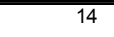 & $0.5 \%$ & 13 & $0.5 \%$ & 79 & $3.0 \%$ & 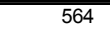 & $21.1 \%$ & (2670 & $25.0 \%$ \\
\hline \multicolumn{11}{|l|}{ Aggressive Deployment } \\
\hline Pricing with Technology & 0 & $0.0 \%$ & 0 & $0.0 \%$ & 0 & $0.0 \%$ & 10 & $0.4 \%$ & 10 & $0.4 \%$ \\
\hline Pricing without Technology & 64 & $2.4 \%$ & 0 & $0.0 \%$ & 19 & $0.7 \%$ & 18 & $0.7 \%$ & 101 & $3.8 \%$ \\
\hline Automated/Direct Load Control & 3 & $0.1 \%$ & 3 & $0.1 \%$ & 3 & $0.1 \%$ & 0 & $0.0 \%$ & 9 & $0.4 \%$ \\
\hline Interruptible/Curtailable Tariffs & 0 & $0.0 \%$ & 0 & $0.0 \%$ & 53 & $2.0 \%$ & 78 & $2.9 \%$ & 131 & $4.9 \%$ \\
\hline Other DR Programs & 0 & $0.0 \%$ & 0 & $0.0 \%$ & 7 & $0.3 \%$ & 484 & $18.1 \%$ & 492 & $18.4 \%$ \\
\hline Total & 66 & $2.5 \%$ & 4 & $0.1 \%$ & 82 & $3.1 \%$ & 590 & $22.0 \%$ & 743 & $27.7 \%$ \\
\hline \multicolumn{11}{|l|}{ Full Deployment } \\
\hline Pricing with Technology & 0 & $0.0 \%$ & 0 & $0.0 \%$ & 0 & $0.0 \%$ & 29 & $1.1 \%$ & 29 & $1.1 \%$ \\
\hline Pricing without Technology & 85 & $3.2 \%$ & 0 & $0.0 \%$ & 31 & $1.2 \%$ & 23 & $0.9 \%$ & 140 & $5.2 \%$ \\
\hline Automated/Direct Load Control & 0 & $0.0 \%$ & 0 & $0.0 \%$ & 0 & $0.0 \%$ & 0 & $0.0 \%$ & 0 & $0.0 \%$ \\
\hline Interruptible/Curtailable Tariffs & 0 & $0.0 \%$ & 0 & $0.0 \%$ & 53 & $2.0 \%$ & 78 & $2.9 \%$ & 131 & $4.9 \%$ \\
\hline Other DR Programs & 0 & $0.0 \%$ & 0 & $0.0 \%$ & 0 & $0.0 \%$ & 484 & $18.1 \%$ & 484 & $18.1 \%$ \\
\hline Total & 85 & $3.2 \%$ & 0 & $0.0 \%$ & 84 & $3.1 \%$ & 615 & $23.0 \%$ & 784 & $29.3 \%$ \\
\hline
\end{tabular}




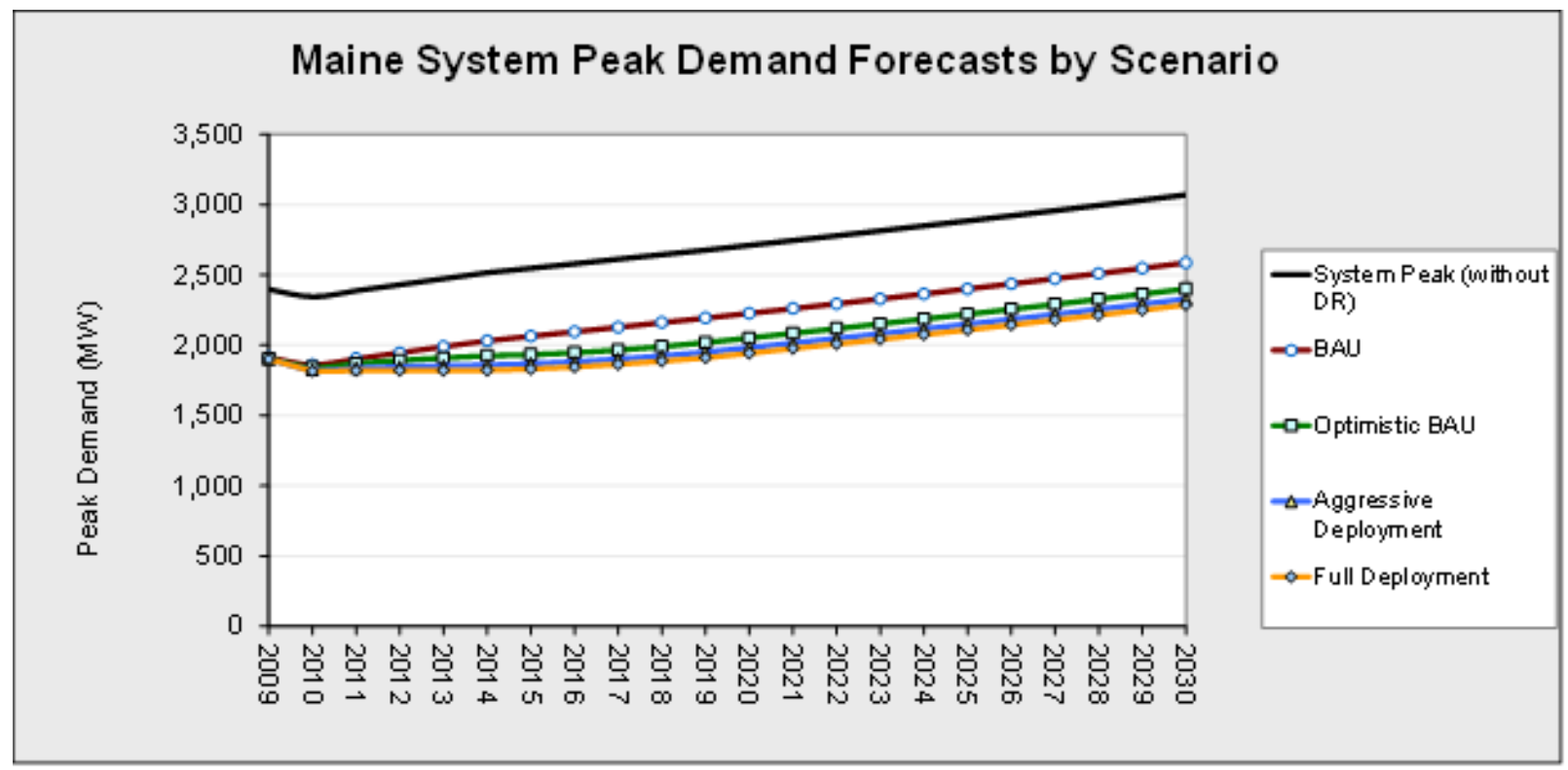

Summary of Monte Carlo Simulation of Potential Peak Load Reduction from Demand Response in Maine by Scenario, Pricing Program and Price Ratio (MW)

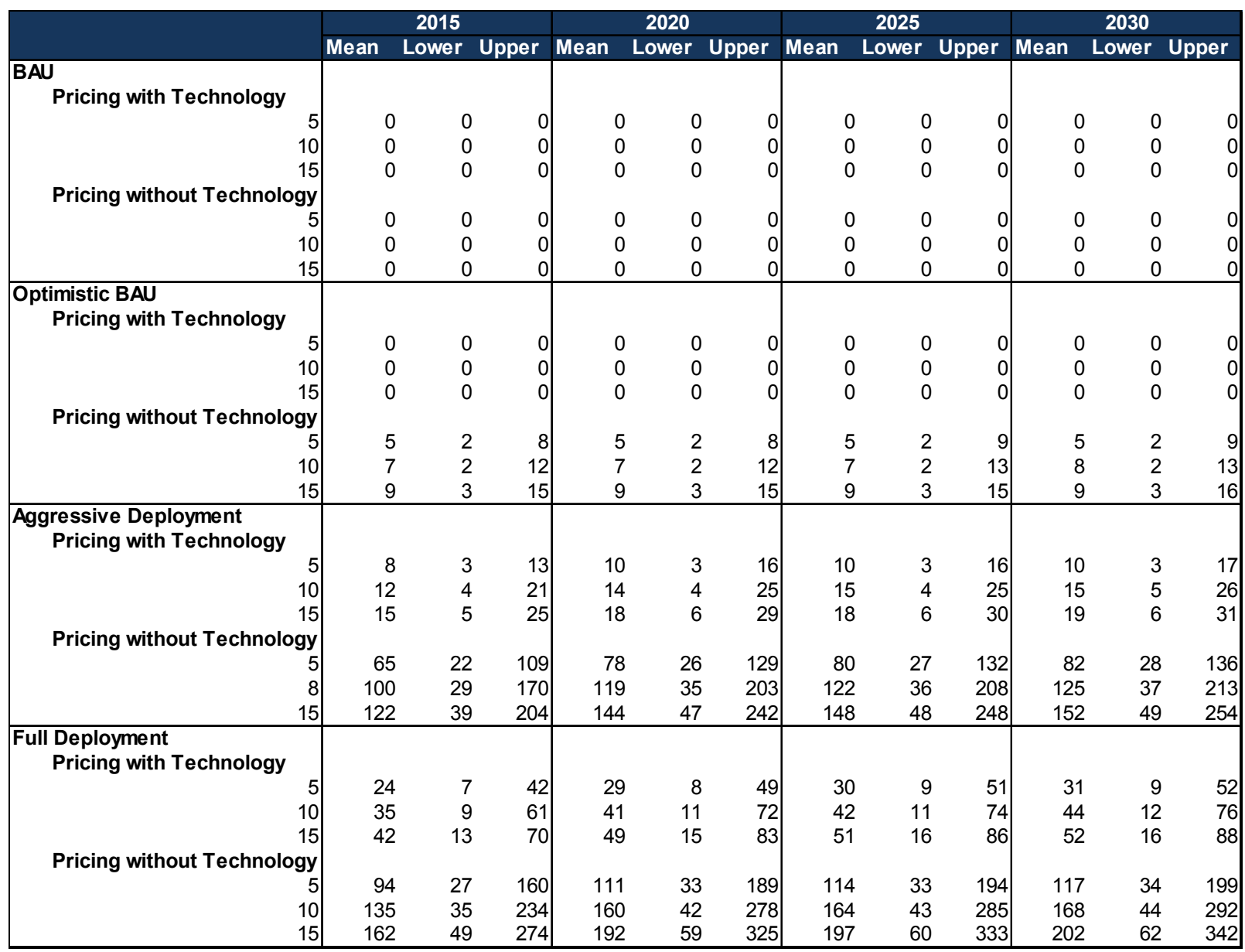




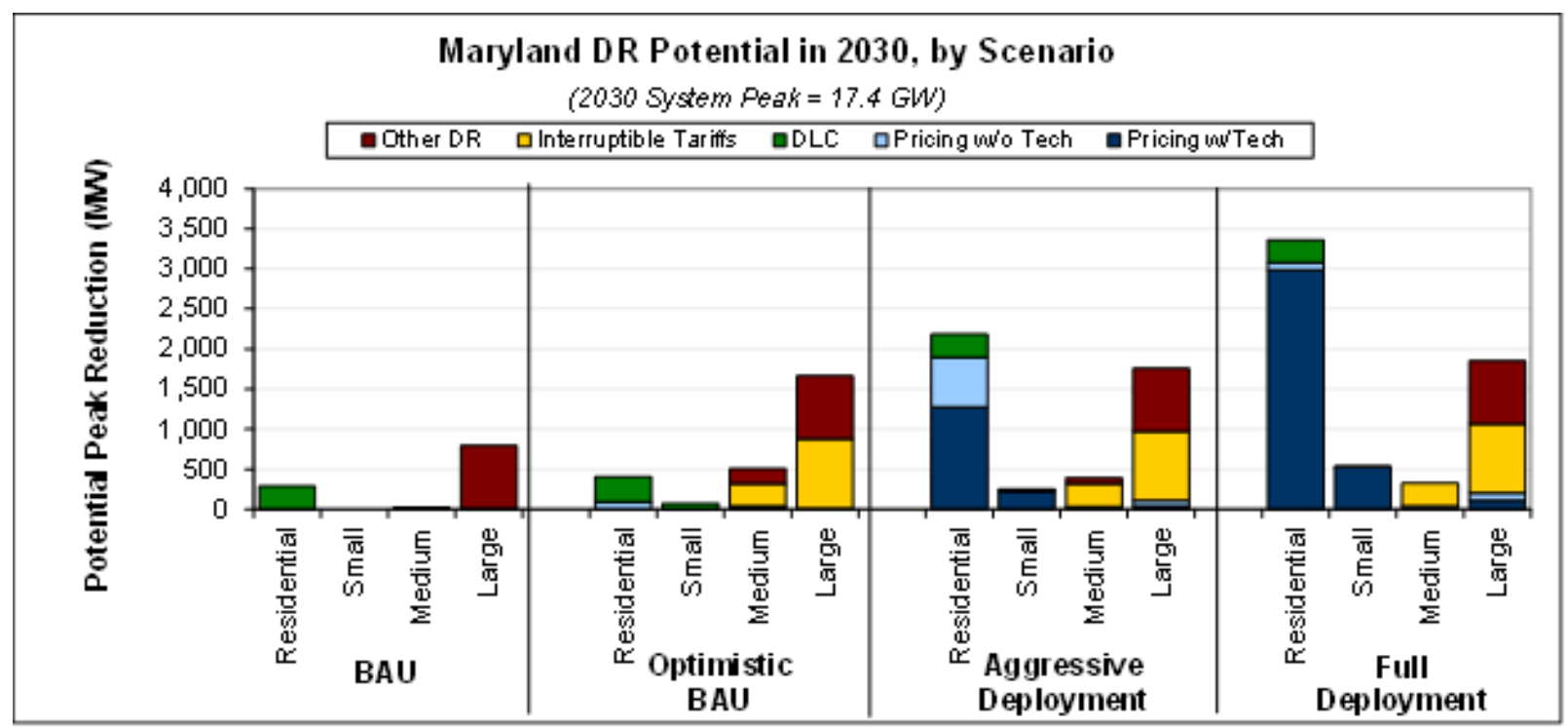

Total Potential Peak Reduction from Demand Response in Maryland, 2030

\begin{tabular}{|c|c|c|c|c|c|c|c|c|c|c|}
\hline & $\begin{array}{l}\text { Residential } \\
\quad(\mathrm{MW})\end{array}$ & $\begin{array}{l}\text { Residential } \\
\text { ( } \% \text { of } \\
\text { svstem) }\end{array}$ & $\begin{array}{l}\text { Small C\&I } \\
(\mathrm{MW})\end{array}$ & $\begin{array}{c}\text { Small C\&I } \\
\text { (\% of } \\
\text { svstem) }\end{array}$ & $\begin{array}{l}\text { Med. C\&I } \\
(\mathrm{MW})\end{array}$ & $\begin{array}{l}\text { Med C\&I } \\
\text { ( } \% \text { of } \\
\text { svstem) }\end{array}$ & $\begin{array}{l}\text { Large C\&I } \\
\quad(\mathrm{MW})\end{array}$ & $\begin{array}{l}\text { Large C\&I } \\
\text { ( } \% \text { of } \\
\text { svstem) }\end{array}$ & $\begin{array}{l}\text { Total } \\
(\mathrm{MW})\end{array}$ & $\begin{array}{c}\text { Total } \\
\text { ( } \% \text { of } \\
\text { svstem) }\end{array}$ \\
\hline \multicolumn{11}{|l|}{ BAU } \\
\hline Pricing with Technology & 0 & $0.0 \%$ & 0 & $0.0 \%$ & 0 & $0.0 \%$ & 0 & $0.0 \%$ & 0 & $0.0 \%$ \\
\hline Pricing without Technology & 1 & $0.0 \%$ & 0 & $0.0 \%$ & 26 & $0.2 \%$ & 0 & $0.0 \%$ & 27 & $0.2 \%$ \\
\hline Automated/Direct Load Control & 286 & $1.9 \%$ & 0 & $0.0 \%$ & 0 & $0.0 \%$ & 0 & $0.0 \%$ & 286 & $1.9 \%$ \\
\hline Interruptible/Curtailable Tariffs & 0 & $0.0 \%$ & 0 & $0.0 \%$ & 0 & $0.0 \%$ & 11 & $0.1 \%$ & 11 & $0.1 \%$ \\
\hline Other DR Programs & 0 & $0.0 \%$ & 0 & $0.0 \%$ & 0 & $0.0 \%$ & 783 & $5.2 \%$ & 783 & $5.2 \%$ \\
\hline Total & 287 & $1.9 \%$ & 0 & $0.0 \%$ & 26 & $0.2 \%$ & 794 & $5.2 \%$ & $\begin{array}{l}1,108 \\
\end{array}$ & $7.3 \%$ \\
\hline \multicolumn{11}{|l|}{ Optimistic BAU } \\
\hline Pricing with Technology & 0 & $0.0 \%$ & 0 & $0.0 \%$ & 0 & $0.0 \%$ & 0 & $0.0 \%$ & 0 & $0.0 \%$ \\
\hline Pricing without Technology & 89 & $0.6 \%$ & 0 & $0.0 \%$ & 26 & $0.2 \%$ & 7 & $0.0 \%$ & 123 & $0.8 \%$ \\
\hline Automated/Direct Load Control & 317 & $2.1 \%$ & 71 & $0.5 \%$ & 11 & $0.1 \%$ & 0 & $0.0 \%$ & 398 & $2.6 \%$ \\
\hline Interruptible/Curtailable Tariffs & 0 & $0.0 \%$ & 0 & $0.0 \%$ & 284 & $1.9 \%$ & 869 & $5.7 \%$ & 1,153 & $7.6 \%$ \\
\hline Other DR Programs & 0 & $0.0 \%$ & 0 & $0.0 \%$ & 185 & $1.2 \%$ & 783 & $5.2 \%$ & 968 & $6.4 \%$ \\
\hline Total & 406 & $2.7 \%$ & 71 & $0.5 \%$ & 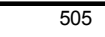 & $3.3 \%$ & $\overline{1,660}$ & $\overline{10.9 \%}$ & 2,642 & $17.4 \%$ \\
\hline \multicolumn{11}{|l|}{ Aggressive Deployment } \\
\hline Pricing with Technology & 1,277 & $8.4 \%$ & 227 & $1.5 \%$ & 0 & $0.0 \%$ & 37 & $0.2 \%$ & 1,541 & $10.2 \%$ \\
\hline Pricing without Technology & 618 & $4.1 \%$ & 4 & $0.0 \%$ & 26 & $0.2 \%$ & 68 & $0.4 \%$ & 716 & $4.7 \%$ \\
\hline Automated/Direct Load Control & 286 & $1.9 \%$ & 19 & $0.1 \%$ & 4 & $0.0 \%$ & 0 & $0.0 \%$ & 309 & $2.0 \%$ \\
\hline Interruptible/Curtailable Tariffs & 0 & $0.0 \%$ & 0 & $0.0 \%$ & 284 & $1.9 \%$ & 869 & $5.7 \%$ & 1,153 & $7.6 \%$ \\
\hline Other DR Programs & 0 & $0.0 \%$ & 0 & $0.0 \%$ & 78 & $0.5 \%$ & 783 & $5.2 \%$ & 861 & $5.7 \%$ \\
\hline Total & 2,181 & $14.4 \%$ & 249 & $1.6 \%$ & 392 & $2.6 \%$ & 1,758 & $11.6 \%$ & 4,581 & $30.2 \%$ \\
\hline \multicolumn{11}{|l|}{ Full Deployment } \\
\hline Pricing with Technology & 2,986 & $19.7 \%$ & 530 & $3.5 \%$ & 0 & $0.0 \%$ & 110 & $0.7 \%$ & 3,626 & $23.9 \%$ \\
\hline Pricing without Technology & 90 & $0.6 \%$ & 2 & $0.0 \%$ & 40 & $0.3 \%$ & 88 & $0.6 \%$ & 220 & $1.5 \%$ \\
\hline Automated/Direct Load Control & 286 & $1.9 \%$ & 0 & $0.0 \%$ & 0 & $0.0 \%$ & 0 & $0.0 \%$ & 286 & $1.9 \%$ \\
\hline Interruptible/Curtailable Tariffs & 0 & $0.0 \%$ & 0 & $0.0 \%$ & 284 & $1.9 \%$ & 869 & $5.7 \%$ & 1,153 & $7.6 \%$ \\
\hline Other DR Programs & 0 & $0.0 \%$ & 0 & $0.0 \%$ & 0 & $0.0 \%$ & 783 & $5.2 \%$ & 783 & $5.2 \%$ \\
\hline $\begin{array}{l}\text { Total } \\
\end{array}$ & 3,363 & $22.2 \%$ & 533 & $3.5 \%$ & 323 & $2.1 \%$ & 1,851 & $12.2 \%$ & 6,070 & $40.0 \%$ \\
\hline
\end{tabular}




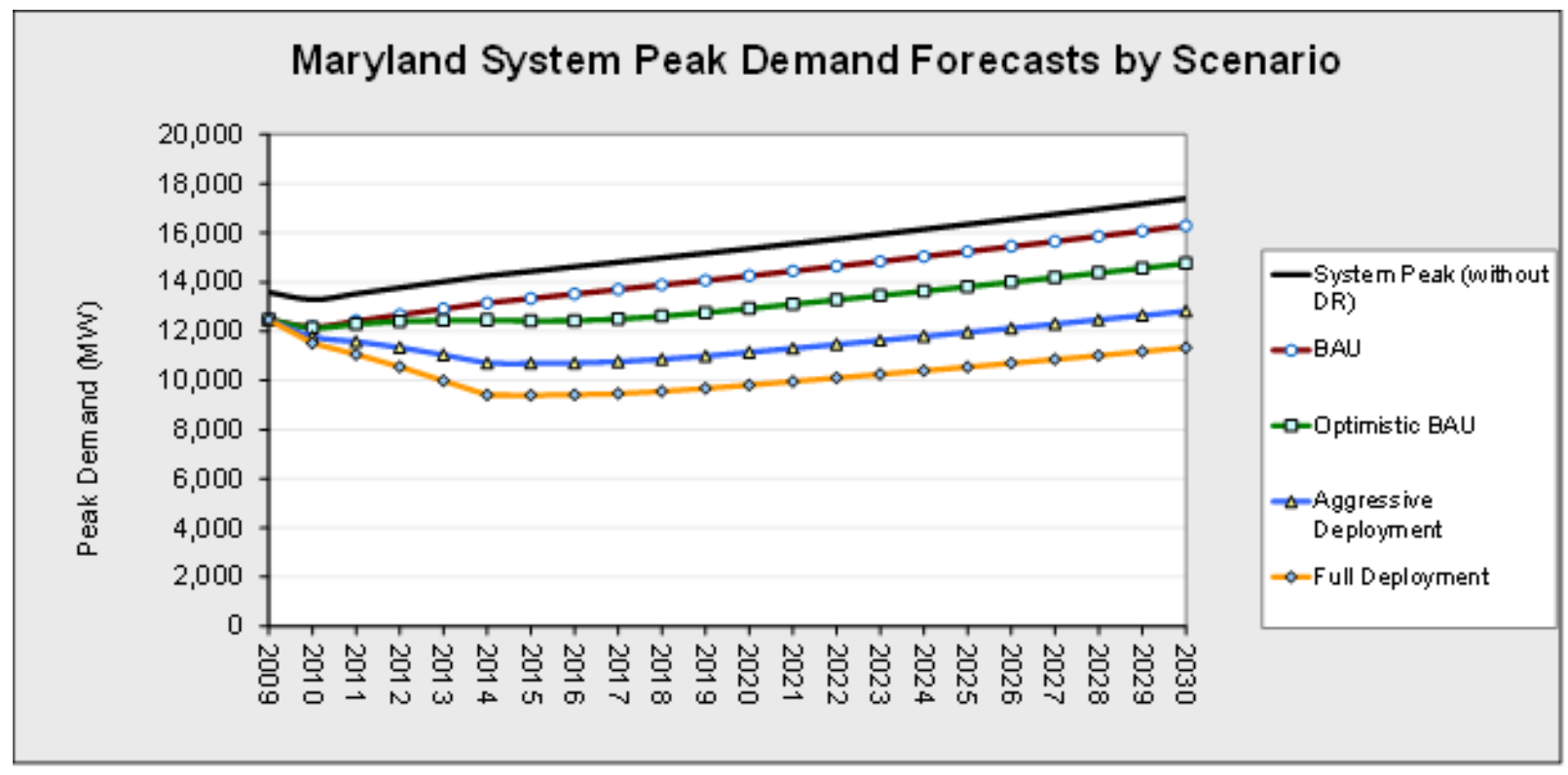

Summary of Monte Carlo Simulation of Potential Peak Load Reduction from Demand Response in Maryland by Scenario, Pricing Program and Price Ratio (MW)

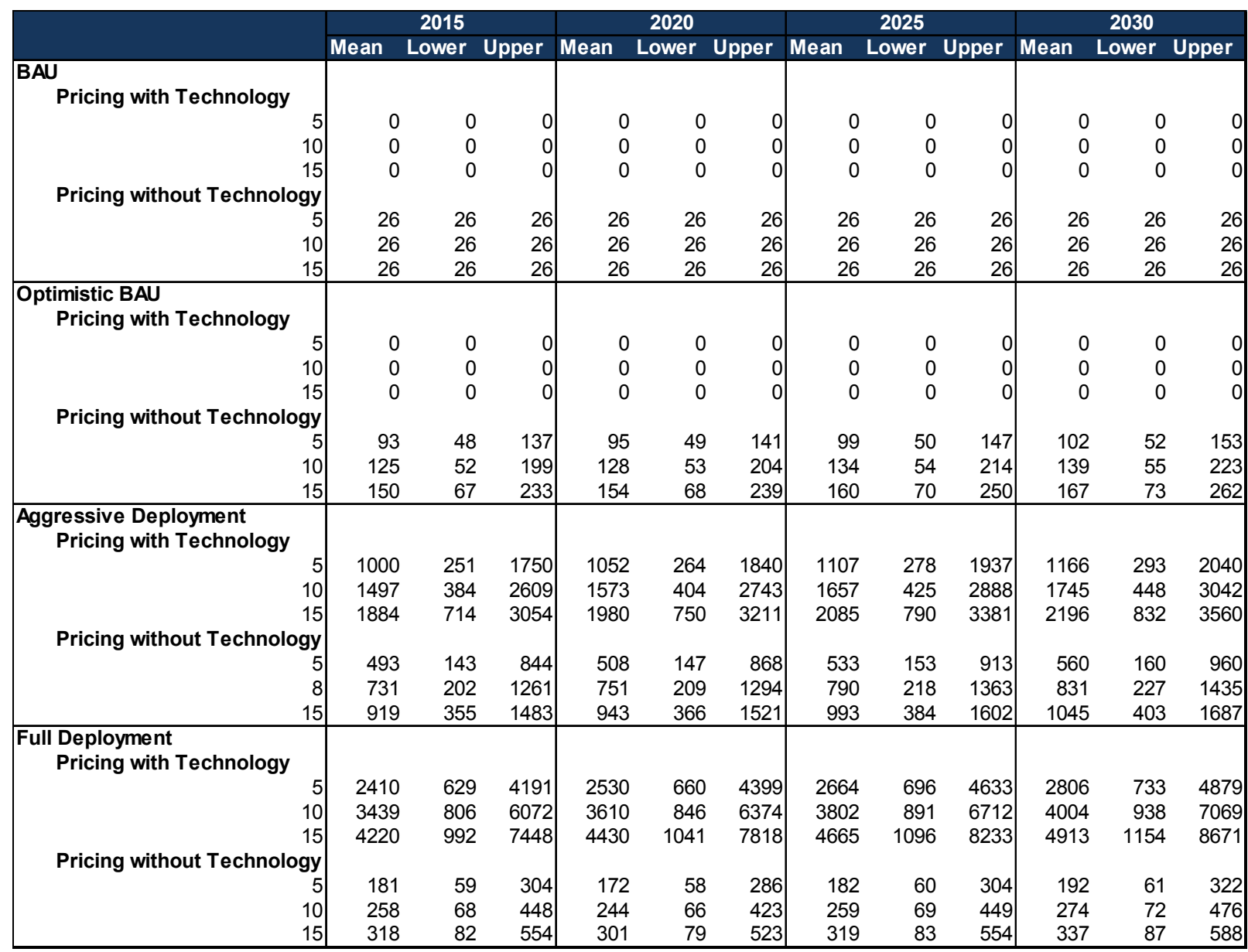




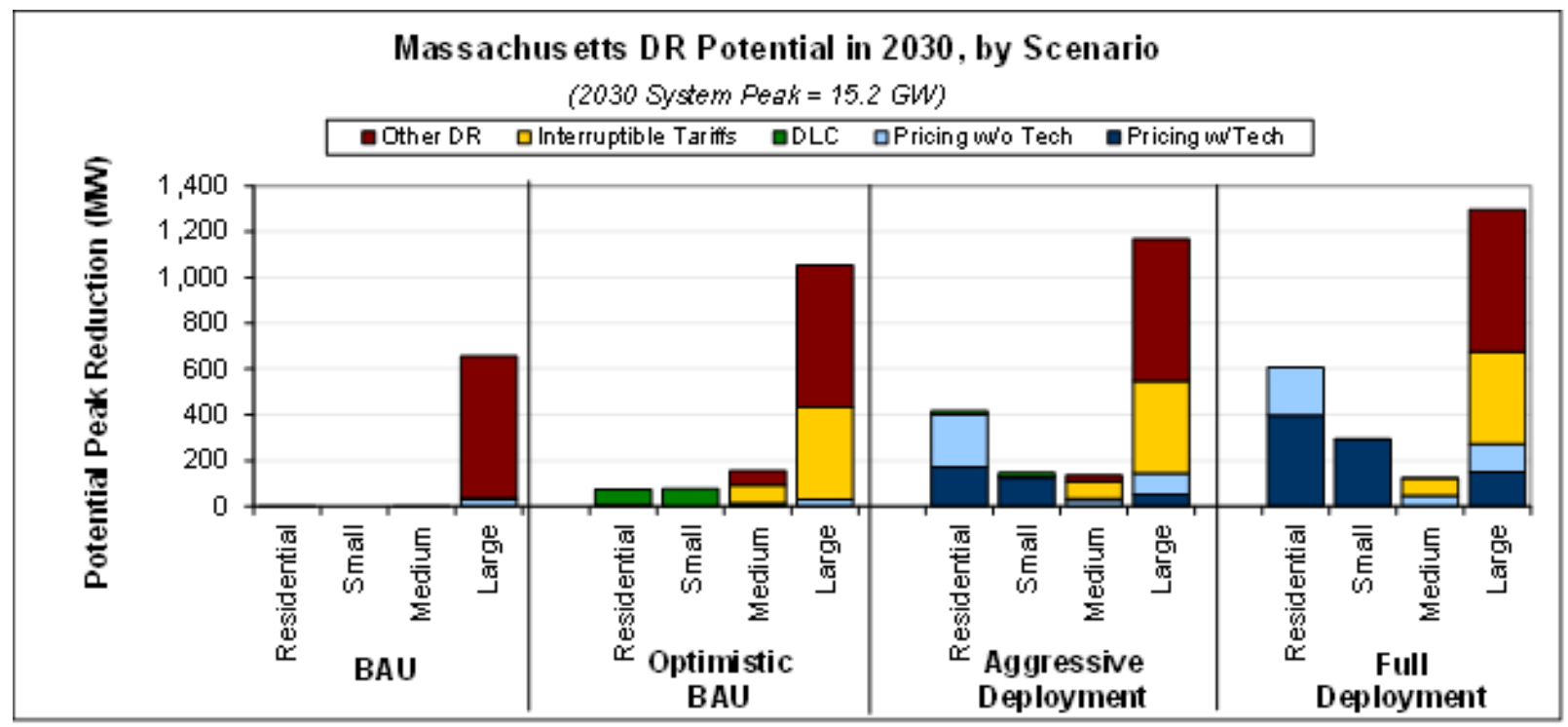

Total Potential Peak Reduction from Demand Response in Massachusetts, 2030

\begin{tabular}{|c|c|c|c|c|c|c|c|c|c|c|}
\hline & $\begin{array}{l}\text { Residential } \\
\text { (MW) }\end{array}$ & $\begin{array}{l}\text { Residential } \\
\text { ( } \% \text { of } \\
\text { svstem) }\end{array}$ & $\begin{array}{c}\text { Small C\&I } \\
(\mathrm{MW})\end{array}$ & $\begin{array}{l}\text { Small C\&I } \\
\text { (\% of } \\
\text { svstem) }\end{array}$ & $\begin{array}{l}\text { Med. C\&I } \\
(\mathrm{MW})\end{array}$ & $\begin{array}{l}\text { Med C\&I } \\
\text { ( } \% \text { of } \\
\text { svstem) }\end{array}$ & $\begin{array}{l}\text { Large C\&I } \\
(\mathrm{MW})\end{array}$ & $\begin{array}{l}\text { Large C\&I } \\
\text { (\% of } \\
\text { svstem) }\end{array}$ & $\begin{array}{l}\text { Total } \\
\text { (MW) }\end{array}$ & $\begin{array}{l}\text { Total } \\
\text { (\% of } \\
\text { svstem) }\end{array}$ \\
\hline \multicolumn{11}{|l|}{ BAU } \\
\hline Pricing with Technology & 0 & $0.0 \%$ & 0 & $0.0 \%$ & 0 & $0.0 \%$ & 0 & $0.0 \%$ & 0 & $0.0 \%$ \\
\hline Pricing without Technology & 0 & $0.0 \%$ & 0 & $0.0 \%$ & 0 & $0.0 \%$ & 31 & $0.2 \%$ & 31 & $0.2 \%$ \\
\hline Automated/Direct Load Control & 0 & $0.0 \%$ & 0 & $0.0 \%$ & 0 & $0.0 \%$ & 0 & $0.0 \%$ & 0 & $0.0 \%$ \\
\hline Interruptible/Curtailable Tariffs & 0 & $0.0 \%$ & 0 & $0.0 \%$ & 0 & $0.0 \%$ & 5 & $0.0 \%$ & 5 & $0.0 \%$ \\
\hline Other DR Programs & 0 & $0.0 \%$ & 0 & $0.0 \%$ & 0 & $0.0 \%$ & 620 & $4.7 \%$ & 620 & $4.7 \%$ \\
\hline Total & 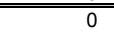 & $0.0 \%$ & 0 & $0.0 \%$ & 0 & $0.0 \%$ & 655 & $4.9 \%$ & 656 & $4.9 \%$ \\
\hline \multicolumn{11}{|l|}{ Optimistic BAU } \\
\hline Pricing with Technology & 0 & $0.0 \%$ & 0 & $0.0 \%$ & 0 & $0.0 \%$ & 0 & $0.0 \%$ & 0 & $0.0 \%$ \\
\hline Pricing without Technology & 6 & $0.0 \%$ & 0 & $0.0 \%$ & 1 & $0.0 \%$ & 31 & $0.2 \%$ & 37 & $0.3 \%$ \\
\hline Automated/Direct Load Control & 68 & $0.5 \%$ & 76 & $0.6 \%$ & 13 & $0.1 \%$ & 0 & $0.0 \%$ & 157 & $1.2 \%$ \\
\hline Interruptible/Curtailable Tariffs & 0 & $0.0 \%$ & 0 & $0.0 \%$ & 77 & $0.6 \%$ & 403 & $3.0 \%$ & 480 & $3.6 \%$ \\
\hline Other DR Programs & 0 & $0.0 \%$ & 0 & $0.0 \%$ & 64 & $0.5 \%$ & 620 & $4.7 \%$ & 684 & $5.2 \%$ \\
\hline Total & $\overline{73}$ & $0.6 \%$ & 77 & $0.6 \%$ & 155 & $1.2 \%$ & 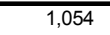 & $7.9 \%$ & 1,359 & $10.2 \%$ \\
\hline \multicolumn{11}{|l|}{ Aggressive Deployment } \\
\hline Pricing with Technology & 170 & $1.3 \%$ & 125 & $0.9 \%$ & 0 & $0.0 \%$ & 51 & $0.4 \%$ & 346 & $2.6 \%$ \\
\hline Pricing without Technology & 229 & $1.7 \%$ & 2 & $0.0 \%$ & 27 & $0.2 \%$ & 94 & $0.7 \%$ & 352 & $2.7 \%$ \\
\hline Automated/Direct Load Control & 17 & $0.1 \%$ & 19 & $0.1 \%$ & 5 & $0.0 \%$ & 0 & $0.0 \%$ & 42 & $0.3 \%$ \\
\hline Interruptible/Curtailable Tariffs & 0 & $0.0 \%$ & 0 & $0.0 \%$ & 77 & $0.6 \%$ & 403 & $3.0 \%$ & 480 & $3.6 \%$ \\
\hline Other DR Programs & 0 & $0.0 \%$ & 0 & $0.0 \%$ & 26 & $0.2 \%$ & 620 & $4.7 \%$ & 646 & $4.9 \%$ \\
\hline Total & 417 & $3.1 \%$ & 146 & $1.1 \%$ & 136 & $1.0 \%$ & 1,168 & $8.8 \%$ & 1,867 & $14.1 \%$ \\
\hline \multicolumn{11}{|l|}{ Full Deployment } \\
\hline Pricing with Technology & 399 & $3.0 \%$ & 291 & $2.2 \%$ & 0 & $0.0 \%$ & 150 & $1.1 \%$ & 840 & $6.3 \%$ \\
\hline Pricing without Technology & 208 & $1.6 \%$ & 2 & $0.0 \%$ & 45 & $0.3 \%$ & 121 & $0.9 \%$ & 376 & $2.8 \%$ \\
\hline Automated/Direct Load Control & 0 & $0.0 \%$ & 0 & $0.0 \%$ & 0 & $0.0 \%$ & 0 & $0.0 \%$ & 0 & $0.0 \%$ \\
\hline Interruptible/Curtailable Tariffs & 0 & $0.0 \%$ & 0 & $0.0 \%$ & 77 & $0.6 \%$ & 403 & $3.0 \%$ & 480 & $3.6 \%$ \\
\hline Other DR Programs & 0 & $0.0 \%$ & 0 & $0.0 \%$ & 0 & $0.0 \%$ & 620 & $4.7 \%$ & 620 & $4.7 \%$ \\
\hline Total & 606 & $4.6 \%$ & 293 & $2.2 \%$ & 123 & $0.9 \%$ & 1,295 & $9.8 \%$ & 2,316 & $17.5 \%$ \\
\hline
\end{tabular}




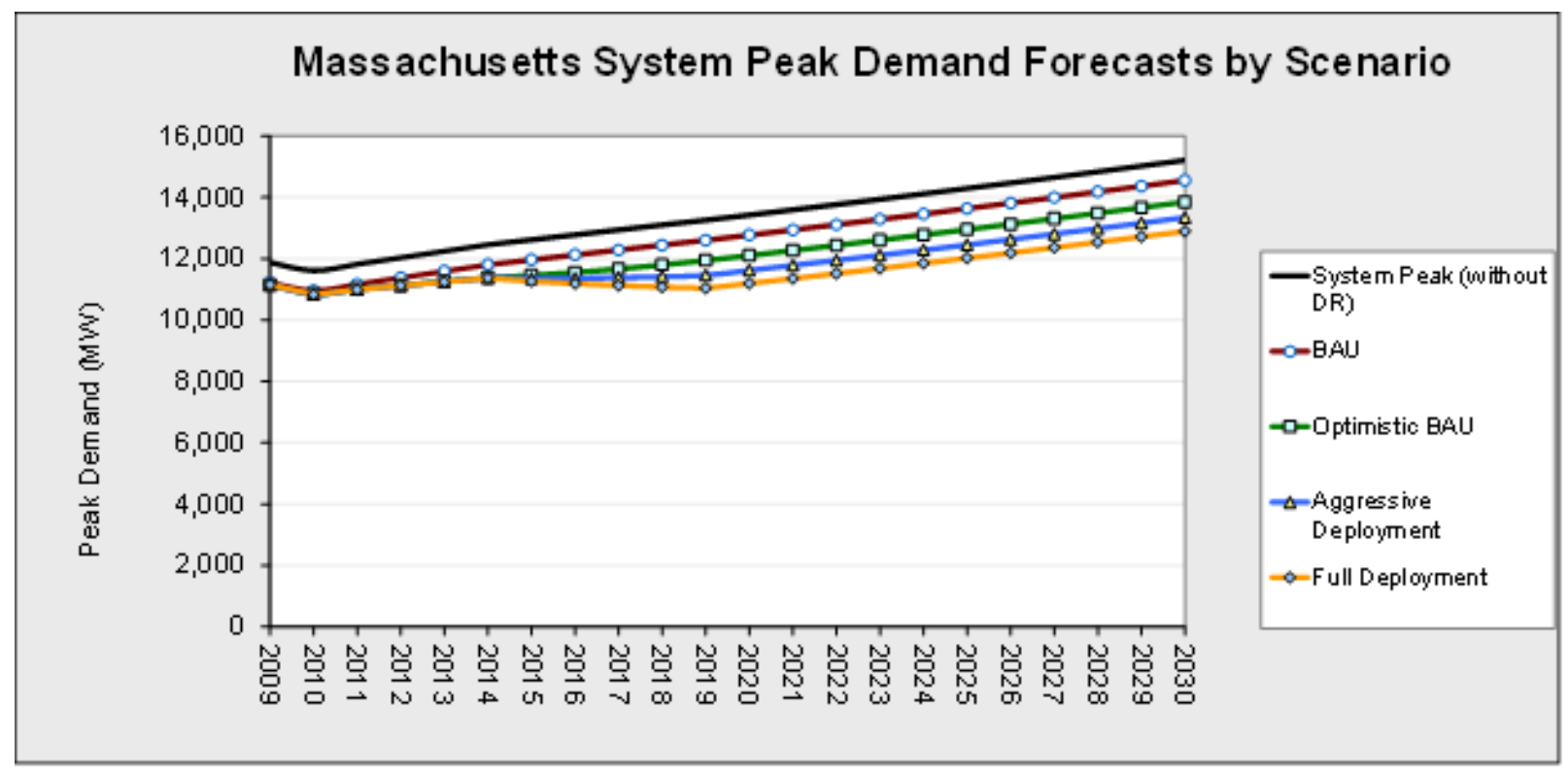

Summary of Monte Carlo Simulation of Potential Peak Load Reduction from Demand Response in Massachusetts by Scenario, Pricing Program and Price Ratio (MW)

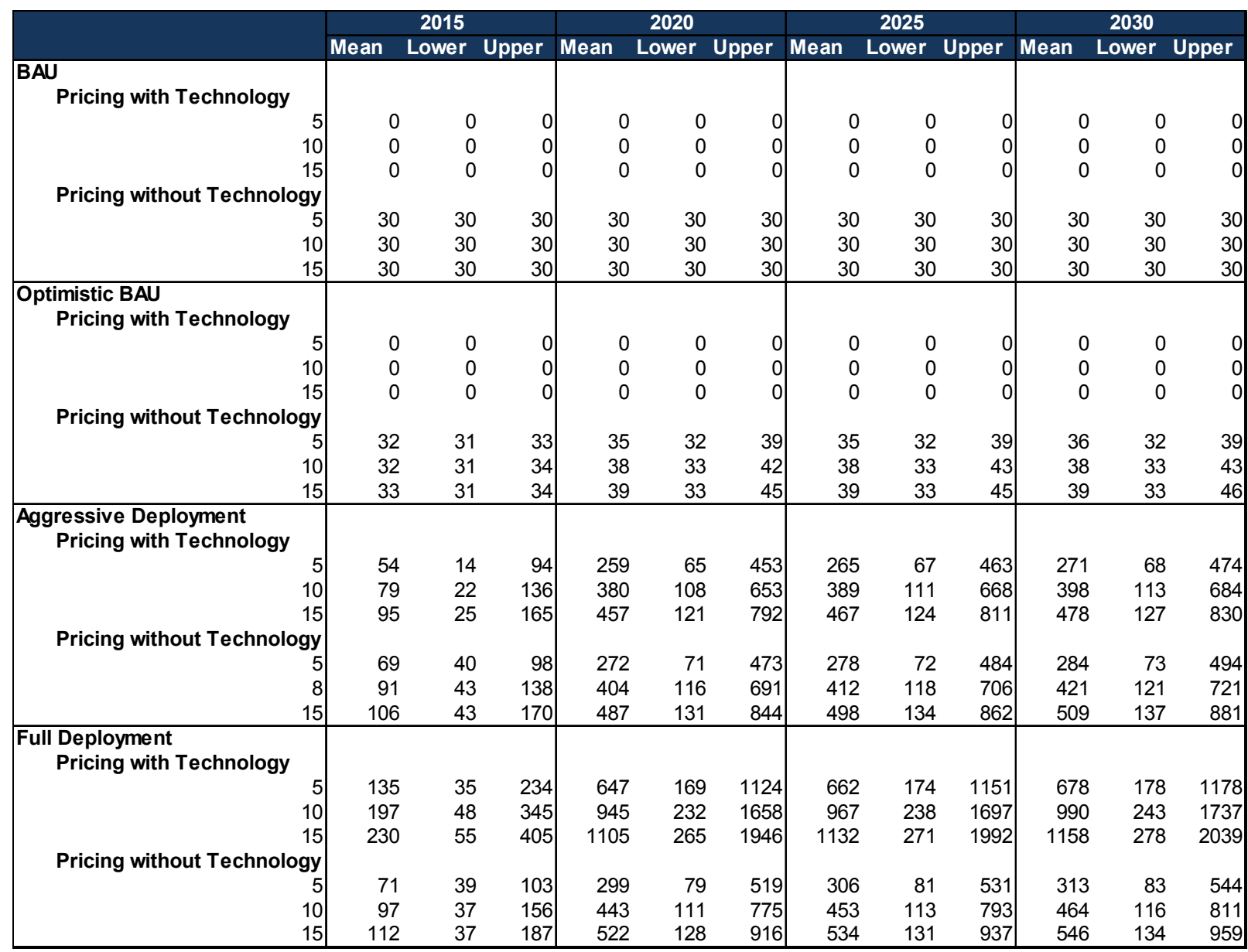




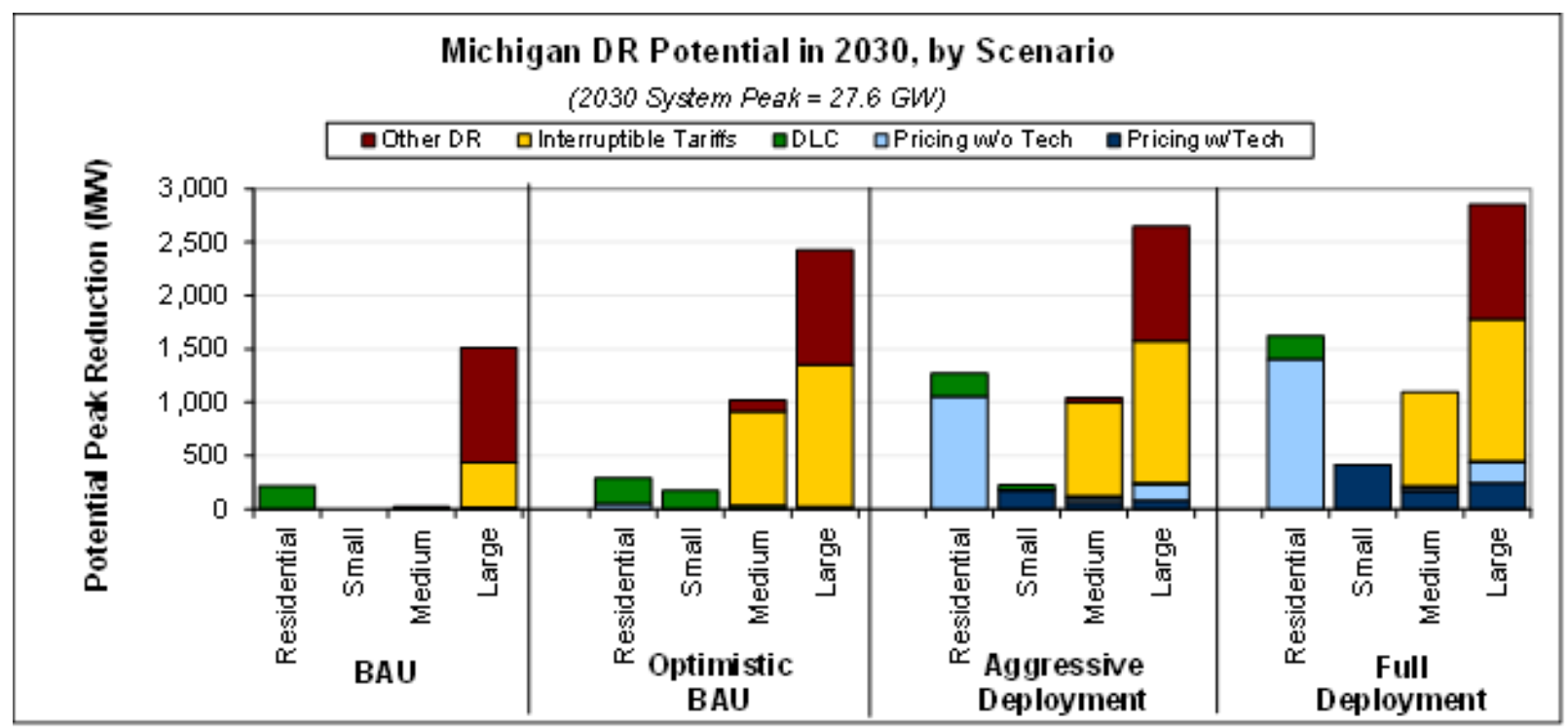

Total Potential Peak Reduction from Demand Response in Michigan, 2030

\begin{tabular}{|c|c|c|c|c|c|c|c|c|c|c|}
\hline & $\begin{array}{l}\text { Residential } \\
\quad(\mathrm{MW})\end{array}$ & $\begin{array}{l}\text { Residential } \\
\text { ( } \% \text { of } \\
\text { svstem) }\end{array}$ & $\begin{array}{l}\text { Small C\&I } \\
(\mathrm{MW})\end{array}$ & $\begin{array}{c}\text { Small C\&I } \\
\text { (\% of } \\
\text { svstem) }\end{array}$ & $\begin{array}{l}\text { Med. C\&I } \\
(\mathrm{MW})\end{array}$ & $\begin{array}{l}\text { Med C\&I } \\
\text { ( } \% \text { of } \\
\text { svstem) }\end{array}$ & $\begin{array}{l}\text { Large C\&I } \\
\quad(\mathrm{MW})\end{array}$ & $\begin{array}{l}\text { Large C\&I } \\
\text { ( } \% \text { of } \\
\text { svstem) }\end{array}$ & $\begin{array}{l}\text { Total } \\
(\mathrm{MW})\end{array}$ & $\begin{array}{c}\text { Total } \\
\text { ( } \% \text { of } \\
\text { svstem) }\end{array}$ \\
\hline \multicolumn{11}{|l|}{ BAU } \\
\hline Pricing with Technology & 0 & $0.0 \%$ & 0 & $0.0 \%$ & 0 & $0.0 \%$ & 0 & $0.0 \%$ & 0 & $0.0 \%$ \\
\hline Pricing without Technology & 0 & $0.0 \%$ & 0 & $0.0 \%$ & 0 & $0.0 \%$ & 3 & $0.0 \%$ & 3 & $0.0 \%$ \\
\hline Automated/Direct Load Control & 217 & $0.9 \%$ & 0 & $0.0 \%$ & 20 & $0.1 \%$ & 12 & $0.0 \%$ & 248 & $1.0 \%$ \\
\hline Interruptible/Curtailable Tariffs & 0 & $0.0 \%$ & 0 & $0.0 \%$ & 0 & $0.0 \%$ & 423 & $1.8 \%$ & 423 & $1.8 \%$ \\
\hline Other DR Programs & 0 & $0.0 \%$ & 0 & $0.0 \%$ & 0 & $0.0 \%$ & 1,072 & $4.5 \%$ & 1,072 & $4.5 \%$ \\
\hline Total & 217 & $0.9 \%$ & 0 & $0.0 \%$ & 20 & $0.1 \%$ & $1,1,509$ & $6.3 \%$ & 1,746 & $7.3 \%$ \\
\hline \multicolumn{11}{|l|}{ Optimistic BAU } \\
\hline Pricing with Technology & 0 & $0.0 \%$ & 0 & $0.0 \%$ & 0 & $0.0 \%$ & 0 & $0.0 \%$ & 0 & $0.0 \%$ \\
\hline Pricing without Technology & 52 & $0.2 \%$ & 0 & $0.0 \%$ & 5 & $0.0 \%$ & 12 & $0.0 \%$ & 69 & $0.3 \%$ \\
\hline Automated/Direct Load Control & 239 & $1.0 \%$ & 174 & $0.7 \%$ & 30 & $0.1 \%$ & 12 & $0.0 \%$ & 455 & $1.9 \%$ \\
\hline Interruptible/Curtailable Tariffs & 0 & $0.0 \%$ & 0 & $0.0 \%$ & 883 & $3.7 \%$ & 1,332 & $5.5 \%$ & 2,215 & $9.2 \%$ \\
\hline Other DR Programs & 0 & $0.0 \%$ & 0 & $0.0 \%$ & 103 & $0.4 \%$ & 1,072 & $4.5 \%$ & 1,175 & $4.9 \%$ \\
\hline Total & 291 & $1.2 \%$ & 175 & $0.7 \%$ & $\overline{1,020}$ & $4.2 \%$ & 2,428 & $\overline{10.1 \%}$ & 3,914 & $16.3 \%$ \\
\hline \multicolumn{11}{|l|}{ Aggressive Deployment } \\
\hline Pricing with Technology & 0 & $0.0 \%$ & 176 & $0.7 \%$ & 58 & $0.2 \%$ & 83 & $0.3 \%$ & 316 & $1.3 \%$ \\
\hline Pricing without Technology & 1,054 & $4.4 \%$ & 3 & $0.0 \%$ & 41 & $0.2 \%$ & 151 & $0.6 \%$ & 1,249 & $5.2 \%$ \\
\hline Automated/Direct Load Control & 217 & $0.9 \%$ & 45 & $0.2 \%$ & 20 & $0.1 \%$ & 12 & $0.0 \%$ & 294 & $1.2 \%$ \\
\hline Interruptible/Curtailable Tariffs & 0 & $0.0 \%$ & 0 & $0.0 \%$ & 883 & $3.7 \%$ & 1,332 & $5.5 \%$ & 2,215 & $9.2 \%$ \\
\hline Other DR Programs & 0 & $0.0 \%$ & 0 & $0.0 \%$ & 43 & $0.2 \%$ & 1,072 & $4.5 \%$ & 1,115 & $4.6 \%$ \\
\hline Total & 1,271 & $5.3 \%$ & 224 & $0.9 \%$ & 1,044 & $4.3 \%$ & 2,649 & $11.0 \%$ & 5,189 & $21.6 \%$ \\
\hline \multicolumn{11}{|l|}{ Full Deployment } \\
\hline Pricing with Technology & 0 & $0.0 \%$ & 411 & $1.7 \%$ & 168 & $0.7 \%$ & 242 & $1.0 \%$ & 821 & $3.4 \%$ \\
\hline Pricing without Technology & 1,405 & $5.8 \%$ & 2 & $0.0 \%$ & 28 & $0.1 \%$ & 195 & $0.8 \%$ & 1,631 & $6.8 \%$ \\
\hline Automated/Direct Load Control & 217 & $0.9 \%$ & 0 & $0.0 \%$ & 20 & $0.1 \%$ & 12 & $0.0 \%$ & 248 & $1.0 \%$ \\
\hline Interruptible/Curtailable Tariffs & 0 & $0.0 \%$ & 0 & $0.0 \%$ & 883 & $3.7 \%$ & 1,332 & $5.5 \%$ & 2,215 & $9.2 \%$ \\
\hline Other DR Programs & 0 & $0.0 \%$ & 0 & $0.0 \%$ & 0 & $0.0 \%$ & 1,072 & $4.5 \%$ & 1,072 & $4.5 \%$ \\
\hline $\begin{array}{l}\text { Total } \\
\end{array}$ & 1,622 & $6.7 \%$ & 413 & $1.7 \%$ & 1,099 & $4.6 \%$ & 2,853 & $11.9 \%$ & 5,987 & $24.9 \%$ \\
\hline
\end{tabular}




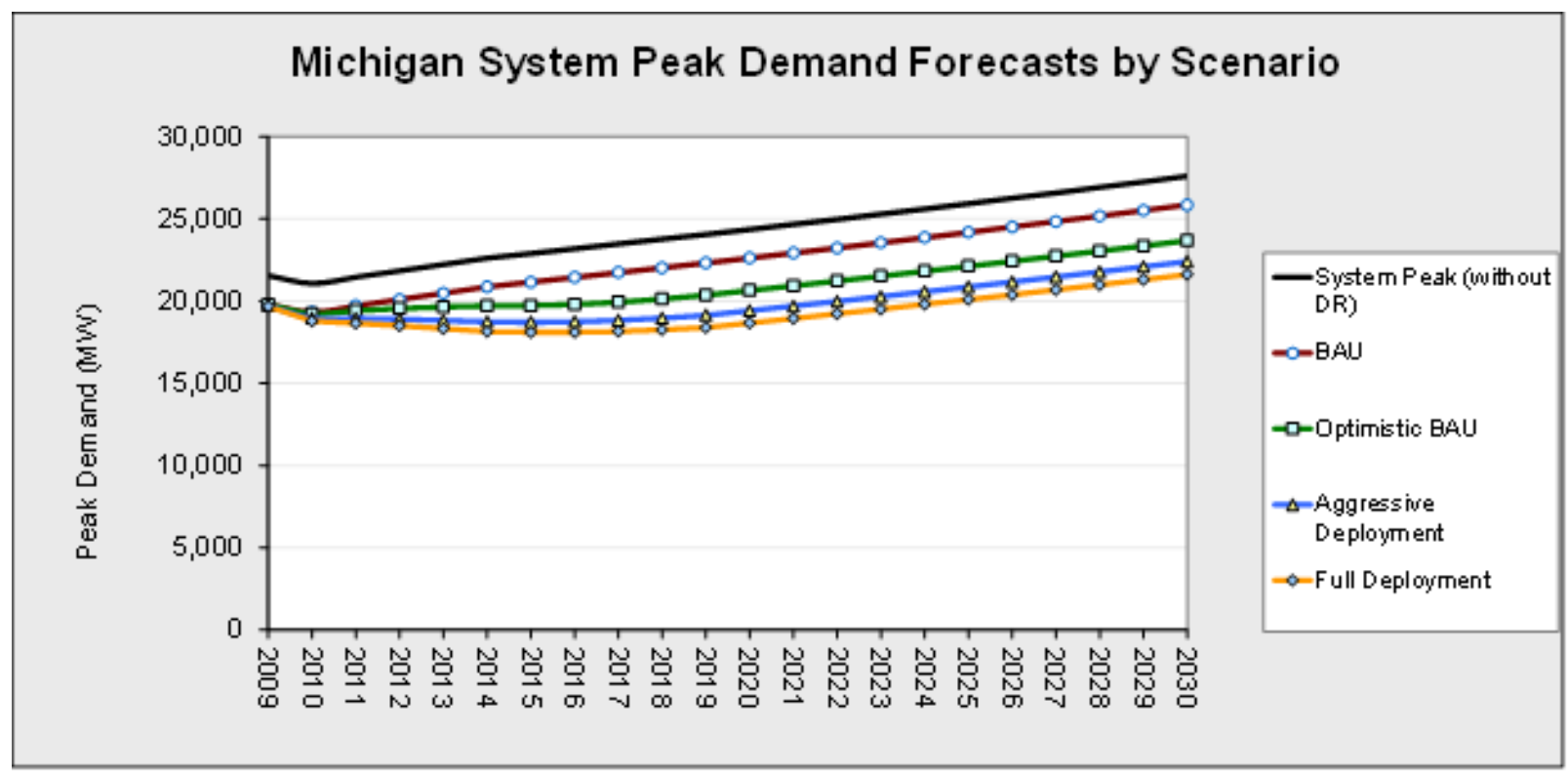

Summary of Monte Carlo Simulation of Potential Peak Load Reduction from Demand Response in Michigan by Scenario, Pricing Program and Price Ratio (MW)

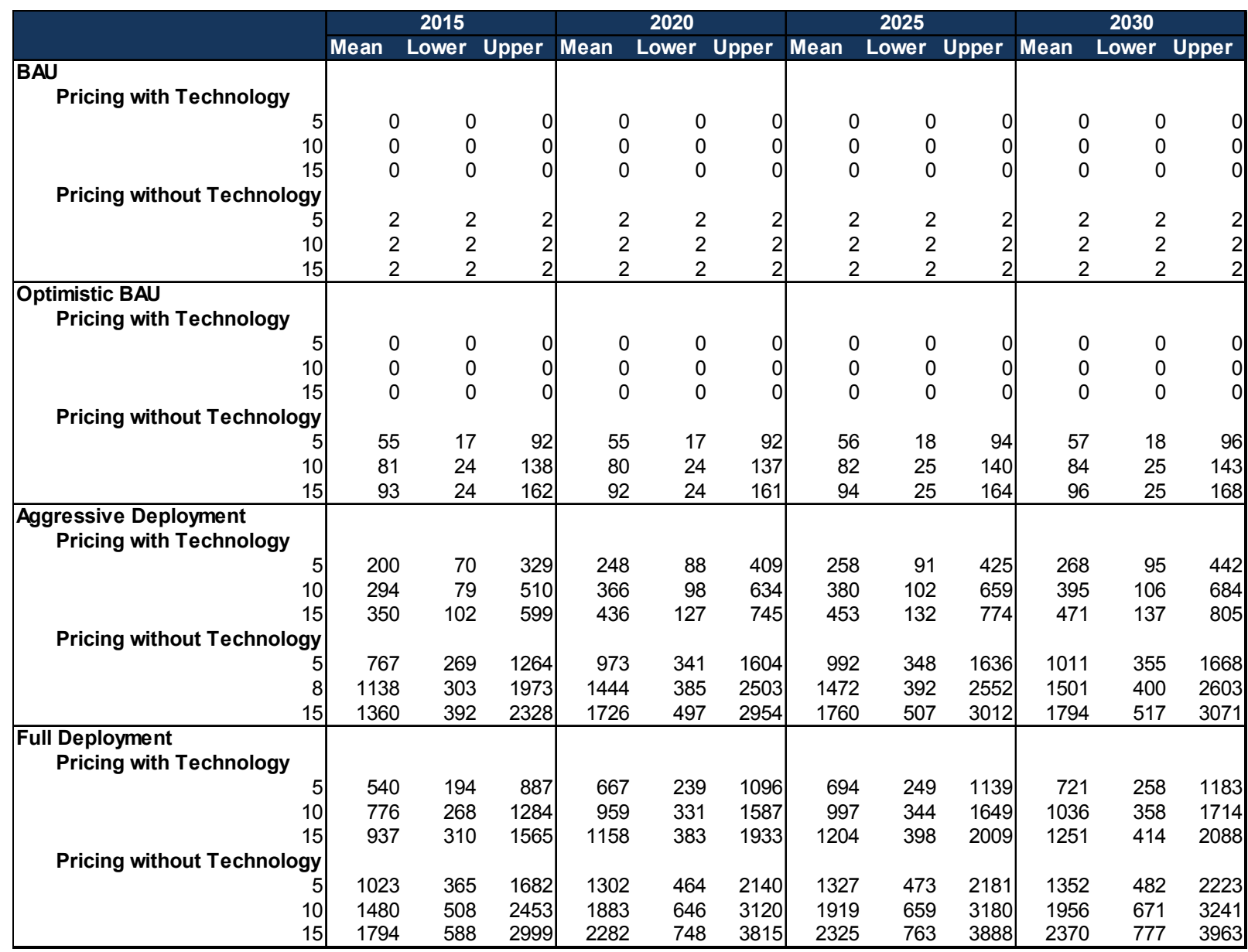




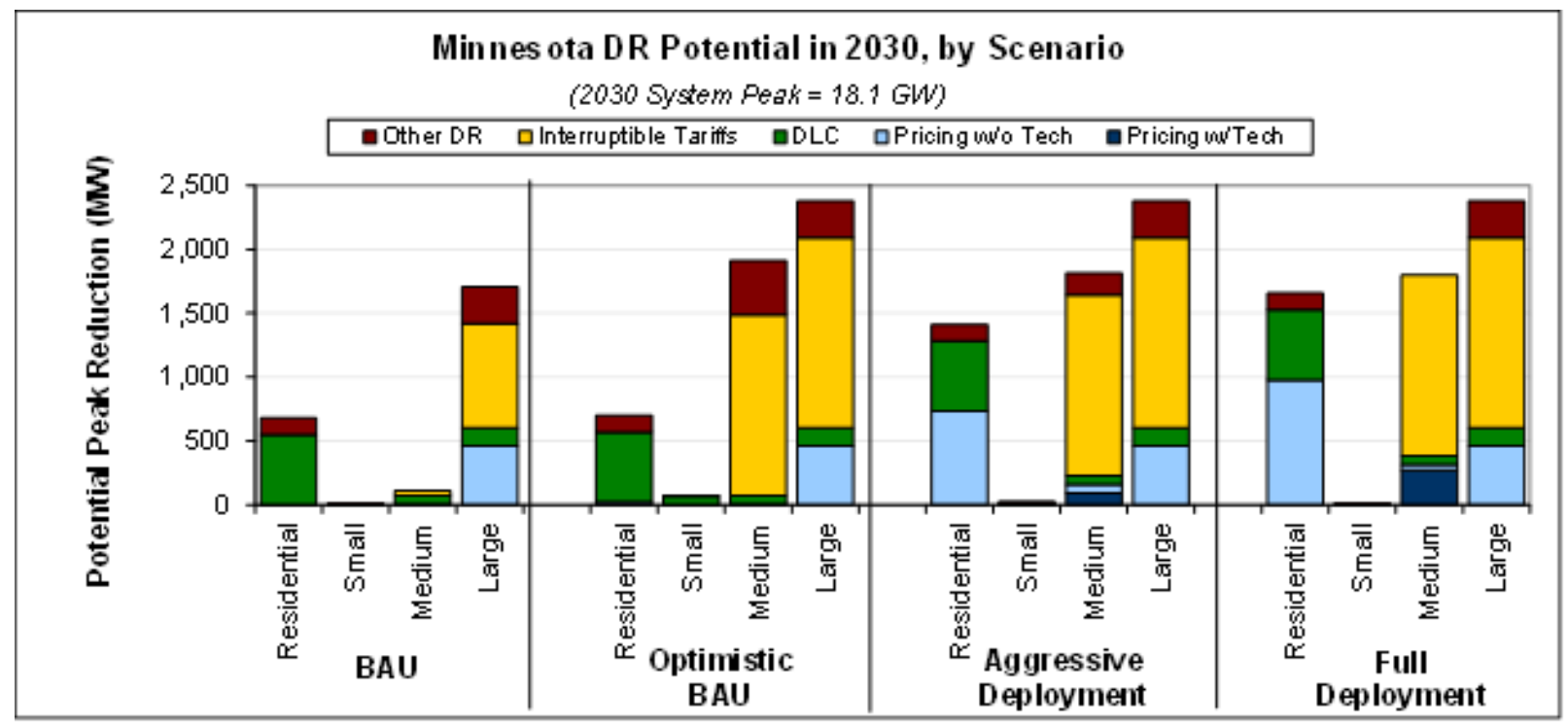

Total Potential Peak Reduction from Demand Response in Minnesota, 2030

\begin{tabular}{|c|c|c|c|c|c|c|c|c|c|c|}
\hline & $\begin{array}{l}\text { Residential } \\
\quad(\mathrm{MW})\end{array}$ & $\begin{array}{l}\text { Residential } \\
\text { ( } \% \text { of } \\
\text { svstem) }\end{array}$ & $\begin{array}{l}\text { Small C\&I } \\
(\mathrm{MW})\end{array}$ & $\begin{array}{c}\text { Small C\&I } \\
\text { (\% of } \\
\text { svstem) }\end{array}$ & $\begin{array}{l}\text { Med. C\&I } \\
(\mathrm{MW})\end{array}$ & $\begin{array}{l}\text { Med C\&I } \\
\text { ( } \% \text { of } \\
\text { svstem) }\end{array}$ & $\begin{array}{l}\text { Large C\&I } \\
\quad(\mathrm{MW})\end{array}$ & $\begin{array}{l}\text { Large C\&I } \\
\text { ( } \% \text { of } \\
\text { svstem) }\end{array}$ & $\begin{array}{l}\text { Total } \\
(\mathrm{MW})\end{array}$ & $\begin{array}{c}\text { Total } \\
\text { ( } \% \text { of } \\
\text { svstem) }\end{array}$ \\
\hline \multicolumn{11}{|l|}{ BAU } \\
\hline Pricing with Technology & 0 & $0.0 \%$ & 0 & $0.0 \%$ & 0 & $0.0 \%$ & 0 & $0.0 \%$ & 0 & $0.0 \%$ \\
\hline Pricing without Technology & 1 & $0.0 \%$ & 1 & $0.0 \%$ & 7 & $0.0 \%$ & 463 & $2.9 \%$ & 472 & $3.0 \%$ \\
\hline Automated/Direct Load Control & 548 & $3.5 \%$ & 3 & $0.0 \%$ & 68 & $0.4 \%$ & 139 & $0.9 \%$ & 758 & $4.8 \%$ \\
\hline Interruptible/Curtailable Tariffs & 0 & $0.0 \%$ & 0 & $0.0 \%$ & 35 & $0.2 \%$ & 815 & $5.2 \%$ & 850 & $5.4 \%$ \\
\hline Other DR Programs & 130 & $0.8 \%$ & 5 & $0.0 \%$ & 0 & $0.0 \%$ & 288 & $1.8 \%$ & 422 & $2.7 \%$ \\
\hline Total & 679 & $4.3 \%$ & 10 & $0.1 \%$ & 110 & $0.7 \%$ & $\begin{array}{l}1,705 \\
\end{array}$ & $10.8 \%$ & 2,503 & $15.9 \%$ \\
\hline \multicolumn{11}{|l|}{ Optimistic BAU } \\
\hline Pricing with Technology & 0 & $0.0 \%$ & 0 & $0.0 \%$ & 0 & $0.0 \%$ & 0 & $0.0 \%$ & 0 & $0.0 \%$ \\
\hline Pricing without Technology & 23 & $0.1 \%$ & 1 & $0.0 \%$ & 7 & $0.0 \%$ & 463 & $2.9 \%$ & 493 & $3.1 \%$ \\
\hline Automated/Direct Load Control & 548 & $3.5 \%$ & 66 & $0.4 \%$ & 68 & $0.4 \%$ & 139 & $0.9 \%$ & 821 & $5.2 \%$ \\
\hline Interruptible/Curtailable Tariffs & 0 & $0.0 \%$ & 0 & $0.0 \%$ & 1,413 & $9.0 \%$ & 1,487 & $9.4 \%$ & 2,900 & $18.4 \%$ \\
\hline Other DR Programs & 130 & $0.8 \%$ & 5 & $0.0 \%$ & 423 & $2.7 \%$ & 288 & $1.8 \%$ & 846 & $5.4 \%$ \\
\hline Total & 700 & $4.4 \%$ & 72 & $0.5 \%$ & $\overline{1,912}$ & $\overline{12.1 \%}$ & $\begin{array}{l}2,376 \\
\end{array}$ & $\overline{15.1 \%}$ & $\overline{5,060}$ & $32.1 \%$ \\
\hline \multicolumn{11}{|l|}{ Aggressive Deployment } \\
\hline Pricing with Technology & 0 & $0.0 \%$ & 0 & $0.0 \%$ & 92 & $0.6 \%$ & 0 & $0.0 \%$ & 92 & $0.6 \%$ \\
\hline Pricing without Technology & 734 & $4.7 \%$ & 1 & $0.0 \%$ & 66 & $0.4 \%$ & 463 & $2.9 \%$ & 1,264 & $8.0 \%$ \\
\hline Automated/Direct Load Control & 548 & $3.5 \%$ & 17 & $0.1 \%$ & 68 & $0.4 \%$ & 139 & $0.9 \%$ & 772 & $4.9 \%$ \\
\hline Interruptible/Curtailable Tariffs & 0 & $0.0 \%$ & 0 & $0.0 \%$ & 1,413 & $9.0 \%$ & 1,487 & $9.4 \%$ & 2,900 & $18.4 \%$ \\
\hline Other DR Programs & 130 & $0.8 \%$ & 5 & $0.0 \%$ & 173 & $1.1 \%$ & 288 & $1.8 \%$ & 596 & $3.8 \%$ \\
\hline Total & 1,412 & $9.0 \%$ & 23 & $0.1 \%$ & 1,813 & $11.5 \%$ & 2,376 & $15.1 \%$ & 5,624 & $35.7 \%$ \\
\hline \multicolumn{11}{|l|}{ Full Deployment } \\
\hline Pricing with Technology & 0 & $0.0 \%$ & 0 & $0.0 \%$ & 270 & $1.7 \%$ & 0 & $0.0 \%$ & 270 & $1.7 \%$ \\
\hline Pricing without Technology & 979 & $6.2 \%$ & 2 & $0.0 \%$ & 45 & $0.3 \%$ & 463 & $2.9 \%$ & 1,488 & $9.5 \%$ \\
\hline Automated/Direct Load Control & 548 & $3.5 \%$ & 3 & $0.0 \%$ & 68 & $0.4 \%$ & 139 & $0.9 \%$ & 758 & $4.8 \%$ \\
\hline Interruptible/Curtailable Tariffs & 0 & $0.0 \%$ & 0 & $0.0 \%$ & 1,413 & $9.0 \%$ & 1,487 & $9.4 \%$ & 2,900 & $18.4 \%$ \\
\hline Other DR Programs & 130 & $0.8 \%$ & 5 & $0.0 \%$ & 0 & $0.0 \%$ & 288 & $1.8 \%$ & 422 & $2.7 \%$ \\
\hline Total & 1,656 & $10.5 \%$ & 10 & $0.1 \%$ & 1,796 & $11.4 \%$ & 2,376 & $15.1 \%$ & 5,839 & $37.1 \%$ \\
\hline
\end{tabular}




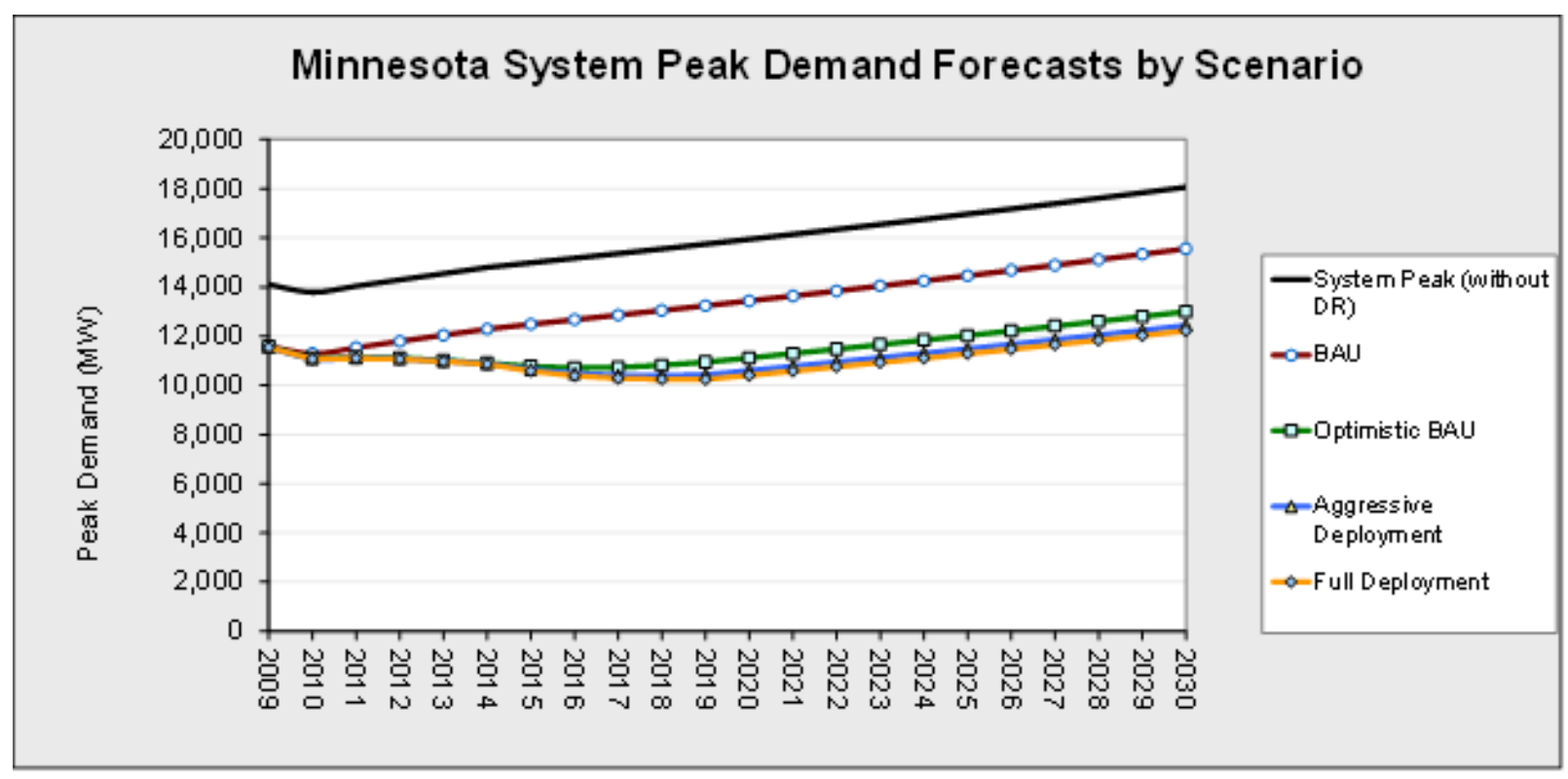

Summary of Monte Carlo Simulation of Potential Peak Load Reduction from Demand Response in Minnesota by Scenario, Pricing Program and Price Ratio (MW)

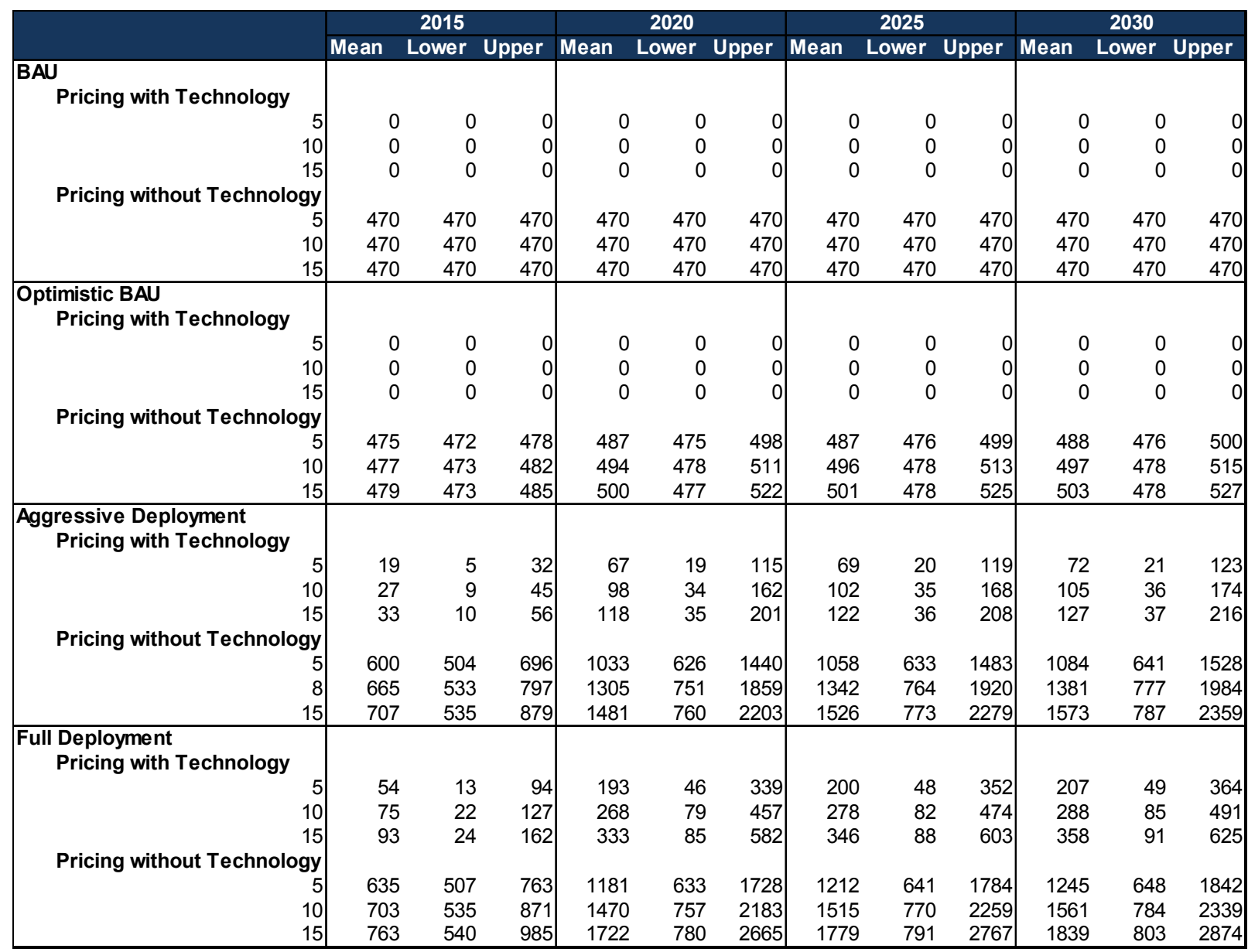




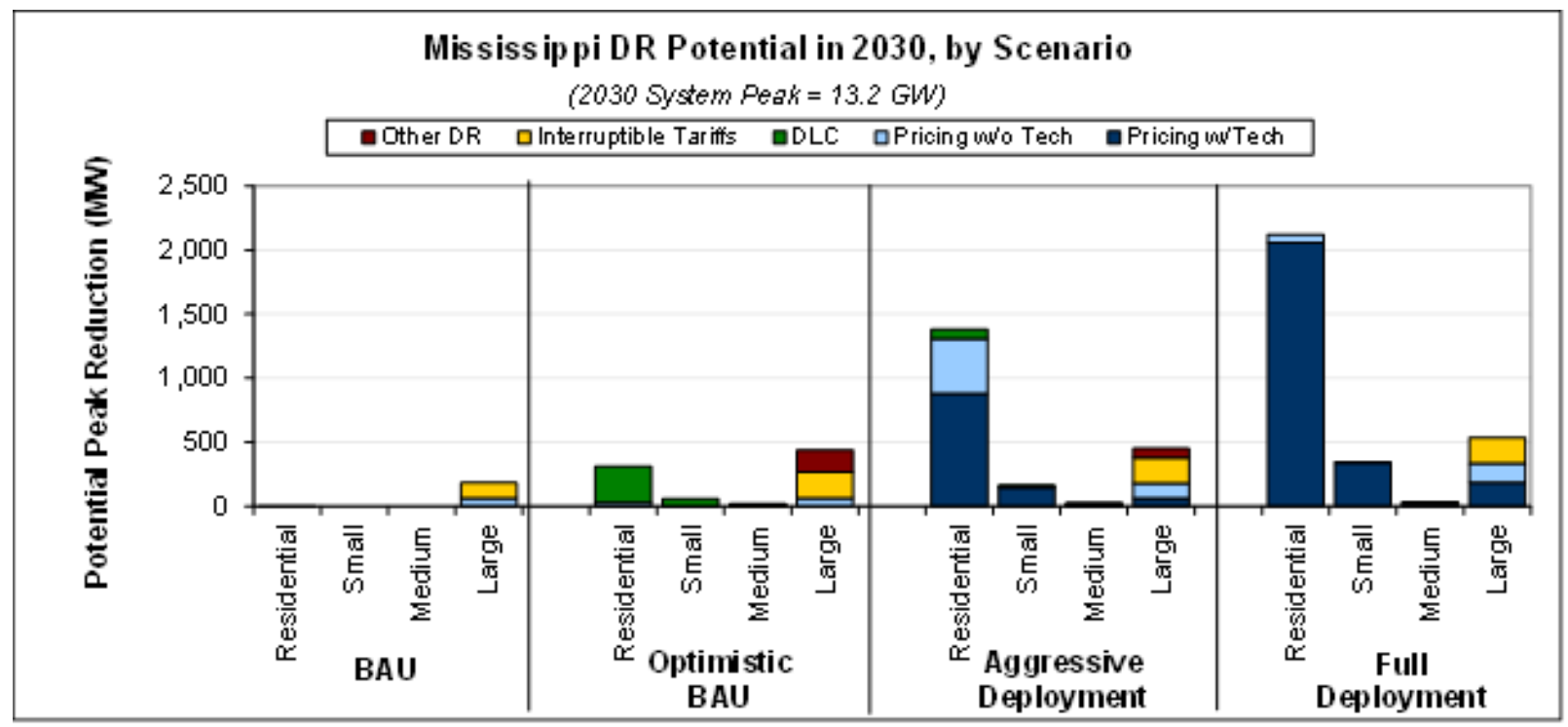

Total Potential Peak Reduction from Demand Response in Mississippi, 2030

\begin{tabular}{|c|c|c|c|c|c|c|c|c|c|c|}
\hline & $\begin{array}{l}\text { Residential } \\
\quad(\mathrm{MW})\end{array}$ & $\begin{array}{l}\text { Residential } \\
\text { ( } \% \text { of } \\
\text { svstem) }\end{array}$ & $\begin{array}{l}\text { Small C\&I } \\
(\mathrm{MW})\end{array}$ & $\begin{array}{c}\text { Small C\&I } \\
\text { (\% of } \\
\text { svstem) }\end{array}$ & $\begin{array}{l}\text { Med. C\&I } \\
(\mathrm{MW})\end{array}$ & $\begin{array}{l}\text { Med C\&I } \\
\text { ( } \% \text { of } \\
\text { svstem) }\end{array}$ & $\begin{array}{l}\text { Large C\&I } \\
\quad(\mathrm{MW})\end{array}$ & $\begin{array}{l}\text { Large C\&I } \\
\text { ( } \% \text { of } \\
\text { svstem) }\end{array}$ & $\begin{array}{l}\text { Total } \\
(\mathrm{MW})\end{array}$ & $\begin{array}{c}\text { Total } \\
\text { ( } \% \text { of } \\
\text { svstem) }\end{array}$ \\
\hline \multicolumn{11}{|l|}{ BAU } \\
\hline Pricing with Technology & 0 & $0.0 \%$ & 0 & $0.0 \%$ & 0 & $0.0 \%$ & 0 & $0.0 \%$ & 0 & $0.0 \%$ \\
\hline Pricing without Technology & 0 & $0.0 \%$ & 0 & $0.0 \%$ & 0 & $0.0 \%$ & 64 & $0.6 \%$ & 64 & $0.6 \%$ \\
\hline Automated/Direct Load Control & 0 & $0.0 \%$ & 0 & $0.0 \%$ & 0 & $0.0 \%$ & 0 & $0.0 \%$ & 0 & $0.0 \%$ \\
\hline Interruptible/Curtailable Tariffs & 0 & $0.0 \%$ & 0 & $0.0 \%$ & 0 & $0.0 \%$ & 119 & $1.0 \%$ & 119 & $1.0 \%$ \\
\hline Other DR Programs & 0 & $0.0 \%$ & 0 & $0.0 \%$ & 0 & $0.0 \%$ & 0 & $0.0 \%$ & 0 & $0.0 \%$ \\
\hline Total & 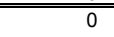 & $0.0 \%$ & 0 & $0.0 \%$ & 0 & $0.0 \%$ & 183 & $1.6 \%$ & 183 & $1.6 \%$ \\
\hline \multicolumn{11}{|l|}{ Optimistic BAU } \\
\hline Pricing with Technology & 0 & $0.0 \%$ & 0 & $0.0 \%$ & 0 & $0.0 \%$ & 0 & $0.0 \%$ & 0 & $0.0 \%$ \\
\hline Pricing without Technology & 26 & $0.2 \%$ & 0 & $0.0 \%$ & 0 & $0.0 \%$ & 64 & $0.6 \%$ & 90 & $0.8 \%$ \\
\hline Automated/Direct Load Control & 286 & $2.5 \%$ & 58 & $0.5 \%$ & 1 & $0.0 \%$ & 0 & $0.0 \%$ & 346 & $3.0 \%$ \\
\hline Interruptible/Curtailable Tariffs & 0 & $0.0 \%$ & 0 & $0.0 \%$ & 11 & $0.1 \%$ & 202 & $1.7 \%$ & 212 & $1.8 \%$ \\
\hline Other DR Programs & 0 & $0.0 \%$ & 0 & $0.0 \%$ & 7 & $0.1 \%$ & 173 & $1.5 \%$ & 180 & $1.6 \%$ \\
\hline Total & 313 & $2.7 \%$ & 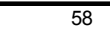 & $0.5 \%$ & 19 & $0.2 \%$ & 438 & $3.8 \%$ & 829 & $7.2 \%$ \\
\hline \multicolumn{11}{|l|}{ Aggressive Deployment } \\
\hline Pricing with Technology & 878 & $7.6 \%$ & 146 & $1.3 \%$ & 7 & $0.1 \%$ & 63 & $0.5 \%$ & 1,094 & $9.5 \%$ \\
\hline Pricing without Technology & 429 & $3.7 \%$ & 3 & $0.0 \%$ & 4 & $0.0 \%$ & 115 & $1.0 \%$ & 550 & $4.8 \%$ \\
\hline Automated/Direct Load Control & 73 & $0.6 \%$ & 15 & $0.1 \%$ & 1 & $0.0 \%$ & 0 & $0.0 \%$ & 89 & $0.8 \%$ \\
\hline Interruptible/Curtailable Tariffs & 0 & $0.0 \%$ & 0 & $0.0 \%$ & 11 & $0.1 \%$ & 202 & $1.7 \%$ & 212 & $1.8 \%$ \\
\hline Other DR Programs & 0 & $0.0 \%$ & 0 & $0.0 \%$ & 3 & $0.0 \%$ & 71 & $0.6 \%$ & 74 & $0.6 \%$ \\
\hline Total & 1,379 & $12.0 \%$ & 163 & $1.4 \%$ & 25 & $0.2 \%$ & 450 & $3.9 \%$ & 2,018 & $17.5 \%$ \\
\hline \multicolumn{11}{|l|}{ Full Deployment } \\
\hline Pricing with Technology & 2,053 & $17.8 \%$ & 341 & $3.0 \%$ & 20 & $0.2 \%$ & 185 & $1.6 \%$ & 2,599 & $22.5 \%$ \\
\hline Pricing without Technology & 67 & $0.6 \%$ & 1 & $0.0 \%$ & 2 & $0.0 \%$ & 149 & $1.3 \%$ & 219 & $1.9 \%$ \\
\hline Automated/Direct Load Control & 0 & $0.0 \%$ & 0 & $0.0 \%$ & 0 & $0.0 \%$ & 0 & $0.0 \%$ & 0 & $0.0 \%$ \\
\hline Interruptible/Curtailable Tariffs & 0 & $0.0 \%$ & 0 & $0.0 \%$ & 11 & $0.1 \%$ & 202 & $1.7 \%$ & 212 & $1.8 \%$ \\
\hline Other DR Programs & 0 & $0.0 \%$ & 0 & $0.0 \%$ & 0 & $0.0 \%$ & 0 & $0.0 \%$ & 0 & $0.0 \%$ \\
\hline $\begin{array}{l}\text { Total } \\
\end{array}$ & 2,120 & $18.4 \%$ & 343 & $3.0 \%$ & 32 & $0.3 \%$ & 535 & $4.6 \%$ & 3,031 & $26.3 \%$ \\
\hline
\end{tabular}




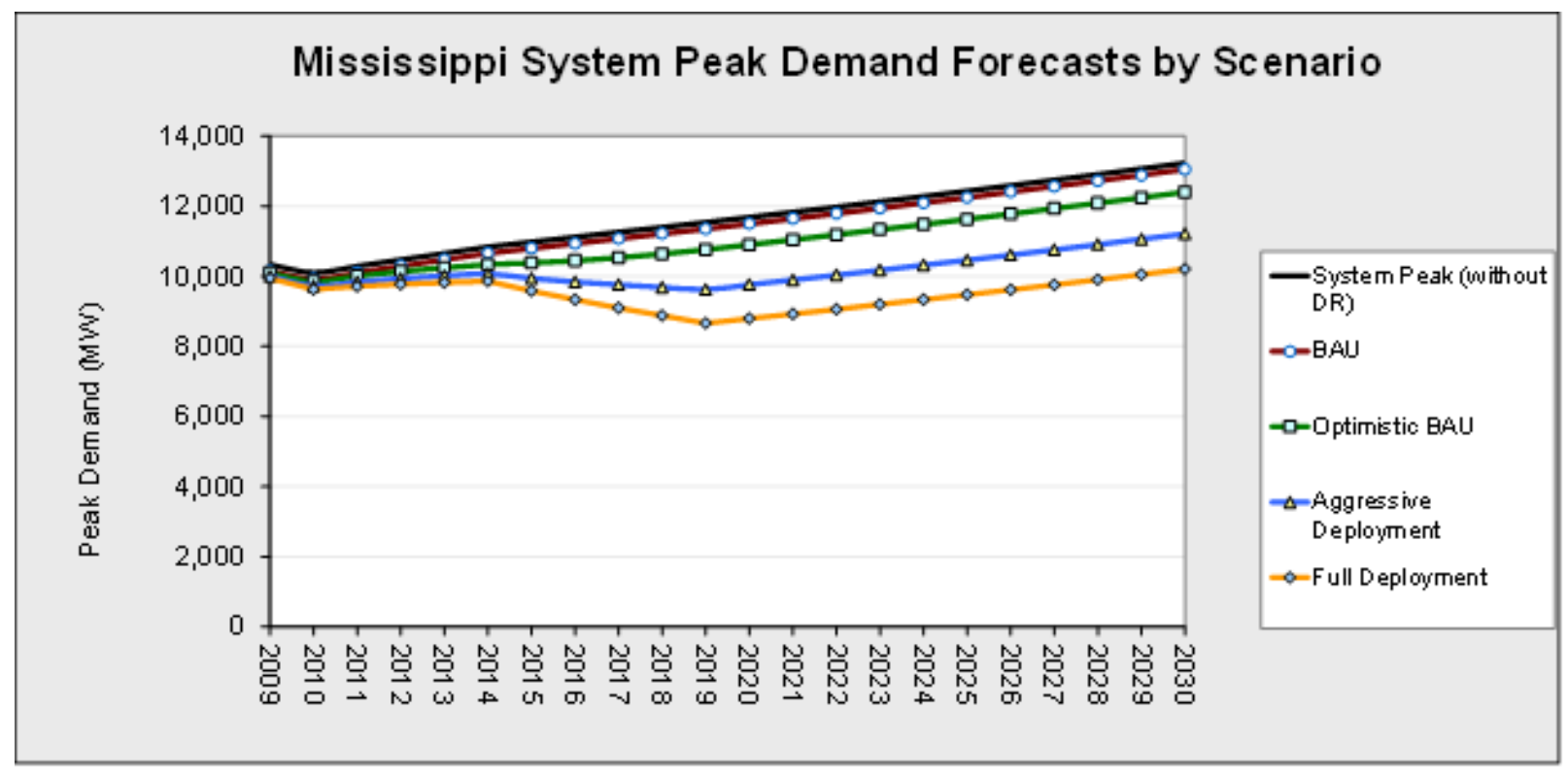

Summary of Monte Carlo Simulation of Potential Peak Load Reduction from Demand Response in Mississippi by Scenario, Pricing Program and Price Ratio (MW)

\begin{tabular}{|c|c|c|c|c|c|c|c|c|c|c|c|c|}
\hline & \multicolumn{3}{|c|}{2015} & \multicolumn{3}{|c|}{2020} & \multicolumn{3}{|c|}{2025} & \multicolumn{3}{|c|}{2030} \\
\hline & Mean & Lower & Upper & Mean & Lower & Upper & Mean & Lower & Upper & Mean & Lower & Upper \\
\hline \multicolumn{13}{|l|}{$\mathrm{BAU}$} \\
\hline 5 & 0 & 0 & 0 & 0 & 0 & 0 & 0 & 0 & 0 & 0 & 0 & 0 \\
\hline 10 & 0 & 0 & 0 & 0 & 0 & 0 & 0 & 0 & 0 & 0 & 0 & 0 \\
\hline 15 & 0 & 0 & 0 & 0 & 0 & 0 & 0 & 0 & 0 & 0 & 0 & 0 \\
\hline \multicolumn{13}{|l|}{ Pricing without Technology } \\
\hline & 63 & 63 & 63 & 63 & 63 & 63 & 63 & 63 & 63 & 63 & 63 & 63 \\
\hline 10 & 63 & 63 & 63 & 63 & 63 & 63 & 63 & 63 & 63 & 63 & 63 & 63 \\
\hline 15 & 63 & 63 & 63 & 63 & 63 & 63 & 63 & 63 & 63 & 63 & 63 & 63 \\
\hline \multirow{2}{*}{\multicolumn{13}{|c|}{$\begin{array}{l}\text { Optimistic BAU } \\
\text { Pricing with Technology }\end{array}$}} \\
\hline & & & & & & & & & & & & \\
\hline H & 0 & 0 & 0 & 0 & 0 & 0 & 0 & 0 & 0 & 0 & 0 & 0 \\
\hline 10 & 0 & 0 & 0 & 0 & 0 & 0 & 0 & 0 & 0 & 0 & 0 & 0 \\
\hline 15 & 0 & 0 & 0 & 0 & 0 & 0 & 0 & 0 & 0 & 0 & 0 & 0 \\
\hline \multicolumn{13}{|l|}{ Pricing without Technology } \\
\hline 5 & 76 & 68 & 84 & 84 & 71 & 97 & 84 & 71 & 97 & 84 & 71 & 98 \\
\hline 10 & 81 & 69 & 94 & 93 & 72 & 114 & 93 & 72 & 114 & 94 & 72 & 115 \\
\hline 15 & 84 & 69 & 99 & 97 & 72 & 122 & 98 & 72 & 123 & 98 & 72 & 124 \\
\hline \multicolumn{13}{|l|}{$\begin{array}{l}\text { Aggressive Deployment } \\
\text { Pricing with Technology }\end{array}$} \\
\hline 5 & 304 & 100 & 508 & 831 & 274 & 1387 & 848 & 280 & 1416 & 866 & 286 & 1446 \\
\hline 10 & 466 & 145 & 788 & 1274 & 396 & 2151 & 1300 & 405 & 2196 & 1328 & 413 & 2242 \\
\hline 15 & 520 & 109 & 930 & 1419 & 297 & 2540 & 1448 & 304 & 2593 & 1479 & 310 & 2648 \\
\hline \multicolumn{13}{|l|}{ Pricing without Technology } \\
\hline 5 & 184 & 104 & 265 & 438 & 158 & 718 & 448 & 161 & 735 & 458 & 163 & 753 \\
\hline 8 & 256 & 113 & 398 & 671 & 216 & 1125 & 686 & 220 & 1151 & 701 & 224 & 1179 \\
\hline 15 & 283 & 94 & 472 & 748 & 163 & 1333 & 765 & 165 & 1364 & 782 & 167 & 1397 \\
\hline \multicolumn{13}{|l|}{$\begin{array}{l}\text { Full Deployment } \\
\text { Pricing with Technology }\end{array}$} \\
\hline 5 & 746 & 242 & 1250 & 2038 & 661 & 3415 & 2082 & 675 & 3489 & 2127 & 690 & 3564 \\
\hline 10 & 1031 & 246 & 1817 & 2817 & 672 & 4963 & 2878 & 686 & 5070 & 2940 & 701 & 5179 \\
\hline 15 & 1295 & 410 & 2180 & 3538 & 1121 & 5956 & 3614 & 1145 & 6083 & 3692 & 1170 & 6215 \\
\hline \multicolumn{13}{|l|}{ Pricing without Technology } \\
\hline 5 & 86 & 65 & 106 & 199 & 73 & 324 & 206 & 75 & 337 & 214 & 77 & 351 \\
\hline 10 & 107 & 54 & 159 & 274 & 69 & 480 & 285 & 70 & 500 & 296 & 72 & 520 \\
\hline 15 & 128 & 56 & 200 & 345 & 111 & 579 & 359 & 116 & 601 & 373 & 120 & 625 \\
\hline
\end{tabular}




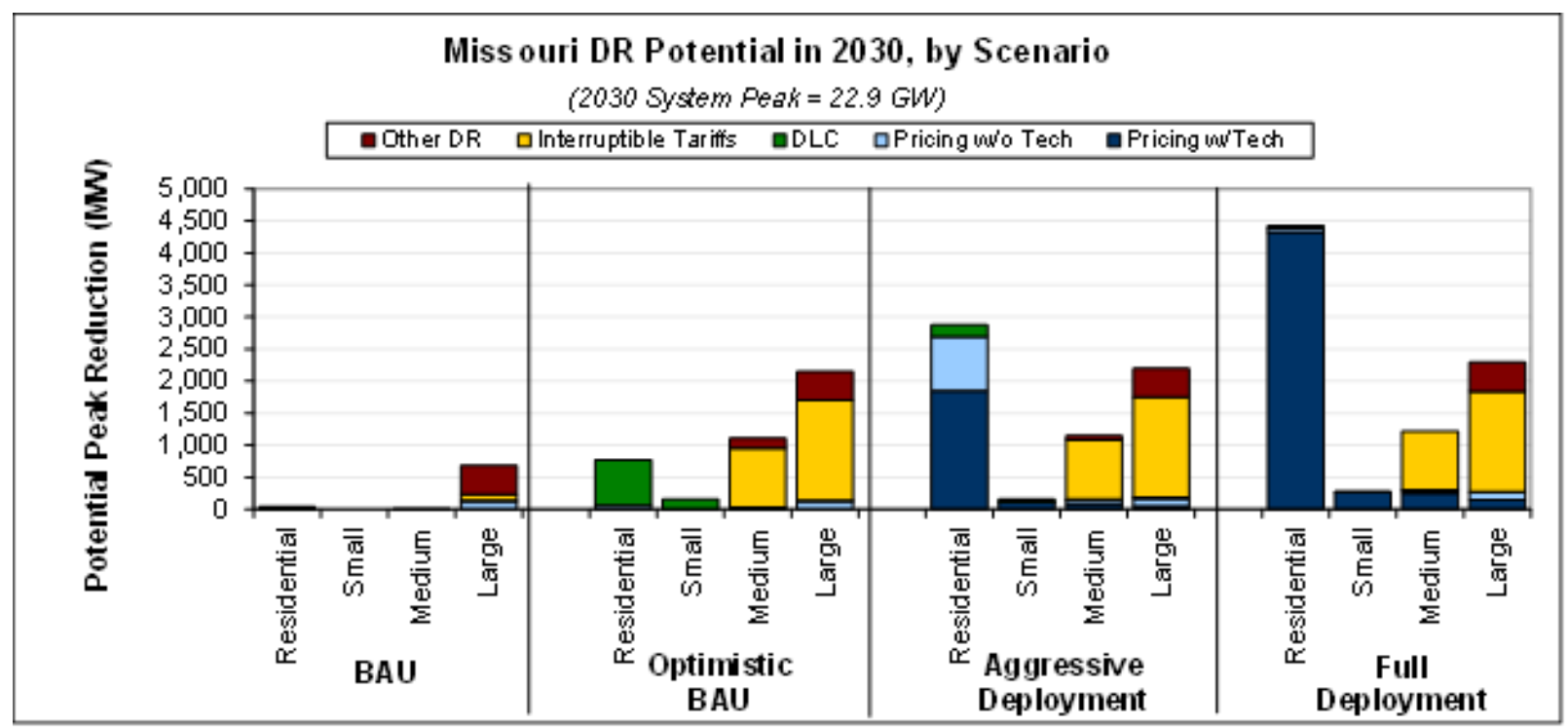

Total Potential Peak Reduction from Demand Response in Missouri, 2030

\begin{tabular}{|c|c|c|c|c|c|c|c|c|c|c|}
\hline & $\begin{array}{l}\text { Residential } \\
\text { (MW) }\end{array}$ & $\begin{array}{l}\text { Residential } \\
\text { ( } \% \text { of } \\
\text { svstem) }\end{array}$ & $\begin{array}{l}\text { Small C\&I } \\
(\mathrm{MW})\end{array}$ & $\begin{array}{l}\text { Small C\&I } \\
\text { (\% of } \\
\text { svstem) }\end{array}$ & $\begin{array}{l}\text { Med. C\&I } \\
(\mathrm{MW})\end{array}$ & $\begin{array}{l}\text { Med C\&I } \\
\text { ( } \% \text { of } \\
\text { svstem) }\end{array}$ & $\begin{array}{l}\text { Large C\&I } \\
(\mathrm{MW})\end{array}$ & $\begin{array}{l}\text { Large C\&I } \\
\text { ( } \% \text { of } \\
\text { svstem) }\end{array}$ & $\begin{array}{l}\text { Total } \\
\text { (MW) }\end{array}$ & $\begin{array}{l}\text { Total } \\
\text { ( } \% \text { of } \\
\text { svstem) }\end{array}$ \\
\hline \multicolumn{11}{|l|}{ BAU } \\
\hline Pricing with Technology & 0 & $0.0 \%$ & 0 & $0.0 \%$ & 0 & $0.0 \%$ & 0 & $0.0 \%$ & 0 & $0.0 \%$ \\
\hline Pricing without Technology & 1 & $0.0 \%$ & 0 & $0.0 \%$ & 0 & $0.0 \%$ & 120 & $0.6 \%$ & 121 & $0.6 \%$ \\
\hline Automated/Direct Load Control & 36 & $0.2 \%$ & 0 & $0.0 \%$ & 2 & $0.0 \%$ & 14 & $0.1 \%$ & 53 & $0.3 \%$ \\
\hline Interruptible/Curtailable Tariffs & 0 & $0.0 \%$ & 0 & $0.0 \%$ & 0 & $0.0 \%$ & 96 & $0.5 \%$ & 96 & $0.5 \%$ \\
\hline Other DR Programs & 0 & $0.0 \%$ & 0 & $0.0 \%$ & 0 & $0.0 \%$ & 448 & $2.2 \%$ & 448 & $2.2 \%$ \\
\hline Total & 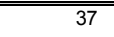 & $0.2 \%$ & 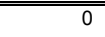 & $0.0 \%$ & 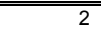 & $0.0 \%$ & 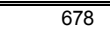 & $3.4 \%$ & $\overline{7718}$ & $\overline{3.6 \%}$ \\
\hline \multicolumn{11}{|l|}{ Optimistic BAU } \\
\hline Pricing with Technology & 0 & $0.0 \%$ & 0 & $0.0 \%$ & 0 & $0.0 \%$ & 0 & $0.0 \%$ & 0 & $0.0 \%$ \\
\hline Pricing without Technology & 57 & $0.3 \%$ & 0 & $0.0 \%$ & 4 & $0.0 \%$ & 120 & $0.6 \%$ & 182 & $0.9 \%$ \\
\hline Automated/Direct Load Control & 711 & $3.6 \%$ & 156 & $0.8 \%$ & 22 & $0.1 \%$ & 14 & $0.1 \%$ & 902 & $4.5 \%$ \\
\hline Interruptible/Curtailable Tariffs & 0 & $0.0 \%$ & 0 & $0.0 \%$ & 923 & $4.6 \%$ & 1,564 & $7.8 \%$ & 2,487 & $12.4 \%$ \\
\hline Other DR Programs & 0 & $0.0 \%$ & 0 & $0.0 \%$ & 156 & $0.8 \%$ & 448 & $2.2 \%$ & 604 & $3.0 \%$ \\
\hline Total & 768 & $3.8 \%$ & 156 & $0.8 \%$ & 1,105 & $5.5 \%$ & 2,145 & $10.7 \%$ & 4 & $20.9 \%$ \\
\hline \multicolumn{11}{|l|}{ Aggressive Deployment } \\
\hline Pricing with Technology & 1,849 & $9.2 \%$ & 114 & $0.6 \%$ & 86 & $0.4 \%$ & 49 & $0.2 \%$ & 2,098 & $10.5 \%$ \\
\hline Pricing without Technology & 844 & $4.2 \%$ & 2 & $0.0 \%$ & 62 & $0.3 \%$ & 120 & $0.6 \%$ & 1,028 & $5.1 \%$ \\
\hline Automated/Direct Load Control & 182 & $0.9 \%$ & 40 & $0.2 \%$ & 9 & $0.0 \%$ & 14 & $0.1 \%$ & 245 & $1.2 \%$ \\
\hline Interruptible/Curtailable Tariffs & 0 & $0.0 \%$ & 0 & $0.0 \%$ & 923 & $4.6 \%$ & 1,564 & $7.8 \%$ & 2,487 & $12.4 \%$ \\
\hline Other DR Programs & 0 & $0.0 \%$ & 0 & $0.0 \%$ & 64 & $0.3 \%$ & 448 & $2.2 \%$ & 511 & $2.6 \%$ \\
\hline Total & 2,875 & $14.4 \%$ & 156 & $0.8 \%$ & 1,143 & $5.7 \%$ & 2,194 & $11.0 \%$ & 6,369 & $31.9 \%$ \\
\hline \multicolumn{11}{|l|}{ Full Deployment } \\
\hline Pricing with Technology & 4,325 & $21.6 \%$ & 267 & $1.3 \%$ & 252 & $1.3 \%$ & 143 & $0.7 \%$ & 4,986 & $24.9 \%$ \\
\hline Pricing without Technology & 63 & $0.3 \%$ & 1 & $0.0 \%$ & 42 & $0.2 \%$ & 120 & $0.6 \%$ & 226 & $1.1 \%$ \\
\hline Automated/Direct Load Control & 36 & $0.2 \%$ & 0 & $0.0 \%$ & 2 & $0.0 \%$ & 14 & $0.1 \%$ & 53 & $0.3 \%$ \\
\hline Interruptible/Curtailable Tariffs & 0 & $0.0 \%$ & 0 & $0.0 \%$ & 923 & $4.6 \%$ & 1,564 & $7.8 \%$ & 2,487 & $12.4 \%$ \\
\hline Other DR Programs & 0 & $0.0 \%$ & 0 & $0.0 \%$ & 0 & $0.0 \%$ & 448 & $2.2 \%$ & 448 & $2.2 \%$ \\
\hline Total & $4,4,424$ & $22.1 \%$ & 269 & $1.3 \%$ & $\overline{1,219}$ & $6.1 \%$ & 2,288 & $11.4 \%$ & 8,200 & $41.0 \%$ \\
\hline
\end{tabular}




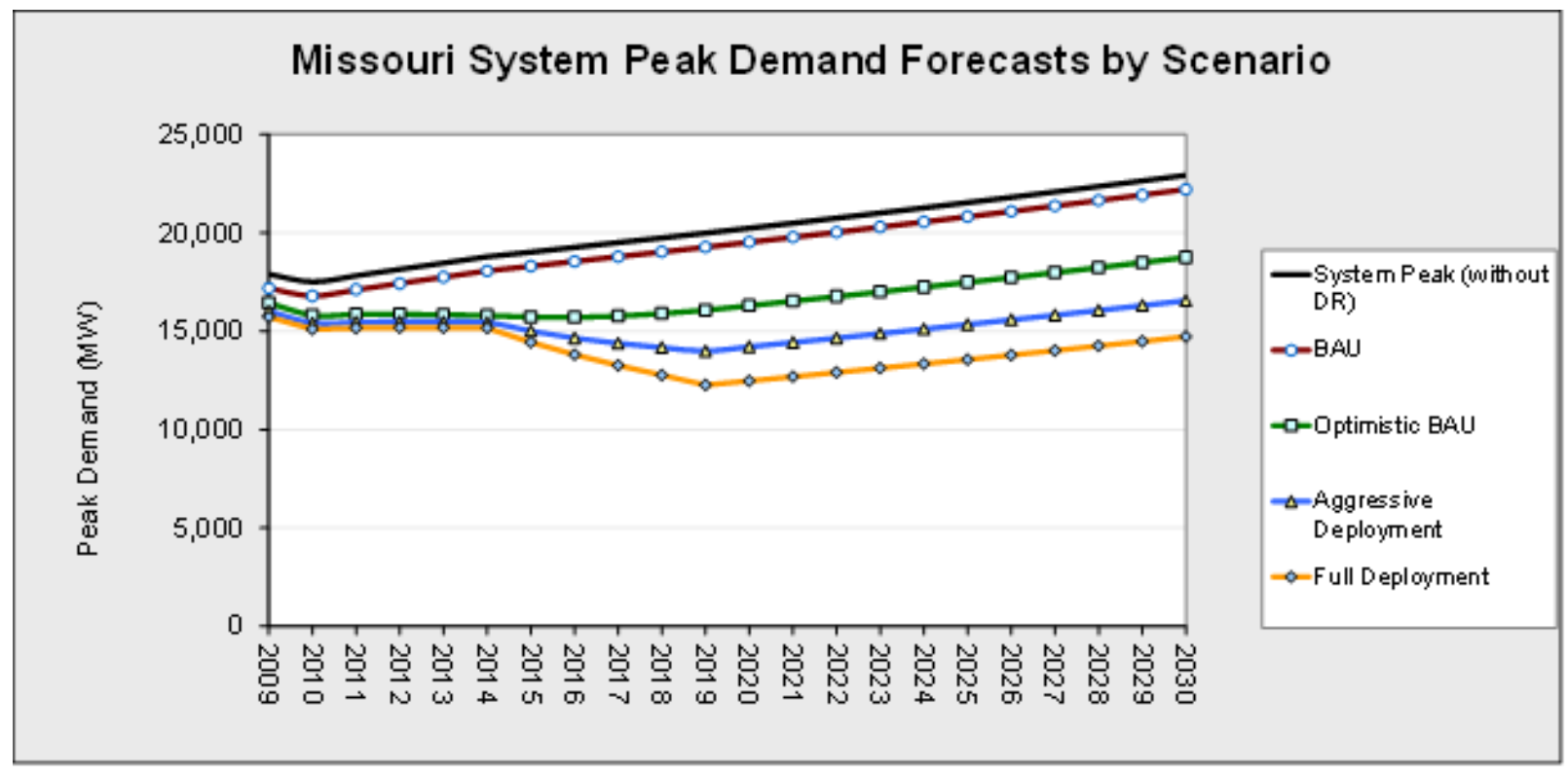

Summary of Monte Carlo Simulation of Potential Peak Load Reduction from Demand Response in Missouri by Scenario, Pricing Program and Price Ratio (MW)

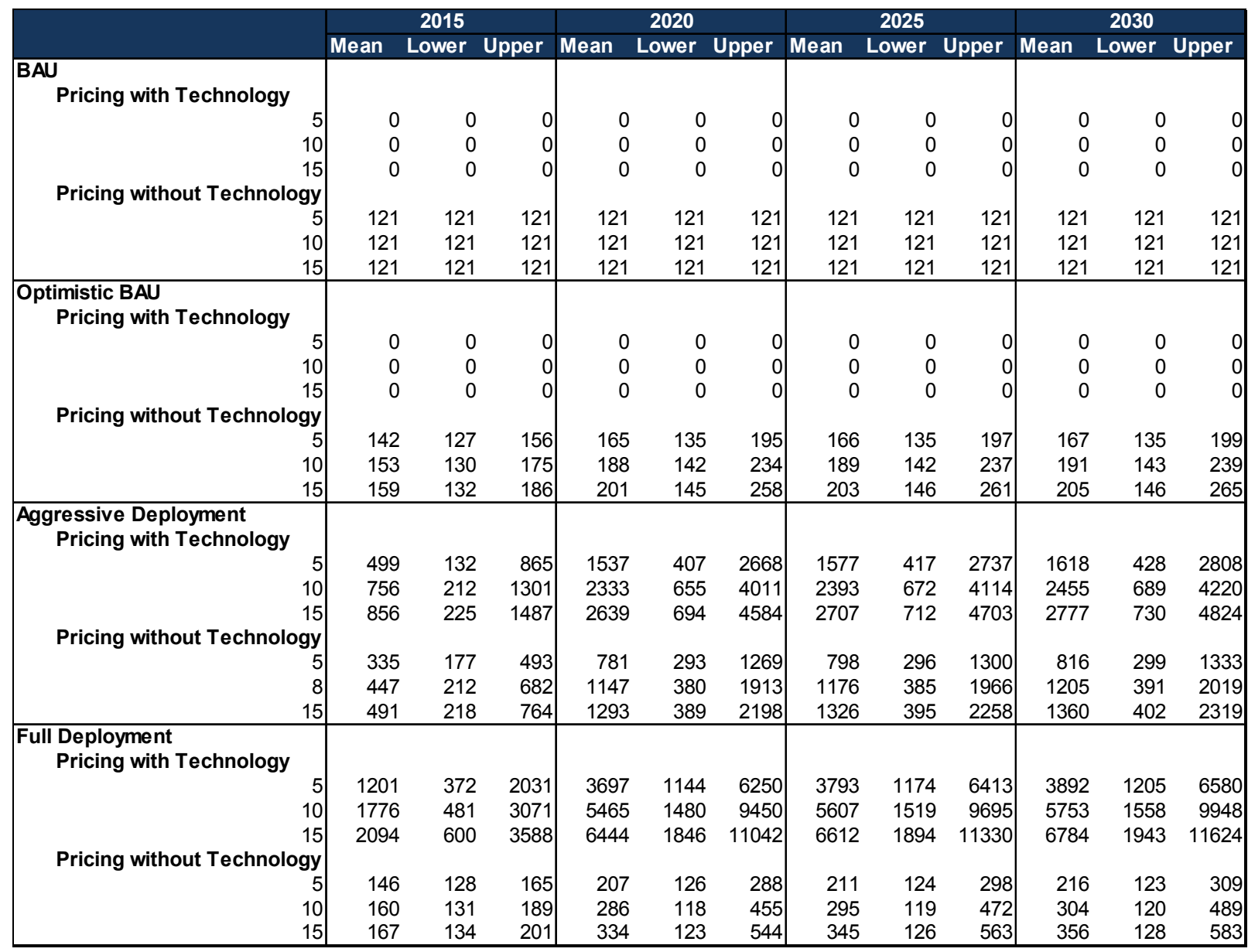




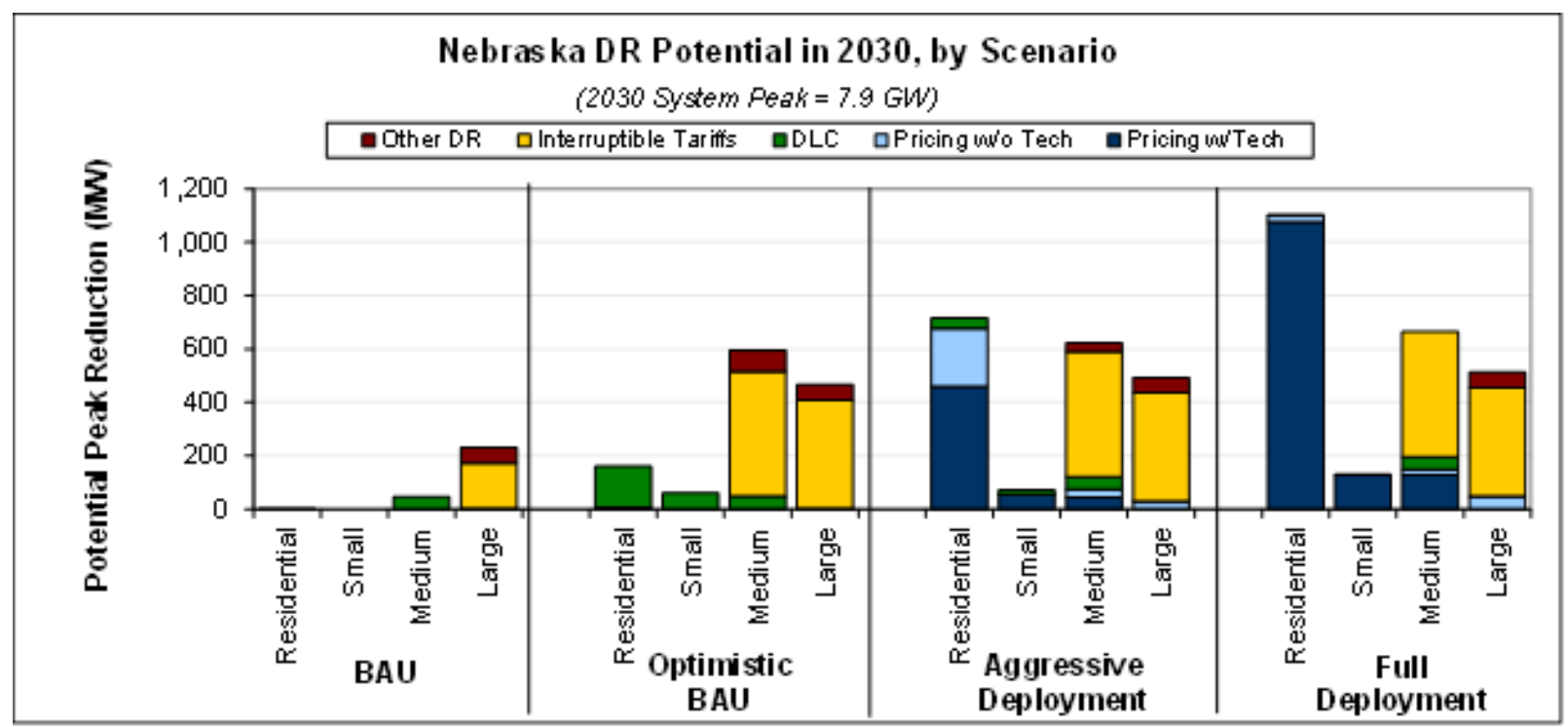

Total Potential Peak Reduction from Demand Response in Nebraska, 2030

\begin{tabular}{|c|c|c|c|c|c|c|c|c|c|c|}
\hline & $\begin{array}{l}\text { Residential } \\
\text { (MW) }\end{array}$ & $\begin{array}{l}\text { Residential } \\
\text { ( } \% \text { of } \\
\text { svstem) }\end{array}$ & $\begin{array}{l}\text { Small C\&I } \\
\text { (MW) }\end{array}$ & $\begin{array}{l}\text { Small C\&I } \\
\text { (\% of } \\
\text { svstem) }\end{array}$ & $\begin{array}{l}\text { Med. C\&I } \\
(\mathrm{MW})\end{array}$ & $\begin{array}{l}\text { Med C\&I } \\
\text { ( } \% \text { of } \\
\text { svstem) }\end{array}$ & $\begin{array}{l}\text { Large C\&I } \\
(\mathrm{MW})\end{array}$ & $\begin{array}{l}\text { Large C\&I } \\
\text { (\% of } \\
\text { svstem) }\end{array}$ & $\begin{array}{l}\text { Total } \\
\text { (MW) }\end{array}$ & $\begin{array}{c}\text { Total } \\
\text { ( } \% \text { of } \\
\text { svstem) }\end{array}$ \\
\hline \multicolumn{11}{|l|}{ BAU } \\
\hline Pricing with Technology & 0 & $0.0 \%$ & 0 & $0.0 \%$ & 0 & $0.0 \%$ & 0 & $0.0 \%$ & 0 & $0.0 \%$ \\
\hline Pricing without Technology & 0 & $0.0 \%$ & 0 & $0.0 \%$ & 0 & $0.0 \%$ & 2 & $0.0 \%$ & 2 & $0.0 \%$ \\
\hline Automated/Direct Load Control & 2 & $0.0 \%$ & 0 & $0.0 \%$ & 47 & $0.7 \%$ & 1 & $0.0 \%$ & 50 & $0.7 \%$ \\
\hline Interruptible/Curtailable Tariffs & 0 & $0.0 \%$ & 0 & $0.0 \%$ & 0 & $0.0 \%$ & 170 & $2.4 \%$ & 170 & $2.4 \%$ \\
\hline Other DR Programs & 0 & $0.0 \%$ & 0 & $0.0 \%$ & 0 & $0.0 \%$ & 58 & $0.8 \%$ & 58 & $0.8 \%$ \\
\hline Total & 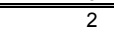 & $0.0 \%$ & 0 & $0.0 \%$ & 47 & $0.7 \%$ & 231 & $3.3 \%$ & 280 & $4.0 \%$ \\
\hline \multicolumn{11}{|l|}{ Optimistic BAU } \\
\hline Pricing with Technology & 0 & $0.0 \%$ & 0 & $0.0 \%$ & 0 & $0.0 \%$ & 0 & $0.0 \%$ & 0 & $0.0 \%$ \\
\hline Pricing without Technology & 6 & $0.1 \%$ & 0 & $0.0 \%$ & 1 & $0.0 \%$ & 2 & $0.0 \%$ & 9 & $0.1 \%$ \\
\hline Automated/Direct Load Control & 155 & $2.2 \%$ & 61 & $0.9 \%$ & 47 & $0.7 \%$ & 1 & $0.0 \%$ & 264 & $3.8 \%$ \\
\hline Interruptible/Curtailable Tariffs & 0 & $0.0 \%$ & 0 & $0.0 \%$ & 468 & $6.7 \%$ & 405 & $5.8 \%$ & 873 & $12.6 \%$ \\
\hline Other DR Programs & 0 & $0.0 \%$ & 0 & $0.0 \%$ & 80 & $1.2 \%$ & 58 & $0.8 \%$ & 138 & $2.0 \%$ \\
\hline Total & 161 & $2.3 \%$ & 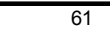 & $0.9 \%$ & (596 & $8.6 \%$ & 466 & $6.7 \%$ & $\begin{array}{l}1,284 \\
\end{array}$ & $18.5 \%$ \\
\hline \multicolumn{11}{|l|}{ Aggressive Deployment } \\
\hline Pricing with Technology & 460 & $6.6 \%$ & 55 & $0.8 \%$ & 44 & $0.6 \%$ & 0 & $0.0 \%$ & 559 & $8.1 \%$ \\
\hline Pricing without Technology & 216 & $3.1 \%$ & 1 & $0.0 \%$ & 31 & $0.5 \%$ & 29 & $0.4 \%$ & 278 & $4.0 \%$ \\
\hline Automated/Direct Load Control & 39 & $0.6 \%$ & 15 & $0.2 \%$ & 47 & $0.7 \%$ & 1 & $0.0 \%$ & 103 & $1.5 \%$ \\
\hline Interruptible/Curtailable Tariffs & 0 & $0.0 \%$ & 0 & $0.0 \%$ & 468 & $6.7 \%$ & 405 & $5.8 \%$ & 873 & $12.6 \%$ \\
\hline Other DR Programs & 0 & $0.0 \%$ & 0 & $0.0 \%$ & 32 & $0.5 \%$ & 58 & $0.8 \%$ & 90 & $1.3 \%$ \\
\hline Total & 715 & $10.3 \%$ & 71 & $1.0 \%$ & 622 & $9.0 \%$ & 493 & $7.1 \%$ & 1,902 & $27.4 \%$ \\
\hline \multicolumn{11}{|l|}{ Full Deployment } \\
\hline Pricing with Technology & 1,076 & $15.5 \%$ & 128 & $1.9 \%$ & 128 & $1.8 \%$ & 0 & $0.0 \%$ & 1,332 & $19.2 \%$ \\
\hline Pricing without Technology & 24 & $0.3 \%$ & 1 & $0.0 \%$ & 21 & $0.3 \%$ & 48 & $0.7 \%$ & 94 & $1.4 \%$ \\
\hline Automated/Direct Load Control & 2 & $0.0 \%$ & 0 & $0.0 \%$ & 47 & $0.7 \%$ & 1 & $0.0 \%$ & 50 & $0.7 \%$ \\
\hline Interruptible/Curtailable Tariffs & 0 & $0.0 \%$ & 0 & $0.0 \%$ & 468 & $6.7 \%$ & 405 & $5.8 \%$ & 873 & $12.6 \%$ \\
\hline Other DR Programs & 0 & $0.0 \%$ & 0 & $0.0 \%$ & 0 & $0.0 \%$ & 58 & $0.8 \%$ & 58 & $0.8 \%$ \\
\hline $\begin{array}{l}\text { Total } \\
\end{array}$ & 1,102 & $15.9 \%$ & 129 & $1.9 \%$ & 664 & $9.6 \%$ & 512 & $7.4 \%$ & 2,407 & $34.7 \%$ \\
\hline
\end{tabular}




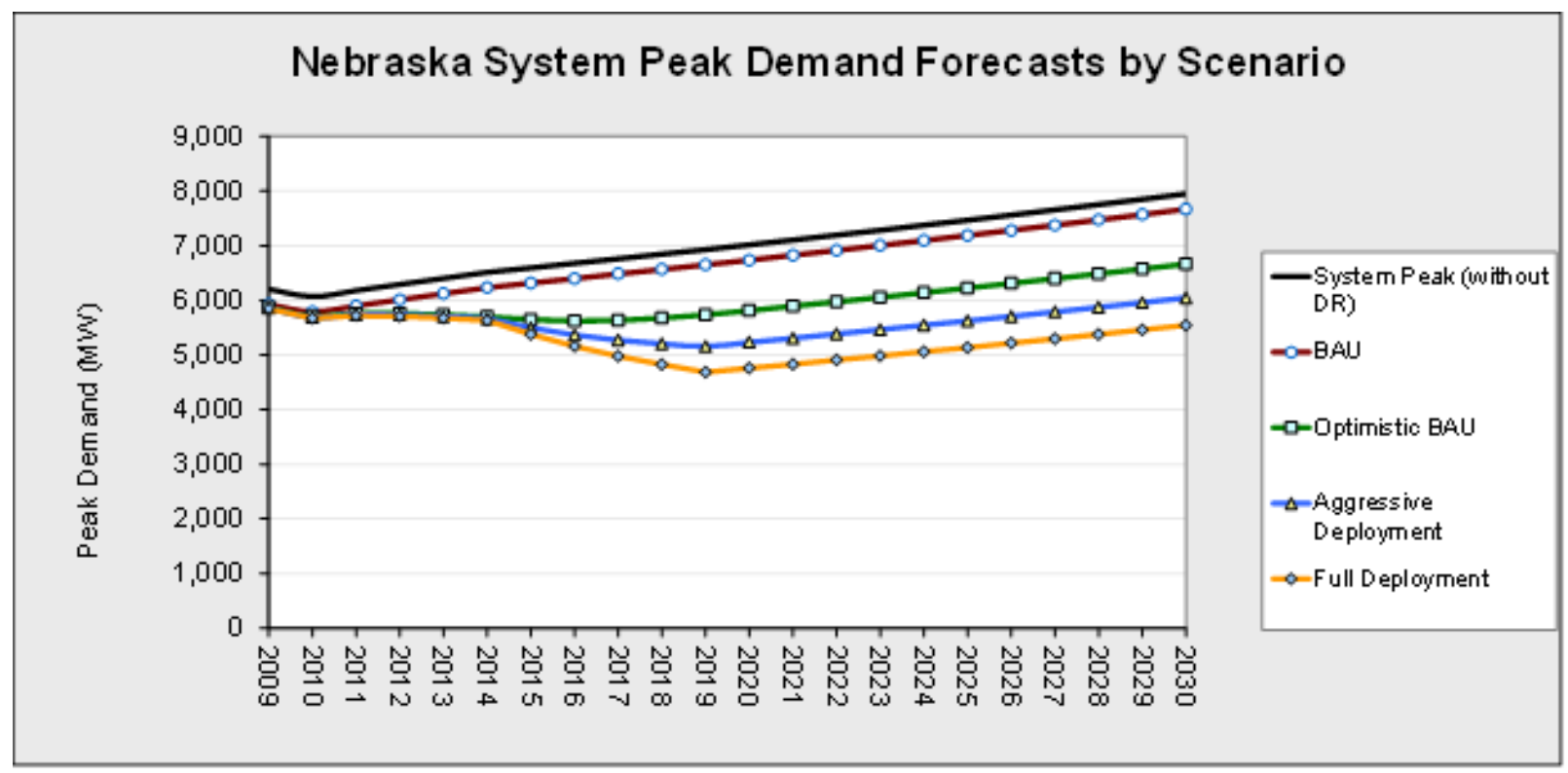

Summary of Monte Carlo Simulation of Potential Peak Load Reduction from Demand Response in Nebraska by Scenario, Pricing Program and Price Ratio (MW)

\begin{tabular}{|c|c|c|c|c|c|c|c|c|c|c|c|c|}
\hline & & \multicolumn{3}{|c|}{2020} & \multicolumn{3}{|c|}{2025} & \multicolumn{3}{|c|}{2030} \\
\hline & \multicolumn{2}{|c|}{\begin{tabular}{|cc} 
& 2015 \\
Mean & Lower
\end{tabular}} & Upper & \multirow[t]{2}{*}{ Mean } & Lower & Upper & \multirow[t]{2}{*}{ Mean } & \multicolumn{2}{|c|}{ Lower Upper } & \multirow[t]{2}{*}{ Mean } & Lower & Upper \\
\hline \multicolumn{10}{|l|}{ Pricing with Technology } & & & \\
\hline 5 & 0 & 0 & 0 & 0 & 0 & 0 & 0 & 0 & 0 & 0 & 0 & 0 \\
\hline 10 & 0 & 0 & 0 & 0 & 0 & 0 & 0 & 0 & 0 & 0 & 0 & 0 \\
\hline 15 & 0 & 0 & 0 & 0 & 0 & 0 & 0 & 0 & 0 & 0 & 0 & 0 \\
\hline \multicolumn{13}{|l|}{ Pricing without Technology } \\
\hline & 1 & 1 & 1 & 1 & 1 & 1 & 1 & 1 & 1 & 1 & 1 & 1 \\
\hline 10 & 1 & 1 & 1 & 1 & 1 & 1 & 1 & 1 & 1 & 1 & 1 & 1 \\
\hline 15 & 1 & 1 & 1 & 1 & 1 & 1 & 1 & 1 & 1 & 1 & 1 & 1 \\
\hline \multicolumn{13}{|l|}{$\begin{array}{l}\text { Optimistic BAU } \\
\text { Pricing with Technology }\end{array}$} \\
\hline 5 & 0 & 0 & 0 & 0 & 0 & 0 & 0 & 0 & 0 & 0 & 0 & 0 \\
\hline 10 & 0 & 0 & 0 & 0 & 0 & 0 & 0 & 0 & 0 & 0 & 0 & 0 \\
\hline 15 & 0 & 0 & 0 & 0 & 0 & 0 & 0 & 0 & 0 & 0 & 0 & 0 \\
\hline \multicolumn{13}{|l|}{ Pricing without Technology } \\
\hline 5 & 4 & 2 & 5 & 7 & 3 & 10 & 7 & 3 & 10 & 7 & 3 & 11 \\
\hline 10 & 5 & 2 & 7 & 9 & 4 & 14 & 9 & 4 & 15 & 9 & 4 & 15 \\
\hline 15 & 6 & 3 & 8 & 11 & 5 & 16 & 11 & 5 & 17 & 11 & 5 & 17 \\
\hline \multicolumn{13}{|l|}{$\begin{array}{l}\text { Aggressive Deployment } \\
\text { Pricing with Technology }\end{array}$} \\
\hline ge & 99 & 27 & 172 & 404 & 108 & 701 & 417 & 111 & 723 & 430 & 115 & 746 \\
\hline 10 & 147 & 33 & 261 & 598 & 136 & 1061 & 617 & 140 & 1094 & 637 & 145 & 1129 \\
\hline 15 & 171 & 44 & 299 & 697 & 180 & 1214 & 719 & 185 & 1253 & 742 & 191 & 1292 \\
\hline \multicolumn{13}{|l|}{ Pricing without Technology } \\
\hline 5 & 52 & 14 & 90 & 207 & 55 & 359 & 214 & 57 & 370 & 220 & 59 & 382 \\
\hline 8 & 77 & 18 & 136 & 307 & 70 & 544 & 317 & 73 & 562 & 327 & 75 & 580 \\
\hline 15 & 90 & 23 & 156 & 359 & 93 & 624 & 370 & 96 & 644 & 382 & 99 & 665 \\
\hline \multicolumn{13}{|l|}{\begin{tabular}{|l|} 
Full Deployment \\
Pricing with Technology
\end{tabular}} \\
\hline 5 & 244 & 65 & 422 & 987 & 263 & 1711 & 1018 & 271 & 1765 & 1050 & 279 & 1821 \\
\hline 10 & 329 & 84 & 575 & 1335 & 338 & 2331 & 1377 & 349 & 2405 & 1420 & 360 & 2481 \\
\hline 15 & 426 & 100 & 751 & 1725 & 405 & 3045 & 1780 & 418 & 3141 & 1836 & 431 & 3240 \\
\hline \multicolumn{13}{|l|}{ Pricing without Technology } \\
\hline 5 & 21 & 6 & 36 & 80 & 22 & 139 & 83 & 22 & 143 & 86 & 23 & 149 \\
\hline 10 & 29 & 7 & 50 & 109 & 28 & 190 & 113 & 29 & 197 & 117 & 30 & 204 \\
\hline 15 & 37 & 9 & 65 & 142 & 34 & 249 & 147 & 35 & 258 & 152 & 37 & 267 \\
\hline
\end{tabular}




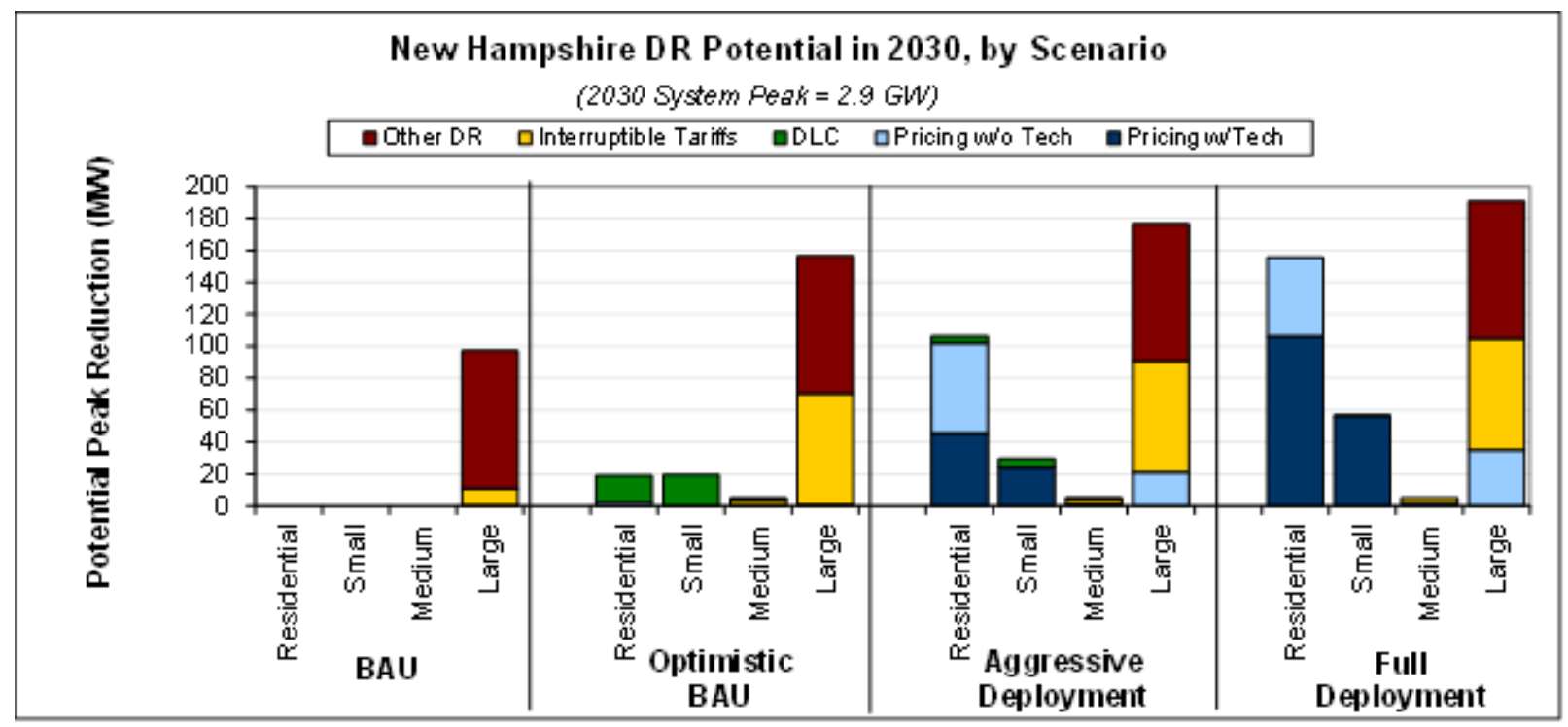

Total Potential Peak Reduction from Demand Response in New Hampshire, 2030

\begin{tabular}{|c|c|c|c|c|c|c|c|c|c|c|}
\hline & $\begin{array}{l}\text { Residential } \\
\text { (MW) }\end{array}$ & $\begin{array}{l}\text { Residential } \\
\text { ( } \% \text { of } \\
\text { svstem) }\end{array}$ & $\begin{array}{l}\text { Small C\&I } \\
\text { (MW) }\end{array}$ & $\begin{array}{c}\text { Small C\&I } \\
\text { (\% of } \\
\text { svstem) }\end{array}$ & $\begin{array}{l}\text { Med. C\&I } \\
(\mathrm{MW})\end{array}$ & $\begin{array}{l}\text { Med C\&I } \\
\text { ( } \% \text { of } \\
\text { svstem) }\end{array}$ & $\begin{array}{l}\text { Large C\&I } \\
\text { (MW) }\end{array}$ & $\begin{array}{c}\text { Large C\&I } \\
\text { ( } \% \text { of } \\
\text { svstem) }\end{array}$ & $\begin{array}{l}\text { Total } \\
\text { (MW) }\end{array}$ & $\begin{array}{c}\text { Total } \\
\text { ( } \% \text { of } \\
\text { svstem) }\end{array}$ \\
\hline \multicolumn{11}{|l|}{ BAU } \\
\hline Pricing with Technology & 0 & $0.0 \%$ & 0 & $0.0 \%$ & 0 & $0.0 \%$ & 0 & $0.0 \%$ & 0 & $0.0 \%$ \\
\hline Pricing without Technology & 0 & $0.0 \%$ & 0 & $0.0 \%$ & 0 & $0.0 \%$ & 0 & $0.0 \%$ & 0 & $0.0 \%$ \\
\hline Automated/Direct Load Control & 0 & $0.0 \%$ & 0 & $0.0 \%$ & 0 & $0.0 \%$ & 0 & $0.0 \%$ & 0 & $0.0 \%$ \\
\hline Interruptible/Curtailable Tariffs & 0 & $0.0 \%$ & 0 & $0.0 \%$ & 0 & $0.0 \%$ & 11 & $0.4 \%$ & 11 & $0.4 \%$ \\
\hline Other DR Programs & 0 & $0.0 \%$ & 0 & $0.0 \%$ & 0 & $0.0 \%$ & 86 & $3.4 \%$ & 86 & $3.4 \%$ \\
\hline Total & 0 & $0.0 \%$ & 0 & $0.0 \%$ & 0 & $0.0 \%$ & 97 & $3.8 \%$ & 97 & $3.8 \%$ \\
\hline \multicolumn{11}{|l|}{ Optimistic BAU } \\
\hline Pricing with Technology & 0 & $0.0 \%$ & 0 & $0.0 \%$ & 0 & $0.0 \%$ & 0 & $0.0 \%$ & 0 & $0.0 \%$ \\
\hline Pricing without Technology & 2 & $0.1 \%$ & 0 & $0.0 \%$ & 0 & $0.0 \%$ & 1 & $0.0 \%$ & 3 & $0.1 \%$ \\
\hline Automated/Direct Load Control & 17 & $0.7 \%$ & 19 & $0.8 \%$ & 0 & $0.0 \%$ & 0 & $0.0 \%$ & 36 & $1.4 \%$ \\
\hline Interruptible/Curtailable Tariffs & 0 & $0.0 \%$ & 0 & $0.0 \%$ & 3 & $0.1 \%$ & 70 & $2.8 \%$ & 73 & $2.9 \%$ \\
\hline Other DR Programs & 0 & $0.0 \%$ & 0 & $0.0 \%$ & 1 & $0.0 \%$ & 86 & $3.4 \%$ & 87 & $3.4 \%$ \\
\hline Total & 19 & $0.8 \%$ & 19 & $0.8 \%$ & 5 & $0.2 \%$ & 156 & $6.2 \%$ & 200 & $7.9 \%$ \\
\hline \multicolumn{11}{|l|}{ Aggressive Deployment } \\
\hline Pricing with Technology & 45 & $1.8 \%$ & 24 & $1.0 \%$ & 0 & $0.0 \%$ & 0 & $0.0 \%$ & 69 & $2.7 \%$ \\
\hline Pricing without Technology & 57 & $2.2 \%$ & 0 & $0.0 \%$ & 1 & $0.0 \%$ & 21 & $0.8 \%$ & 79 & $3.1 \%$ \\
\hline Automated/Direct Load Control & 4 & $0.2 \%$ & 5 & $0.2 \%$ & 0 & $0.0 \%$ & 0 & $0.0 \%$ & 9 & $0.4 \%$ \\
\hline Interruptible/Curtailable Tariffs & 0 & $0.0 \%$ & 0 & $0.0 \%$ & 3 & $0.1 \%$ & 70 & $2.8 \%$ & 73 & $2.9 \%$ \\
\hline Other DR Programs & 0 & $0.0 \%$ & 0 & $0.0 \%$ & 0 & $0.0 \%$ & 86 & $3.4 \%$ & 86 & $3.4 \%$ \\
\hline Total & 106 & $4.2 \%$ & 30 & $1.2 \%$ & 5 & $0.2 \%$ & 176 & $7.0 \%$ & 317 & $12.5 \%$ \\
\hline \multicolumn{11}{|l|}{ Full Deployment } \\
\hline Pricing with Technology & 106 & $4.2 \%$ & 56 & $2.2 \%$ & 0 & $0.0 \%$ & 0 & $0.0 \%$ & 162 & $6.4 \%$ \\
\hline Pricing without Technology & 50 & $2.0 \%$ & 0 & $0.0 \%$ & 2 & $0.1 \%$ & 35 & $1.4 \%$ & 87 & $3.4 \%$ \\
\hline Automated/Direct Load Control & 0 & $0.0 \%$ & 0 & $0.0 \%$ & 0 & $0.0 \%$ & 0 & $0.0 \%$ & 0 & $0.0 \%$ \\
\hline Interruptible/Curtailable Tariffs & 0 & $0.0 \%$ & 0 & $0.0 \%$ & 3 & $0.1 \%$ & 70 & $2.8 \%$ & 73 & $2.9 \%$ \\
\hline Other DR Programs & 0 & $0.0 \%$ & 0 & $0.0 \%$ & 0 & $0.0 \%$ & 86 & $3.4 \%$ & 86 & $3.4 \%$ \\
\hline Total & 156 & $6.2 \%$ & 57 & $2.2 \%$ & 5 & $0.2 \%$ & 190 & $7.5 \%$ & 408 & $16.1 \%$ \\
\hline
\end{tabular}




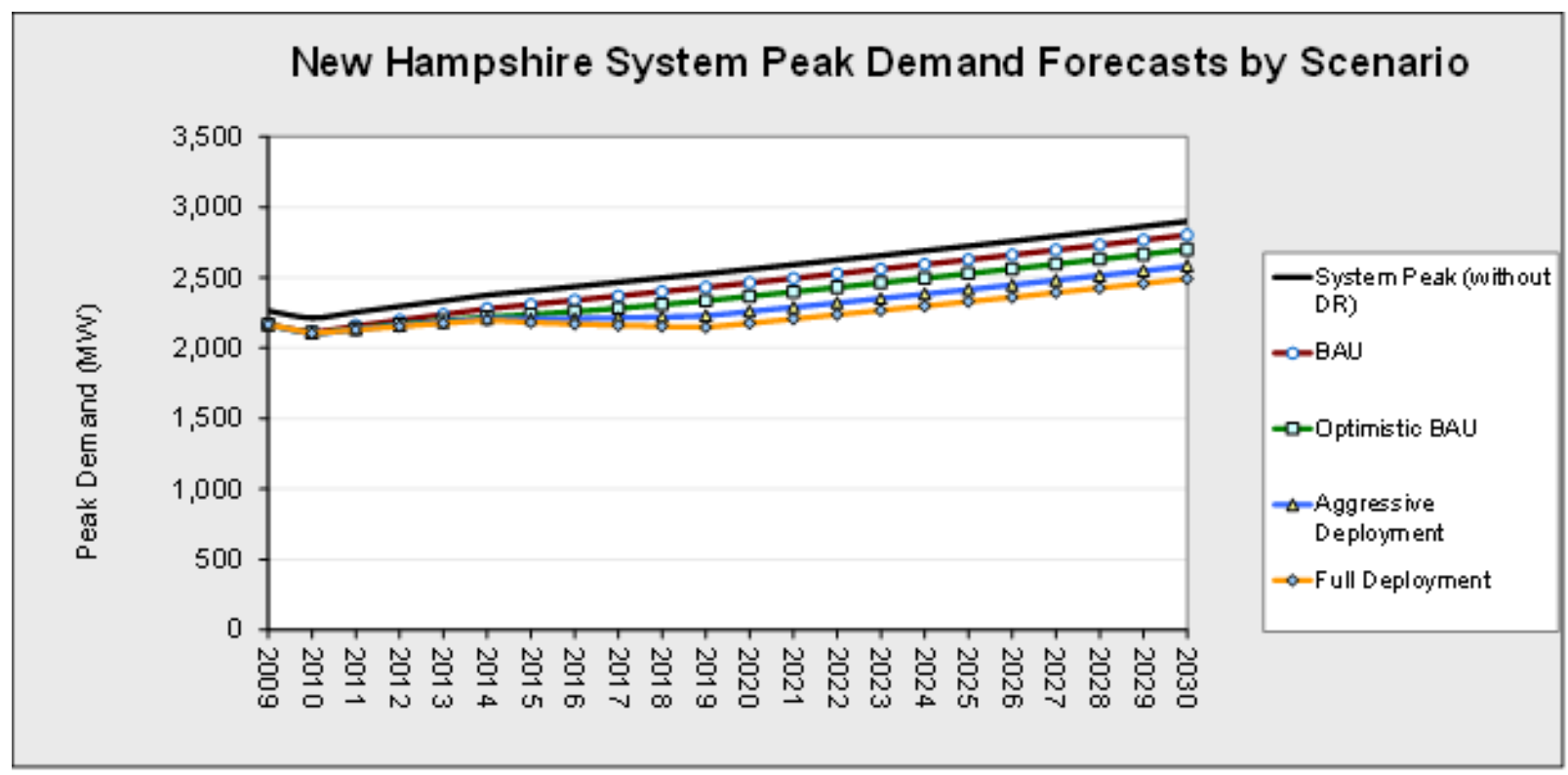

Summary of Monte Carlo Simulation of Potential Peak Load Reduction from Demand Response in New Hampshire by Scenario, Pricing Program and Price Ratio (MW)

\begin{tabular}{|c|c|c|c|c|c|c|c|c|c|c|c|c|}
\hline & \multicolumn{3}{|c|}{2015} & \multicolumn{3}{|c|}{2020} & \multicolumn{3}{|c|}{2025} & \multicolumn{3}{|c|}{2030} \\
\hline & \multirow[t]{2}{*}{ Mean } & Lower & Upper & \multirow[t]{2}{*}{ Mean } & \multicolumn{2}{|c|}{ Lower Upper } & \multirow[t]{3}{*}{ Mean } & \multicolumn{2}{|c|}{ Lower Upper } & \multicolumn{3}{|c|}{ Mean Lower Upper } \\
\hline \multirow{2}{*}{\multicolumn{12}{|c|}{$\begin{array}{l}\text { BAU } \\
\text { Pricing }\end{array}$}} & \\
\hline & & & & & & & & & & & & \\
\hline 5 & 0 & c & 0 & 0 & 0 & 0 & 0 & 0 & 0 & 0 & 0 & \\
\hline 10 & 0 & c & 0 & 0 & 0 & 0 & 0 & 0 & 0 & 0 & 0 & \\
\hline 15 & 0 & c & 0 & 0 & 0 & 0 & 0 & 0 & 0 & 0 & 0 & \\
\hline \multicolumn{13}{|l|}{ Pricing without Technology } \\
\hline 5 & 0 & c & 0 & 0 & 0 & 0 & 0 & 0 & 0 & 0 & 0 & \\
\hline 10 & 0 & 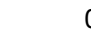 & 0 & 0 & 0 & 0 & 0 & 0 & 0 & 0 & 0 & \\
\hline 15 & 0 & c & 0 & 0 & 0 & 0 & 0 & 0 & 0 & 0 & 0 & \\
\hline \multirow{2}{*}{\multicolumn{13}{|c|}{\begin{tabular}{|l|} 
Optimistic BAU \\
$\quad$ Pricing with Technology
\end{tabular}}} \\
\hline & & & & & & & & & & & & \\
\hline $\begin{array}{r}5 \\
10\end{array}$ & 0 & 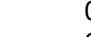 & 0 & 0 & c & 0 & 0 & 0 & 0 & 0 & 0 & \\
\hline $\begin{array}{l}10 \\
15\end{array}$ & 0 & c & 0 & 0 & c & 0 & 0 & 0 & 0 & 0 & 0 & \\
\hline 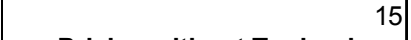 & 0 & 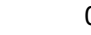 & 0 & 0 & 0 & 0 & 0 & 0 & 0 & 0 & 0 & \\
\hline \multicolumn{13}{|l|}{ Pricing without Technology } \\
\hline 5 & 1 & & 2 & 3 & 1 & 4 & 3 & 1 & 4 & 3 & 1 & \\
\hline 10 & 1 & & 2 & 4 & 1 & 6 & 4 & 1 & 7 & 4 & 1 & \\
\hline 15 & 2 & & 3 & 4 & 1 & 7 & 5 & 1 & 8 & 5 & 1 & \\
\hline \multicolumn{13}{|l|}{\begin{tabular}{|l|} 
Aggressive Deployment \\
Pricing with Technology
\end{tabular}} \\
\hline 5 & 14 & 2 & 24 & 50 & 15 & 85 & 52 & 16 & 88 & 54 & 16 & 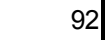 \\
\hline 10 & 20 & 5 & 35 & 73 & 20 & 127 & 76 & 20 & 132 & 80 & 21 & \\
\hline 15 & 24 & 7 & 41 & 88 & 26 & 149 & 91 & 27 & 155 & 95 & 29 & 16 \\
\hline \multicolumn{13}{|l|}{ Pricing without Technology } \\
\hline 5 & 17 & 5 & 29 & 61 & 19 & 104 & 64 & 19 & 109 & 67 & 20 & 113 \\
\hline 8 & 25 & - & 44 & 91 & 25 & 157 & 95 & 26 & 164 & 99 & 27 & 17 \\
\hline 15 & 31 & 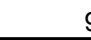 & 52 & 110 & 33 & 186 & 114 & 35 & 194 & 119 & 36 & 20 \\
\hline \multicolumn{13}{|l|}{$\begin{array}{l}\text { Full Deployment } \\
\text { Pricing with Technology }\end{array}$} \\
\hline Pricing with Technology & 32 & $\mathrm{~s}$ & 56 & 116 & 31 & 201 & 121 & 33 & 210 & 126 & 34 & 21 \\
\hline 10 & 49 & 17 & 81 & 178 & 63 & 293 & 186 & 65 & 306 & 194 & 68 & 31 \\
\hline 15 & 55 & 14 & 96 & 199 & 51 & 347 & 208 & 53 & 362 & 217 & 55 & $37 \varepsilon$ \\
\hline \multicolumn{13}{|l|}{ Pricing without Technology } \\
\hline 5 & 20 & 5 & 34 & 70 & 19 & 121 & 73 & 20 & 125 & 76 & 21 & 130 \\
\hline 10 & 30 & 11 & 50 & 108 & 39 & 178 & 113 & 40 & 185 & 117 & 42 & 19 \\
\hline 15 & 34 & $c_{0}+2-2$ & 60 & 122 & 32 & 212 & 127 & 33 & 220 & 132 & 35 & 22 \\
\hline
\end{tabular}




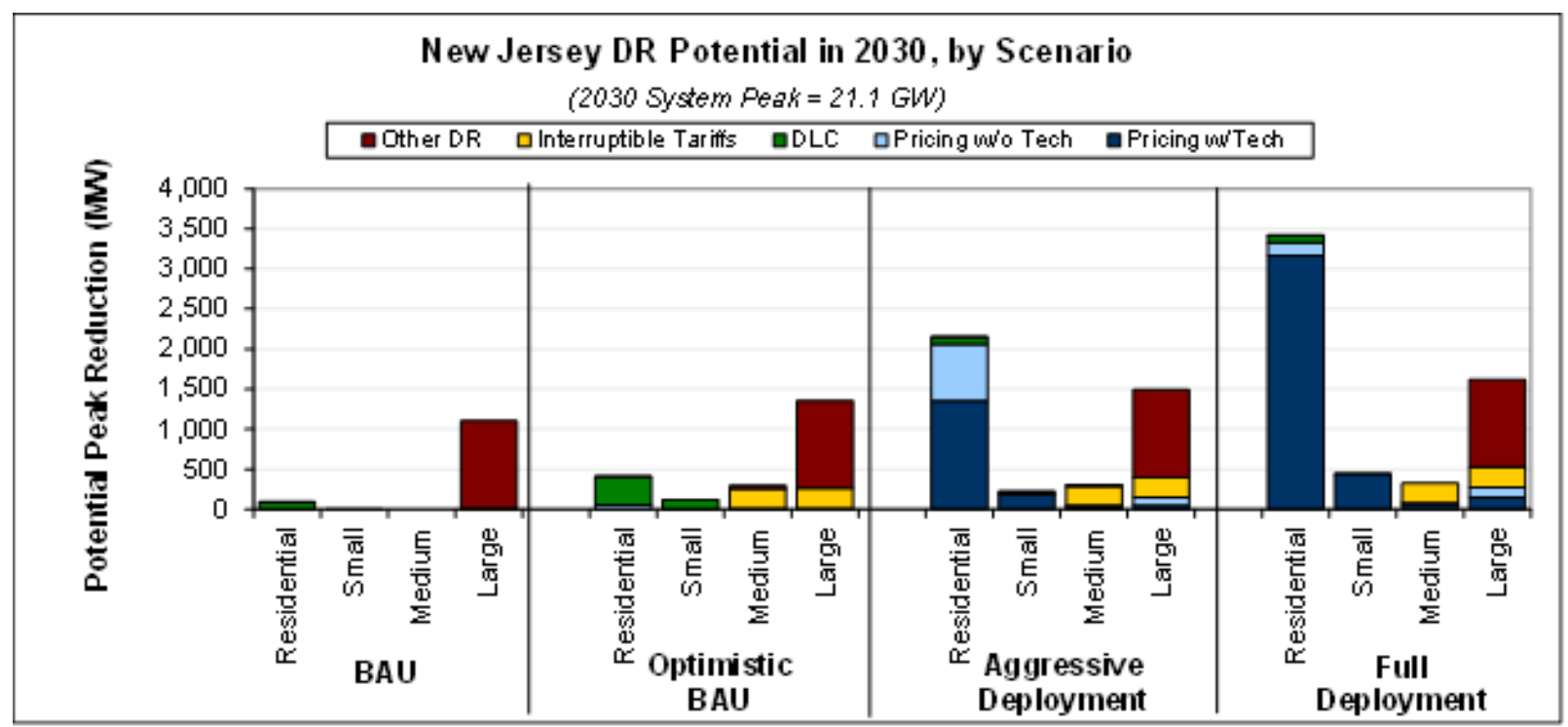

Total Potential Peak Reduction from Demand Response in New Jersey, 2030

\begin{tabular}{|c|c|c|c|c|c|c|c|c|c|c|}
\hline & $\begin{array}{l}\text { Residential } \\
\quad(\mathrm{MW})\end{array}$ & $\begin{array}{l}\text { Residential } \\
\text { ( } \% \text { of } \\
\text { svstem) }\end{array}$ & $\begin{array}{l}\text { Small C\&I } \\
(\mathrm{MW})\end{array}$ & $\begin{array}{c}\text { Small C\&I } \\
\text { (\% of } \\
\text { svstem) }\end{array}$ & $\begin{array}{l}\text { Med. C\&I } \\
(\mathrm{MW})\end{array}$ & $\begin{array}{l}\text { Med C\&I } \\
\text { ( } \% \text { of } \\
\text { svstem) }\end{array}$ & $\begin{array}{l}\text { Large C\&I } \\
\quad(\mathrm{MW})\end{array}$ & $\begin{array}{l}\text { Large C\&I } \\
\text { ( } \% \text { of } \\
\text { svstem) }\end{array}$ & $\begin{array}{l}\text { Total } \\
(\mathrm{MW})\end{array}$ & $\begin{array}{c}\text { Total } \\
\text { ( } \% \text { of } \\
\text { svstem) }\end{array}$ \\
\hline \multicolumn{11}{|l|}{ BAU } \\
\hline Pricing with Technology & 0 & $0.0 \%$ & 0 & $0.0 \%$ & 0 & $0.0 \%$ & 0 & $0.0 \%$ & 0 & $0.0 \%$ \\
\hline Pricing without Technology & 0 & $0.0 \%$ & 0 & $0.0 \%$ & 0 & $0.0 \%$ & 0 & $0.0 \%$ & 0 & $0.0 \%$ \\
\hline Automated/Direct Load Control & 88 & $0.5 \%$ & 0 & $0.0 \%$ & 0 & $0.0 \%$ & 0 & $0.0 \%$ & 88 & $0.5 \%$ \\
\hline Interruptible/Curtailable Tariffs & 0 & $0.0 \%$ & 0 & $0.0 \%$ & 0 & $0.0 \%$ & 8 & $0.0 \%$ & 8 & $0.0 \%$ \\
\hline Other DR Programs & 1 & $0.0 \%$ & 0 & $0.0 \%$ & 0 & $0.0 \%$ & 1,093 & $5.9 \%$ & 1,094 & $6.0 \%$ \\
\hline Total & 90 & $0.5 \%$ & 0 & $0.0 \%$ & 0 & $0.0 \%$ & $1,1,100$ & $6.0 \%$ & $1,1,190$ & $6.5 \%$ \\
\hline \multicolumn{11}{|l|}{ Optimistic BAU } \\
\hline Pricing with Technology & 0 & $0.0 \%$ & 0 & $0.0 \%$ & 0 & $0.0 \%$ & 0 & $0.0 \%$ & 0 & $0.0 \%$ \\
\hline Pricing without Technology & 55 & $0.3 \%$ & 0 & $0.0 \%$ & 1 & $0.0 \%$ & 6 & $0.0 \%$ & 62 & $0.3 \%$ \\
\hline Automated/Direct Load Control & 353 & $1.9 \%$ & 120 & $0.7 \%$ & 6 & $0.0 \%$ & 0 & $0.0 \%$ & 478 & $2.6 \%$ \\
\hline Interruptible/Curtailable Tariffs & 0 & $0.0 \%$ & 0 & $0.0 \%$ & 245 & $1.3 \%$ & 256 & $1.4 \%$ & 501 & $2.7 \%$ \\
\hline Other DR Programs & 1 & $0.0 \%$ & 0 & $0.0 \%$ & 41 & $0.2 \%$ & 1,093 & $5.9 \%$ & 1,135 & $6.2 \%$ \\
\hline Total & 409 & $2.2 \%$ & 120 & $0.7 \%$ & 293 & $1.6 \%$ & $1,1,354$ & $7.4 \%$ & 2,176 & $11.8 \%$ \\
\hline \multicolumn{11}{|l|}{ Aggressive Deployment } \\
\hline Pricing with Technology & 1,352 & $7.4 \%$ & 188 & $1.0 \%$ & 23 & $0.1 \%$ & 51 & $0.3 \%$ & 1,614 & $8.8 \%$ \\
\hline Pricing without Technology & 707 & $3.8 \%$ & 4 & $0.0 \%$ & 16 & $0.1 \%$ & 93 & $0.5 \%$ & 820 & $4.5 \%$ \\
\hline Automated/Direct Load Control & 91 & $0.5 \%$ & 31 & $0.2 \%$ & 2 & $0.0 \%$ & 0 & $0.0 \%$ & 124 & $0.7 \%$ \\
\hline Interruptible/Curtailable Tariffs & 0 & $0.0 \%$ & 0 & $0.0 \%$ & 245 & $1.3 \%$ & 256 & $1.4 \%$ & 501 & $2.7 \%$ \\
\hline Other DR Programs & 1 & $0.0 \%$ & 0 & $0.0 \%$ & 17 & $0.1 \%$ & 1,093 & $5.9 \%$ & 1,111 & $6.0 \%$ \\
\hline Total & 2,151 & $11.7 \%$ & 223 & $1.2 \%$ & 304 & $1.7 \%$ & 1,492 & $8.1 \%$ & 4,170 & $22.7 \%$ \\
\hline \multicolumn{11}{|l|}{ Full Deployment } \\
\hline Pricing with Technology & 3,162 & $17.2 \%$ & 440 & $2.4 \%$ & 68 & $0.4 \%$ & 149 & $0.8 \%$ & 3,819 & $20.8 \%$ \\
\hline Pricing without Technology & 166 & $0.9 \%$ & 2 & $0.0 \%$ & 11 & $0.1 \%$ & 120 & $0.7 \%$ & 300 & $1.6 \%$ \\
\hline Automated/Direct Load Control & 88 & $0.5 \%$ & 0 & $0.0 \%$ & 0 & $0.0 \%$ & 0 & $0.0 \%$ & 88 & $0.5 \%$ \\
\hline Interruptible/Curtailable Tariffs & 0 & $0.0 \%$ & 0 & $0.0 \%$ & 245 & $1.3 \%$ & 256 & $1.4 \%$ & 501 & $2.7 \%$ \\
\hline Other DR Programs & 1 & $0.0 \%$ & 0 & $0.0 \%$ & 0 & $0.0 \%$ & 1,093 & $5.9 \%$ & 1,094 & $6.0 \%$ \\
\hline$\overline{\text { Total }}$ & 3,418 & $18.6 \%$ & 443 & $2.4 \%$ & 324 & $1.8 \%$ & 1,618 & $8.8 \%$ & 5,802 & $31.6 \%$ \\
\hline
\end{tabular}




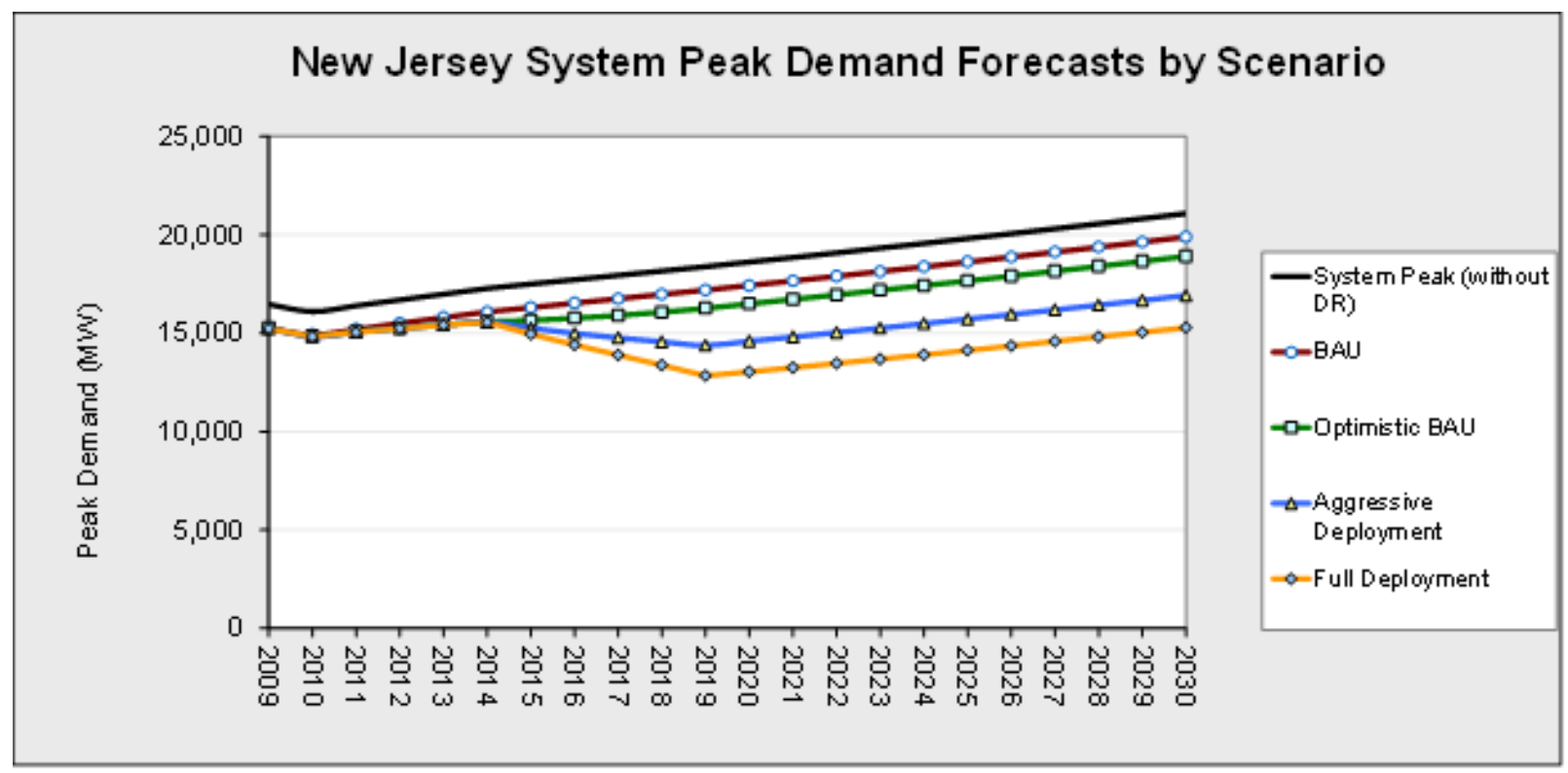

Summary of Monte Carlo Simulation of Potential Peak Load Reduction from Demand Response in New Jersey by Scenario, Pricing Program and Price Ratio (MW)

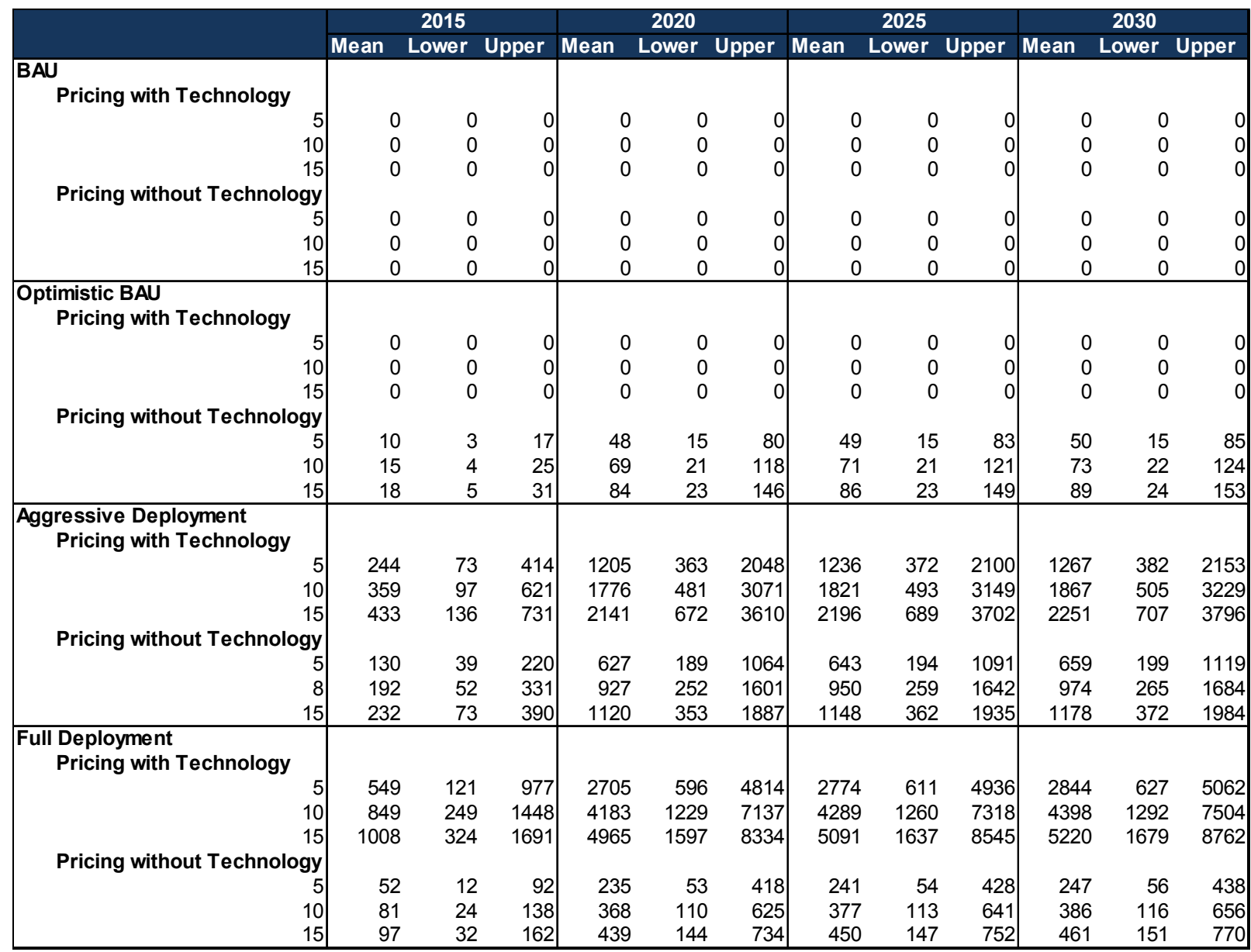




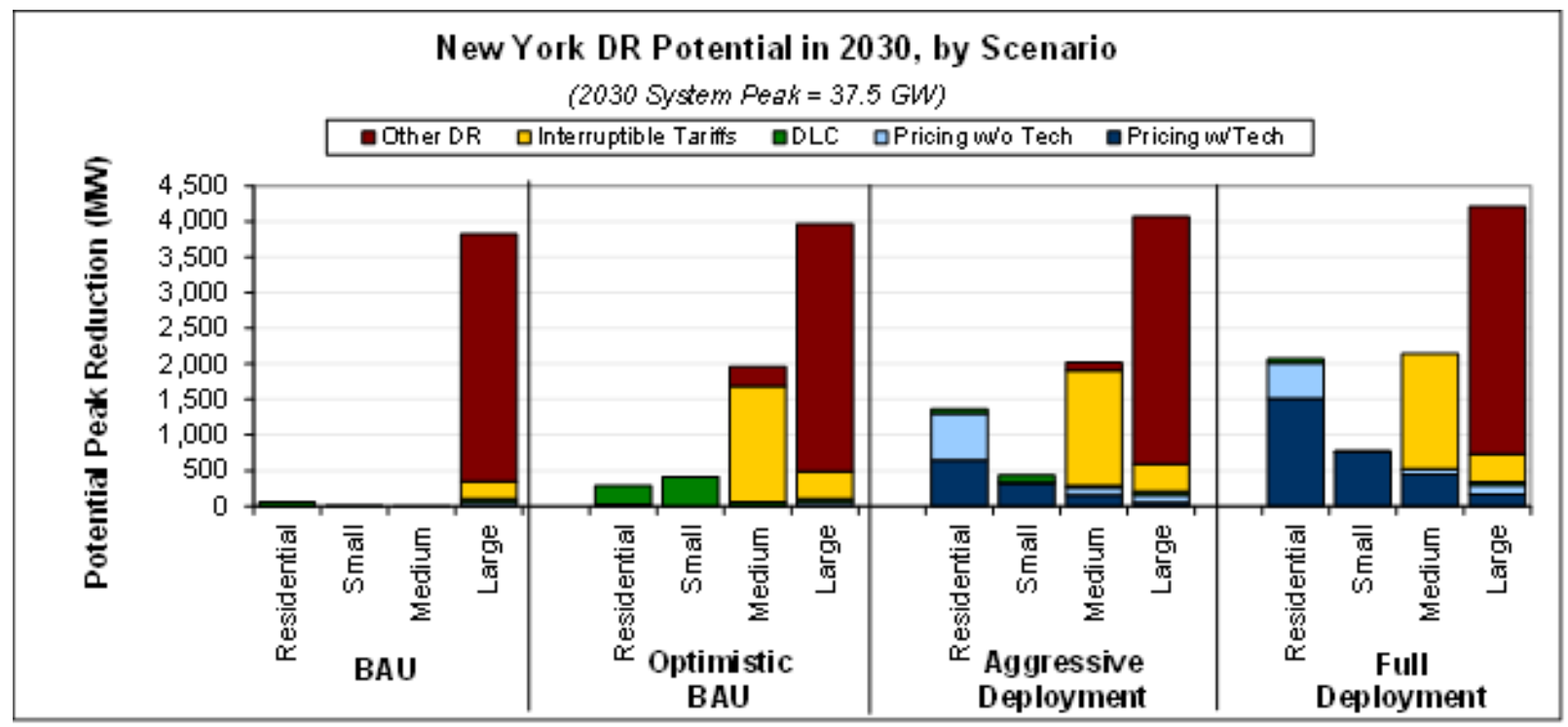

Total Potential Peak Reduction from Demand Response in New York, 2030

\begin{tabular}{|c|c|c|c|c|c|c|c|c|c|c|}
\hline & $\begin{array}{l}\text { Residential } \\
\quad(\mathrm{MW})\end{array}$ & $\begin{array}{l}\text { Residential } \\
\text { ( } \% \text { of } \\
\text { svstem) }\end{array}$ & $\begin{array}{l}\text { Small C\&I } \\
(\mathrm{MW})\end{array}$ & $\begin{array}{c}\text { Small C\&I } \\
\text { (\% of } \\
\text { svstem) }\end{array}$ & $\begin{array}{l}\text { Med. C\&l } \\
(\mathrm{MW})\end{array}$ & $\begin{array}{l}\text { Med C\&I } \\
\text { ( } \% \text { of } \\
\text { svstem) }\end{array}$ & $\begin{array}{l}\text { Large C\&I } \\
\quad(\mathrm{MW})\end{array}$ & $\begin{array}{l}\text { Large C\&I } \\
\text { ( } \% \text { of } \\
\text { svstem) }\end{array}$ & $\begin{array}{l}\text { Total } \\
(\mathrm{MW})\end{array}$ & $\begin{array}{c}\text { Total } \\
\text { ( } \% \text { of } \\
\text { svstem) }\end{array}$ \\
\hline \multicolumn{11}{|l|}{ BAU } \\
\hline Pricing with Technology & 0 & $0.0 \%$ & 0 & $0.0 \%$ & 0 & $0.0 \%$ & 0 & $0.0 \%$ & 0 & $0.0 \%$ \\
\hline Pricing without Technology & 1 & $0.0 \%$ & 0 & $0.0 \%$ & 0 & $0.0 \%$ & 53 & $0.2 \%$ & 53 & $0.2 \%$ \\
\hline Automated/Direct Load Control & 57 & $0.2 \%$ & 11 & $0.0 \%$ & 1 & $0.0 \%$ & 47 & $0.1 \%$ & 117 & $0.3 \%$ \\
\hline Interruptible/Curtailable Tariffs & 0 & $0.0 \%$ & 0 & $0.0 \%$ & 0 & $0.0 \%$ & 249 & $0.7 \%$ & 249 & $0.7 \%$ \\
\hline Other DR Programs & 0 & $0.0 \%$ & 0 & $0.0 \%$ & 0 & $0.0 \%$ & 3,473 & $9.9 \%$ & 3,473 & $9.9 \%$ \\
\hline Total & $\overline{58}$ & $0.2 \%$ & 11 & $0.0 \%$ & 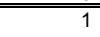 & $0.0 \%$ & 3,821 & $10.9 \%$ & 3,891 & $11.1 \%$ \\
\hline \multicolumn{11}{|l|}{ Optimistic BAU } \\
\hline Pricing with Technology & 0 & $0.0 \%$ & 0 & $0.0 \%$ & 0 & $0.0 \%$ & 0 & $0.0 \%$ & 0 & $0.0 \%$ \\
\hline Pricing without Technology & 29 & $0.1 \%$ & 0 & $0.0 \%$ & 7 & $0.0 \%$ & 53 & $0.2 \%$ & 89 & $0.3 \%$ \\
\hline Automated/Direct Load Control & 261 & $0.7 \%$ & 412 & $1.2 \%$ & 55 & $0.2 \%$ & 47 & $0.1 \%$ & 776 & $2.2 \%$ \\
\hline Interruptible/Curtailable Tariffs & 0 & $0.0 \%$ & 0 & $0.0 \%$ & 1,624 & $4.6 \%$ & 391 & $1.1 \%$ & 2,015 & $5.8 \%$ \\
\hline Other DR Programs & 0 & $0.0 \%$ & 0 & $0.0 \%$ & 274 & $0.8 \%$ & 3,473 & $9.9 \%$ & 3,747 & $10.7 \%$ \\
\hline Total & 290 & $0.8 \%$ & 4 & $1.2 \%$ & $\overline{1,960}$ & (5.6\% & 3,964 & $\overline{111.3 \%}$ & 6,626 & $18.9 \%$ \\
\hline \multicolumn{11}{|l|}{ Aggressive Deployment } \\
\hline Pricing with Technology & 647 & $1.8 \%$ & 325 & $0.9 \%$ & 153 & $0.4 \%$ & 56 & $0.2 \%$ & 1,182 & $3.4 \%$ \\
\hline Pricing without Technology & 653 & $1.9 \%$ & 6 & $0.0 \%$ & 108 & $0.3 \%$ & 102 & $0.3 \%$ & 870 & $2.5 \%$ \\
\hline Automated/Direct Load Control & 67 & $0.2 \%$ & 105 & $0.3 \%$ & 23 & $0.1 \%$ & 47 & $0.1 \%$ & 242 & $0.7 \%$ \\
\hline Interruptible/Curtailable Tariffs & 0 & $0.0 \%$ & 0 & $0.0 \%$ & 1,624 & $4.6 \%$ & 391 & $1.1 \%$ & 2,015 & $5.8 \%$ \\
\hline Other DR Programs & 0 & $0.0 \%$ & 0 & $0.0 \%$ & 112 & $0.3 \%$ & 3,473 & $9.9 \%$ & 3,585 & $10.2 \%$ \\
\hline Total & 1,367 & $3.9 \%$ & 437 & $1.2 \%$ & 2,019 & $5.8 \%$ & 4,069 & $11.6 \%$ & 7,892 & $22.6 \%$ \\
\hline \multicolumn{11}{|l|}{ Full Deployment } \\
\hline Pricing with Technology & 1,513 & $4.3 \%$ & 761 & $2.2 \%$ & 449 & $1.3 \%$ & 164 & $0.5 \%$ & 2,887 & $8.3 \%$ \\
\hline Pricing without Technology & 499 & $1.4 \%$ & 4 & $0.0 \%$ & 71 & $0.2 \%$ & 132 & $0.4 \%$ & 707 & $2.0 \%$ \\
\hline Automated/Direct Load Control & 57 & $0.2 \%$ & 11 & $0.0 \%$ & 1 & $0.0 \%$ & 47 & $0.1 \%$ & 117 & $0.3 \%$ \\
\hline Interruptible/Curtailable Tariffs & 0 & $0.0 \%$ & 0 & $0.0 \%$ & 1,624 & $4.6 \%$ & 391 & $1.1 \%$ & 2,015 & $5.8 \%$ \\
\hline Other DR Programs & 0 & $0.0 \%$ & 0 & $0.0 \%$ & 0 & $0.0 \%$ & 3,473 & $9.9 \%$ & 3,473 & $9.9 \%$ \\
\hline Total & 2,070 & $5.9 \%$ & 776 & $2.2 \%$ & 2,144 & $6.1 \%$ & 4,207 & $12.0 \%$ & 9,197 & $26.3 \%$ \\
\hline
\end{tabular}




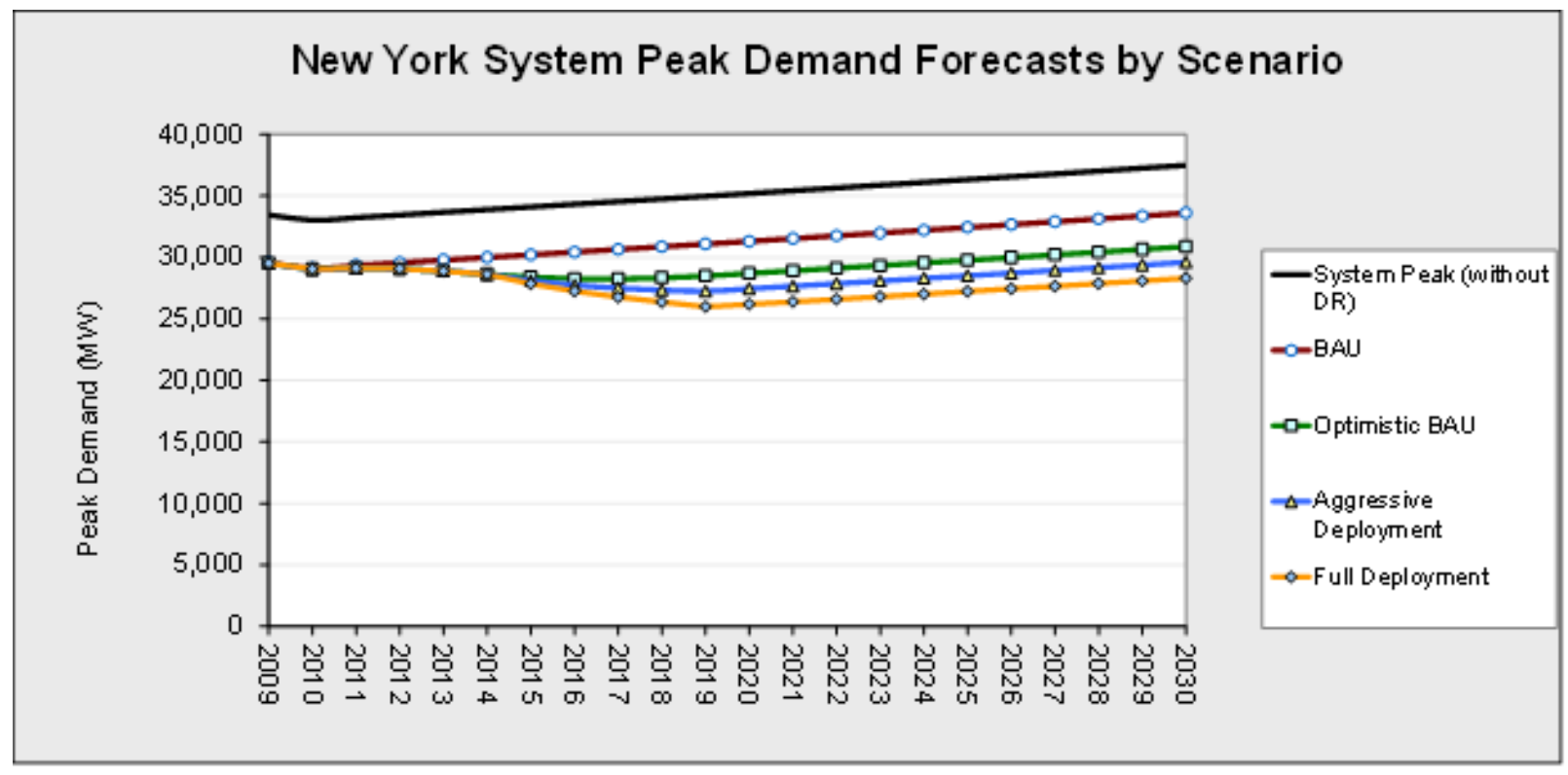

Summary of Monte Carlo Simulation of Potential Peak Load Reduction from Demand Response in New York by Scenario, Pricing Program and Price Ratio (MW)

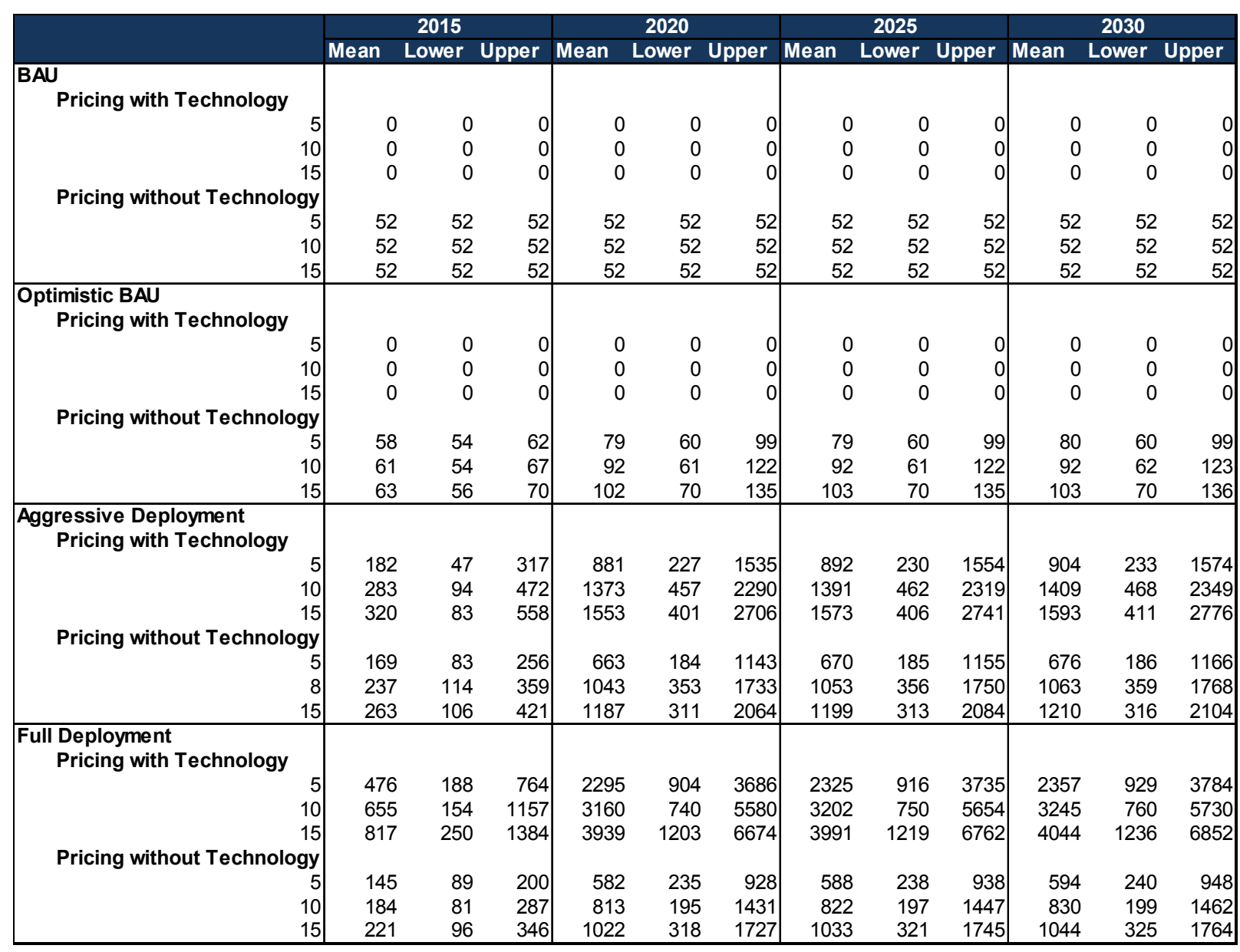




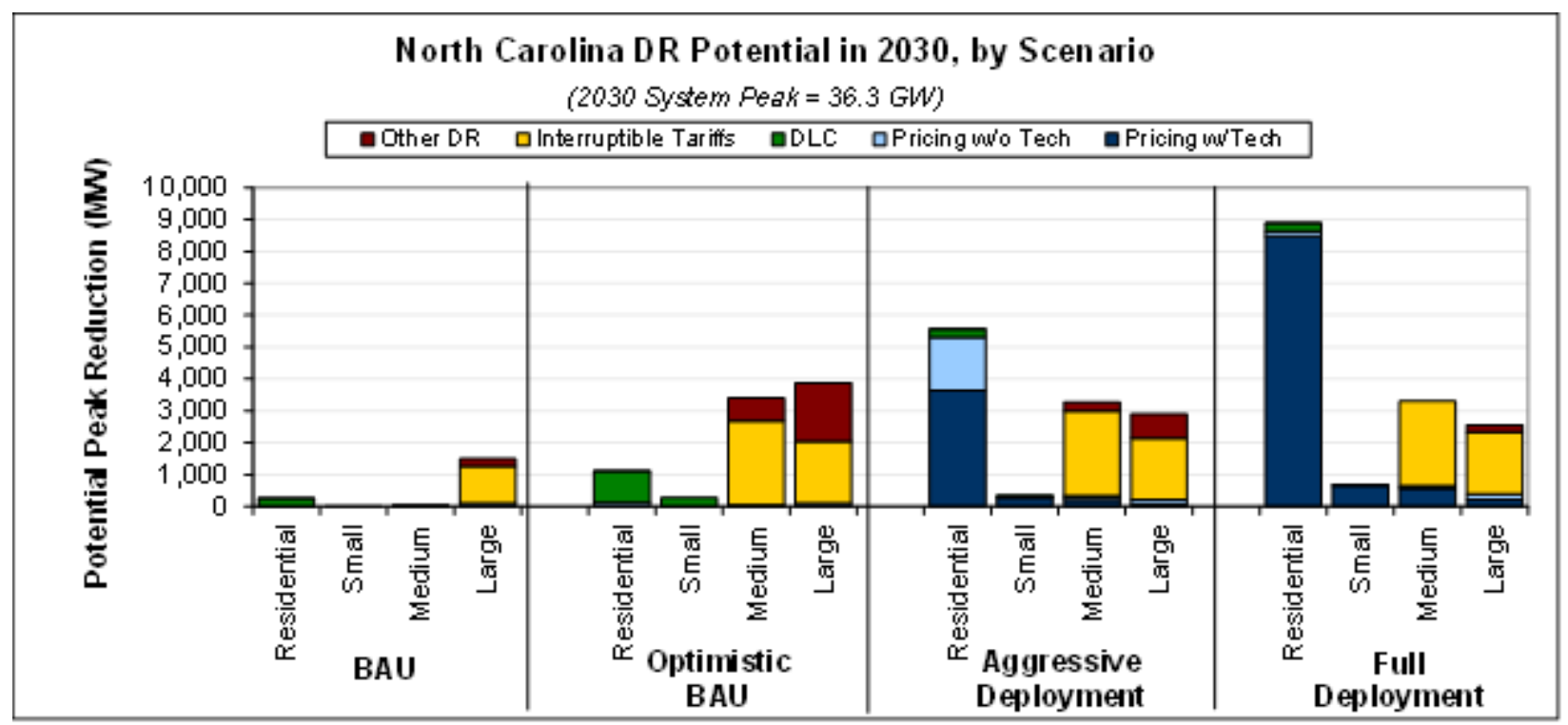

Total Potential Peak Reduction from Demand Response in North Carolina, 2030

\begin{tabular}{|c|c|c|c|c|c|c|c|c|c|c|}
\hline & $\begin{array}{l}\text { Residential } \\
\text { (MW) }\end{array}$ & $\begin{array}{l}\text { Residential } \\
\text { ( } \% \text { of } \\
\text { svstem) }\end{array}$ & $\begin{array}{l}\text { Small C\&I } \\
(\mathrm{MW})\end{array}$ & $\begin{array}{c}\text { Small C\&I } \\
\text { ( } \% \text { of } \\
\text { svstem) }\end{array}$ & $\begin{array}{l}\text { Med. C\&I } \\
(\mathrm{MW})\end{array}$ & $\begin{array}{l}\text { Med C\&I } \\
\text { ( } \% \text { of } \\
\text { svstem) }\end{array}$ & $\begin{array}{l}\text { Large C\&l } \\
\quad(\mathrm{MW})\end{array}$ & $\begin{array}{c}\text { Large C\&I } \\
\text { (\% of } \\
\text { svstem) }\end{array}$ & $\begin{array}{l}\text { Total } \\
\text { (MW) }\end{array}$ & $\begin{array}{c}\text { Total } \\
\text { ( } \% \text { of } \\
\text { svstem) }\end{array}$ \\
\hline \multicolumn{11}{|l|}{ BAU } \\
\hline Pricing with Technology & 0 & $0.0 \%$ & 0 & $0.0 \%$ & 0 & $0.0 \%$ & 0 & $0.0 \%$ & 0 & $0.0 \%$ \\
\hline Pricing without Technology & 2 & $0.0 \%$ & 0 & $0.0 \%$ & 3 & $0.0 \%$ & 102 & $0.3 \%$ & 107 & $0.3 \%$ \\
\hline Automated/Direct Load Control & 246 & $0.8 \%$ & 1 & $0.0 \%$ & 18 & $0.1 \%$ & 0 & $0.0 \%$ & 265 & $0.8 \%$ \\
\hline Interruptible/Curtailable Tariffs & 0 & $0.0 \%$ & 0 & $0.0 \%$ & 1 & $0.0 \%$ & 1,162 & $3.7 \%$ & 1,163 & $3.7 \%$ \\
\hline Other DR Programs & 1 & $0.0 \%$ & 0 & $0.0 \%$ & 0 & $0.0 \%$ & 222 & $0.7 \%$ & 222 & $0.7 \%$ \\
\hline Total & 249 & $0.8 \%$ & 1 & $0.0 \%$ & 21 & $0.1 \%$ & 1,486 & $4.7 \%$ & 1,757 & $5.5 \%$ \\
\hline \multicolumn{11}{|l|}{ Optimistic BAU } \\
\hline Pricing with Technology & 0 & $0.0 \%$ & 0 & $0.0 \%$ & 0 & $0.0 \%$ & 0 & $0.0 \%$ & 0 & $0.0 \%$ \\
\hline Pricing without Technology & 118 & $0.4 \%$ & 0 & $0.0 \%$ & 9 & $0.0 \%$ & 102 & $0.3 \%$ & 229 & $0.7 \%$ \\
\hline Automated/Direct Load Control & 987 & $3.1 \%$ & 268 & $0.8 \%$ & 25 & $0.1 \%$ & 0 & $0.0 \%$ & 1,280 & $4.0 \%$ \\
\hline Interruptible/Curtailable Tariffs & 0 & $0.0 \%$ & 0 & $0.0 \%$ & 2,658 & $8.4 \%$ & 1,937 & $6.1 \%$ & 4,594 & $14.5 \%$ \\
\hline Other DR Programs & 1 & $0.0 \%$ & 0 & $0.0 \%$ & 707 & $2.2 \%$ & 1,833 & $5.8 \%$ & 2,541 & $8.0 \%$ \\
\hline Total & $1,1,105$ & $3.5 \%$ & 269 & $0.8 \%$ & 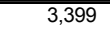 & $10.7 \%$ & 3,871 & $12.2 \%$ & 8,644 & $27.3 \%$ \\
\hline \multicolumn{11}{|l|}{ Aggressive Deployment } \\
\hline Pricing with Technology & 3,625 & $11.4 \%$ & 280 & $0.9 \%$ & 194 & $0.6 \%$ & 74 & $0.2 \%$ & 4,174 & $13.2 \%$ \\
\hline Pricing without Technology & 1,677 & $5.3 \%$ & 5 & $0.0 \%$ & 116 & $0.4 \%$ & 135 & $0.4 \%$ & 1,933 & $6.1 \%$ \\
\hline Automated/Direct Load Control & 253 & $0.8 \%$ & 69 & $0.2 \%$ & 18 & $0.1 \%$ & 0 & $0.0 \%$ & 339 & $1.1 \%$ \\
\hline Interruptible/Curtailable Tariffs & 0 & $0.0 \%$ & 0 & $0.0 \%$ & 2,658 & $8.4 \%$ & 1,937 & $6.1 \%$ & 4,594 & $14.5 \%$ \\
\hline Other DR Programs & 1 & $0.0 \%$ & 0 & $0.0 \%$ & 290 & $0.9 \%$ & 751 & $2.4 \%$ & 1,041 & $3.3 \%$ \\
\hline Total & 5,556 & $17.5 \%$ & 354 & $1.1 \%$ & 3,274 & $10.3 \%$ & 2,897 & $9.1 \%$ & 12,081 & $38.1 \%$ \\
\hline \multicolumn{11}{|l|}{ Full Deployment } \\
\hline Pricing with Technology & 8,480 & $26.8 \%$ & 656 & $2.1 \%$ & 566 & $1.8 \%$ & 217 & $0.7 \%$ & 9,920 & $31.3 \%$ \\
\hline Pricing without Technology & 152 & $0.5 \%$ & 3 & $0.0 \%$ & 56 & $0.2 \%$ & 175 & $0.6 \%$ & 386 & $1.2 \%$ \\
\hline Automated/Direct Load Control & 246 & $0.8 \%$ & 1 & $0.0 \%$ & 18 & $0.1 \%$ & 0 & $0.0 \%$ & 265 & $0.8 \%$ \\
\hline Interruptible/Curtailable Tariffs & 0 & $0.0 \%$ & 0 & $0.0 \%$ & 2,658 & $8.4 \%$ & 1,937 & $6.1 \%$ & 4,594 & $14.5 \%$ \\
\hline Other DR Programs & 1 & $0.0 \%$ & 0 & $0.0 \%$ & 0 & $0.0 \%$ & 222 & $0.7 \%$ & 222 & $0.7 \%$ \\
\hline Total & 8,880 & $28.0 \%$ & 660 & $2.1 \%$ & 3,298 & $10.4 \%$ & 2,551 & $8.1 \%$ & 15,388 & $48.6 \%$ \\
\hline
\end{tabular}




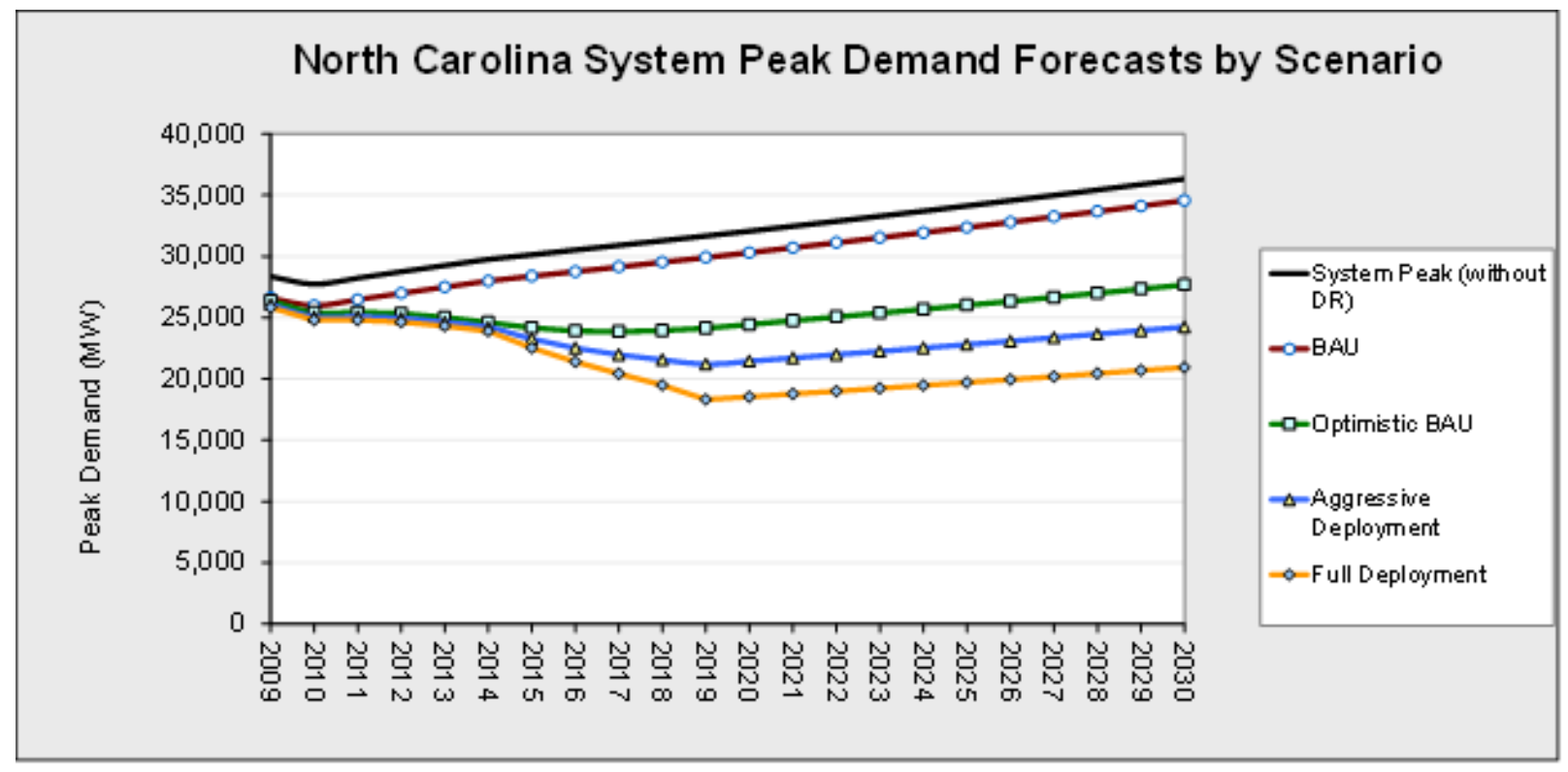

Summary of Monte Carlo Simulation of Potential Peak Load Reduction from Demand Response in North Carolina by Scenario, Pricing Program and Price Ratio (MW)

\begin{tabular}{|c|c|c|c|c|c|c|c|c|c|c|c|c|}
\hline & \multicolumn{3}{|c|}{2015} & \multicolumn{3}{|c|}{2020} & \multicolumn{3}{|c|}{2025} & \multicolumn{3}{|c|}{2030} \\
\hline & Mean & Lower & Upper & Mean & Lower & Upper & Mean & Lower & Upper & Mean & Lower & Upper \\
\hline & \multicolumn{12}{|c|}{ BAU } \\
\hline \multicolumn{13}{|l|}{ Pricing with Technology } \\
\hline 5 & 0 & 0 & 0 & 0 & 0 & 0 & 0 & 0 & 0 & 0 & 0 & 0 \\
\hline 10 & 0 & 0 & 0 & 0 & 0 & 0 & 0 & 0 & 0 & 0 & 0 & 0 \\
\hline 15 & 0 & 0 & 0 & 0 & 0 & 0 & 0 & 0 & 0 & 0 & 0 & 0 \\
\hline \multicolumn{13}{|l|}{ Pricing without Technology } \\
\hline 5 & 105 & 105 & 105 & 105 & 105 & 105 & 105 & 105 & 105 & 105 & 105 & 105 \\
\hline 10 & 105 & 105 & 105 & 105 & 105 & 105 & 105 & 105 & 105 & 105 & 105 & 105 \\
\hline 15 & 105 & 105 & 105 & 105 & 105 & 105 & 105 & 105 & 105 & 105 & 105 & 105 \\
\hline \multicolumn{13}{|l|}{$\begin{array}{l}\text { Optimistic BAU } \\
\text { Pricing with Technology }\end{array}$} \\
\hline 5 & 0 & 0 & 0 & 0 & 0 & 0 & 0 & 0 & 0 & 0 & 0 & 0 \\
\hline 10 & 0 & 0 & 0 & 0 & 0 & 0 & 0 & 0 & 0 & 0 & 0 & 0 \\
\hline 15 & 0 & 0 & 0 & 0 & 0 & 0 & 0 & 0 & 0 & 0 & 0 & 0 \\
\hline \multicolumn{13}{|l|}{ Pricing without Technology } \\
\hline 5 & 135 & 113 & 158 & 185 & 125 & 245 & 191 & 127 & 256 & 198 & 129 & 267 \\
\hline 10 & 150 & 114 & 186 & 223 & 130 & 316 & 232 & 132 & 331 & 241 & 134 & 347 \\
\hline 15 & 162 & 123 & 202 & 255 & 153 & 357 & 266 & 157 & 375 & 278 & 160 & 395 \\
\hline \multicolumn{13}{|l|}{$\begin{array}{l}\text { Aggressive Deployment } \\
\text { Pricing with Technology }\end{array}$} \\
\hline 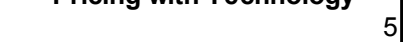 & 818 & 238 & 1398 & 2872 & 835 & 4908 & 3074 & 894 & 5253 & 3290 & 957 & 5623 \\
\hline 10 & 1185 & 381 & 1989 & 4162 & 1338 & 6985 & 4455 & 1432 & 7477 & 4768 & 1533 & 8004 \\
\hline 15 & 1441 & 469 & 2412 & 5059 & 1648 & 8470 & 5415 & 1764 & 9066 & 5796 & 1888 & 9705 \\
\hline \multicolumn{13}{|l|}{ Pricing without Technology } \\
\hline 5 & 452 & 204 & 700 & 1360 & 434 & 2286 & 1453 & 457 & 2449 & 1554 & 483 & 2624 \\
\hline 8 & 611 & 266 & 955 & 1966 & 653 & 3278 & 2103 & 696 & 3510 & 2251 & 742 & 3759 \\
\hline 15 & 721 & 304 & 1138 & 2391 & 797 & 3985 & 2559 & 850 & 4267 & 2738 & 907 & 4569 \\
\hline \multicolumn{13}{|l|}{\begin{tabular}{|l|} 
Full Deployment \\
Pricing with Technology
\end{tabular}} \\
\hline 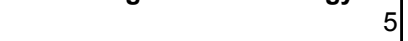 & 1866 & 524 & 3208 & 6535 & 1834 & 11235 & 6994 & 1963 & 12025 & 7486 & 2101 & 12871 \\
\hline 10 & 2821 & 800 & 4841 & 9880 & 2803 & 16956 & 10574 & 3000 & 18148 & 11318 & 3211 & 19425 \\
\hline 15 & 3377 & 872 & 5882 & 11826 & 3053 & 20600 & 12658 & 3267 & 22048 & 13548 & 3497 & 23599 \\
\hline \multicolumn{13}{|l|}{ Pricing without Technology } \\
\hline & 142 & 113 & 171 & 297 & 116 & 478 & 316 & 119 & 512 & 336 & 123 & 549 \\
\hline 10 & 165 & 118 & 212 & 445 & 145 & 745 & 474 & 152 & 797 & 505 & 158 & 853 \\
\hline 15 & 183 & 112 & 254 & 533 & 151 & 916 & 568 & 157 & 979 & 606 & 165 & 1047 \\
\hline
\end{tabular}




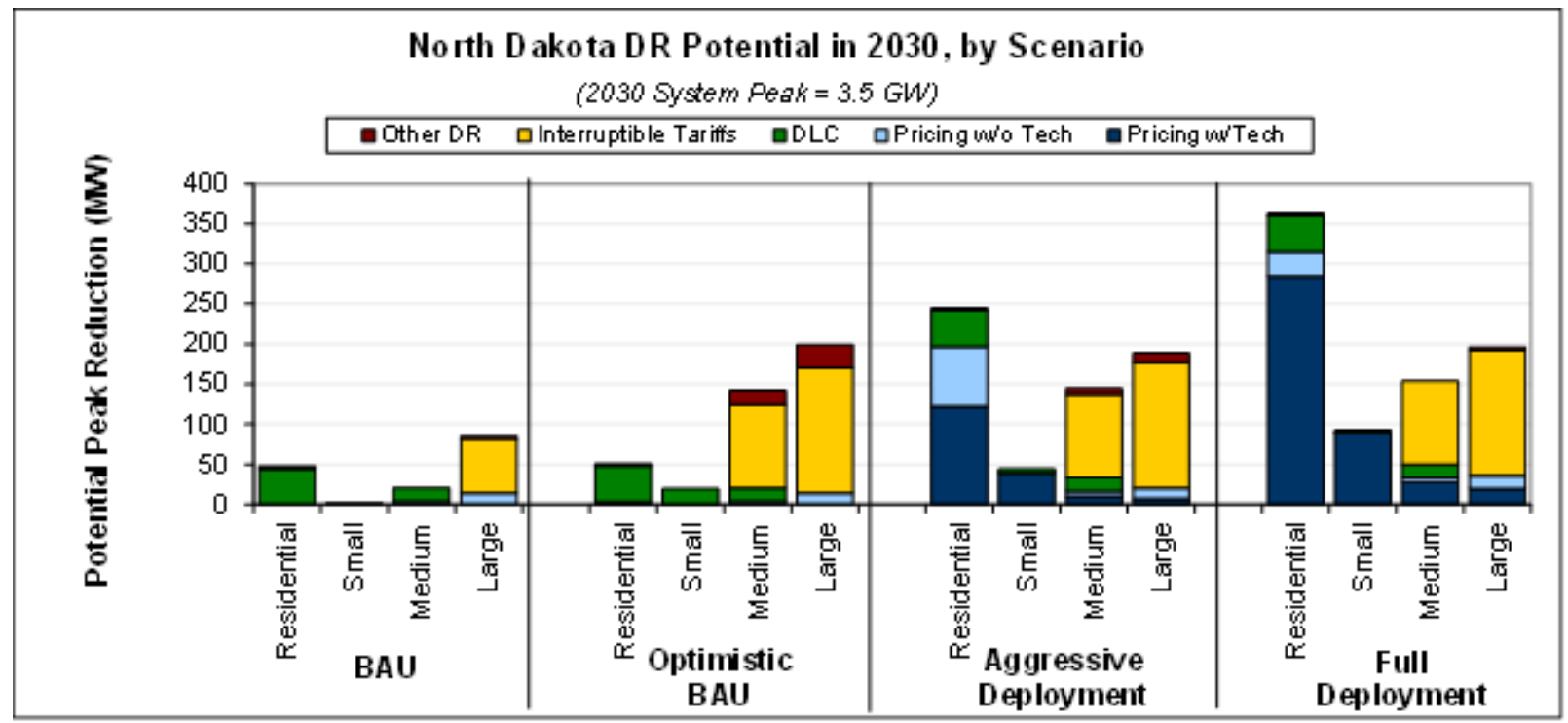

Total Potential Peak Reduction from Demand Response in North Dakota, 2030

\begin{tabular}{|c|c|c|c|c|c|c|c|c|c|c|}
\hline & $\begin{array}{l}\text { Residential } \\
\quad(\mathrm{MW})\end{array}$ & $\begin{array}{l}\text { Residential } \\
\text { ( } \% \text { of } \\
\text { svstem) }\end{array}$ & $\begin{array}{l}\text { Small C\&I } \\
(\mathrm{MW})\end{array}$ & $\begin{array}{c}\text { Small C\&I } \\
\text { (\% of } \\
\text { svstem) }\end{array}$ & $\begin{array}{l}\text { Med. C\&I } \\
(\mathrm{MW})\end{array}$ & $\begin{array}{l}\text { Med C\&I } \\
\text { ( } \% \text { of } \\
\text { svstem) }\end{array}$ & $\begin{array}{l}\text { Large C\&I } \\
\quad(\mathrm{MW})\end{array}$ & $\begin{array}{l}\text { Large C\&I } \\
\text { ( } \% \text { of } \\
\text { svstem) }\end{array}$ & $\begin{array}{l}\text { Total } \\
(\mathrm{MW})\end{array}$ & $\begin{array}{c}\text { Total } \\
\text { ( } \% \text { of } \\
\text { svstem) }\end{array}$ \\
\hline \multicolumn{11}{|l|}{ BAU } \\
\hline Pricing with Technology & 0 & $0.0 \%$ & 0 & $0.0 \%$ & 0 & $0.0 \%$ & 0 & $0.0 \%$ & 0 & $0.0 \%$ \\
\hline Pricing without Technology & 0 & $0.0 \%$ & 0 & $0.0 \%$ & 4 & $0.1 \%$ & 14 & $0.5 \%$ & 17 & $0.6 \%$ \\
\hline Automated/Direct Load Control & 45 & $1.5 \%$ & 2 & $0.1 \%$ & 17 & $0.6 \%$ & 0 & $0.0 \%$ & 63 & $2.1 \%$ \\
\hline Interruptible/Curtailable Tariffs & 0 & $0.0 \%$ & 0 & $0.0 \%$ & 0 & $0.0 \%$ & 68 & $2.3 \%$ & 68 & $2.3 \%$ \\
\hline Other DR Programs & 3 & $0.1 \%$ & 0 & $0.0 \%$ & 0 & $0.0 \%$ & 4 & $0.1 \%$ & 7 & $0.2 \%$ \\
\hline Total & 47 & $1.6 \%$ & 2 & $0.1 \%$ & 20 & $0.7 \%$ & 86 & $2.9 \%$ & 156 & $5.2 \%$ \\
\hline \multicolumn{11}{|l|}{ Optimistic BAU } \\
\hline Pricing with Technology & 0 & $0.0 \%$ & 0 & $0.0 \%$ & 0 & $0.0 \%$ & 0 & $0.0 \%$ & 0 & $0.0 \%$ \\
\hline Pricing without Technology & 3 & $0.1 \%$ & 0 & $0.0 \%$ & 4 & $0.1 \%$ & 14 & $0.5 \%$ & 21 & $0.7 \%$ \\
\hline Automated/Direct Load Control & 45 & $1.5 \%$ & 19 & $0.6 \%$ & 17 & $0.6 \%$ & 0 & $0.0 \%$ & 81 & $2.7 \%$ \\
\hline Interruptible/Curtailable Tariffs & 0 & $0.0 \%$ & 0 & $0.0 \%$ & 104 & $3.5 \%$ & 156 & $5.2 \%$ & 260 & $8.7 \%$ \\
\hline Other DR Programs & 3 & $0.1 \%$ & 0 & $0.0 \%$ & 18 & $0.6 \%$ & 29 & $1.0 \%$ & 49 & $1.6 \%$ \\
\hline Total & 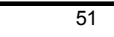 & $1.7 \%$ & 19 & $0.6 \%$ & 142 & $4.7 \%$ & 199 & $6.6 \%$ & 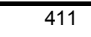 & $13.7 \%$ \\
\hline \multicolumn{11}{|l|}{ Aggressive Deployment } \\
\hline Pricing with Technology & 122 & $4.0 \%$ & 38 & $1.3 \%$ & 10 & $0.3 \%$ & 7 & $0.2 \%$ & 177 & $5.9 \%$ \\
\hline Pricing without Technology & 75 & $2.5 \%$ & 1 & $0.0 \%$ & 7 & $0.2 \%$ & 14 & $0.5 \%$ & 97 & $3.2 \%$ \\
\hline Automated/Direct Load Control & 45 & $1.5 \%$ & 5 & $0.2 \%$ & 17 & $0.6 \%$ & 0 & $0.0 \%$ & 66 & $2.2 \%$ \\
\hline Interruptible/Curtailable Tariffs & 0 & $0.0 \%$ & 0 & $0.0 \%$ & 104 & $3.5 \%$ & 156 & $5.2 \%$ & 260 & $8.7 \%$ \\
\hline Other DR Programs & 3 & $0.1 \%$ & 0 & $0.0 \%$ & 7 & $0.2 \%$ & 12 & $0.4 \%$ & 22 & $0.7 \%$ \\
\hline Total & 245 & $8.1 \%$ & 44 & $1.5 \%$ & 145 & $4.8 \%$ & 189 & $6.3 \%$ & 622 & $20.7 \%$ \\
\hline \multicolumn{11}{|l|}{ Full Deployment } \\
\hline Pricing with Technology & 285 & $9.5 \%$ & 90 & $3.0 \%$ & 28 & $0.9 \%$ & 20 & $0.7 \%$ & 423 & $14.0 \%$ \\
\hline Pricing without Technology & 31 & $1.0 \%$ & 0 & $0.0 \%$ & 5 & $0.2 \%$ & 16 & $0.5 \%$ & 52 & $1.7 \%$ \\
\hline Automated/Direct Load Control & 45 & $1.5 \%$ & 2 & $0.1 \%$ & 17 & $0.6 \%$ & 0 & $0.0 \%$ & 63 & $2.1 \%$ \\
\hline Interruptible/Curtailable Tariffs & 0 & $0.0 \%$ & 0 & $0.0 \%$ & 104 & $3.5 \%$ & 156 & $5.2 \%$ & 260 & $8.7 \%$ \\
\hline Other DR Programs & 3 & $0.1 \%$ & 0 & $0.0 \%$ & 0 & $0.0 \%$ & 4 & $0.1 \%$ & 7 & $0.2 \%$ \\
\hline Total & 363 & $12.1 \%$ & 92 & $3.1 \%$ & 154 & $5.1 \%$ & 196 & $6.5 \%$ & 805 & $26.8 \%$ \\
\hline
\end{tabular}




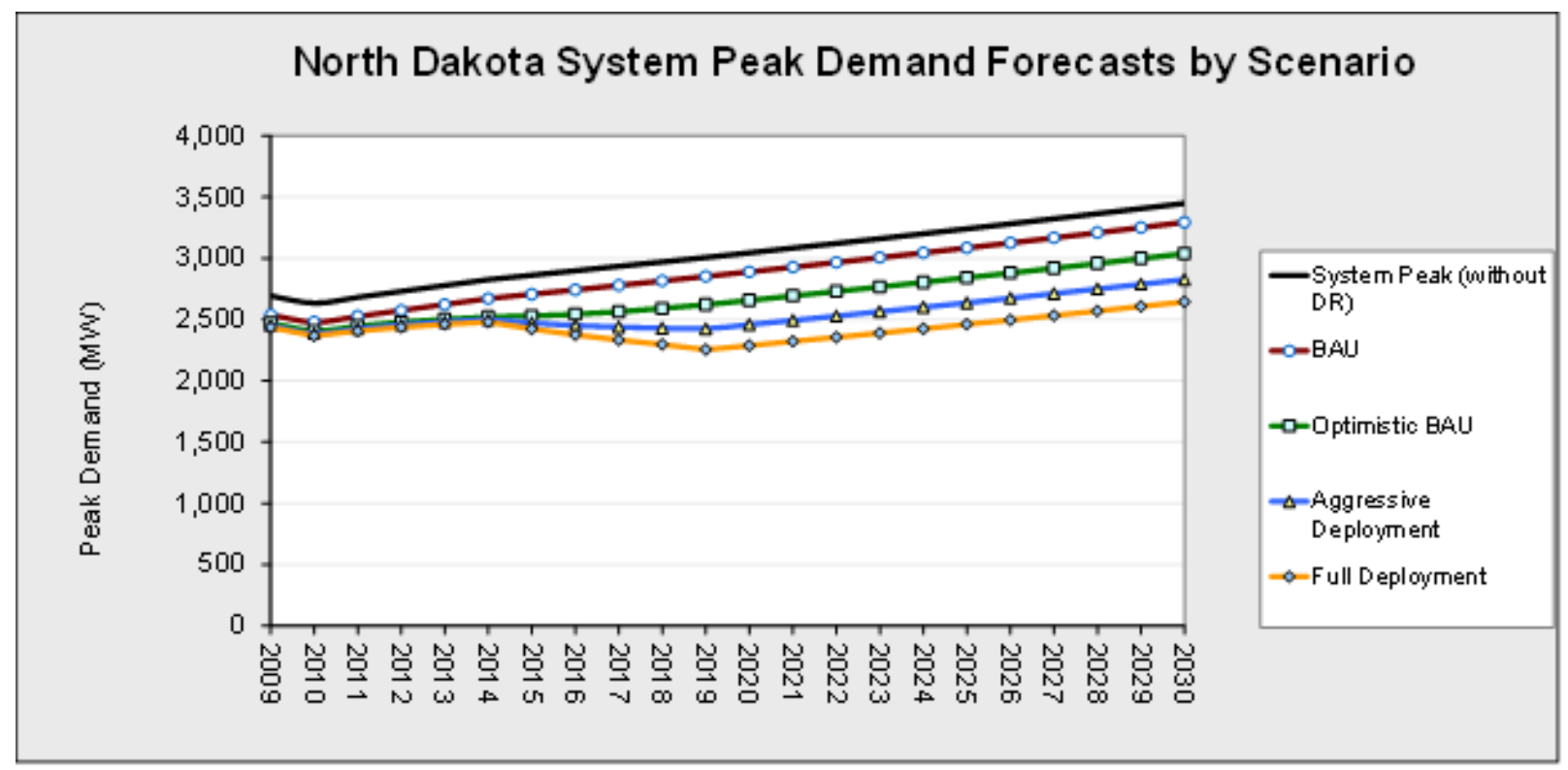

Summary of Monte Carlo Simulation of Potential Peak Load Reduction from Demand Response in North Dakota by Scenario, Pricing Program and Price Ratio (MW)

\begin{tabular}{|c|c|c|c|c|c|c|c|c|c|c|c|c|}
\hline \multirow[b]{3}{*}{ 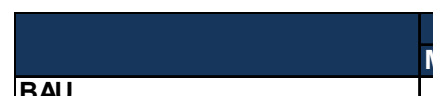 } & \multicolumn{3}{|c|}{2015} & \multicolumn{3}{|c|}{2020} & \multicolumn{3}{|c|}{2025} & \multicolumn{3}{|c|}{2030} \\
\hline & \multirow[t]{2}{*}{ Mean } & Lower & Upper & \multirow[t]{2}{*}{ Mean } & Lower & Upper & \multirow[t]{2}{*}{ Mean } & Lower & Upper & \multirow[t]{2}{*}{ Mean } & Lower & Upper \\
\hline & & & & & & & & & & & & \\
\hline \multicolumn{13}{|l|}{ Pricing with Technology } \\
\hline 5 & 0 & 0 & 0 & 0 & 0 & 0 & 0 & 0 & 0 & 0 & 0 & \\
\hline 10 & 0 & 0 & 0 & 0 & 0 & 0 & 0 & 0 & 0 & 0 & 0 & \\
\hline 15 & 0 & 0 & 0 & 0 & 0 & 0 & 0 & 0 & 0 & 0 & 0 & \\
\hline \multicolumn{13}{|l|}{ Pricing without Technology } \\
\hline 5 & 16 & 16 & 16 & 16 & 16 & 16 & 16 & 16 & 16 & 16 & 16 & \\
\hline 10 & 16 & 16 & 16 & 16 & 16 & 16 & 16 & 16 & 16 & 16 & 16 & 16 \\
\hline 15 & 16 & 16 & 16 & 16 & 16 & 16 & 16 & 16 & 16 & 16 & 16 & 16 \\
\hline \multirow{2}{*}{\multicolumn{13}{|c|}{\begin{tabular}{|l|} 
Optimistic BAU \\
$\quad$ Pricing with Technology
\end{tabular}}} \\
\hline & & & & & & & & & & & & \\
\hline 10 & 0 & 0 & 0 & 0 & 0 & 0 & 0 & 0 & 0 & 0 & 0 & \\
\hline 15 & 0 & 0 & 0 & 0 & 0 & 0 & 0 & 0 & 0 & 0 & 0 & \\
\hline \multicolumn{13}{|l|}{ Pricing without Technology } \\
\hline 5 & 18 & 18 & 19 & 20 & 18 & 21 & 20 & 18 & 21 & 20 & 18 & 2 \\
\hline 10 & 19 & 18 & 20 & 21 & 18 & 23 & 21 & 18 & 23 & 21 & 18 & \\
\hline 15 & 19 & 18 & 21 & 22 & 19 & 25 & 22 & 19 & 25 & 22 & 19 & \\
\hline \multicolumn{13}{|l|}{$\begin{array}{l}\text { Aggressive Deployment } \\
\text { Pricing with Technology }\end{array}$} \\
\hline 5 & 36 & 11 & 61 & 128 & 40 & 216 & 132 & 41 & 223 & 136 & 42 & \\
\hline 10 & 56 & 19 & 93 & 196 & 66 & 327 & 203 & 68 & 337 & 209 & 70 & 34 \\
\hline 15 & 66 & 20 & 112 & 232 & 71 & 393 & 240 & 74 & 406 & 248 & 76 & 41 \\
\hline \multicolumn{13}{|l|}{ Pricing without Technology } \\
\hline 5 & 33 & 22 & 43 & 74 & 32 & 116 & 76 & 33 & 119 & 78 & 33 & 12 \\
\hline 8 & 41 & 25 & 57 & 110 & 42 & 179 & 114 & 42 & 185 & 117 & 43 & 19 \\
\hline 15 & 46 & 26 & 66 & 131 & 45 & 218 & 135 & 46 & 225 & 139 & 47 & 23 \\
\hline \multicolumn{13}{|l|}{$\begin{array}{l}\text { Full Deployment } \\
\text { Pricing with Technology }\end{array}$} \\
\hline 5 & 83 & 17 & 148 & 290 & 60 & 520 & 299 & 62 & 537 & 309 & 64 & \\
\hline 10 & 138 & 49 & 227 & 485 & 173 & 797 & 501 & 178 & 823 & 517 & 184 & 85 \\
\hline 15 & 162 & 62 & 261 & 568 & 219 & 917 & 586 & 226 & 946 & 605 & 234 & 97 \\
\hline \multicolumn{13}{|l|}{ Pricing without Technology } \\
\hline 5 & 23 & 19 & 28 & 41 & 18 & 64 & 42 & 18 & 66 & 43 & 17 & 6 \\
\hline 10 & 27 & 21 & 34 & 65 & 27 & 103 & 67 & 28 & 107 & 69 & 28 & 11 \\
\hline 15 & 29 & 22 & 36 & 76 & 32 & 121 & 79 & 33 & 125 & 82 & 34 & 12 \\
\hline
\end{tabular}




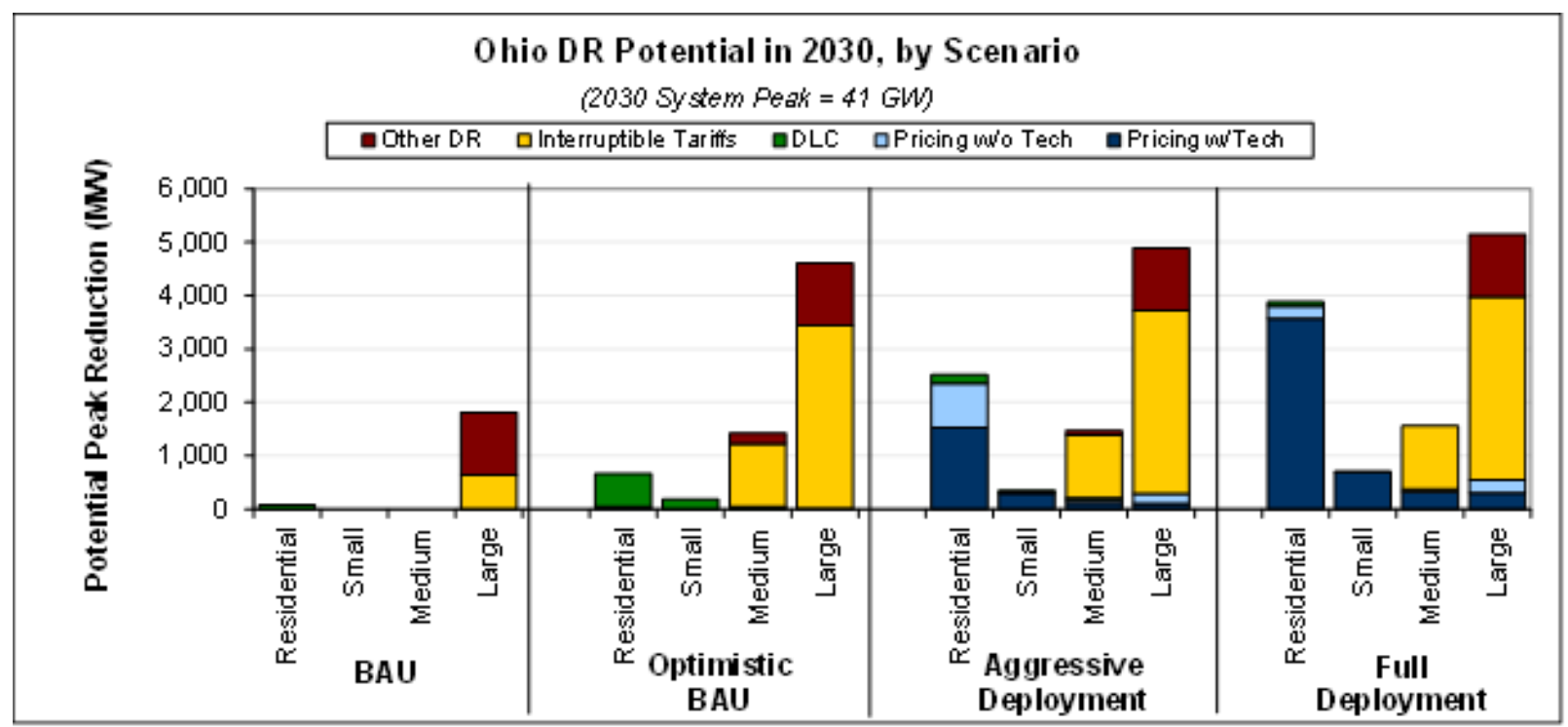

Total Potential Peak Reduction from Demand Response in Ohio, 2030

\begin{tabular}{|c|c|c|c|c|c|c|c|c|c|c|}
\hline & $\begin{array}{l}\text { Residential } \\
\text { (MW) }\end{array}$ & $\begin{array}{l}\text { Residential } \\
\text { ( } \% \text { of } \\
\text { svstem) }\end{array}$ & $\begin{array}{l}\text { Small C\&I } \\
\text { (MW) }\end{array}$ & $\begin{array}{l}\text { Small C\&I } \\
\text { (\% of } \\
\text { svstem) }\end{array}$ & $\begin{array}{l}\text { Med. C\&I } \\
(\mathrm{MW})\end{array}$ & $\begin{array}{l}\text { Med C\&I } \\
\text { ( } \% \text { of } \\
\text { svstem) }\end{array}$ & $\begin{array}{l}\text { Large C\&I } \\
(\mathrm{MW})\end{array}$ & $\begin{array}{l}\text { Large C\&I } \\
\text { (\% of } \\
\text { svstem) }\end{array}$ & $\begin{array}{l}\text { Total } \\
\text { (MW) }\end{array}$ & $\begin{array}{c}\text { Total } \\
\text { ( } \% \text { of } \\
\text { svstem) }\end{array}$ \\
\hline \multicolumn{11}{|l|}{ BAU } \\
\hline Pricing with Technology & 0 & $0.0 \%$ & 0 & $0.0 \%$ & 0 & $0.0 \%$ & 0 & $0.0 \%$ & 0 & $0.0 \%$ \\
\hline Pricing without Technology & 0 & $0.0 \%$ & 0 & $0.0 \%$ & 0 & $0.0 \%$ & 5 & $0.0 \%$ & 5 & $0.0 \%$ \\
\hline Automated/Direct Load Control & 80 & $0.2 \%$ & 0 & $0.0 \%$ & 0 & $0.0 \%$ & 0 & $0.0 \%$ & 80 & $0.2 \%$ \\
\hline Interruptible/Curtailable Tariffs & 0 & $0.0 \%$ & 0 & $0.0 \%$ & 0 & $0.0 \%$ & 633 & $1.8 \%$ & 633 & $1.8 \%$ \\
\hline Other DR Programs & 0 & $0.0 \%$ & 0 & $0.0 \%$ & 0 & $0.0 \%$ & 1,174 & $3.3 \%$ & 1,174 & $3.3 \%$ \\
\hline Total & 80 & $0.2 \%$ & 0 & $0.0 \%$ & 0 & $0.0 \%$ & 1,812 & $5.1 \%$ & 1,892 & $5.3 \%$ \\
\hline \multicolumn{11}{|l|}{ Optimistic BAU } \\
\hline Pricing with Technology & 0 & $0.0 \%$ & 0 & $0.0 \%$ & 0 & $0.0 \%$ & 0 & $0.0 \%$ & 0 & $0.0 \%$ \\
\hline Pricing without Technology & 45 & $0.1 \%$ & 0 & $0.0 \%$ & 5 & $0.0 \%$ & 8 & $0.0 \%$ & 57 & $0.2 \%$ \\
\hline Automated/Direct Load Control & 623 & $1.7 \%$ & 186 & $0.5 \%$ & 37 & $0.1 \%$ & 0 & $0.0 \%$ & 846 & $2.4 \%$ \\
\hline Interruptible/Curtailable Tariffs & 0 & $0.0 \%$ & 0 & $0.0 \%$ & 1,184 & $3.3 \%$ & 3,428 & $9.6 \%$ & 4,612 & $12.9 \%$ \\
\hline Other DR Programs & 0 & $0.0 \%$ & 0 & $0.0 \%$ & 201 & $0.6 \%$ & 1,174 & $3.3 \%$ & 1,374 & $3.8 \%$ \\
\hline Total & 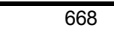 & $1.9 \%$ & 186 & $0.5 \%$ & $\overline{1,426}$ & $4.0 \%$ & 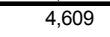 & $\overline{12.9 \%}$ & 6,889 & $19.2 \%$ \\
\hline \multicolumn{11}{|l|}{ Aggressive Deployment } \\
\hline Pricing with Technology & 1,526 & $4.3 \%$ & 299 & $0.8 \%$ & 110 & $0.3 \%$ & 103 & $0.3 \%$ & 2,039 & $5.7 \%$ \\
\hline Pricing without Technology & 831 & $2.3 \%$ & 6 & $0.0 \%$ & 79 & $0.2 \%$ & 188 & $0.5 \%$ & 1,104 & $3.1 \%$ \\
\hline Automated/Direct Load Control & 159 & $0.4 \%$ & 47 & $0.1 \%$ & 15 & $0.0 \%$ & 0 & $0.0 \%$ & 221 & $0.6 \%$ \\
\hline Interruptible/Curtailable Tariffs & 0 & $0.0 \%$ & 0 & $0.0 \%$ & 1,184 & $3.3 \%$ & 3,428 & $9.6 \%$ & 4,612 & $12.9 \%$ \\
\hline Other DR Programs & 0 & $0.0 \%$ & 0 & $0.0 \%$ & 82 & $0.2 \%$ & 1,174 & $3.3 \%$ & 1,256 & $3.5 \%$ \\
\hline Total & 2,516 & $7.0 \%$ & 352 & $1.0 \%$ & 1,471 & $4.1 \%$ & 4,893 & $13.7 \%$ & 9,231 & $25.8 \%$ \\
\hline \multicolumn{11}{|l|}{ Full Deployment } \\
\hline Pricing with Technology & 3,570 & $10.0 \%$ & 698 & $2.0 \%$ & 323 & $0.9 \%$ & 302 & $0.8 \%$ & 4,894 & $13.7 \%$ \\
\hline Pricing without Technology & 231 & $0.6 \%$ & 3 & $0.0 \%$ & 54 & $0.2 \%$ & 244 & $0.7 \%$ & 532 & $1.5 \%$ \\
\hline Automated/Direct Load Control & 80 & $0.2 \%$ & 0 & $0.0 \%$ & 0 & $0.0 \%$ & 0 & $0.0 \%$ & 80 & $0.2 \%$ \\
\hline Interruptible/Curtailable Tariffs & 0 & $0.0 \%$ & 0 & $0.0 \%$ & 1,184 & $3.3 \%$ & 3,428 & $9.6 \%$ & 4,612 & $12.9 \%$ \\
\hline Other DR Programs & 0 & $0.0 \%$ & 0 & $0.0 \%$ & 0 & $0.0 \%$ & 1,174 & $3.3 \%$ & 1,174 & $3.3 \%$ \\
\hline Total & 3,881 & $10.8 \%$ & $\overline{702}$ & $2.0 \%$ & 1,561 & $4.4 \%$ & 5,147 & $14.4 \%$ & 11,291 & $31.5 \%$ \\
\hline
\end{tabular}




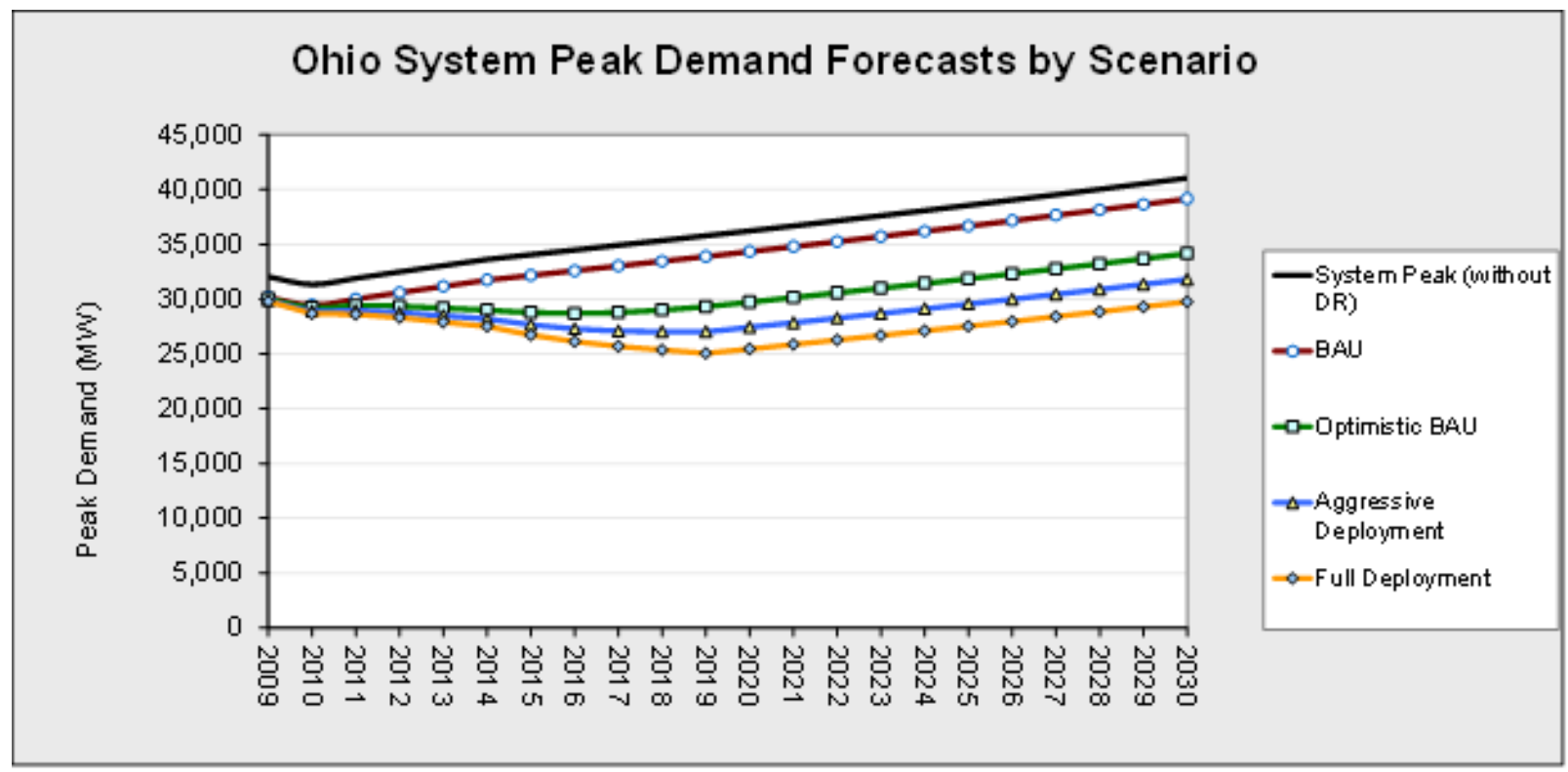

Summary of Monte Carlo Simulation of Potential Peak Load Reduction from Demand Response in Ohio by Scenario, Pricing Program and Price Ratio (MW)

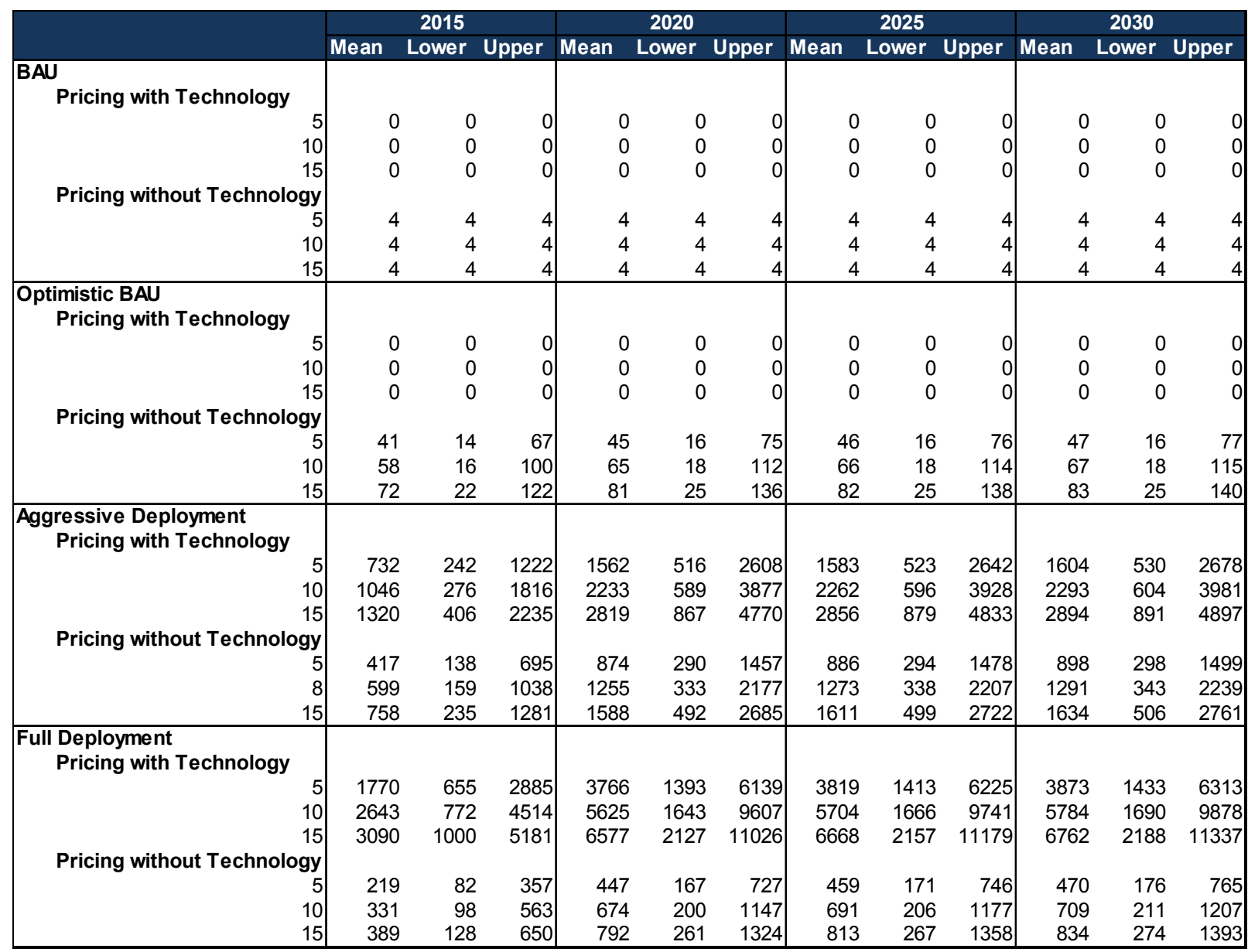




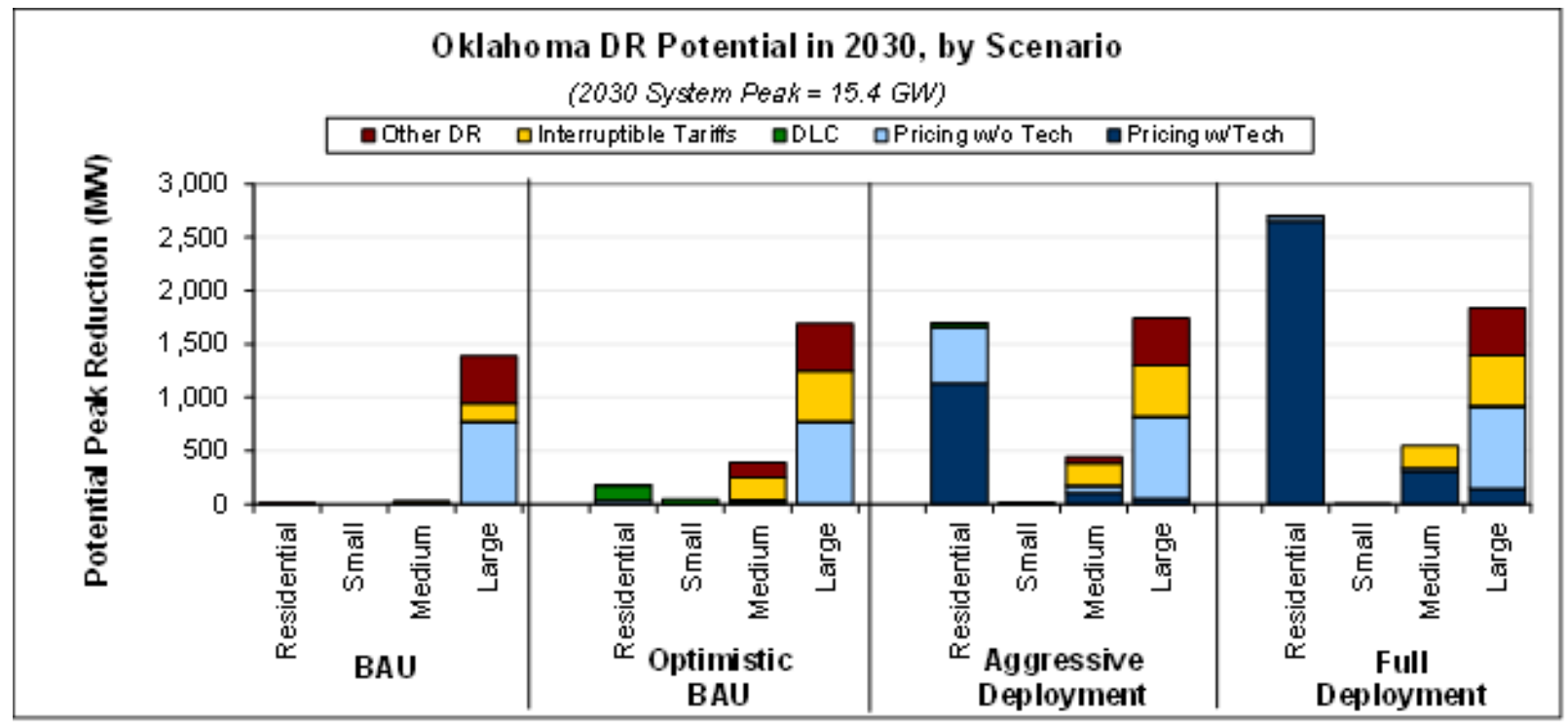

Total Potential Peak Reduction from Demand Response in Oklahoma, 2030

\begin{tabular}{|c|c|c|c|c|c|c|c|c|c|c|}
\hline & $\begin{array}{l}\text { Residential } \\
\text { (MW) }\end{array}$ & $\begin{array}{l}\text { Residential } \\
\text { ( } \% \text { of } \\
\text { svstem) }\end{array}$ & $\begin{array}{l}\text { Small C\&I } \\
(\mathrm{MW})\end{array}$ & $\begin{array}{c}\text { Small C\&I } \\
\text { ( } \% \text { of } \\
\text { svstem) }\end{array}$ & $\begin{array}{l}\text { Med. C\&I } \\
(\mathrm{MW})\end{array}$ & $\begin{array}{l}\text { Med C\&I } \\
\text { ( } \% \text { of } \\
\text { svstem) }\end{array}$ & $\begin{array}{l}\text { Large C\&I } \\
(\mathrm{MW})\end{array}$ & $\begin{array}{l}\text { Large C\&I } \\
\text { ( } \% \text { of } \\
\text { svstem) }\end{array}$ & $\begin{array}{l}\text { Total } \\
\text { (MW) }\end{array}$ & $\begin{array}{c}\text { Total } \\
\text { ( } \% \text { of } \\
\text { svstem) }\end{array}$ \\
\hline \multicolumn{11}{|l|}{ BAU } \\
\hline Pricing with Technology & 0 & $0.0 \%$ & 0 & $0.0 \%$ & 0 & $0.0 \%$ & 0 & $0.0 \%$ & 0 & $0.0 \%$ \\
\hline Pricing without Technology & 7 & $0.0 \%$ & 0 & $0.0 \%$ & 22 & $0.2 \%$ & 762 & $5.7 \%$ & 790 & $5.9 \%$ \\
\hline Automated/Direct Load Control & 0 & $0.0 \%$ & 0 & $0.0 \%$ & 0 & $0.0 \%$ & 12 & $0.1 \%$ & 12 & $0.1 \%$ \\
\hline Interruptible/Curtailable Tariffs & 0 & $0.0 \%$ & 0 & $0.0 \%$ & 7 & $0.0 \%$ & 169 & $1.3 \%$ & 176 & $1.3 \%$ \\
\hline Other DR Programs & 4 & $0.0 \%$ & 0 & $0.0 \%$ & 0 & $0.0 \%$ & 444 & $3.3 \%$ & 448 & $3.3 \%$ \\
\hline Total & 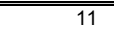 & $0.1 \%$ & 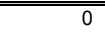 & $0.0 \%$ & 29 & $0.2 \%$ & $\overline{1,386}$ & $\overline{10.3 \%}$ & $\overline{1,426}$ & $\overline{10.6 \%}$ \\
\hline \multicolumn{11}{|l|}{ Optimistic BAU } \\
\hline Pricing with Technology & 0 & $0.0 \%$ & 0 & $0.0 \%$ & 0 & $0.0 \%$ & 0 & $0.0 \%$ & 0 & $0.0 \%$ \\
\hline Pricing without Technology & 32 & $0.2 \%$ & 0 & $0.0 \%$ & 22 & $0.2 \%$ & 762 & $5.7 \%$ & 816 & $6.1 \%$ \\
\hline Automated/Direct Load Control & 146 & $1.1 \%$ & 48 & $0.4 \%$ & 16 & $0.1 \%$ & 12 & $0.1 \%$ & 222 & $1.7 \%$ \\
\hline Interruptible/Curtailable Tariffs & 0 & $0.0 \%$ & 0 & $0.0 \%$ & 211 & $1.6 \%$ & 475 & $3.5 \%$ & 686 & $5.1 \%$ \\
\hline Other DR Programs & 4 & $0.0 \%$ & 0 & $0.0 \%$ & 140 & $1.0 \%$ & 444 & $3.3 \%$ & 588 & $4.4 \%$ \\
\hline Total & 182 & $1.4 \%$ & 48 & $0.4 \%$ & 390 & $2.9 \%$ & $\overline{1,691}$ & $12.6 \%$ & 2,312 & $17.2 \%$ \\
\hline \multicolumn{11}{|l|}{ Aggressive Deployment } \\
\hline Pricing with Technology & 1,131 & $8.4 \%$ & 0 & $0.0 \%$ & 105 & $0.8 \%$ & 50 & $0.4 \%$ & 1,286 & $9.6 \%$ \\
\hline Pricing without Technology & 525 & $3.9 \%$ & 2 & $0.0 \%$ & 63 & $0.5 \%$ & 762 & $5.7 \%$ & 1,352 & $10.1 \%$ \\
\hline Automated/Direct Load Control & 37 & $0.3 \%$ & 12 & $0.1 \%$ & 7 & $0.0 \%$ & 12 & $0.1 \%$ & 68 & $0.5 \%$ \\
\hline Interruptible/Curtailable Tariffs & 0 & $0.0 \%$ & 0 & $0.0 \%$ & 211 & $1.6 \%$ & 475 & $3.5 \%$ & 686 & $5.1 \%$ \\
\hline Other DR Programs & 4 & $0.0 \%$ & 0 & $0.0 \%$ & 57 & $0.4 \%$ & 444 & $3.3 \%$ & 505 & $3.8 \%$ \\
\hline Total & 1,698 & $12.6 \%$ & 15 & $0.1 \%$ & 443 & $3.3 \%$ & 1,741 & $13.0 \%$ & 3,897 & $29.0 \%$ \\
\hline \multicolumn{11}{|l|}{ Full Deployment } \\
\hline Pricing with Technology & 2,646 & $19.7 \%$ & 0 & $0.0 \%$ & 308 & $2.3 \%$ & 146 & $1.1 \%$ & 3,100 & $23.1 \%$ \\
\hline Pricing without Technology & 50 & $0.4 \%$ & 3 & $0.0 \%$ & 31 & $0.2 \%$ & 762 & $5.7 \%$ & 845 & $6.3 \%$ \\
\hline Automated/Direct Load Control & 0 & $0.0 \%$ & 0 & $0.0 \%$ & 0 & $0.0 \%$ & 12 & $0.1 \%$ & 12 & $0.1 \%$ \\
\hline Interruptible/Curtailable Tariffs & 0 & $0.0 \%$ & 0 & $0.0 \%$ & 211 & $1.6 \%$ & 475 & $3.5 \%$ & 686 & $5.1 \%$ \\
\hline Other DR Programs & 4 & $0.0 \%$ & 0 & $0.0 \%$ & 0 & $0.0 \%$ & 444 & $3.3 \%$ & 448 & $3.3 \%$ \\
\hline Total & 2,700 & $20.1 \%$ & $\overline{3}$ & $0.0 \%$ & $\overline{550}$ & $4.1 \%$ & 1,838 & $\overline{13.7 \%}$ & $\overline{5,091}$ & $37.9 \%$ \\
\hline
\end{tabular}




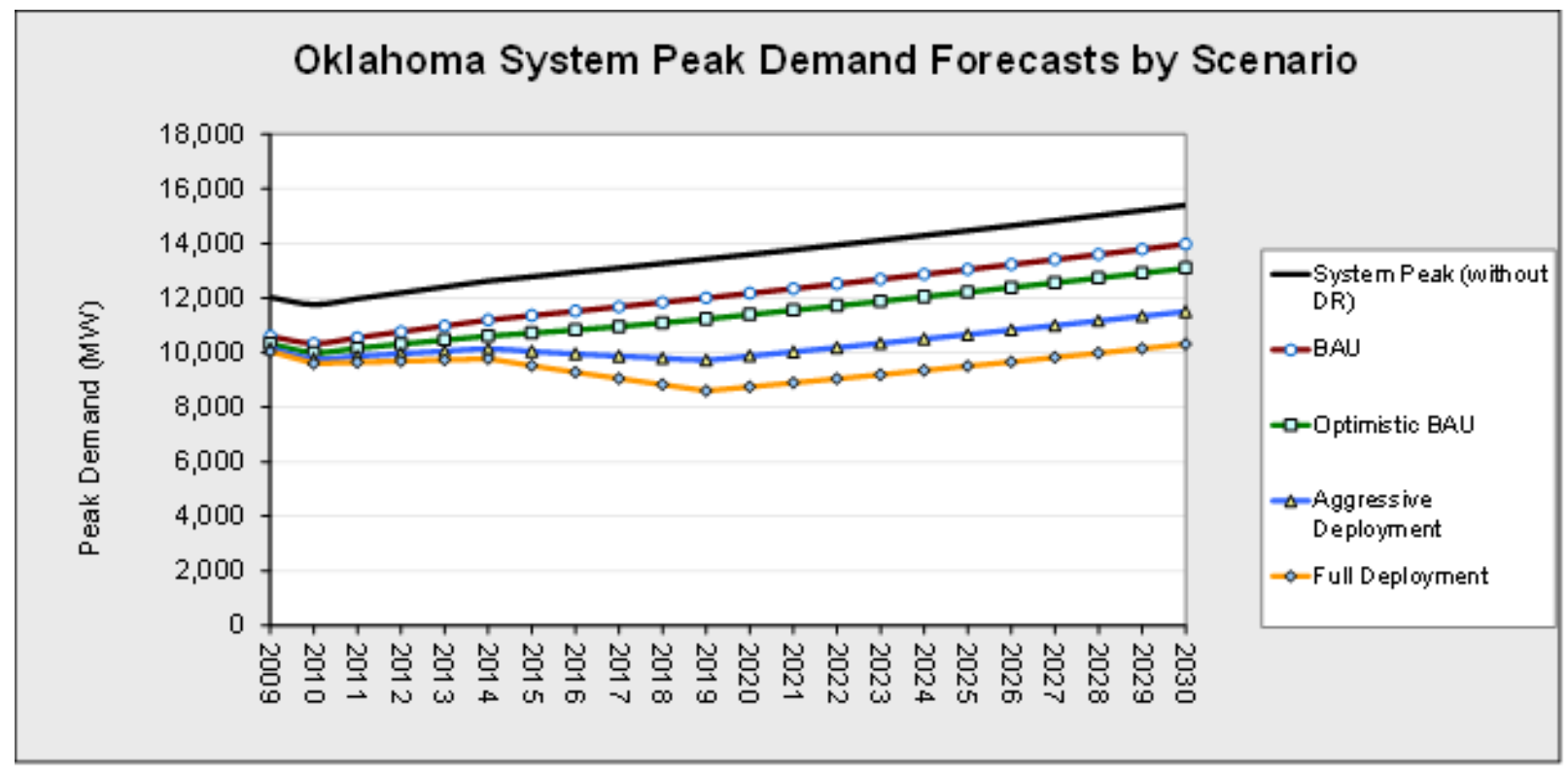

Summary of Monte Carlo Simulation of Potential Peak Load Reduction from Demand Response in Oklahoma by Scenario, Pricing Program and Price Ratio (MW)

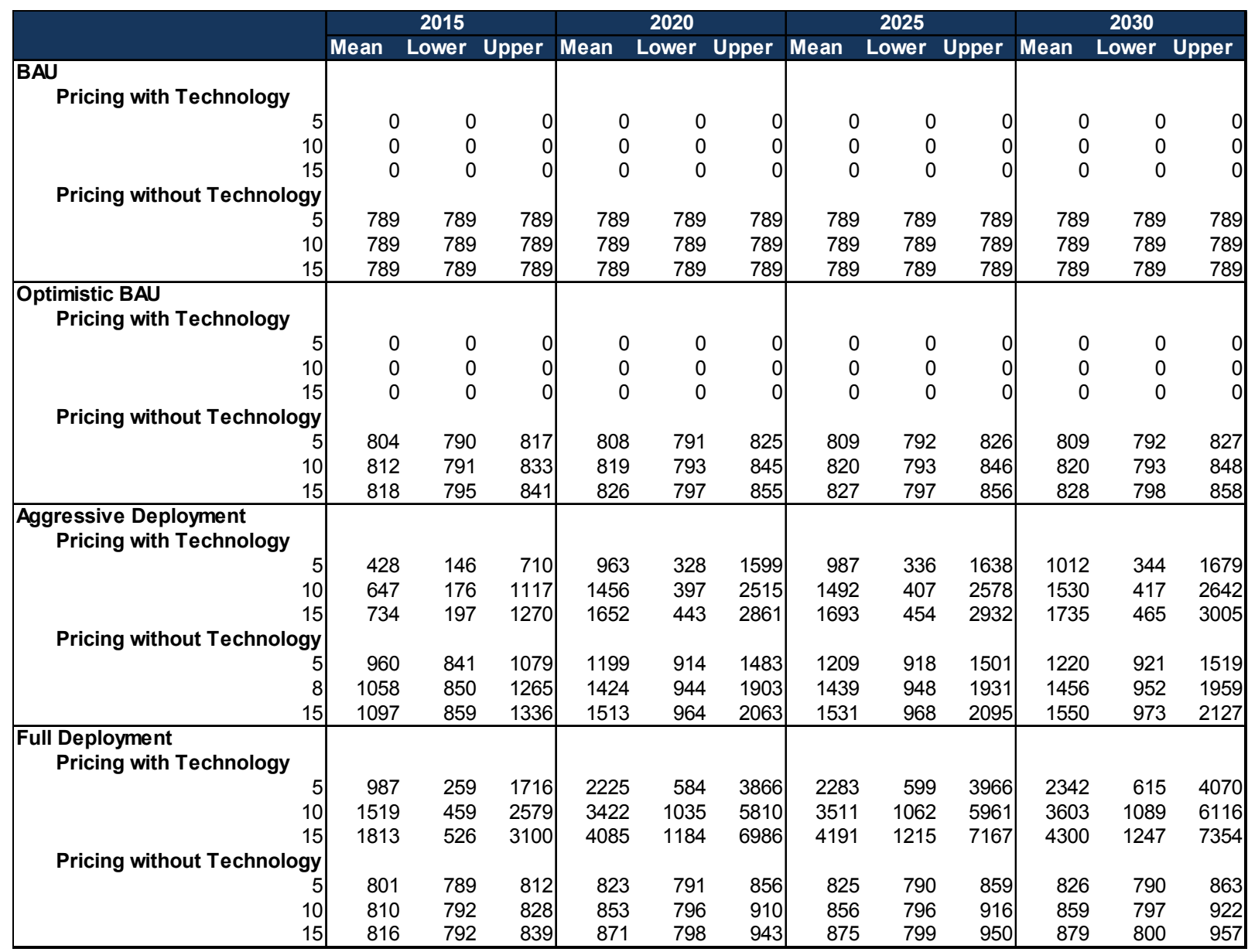




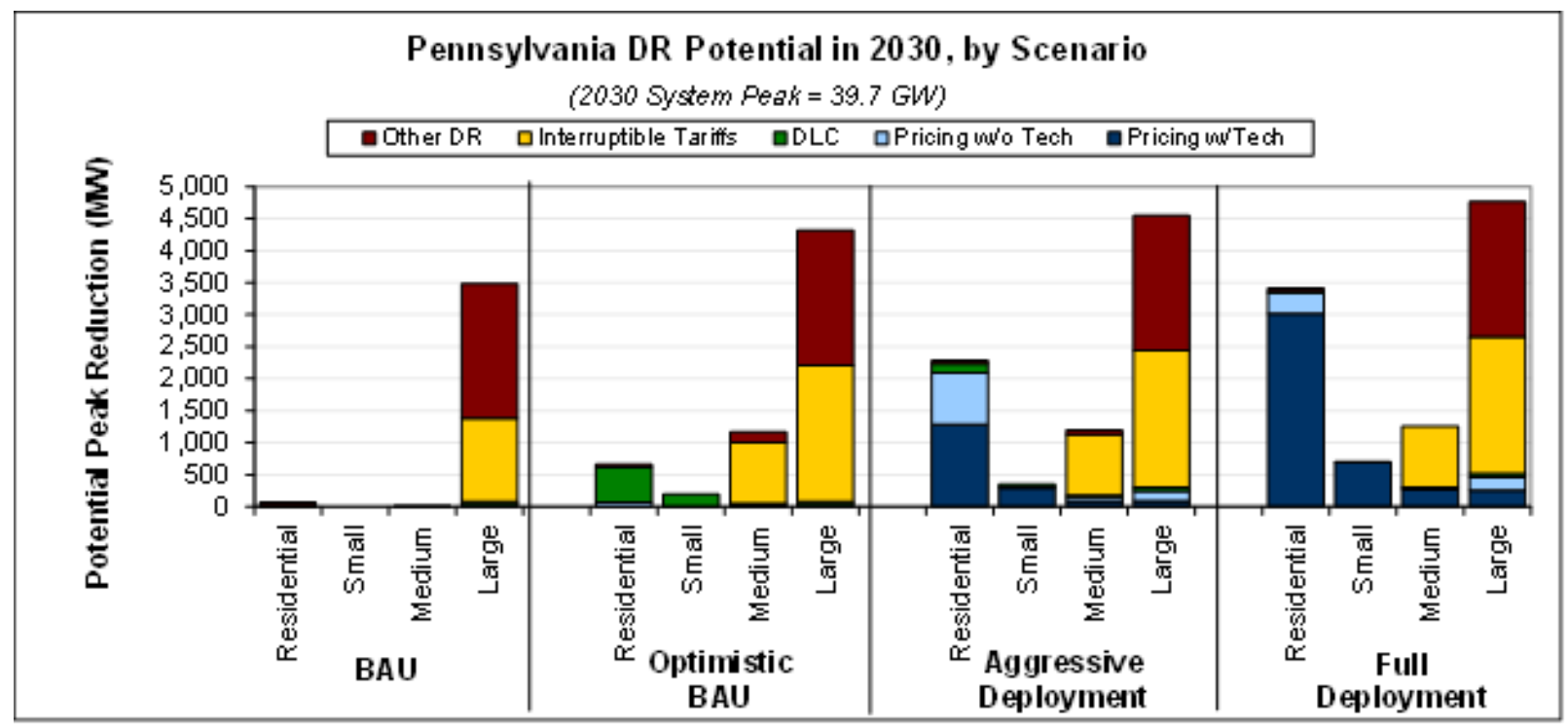

Total Potential Peak Reduction from Demand Response in Pennsylvania, 2030

\begin{tabular}{|c|c|c|c|c|c|c|c|c|c|c|}
\hline & $\begin{array}{l}\text { Residential } \\
\text { (MW) }\end{array}$ & $\begin{array}{l}\text { Residential } \\
\text { ( } \% \text { of } \\
\text { svstem) }\end{array}$ & $\begin{array}{l}\text { Small C\&I } \\
\text { (MW) }\end{array}$ & $\begin{array}{c}\text { Small C\&I } \\
\text { (\% of } \\
\text { svstem) }\end{array}$ & $\begin{array}{l}\text { Med. C\&I } \\
(\mathrm{MW})\end{array}$ & $\begin{array}{l}\text { Med C\&I } \\
\text { ( } \% \text { of } \\
\text { svstem) }\end{array}$ & $\begin{array}{l}\text { Large C\&I } \\
\text { (MW) }\end{array}$ & $\begin{array}{l}\text { Large C\&I } \\
\text { ( } \% \text { of } \\
\text { svstem) }\end{array}$ & $\begin{array}{l}\text { Total } \\
\text { (MW) }\end{array}$ & $\begin{array}{c}\text { Total } \\
\text { ( } \% \text { of } \\
\text { svstem) }\end{array}$ \\
\hline \multicolumn{11}{|l|}{ BAU } \\
\hline Pricing with Technology & 0 & $0.0 \%$ & 0 & $0.0 \%$ & 0 & $0.0 \%$ & 0 & $0.0 \%$ & 0 & $0.0 \%$ \\
\hline Pricing without Technology & 1 & $0.0 \%$ & 0 & $0.0 \%$ & 2 & $0.0 \%$ & 15 & $0.0 \%$ & 18 & $0.1 \%$ \\
\hline Automated/Direct Load Control & 20 & $0.1 \%$ & 0 & $0.0 \%$ & 0 & $0.0 \%$ & 60 & $0.2 \%$ & 80 & $0.2 \%$ \\
\hline Interruptible/Curtailable Tariffs & 0 & $0.0 \%$ & 0 & $0.0 \%$ & 1 & $0.0 \%$ & 1,300 & $3.8 \%$ & 1,301 & $3.8 \%$ \\
\hline Other DR Programs & 48 & $0.1 \%$ & 0 & $0.0 \%$ & 0 & $0.0 \%$ & 2,108 & $6.1 \%$ & 2,156 & $6.2 \%$ \\
\hline Total & 69 & $0.2 \%$ & 0 & $0.0 \%$ & 3 & $0.0 \%$ & 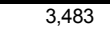 & $10.1 \%$ & 3,555 & $10.3 \%$ \\
\hline \multicolumn{11}{|l|}{ Optimistic BAU } \\
\hline Pricing with Technology & 0 & $0.0 \%$ & 0 & $0.0 \%$ & 0 & $0.0 \%$ & 0 & $0.0 \%$ & 0 & $0.0 \%$ \\
\hline Pricing without Technology & 65 & $0.2 \%$ & 0 & $0.0 \%$ & 6 & $0.0 \%$ & 15 & $0.0 \%$ & 87 & $0.3 \%$ \\
\hline Automated/Direct Load Control & 545 & $1.6 \%$ & 190 & $0.6 \%$ & 45 & $0.1 \%$ & 60 & $0.2 \%$ & 841 & $2.4 \%$ \\
\hline Interruptible/Curtailable Tariffs & 0 & $0.0 \%$ & 0 & $0.0 \%$ & 954 & $2.8 \%$ & 2,131 & $6.2 \%$ & 3,085 & $8.9 \%$ \\
\hline Other DR Programs & 48 & $0.1 \%$ & 0 & $0.0 \%$ & 159 & $0.5 \%$ & 2,108 & $6.1 \%$ & 2,315 & $6.7 \%$ \\
\hline Total & 658 & $1.9 \%$ & 191 & $0.6 \%$ & 1,164 & $3.4 \%$ & 4,314 & $12.5 \%$ & 6,328 & $18.3 \%$ \\
\hline \multicolumn{11}{|l|}{ Aggressive Deployment } \\
\hline Pricing with Technology & 1,286 & $3.7 \%$ & 296 & $0.9 \%$ & 90 & $0.3 \%$ & 87 & $0.3 \%$ & 1,759 & $5.1 \%$ \\
\hline Pricing without Technology & 807 & $2.3 \%$ & 6 & $0.0 \%$ & 63 & $0.2 \%$ & 158 & $0.5 \%$ & 1,033 & $3.0 \%$ \\
\hline Automated/Direct Load Control & 141 & $0.4 \%$ & 49 & $0.1 \%$ & 19 & $0.1 \%$ & 60 & $0.2 \%$ & 269 & $0.8 \%$ \\
\hline Interruptible/Curtailable Tariffs & 0 & $0.0 \%$ & 0 & $0.0 \%$ & 954 & $2.8 \%$ & 2,131 & $6.2 \%$ & 3,085 & $8.9 \%$ \\
\hline Other DR Programs & 48 & $0.1 \%$ & 0 & $0.0 \%$ & 66 & $0.2 \%$ & 2,108 & $6.1 \%$ & 2,222 & $6.4 \%$ \\
\hline Total & 2,281 & $6.6 \%$ & 351 & $1.0 \%$ & 1,192 & $3.4 \%$ & 4,544 & $13.1 \%$ & 8,368 & $24.2 \%$ \\
\hline \multicolumn{11}{|l|}{ Full Deployment } \\
\hline Pricing with Technology & 3,008 & $8.7 \%$ & 693 & $2.0 \%$ & 264 & $0.8 \%$ & 253 & $0.7 \%$ & 4,217 & $12.2 \%$ \\
\hline Pricing without Technology & 336 & $1.0 \%$ & 4 & $0.0 \%$ & 42 & $0.1 \%$ & 204 & $0.6 \%$ & 586 & $1.7 \%$ \\
\hline Automated/Direct Load Control & 20 & $0.1 \%$ & 0 & $0.0 \%$ & 0 & $0.0 \%$ & 60 & $0.2 \%$ & 80 & $0.2 \%$ \\
\hline Interruptible/Curtailable Tariffs & 0 & $0.0 \%$ & 0 & $0.0 \%$ & 954 & $2.8 \%$ & 2,131 & $6.2 \%$ & 3,085 & $8.9 \%$ \\
\hline Other DR Programs & 48 & $0.1 \%$ & 0 & $0.0 \%$ & 0 & $0.0 \%$ & 2,108 & $6.1 \%$ & 2,156 & $6.2 \%$ \\
\hline Total & 3,412 & $9.9 \%$ & 696 & $2.0 \%$ & 1,259 & $3.6 \%$ & 4,757 & $13.8 \%$ & 10,124 & $29.3 \%$ \\
\hline
\end{tabular}




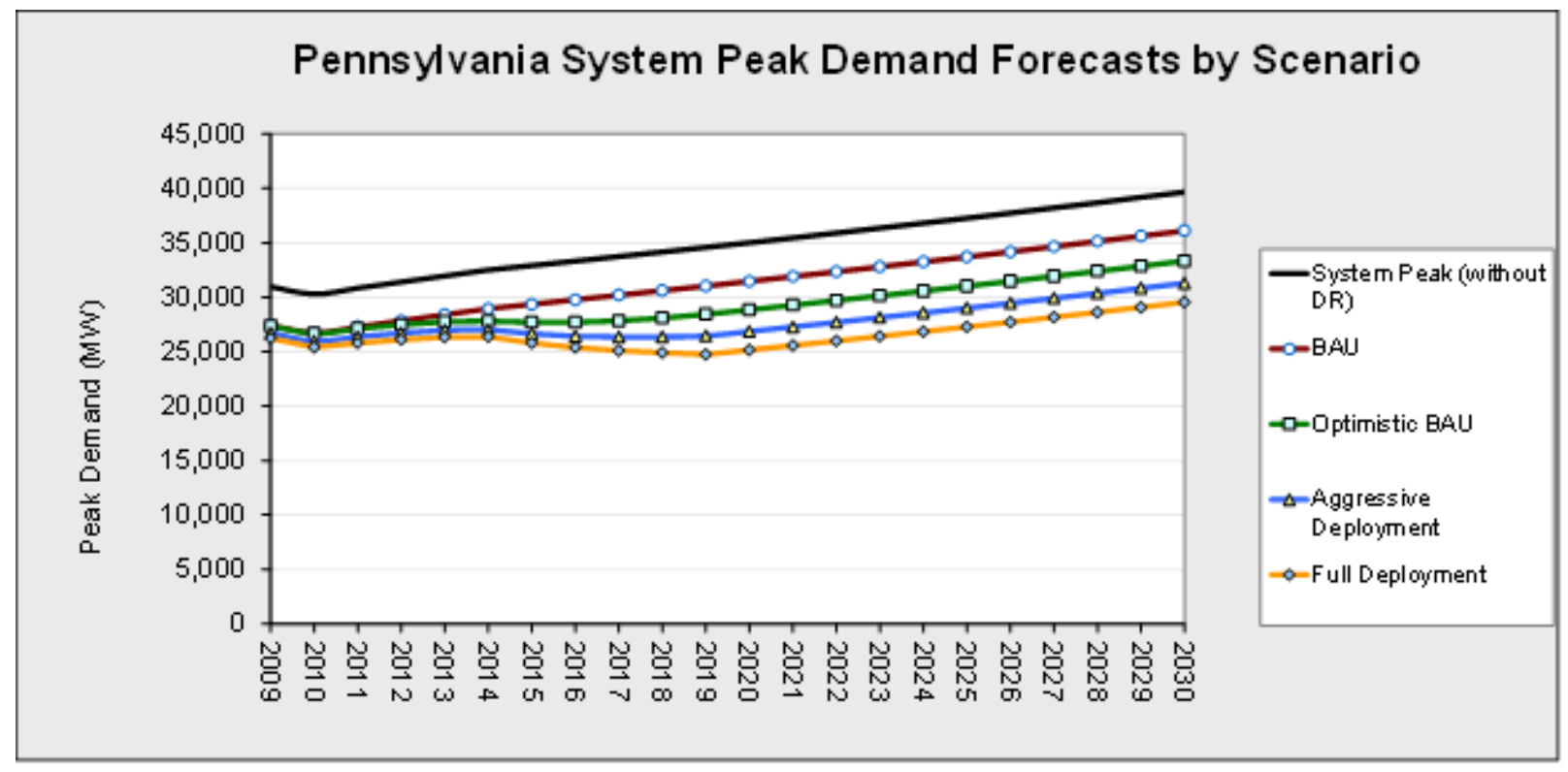

Summary of Monte Carlo Simulation of Potential Peak Load Reduction from Demand Response in Pennsylvania by Scenario, Pricing Program and Price Ratio (MW)

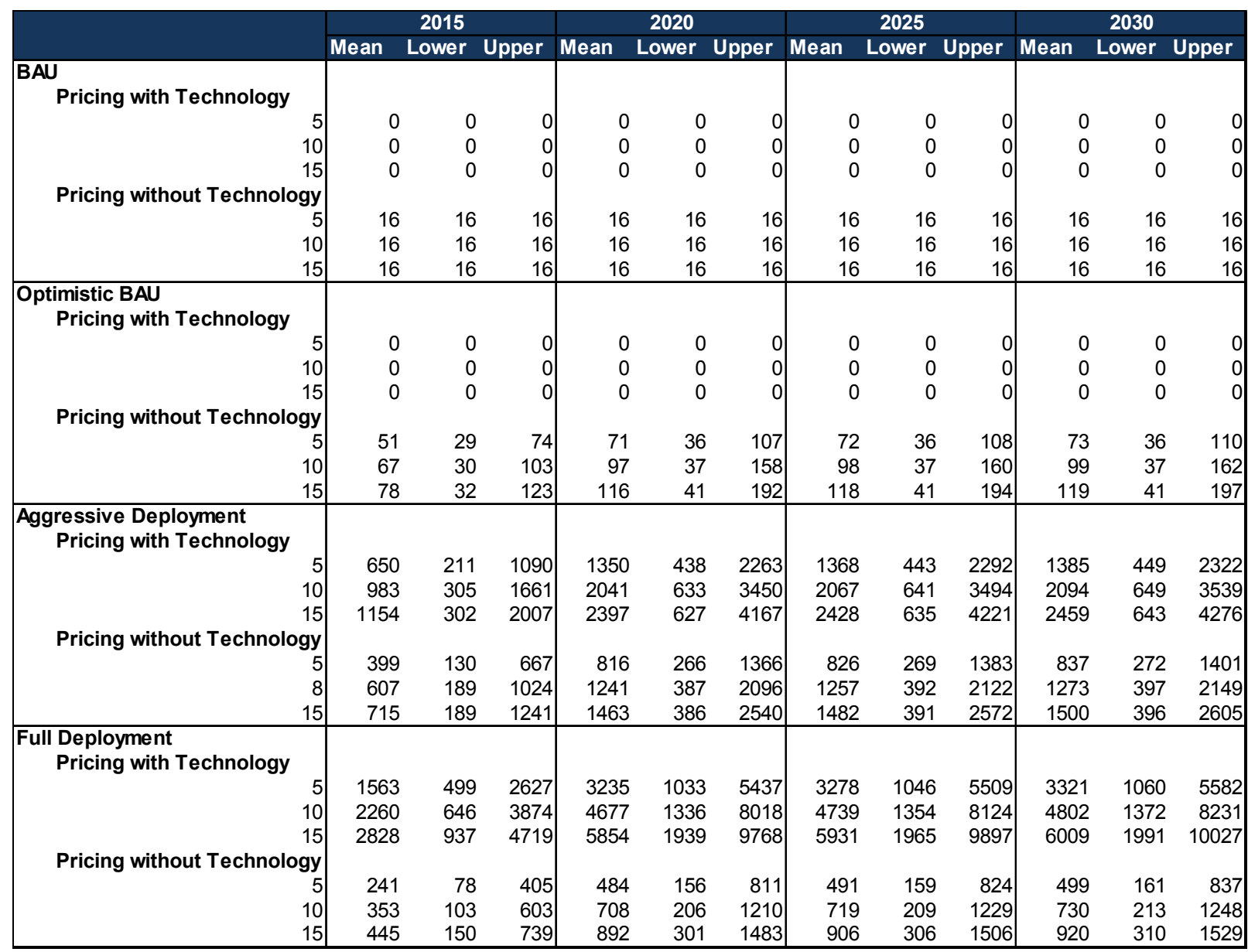




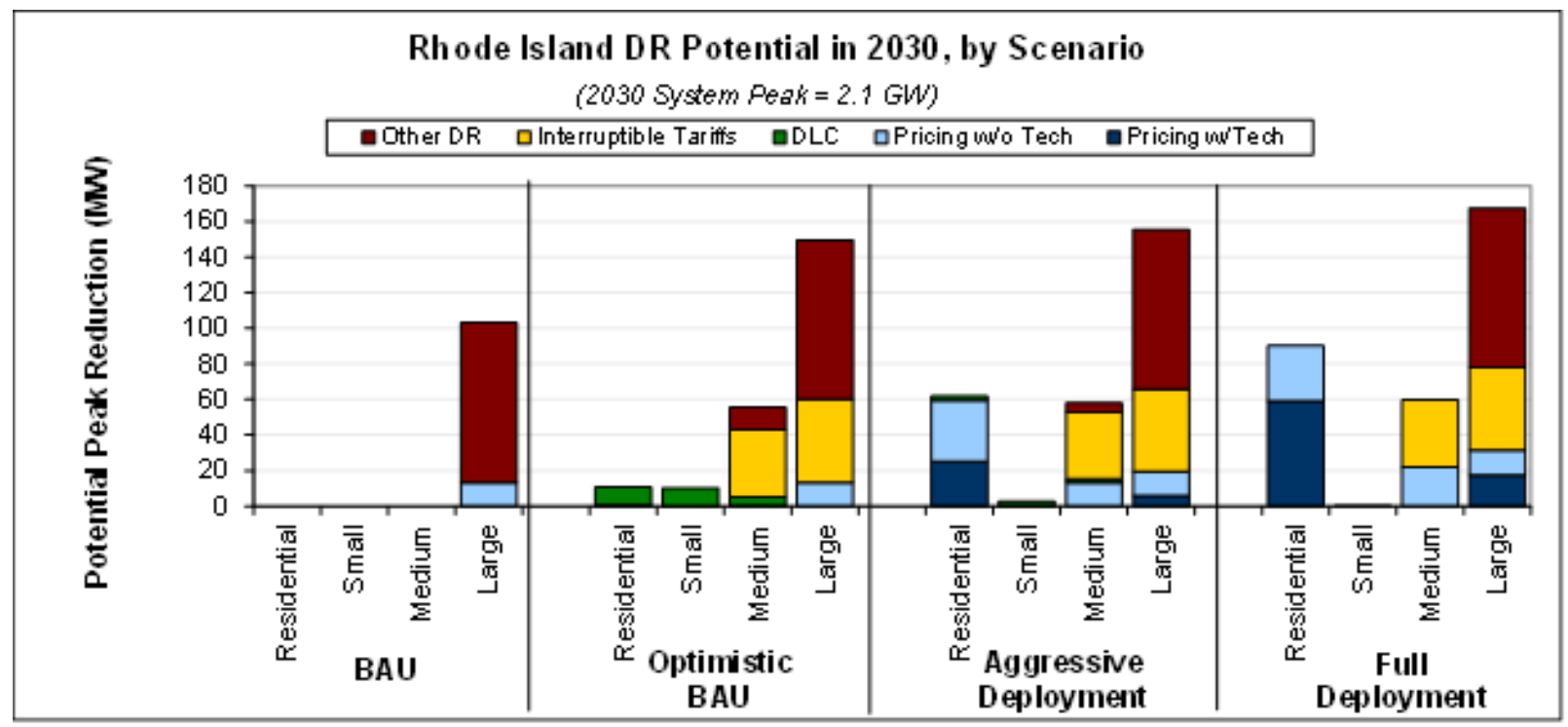

Total Potential Peak Reduction from Demand Response in Rhode Island, 2030

\begin{tabular}{|c|c|c|c|c|c|c|c|c|c|c|}
\hline & $\begin{array}{l}\text { Residential } \\
\text { (MW) }\end{array}$ & $\begin{array}{l}\text { Residential } \\
\text { ( } \% \text { of } \\
\text { svstem) }\end{array}$ & $\begin{array}{c}\text { Small C\&I } \\
(\mathrm{MW})\end{array}$ & $\begin{array}{l}\text { Small C\&I } \\
\text { (\% of } \\
\text { svstem) }\end{array}$ & $\begin{array}{l}\text { Med. C\&I } \\
(\mathrm{MW})\end{array}$ & $\begin{array}{l}\text { Med C\&I } \\
\text { ( } \% \text { of } \\
\text { svstem) }\end{array}$ & $\begin{array}{l}\text { Large C\&I } \\
(\mathrm{MW})\end{array}$ & $\begin{array}{l}\text { Large C\&I } \\
\text { (\% of } \\
\text { svstem) }\end{array}$ & $\begin{array}{l}\text { Total } \\
\text { (MW) }\end{array}$ & $\begin{array}{c}\text { Total } \\
\text { ( } \% \text { of } \\
\text { svstem) }\end{array}$ \\
\hline \multicolumn{11}{|l|}{ BAU } \\
\hline Pricing with Technology & 0 & $0.0 \%$ & 0 & $0.0 \%$ & 0 & $0.0 \%$ & 0 & $0.0 \%$ & 0 & $0.0 \%$ \\
\hline Pricing without Technology & 0 & $0.0 \%$ & 0 & $0.0 \%$ & 0 & $0.0 \%$ & 13 & $0.7 \%$ & 13 & $0.7 \%$ \\
\hline Automated/Direct Load Control & 0 & $0.0 \%$ & 0 & $0.0 \%$ & 0 & $0.0 \%$ & 0 & $0.0 \%$ & 0 & $0.0 \%$ \\
\hline Interruptible/Curtailable Tariffs & 0 & $0.0 \%$ & 0 & $0.0 \%$ & 0 & $0.0 \%$ & 0 & $0.0 \%$ & 0 & $0.0 \%$ \\
\hline Other DR Programs & 0 & $0.0 \%$ & 0 & $0.0 \%$ & 0 & $0.0 \%$ & 90 & $4.9 \%$ & 90 & $4.9 \%$ \\
\hline Total & 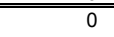 & $0.0 \%$ & 0 & $0.0 \%$ & 0 & $0.0 \%$ & 103 & $5.7 \%$ & 103 & $5.7 \%$ \\
\hline \multicolumn{11}{|l|}{ Optimistic BAU } \\
\hline Pricing with Technology & 0 & $0.0 \%$ & 0 & $0.0 \%$ & 0 & $0.0 \%$ & 0 & $0.0 \%$ & 0 & $0.0 \%$ \\
\hline Pricing without Technology & 1 & $0.0 \%$ & 0 & $0.0 \%$ & 0 & $0.0 \%$ & 13 & $0.7 \%$ & 15 & $0.8 \%$ \\
\hline Automated/Direct Load Control & 10 & $0.5 \%$ & 10 & $0.6 \%$ & 5 & $0.3 \%$ & 0 & $0.0 \%$ & 25 & $1.4 \%$ \\
\hline Interruptible/Curtailable Tariffs & 0 & $0.0 \%$ & 0 & $0.0 \%$ & 38 & $2.1 \%$ & 47 & $2.6 \%$ & 84 & $4.6 \%$ \\
\hline Other DR Programs & 0 & $0.0 \%$ & 0 & $0.0 \%$ & 13 & $0.7 \%$ & 90 & $4.9 \%$ & 102 & $5.6 \%$ \\
\hline Total & $\overline{111}$ & $0.6 \%$ & 10 & $0.6 \%$ & 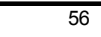 & $3.1 \%$ & 150 & $8.3 \%$ & 226 & $12.5 \%$ \\
\hline \multicolumn{11}{|l|}{ Aggressive Deployment } \\
\hline Pricing with Technology & 25 & $1.4 \%$ & 0 & $0.0 \%$ & 0 & $0.0 \%$ & 6 & $0.3 \%$ & 31 & $1.7 \%$ \\
\hline Pricing without Technology & 34 & $1.9 \%$ & 0 & $0.0 \%$ & 13 & $0.7 \%$ & 13 & $0.7 \%$ & 61 & $3.4 \%$ \\
\hline Automated/Direct Load Control & 3 & $0.1 \%$ & 3 & $0.1 \%$ & 2 & $0.1 \%$ & 0 & $0.0 \%$ & 7 & $0.4 \%$ \\
\hline Interruptible/Curtailable Tariffs & 0 & $0.0 \%$ & 0 & $0.0 \%$ & 38 & $2.1 \%$ & 47 & $2.6 \%$ & 84 & $4.6 \%$ \\
\hline Other DR Programs & 0 & $0.0 \%$ & 0 & $0.0 \%$ & 5 & $0.3 \%$ & 90 & $4.9 \%$ & 95 & $5.2 \%$ \\
\hline Total & 62 & $3.4 \%$ & 3 & $0.2 \%$ & 58 & $3.2 \%$ & 155 & $8.6 \%$ & 278 & $15.4 \%$ \\
\hline \multicolumn{11}{|l|}{ Full Deployment } \\
\hline Pricing with Technology & 59 & $3.3 \%$ & 0 & $0.0 \%$ & 0 & $0.0 \%$ & 17 & $1.0 \%$ & 76 & $4.2 \%$ \\
\hline Pricing without Technology & 31 & $1.7 \%$ & 0 & $0.0 \%$ & 22 & $1.2 \%$ & 14 & $0.8 \%$ & 67 & $3.7 \%$ \\
\hline Automated/Direct Load Control & 0 & $0.0 \%$ & 0 & $0.0 \%$ & 0 & $0.0 \%$ & 0 & $0.0 \%$ & 0 & $0.0 \%$ \\
\hline Interruptible/Curtailable Tariffs & 0 & $0.0 \%$ & 0 & $0.0 \%$ & 38 & $2.1 \%$ & 47 & $2.6 \%$ & 84 & $4.6 \%$ \\
\hline Other DR Programs & 0 & $0.0 \%$ & 0 & $0.0 \%$ & 0 & $0.0 \%$ & 90 & $4.9 \%$ & 90 & $4.9 \%$ \\
\hline Total & 90 & $5.0 \%$ & 0 & $0.0 \%$ & 60 & $3.3 \%$ & 167 & $9.2 \%$ & 318 & $17.5 \%$ \\
\hline
\end{tabular}




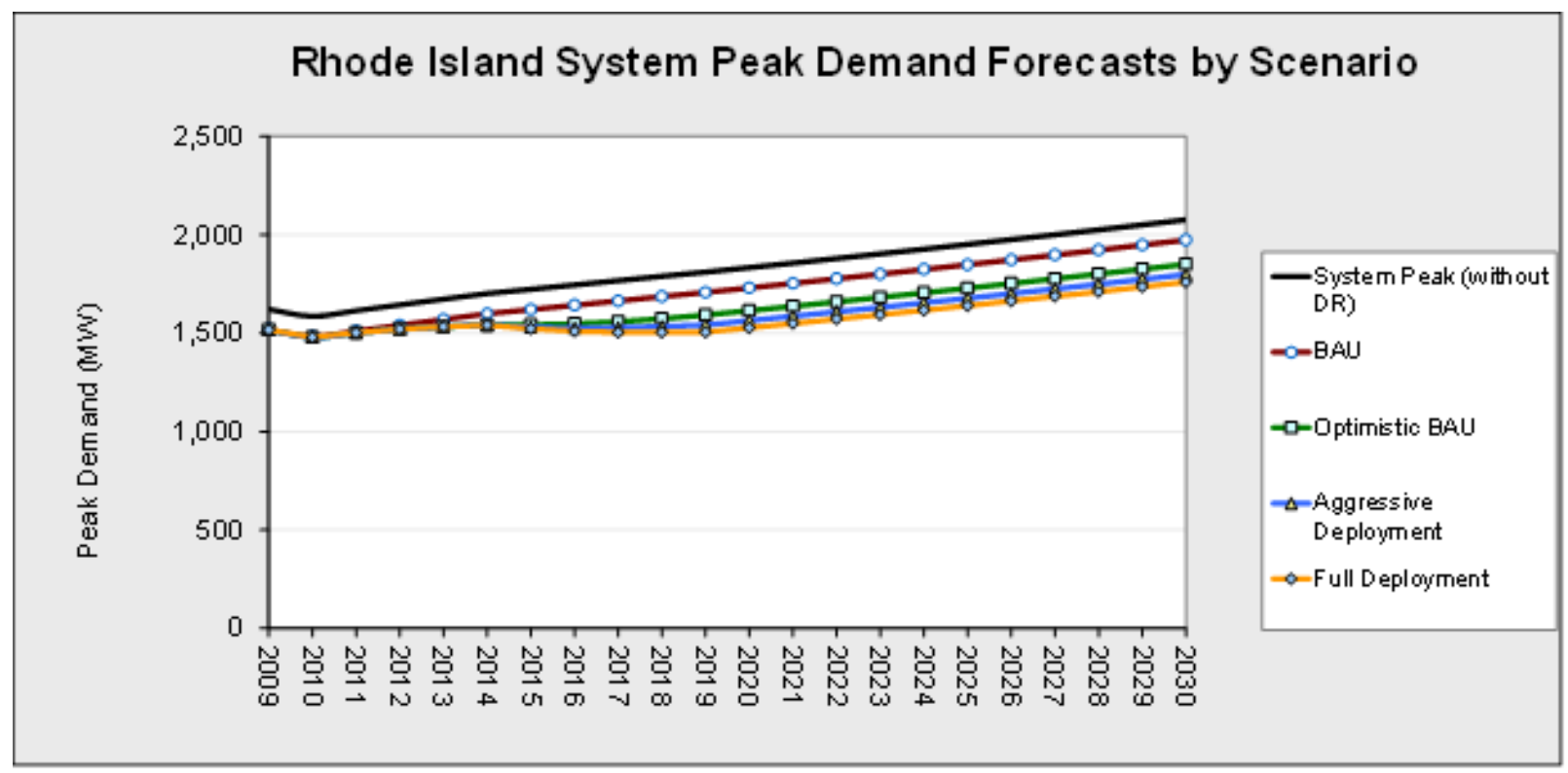

Summary of Monte Carlo Simulation of Potential Peak Load Reduction from Demand Response in Rhode Island by Scenario, Pricing Program and Price Ratio (MW)

\begin{tabular}{|c|c|c|c|c|c|c|c|c|c|c|c|c|}
\hline & \multicolumn{3}{|c|}{2015} & \multicolumn{3}{|c|}{2020} & \multicolumn{3}{|c|}{2025} & \multicolumn{3}{|c|}{2030} \\
\hline & \multirow[t]{2}{*}{ Mean } & Lower & Upper & \multirow[t]{2}{*}{ Mean } & \multicolumn{2}{|c|}{ Lower Upper } & \multirow[t]{3}{*}{ Mean } & \multicolumn{2}{|c|}{ Lower Upper } & \multirow[t]{3}{*}{ Mean } & \multicolumn{2}{|c|}{ Lower Upper } \\
\hline \multirow{2}{*}{\multicolumn{11}{|c|}{$\begin{array}{l}\text { BAU } \\
\text { Pricir }\end{array}$}} & & \\
\hline & & & & & & & & & & & & \\
\hline 5 & 0 & c & 0 & 0 & 0 & 0 & 0 & 0 & 0 & 0 & 0 & \\
\hline 10 & 0 & c & 0 & 0 & 0 & 0 & 0 & 0 & 0 & 0 & 0 & \\
\hline 15 & 0 & c & 0 & 0 & 0 & 0 & 0 & 0 & 0 & 0 & 0 & \\
\hline \multicolumn{13}{|l|}{ Pricing without Technology } \\
\hline 5 & 13 & 13 & 13 & 13 & 13 & 13 & 13 & 13 & 13 & 13 & 13 & \\
\hline 10 & 13 & 13 & 13 & 13 & 13 & 13 & 13 & 13 & 13 & 13 & 13 & ta \\
\hline 15 & 13 & 13 & 13 & 13 & 13 & 13 & 13 & 13 & 13 & 13 & 13 & 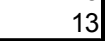 \\
\hline \multirow{2}{*}{\multicolumn{13}{|c|}{$\begin{array}{l}\text { Optimistic BAU } \\
\quad \text { Pricing with Technology }\end{array}$}} \\
\hline & & & & & & & & & & & & \\
\hline $\begin{array}{r}5 \\
10\end{array}$ & 0 & c & 0 & 0 & c & 0 & 0 & 0 & 0 & 0 & 0 & \\
\hline 10 & 0 & c & 0 & 0 & 0 & 0 & 0 & 0 & 0 & 0 & 0 & \\
\hline 15 & 0 & c & 0 & 0 & 0 & 0 & 0 & 0 & 0 & 0 & 0 & \\
\hline \multicolumn{13}{|l|}{ Pricing without Technology } \\
\hline 5 & 14 & 12 & 14 & 14 & 14 & 15 & 14 & 14 & 15 & 14 & 14 & \\
\hline 10 & 14 & 12 & 14 & 15 & 14 & 15 & 15 & 14 & 15 & 15 & 14 & \\
\hline 15 & 14 & 14 & 14 & 15 & 14 & 16 & 15 & 14 & 16 & 15 & 14 & 1 \\
\hline \multicolumn{13}{|l|}{\begin{tabular}{|l|} 
Aggressive Deployment \\
Pricing with Technology
\end{tabular}} \\
\hline 5 & 5 & 1 & 9 & 24 & 5 & 44 & 25 & 5 & 44 & 25 & 5 & \\
\hline 10 & 7 & 2 & 12 & 35 & g & 60 & 36 & 9 & 62 & 36 & 10 & \\
\hline 15 & 9 & 2 & 15 & 47 & 18 & 75 & 48 & 19 & 77 & 49 & 19 & 78 \\
\hline \multicolumn{13}{|l|}{ Pricing without Technology } \\
\hline 5 & 20 & 15 & 26 & 49 & 20 & 77 & 49 & 20 & 79 & 50 & 20 & 81 \\
\hline 8 & 24 & 16 & 31 & 67 & 24 & 110 & 68 & 24 & 112 & 70 & 24 & 115 \\
\hline 15 & 27 & $1 \mathrm{~s}$ & 35 & 88 & 37 & 138 & 90 & 38 & 142 & 92 & 39 & 14 \\
\hline \multirow{2}{*}{\multicolumn{13}{|c|}{$\begin{array}{l}\text { Full Deployment } \\
\text { Pricing with Technology }\end{array}$}} \\
\hline & & & & & & & & & & & & \\
\hline 10 & 18 & 5 & 30 & 87 & 27 & 147 & 89 & 28 & 151 & $\begin{array}{l}02 \\
91\end{array}$ & 28 & \\
\hline 15 & 20 & 5 & 36 & 101 & 26 & 176 & 104 & 27 & 180 & 106 & 28 & 18 \\
\hline \multicolumn{13}{|l|}{ Pricing without Technology } \\
\hline 5 & 21 & 15 & 27 & 53 & 20 & 86 & 54 & 20 & 88 & 56 & 20 & \\
\hline 10 & 25 & 17 & 33 & 77 & 28 & 126 & 79 & 28 & 130 & 81 & 29 & 13 \\
\hline 15 & 27 & 17 & 37 & 90 & 27 & 153 & 92 & 28 & 157 & 95 & 28 & 16 \\
\hline
\end{tabular}




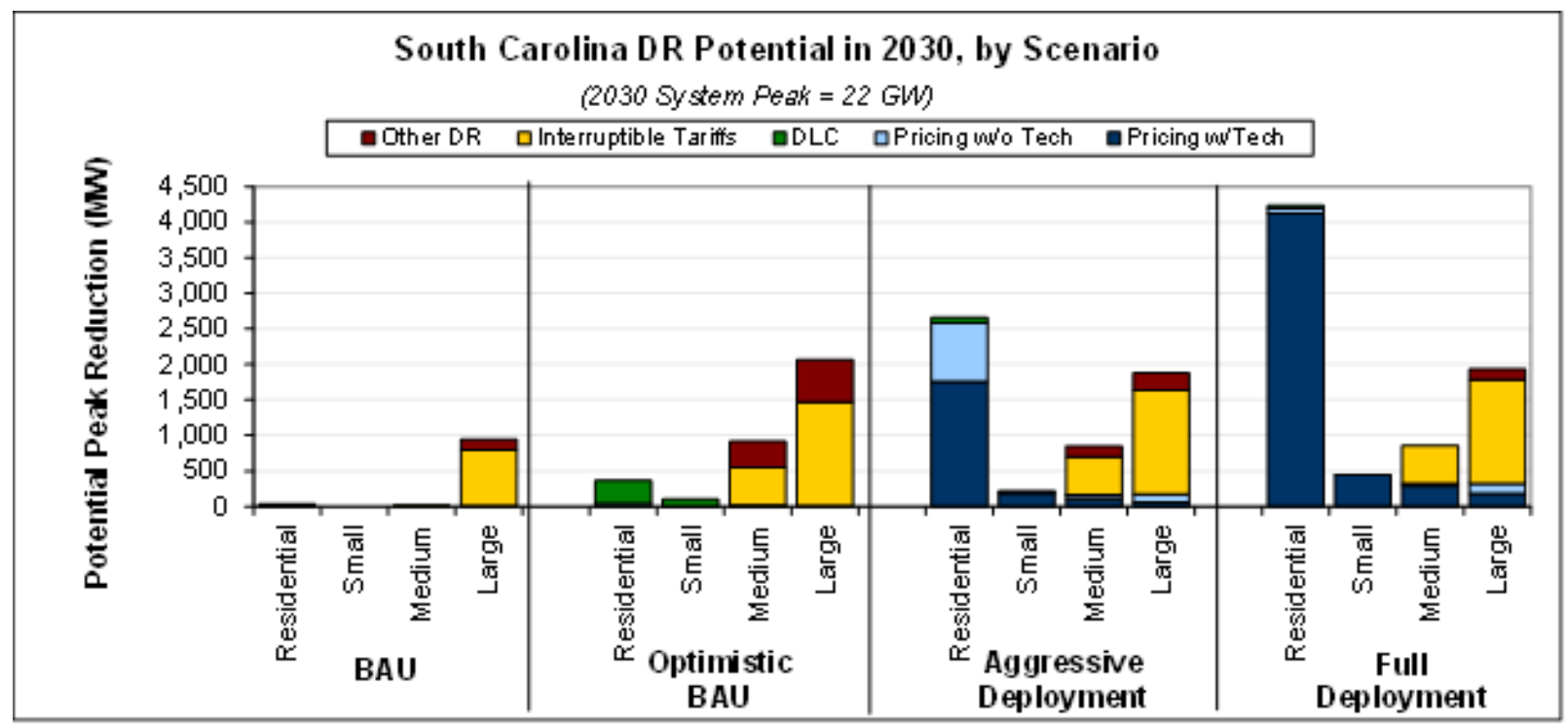

Total Potential Peak Reduction from Demand Response in South Carolina, 2030

\begin{tabular}{|c|c|c|c|c|c|c|c|c|c|c|}
\hline & $\begin{array}{l}\text { Residential } \\
\text { (MW) }\end{array}$ & $\begin{array}{l}\text { Residential } \\
\text { ( } \% \text { of } \\
\text { svstem) }\end{array}$ & $\begin{array}{l}\text { Small C\&l } \\
(\mathrm{MW})\end{array}$ & $\begin{array}{c}\text { Small C\&I } \\
\text { ( } \% \text { of } \\
\text { svstem) }\end{array}$ & $\begin{array}{l}\text { Med. C\&l } \\
(\mathrm{MW})\end{array}$ & $\begin{array}{l}\text { Med C\&I } \\
\text { ( } \% \text { of } \\
\text { svstem) }\end{array}$ & $\begin{array}{l}\text { Large C\&l } \\
\quad(\mathrm{MW})\end{array}$ & $\begin{array}{c}\text { Large C\&I } \\
\text { ( } \% \text { of } \\
\text { svstem) }\end{array}$ & $\begin{array}{l}\text { Total } \\
(\mathrm{MW})\end{array}$ & $\begin{array}{c}\text { Total } \\
\text { ( } \% \text { of } \\
\text { svstem) }\end{array}$ \\
\hline \multicolumn{11}{|l|}{ BAU } \\
\hline Pricing with Technology & 0 & $0.0 \%$ & 0 & $0.0 \%$ & 0 & $0.0 \%$ & 0 & $0.0 \%$ & 0 & $0.0 \%$ \\
\hline Pricing without Technology & 0 & $0.0 \%$ & 0 & $0.0 \%$ & 1 & $0.0 \%$ & 7 & $0.0 \%$ & 8 & $0.0 \%$ \\
\hline Automated/Direct Load Control & 37 & $0.2 \%$ & 0 & $0.0 \%$ & 0 & $0.0 \%$ & 0 & $0.0 \%$ & 37 & $0.2 \%$ \\
\hline Interruptible/Curtailable Tariffs & 0 & $0.0 \%$ & 0 & $0.0 \%$ & 15 & $0.1 \%$ & 784 & $4.1 \%$ & 799 & $4.2 \%$ \\
\hline Other DR Programs & 0 & $0.0 \%$ & 0 & $0.0 \%$ & 0 & $0.0 \%$ & 151 & $0.8 \%$ & 151 & $0.8 \%$ \\
\hline Total & 37 & $0.2 \%$ & 0 & $0.0 \%$ & 16 & $0.1 \%$ & 942 & $4.9 \%$ & 995 & $5.2 \%$ \\
\hline \multicolumn{11}{|l|}{ Optimistic BAU } \\
\hline Pricing with Technology & 0 & $0.0 \%$ & 0 & $0.0 \%$ & 0 & $0.0 \%$ & 0 & $0.0 \%$ & 0 & $0.0 \%$ \\
\hline Pricing without Technology & 44 & $0.2 \%$ & 0 & $0.0 \%$ & 4 & $0.0 \%$ & 7 & $0.0 \%$ & 55 & $0.3 \%$ \\
\hline Automated/Direct Load Control & 319 & $1.7 \%$ & 102 & $0.5 \%$ & 10 & $0.1 \%$ & 0 & $0.0 \%$ & 430 & $2.2 \%$ \\
\hline Interruptible/Curtailable Tariffs & 0 & $0.0 \%$ & 0 & $0.0 \%$ & 537 & $2.8 \%$ & 1,458 & $7.6 \%$ & 1,995 & $10.4 \%$ \\
\hline Other DR Programs & 0 & $0.0 \%$ & 0 & $0.0 \%$ & 368 & $1.9 \%$ & 601 & $3.1 \%$ & 970 & $5.1 \%$ \\
\hline Total & 363 & $1.9 \%$ & 102 & $0.5 \%$ & 918 & "4.8\% & 2,067 & $10.8 \%$ & $3,3,450$ & $18.0 \%$ \\
\hline \multicolumn{11}{|l|}{ Aggressive Deployment } \\
\hline Pricing with Technology & 1,763 & $9.2 \%$ & 191 & $1.0 \%$ & 100 & $0.5 \%$ & 62 & $0.3 \%$ & 2,116 & $11.0 \%$ \\
\hline Pricing without Technology & 813 & $4.2 \%$ & 3 & $0.0 \%$ & 60 & $0.3 \%$ & 112 & $0.6 \%$ & 988 & $5.2 \%$ \\
\hline Automated/Direct Load Control & 81 & $0.4 \%$ & 26 & $0.1 \%$ & 4 & $0.0 \%$ & 0 & $0.0 \%$ & 111 & $0.6 \%$ \\
\hline Interruptible/Curtailable Tariffs & 0 & $0.0 \%$ & 0 & $0.0 \%$ & 537 & $2.8 \%$ & 1,458 & $7.6 \%$ & 1,995 & $10.4 \%$ \\
\hline Other DR Programs & 0 & $0.0 \%$ & 0 & $0.0 \%$ & 150 & $0.8 \%$ & 245 & $1.3 \%$ & 395 & $2.1 \%$ \\
\hline Total & 2,657 & $13.9 \%$ & 221 & $1.2 \%$ & 851 & $4.4 \%$ & 1,877 & $9.8 \%$ & 5,605 & $29.3 \%$ \\
\hline \multicolumn{11}{|l|}{ Full Deployment } \\
\hline Pricing with Technology & 4,123 & $21.5 \%$ & 447 & $2.3 \%$ & 293 & $1.5 \%$ & 180 & $0.9 \%$ & 5,044 & $26.3 \%$ \\
\hline Pricing without Technology & 71 & $0.4 \%$ & 2 & $0.0 \%$ & 29 & $0.2 \%$ & 145 & $0.8 \%$ & 247 & $1.3 \%$ \\
\hline Automated/Direct Load Control & 37 & $0.2 \%$ & 0 & $0.0 \%$ & 0 & $0.0 \%$ & 0 & $0.0 \%$ & 37 & $0.2 \%$ \\
\hline Interruptible/Curtailable Tariffs & 0 & $0.0 \%$ & 0 & $0.0 \%$ & 537 & $2.8 \%$ & 1,458 & $7.6 \%$ & 1,995 & $10.4 \%$ \\
\hline Other DR Programs & 0 & $0.0 \%$ & 0 & $0.0 \%$ & 0 & $0.0 \%$ & 151 & $0.8 \%$ & 151 & $0.8 \%$ \\
\hline Total & 4,231 & $22.1 \%$ & 449 & $2.3 \%$ & 859 & $4.5 \%$ & 1,935 & $10.1 \%$ & 7,474 & $39.0 \%$ \\
\hline
\end{tabular}




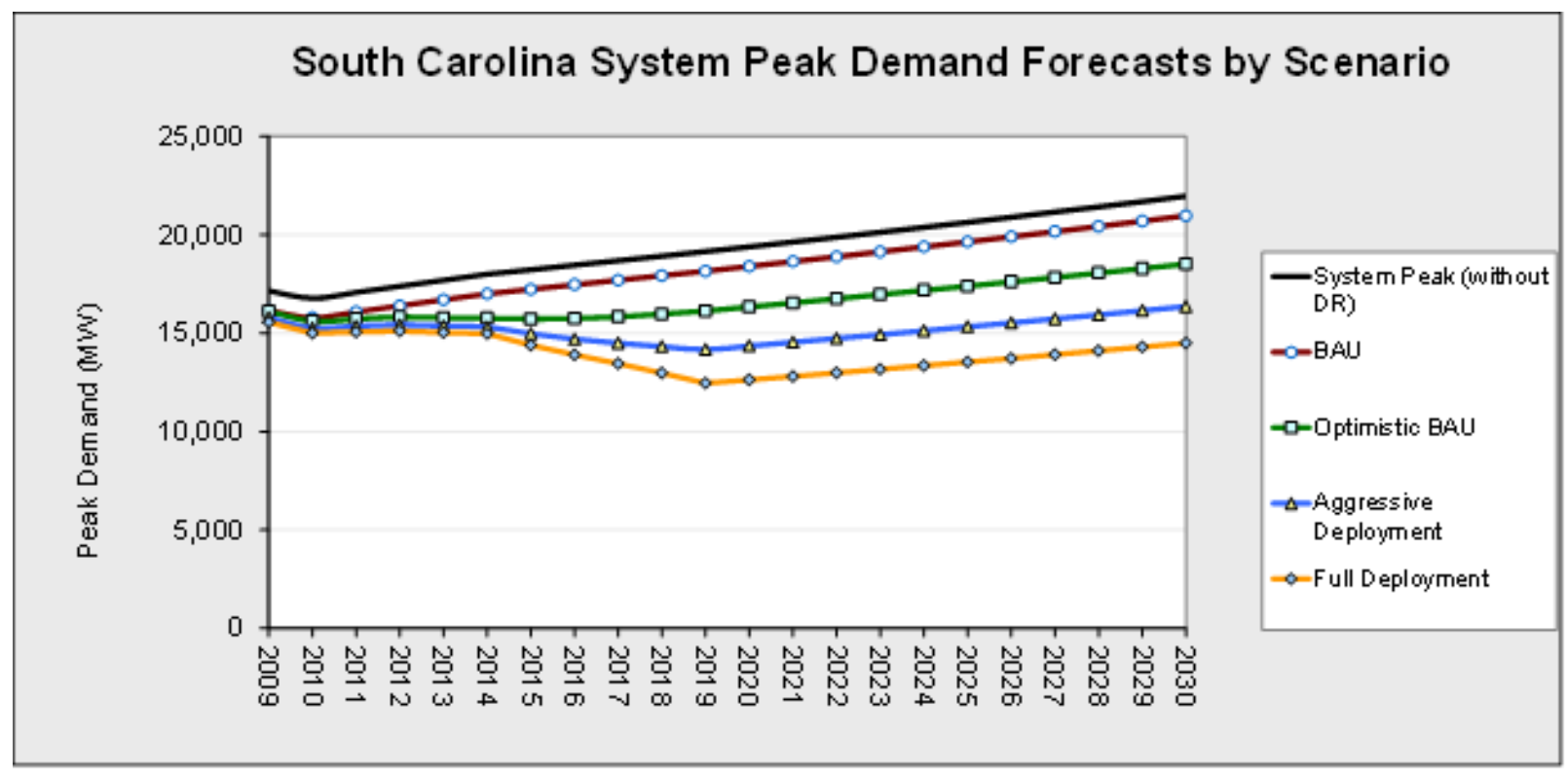

Summary of Monte Carlo Simulation of Potential Peak Load Reduction from Demand Response in South Carolina by Scenario, Pricing Program and Price Ratio (MW)

\begin{tabular}{|c|c|c|c|c|c|c|c|c|c|c|c|c|}
\hline & \multicolumn{3}{|c|}{2015} & \multicolumn{3}{|c|}{2020} & \multicolumn{3}{|c|}{2025} & \multicolumn{3}{|c|}{2030} \\
\hline & Mean & Lower & Upper & Mean & Lower & Upper & Mean & Lower & Upper & Mean & Lower & Upper \\
\hline & \multicolumn{12}{|c|}{ 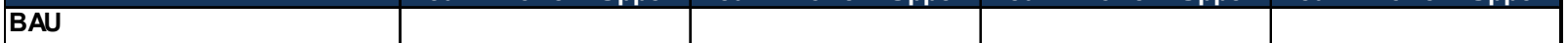 } \\
\hline \multicolumn{13}{|l|}{ Pricing with Technology } \\
\hline-5 & 0 & 0 & 0 & 0 & 0 & 0 & 0 & 0 & 0 & 0 & 0 & \\
\hline 10 & 0 & 0 & 0 & 0 & 0 & 0 & 0 & 0 & 0 & 0 & 0 & \\
\hline 15 & 0 & 0 & 0 & 0 & 0 & 0 & 0 & 0 & 0 & 0 & 0 & \\
\hline \multicolumn{13}{|l|}{ Pricing without Technology } \\
\hline 5 & 7 & 7 & 7 & 7 & 7 & 7 & 7 & 7 & 7 & 7 & 7 & \\
\hline 10 & 7 & 7 & 7 & 7 & 7 & 7 & 7 & 7 & 7 & 7 & 7 & \\
\hline 15 & 7 & 7 & 7 & 7 & 7 & 7 & 7 & 7 & 7 & 7 & 7 & \\
\hline \multicolumn{13}{|l|}{\begin{tabular}{|l|} 
Optimistic BAU \\
$\quad$ Pricing with Technology
\end{tabular}} \\
\hline 5 & 0 & 0 & 0 & 0 & 0 & 0 & 0 & 0 & 0 & 0 & 0 & \\
\hline 10 & 0 & 0 & 0 & 0 & 0 & 0 & 0 & 0 & 0 & 0 & 0 & \\
\hline 15 & 0 & 0 & 0 & 0 & 0 & 0 & 0 & 0 & 0 & 0 & 0 & \\
\hline \multicolumn{13}{|l|}{ Pricing without Technology } \\
\hline 5 & 29 & 14 & 44 & 40 & 17 & 63 & 42 & 18 & 66 & 44 & 18 & \\
\hline 10 & 41 & 18 & 65 & 60 & 22 & 97 & 62 & 23 & 101 & 65 & 23 & 10 \\
\hline 15 & 46 & 17 & 75 & 68 & 22 & 114 & 71 & 22 & 120 & 74 & 23 & 12 \\
\hline \multicolumn{13}{|l|}{\begin{tabular}{|l|} 
Aggressive Deployment \\
Pricing with Technology
\end{tabular}} \\
\hline 5 & 528 & 164 & 892 & 1461 & 454 & 2468 & 1530 & 475 & 2584 & 1602 & 498 & 270 \\
\hline 10 & 800 & 242 & 1359 & 2213 & 668 & 3757 & 2317 & 700 & 3934 & 2426 & 733 & 411 \\
\hline 15 & 935 & 226 & 1643 & 2584 & 626 & 4543 & 2706 & 655 & 4756 & 2833 & 686 & 498 \\
\hline \multicolumn{13}{|l|}{ Pricing without Technology } \\
\hline 5 & 255 & 79 & 430 & 699 & 218 & 1180 & 732 & 228 & 1236 & 767 & 239 & 129 \\
\hline 8 & 387 & 117 & 656 & 1061 & 321 & 1800 & 1111 & 337 & 1886 & 1165 & 353 & 197 \\
\hline 15 & 452 & 110 & 794 & 1241 & 302 & 2180 & 1300 & 316 & 2284 & 1362 & 331 & 239 \\
\hline \multicolumn{13}{|l|}{\begin{tabular}{|l|} 
Full Deployment \\
Pricing with Technology
\end{tabular}} \\
\hline 5 & 1339 & 420 & 2258 & 3696 & 1159 & 6234 & 3872 & 1214 & 6530 & 4055 & 1271 & 683 \\
\hline 10 & 1930 & 449 & 3410 & 5327 & 1240 & 9414 & 5580 & 1299 & 9860 & 5844 & 1361 & 1032 \\
\hline 15 & 2297 & 597 & 3996 & 6340 & 1648 & 11032 & 6641 & 1726 & 11555 & 6956 & 1808 & 1210 \\
\hline \multicolumn{13}{|l|}{ Pricing without Technology } \\
\hline 5 & 77 & 25 & 130 & 207 & 66 & 348 & 219 & 70 & 369 & 232 & 74 & \\
\hline 10 & 112 & 27 & 198 & 300 & 72 & 528 & 318 & 76 & 560 & 337 & 80 & \\
\hline 15 & 134 & 36 & 232 & 358 & 95 & 621 & 380 & 101 & 658 & 402 & 107 & \\
\hline
\end{tabular}




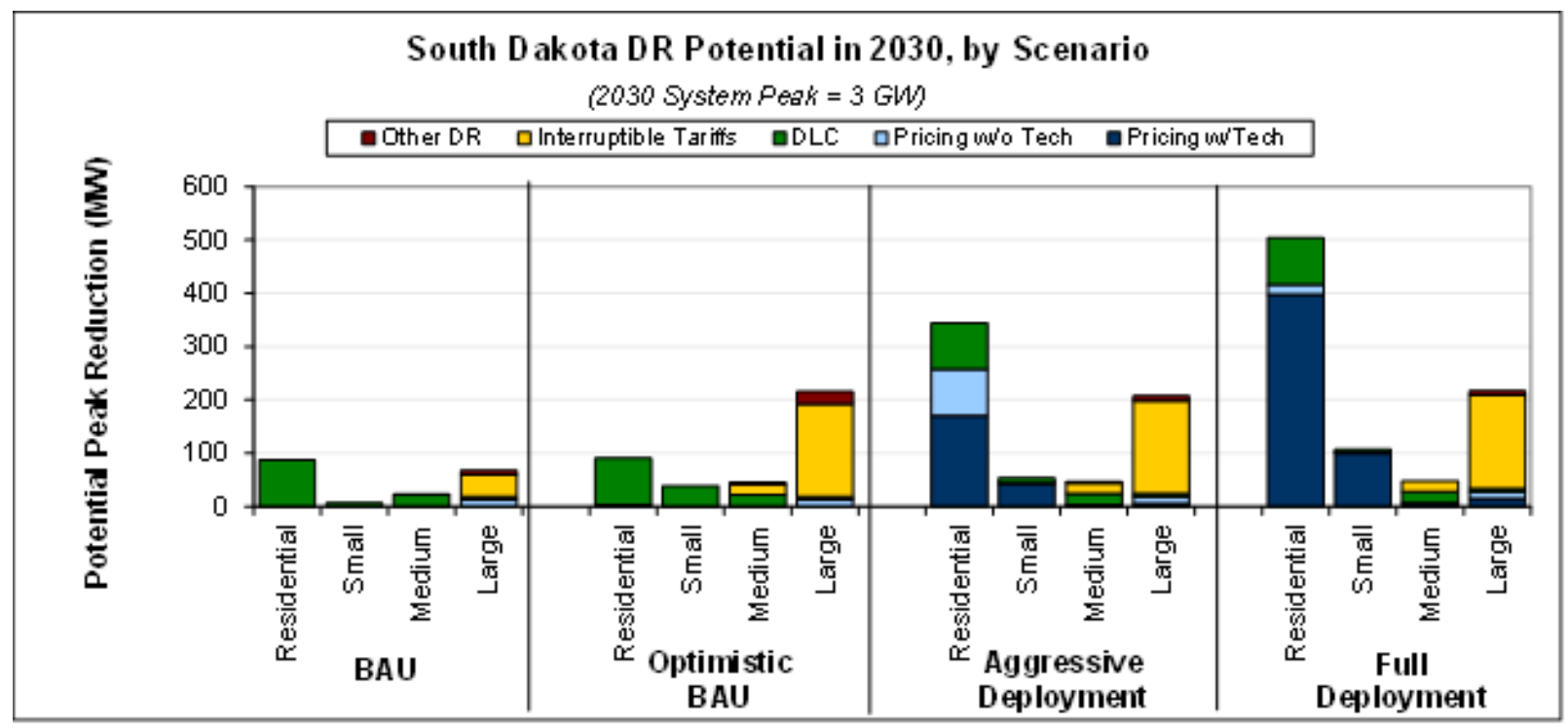

Total Potential Peak Reduction from Demand Response in South Dakota, 2030

\begin{tabular}{|c|c|c|c|c|c|c|c|c|c|c|}
\hline & $\begin{array}{l}\text { Residential } \\
\text { (MW) }\end{array}$ & $\begin{array}{l}\text { Residential } \\
\text { ( } \% \text { of } \\
\text { svstem) }\end{array}$ & $\begin{array}{c}\text { Small C\&I } \\
(\mathrm{MW})\end{array}$ & $\begin{array}{l}\text { Small C\&I } \\
\text { (\% of } \\
\text { svstem) }\end{array}$ & $\begin{array}{l}\text { Med. C\&I } \\
(\mathrm{MW})\end{array}$ & $\begin{array}{l}\text { Med C\&I } \\
\text { ( } \% \text { of } \\
\text { svstem) }\end{array}$ & $\begin{array}{l}\text { Large C\&I } \\
(\mathrm{MW})\end{array}$ & $\begin{array}{l}\text { Large C\&I } \\
\text { ( } \% \text { of } \\
\text { svstem) }\end{array}$ & $\begin{array}{l}\text { Total } \\
\text { (MW) }\end{array}$ & $\begin{array}{c}\text { Total } \\
\text { ( } \% \text { of } \\
\text { svstem) }\end{array}$ \\
\hline \multicolumn{11}{|l|}{ BAU } \\
\hline Pricing with Technology & 0 & $0.0 \%$ & 0 & $0.0 \%$ & 0 & $0.0 \%$ & 0 & $0.0 \%$ & 0 & $0.0 \%$ \\
\hline Pricing without Technology & 0 & $0.0 \%$ & 0 & $0.0 \%$ & 0 & $0.0 \%$ & 13 & $0.5 \%$ & 13 & $0.5 \%$ \\
\hline Automated/Direct Load Control & 87 & $3.3 \%$ & 6 & $0.2 \%$ & 22 & $0.8 \%$ & 6 & $0.2 \%$ & 121 & $4.6 \%$ \\
\hline Interruptible/Curtailable Tariffs & 0 & $0.0 \%$ & 0 & $0.0 \%$ & 1 & $0.0 \%$ & 41 & $1.5 \%$ & 42 & $1.6 \%$ \\
\hline Other DR Programs & 0 & $0.0 \%$ & 0 & $0.0 \%$ & 0 & $0.0 \%$ & 8 & $0.3 \%$ & 8 & $0.3 \%$ \\
\hline Total & 87 & $3.3 \%$ & 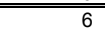 & $0.2 \%$ & 23 & $0.9 \%$ & 67 & $2.5 \%$ & 184 & $7.0 \%$ \\
\hline \multicolumn{11}{|l|}{ Optimistic BAU } \\
\hline Pricing with Technology & 0 & $0.0 \%$ & 0 & $0.0 \%$ & 0 & $0.0 \%$ & 0 & $0.0 \%$ & 0 & $0.0 \%$ \\
\hline Pricing without Technology & 3 & $0.1 \%$ & 0 & $0.0 \%$ & 0 & $0.0 \%$ & 13 & $0.5 \%$ & 17 & $0.6 \%$ \\
\hline Automated/Direct Load Control & 87 & $3.3 \%$ & 39 & $1.5 \%$ & 22 & $0.8 \%$ & 6 & $0.2 \%$ & 153 & $5.8 \%$ \\
\hline Interruptible/Curtailable Tariffs & 0 & $0.0 \%$ & 0 & $0.0 \%$ & 20 & $0.8 \%$ & 174 & $6.6 \%$ & 194 & $7.4 \%$ \\
\hline Other DR Programs & 0 & $0.0 \%$ & 0 & $0.0 \%$ & 3 & $0.1 \%$ & 23 & $0.9 \%$ & 26 & $1.0 \%$ \\
\hline Total & $\overline{991}$ & $3.4 \%$ & 39 & $1.5 \%$ & $\overline{455}$ & $1.7 \%$ & 215 & $8.2 \%$ & 390 & $14.8 \%$ \\
\hline \multicolumn{11}{|l|}{ Aggressive Deployment } \\
\hline Pricing with Technology & 170 & $6.4 \%$ & 43 & $1.6 \%$ & 2 & $0.1 \%$ & 5 & $0.2 \%$ & 220 & $8.3 \%$ \\
\hline Pricing without Technology & 87 & $3.3 \%$ & 1 & $0.0 \%$ & 1 & $0.1 \%$ & 13 & $0.5 \%$ & 102 & $3.9 \%$ \\
\hline Automated/Direct Load Control & 87 & $3.3 \%$ & 10 & $0.4 \%$ & 22 & $0.8 \%$ & 6 & $0.2 \%$ & 124 & $4.7 \%$ \\
\hline Interruptible/Curtailable Tariffs & 0 & $0.0 \%$ & 0 & $0.0 \%$ & 20 & $0.8 \%$ & 174 & $6.6 \%$ & 194 & $7.4 \%$ \\
\hline Other DR Programs & 0 & $0.0 \%$ & 0 & $0.0 \%$ & 1 & $0.1 \%$ & 9 & $0.3 \%$ & 11 & $0.4 \%$ \\
\hline Total & 345 & $13.1 \%$ & 54 & $2.0 \%$ & 46 & $1.7 \%$ & 207 & $7.9 \%$ & 651 & $24.7 \%$ \\
\hline \multicolumn{11}{|l|}{ Full Deployment } \\
\hline Pricing with Technology & 398 & $15.1 \%$ & 101 & $3.8 \%$ & 5 & $0.2 \%$ & 15 & $0.6 \%$ & 519 & $19.7 \%$ \\
\hline Pricing without Technology & 19 & $0.7 \%$ & 1 & $0.0 \%$ & 1 & $0.0 \%$ & 13 & $0.5 \%$ & 33 & $1.3 \%$ \\
\hline Automated/Direct Load Control & 87 & $3.3 \%$ & 6 & $0.2 \%$ & 22 & $0.8 \%$ & 6 & $0.2 \%$ & 121 & $4.6 \%$ \\
\hline Interruptible/Curtailable Tariffs & 0 & $0.0 \%$ & 0 & $0.0 \%$ & 20 & $0.8 \%$ & 174 & $6.6 \%$ & 194 & $7.4 \%$ \\
\hline Other DR Programs & 0 & $0.0 \%$ & 0 & $0.0 \%$ & 0 & $0.0 \%$ & 8 & $0.3 \%$ & 8 & $0.3 \%$ \\
\hline Total & 504 & $19.1 \%$ & 107 & $4.1 \%$ & 48 & $1.8 \%$ & 216 & $8.2 \%$ & 875 & $33.2 \%$ \\
\hline
\end{tabular}




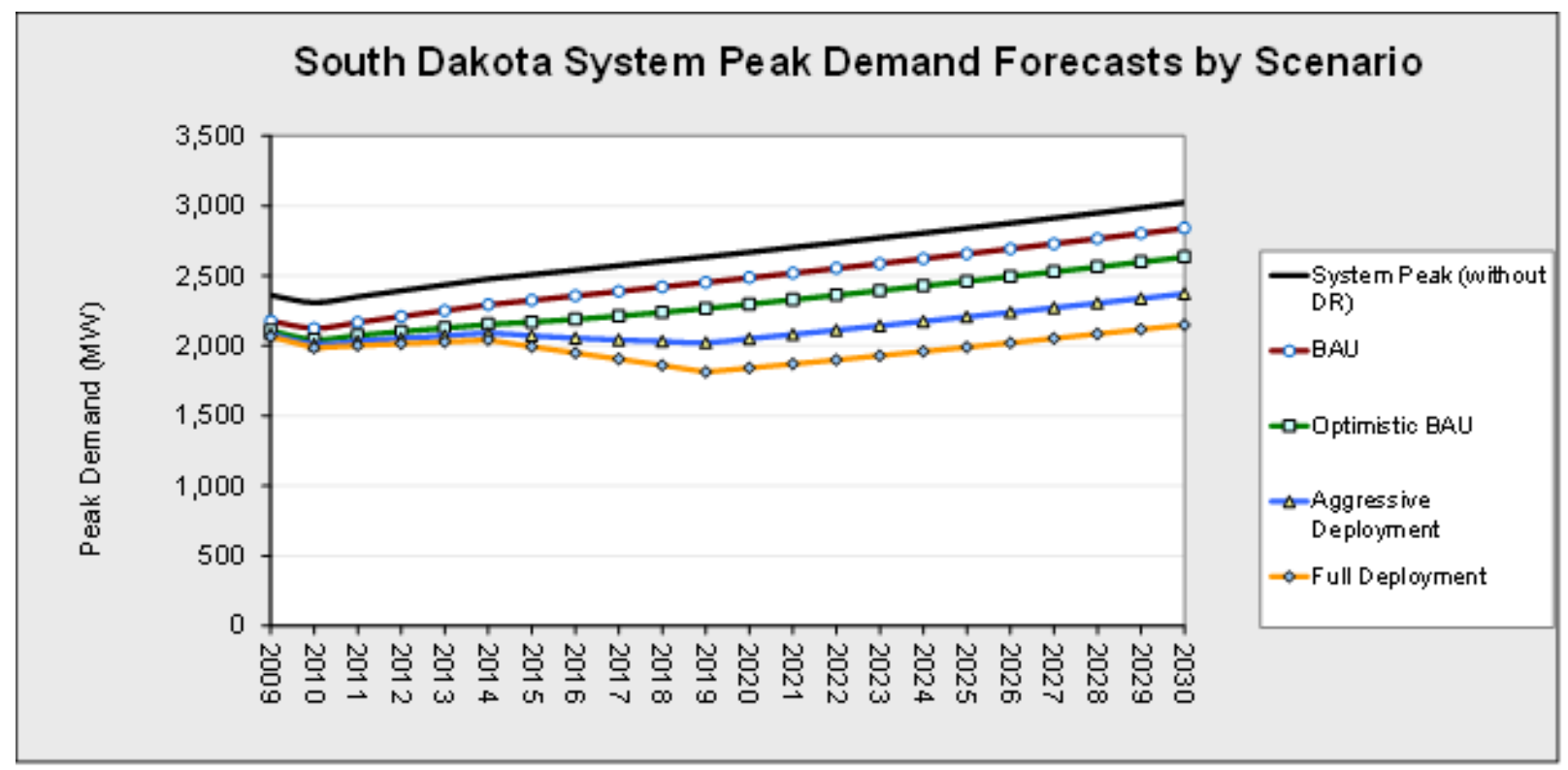

Summary of Monte Carlo Simulation of Potential Peak Load Reduction from Demand Response in South Dakota by Scenario, Pricing Program and Price Ratio (MW)

\begin{tabular}{|c|c|c|c|c|c|c|c|c|c|c|c|c|}
\hline & \multicolumn{3}{|c|}{2015} & \multicolumn{3}{|c|}{2020} & \multicolumn{3}{|c|}{2025} & \multicolumn{3}{|c|}{2030} \\
\hline & Mean & Lower & Upper & Mean & Lower & Upper & Mean & Lower & Upper & Mean & Lower & Upper \\
\hline & \multicolumn{12}{|c|}{ BAU } \\
\hline \multicolumn{13}{|l|}{ Pricing with Technology } \\
\hline 5 & 0 & 0 & 0 & 0 & 0 & 0 & 0 & 0 & 0 & 0 & 0 & \\
\hline 10 & 0 & 0 & 0 & 0 & 0 & 0 & 0 & 0 & 0 & 0 & 0 & \\
\hline 15 & 0 & 0 & 0 & 0 & 0 & 0 & 0 & 0 & 0 & 0 & 0 & \\
\hline \multicolumn{13}{|l|}{ Pricing without Technology } \\
\hline 5 & 12 & 12 & 12 & 12 & 12 & 12 & 12 & 12 & 12 & 12 & 12 & \\
\hline 10 & 12 & 12 & 12 & 12 & 12 & 12 & 12 & 12 & 12 & 12 & 12 & 12 \\
\hline 15 & 12 & 12 & 12 & 12 & 12 & 12 & 12 & 12 & 12 & 12 & 12 & 12 \\
\hline \multirow{2}{*}{\multicolumn{13}{|c|}{\begin{tabular}{|l|} 
Optimistic BAU \\
$\quad$ Pricing with Technology
\end{tabular}}} \\
\hline & & & & & & & & & & & & \\
\hline 10 & 0 & 0 & 0 & 0 & 0 & 0 & 0 & 0 & 0 & 0 & 0 & \\
\hline 15 & 0 & 0 & 0 & 0 & 0 & 0 & 0 & 0 & 0 & 0 & 0 & \\
\hline \multicolumn{13}{|l|}{ Pricing without Technology } \\
\hline 5 & 15 & 14 & 17 & 16 & 14 & 17 & 16 & 14 & 17 & 16 & 14 & 17 \\
\hline 10 & 16 & 14 & 19 & 17 & 14 & 19 & 17 & 14 & 19 & 17 & 14 & 20 \\
\hline 15 & 17 & 14 & 20 & 17 & 14 & 20 & 17 & 14 & 21 & 18 & 14 & 21 \\
\hline \multicolumn{13}{|l|}{$\begin{array}{l}\text { Aggressive Deployment } \\
\text { Pricing with Technology }\end{array}$} \\
\hline 5 & 63 & 19 & 108 & 162 & 48 & 277 & 167 & 49 & 286 & 173 & 51 & \\
\hline 10 & 94 & 26 & 161 & 240 & 66 & 414 & 248 & 68 & 427 & 256 & 70 & 441 \\
\hline 15 & 106 & 31 & 181 & 272 & 79 & 466 & 281 & 81 & 480 & 290 & 84 & 49 \\
\hline \multicolumn{13}{|l|}{ Pricing without Technology } \\
\hline 5 & 38 & 20 & 56 & 78 & 32 & 125 & 80 & 32 & 129 & 83 & 33 & 13 \\
\hline 8 & 51 & 23 & 78 & 113 & 37 & 188 & 116 & 38 & 194 & 119 & 38 & 20 \\
\hline 15 & 56 & 25 & 87 & 127 & 42 & 213 & 131 & 42 & 220 & 135 & 43 & 22 \\
\hline \multicolumn{13}{|l|}{$\begin{array}{l}\text { Full Deployment } \\
\text { Pricing with Technology }\end{array}$} \\
\hline 5 & 147 & 43 & 252 & 378 & 109 & 647 & 390 & 113 & 667 & 402 & 116 & 68 \\
\hline 10 & 215 & 60 & 369 & 551 & 154 & 948 & 569 & 159 & 978 & 587 & 164 & 1009 \\
\hline 15 & 260 & 66 & 455 & 669 & 170 & 1168 & 690 & 175 & 1205 & 712 & 181 & 124 \\
\hline \multicolumn{13}{|l|}{ Pricing without Technology } \\
\hline 5 & 19 & 15 & 22 & 28 & 15 & 41 & 29 & 15 & 43 & 30 & 15 & 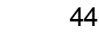 \\
\hline 10 & 21 & 15 & 27 & 39 & 16 & 63 & 41 & 16 & 65 & 42 & 16 & 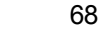 \\
\hline 15 & 23 & 16 & 31 & 48 & 16 & 79 & 49 & 16 & 82 & 51 & 16 & 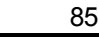 \\
\hline
\end{tabular}




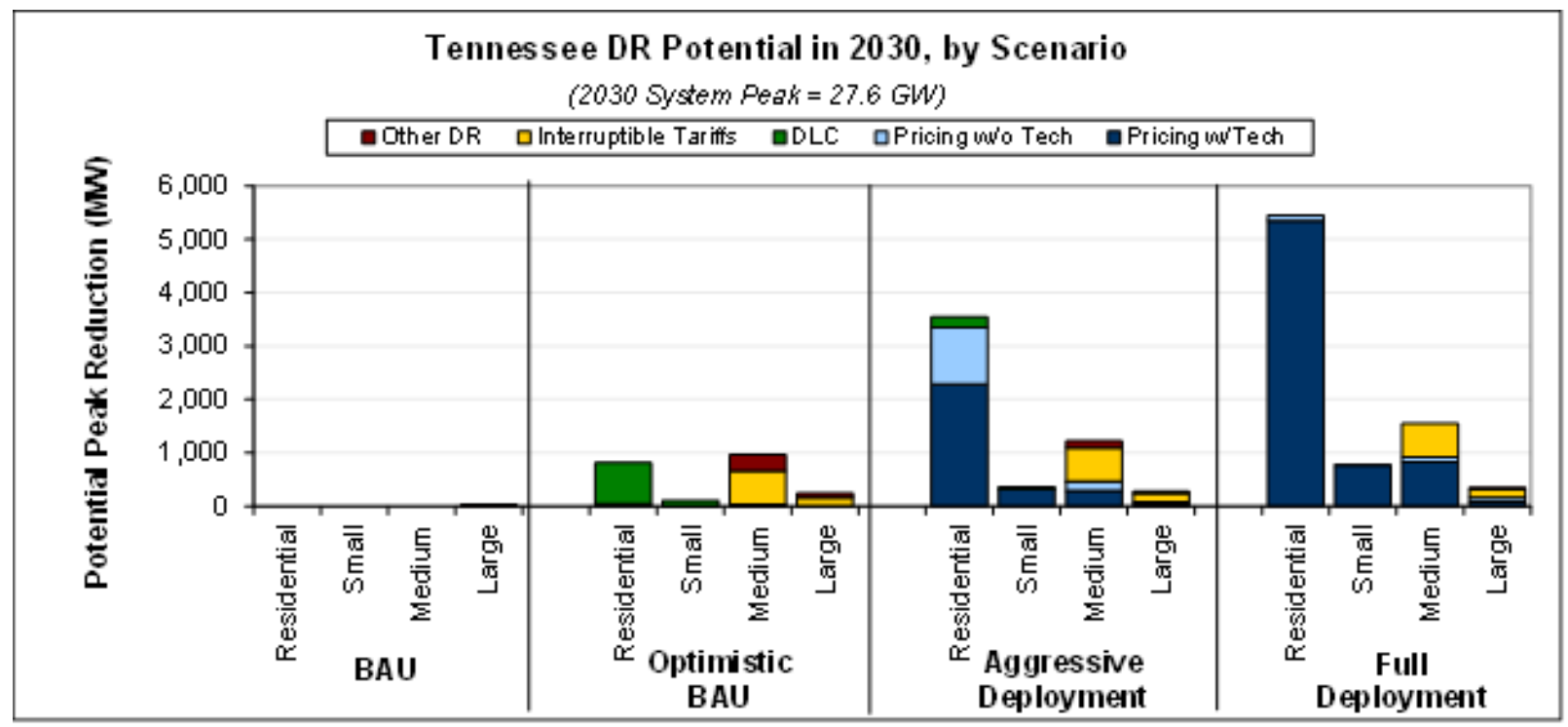

Total Potential Peak Reduction from Demand Response in Tennessee, 2030

\begin{tabular}{|c|c|c|c|c|c|c|c|c|c|c|}
\hline & $\begin{array}{l}\text { Residential } \\
\quad(\mathrm{MW})\end{array}$ & $\begin{array}{l}\text { Residential } \\
\text { ( } \% \text { of } \\
\text { svstem) }\end{array}$ & $\begin{array}{l}\text { Small C\&I } \\
(\mathrm{MW})\end{array}$ & $\begin{array}{c}\text { Small C\&I } \\
\text { (\% of } \\
\text { svstem) }\end{array}$ & $\begin{array}{l}\text { Med. C\&I } \\
(\mathrm{MW})\end{array}$ & $\begin{array}{l}\text { Med C\&I } \\
\text { ( } \% \text { of } \\
\text { svstem) }\end{array}$ & $\begin{array}{l}\text { Large C\&I } \\
\quad(\mathrm{MW})\end{array}$ & $\begin{array}{l}\text { Large C\&I } \\
\text { ( } \% \text { of } \\
\text { svstem) }\end{array}$ & $\begin{array}{l}\text { Total } \\
(\mathrm{MW})\end{array}$ & $\begin{array}{c}\text { Total } \\
\text { ( } \% \text { of } \\
\text { svstem) }\end{array}$ \\
\hline \multicolumn{11}{|l|}{ BAU } \\
\hline Pricing with Technology & 0 & $0.0 \%$ & 0 & $0.0 \%$ & 0 & $0.0 \%$ & 0 & $0.0 \%$ & 0 & $0.0 \%$ \\
\hline Pricing without Technology & 0 & $0.0 \%$ & 0 & $0.0 \%$ & 0 & $0.0 \%$ & 0 & $0.0 \%$ & 0 & $0.0 \%$ \\
\hline Automated/Direct Load Control & 0 & $0.0 \%$ & 0 & $0.0 \%$ & 0 & $0.0 \%$ & 0 & $0.0 \%$ & 0 & $0.0 \%$ \\
\hline Interruptible/Curtailable Tariffs & 0 & $0.0 \%$ & 0 & $0.0 \%$ & 0 & $0.0 \%$ & 0 & $0.0 \%$ & 0 & $0.0 \%$ \\
\hline Other DR Programs & 0 & $0.0 \%$ & 0 & $0.0 \%$ & 0 & $0.0 \%$ & 29 & $0.1 \%$ & 29 & $0.1 \%$ \\
\hline Total & 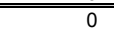 & $0.0 \%$ & 0 & $0.0 \%$ & 0 & $0.0 \%$ & 29 & $0.1 \%$ & 29 & $0.1 \%$ \\
\hline \multicolumn{11}{|l|}{ Optimistic BAU } \\
\hline Pricing with Technology & 0 & $0.0 \%$ & 0 & $0.0 \%$ & 0 & $0.0 \%$ & 0 & $0.0 \%$ & 0 & $0.0 \%$ \\
\hline Pricing without Technology & 45 & $0.2 \%$ & 0 & $0.0 \%$ & 8 & $0.0 \%$ & 2 & $0.0 \%$ & 55 & $0.2 \%$ \\
\hline Automated/Direct Load Control & 764 & $3.2 \%$ & 110 & $0.5 \%$ & 24 & $0.1 \%$ & 0 & $0.0 \%$ & 898 & $3.7 \%$ \\
\hline Interruptible/Curtailable Tariffs & 0 & $0.0 \%$ & 0 & $0.0 \%$ & 629 & $2.6 \%$ & 159 & $0.7 \%$ & 788 & $3.3 \%$ \\
\hline Other DR Programs & 0 & $0.0 \%$ & 0 & $0.0 \%$ & 307 & $1.3 \%$ & 82 & $0.3 \%$ & 389 & $1.6 \%$ \\
\hline Total & 809 & $3.4 \%$ & 1110 & $0.5 \%$ & 969 & $4.0 \%$ & 242 & $1.0 \%$ & 2,130 & $8.9 \%$ \\
\hline \multicolumn{11}{|l|}{ Aggressive Deployment } \\
\hline Pricing with Technology & 2,282 & $9.5 \%$ & 327 & $1.4 \%$ & 285 & $1.2 \%$ & 30 & $0.1 \%$ & 2,924 & $12.2 \%$ \\
\hline Pricing without Technology & 1,068 & $4.4 \%$ & 6 & $0.0 \%$ & 170 & $0.7 \%$ & 54 & $0.2 \%$ & 1,298 & $5.4 \%$ \\
\hline Automated/Direct Load Control & 194 & $0.8 \%$ & 28 & $0.1 \%$ & 10 & $0.0 \%$ & 0 & $0.0 \%$ & 231 & $1.0 \%$ \\
\hline Interruptible/Curtailable Tariffs & 0 & $0.0 \%$ & 0 & $0.0 \%$ & 629 & $2.6 \%$ & 159 & $0.7 \%$ & 788 & $3.3 \%$ \\
\hline Other DR Programs & 0 & $0.0 \%$ & 0 & $0.0 \%$ & 125 & $0.5 \%$ & 33 & $0.1 \%$ & 158 & $0.7 \%$ \\
\hline Total & 3,543 & $14.7 \%$ & 361 & $1.5 \%$ & 1,220 & $5.1 \%$ & 276 & $1.1 \%$ & 5,399 & $22.5 \%$ \\
\hline \multicolumn{11}{|l|}{ Full Deployment } \\
\hline Pricing with Technology & 5,338 & $22.2 \%$ & 765 & $3.2 \%$ & 834 & $3.5 \%$ & 87 & $0.4 \%$ & 7,024 & $29.2 \%$ \\
\hline Pricing without Technology & 112 & $0.5 \%$ & 3 & $0.0 \%$ & 83 & $0.3 \%$ & 70 & $0.3 \%$ & 268 & $1.1 \%$ \\
\hline Automated/Direct Load Control & 0 & $0.0 \%$ & 0 & $0.0 \%$ & 0 & $0.0 \%$ & 0 & $0.0 \%$ & 0 & $0.0 \%$ \\
\hline Interruptible/Curtailable Tariffs & 0 & $0.0 \%$ & 0 & $0.0 \%$ & 629 & $2.6 \%$ & 159 & $0.7 \%$ & 788 & $3.3 \%$ \\
\hline Other DR Programs & 0 & $0.0 \%$ & 0 & $0.0 \%$ & 0 & $0.0 \%$ & 29 & $0.1 \%$ & 29 & $0.1 \%$ \\
\hline Total & 5,450 & $22.7 \%$ & 768 & $3.2 \%$ & 1,546 & $6.4 \%$ & 345 & $1.4 \%$ & 8,109 & $33.7 \%$ \\
\hline
\end{tabular}




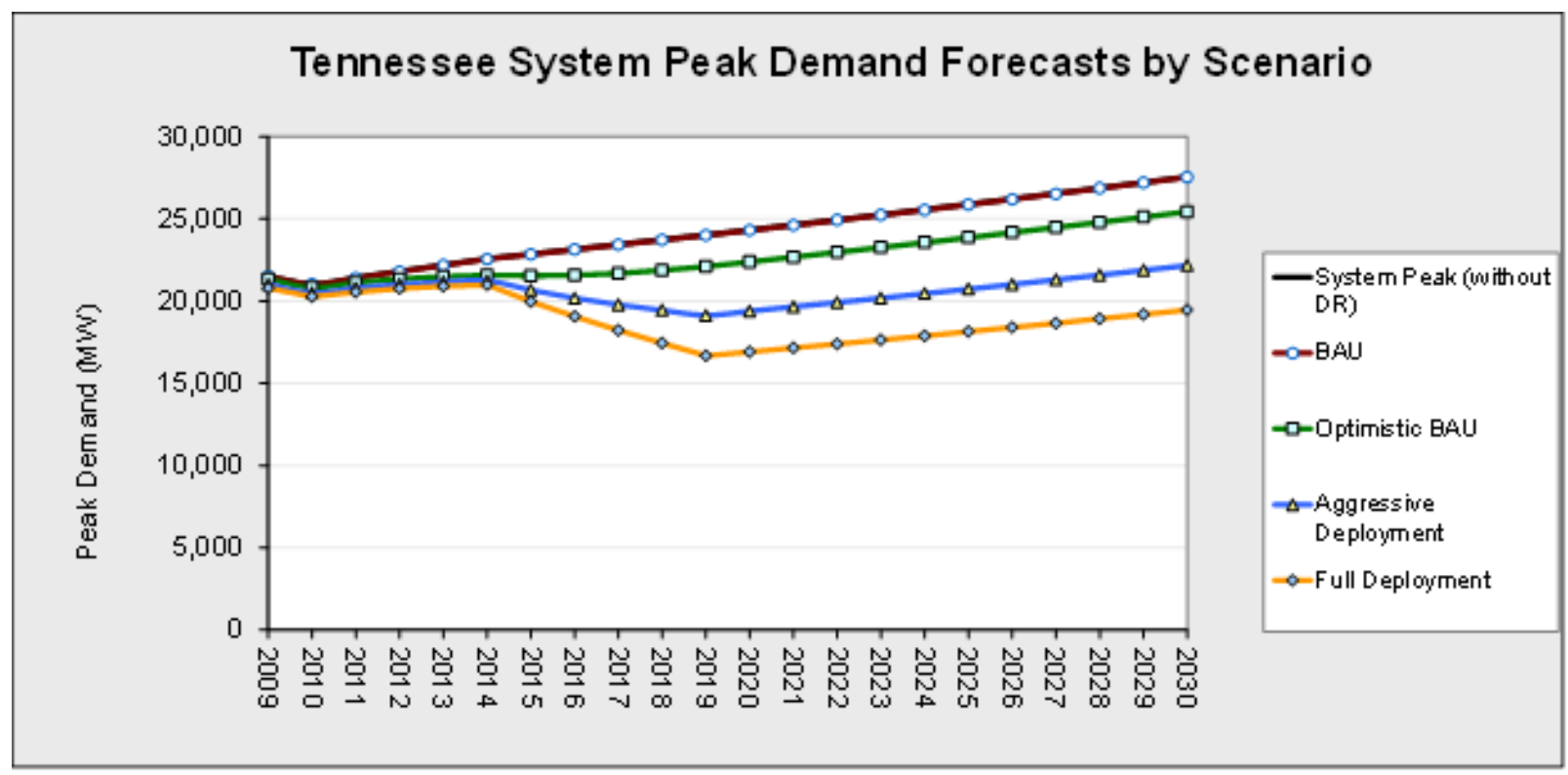

Summary of Monte Carlo Simulation of Potential Peak Load Reduction from Demand Response in Tennessee by Scenario, Pricing Program and Price Ratio (MW)

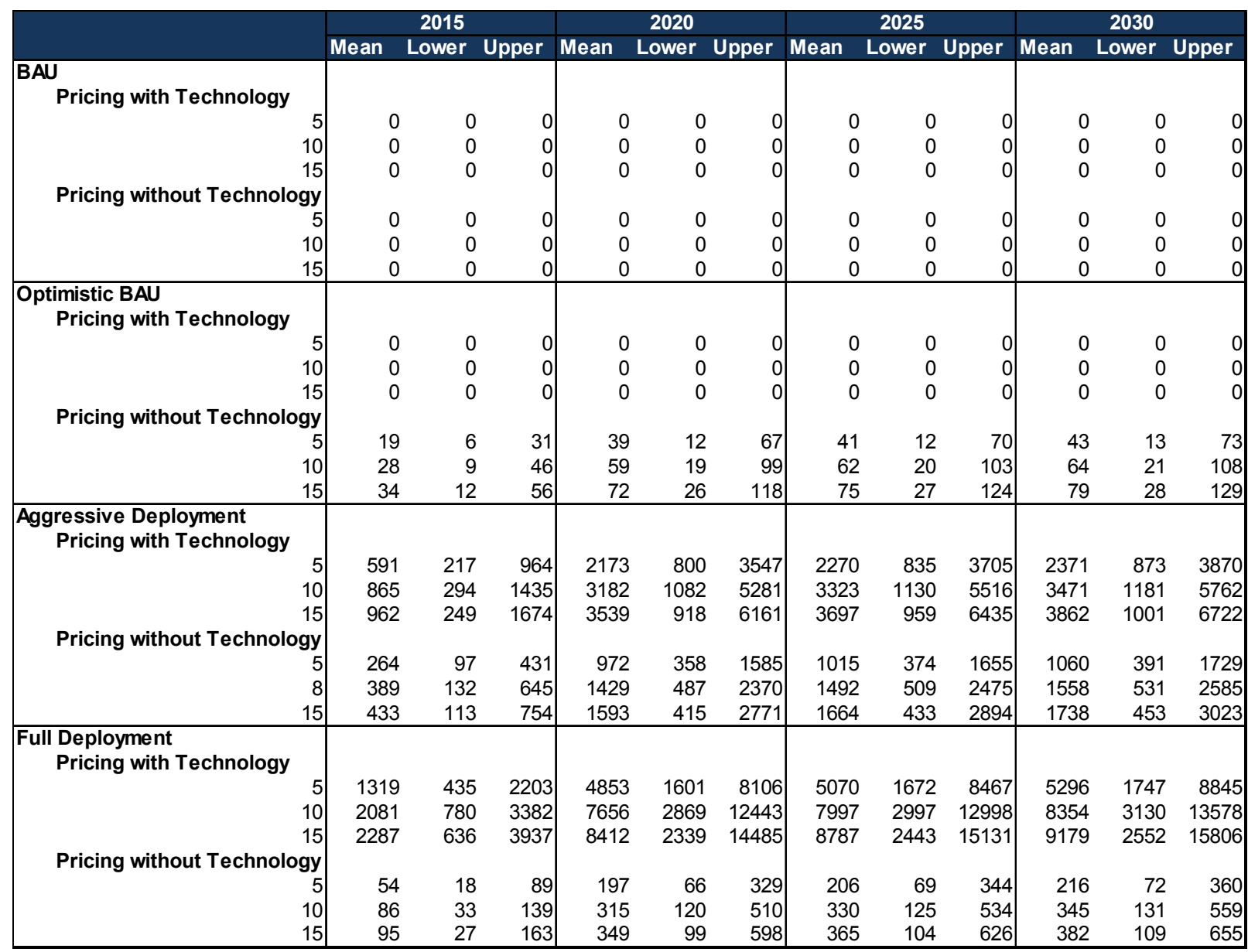




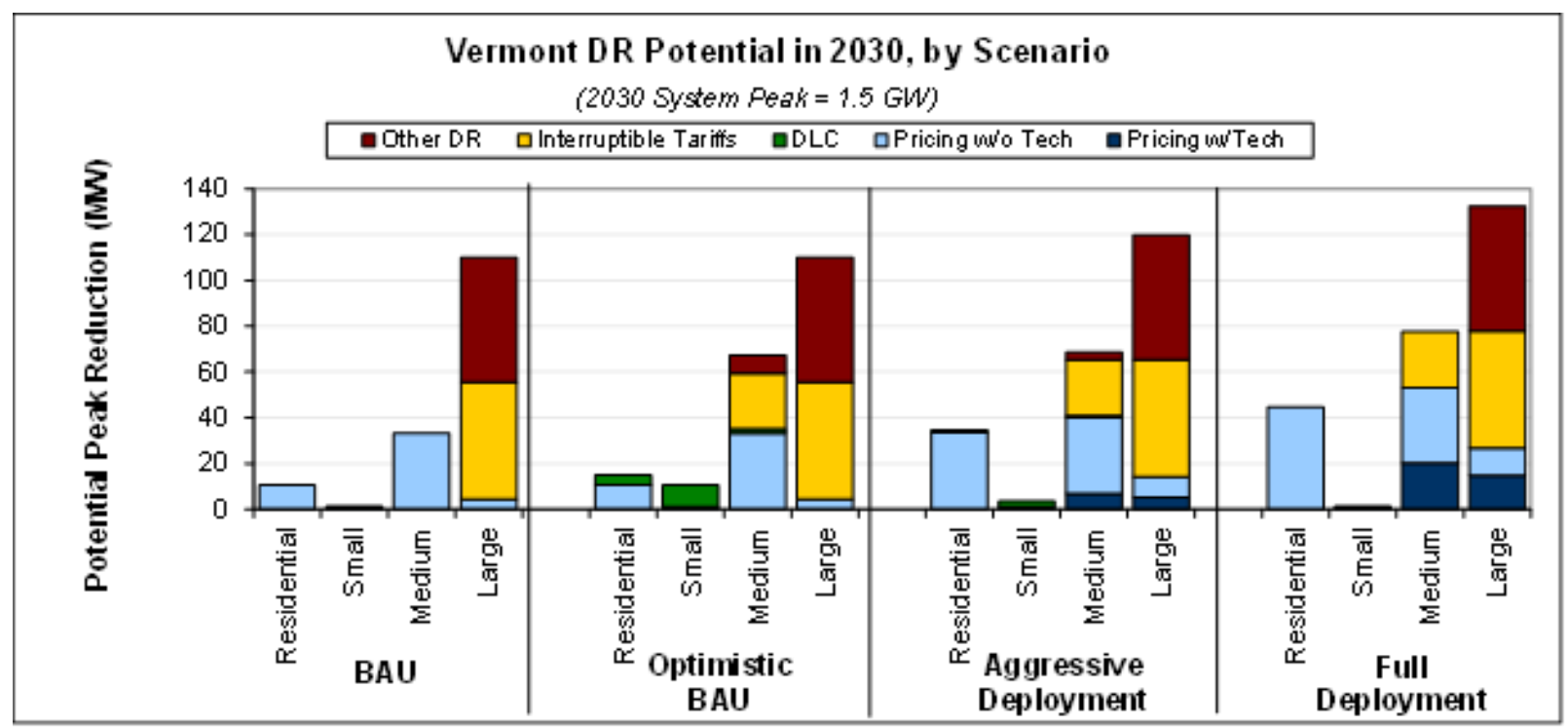

Total Potential Peak Reduction from Demand Response in Vermont, 2030

\begin{tabular}{|c|c|c|c|c|c|c|c|c|c|c|}
\hline & $\begin{array}{l}\text { Residential } \\
\quad(\mathrm{MW})\end{array}$ & $\begin{array}{l}\text { Residential } \\
\text { ( } \% \text { of } \\
\text { svstem) }\end{array}$ & $\begin{array}{l}\text { Small C\&I } \\
(\mathrm{MW})\end{array}$ & $\begin{array}{c}\text { Small C\&I } \\
\text { (\% of } \\
\text { svstem) }\end{array}$ & $\begin{array}{l}\text { Med. C\&l } \\
(\mathrm{MW})\end{array}$ & $\begin{array}{l}\text { Med C\&I } \\
\text { ( } \% \text { of } \\
\text { svstem) }\end{array}$ & $\begin{array}{l}\text { Large C\&I } \\
\quad(\mathrm{MW})\end{array}$ & $\begin{array}{l}\text { Large C\&I } \\
\text { ( } \% \text { of } \\
\text { svstem) }\end{array}$ & $\begin{array}{l}\text { Total } \\
(\mathrm{MW})\end{array}$ & $\begin{array}{c}\text { Total } \\
\text { ( } \% \text { of } \\
\text { svstem) }\end{array}$ \\
\hline \multicolumn{11}{|l|}{ BAU } \\
\hline Pricing with Technology & 0 & $0.0 \%$ & 0 & $0.0 \%$ & 0 & $0.0 \%$ & 0 & $0.0 \%$ & 0 & $0.0 \%$ \\
\hline Pricing without Technology & 11 & $0.8 \%$ & 1 & $0.1 \%$ & 33 & $2.6 \%$ & 4 & $0.3 \%$ & 49 & $3.8 \%$ \\
\hline Automated/Direct Load Control & 0 & $0.0 \%$ & 0 & $0.0 \%$ & 0 & $0.0 \%$ & 0 & $0.0 \%$ & 0 & $0.0 \%$ \\
\hline Interruptible/Curtailable Tariffs & 0 & $0.0 \%$ & 0 & $0.0 \%$ & 0 & $0.0 \%$ & 51 & $3.9 \%$ & 51 & $3.9 \%$ \\
\hline Other DR Programs & 0 & $0.0 \%$ & 0 & $0.0 \%$ & 0 & $0.0 \%$ & 55 & $4.2 \%$ & 55 & $4.2 \%$ \\
\hline Total & 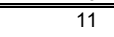 & $0.8 \%$ & 1 & $0.1 \%$ & 33 & $2.6 \%$ & 110 & $8.5 \%$ & 155 & $11.9 \%$ \\
\hline \multicolumn{11}{|l|}{ Optimistic BAU } \\
\hline Pricing with Technology & 0 & $0.0 \%$ & 0 & $0.0 \%$ & 0 & $0.0 \%$ & 0 & $0.0 \%$ & 0 & $0.0 \%$ \\
\hline Pricing without Technology & 11 & $0.8 \%$ & 1 & $0.1 \%$ & 33 & $2.6 \%$ & 4 & $0.3 \%$ & 49 & $3.8 \%$ \\
\hline Automated/Direct Load Control & 4 & $0.3 \%$ & 9 & $0.7 \%$ & 2 & $0.1 \%$ & 0 & $0.0 \%$ & 16 & $1.2 \%$ \\
\hline Interruptible/Curtailable Tariffs & 0 & $0.0 \%$ & 0 & $0.0 \%$ & 24 & $1.9 \%$ & 51 & $3.9 \%$ & 76 & $5.8 \%$ \\
\hline Other DR Programs & 0 & $0.0 \%$ & 0 & $0.0 \%$ & 8 & $0.6 \%$ & 55 & $4.2 \%$ & 62 & $4.8 \%$ \\
\hline Total & $\overline{15}$ & $1.1 \%$ & $\overline{10}$ & $0.8 \%$ & 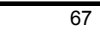 & $5.2 \%$ & 110 & $8.5 \%$ & 203 & $15.6 \%$ \\
\hline \multicolumn{11}{|l|}{ Aggressive Deployment } \\
\hline Pricing with Technology & 0 & $0.0 \%$ & 0 & $0.0 \%$ & 7 & $0.5 \%$ & 5 & $0.4 \%$ & 12 & $0.9 \%$ \\
\hline Pricing without Technology & 33 & $2.6 \%$ & 1 & $0.1 \%$ & 33 & $2.6 \%$ & 9 & $0.7 \%$ & 77 & $5.9 \%$ \\
\hline Automated/Direct Load Control & 1 & $0.1 \%$ & 2 & $0.2 \%$ & 1 & $0.1 \%$ & 0 & $0.0 \%$ & 4 & $0.3 \%$ \\
\hline Interruptible/Curtailable Tariffs & 0 & $0.0 \%$ & 0 & $0.0 \%$ & 24 & $1.9 \%$ & 51 & $3.9 \%$ & 76 & $5.8 \%$ \\
\hline Other DR Programs & 0 & $0.0 \%$ & 0 & $0.0 \%$ & 3 & $0.3 \%$ & 55 & $4.2 \%$ & 58 & $4.5 \%$ \\
\hline Total & 35 & $2.7 \%$ & 3 & $0.3 \%$ & 69 & $5.3 \%$ & 120 & $9.2 \%$ & 227 & $17.4 \%$ \\
\hline \multicolumn{11}{|l|}{ Full Deployment } \\
\hline Pricing with Technology & 0 & $0.0 \%$ & 0 & $0.0 \%$ & 20 & $1.5 \%$ & 15 & $1.1 \%$ & 35 & $2.7 \%$ \\
\hline Pricing without Technology & 45 & $3.4 \%$ & 1 & $0.1 \%$ & 33 & $2.6 \%$ & 12 & $0.9 \%$ & 91 & $7.0 \%$ \\
\hline Automated/Direct Load Control & 0 & $0.0 \%$ & 0 & $0.0 \%$ & 0 & $0.0 \%$ & 0 & $0.0 \%$ & 0 & $0.0 \%$ \\
\hline Interruptible/Curtailable Tariffs & 0 & $0.0 \%$ & 0 & $0.0 \%$ & 24 & $1.9 \%$ & 51 & $3.9 \%$ & 76 & $5.8 \%$ \\
\hline Other DR Programs & 0 & $0.0 \%$ & 0 & $0.0 \%$ & 0 & $0.0 \%$ & 55 & $4.2 \%$ & 55 & $4.2 \%$ \\
\hline Total & 45 & $3.4 \%$ & 1 & $0.1 \%$ & 78 & $6.0 \%$ & 132 & $10.2 \%$ & 256 & $19.7 \%$ \\
\hline
\end{tabular}




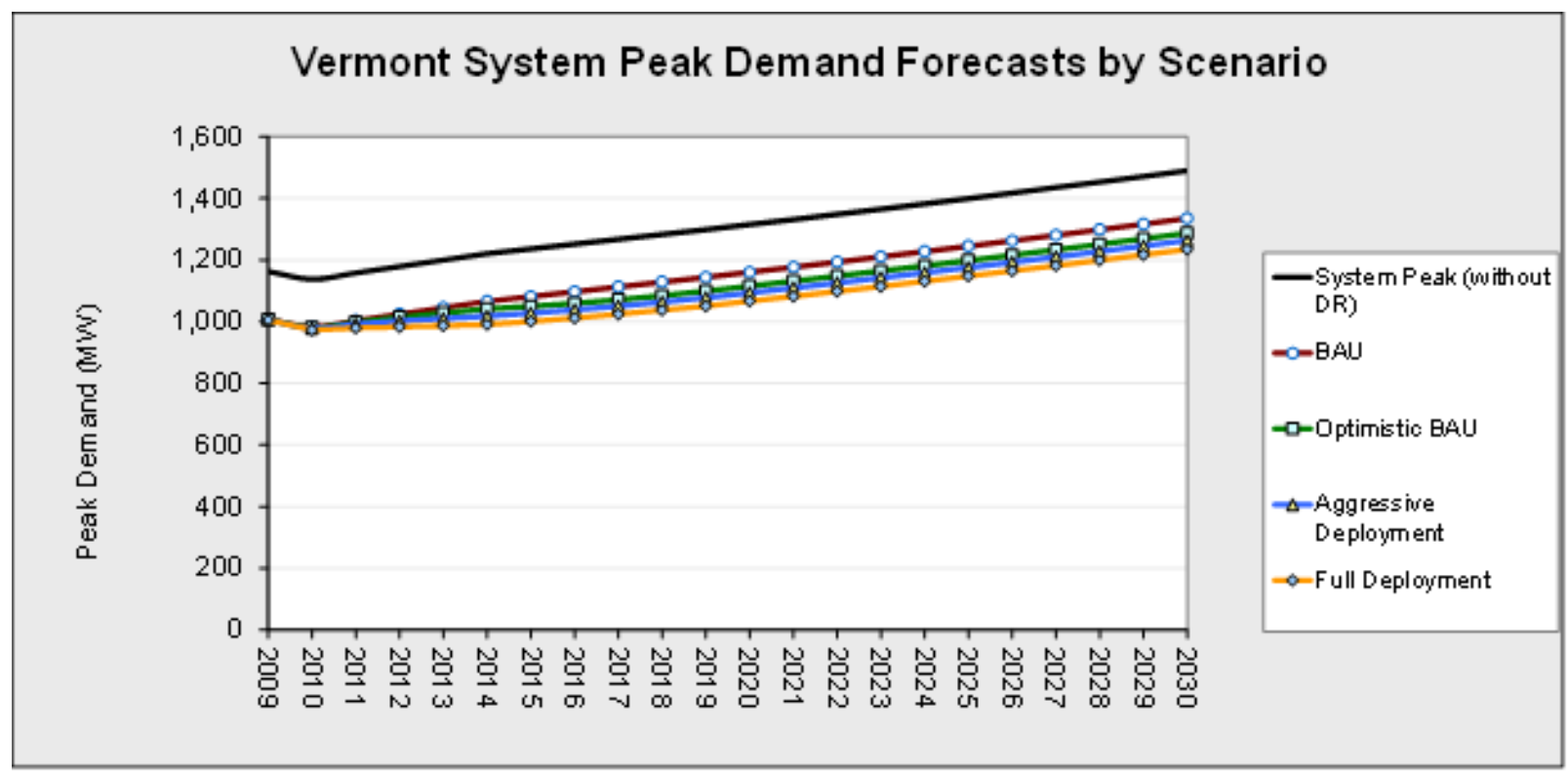

Summary of Monte Carlo Simulation of Potential Peak Load Reduction from Demand Response in Vermont by Scenario, Pricing Program and Price Ratio (MW)

\begin{tabular}{|c|c|c|c|c|c|c|c|c|c|c|c|c|}
\hline & \multicolumn{3}{|c|}{2015} & \multicolumn{3}{|c|}{2020} & \multicolumn{3}{|c|}{2025} & \multicolumn{3}{|c|}{2030} \\
\hline & \multicolumn{3}{|c|}{ Mean Lower Upper } & \multicolumn{3}{|c|}{ Mean Lower Upper } & \multicolumn{3}{|c|}{ Mean Lower Upper } & \multicolumn{3}{|c|}{ Mean Lower Upper } \\
\hline \multicolumn{13}{|l|}{ BAU } \\
\hline \multicolumn{13}{|l|}{ Pricing with Technology } \\
\hline 5 & 0 & 0 & 0 & 0 & 0 & 0 & 0 & 0 & 0 & 0 & 0 & 0 \\
\hline 10 & 0 & 0 & 0 & 0 & 0 & 0 & 0 & 0 & 0 & 0 & 0 & 0 \\
\hline 15 & 0 & 0 & 0 & 0 & 0 & 0 & 0 & 0 & 0 & 0 & 0 & 0 \\
\hline \multicolumn{13}{|l|}{ Pricing without Technology } \\
\hline & 48 & 48 & 48 & 48 & 48 & 48 & 48 & 48 & 48 & 48 & 48 & 48 \\
\hline 10 & 48 & 48 & 48 & 48 & 48 & 48 & 48 & 48 & 48 & 48 & 48 & 48 \\
\hline 15 & 48 & 48 & 48 & 48 & 48 & 48 & 48 & 48 & 48 & 48 & 48 & 48 \\
\hline \multicolumn{13}{|l|}{$\begin{array}{l}\text { Optimistic BAU } \\
\text { Pricing with Technology }\end{array}$} \\
\hline ricing witu tectimoiogy & 0 & 0 & 0 & 0 & 0 & 0 & 0 & 0 & 0 & 0 & 0 & 0 \\
\hline 10 & 0 & 0 & 0 & 0 & 0 & 0 & 0 & 0 & 0 & 0 & 0 & 0 \\
\hline 15 & 0 & 0 & 0 & 0 & 0 & 0 & 0 & 0 & 0 & 0 & 0 & 0 \\
\hline \multicolumn{13}{|l|}{ Pricing without Technology } \\
\hline 5 & 49 & 49 & 49 & 49 & 49 & 49 & 49 & 49 & 49 & 49 & 49 & 49 \\
\hline 10 & 49 & 49 & 49 & 49 & 49 & 49 & 49 & 49 & 49 & 49 & 49 & 49 \\
\hline 15 & 49 & 49 & 49 & 49 & 49 & 49 & 49 & 49 & 49 & 49 & 49 & 49 \\
\hline \multicolumn{13}{|l|}{$\begin{array}{l}\text { Aggressive Deployment } \\
\text { Pricing with Technology }\end{array}$} \\
\hline 5 & 9 & 3 & 16 & 10 & 3 & 17 & 10 & 3 & 17 & 10 & 3 & 18 \\
\hline 10 & 13 & 4 & 23 & 14 & 4 & 24 & 15 & 4 & 25 & 15 & 4 & 26 \\
\hline 15 & 16 & 4 & 28 & 17 & 4 & 30 & 18 & 4 & 31 & 18 & 4 & 32 \\
\hline \multicolumn{13}{|l|}{ Pricing without Technology } \\
\hline 5 & 65 & 45 & 84 & 67 & 46 & 89 & 68 & 46 & 91 & 69 & 46 & 93 \\
\hline 8 & 78 & 47 & 109 & 82 & 48 & 117 & 84 & 48 & 119 & 85 & 49 & 122 \\
\hline 15 & 87 & 47 & 128 & 93 & 48 & 137 & 94 & 48 & 140 & 96 & 49 & 143 \\
\hline \multicolumn{13}{|l|}{$\begin{array}{l}\text { Full Deployment } \\
\text { Pricing with Technology }\end{array}$} \\
\hline - & 26 & 5 & 46 & 27 & 5 & 49 & 28 & 6 & 51 & 29 & 6 & 52 \\
\hline 10 & 39 & 11 & 66 & 41 & 11 & 71 & 43 & 12 & 73 & 44 & 12 & 76 \\
\hline 15 & 48 & 14 & 81 & 51 & 15 & 87 & 53 & 15 & 90 & 54 & 16 & 92 \\
\hline \multicolumn{13}{|l|}{ Pricing without Technology } \\
\hline 5 & 72 & 44 & 101 & 76 & 44 & 108 & 77 & 44 & 111 & 78 & 44 & 113 \\
\hline 10 & 92 & 50 & 133 & 97 & 52 & 143 & 99 & 52 & 147 & 101 & 53 & 150 \\
\hline 15 & 106 & 55 & 156 & 113 & 57 & 168 & 115 & 58 & 172 & 118 & 59 & 176 \\
\hline
\end{tabular}




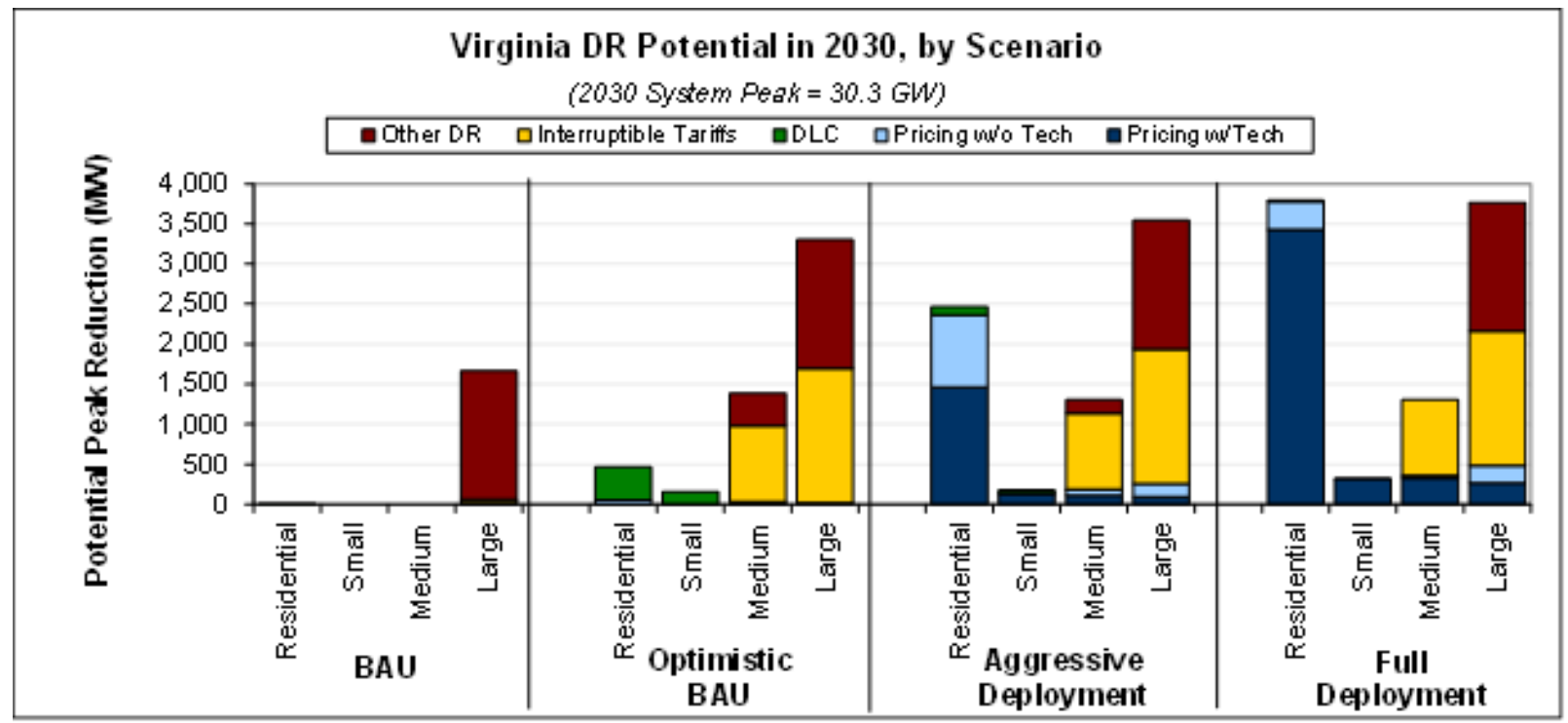

Total Potential Peak Reduction from Demand Response in Virginia, 2030

\begin{tabular}{|c|c|c|c|c|c|c|c|c|c|c|}
\hline & $\begin{array}{l}\text { Residential } \\
\text { (MW) }\end{array}$ & $\begin{array}{l}\text { Residential } \\
\text { ( } \% \text { of } \\
\text { svstem) }\end{array}$ & $\begin{array}{l}\text { Small C\&I } \\
(\mathrm{MW})\end{array}$ & $\begin{array}{l}\text { Small C\&I } \\
\text { (\% of } \\
\text { svstem) }\end{array}$ & $\begin{array}{l}\text { Med. C\&I } \\
(\mathrm{MW})\end{array}$ & $\begin{array}{l}\text { Med C\&I } \\
\text { ( } \% \text { of } \\
\text { svstem) }\end{array}$ & $\begin{array}{l}\text { Large C\&I } \\
(\mathrm{MW})\end{array}$ & $\begin{array}{l}\text { Large C\&I } \\
\text { ( } \% \text { of } \\
\text { svstem) }\end{array}$ & $\begin{array}{l}\text { Total } \\
\text { (MW) }\end{array}$ & $\begin{array}{l}\text { Total } \\
\text { ( } \% \text { of } \\
\text { svstem) }\end{array}$ \\
\hline \multicolumn{11}{|l|}{ BAU } \\
\hline Pricing with Technology & 0 & $0.0 \%$ & 0 & $0.0 \%$ & 0 & $0.0 \%$ & 0 & $0.0 \%$ & 0 & $0.0 \%$ \\
\hline Pricing without Technology & 0 & $0.0 \%$ & 0 & $0.0 \%$ & 0 & $0.0 \%$ & 14 & $0.1 \%$ & 14 & $0.1 \%$ \\
\hline Automated/Direct Load Control & 11 & $0.0 \%$ & 0 & $0.0 \%$ & 0 & $0.0 \%$ & 0 & $0.0 \%$ & 11 & $0.0 \%$ \\
\hline Interruptible/Curtailable Tariffs & 0 & $0.0 \%$ & 0 & $0.0 \%$ & 0 & $0.0 \%$ & 45 & $0.2 \%$ & 45 & $0.2 \%$ \\
\hline Other DR Programs & 0 & $0.0 \%$ & 0 & $0.0 \%$ & 0 & $0.0 \%$ & 1,605 & $6.1 \%$ & 1,605 & $6.1 \%$ \\
\hline Total & 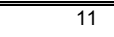 & $0.0 \%$ & 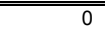 & $0.0 \%$ & 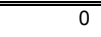 & $0.0 \%$ & $\overline{1,664}$ & $6.3 \%$ & 1,675 & $\overline{6.3 \%}$ \\
\hline \multicolumn{11}{|l|}{ Optimistic BAU } \\
\hline Pricing with Technology & 0 & $0.0 \%$ & 0 & $0.0 \%$ & 0 & $0.0 \%$ & 0 & $0.0 \%$ & 0 & $0.0 \%$ \\
\hline Pricing without Technology & 53 & $0.2 \%$ & 0 & $0.0 \%$ & 5 & $0.0 \%$ & 14 & $0.1 \%$ & 72 & $0.3 \%$ \\
\hline Automated/Direct Load Control & 410 & $1.6 \%$ & 154 & $0.6 \%$ & 27 & $0.1 \%$ & 0 & $0.0 \%$ & 590 & $2.2 \%$ \\
\hline Interruptible/Curtailable Tariffs & 0 & $0.0 \%$ & 0 & $0.0 \%$ & 949 & $3.6 \%$ & 1,683 & $6.4 \%$ & 2,632 & $10.0 \%$ \\
\hline Other DR Programs & 0 & $0.0 \%$ & 0 & $0.0 \%$ & 404 & $1.5 \%$ & 1,605 & $6.1 \%$ & 2,009 & $7.6 \%$ \\
\hline Total & 463 & $1.8 \%$ & 154 & $0.6 \%$ & 1,385 & $5.2 \%$ & 3,302 & $12.5 \%$ & 5,304 & $20.1 \%$ \\
\hline \multicolumn{11}{|l|}{ Aggressive Deployment } \\
\hline Pricing with Technology & 1,465 & $5.5 \%$ & 135 & $0.5 \%$ & 111 & $0.4 \%$ & 91 & $0.3 \%$ & 1,802 & $6.8 \%$ \\
\hline Pricing without Technology & 896 & $3.4 \%$ & 2 & $0.0 \%$ & 66 & $0.3 \%$ & 165 & $0.6 \%$ & 1,130 & $4.3 \%$ \\
\hline Automated/Direct Load Control & 105 & $0.4 \%$ & 39 & $0.1 \%$ & 11 & $0.0 \%$ & 0 & $0.0 \%$ & 155 & $0.6 \%$ \\
\hline Interruptible/Curtailable Tariffs & 0 & $0.0 \%$ & 0 & $0.0 \%$ & 949 & $3.6 \%$ & 1,683 & $6.4 \%$ & 2,632 & $10.0 \%$ \\
\hline Other DR Programs & 0 & $0.0 \%$ & 0 & $0.0 \%$ & 165 & $0.6 \%$ & 1,605 & $6.1 \%$ & 1,771 & $6.7 \%$ \\
\hline Total & 2,466 & $9.3 \%$ & 177 & $0.7 \%$ & 1,302 & $4.9 \%$ & 3,543 & $13.4 \%$ & 7,489 & $28.3 \%$ \\
\hline \multicolumn{11}{|l|}{ Full Deployment } \\
\hline Pricing with Technology & 3,428 & $13.0 \%$ & 316 & $1.2 \%$ & 323 & $1.2 \%$ & 265 & $1.0 \%$ & 4,332 & $16.4 \%$ \\
\hline Pricing without Technology & 353 & $1.3 \%$ & 1 & $0.0 \%$ & 32 & $0.1 \%$ & 214 & $0.8 \%$ & 600 & $2.3 \%$ \\
\hline Automated/Direct Load Control & 11 & $0.0 \%$ & 0 & $0.0 \%$ & 0 & $0.0 \%$ & 0 & $0.0 \%$ & 11 & $0.0 \%$ \\
\hline Interruptible/Curtailable Tariffs & 0 & $0.0 \%$ & 0 & $0.0 \%$ & 949 & $3.6 \%$ & 1,683 & $6.4 \%$ & 2,632 & $10.0 \%$ \\
\hline Other DR Programs & 0 & $0.0 \%$ & 0 & $0.0 \%$ & 0 & $0.0 \%$ & 1,605 & $6.1 \%$ & 1,605 & $6.1 \%$ \\
\hline 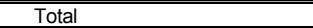 & 3,792 & $\overline{14.3 \%}$ & 317 & $1.2 \%$ & 1,305 & $4.9 \%$ & 3,766 & $\overline{14.3 \%}$ & 9,180 & $34.7 \%$ \\
\hline
\end{tabular}




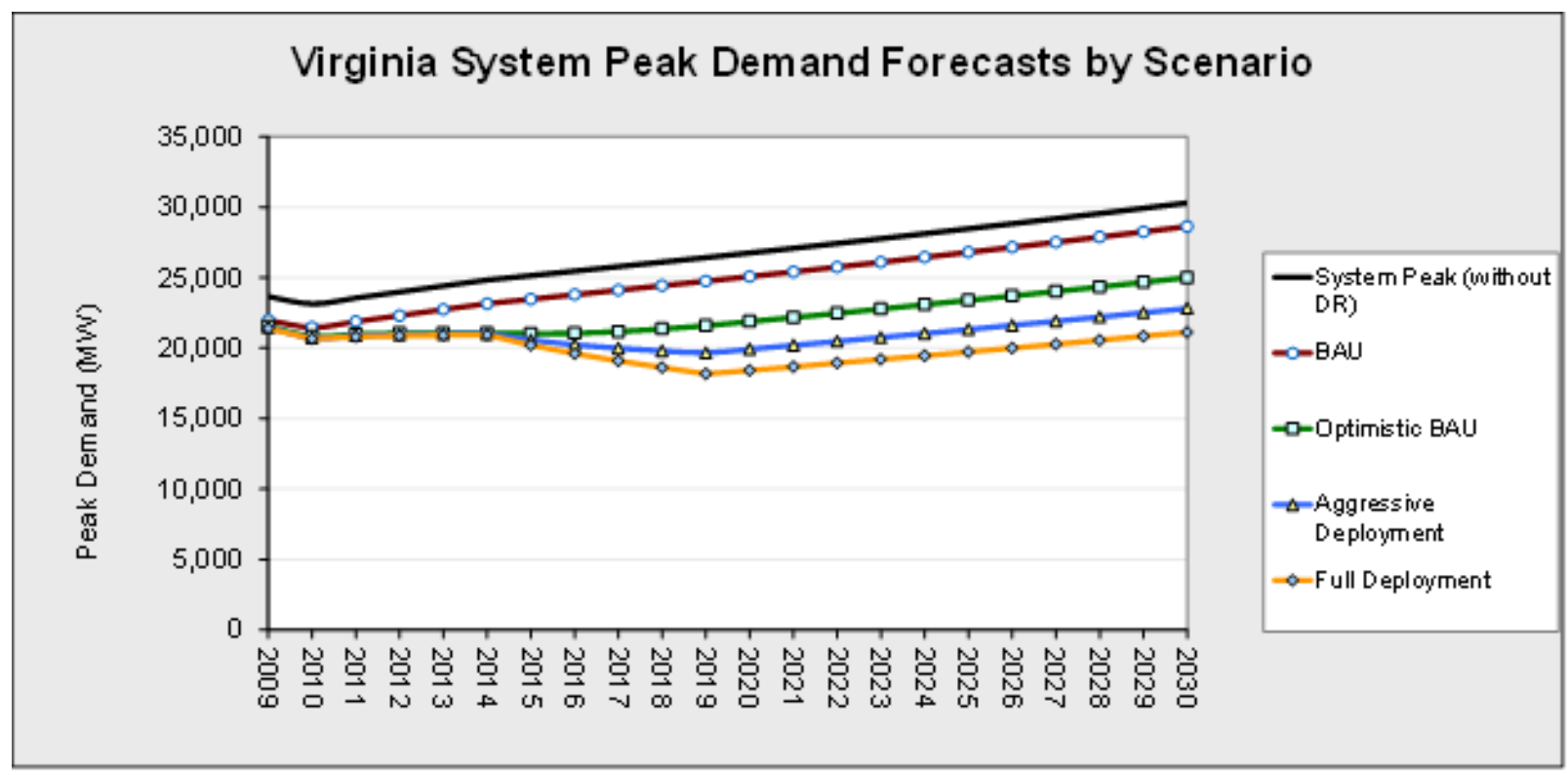

Summary of Monte Carlo Simulation of Potential Peak Load Reduction from Demand Response in Virginia by Scenario, Pricing Program and Price Ratio (MW)

\begin{tabular}{|c|c|c|c|c|c|c|c|c|c|c|c|c|}
\hline \multirow[b]{3}{*}{ BAU } & \multicolumn{3}{|c|}{2015} & \multicolumn{3}{|c|}{2020} & \multicolumn{3}{|c|}{2025} & \multicolumn{3}{|c|}{2030} \\
\hline & \multirow[t]{2}{*}{ Mean 1} & Lower & Upper & \multirow[t]{2}{*}{ Mean } & Lower & Upper & \multirow[t]{2}{*}{ Mean } & \multicolumn{2}{|c|}{ Lower Upper } & \multirow[t]{3}{*}{ Mean } & Lower & Upper \\
\hline & & & & & & & & & & & & \\
\hline \multicolumn{12}{|l|}{ Pricing with Technology } & \\
\hline 5 & 0 & 0 & 0 & 0 & 0 & 0 & 0 & 0 & 0 & 0 & 0 & c \\
\hline 10 & 0 & 0 & 0 & 0 & 0 & 0 & 0 & 0 & 0 & 0 & 0 & \\
\hline 15 & 0 & 0 & 0 & 0 & 0 & 0 & 0 & 0 & 0 & 0 & 0 & \\
\hline \multicolumn{13}{|l|}{ Pricing without Technology } \\
\hline 5 & 14 & 14 & 14 & 14 & 14 & 14 & 14 & 14 & 14 & 14 & 14 & 14 \\
\hline 10 & 14 & 14 & 14 & 14 & 14 & 14 & 14 & 14 & 14 & 14 & 14 & 14 \\
\hline 15 & 14 & 14 & 14 & 14 & 14 & 14 & 14 & 14 & 14 & 14 & 14 & 14 \\
\hline \multicolumn{13}{|l|}{\begin{tabular}{|l|} 
Optimistic BAU \\
Pricing with Technology
\end{tabular}} \\
\hline 5 & 0 & 0 & 0 & 0 & 0 & 0 & 0 & 0 & 0 & 0 & 0 & \\
\hline 10 & 0 & 0 & 0 & 0 & 0 & 0 & 0 & 0 & 0 & 0 & 0 & \\
\hline 15 & 0 & 0 & 0 & 0 & 0 & 0 & 0 & 0 & 0 & 0 & 0 & \\
\hline \multicolumn{13}{|l|}{ Pricing without Technology } \\
\hline 5 & 25 & 18 & 32 & 55 & 28 & 83 & 57 & 28 & 87 & 60 & 29 & 91 \\
\hline 10 & 30 & 19 & 41 & 73 & 30 & 116 & 77 & 31 & 123 & 81 & 31 & 130 \\
\hline 15 & 33 & 20 & 47 & 87 & 32 & 141 & 91 & 33 & 150 & 96 & 34 & $15 \mathrm{~s}$ \\
\hline \multicolumn{13}{|l|}{\begin{tabular}{|l|} 
Aggressive Deployment \\
Pricing with Technology
\end{tabular}} \\
\hline 5 & 277 & 71 & 484 & 1218 & 311 & 2125 & 1289 & 329 & 2249 & 1364 & 348 & 2380 \\
\hline 10 & 420 & 118 & 721 & 1843 & 518 & 3168 & 1951 & 548 & 3353 & 2064 & 580 & 3548 \\
\hline & 512 & 190 & 834 & 2249 & 835 & 3662 & 2380 & 883 & 3876 & 2518 & 935 & 410 \\
\hline \multicolumn{13}{|l|}{ Pricing without Technology } \\
\hline & 180 & 48 & 312 & 783 & 201 & 1365 & 829 & 213 & 1445 & 877 & 225 & 1529 \\
\hline 8 & 273 & 77 & 469 & 1192 & 337 & 2046 & 1261 & 357 & 2166 & 1335 & 378 & 2292 \\
\hline 15 & 334 & 125 & 544 & 1458 & 545 & 2372 & 1544 & 577 & 2511 & 1634 & 611 & 2658 \\
\hline \multicolumn{13}{|l|}{$\begin{array}{l}\text { Full Deployment } \\
\text { Pricing with Technology }\end{array}$} \\
\hline Pricing witn I ectnoloiogy & 720 & 229 & 1211 & 3152 & 1001 & 5303 & 3336 & 1059 & 5613 & 3531 & 1121 & 5941 \\
\hline 10 & 1016 & 302 & 1731 & 4448 & 1321 & 7576 & 4708 & 1398 & 8018 & 4983 & 1480 & 8487 \\
\hline 15 & 1246 & 380 & 2111 & 5452 & 1663 & 9242 & 5771 & 1760 & 9782 & 6108 & 1863 & 10353 \\
\hline \multicolumn{13}{|l|}{ Pricing without Technology } \\
\hline 5 & 109 & 35 & 183 & 471 & 151 & 790 & 499 & 161 & 838 & 530 & 170 & 889 \\
\hline 10 & 156 & 47 & 265 & 672 & 203 & 1141 & 713 & 215 & 1210 & 756 & 229 & 1283 \\
\hline 15 & 192 & 60 & 325 & 829 & 258 & 1400 & 879 & 273 & 1484 & 932 & 290 & 1574 \\
\hline
\end{tabular}




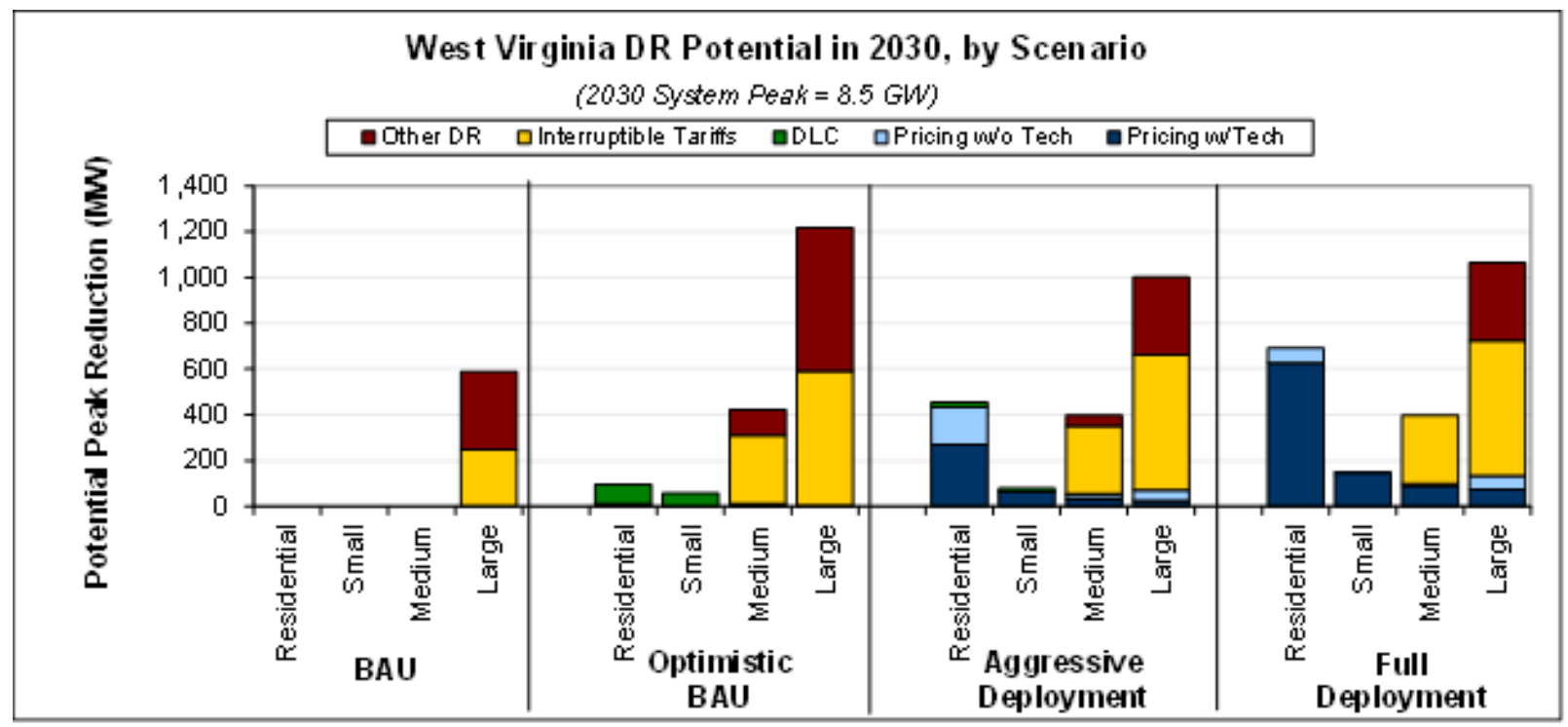

Total Potential Peak Reduction from Demand Response in West Virginia, 2030

\begin{tabular}{|c|c|c|c|c|c|c|c|c|c|c|}
\hline & $\begin{array}{l}\text { Residential } \\
\text { (MW) }\end{array}$ & $\begin{array}{l}\text { Residential } \\
\text { ( } \% \text { of } \\
\text { svstem) }\end{array}$ & $\begin{array}{c}\text { Small C\&I } \\
(\mathrm{MW})\end{array}$ & $\begin{array}{l}\text { Small C\&I } \\
\text { (\% of } \\
\text { svstem) }\end{array}$ & $\begin{array}{l}\text { Med. C\&I } \\
(\mathrm{MW})\end{array}$ & $\begin{array}{l}\text { Med C\&I } \\
\text { ( } \% \text { of } \\
\text { svstem) }\end{array}$ & $\begin{array}{l}\text { Large C\&I } \\
(\mathrm{MW})\end{array}$ & $\begin{array}{l}\text { Large C\&I } \\
\text { (\% of } \\
\text { svstem) }\end{array}$ & $\begin{array}{l}\text { Total } \\
\text { (MW) }\end{array}$ & $\begin{array}{c}\text { Total } \\
\text { ( } \% \text { of } \\
\text { svstem) }\end{array}$ \\
\hline \multicolumn{11}{|l|}{ BAU } \\
\hline Pricing with Technology & 0 & $0.0 \%$ & 0 & $0.0 \%$ & 0 & $0.0 \%$ & 0 & $0.0 \%$ & 0 & $0.0 \%$ \\
\hline Pricing without Technology & 0 & $0.0 \%$ & 0 & $0.0 \%$ & 0 & $0.0 \%$ & 0 & $0.0 \%$ & 0 & $0.0 \%$ \\
\hline Automated/Direct Load Control & 0 & $0.0 \%$ & 0 & $0.0 \%$ & 0 & $0.0 \%$ & 0 & $0.0 \%$ & 0 & $0.0 \%$ \\
\hline Interruptible/Curtailable Tariffs & 0 & $0.0 \%$ & 0 & $0.0 \%$ & 0 & $0.0 \%$ & 246 & $3.3 \%$ & 246 & $3.3 \%$ \\
\hline Other DR Programs & 0 & $0.0 \%$ & 0 & $0.0 \%$ & 0 & $0.0 \%$ & 341 & $4.6 \%$ & 341 & $4.6 \%$ \\
\hline Total & 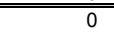 & $0.0 \%$ & 0 & $0.0 \%$ & 0 & $0.0 \%$ & 587 & $7.9 \%$ & (587 & $7.9 \%$ \\
\hline \multicolumn{11}{|l|}{ Optimistic BAU } \\
\hline Pricing with Technology & 0 & $0.0 \%$ & 0 & $0.0 \%$ & 0 & $0.0 \%$ & 0 & $0.0 \%$ & 0 & $0.0 \%$ \\
\hline Pricing without Technology & 9 & $0.1 \%$ & 0 & $0.0 \%$ & 1 & $0.0 \%$ & 2 & $0.0 \%$ & 13 & $0.2 \%$ \\
\hline Automated/Direct Load Control & 87 & $1.2 \%$ & 56 & $0.8 \%$ & 9 & $0.1 \%$ & 0 & $0.0 \%$ & 153 & $2.1 \%$ \\
\hline Interruptible/Curtailable Tariffs & 0 & $0.0 \%$ & 0 & $0.0 \%$ & 299 & $4.0 \%$ & 589 & $7.9 \%$ & 888 & $11.9 \%$ \\
\hline Other DR Programs & 0 & $0.0 \%$ & 0 & $0.0 \%$ & 113 & $1.5 \%$ & 626 & $8.4 \%$ & 739 & $9.9 \%$ \\
\hline Total & $\overline{997}$ & $1.3 \%$ & 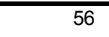 & $0.8 \%$ & 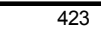 & $5.7 \%$ & $\begin{array}{l}1,217 \\
\end{array}$ & $\overline{16.4 \%}$ & 1,793 & $24.1 \%$ \\
\hline \multicolumn{11}{|l|}{ Aggressive Deployment } \\
\hline Pricing with Technology & 268 & $3.6 \%$ & 63 & $0.8 \%$ & 31 & $0.4 \%$ & 25 & $0.3 \%$ & 387 & $5.2 \%$ \\
\hline Pricing without Technology & 164 & $2.2 \%$ & 1 & $0.0 \%$ & 18 & $0.2 \%$ & 46 & $0.6 \%$ & 230 & $3.1 \%$ \\
\hline Automated/Direct Load Control & 22 & $0.3 \%$ & 14 & $0.2 \%$ & 4 & $0.1 \%$ & 0 & $0.0 \%$ & 40 & $0.5 \%$ \\
\hline Interruptible/Curtailable Tariffs & 0 & $0.0 \%$ & 0 & $0.0 \%$ & 299 & $4.0 \%$ & 589 & $7.9 \%$ & 888 & $11.9 \%$ \\
\hline Other DR Programs & 0 & $0.0 \%$ & 0 & $0.0 \%$ & 46 & $0.6 \%$ & 341 & $4.6 \%$ & 387 & $5.2 \%$ \\
\hline Total & 454 & $6.1 \%$ & 78 & $1.1 \%$ & 398 & $5.4 \%$ & 1,001 & $13.5 \%$ & 1,932 & $26.0 \%$ \\
\hline \multicolumn{11}{|l|}{ Full Deployment } \\
\hline Pricing with Technology & 626 & $8.4 \%$ & 146 & $2.0 \%$ & 90 & $1.2 \%$ & 74 & $1.0 \%$ & 937 & $12.6 \%$ \\
\hline Pricing without Technology & 65 & $0.9 \%$ & 1 & $0.0 \%$ & 9 & $0.1 \%$ & 60 & $0.8 \%$ & 134 & $1.8 \%$ \\
\hline Automated/Direct Load Control & 0 & $0.0 \%$ & 0 & $0.0 \%$ & 0 & $0.0 \%$ & 0 & $0.0 \%$ & 0 & $0.0 \%$ \\
\hline Interruptible/Curtailable Tariffs & 0 & $0.0 \%$ & 0 & $0.0 \%$ & 299 & $4.0 \%$ & 589 & $7.9 \%$ & 888 & $11.9 \%$ \\
\hline Other DR Programs & 0 & $0.0 \%$ & 0 & $0.0 \%$ & 0 & $0.0 \%$ & 341 & $4.6 \%$ & 341 & $4.6 \%$ \\
\hline $\begin{array}{l}\text { Total } \\
\end{array}$ & 692 & $9.3 \%$ & 147 & $2.0 \%$ & 398 & $5.4 \%$ & 1,064 & $14.3 \%$ & 2,301 & $30.9 \%$ \\
\hline
\end{tabular}




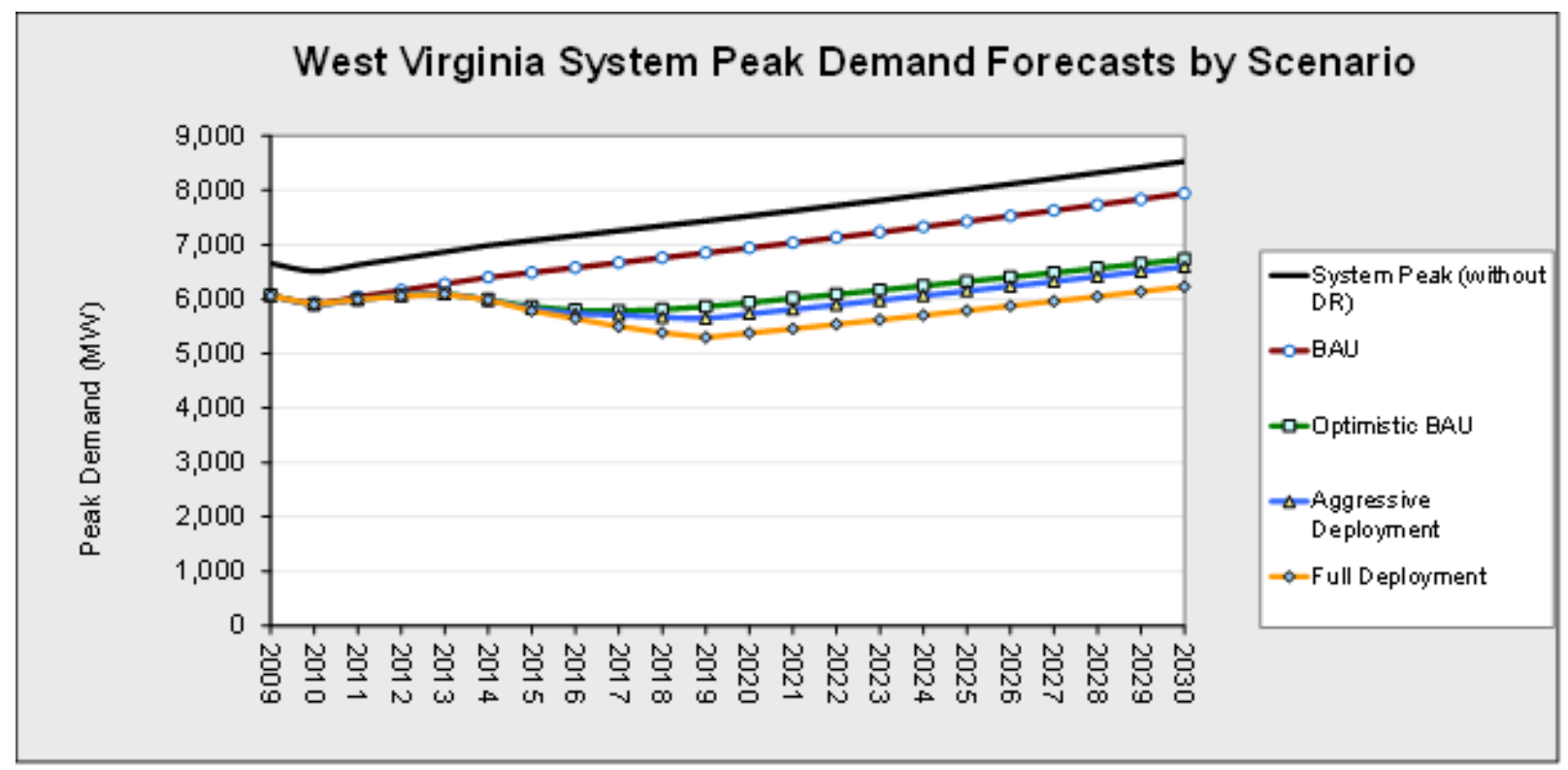

Summary of Monte Carlo Simulation of Potential Peak Load Reduction from Demand Response in West Virginia by Scenario, Pricing Program and Price Ratio (MW)

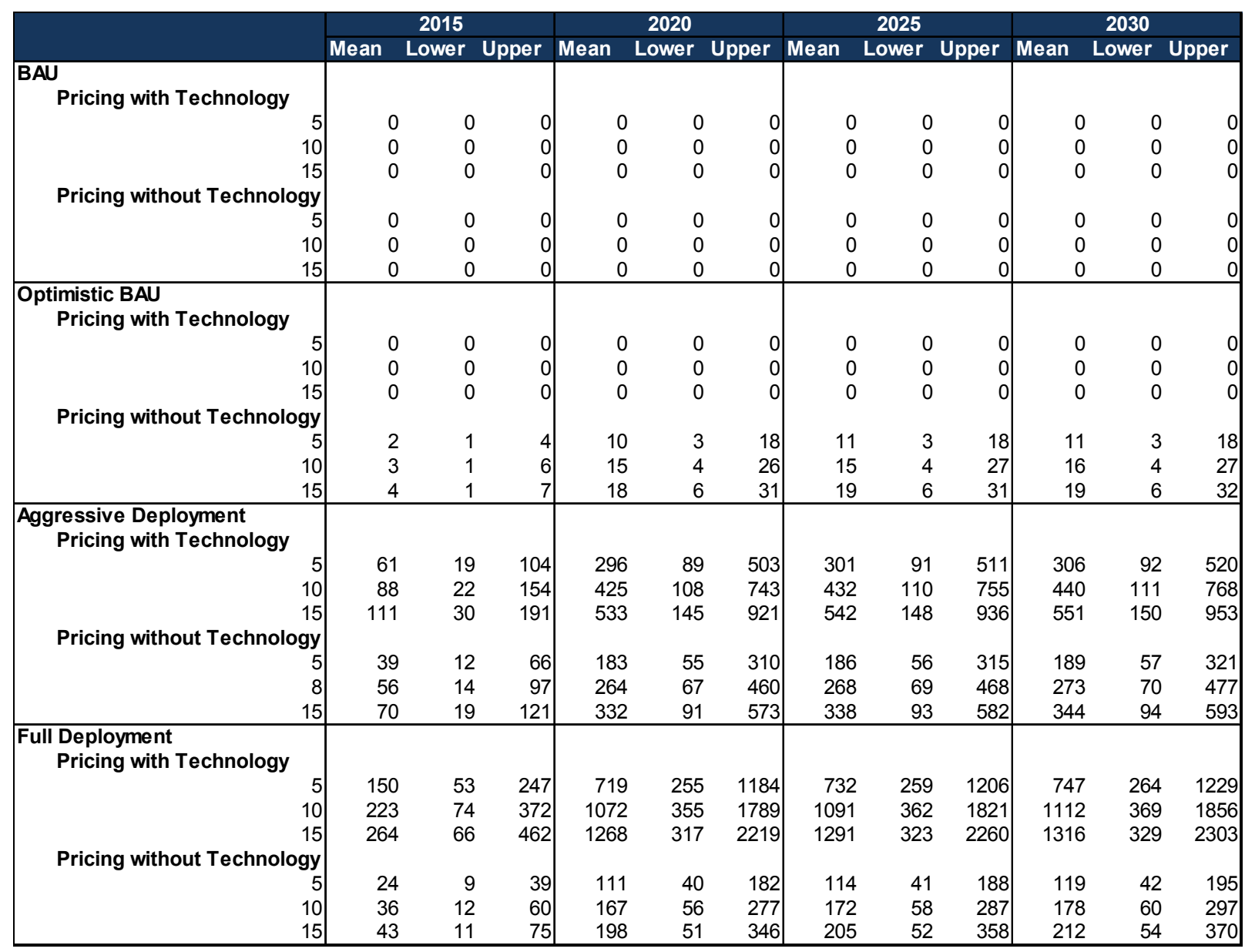




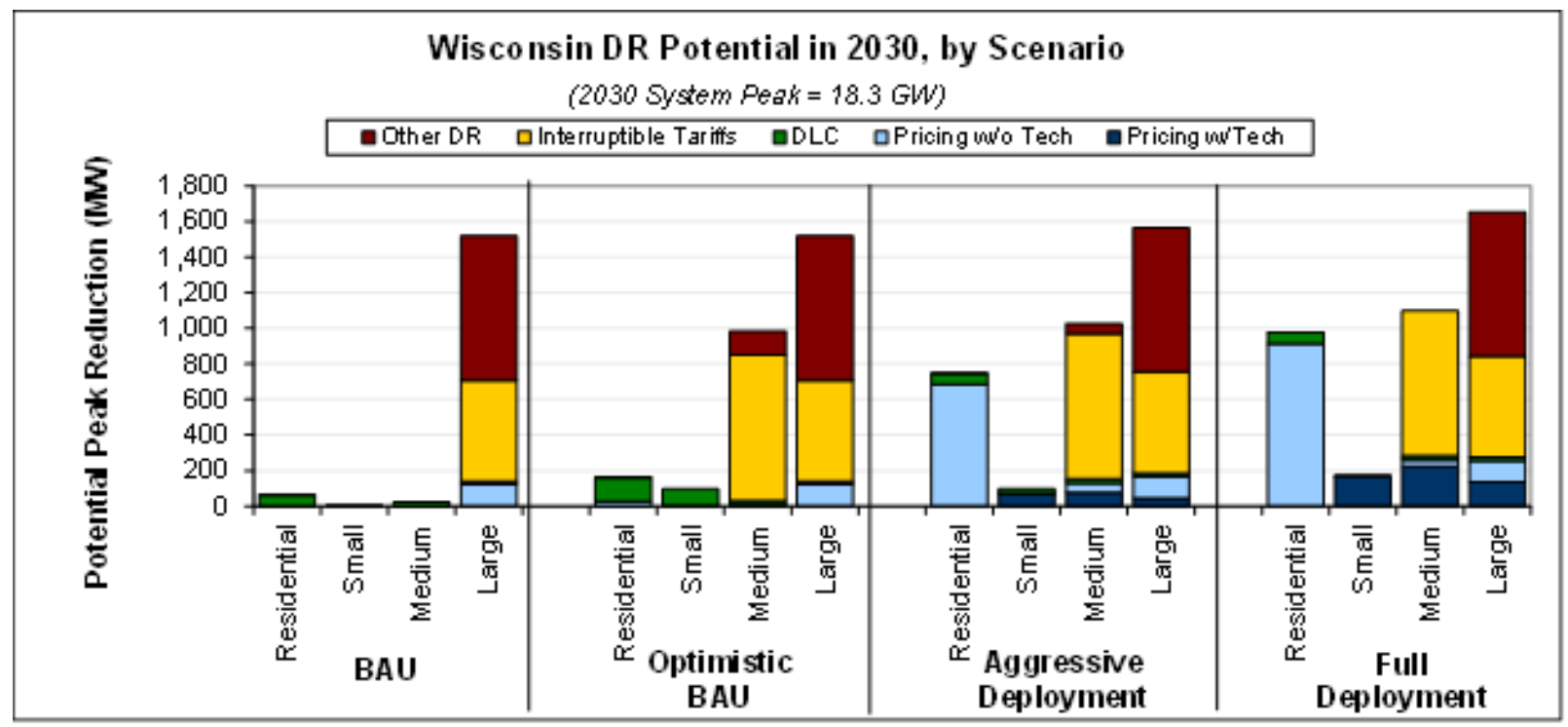

Total Potential Peak Reduction from Demand Response in Wisconsin, 2030

\begin{tabular}{|c|c|c|c|c|c|c|c|c|c|c|}
\hline & $\begin{array}{l}\text { Residential } \\
\quad(\mathrm{MW})\end{array}$ & $\begin{array}{l}\text { Residential } \\
\text { ( } \% \text { of } \\
\text { svstem) }\end{array}$ & $\begin{array}{l}\text { Small C\&I } \\
(\mathrm{MW})\end{array}$ & $\begin{array}{c}\text { Small C\&I } \\
\text { (\% of } \\
\text { svstem) }\end{array}$ & $\begin{array}{l}\text { Med. C\&I } \\
(\mathrm{MW})\end{array}$ & $\begin{array}{l}\text { Med C\&I } \\
\text { ( } \% \text { of } \\
\text { svstem) }\end{array}$ & $\begin{array}{l}\text { Large C\&I } \\
\quad(\mathrm{MW})\end{array}$ & $\begin{array}{l}\text { Large C\&I } \\
\text { ( } \% \text { of } \\
\text { svstem) }\end{array}$ & $\begin{array}{l}\text { Total } \\
(\mathrm{MW})\end{array}$ & $\begin{array}{c}\text { Total } \\
\text { ( } \% \text { of } \\
\text { svstem) }\end{array}$ \\
\hline \multicolumn{11}{|l|}{ BAU } \\
\hline Pricing with Technology & 0 & $0.0 \%$ & 0 & $0.0 \%$ & 0 & $0.0 \%$ & 0 & $0.0 \%$ & 0 & $0.0 \%$ \\
\hline Pricing without Technology & 1 & $0.0 \%$ & 2 & $0.0 \%$ & 1 & $0.0 \%$ & 121 & $0.8 \%$ & 124 & $0.8 \%$ \\
\hline Automated/Direct Load Control & 62 & $0.4 \%$ & 1 & $0.0 \%$ & 23 & $0.1 \%$ & 20 & $0.1 \%$ & 106 & $0.7 \%$ \\
\hline Interruptible/Curtailable Tariffs & 0 & $0.0 \%$ & 0 & $0.0 \%$ & 0 & $0.0 \%$ & 568 & $3.6 \%$ & 568 & $3.6 \%$ \\
\hline Other DR Programs & 0 & $0.0 \%$ & 0 & $0.0 \%$ & 0 & $0.0 \%$ & 809 & $5.1 \%$ & 809 & $5.1 \%$ \\
\hline Total & 63 & $0.4 \%$ & 3 & $0.0 \%$ & 23 & $0.1 \%$ & $\begin{array}{l}1,517 \\
\end{array}$ & $9.5 \%$ & $\begin{array}{l}1,607 \\
\end{array}$ & $10.1 \%$ \\
\hline \multicolumn{11}{|l|}{ Optimistic BAU } \\
\hline Pricing with Technology & 0 & $0.0 \%$ & 0 & $0.0 \%$ & 0 & $0.0 \%$ & 0 & $0.0 \%$ & 0 & $0.0 \%$ \\
\hline Pricing without Technology & 29 & $0.2 \%$ & 2 & $0.0 \%$ & 5 & $0.0 \%$ & 121 & $0.8 \%$ & 157 & $1.0 \%$ \\
\hline Automated/Direct Load Control & 132 & $0.8 \%$ & 94 & $0.6 \%$ & 27 & $0.2 \%$ & 20 & $0.1 \%$ & 274 & $1.7 \%$ \\
\hline Interruptible/Curtailable Tariffs & 0 & $0.0 \%$ & 0 & $0.0 \%$ & 816 & $5.1 \%$ & 568 & $3.6 \%$ & 1,384 & $8.7 \%$ \\
\hline Other DR Programs & 0 & $0.0 \%$ & 0 & $0.0 \%$ & 137 & $0.9 \%$ & 809 & $5.1 \%$ & 946 & $5.9 \%$ \\
\hline Total & 162 & $1.0 \%$ & $\overline{996}$ & $0.6 \%$ & 985 & $6.2 \%$ & $\bar{~} 1,517$ & $9.5 \%$ & 2,761 & $17.3 \%$ \\
\hline \multicolumn{11}{|l|}{ Aggressive Deployment } \\
\hline Pricing with Technology & 0 & $0.0 \%$ & 72 & $0.5 \%$ & 76 & $0.5 \%$ & 46 & $0.3 \%$ & 194 & $1.2 \%$ \\
\hline Pricing without Technology & 684 & $4.3 \%$ & 2 & $0.0 \%$ & 55 & $0.3 \%$ & 121 & $0.8 \%$ & 862 & $5.4 \%$ \\
\hline Automated/Direct Load Control & 62 & $0.4 \%$ & 24 & $0.2 \%$ & 23 & $0.1 \%$ & 20 & $0.1 \%$ & 129 & $0.8 \%$ \\
\hline Interruptible/Curtailable Tariffs & 0 & $0.0 \%$ & 0 & $0.0 \%$ & 816 & $5.1 \%$ & 568 & $3.6 \%$ & 1,384 & $8.7 \%$ \\
\hline Other DR Programs & 0 & $0.0 \%$ & 0 & $0.0 \%$ & 56 & $0.4 \%$ & 809 & $5.1 \%$ & 865 & $5.4 \%$ \\
\hline Total & 746 & $4.7 \%$ & 99 & $0.6 \%$ & 1,026 & $6.4 \%$ & 1,564 & $9.8 \%$ & 3,434 & $21.5 \%$ \\
\hline \multicolumn{11}{|l|}{ Full Deployment } \\
\hline Pricing with Technology & 0 & $0.0 \%$ & 169 & $1.1 \%$ & 223 & $1.4 \%$ & 135 & $0.8 \%$ & 526 & $3.3 \%$ \\
\hline Pricing without Technology & 913 & $5.7 \%$ & 2 & $0.0 \%$ & 37 & $0.2 \%$ & 121 & $0.8 \%$ & 1,073 & $6.7 \%$ \\
\hline Automated/Direct Load Control & 62 & $0.4 \%$ & 1 & $0.0 \%$ & 23 & $0.1 \%$ & 20 & $0.1 \%$ & 106 & $0.7 \%$ \\
\hline Interruptible/Curtailable Tariffs & 0 & $0.0 \%$ & 0 & $0.0 \%$ & 816 & $5.1 \%$ & 568 & $3.6 \%$ & 1,384 & $8.7 \%$ \\
\hline Other DR Programs & 0 & $0.0 \%$ & 0 & $0.0 \%$ & 0 & $0.0 \%$ & 809 & $5.1 \%$ & 809 & $5.1 \%$ \\
\hline $\begin{array}{l}\text { Total } \\
\end{array}$ & 975 & $6.1 \%$ & 172 & $1.1 \%$ & 1,099 & $6.9 \%$ & 1,652 & $10.4 \%$ & 3,898 & $24.4 \%$ \\
\hline
\end{tabular}




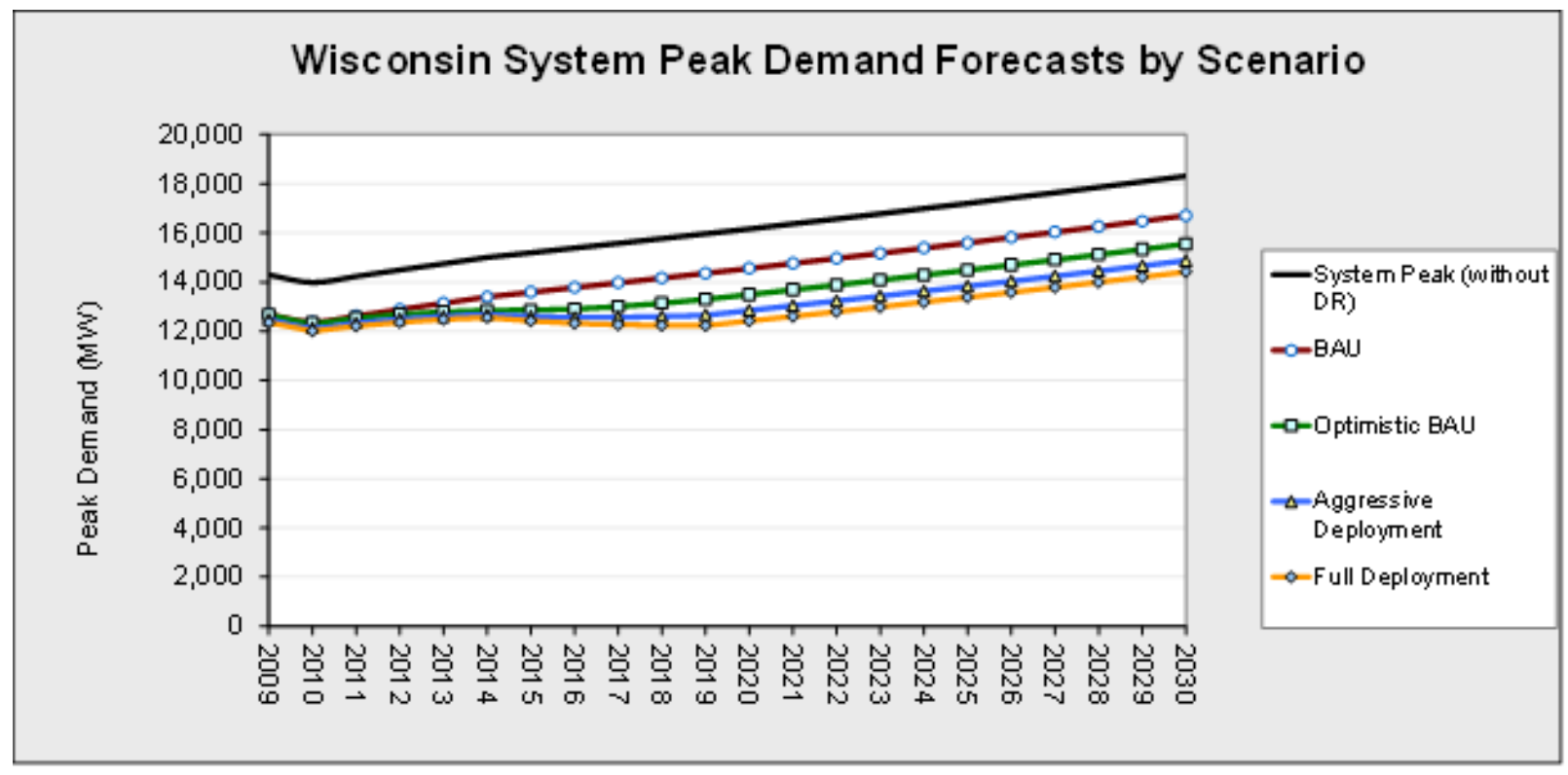

Summary of Monte Carlo Simulation of Potential Peak Load Reduction from Demand Response in Wisconsin by Scenario, Pricing Program and Price Ratio (MW)

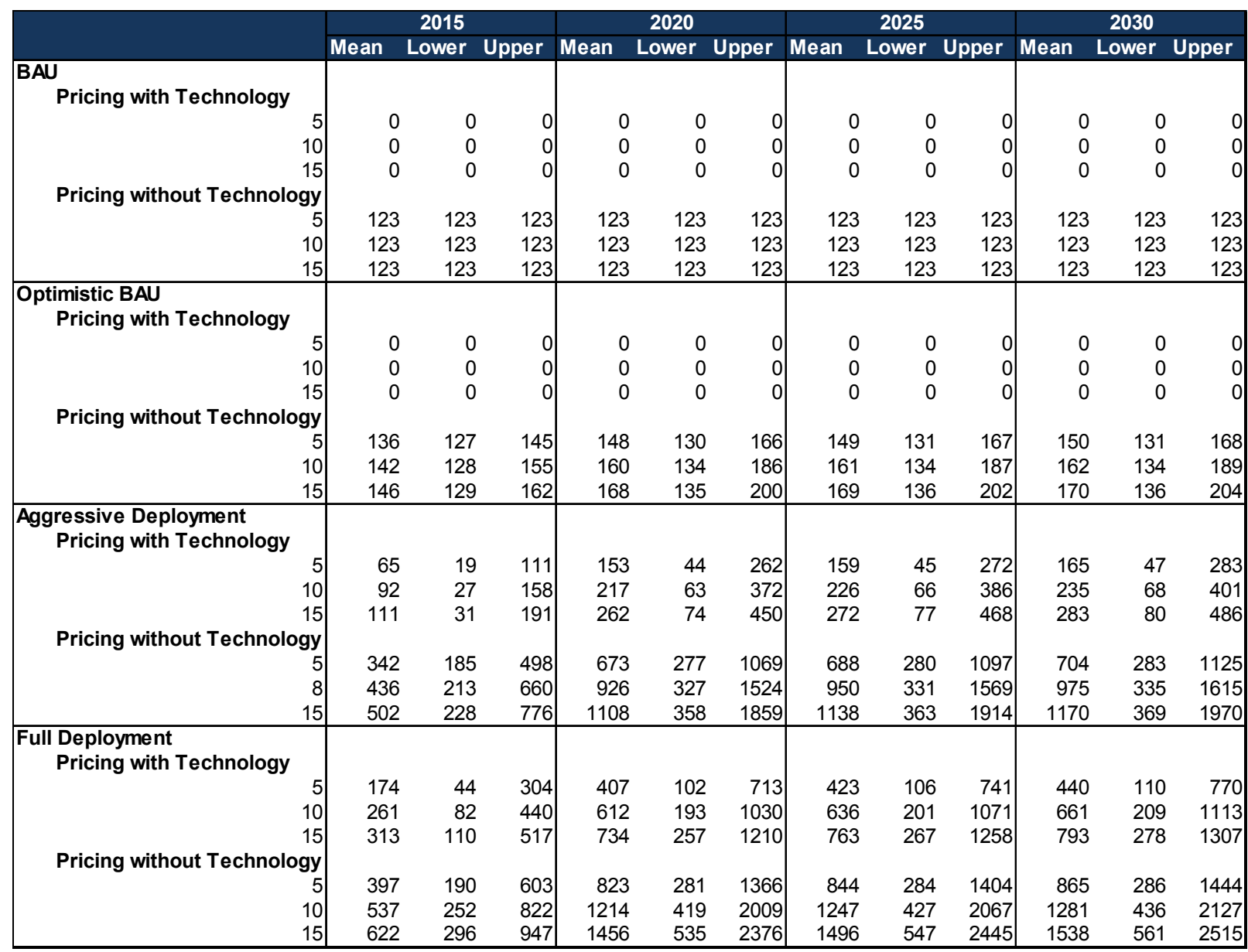





\section{APPENDIX C. BENEFIT-COST TESTS TYPICALLY APPLIED TO DR PROGRAMS}

\begin{tabular}{|c|c|c|}
\hline Benefits Considered & Costs Considered & Implications \\
\hline \multicolumn{3}{|c|}{ Participant Cost Test (PCT) } \\
\hline $\begin{array}{l}\text { Incentive Payments, Bill Savings } \\
\text { Realized, Applicable Tax Credits or } \\
\text { Incentives }\end{array}$ & $\begin{array}{l}\text { Incremental Equipment Costs, } \\
\text { Incremental Installation Costs }\end{array}$ & $\begin{array}{l}\text { Positive PCT shows that } \\
\text { program provides net } \\
\text { savings for customer }\end{array}$ \\
\hline \multicolumn{3}{|c|}{ Program Administrator Test (PACT) } \\
\hline $\begin{array}{l}\text { Energy-Related costs avoided by } \\
\text { utility, Capacity-related costs } \\
\text { avoided by utility (including } \\
\text { generation, transmission, and } \\
\text { distribution) }\end{array}$ & $\begin{array}{l}\text { Program overhead costs, } \\
\text { Utility/program administrator } \\
\text { incentive costs, } \\
\text { Utility/program administrator } \\
\text { installation costs }\end{array}$ & $\begin{array}{l}\text { Positive PACT shows that } \\
\text { costs of saving energy are } \\
\text { less than costs of delivering } \\
\text { energy. }\end{array}$ \\
\hline \multicolumn{3}{|c|}{ Ratepayer Impact Measure (RIM) } \\
\hline $\begin{array}{l}\text { Energy-Related costs avoided by } \\
\text { utility, Capacity-related costs } \\
\text { avoided by utility (including } \\
\text { generation, transmission, and } \\
\text { distribution) }\end{array}$ & $\begin{array}{l}\text { Program overhead costs, } \\
\text { Utility/program administrator } \\
\text { incentive costs, } \\
\text { Utility/program administrator } \\
\text { installation costs, lost revenue } \\
\text { due to reduced energy bills }\end{array}$ & $\begin{array}{l}\text { Negative RIM implies that } \\
\text { rates would need to increase } \\
\text { in the short term for utility } \\
\text { to maintain current earnings }\end{array}$ \\
\hline \multicolumn{3}{|c|}{ Total Resource Cost Test (TRC) } \\
\hline $\begin{array}{l}\text { Energy-Related costs avoided by } \\
\text { utility, Capacity-related costs } \\
\text { avoided by utility (including } \\
\text { generation, transmission, and } \\
\text { distribution), Additional Resource } \\
\text { Savings (e.g. gas and water), } \\
\text { Monetized environmental and non- } \\
\text { energy benefits (e.g. avoided fines), } \\
\text { Applicable tax credits }\end{array}$ & $\begin{array}{l}\text { Program overhead costs, } \\
\text { Program installation costs, } \\
\text { Incremental measure costs } \\
\text { (whether paid by the customer } \\
\text { or the utility) }\end{array}$ & $\begin{array}{l}\text { Positive TRC shows that } \\
\text { entire program has net } \\
\text { benefits to the region as a } \\
\text { whole }\end{array}$ \\
\hline \multicolumn{3}{|c|}{ Societal Cost Test (SCT) } \\
\hline $\begin{array}{l}\text { Energy-Related costs avoided by } \\
\text { utility, Capacity-related costs } \\
\text { avoided by utility (including } \\
\text { generation, transmission, and } \\
\text { distribution), Additional Resource } \\
\text { Savings (e.g. gas and water), Non- } \\
\text { monetized environmental and non- } \\
\text { energy benefits (e.g. health and } \\
\text { climate improvements) }\end{array}$ & $\begin{array}{l}\text { Program overhead costs, } \\
\text { Program installation costs, } \\
\text { Incremental measure costs } \\
\text { (whether paid by the customer } \\
\text { or the utility) }\end{array}$ & $\begin{array}{l}\text { Positive SCT shows that the } \\
\text { program has net benefits to } \\
\text { those do not participate in it } \\
\text { and who are not customers } \\
\text { of the utility administering } \\
\text { the program, i.e. the } \\
\text { program is beneficial to } \\
\text { third parties }\end{array}$ \\
\hline
\end{tabular}



APPENDIX D. COST AND DEVICE DEPLOYMENT ESTIMATES FOR CENSUS DIVISIONS IN ORNL-NADR

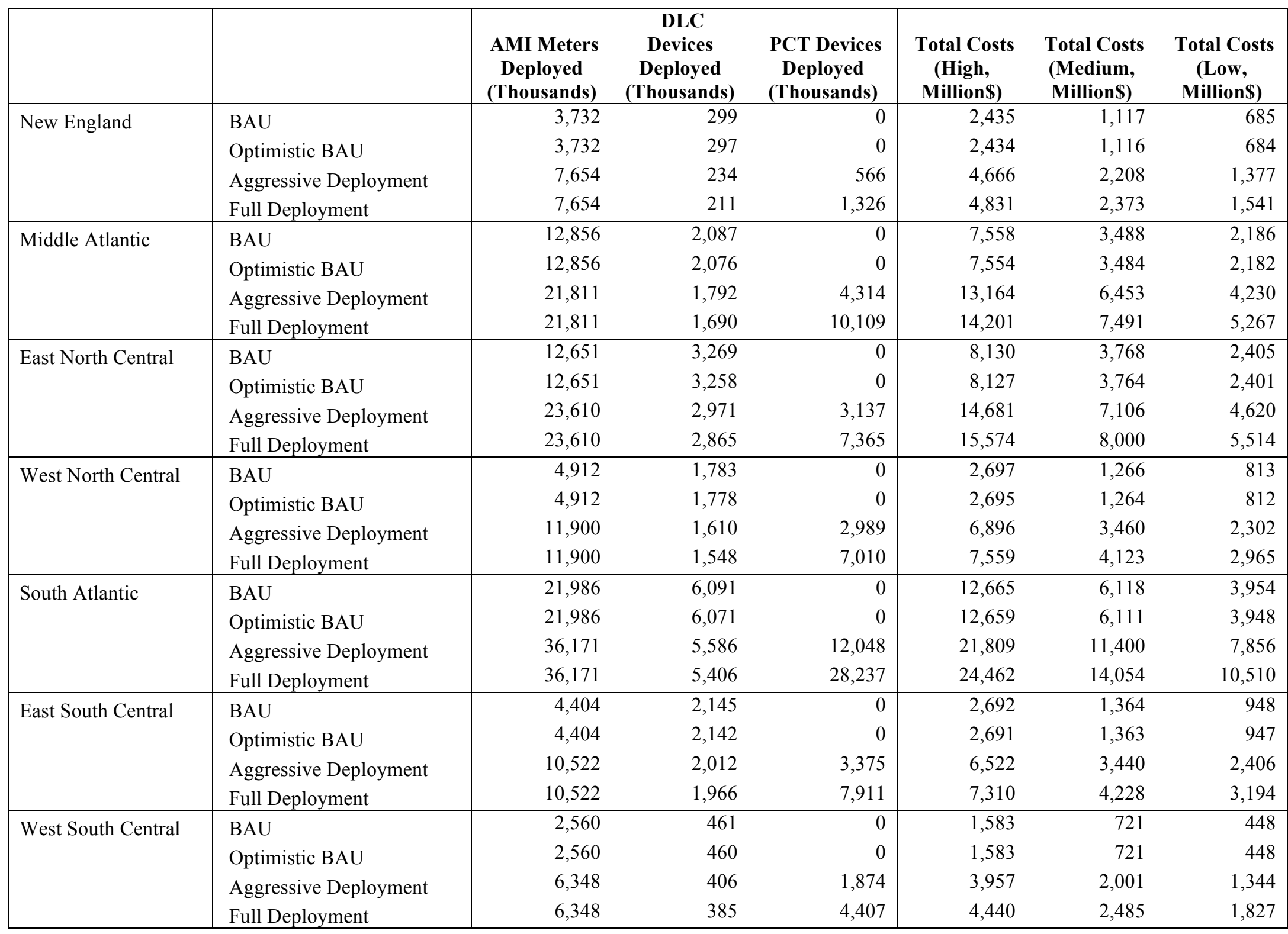




\begin{tabular}{|c|c|c|c|c|c|c|c|}
\hline & & $\begin{array}{l}\text { AMI Meters } \\
\text { Deployed } \\
\text { (Thousands) }\end{array}$ & $\begin{array}{c}\text { DLC } \\
\text { Devices } \\
\text { Deployed } \\
\text { (Thousands) }\end{array}$ & $\begin{array}{l}\text { PCT Devices } \\
\text { Deployed } \\
\text { (Thousands) }\end{array}$ & $\begin{array}{l}\text { Total Costs } \\
\text { (High, } \\
\text { Million\$) }\end{array}$ & $\begin{array}{l}\text { Total Costs } \\
\text { (Medium, } \\
\text { Million\$) }\end{array}$ & $\begin{array}{l}\text { Total Costs } \\
\text { (Low, } \\
\text { Million\$) }\end{array}$ \\
\hline \multirow{4}{*}{$\begin{array}{l}\text { Eastern Inter- } \\
\text { connection Total }\end{array}$} & BAU & 63,101 & 16,136 & $\mathbf{0}$ & 37,761 & 17,841 & 11,439 \\
\hline & Optimistic BAU & 63,101 & 16,082 & $\mathbf{0}$ & 37,743 & 17,824 & 11,421 \\
\hline & Aggressive Deployment & 118,016 & 14,610 & 28,303 & 71,694 & 36,069 & 24,135 \\
\hline & Full Deployment & 118,016 & 14,071 & 66,365 & 78,378 & 42,752 & 30,818 \\
\hline
\end{tabular}

